
ALBERT R. MANN
LIBRARY
AT
CORNELL UNIVERSTTY 


\section{DATE DUE}

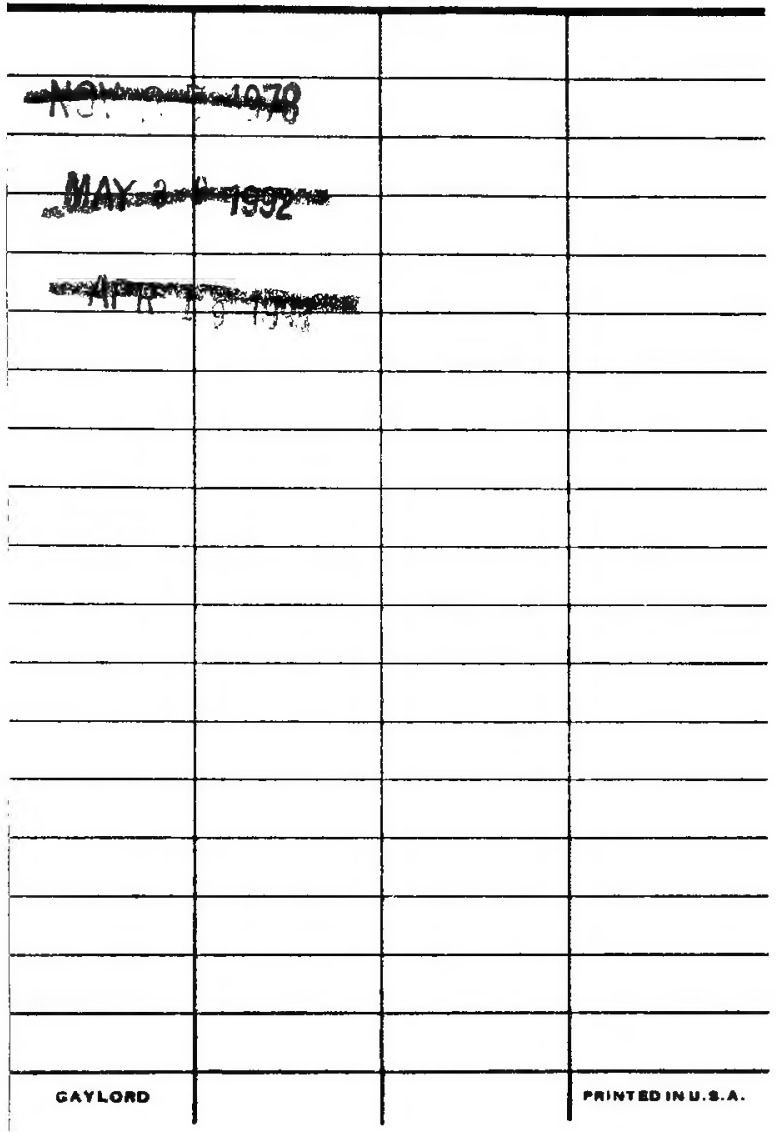

Cornell University Library

SB 405.B24 1922

Fritz Bahr's commercial floriculture; a p

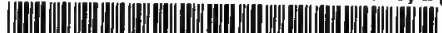




\section{Cornell University Library}

The original of this book is in the Cornell University Library.

There are no known copyright restrictions in the United States on the use of the text. 




\section{FRITZ BAHR'S}

Commercial Floriculture 



\section{DEDICATION}

Il am dedicating this book to my friend, Mr. A. T. De La Mare, the able editor of The Florists Exchange, as a token of my appreciation of his untiring efforts in promoting and encouraging everything making for the advancement of American floriculture. To me a kind thought, word, or deed right now, means so much more than a marble monument a little later. 


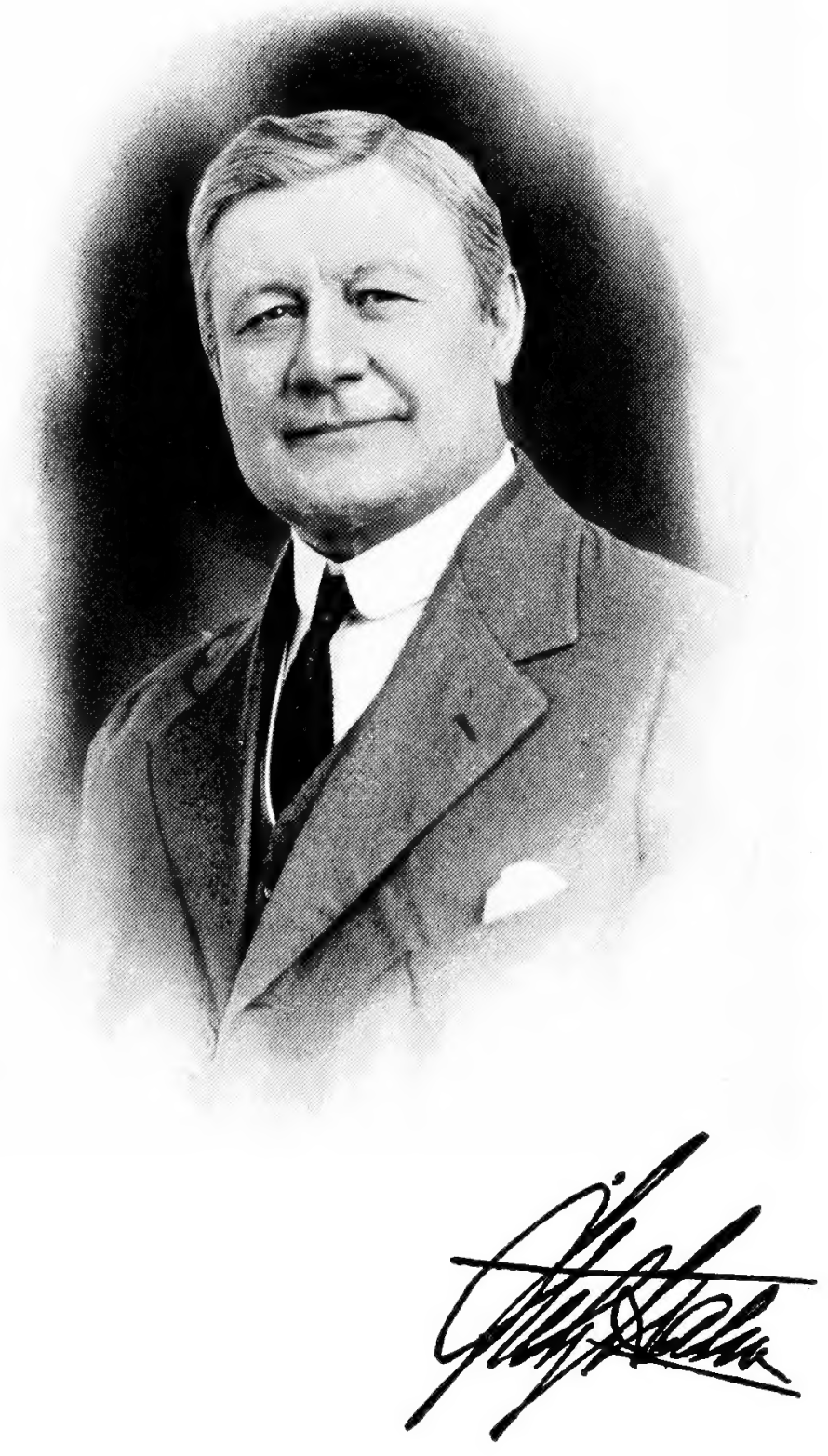




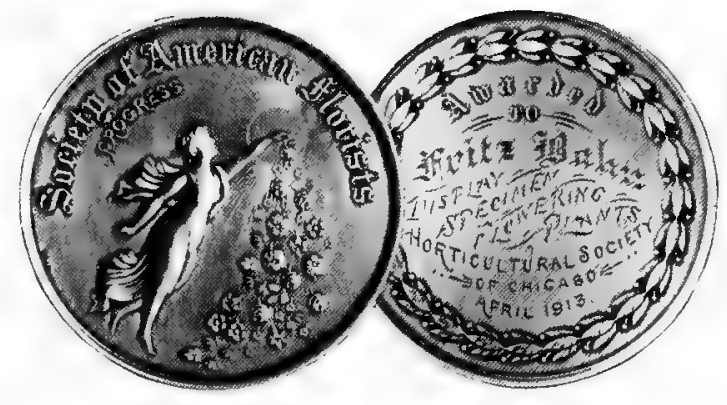

\section{FLORICULTURE}

To my mind, as wonderful as anything connected with the growing of plants, is the contents of a package of seeds, say, for instance, of Cinerarias. Looking at the tiny, hard specks it seems almost impossible that within them lies, in a dormant state, that which with a little earth, moisture, warmth, sunshine and air, will in the course of a few months, grow and develop into hundreds of plants covered with thousands of bright, cheerful blossoms in an endless array of shades and color combinations, hardly two of them alike, to greet us in the greenhouse, while a blizzard and zero weather may rage outdoors.

I cannot look at those flowers and think of the seeds they came from, without realizing how little we actually know about the phenomena of Nature and all the hidden forces behind her. I keep on wondering, and finally come to the conclusion that while man may some day solve all mysteries, it won't be in our time. Meanwhile, why not be happy in being able to have a hand in growing the plants from seed to blossom time? It surely is a great privilege.

To be gardeners, to enjoy and appreciate the chance to work among living plants, should help make us better men, with a higher conception of our responsibilities and duties in life, a keener realization of life itself, a greater consideration for the rights of all our fellow men, and a deeper sense of gratefulness.

F. B. 


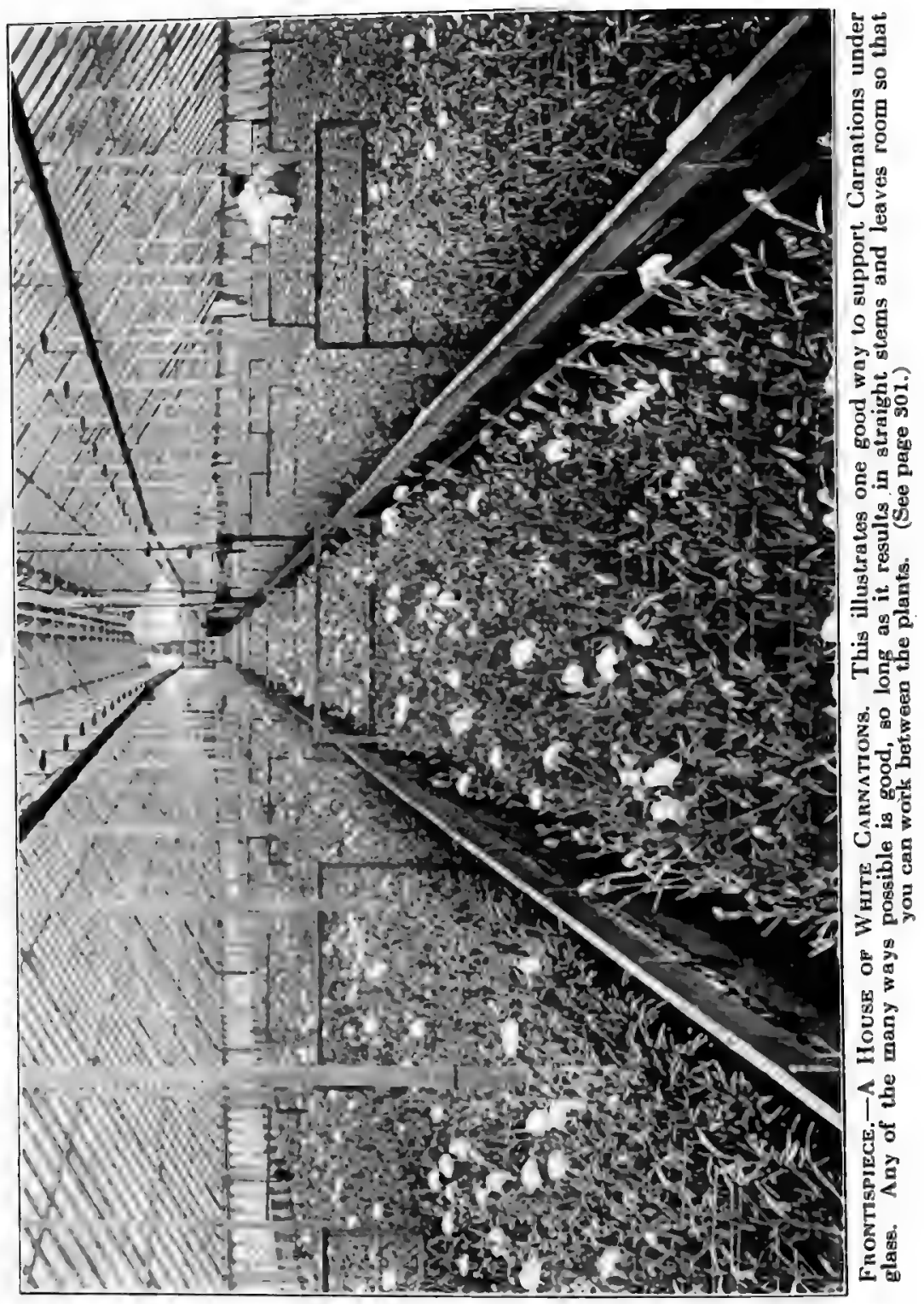




\title{
FRITZ BAHR'S
}

\section{COMMERCIAL \\ FLORICULTURE}

\section{A Practical Manual for the Retail Grower}

\author{
By \\ FRITZ BAHR \\ Highland Park, Illinois
}

With Two Hundred and.

Eighty-eight Illustrations

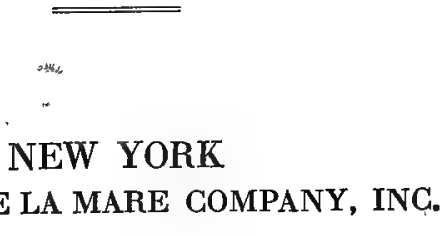

THE A. T. DE LA MARE COMPANY, INC. 
Copyright 1922 by

The A. T. De La Mare Co., Inc.

(All rights reserved)

(a) $3 / 190$

Second Printing

June, 1923 
Dedication.......................

A Few Words on Floriculture... ............ 7

Preface.............. . . 15

\section{PART I}

\section{THE RETAIL GROWER'S METHODS}

Chapter 1. The Retail Grower and His Business.....17-36

The Retail Grower of Today, 17-Changes from Yesterday, 19-The Outlook for the Future, 21-Starting into Business, 23-The Wisdom of Branching Out, 29-A Few Pointers for the Beginner, 30-The Value of Advertising, 31-A Few Words about Success, 34.

Chapter 2. Indoors and Outdoons All the Year 'Round.37-72

Things to be Done and Thought of by the Busy Man During each Month of the Year: January, 38-February, 42-March, 45-April, 48-May, 51-June, 54July, 56-August, 57-September, 59-October, 64-November, 67-December, 69.

Chapter 3. The Retail Grower and His Equipment..73-100

The Retail Grower's Establishment, 73-The Show Ground, 78-The Retail Grower's Benches, 80-The Propagating Bench, 82-Hotbeds, 85-Coldframes, 87The Soil, 90-Composts, 93-Manures and Fertilizers, 94.

Chapter 4. Practical Operations in the Growing End OF THE Business... .... 101-122

Greenhouse Heating, 101-Watering Plants Indoors, 102-Ventilating, 104-Shading, 108-Soil Drainage Principles, 109-Seed Sowing, 111-The Art of Potting, 111 - Crop Rotation and Its Results, 113-Fumigating and Spraying, 116-Notes on Diseases of Plants, 118-The Winter Protection of Hardy Plants, 119.

Chapter 5. Side Line Possibilities for Retail Growers. 123-156

Landscape Gardening: Is It Worth Considering? 123Drainage Work and Grading, 127-Laying Out Walks and Drives, 128-How to Make a New Lawn, 131-Border and Shrub Planting, 133-Special Features in the Garden, 137-Raising Shrubs as a Side Line, 138-How About Hedges? 142-Handling Conifers and Other Trees, 145-Raising Fruit Trees and What It Offers, 146-Seed Selling, 148-Selling Fertilizers, 149-Storing Plants for Your Customers, 150-The Importance of Cut Flower Arrangements, 152. 
Chapter 6. Important Flower Days of the Year...157-180

Christmas and Its Increasing Importance, 157-Christmas Advertising, 159-Preparing for Christmas, 160-Displaying the Holiday Stock, 162-Delivering Christmas Orders, 163-Keeping a Record Afterward, 163-Made-up Christmas Baskets, 164-Holly and Holly Wreaths, 166-Boxwood's Increasing Importance, 167-Flowering, Berried, and Decorative Foliage Plants, 169-Christmas Bulb Stock, 170-Cut Flowers at Christmas, 171-Easter and Its Activities, 172-Preparations for Easter, 174-Memorial Day, 175-Mother's Day, 177-Other Flower Days, 179.

Chapter 7. All Kinds of Plant Materials for the Retall Grower........................ . 181-234

Annuals, What They Are and Do, 181-For Summer Flowering, 182-For Flowering Under Glass, 183-Aquatics, 185-Basket and Window Box Plants, 188-Bedding Stock, 193-Bulbs, 197-Conifers for the Florist to Grow On, 203-Hardy Ferns, 206-Perennials and Biennials and How to Use Them, 212-Plants for Rockeries and Rock Gardens, 221-Roses for Outdoor Flowering, 224Trees for Lawn and Street Planting, 226-Miscellaneous Flower and Plant Lists, 233.

\section{PART II}

\section{A GULTURAL MANUAL FOR RETAIL GROWERS}

Plants for the Retail Grower and How to Grow Them-

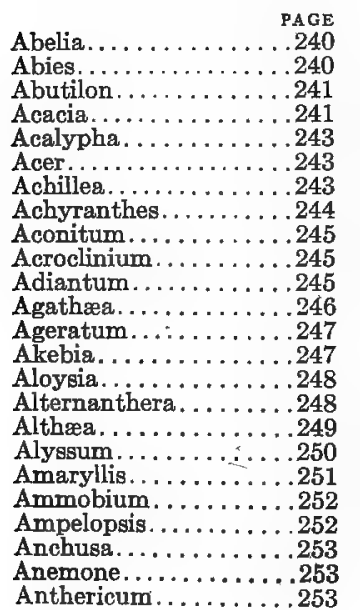

Antirrhinum........255

Aquilegia. .........257

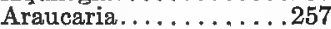

Ardisia. . . . . . . . . . 258

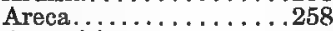

Artemisia. . . . . . . . . . 259

Asparagus..........259

Aspidistra. . . . . . . . . 263

Asters.............265

Astilbe ... . . . . . . . . 269

Aubretia...........270

Aucuba. . . . . . . . . . .270

Azaleas...........272

Baptisia...........274

Begonias. . . . . . . . . . . 274

Bellis............. . 281

Berberis. . . . . . . . . . 281

Bignonia. . . . . . . . . . . 283

Bocconia............283

Boltonia. . . . . . . . . . . 284

Boronia. . . . . . . . . . . . . . 284

Bougainvillea. . . . . . . . 285

Bouvardia. . . . . . . . . . 286

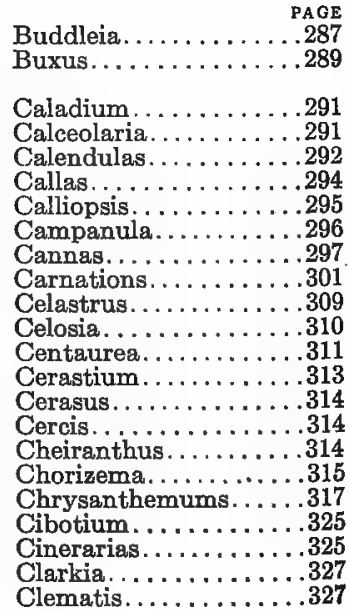

Buddleia. . . . . . . . . 287
Buxus............289

Caladium . . . . . . . . . . 291

Calceolaria.... . . . . . . . 291
Calendulas... . . . . . . 292

Callas. ... . . . . . . . 294

Campanula. . . . . . . . . . 296

Cannas............297

Carnations...........301

Celastrus. . . . . . . . . . .309

Celosia...............310

Centaurea. . . . . . . . . . . . 311

Cerastium. ...........313

Cerasus..............314

Cercis...............314

Cheiranthus. . . . . . . . . .314

Chorizema...........315

Chrysanthemums... . . . 317

Cibotium. . . . . . . . . 325

Clarkia. . . . . . . . . . . .327

Clematis..............327 
GONTENTS-Continued

\begin{tabular}{|c|c|c|}
\hline & & \\
\hline Cobæa. & Iberis. & Platycodon. \\
\hline Cocos. & .409 & Poinsettias. \\
\hline Coleus. & mpatiens. & Primula. \\
\hline Coreopsis & Ipomce. . & Privet. . \\
\hline$\cdots \cdots$ & Iris. & 486 \\
\hline $\begin{array}{l}\ldots \ldots 332 \\
\ldots \ldots 332\end{array}$ & Juniperus. . & $\begin{array}{l}\text { Pueraria... } \\
\text { Pyrethrum. }\end{array}$ \\
\hline$\ldots \ldots 332$ & 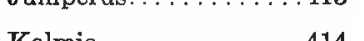 & Pyrus.... \\
\hline Crotons. & Kalmia... . & \\
\hline $\begin{array}{l}\text { Cuphra. } \\
\text { Cyeas... }\end{array}$ & 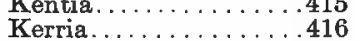 & Ranunculus..... \\
\hline $\begin{array}{l}5300 \\
337\end{array}$ & & $x=0$ \\
\hline & Lantana.. & drons. \\
\hline & spur. . & 494 \\
\hline . & $\begin{array}{l}\text { Latania..... } \\
\text { Lathyrus... }\end{array}$ & Ril \\
\hline ah & Lavendula. & \\
\hline & Lilies............. & Rose \\
\hline & Lily of the Valley.. & Rudbeckia. \\
\hline$\cdots \cdots$ & $\begin{array}{l}\text { Lobelia.............. } \\
\text { Lonicera......... }\end{array}$ & \\
\hline$\cdots \cdots$ & Lupinus.............. & S \\
\hline 353 & Lychnis. & \\
\hline$\ldots \ldots \ldots 353$ & Lycium. . & 517 \\
\hline$\ldots \ldots$ & 431 & \\
\hline eca.......35 & 400 & hus. \\
\hline & $\operatorname{Max}$ & Se \\
\hline 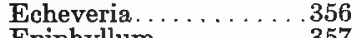 & & \\
\hline & yanthemuna. . .434 & Daisy. \\
\hline$\cdots \cdots$ & $\mathrm{s} \ldots \ldots \ldots \mathrm{A}$ & 522 \\
\hline$\cdots$ & $\cdots$ & $\begin{array}{l}\text { So } \\
\text { St }\end{array}$ \\
\hline$\vec{E}$ & .43 & \\
\hline (5) & .43 & \\
\hline verlastings . . . . . & $\ldots \ldots \ldots$ & Sto \\
\hline $\mathbf{F}$ & $\ldots \ldots \ldots$ & $\begin{array}{l}\text { Sto } \\
\text { Sw }\end{array}$ \\
\hline & 43 & \\
\hline & .44 & $\operatorname{arpos} \ldots$ \\
\hline & Nepeta & Syringa. \\
\hline & $\begin{array}{l}\text { Nierembergia } \ldots \ldots \ldots \ldots 446 \\
\text { Nigella............447 }\end{array}$ & $\mathrm{Ta}$ \\
\hline aill & Nymphras and Nelum- & $\begin{array}{l}\mathbf{T} \\
\mathrm{T}\end{array}$ \\
\hline Geraniums......... & & Thunbergia.......... \\
\hline Geum ............. & re & \\
\hline diolis & $3 . \ldots 45$ & To \\
\hline . & age. & antia....... \\
\hline$\ldots \ldots$ & & \\
\hline$\cdots$ & $\begin{array}{l}.455 \\
.456\end{array}$ & $\mathrm{Tu}$ \\
\hline 200 & 政 & Valeri \\
\hline & & 54 \\
\hline & & $\mathrm{m}$. \\
\hline & emon. & \\
\hline ... $>>>>$ & & \\
\hline & hu & Violets. \\
\hline & 71 & Wistaria...........553 \\
\hline & Phoenix. & Xeranthemum...... \\
\hline$\ldots . .6$ & $\mathrm{Pl}$ & ucca. . \\
\hline$\cdots . .$. & & \\
\hline 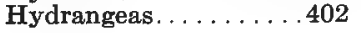 & Pin & \\
\hline
\end{tabular}

\section{For complete list and index of illustrations (288 in number) see page $\mathbf{5 5 5}$.}





\section{PREFACE}

The purpose of this book is to assist the retail grower in conducting his business along uptodate, modern methods. It is not intended to replace, or even improve on, the many valuable works we already have treating on horticultural matters in general, or such as deal with specialties in their respective lines.

There are today thousands of florists, located mostly in the smaller cities and towns and depending on a local trade, who no longer confine their activities within the walls of their greenhouses, but have already branched out into the so-called side lines or are about to do so, and in the majority of cases they soon learn to appreciate the great field and future there is in store for them in the handling of shrubs, evergreens and other hardy stock, fertilizers, seeds, and landscape problems of all kinds.

To build up a retail establishment, starting with a rather limited knowledge of how to grow greenhouse stock and not enough money to pay for twenty-five hotbed sash, means many years of hard work; as many more are needed to acquire and build up the above-mentioned side lines, particularly when one has little trustworthy advice to assist him in getting started on the right road.

I went through all this, and while I have been in the business for over forty years without interruption, I can honestly say that had there been within my reach a "counselor and guide," such as this book is designed to be, it would have been an easier matter for me to navigate, and would have meant the saving of a lot of money spent in finding out things, not to mention the saving of valuable time taken up in experimenting.

These facts and the many inquiries I have answered from readers of The Florists Exchange during the past fourteen years, while conducting the "Week's Work" Department (without, if I may say so, missing a single issue), have prompted me to undertake writing this book in the hope that it may benefit, not only beginners, but also those who, though established, are looking for suggestions regarding the building and maintenance of an uptodate business, who are looking for more trade, and who are anxious to grow, branch out and prosper.

Acknowledgement is made to friends who have supplied some of the illustrations, and to Mr. E: L. D. Seymour for suggestions and assistance in connection with the arrangement of the material and the entire editorial preparation of the book.

Fritz Bahr.

Highland Park, Ill.

August, 1922. 



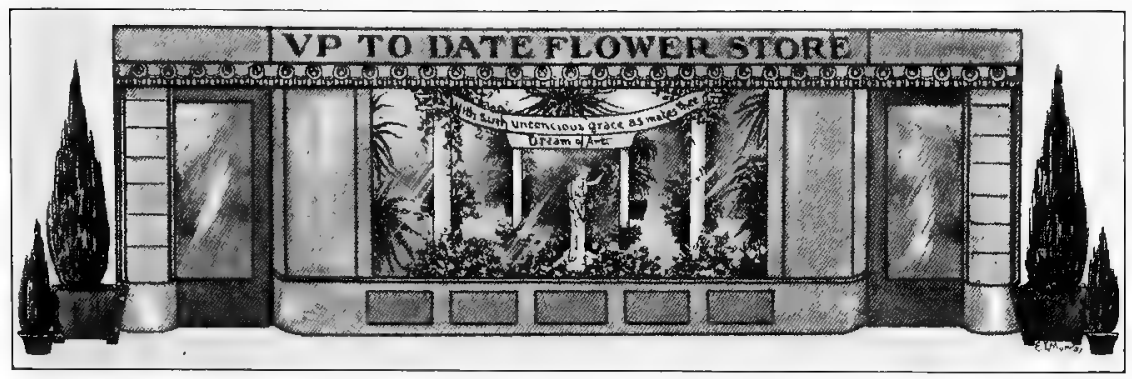

\section{PART ONE}

CHAPTER I

\section{THE RETAIL GROWER AND HIS BUSINESS}

\section{THE RETAIL GROWER OF TODAY}

W HETHER you are aware of it or not, it is nevertheless a fact that the retail grower is the most independent of all who are engaged in such businesses as those of florists, seedsmen, nurserymen, landscape gardeners, and other members of the allied industries. To quite an extent he has to have a general knowledge of all these different branches and can make profitable side lines out of them.

As retail growers I class all those florists who are located around the larger cities or in their suburbs, in the smaller cities and throughout the country towns, and who grow a part of their requirements for retail sale to a local trade. Anyone so located experiences but few of the troubles the wholesale grower comes up against in periods of a glutted market; but few of the crop failure difficulties of the specialist, or the waste and high (overhead) running expenses the retailer in the large city is subjected to; but few of the trials of the man who has only a small store to do business in, who has to purchase every bit of the greens and small ferns he uses, and who has to quickly dispose of the flowering plants he handles, so they will not die on his hands.

The retail grower with greenhouses, frames, proper storage facilities and a few acres of land, has a chance to run his affairs most economically. He is not confined to just one line, or affected 


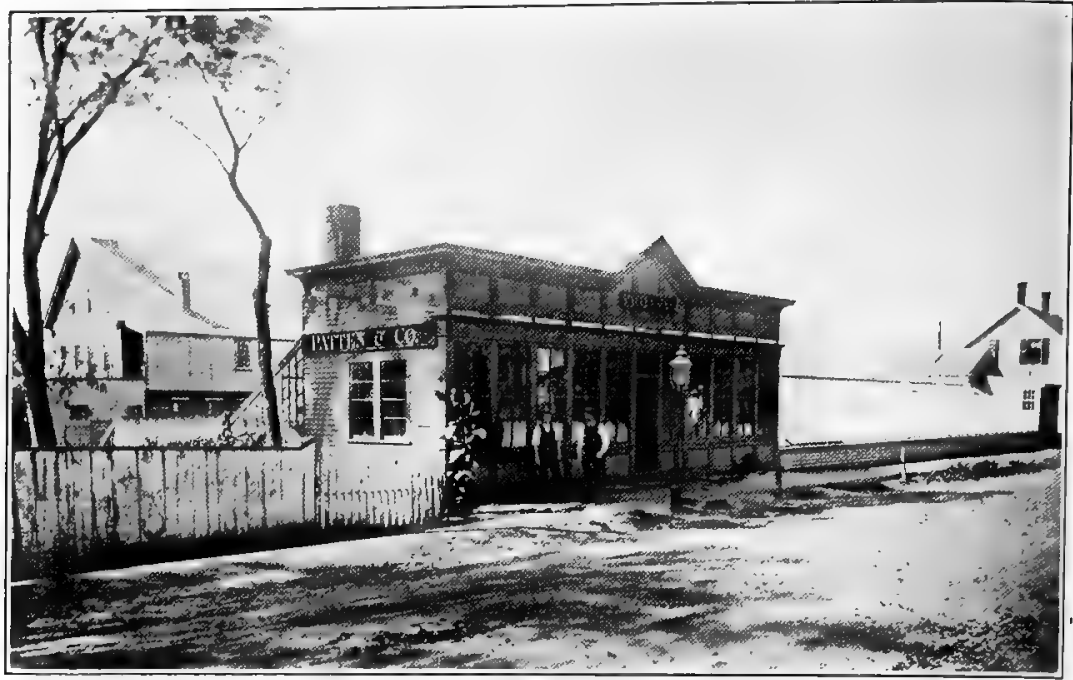

Fig. 1.-A Retail Grower's Establishment of Yesterday. The store of Patten \& Co., Lowell, Mass., as it looked between 1876 and 1887. This and the photo below were lent by G. Thommen, Somerville, Mass., who worked for this concern when he first came to the United States from Europe

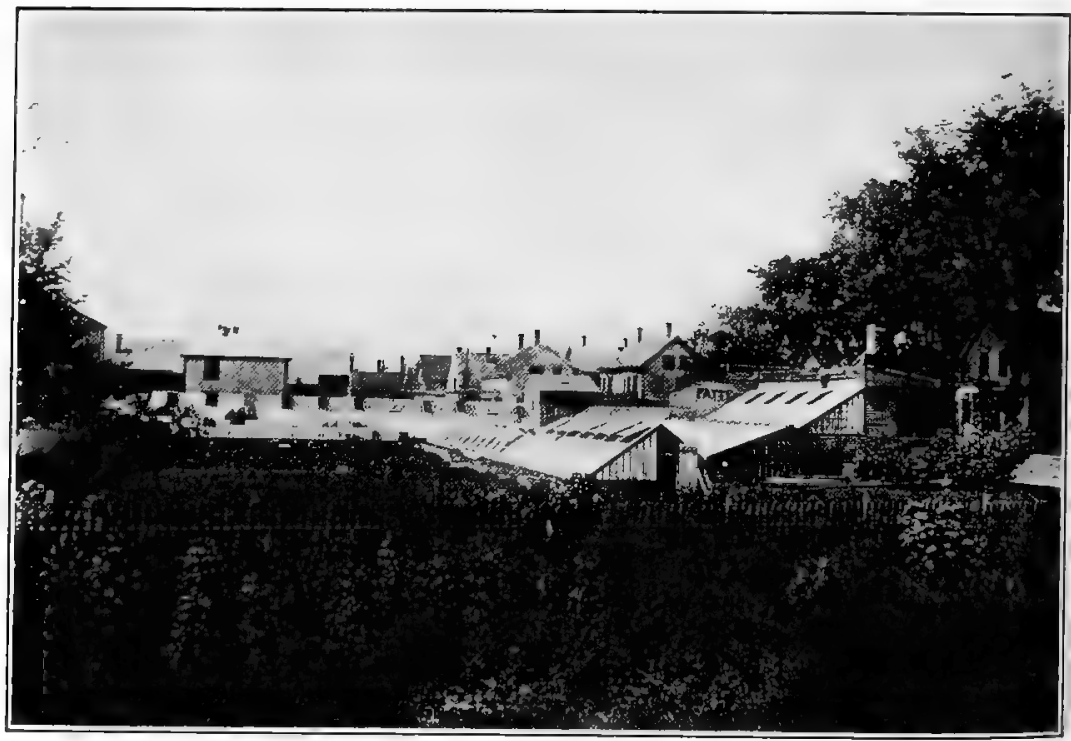

Fig. 2.-An Oldtime Range of Glass. The Patten greenhouses started in 1870, grew a general collection of stock for retail trade, especially bedding plants and a large collection of Azaleas and Camellias. A Rose house (one of the few then in New England) and the two Hitchings "saddleback" hard coal boilers were interesting features 
much by so-called dull or hard times. It is for these reasons that he is, indeed, most independent.

There are exceptions, of course, but, for that matter, most men in business (especially those in the large cities) don't always enjoy their occupations. The monotony of a daily grind is the cause of it. They are more like machines than anything else, and each year they value more highly as their most enjoyable and healthy recreation, gardening in its varied branches-the very thing that makes up the daily life of the retail grower. To my mind, those florists who cannot appreciate this fact, who cannot enjoy to the fullest extent their occupation, and who cannot become better men because of it, will hardly ever find a fair compensation for their work in the money they get out of the business.

There have been and are men who have become rich in the florist business, and there will be more in the future, but the great majority of successful men are only comfortably fixed, and it is that class which enjoys work and play in moderation, that lives the longest. The man who can acquire that habit is indeed among the richest and doesn't have to live one hundred years in order to have lived a long and useful life.

\section{CHANGES FROM YESTERDAY}

Those who can remember forty years and more back have no trouble in recalling the retail grower or florist of the smaller towns. In most cases it was just a matter of existing. There was good stock grown, but for so little money that there was little chance of profit or hope of settling bills once a month. The average florist and the gardener were on a level with the coachman, and even the retailer in the larger cities had trouble when rent day came around.

All this is changed. The business of the florist has become a regular business. It has evolved with other lines. In New York, Chicago or San Francisco on the streets where rents are highest you are sure to find the flower shop. Similarly on the main street of the small town you notice the attractive window. of the local florist. He is one of the leading business men of the town; he has a nice home; he takes an interest in politics and the affairs of the community; he belongs to the Booster's Club; he supports the good roads movement, and, in fact, anything that stands for progress. And if he happens to be a man just starting into business no matter on how small a scale, it won't be long before he becomes prominent, for he cannot very well read the trade papers, join a florists club, or the S.A.F., and mingle with progressive men without becoming one of them himself. 


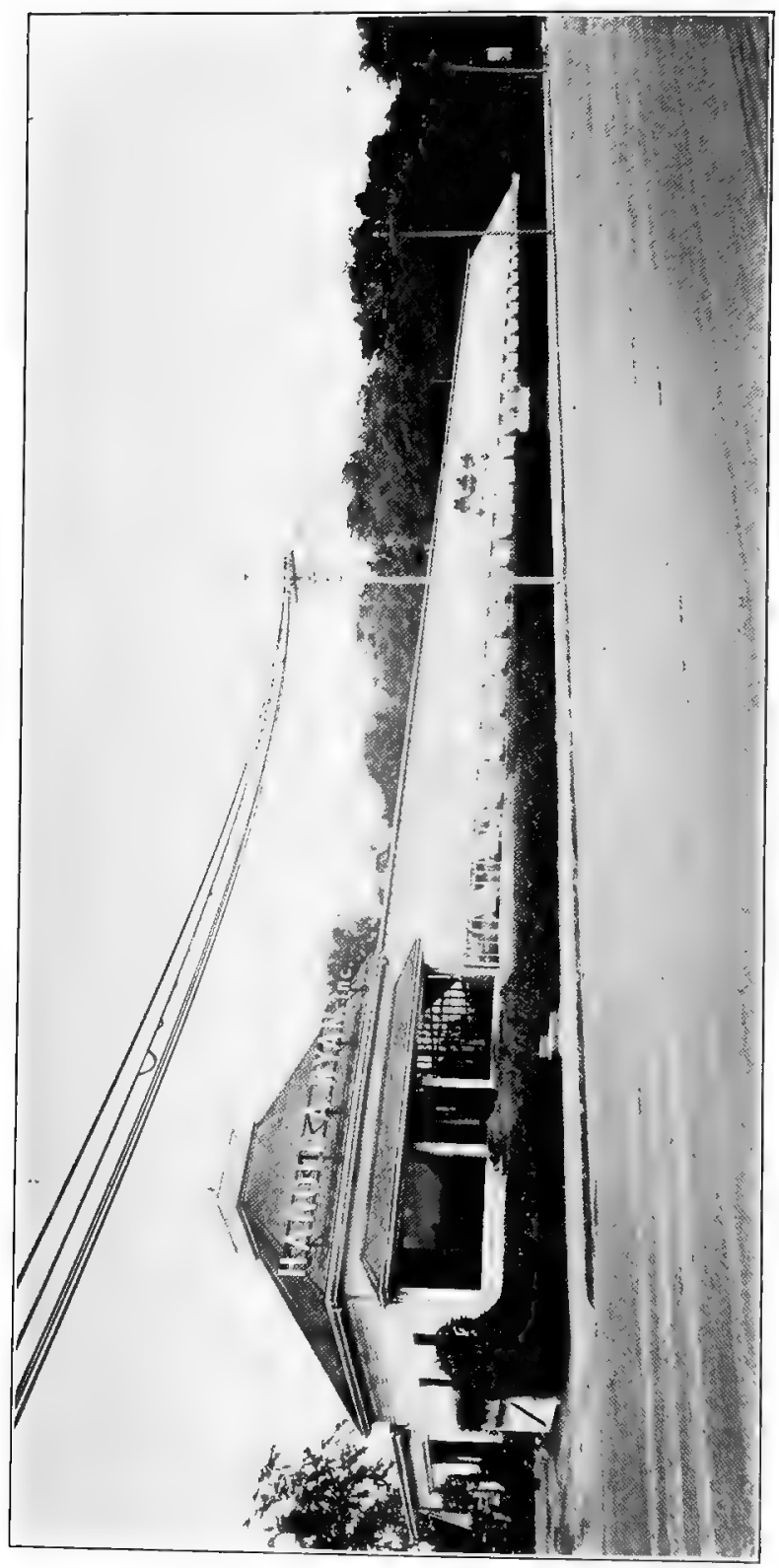

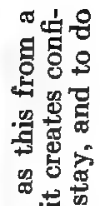

영움 오

ต

붕

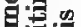

을

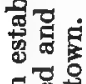

동우

ช.ำ

엉을

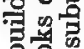

द्वा요

의

स:우

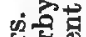

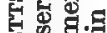

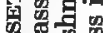

\%

웅요의

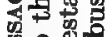

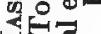

$\sum$ 㐘

रु่:

똥응

벙

击安

的要

요요

늘

뚱음

उु

离

.

政

른

z

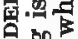

요

要

<

1.8 .5

的要 
It used to be that the man with one, two or three greenhouses would grow everything he retailed-and the greenhouses as well as the stock looked the part. He would depend on what he grew himself, and his customers had to make the best of it. When the first few short-stemmed Marechal Neil Roses, Camellias, or Bouvardias were cut, that was all there was to it until more opened.

Today in many of the most successful and profitable retail grower establishments what is grown at home constitutes only the smallest part of that which is sold. The owner realizes that he cannot compete with the Rose or Carnation specialist; he cannot grow as fine Crotons or Cyclamens as they do in Philadelphia or elsewhere; he cannot produce on a small scale specimen Cincinnati Begonias, Ericas, palms, orchids and a lot of other items; so he purchases all these ready for the counter. He does as much business around Christmas as, a few years ago, he did all through the year.

But, on the other hand, he figures out that each year it is more essential to have on the benches paying crops of the things he cannot purchase as easily as he can grow them. Bench space is worth more than ever, and there is no room now for Cacti, woody Heliotropes or out of date Begonias kept merely in order to have something on the benches. He is no longer content to be confined within greenhouse walls, but gets outdoors and finds a most profitable field in landscape work, in growing on hardy stock, etc. He has no more dull seasons, for there is something doing every day. And there results an ever higher standard of living for himself and those who work for him, as he keeps on looking for more business, accomplishes more each day, and pays living wages. He doesn't wait for things to come his way, but, with advertising, he goes after them. He is a "live wire" if there ever was one.

\section{THE OUTLOOK FOR THE FUTURE}

As we look back, it does seem wonderful-all that has been accomplished, and the prosperous times that the florists have known in spite of the World War. To some it even may appear as if we had reached the high water mark, but this is not so. As we go on-and we will go on-more flowers than ever will be needed. They are no longer considered a luxury, but are viewed as a necessity; it isn't only the rich who buy them. Everybody does. With each new home is created a new demand. As more homes, even if only of moderate size, are built in the country, a greater and greater demand is created for flowers, trees, shrubs and perennials with which to beautify their grounds.

The florist didn't begin to prosper until the country at large prospered. He couldn't have done it by himself. You cannot sell flowers where there isn't money for bread, no matter how you 


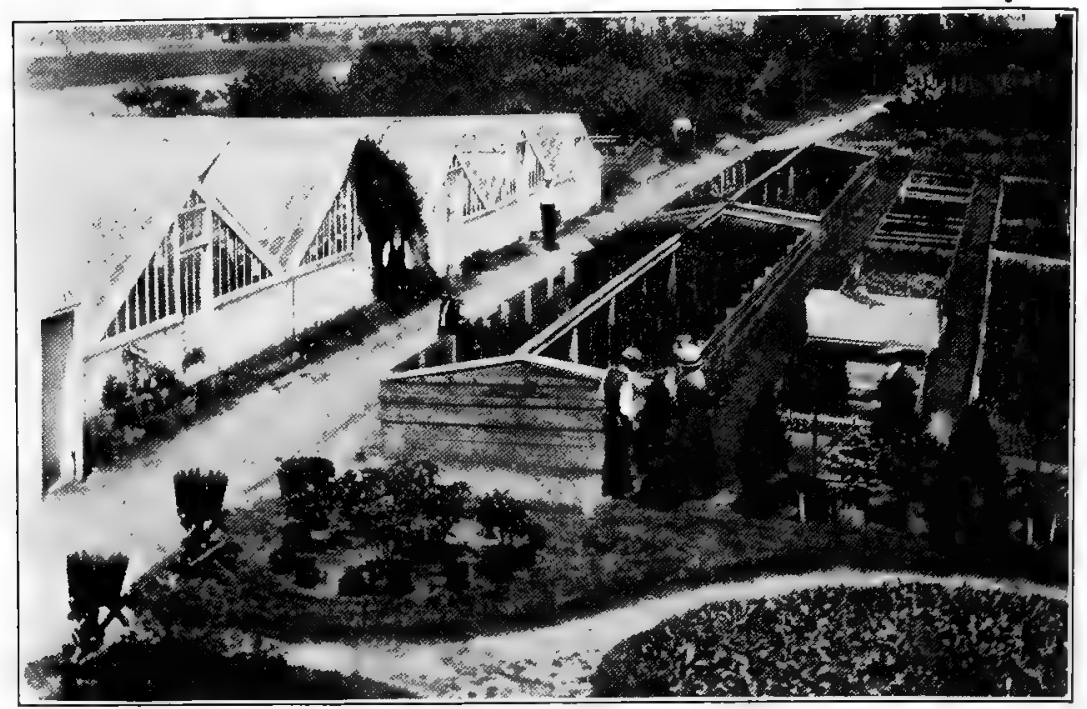

Fig. 4.-Retail Growivg As It Used To Be. This picture, taken in 1908, and lent by Charles .Zeller \& Son of Brooklyn, N. Y., shows an establishmeut thoroughly up to the average for its day and generation. How far we have progressed in less than a score of years is shown by the views of other modern places reproduced throughout this book

advertise or organize. But the United States leads the world in prosperity, and will continue to lead. It has the people and the resources to do it with. You may point to cases of extravaganceand there is extravagance-but that exists all over the world, even in many parts of starving Europe. It always has existed, and always will. Riding in an automobile would a few years ago have been considered extravagant; so would have been the modern lunchroom with marble floor, walls and counters, or the tiled bathroom. As we go on, people demand better things, and so it should be. The worker today buys flowers, he fixes up his little front yard, he plants shrubs and perennials, he has porch boxes. The fact that he is getting better wages than ever makes him spend more than ever.

We are going on, going forward. Some, of course, will misuse what they are being blessed with, but more money than ever before will be spent on flowers for all occasions, and for the beautifying of the home grounds.

I am convinced that the future of the florist business rests entirely in our own hands. In no other part of the world is there a better chance to develop this industry than here, or a better market. At present it is a matter of producing to supply the demand; and by means of cooperative work through the S. A. F. and the F. T. D., and by means of continuous advertising to educate the public, each, year will be made a better one than that which preceded it. 
The money is there. People are spending it and paying more for service than ever, but as yet only a small part of the population "Say it with Flowers." The more they hear and see of them, the more they will use them. Even should all of these predictions fail, most of us in business today know that good florists' stock never sold at a higher price than at present, and that this is no time to retrench, but a time to go on, to build, to expand, to produce still better stock, to advertise, to give better and still more courteous service. Come what may, flowers will always be used, and there is absolutely nothing to fear for those who attend to their business and "watch their step."

\section{STARTING INTO BUSINESS}

The great majority of those who are successful retail growers today, started with little or no capital. That, of course, doesn't say anything about the many who started and failed. Most of them are forgotten.

Under the existing conditions, the man who wants to start and has a capital of say $\$ 10,000$ will be looking around for more capital by the time he has a suitable lot, a little store and a couple of greenhouses. Yet, if he has a knowledge of the business, and is a business man he has, of course, a great advantage over the one who hasn't that amount of money to begin with.

The first requirement, however, in either case is a knowledge of the business-not in all its branches, but in the particular one he wants to enter, and for which he sees an opening. Generally speaking, a man with $\$ 10,000$ capital should put not over one-half of that amount into buildings, and reserve the other half for working capital. To put in every cent and borrow funds to work with is dangerous, particularly with those so located that they can buy from the wholesale market the cut flowers they need, or from the wholesale grower the plants they require. A lack of working capital has made many a man close up. When once established for a year or two, things are different. If you have kept a correct record you can find out at a glance the amount of business done, which will give the best possible idea of what could be done. Misusing credit, however, is skating on thin ice.

There is this advantage about starting in as a retail grower: the growing end of the concern is the last to be considered. The first and main problem is a suitable place in which to do business. There is plenty of stock in the country that you can buy ready for the counter and sell at a good profit, but to grow, and especially to grow cut flowers, requires modern houses. You can successfully grow bedding stock in a sash house, but in such a building Roses or Carnations would prove a failure. Starting in on a small scale, a little store-no matter how simply constructed, a small show house 
-even if only $20 \times 20 \mathrm{ft}$. or $25 \mathrm{ft}$. in size, and a $12-\mathrm{ft}$. wide plant house, can be made the foundation to build upon. There are today any number of towns where there is an opening for the right man. As we increase in population, so will the opportunities for more such openings increase.

You may come to a small city or town and admire the layout of the modern retail grower's establishment, but hardly ever will you find such a place where the owner didn't start with very limited means, adding and improving as he went along, until he got where he is today. That is the natural way. There are cases, of course, where two or more men put in $\$ 10,000, \$ 20,000$, or more, started out with an uptodate establishment and succeeded, but these are the exceptions.

Were I to offer any suggestions to those with capital starting into business, here they are: Begin with a knowledge of the business; select a proper location, one where there will be room for expansion, yet near enough to the town and on a main road; invest only about one-half of the capital on hand to begin with, and pay more attention to an attractive front, a store, and a show house than all else. As you go on, you will soon find out where there would be an advantage in erecting a house for a particular crop or in growing on certain stock that you use but cannot always buy satisfactorily from others. But from the very start, put on a good front, buy according to your requirements, pay your bills as you go along, live within your income, advertise, and keep it up.

\section{Starting Without Capital}

The man who really wants to start in business for himself is going to do it whether he has money to do it with or not. He doesn't need pointers from others on how to do it-for there are none they could give him. If you were to hear their stories from fifty men who started with little or nothing and succeeded, there wouldn't be two cases alike. It isn't always the man who knows most or is the best florist who succeeds. In fact, I am convined that there are right now more of such men working for others than are in business for themselves. There are cases where the owner of a notion or drug store started to handle cut flowers in one corner of the store and later took on flowering plants; then he hired someone to make up floral designs, and finally went into growing on stock and devoted his whole time to it with great success. Then we know of those who never grew anything but Lettuce and Cucumbers under glass, but who changed to flowers and made it pay; also the man who never handled a Rose, but went into Rose growing and succeeded.

Any man who wants to succeed as a retail grower has to be not only a florist, but also a business man. He not only has to love flowers and be able to grow them, but he also has to know how to buy 
and sell to advantage, how to handle his patrons and satisfy them; he must be a good mixer, liberal minded, always informed as to his assets and liabilities and ready to act accordingly. He must be conservative, yet optimistic. Lacking some of these traits makes some fail, while others succeed in spite of the lack. But the man who is good at business, has the advantage. Those who have it in mind to start without capital may claim that to do so twenty or thirty years ago was an easy matter, but that it cannot be done today. But this is wrong. There are greater opportunities today by far, than there were in former times. Right now, there are men all over the country, perhaps struggling along, not knowing where the money for the next ton of coal is coming from; men who have to do their own delivering, who in a few years will be among the successful men of their day. There is a crop of just such men among the leaders of today; and other crops, and much larger ones, will follow as the years pass by.

A man without any capital to speak of should know his business, should be able bodied, willing to work eighteen hours every day, if necessary, and be determined to succeed. It is proper that I should present in this chapter my idea of at least one way in which a man

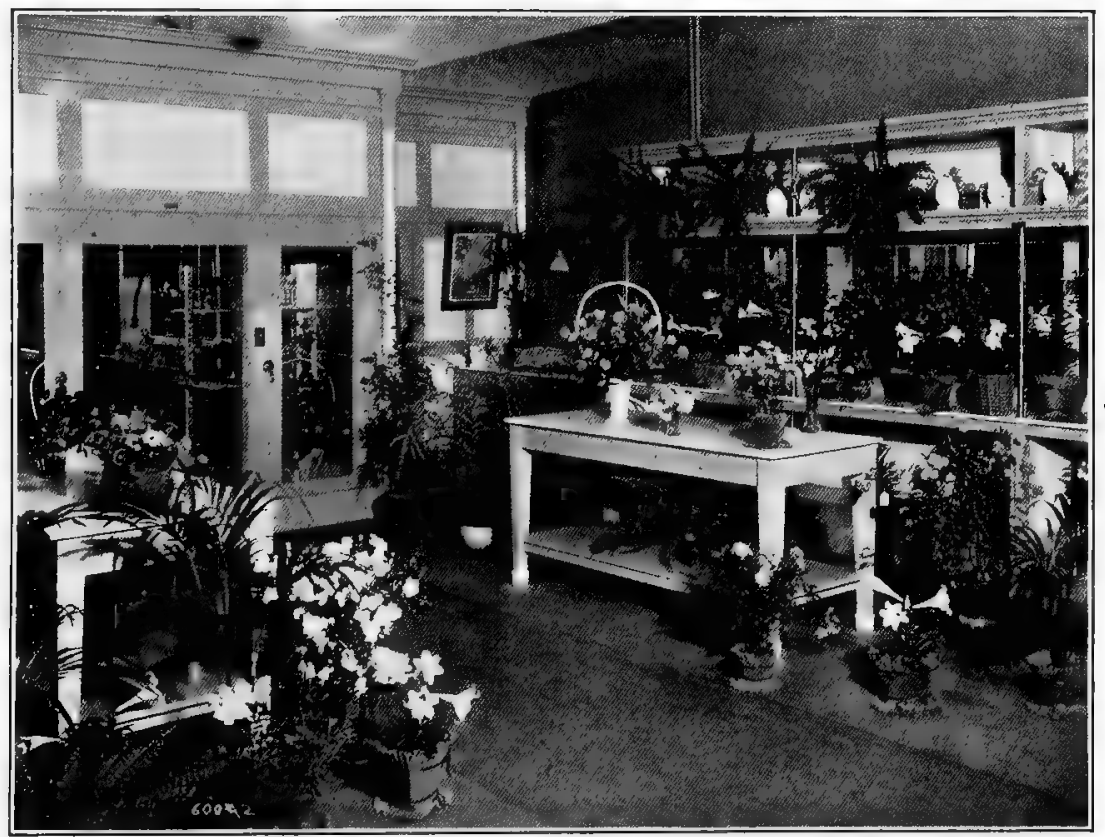

Fig. 5.-A Flower Shop Interion. A good example of a neat, inviting flower shop in Peoria, Ill. The retail grower who is equipped in similar manner as well as with adequate, uptodate greenhouses is fortunate indeed 
might start and succeed. It is but one of a hundred other, perhaps better ways, yet the reading of these notes may lead someone to think of a better way, and thereby help him.

To start today in the florist business a man wants to locate where things are humming, where they do things. I don't know of a better section than the great Middle West. That is not to say, however that similar opportunities are not to be found in the East, and South, or along the Western Coast. The smaller inland towns are good places to live in, but it is the big cities that are making the most headway. Around almost any of these cities, often for a distance of thirty miles or more, we find the suburban sections where are located the homes of those doing business in the cities. It is in these suburbs that there is, to my mind, the best field today for the retail grower to start into business.

In localities where there are already one or two florists, there is room for another, and wherever as yet there is none, conditions are even better. To hunt up such a place is the first thing, and if it is done in early Spring and you mean business, you won't have any trouble in getting all the work you can attend to putting people's home grounds in order. If you have no money, don't say anything about it to the parties you work for, who are in need of shrubs and perennials, but do your work well and stick to it. Make arrangements to take care of a place for so much a month during Summer. Plan to work ten or twelve hours every day.

\section{WoRking Up a Stock}

If you get a few dollars, buy seeds of biennials and perennials and sow them in a frame outdoors on a piece of land you have rented for a year. You won't need sashes till Fall and by that time you will have a nice lot of Pansies, Bellis, Myosotis, Larkspur, Canterbury Bells, Foxgloves, Hollyhocks, Gaillardias, Columbines, Coreopsis, Shasta Daisies, Pyrethrums, Achillea, Gypsophila, Sweet Williams, Border Pinks, Heliopsis, Rudbeckia and others. Seed of most of these sown in early April will give you salable stock that Fall and the following Spring. Of course, the Pansies, Bellis and Myosotis you sow 'ater. Thirty-five dollars invested in seed will give you thousands of plants worth hundreds of dollars a year later on. In the Fall, invest in a few sashes-the Foxgloves and Canterbury Bells will need them and some of the others are better off covered. Work hard that first Summer and please everybody, and no doubt you will have charge of most of the places during the following Winter. If not, work at anything that comes along, it doesn't make any difference what. By the following Spring you have not only your labor for sale, but stock, too. Everybody wants hardy stock, and you will want someone to help you do the work in Spring. 
There are the lawns to get in order, fertilizer and grass seed to sell, and maybe, a few shrubs. Plant out more seed and purchase a few good Phlox, Iris and Peonies, if you didn't do so the Fall before. Don't spend a cent on yourself unnecessarily, but put every nickel into more sashes and stock. Rent more land, too; maybe a better piece.

How about approaching someone you work for in regard to making a loan to enable you to put up a little greenhouse? Why not? If you can't do it, keep on hammering harder than ever, and put in another Winter the same way as the first. By the second Spring you are in better shape than ever. Work eight hours a day for other people and ten for yourself. You will have annuals and perennials for sale and flowers to cut all Summer. If you have too many perennials for your retail trade, advertise and sell wholesale. By the third Fall, I bet you will have a little greenhouse and a square show room with a display cooler, and will be equipped to furnish anything in floral designs.

That not only sounds well, but, if you are of the right stuff, you can do it. If you are not foolish enough to try to undersell the fellow who is already established, you will succeed and grow with the town you live in. Any man with open eyes, who has for years worked in and about a greenhouse, will have no trouble in doing outdoor work on a private place. He also will have no difficulty in finding out what he doesn't know about hardy stock. There isn't a home ground today, no matter how well laid out or kept, where there isn't room for changes to be made. Besides all that, new homes are being built and the wideawake man will land the work on some of them, at least.

Those who started twenty-five or thirty years ago didn't have anywhere near the opportunities that are offered today. The town without a florist or landscape gardener gets along nicely without either of them, but the more florists and landscape gardeners are seen in a section, the more flowers are used, and the more work there is for both-and the home grounds show it. Where there isn't a demand for flowers, create one; where people are in the habit of buying cheap flowers, educate them to want better ones. No one florist can please all the people of a town, and no matter how many are there doing business, there is always room for the new fellow. It is up to him whether or not he is going to stay.

If you stick in the Rose or Carnation section of a large concern, there is but little chance of ever starting into business for yourself. This is not to say that maybe, with a good salary you are not as well off there; but not all of us are contented with that. Even a man without capital can start in business for himself; his labor is his capital and he simply has to work, and keep working, and then 


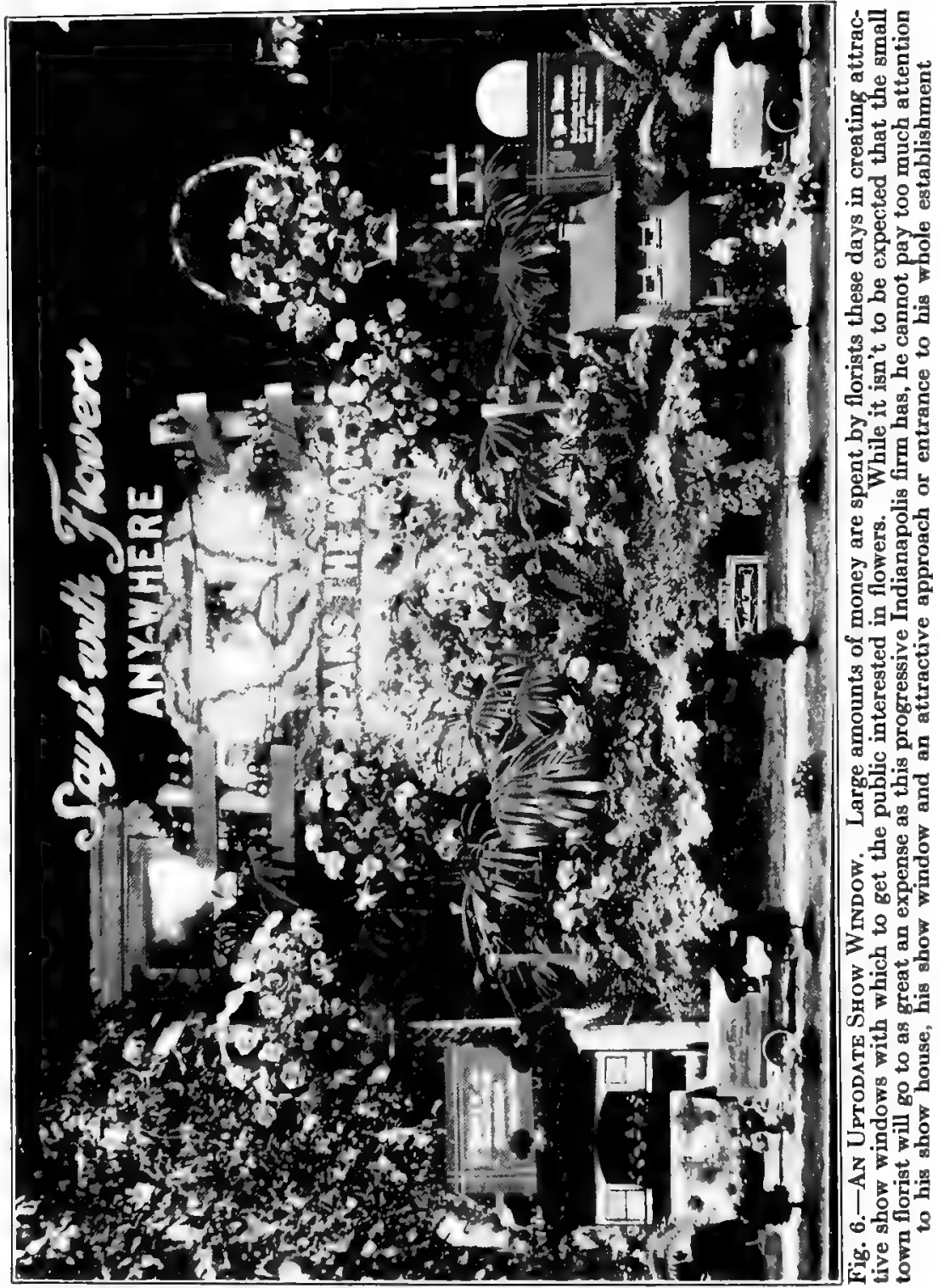


work some more at anything to get some money, and so get on his feet. It can be done and is being done every day. Eight hours is enough if you get paid for eight hours, but the man who starts in business for himself, knows no hours-he cannot if he wants to succeed. He knows no discouragement and keeps on looking ahead. Ask any man who is successful today and who started with nothing, if this isn't so.

\section{THE WISDOM OF BRANCHING OUT}

With a proper organization there is no limit for the retail grower in branching out; that is, for him who wants to branch out. There are in the business today men who don't confine themselves to the greenhouse and the store, but who do landscape work, road building, have a nursery, do tree surgery and spray trees, carry a complete line of garden furniture, sell phonographs, birds and goldfish, and always have a large display of fancy baskets and jardinières. The farther a town is located from a large city the more all these side lines pay. There are cases where a local florist has worked up a trade in flower, garden and field seeds and fertilizers, and made it more profitable than anything else he does. Lawn grass seed is another profitable line. Who in a town can carry all these items better than the florist? They, and everything that is used in connection with flowers or the home grounds, all go hand in hand with his business.

However, I don't think it best for a man who isn't well established, to go into too many things. Let him stick to just one or two lines to start with, and those the best lines. What they are also differs in almost every locality. The more lines you get into the better the organization must be, and the more system is required to make a success of it. One man can for awhile do it all; you can get started and see to quite a lot, but as you grow and branch out, you need help, and there is always one man or woman more fit to do a certain thing than another.

There are today in the country firms that are in the seed business and carry everything in that line, as well as tools, bulbs, etc., and that include, besides, large greenhouse establishments, selling at both wholesale and retail, and a well-stocked extensive nursery in addition. The florist in the smaller cities and towns can do the same thing, on a smaller scale. There is no good reason why he cannot, but to start out with all of those lines, is very apt to result in failure, unless there is an unlimited amount of capital available. A far better way is to start slowly and grow into it. I know of no other line of business conducted in a town in which there is a greater or better chance to branch out than in that of the retail grower, but very few men have as yet taken advantage of the fact. They are either too busy attending to the growing and selling of plants and 
flowers out of the greenhouses and trying to do most of the work themselves, or else they don't care to branch out farther.

\section{A FEW POINTERS FOR THE BEGINNER}

First of all, find out what is in most demand in the locality in which you want to do business. Grow or have for sale that for which there is already a demand. Don't try to make people buy what you think is best for them. Making a show counts for more than anything else. The retail florist's business is a show business in every sense of the word, so if you start with sufficient capital, have the show house and the store in mind before anything else. No matter where you are located there will be a way to purchase palms, ferns and other decorative stock with which to make a proper display. With such surroundings you will have the confidence of your customers, or soon obtain it. They will feel satisfied that you are capable of attending to their orders, and it will be as easy again to take orders for outdoor stock and landscape work.

No matter how hot the Summer, always keep the display cooler full of stock, and vases and baskets filled with garden flowers. What of it, if you do have to throw some of them away? Keep up a show every day of the year, and if you are starting out with only limited means, again have the show room or store first in mind. If you are a florist you know what you can do with a square room with hardly anything in it, if you have ferns and a few palms to decorate with. Set aside a part of the greenhouse nearest to the entrance and use it as a little show house.

This is the idea: Display to the very best advantage the stock for which there is a demand. Always have that in mind. Everybody realizes today the necessity of acting on the square, of giving people their money's worth, of being courteous, prompt in delivering orders, and as particular in filling little orders as large ones.

From the very start do some advertising. No matter how little it is, keep on letting people know about y.ou. Always figure out what it is best to buy ready grown, and what it is best for you to grow on. The man who has to buy every bit of bedding stock usually doesn't make much on it, so the more of it you can grow on yourself, the better for you. Usually there are certain things that will do better in one place than another, and it is those that one should make a specialty of, rather than waste time insisting on growing others which cannot be done. The sooner one gets away from the idea of growing everything, the better. The same is true with trying to make fifty-seven varieties all do well in one house. If you need one hundred pots of Lilies for Easter, you are making a mistake in trying to grow them. The cheapest, best and surest way to have them for Easter week is to buy them in bud from the specialist. 
Always study conditions around you, what people want, what there is a demand for, or what you might create a demand for such as exists in other localities. Be ever on the outlook for novelties or something out of the ordinary for the show house. There are a lot of plants and flowers so old and long forgotten, that they are new to most of your customers.

Keep posted on what is going on in other parts of the country; read the trade papers; read the garden magazines; read good horticultural books; join the local florist club if there is one, or the nearest one to you. Join the S. A. F. and the F. T. D. A., and look to the large city retailer for the newest ideas in floral art.

Visit, whenever you can, the large stores and the big greenhouse establishments of your neighborhood, and profit by their experience. If you notice in the ads of the large growers just what varieties of Carnations or Roses or Chrysanthemums they offer, you can quickly tell which are the best for your commercial purposes.

Go slowly. "Stop, Look and Listen." Don't overreach. Watch your step. Borrowed money never sleeps. Work as many hours as necessary, but keep on thinking at the same time. A weak mind and a strong back make a good ditch digger, but never a florist. Too many men start and get dizzy from doing too well at the beginning. The man who never experienced any bumps as he went along, most likely will have them coming to him later on. In other words, if you don't get them before you are thirty, you'll probably get them later.

If there is any underselling to be done, let the other fellow do it. If your competitor won't work with you along cooperative lines, don't try to get even with him; let him alone. Figure on a fair margin of profit and keep on making new friends, but keep the old ones, too. There is no better time to start to collect what is due you than right at the beginning. "Pay and collect as you go," has never yet been the cause of a business failure.

\section{THE VALUE OF ADVERTISING}

Nowadays, unless you advertise, even if you have a superior article to offer, people will not find it out, hunt you up, or make a path to your door. You would have to have a wonderful lot of patience if you were to wait for them to come, for they want to be invited; they want a well-paved roadway to drive their machines on; they want an attractive entrance to your place of business; they want to be greeted with a welcoming smile, treated with courtesy and to purchase on a "one-price-to-all, money-cheerfully-refunded-ifgoods-are-not-as-represented" basis. To have the goods is not enough; you must have the rest. In order to succeed you have to advertise, whether you wholesale or retail, whether you are big or small. Make people think and talk about your goods and you will 
either sell them or keep them. But keep what you have to offer a secret, and no one ever will try to find out about it.

Every successful man advertises one way or another. Why? Because the public demands it. The modern magazine is threefourths advertisements. Why? Because the reading public like it that way. Many of these ads furnish more interesting reading than some of the so-called "reading matter" in the magazines.

Advertising that lets others know what you have to offer, if well written, is always interesting. It belongs to our age. If you have what others need, advertise it, fulfill your promises and you will grow and prosper. And keep on advertising more and more as you go along.

Take the biggest business houses of the country-they are known all over, yet they keep on advertising. They keep their names before the public. They put their advertising campaigns in the hands of experts in order to make their ads more attractive, if possible, than those of their competitors.

Wouldn't you think a Macy, a Wanamaker, or a Marshall Field wouldn't need to advertise? Yet they do, and the bigger they grow, the more they do it. So must the small business man, no matter what he has to sell, if he wants to go on and grow. If you don't advertise you draw a circle around yourself, and shut yourself off from the rest of the world. Advertise and you branch out, you find new fields opening up, nd more business is bound to follow.

* Failure in business is hardly ever caused by too much advertising. Only too often it results from not enough of it. Creating new outlets for your goods spells progress, and advertising will help do it. You buy a well-known brand of clothes, hats or shoes largely because they are well known, and the way they became well known was through advertising. According to one of the leading authorities on financial matters, eighty-four per.cent of the failures in the United: States in 1920 were of concerns that did not advertise.

There is no business so small that it is not able to advertise. The only time you cannot afford it, is when you have nothing to talk about. The man who says he has all he can do without advertising is succeeding in spite of himself and needs a competitor to cause him to change his mind and to wake him up.

Anyone starting out in business should give a part of his time to the study of adyertising. The larger concerns in his line will give him a good example of uptodate methods. Not that it is a matter of imitating, but from them he can get ideas and suggestions as to what will suit his own requirements best. By so doing he will at the same time work to keep up an attractive and inviting establishment. This, in turn, will make him take pride in showing what he has to offer to the best advantage and in giving real service. Advertising puts life into a man's business and into the man himself: 


\section{You Needn't Be a Genius to Win Sugcess}

You don't need to be a genius in order to be successful. George Washington was not a genius in any one line. Among the group of great men of the American Revolution and the fifty-six signers of the Declaration of Independence were men of remarkable abilities, yet none of them combined to such a degree the characteristics of good sense, sincerity of purpose, foresight, consideration for others, calmness, and determination that Washington possessed. Such good qualities may not be the rule with all human beings, yet it pays to cultivate them. They hardly ever make for great wealth, but strongly tend toward moderation in all things, whether work or play. They make for a healthy body and mind, for a successful life. We need the radical in the world so as to help evolution along, and with the reactionary element holding back a little, we find our balance. But a nation's greatest asset is those who make moderation the keynote in their daily lives and practice the Golden Rule.

If it is true that the world at present is going at an awful pace, it is just as certain that, at the same time, we are making for a saner tomorrow. Many a man, in order to achieve so-called success and leadership, sacrifices all that goes to make up the ideal home life. Even a night fireman may be a success in life, if he makes the best use of his opportunities, fulfills his duties conscientiously, appreciates

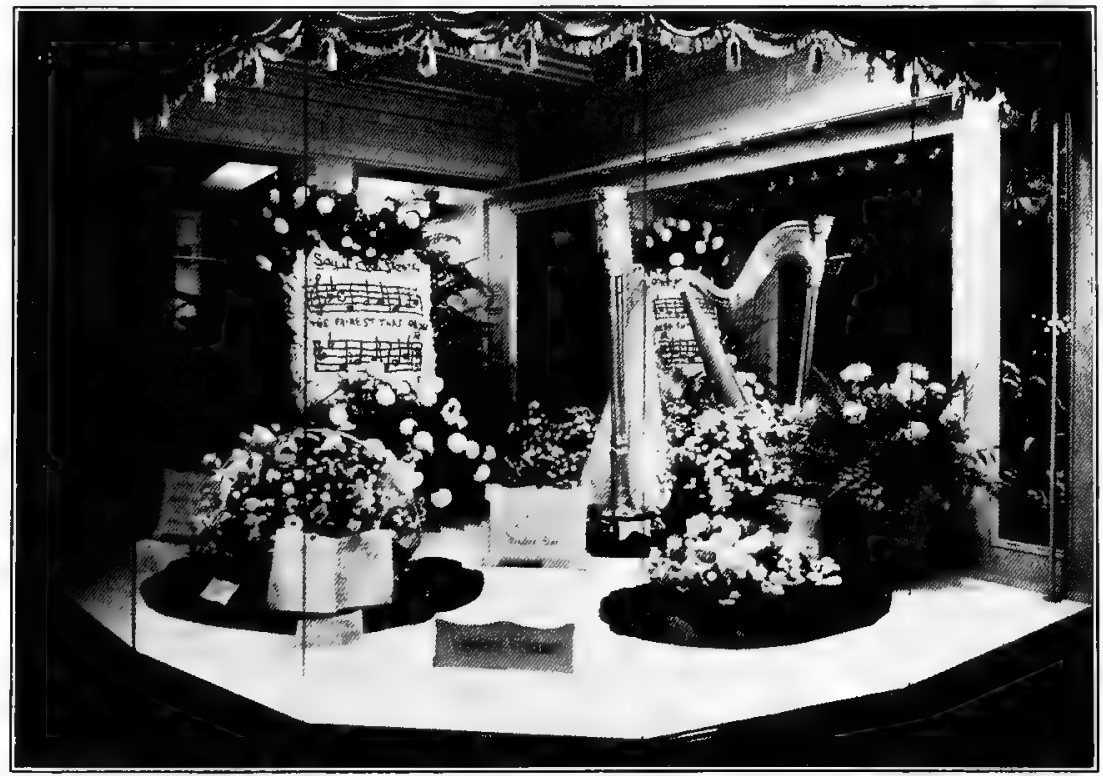

Fig. 7.-Floral Decorations for Other Lines. To be progressive and uptodate means that you must follow the example of other successful firms and let no opportunity to boost the use of flowers slip by unheeded. The above display, arranged for Music Week in Seattle, Wash., is an example of such an opportunity 
his home and those in it; and is respected by those with whom he comes in contact.

It is the easiest thing in the world for a florist to acquire the spending habit from some of his patrons or succumb to the temptation to buy doubtful stocks when he could invest his profits to good advantage in his own business-from which they came. To be successful in business and make money is one thing; to live a useful life and spend your money to best advantage is quite another. There is many a nervous breakdown that isn't caused by overwork: Yet it is well to get into the habit of forgetting all about your business when you reach home, and into the "smiling face" habit. This acts like sunshine upon those with whom you come in contact.

You rise not by pulling others down, but rather as the result of helping others up. You cannot gain anything by envying those with lots of money, but you profit much by imitating those blessed with little, but who make the best use of it. The real optimist is he who lives and works to make himself optimistic. As to troubles, "today" is the "tomorrow" you worried about yesterday-but you have lived through it.

\section{A FEW WORDS ABOUT SUGGESS}

If I depart here for a moment from the usual course one is supposed to pursue in writing a book of this kind, it is because I wouldn't consider my work complete without touching on this subject.

To be successful in whatever we undertake is what we are after. But all too often a man will think of nothing else under that name but the making of money. So much in life is valued in terms of dollars and cents, that to show a way to get hold of the dollars, and if possible, to get them easily, is frequently regarded as all important. While I sincerely hope that the contents of this book may help a good many to do that very thing, I feel as if I ought to present also my view on the deeper meaning of the word "Success," the practice of which on my part has helped me to a better understanding of life and a keener appreciation of the good and enjoyment there is in it.

It is the easiest thing in the world to dish out advice. Quite frequently those who are most liberal with it heed but little of it themselves, although oftentimes they are most in need of it. They are like the fellow who knows all about potting; who knows and can tell you just how to do it, but who, in the potting shed, accomplishes less than any of the others who don't say much, but keep on potting.

The offering of suggestions on how to be, or become, successful in life (which includes business) might be taken the same way. Yet as we go on through life, the ups and downs and changing environments are bound to make impressions on us, shape our thoughts and give rise to opinions, which sometimes may be of use to others. 
It is true that our own experiences, trials and hardships can be of but little use to the young man or woman starting out in life. In fact, I think there are but few cases wherein the son ever profited by what his father went through. On the other hand, many a socalled self-made man makes the mistake of trying to shield his boy from the very knocks and bumps that helped to make a man out of him. And the boy needs those knocks and bumps so badly! Only those who actually have had them can truly appreciate socalled success later on, while those who, in youth, always traveled on a smooth road, are hardly ever capable of getting the most out of life, no matter how long they live. Besides, in the case of reverses or a cloudy sky, they have a hard time retrenching or facing the conditions.

\section{Every Man's Responsibilities}

I haven't the young man or woman in mind just now, but rather those who either are starting into business, or are in it and might be benefited by what, to my way of thinking, makes toward a successful life. None of us, if we travel long enough, can escape moments when we ask ourselves the same question that philosopher Kant asked about life and our struggles over one hundred and fifty years ago: "What is it really all about?" But we usually get over that, and those with healthy minds will find, as man in all ages has found, that there is a lot to be thankful for, and that there are great things to be done. While we really don't know the first thing about how it all came about, we become conscious of duties we have to perform, involving ourselves and others. We recognize our responsibilities - and each one, if at all a useful member of society, has them. Whether we are rich or poor, there is work to do and a lot of it; not only in connection with our own personal affairs, but for others. These things make life worth while, and each of us can help best by doing just a little to make it pleasant for those about us, and who come within the circle of our reach.

As florists, we are very apt to judge a man's success by the amount of glass he possesses. In reality there is much more to it. To build up a large establishment, acquire wealth and reach the head of a large business are all accomplishments to be proud of, but the man with only a small establishment may, for all that, be every bit as successful, if not more so. It all depends on what use he makes of life itself and whatever he may be blessed with.

The most foolish thing is to find fault with the times and the way things are going. You can do your share in trying to solve the great problems confronting humanity-and there are and always have been some mighty serious ones. Conditions exist today for which there is no good reason. They wouldn't exist if we but knew enough, had advanced far enough and would practice more conscientiously the policy of STOP, LOOK AND LISTEN. 
We cannot change the times in which we live, but a great deal of good will come out of trying to adjust ourselves to them and to do the best we can.

In order to be successful in life, you must make the best possible use of opportunities as they present themselves. Work, play and have consideration for others.

\section{Brain Work Plus Hand Work}

John Ruskin said: "It is only by labor that thought can be made healthy, and only by thought that labor can be made happy; the two cannot be separated with impnuity."

In no other line of business has a man a better chance to love his work than in the case of the florist. In growing and selling flowers the retail grower in particular can directly and indirectly cause a whole lot of happiness. The man with a neat establishment who depends on a local trade is indeed "King Bee." He may imagine he has worries, but they are nothing compared with those of men in other lines of business, who, due to the nature of their work, actually hate it. Many of them have no chance to get the least bit of pleasure out of their daily toil. They may even acquire a fortune and yet not get anywhere near out of life what the florist in moderate circumstances is able to, day by day. That, after all counts for mostto make of each day the best you can, to enjoy your work, to take an interest in your business and all that is connected with it. Act on the square in your town and government, have things cheerful at home, be a companion to your boy or girl, read good books and help others. What more can any one do? And where is the florist who cannot practice these things?

If you do practice them, you will be truly successful.

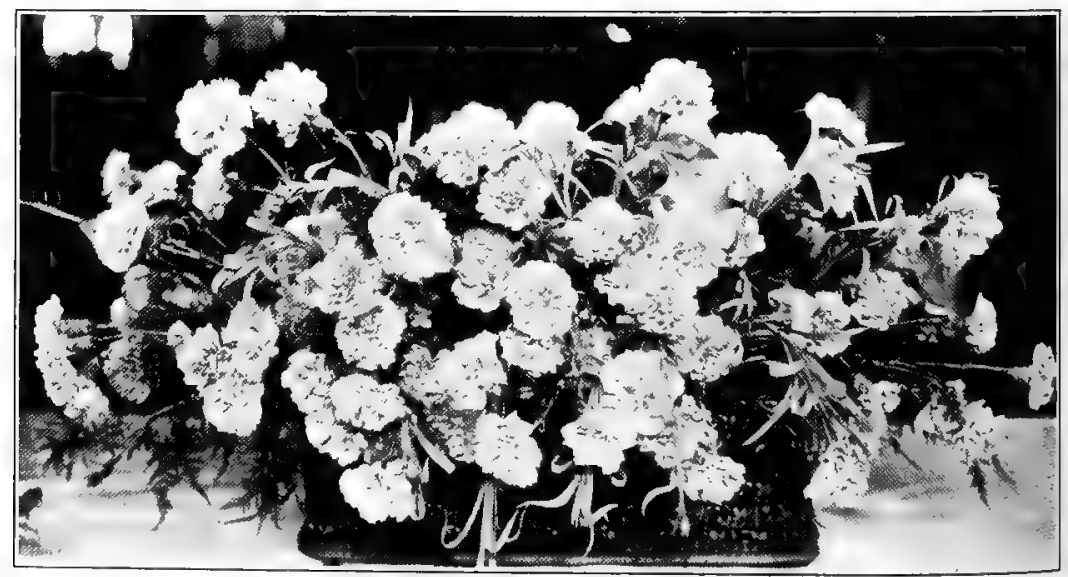




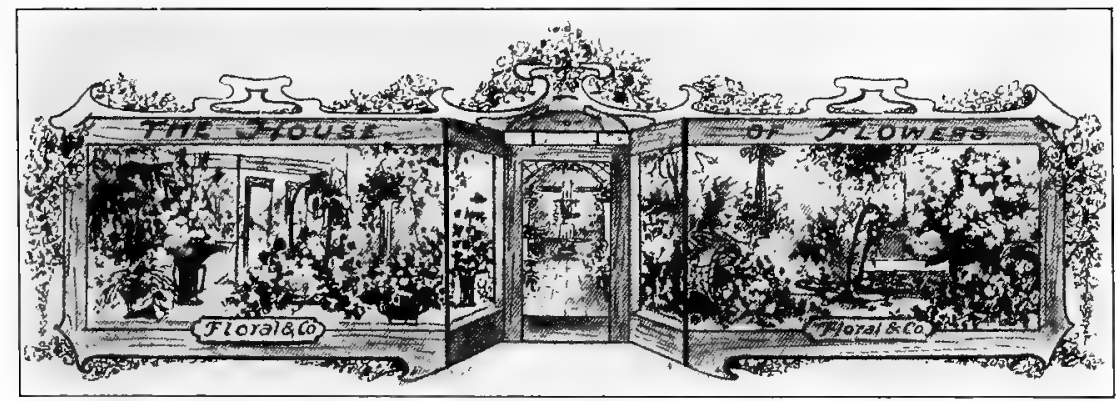

CHAPTER II

\section{INDOORS AND OUTDOORS ALL THE YEAR 'ROUND}

Things, Both Old and New, to be Done and Thought of by the Busy Man During Each Month of the Year

TN no other branch of the florist business are there more things to be thought of and more details to be attended to just at the 1 right moment, than in that of those who retail the stock they grow, who supply a part or all of the demand for hardy stock in the city or town in which they are located, and do general gardening and landscape work. All of these so-called side lines go hand in hand, and each month certain things have to be attended to in preparing for the future.

No matter how much experience we have had or how many years we have been in the harness, every. once in a while we find we have overlooked something which should have been attended to, but wasn't. To help the reader avoid this is the object of this chapter.

These notes by no means cover anywhere near all that is to be done and thought of each month. In fact, they only hit some of the high spots. But they are guaranteed to keep the average man busy and should prove of value to many, especially those who feel in need of a little reminding and assistance in order to plan and work to the best advantage. 


\section{JANUARY}

\section{General Gultural Notes}

IANUARY the first finds us in the midst of Winter, when careful $J_{\text {watering and watching the thermometer play an important }}$ part in the Carnation, Rose and other houses where plants for cut flowers are grown.

You can never go wrong with an even night temperature of 50 deg. in the Carnation houses. You may not cut quite as many flowers as those who maintain $52 \mathrm{deg}$. or over, but you are on the safe side, for you subject the plants less to chances of weak growth and disease. Your Roses according to the varieties, will stand from 8 to $10 \mathrm{deg}$. more than the Carnations, but these, too, always do best in an even temperature at night. There isn't much danger of the temperature running up too high during the day time, but whenever the sun does warm up things, give a crack of air.

Always examine the soil in the benches before you water. The appearance of the surface doesn't prove anything, for a wet surface may cover a dry bottom, and a dry surface hide a soil soaking wet below. Excess of moisture during dark weather breeds trouble, while soil reduced to a dry state by heating pipes near the benches is as bad. To my mind, there is nothing in the assertion that it is a good thing to let the soil in the benches dry out thoroughly every once in a while to keep it sweet. When you have perfect drainage and healthy plants growing in the benches, you can best encourage their future development by maintaining as nearly as possible an even degree of moisture at all times. But don't mistake for that a soaking wet condition often caused by a lack of drainage. With Roses in particular, the mistake is frequently made, according to no less an authority than E. G. Hill, of not watering them enough.

With proper drainage there isn't much danger of overwatering a bench holding 5 in. of soil, that is, if you just use a little judgment. With poor drainage you will have trouble no matter how little you water.

Do your watering in the forenoon, so as to avoid wet foliage overnight. The giganteum Lilies need a 60-deg. house from the time they are making growth, and should have a sunny bench. The formosums can get along nicely in a 50-deg. house, and those planted during October should have made from 6 to $10 \mathrm{in}$. of growth. Should you want them before Easter, let them have more heat.

The Sweet Peas may drop some of their first buds. Dark, cloudy weather often has this effect on them. Fifty degrees is enough for them. The Violets have to be watched; keep them clean and the 
soil between them cultivated. A night temperature of $45 \mathrm{deg}$. will suit them best and is enough for Snapdragons during this month. The same with Calendulas, Mignonette, Pansies, Forget-me-nots, Polyanthus Primulas, Canterbury Bells and Wallflowers. The small flowering Bouvardias can stand 55 deg., Marguerites, 50 deg., and Lupines, $48 \mathrm{deg}$.

\section{Roses for EAster}

While a great deal depends upon just what date Easter falls on, you can never make a mistake by getting the Ramblers intended for that day under way early. By that I mean let the plants, whether grown on in pots or field plants potted up in late Fall, come along in a house of 45-deg. or a little over. This will result not so much in a marked growth of the young breaks, as in the roots getting active, which will mean later on that the plants will respond more freely when subjected to more heat and more moisture. Never allow the soil in the pots to become dry, even while the plants are in a dormant state in a cold house.

You can, if necessary, give the plants during the last few weeks before Easter, a 70-deg. or 80-deg. house, if they have a 45-deg. house during January and have been getting ready to start since the end of December. But you cannot have them in a high temperature in February and then let them have a 50-deg. house three weeks before Easter in order to hold them back.

\section{Various Easter Stocks}

Hydrangeas, Bougainvilleas, Genistas, Rhododendrons, Deutzias, Azaleas, Ericas, Kalmias - all of these want not more than 45 deg. during January. Keep them cool, with the exception, perhaps, of the Hydrangeas, which during the latter part of the month might be given a few degrees more. With Hydrangeas it is always best to get them under way early; you will have no trouble in holding them back a little later on, but it is a mean job to be obliged to force them hard a few days before Easter and have to offer soft, sickly colored stock, which usually means trouble before you get through with it.

\section{Bedding Stock}

The 2-in. or 21/2-in. Geraniums most likely will need a shift, and every available cutting, if of fair size, should be placed in the propagating bench. Don't delay ordering, if you are short on stock; there is nothing to be gained by it. If there are stock plants of Salvias, Heliotrope, Ageratum, double Lobelia, Fuchsias and others still under the benches where they were placed for the lack of space, get them up now. Let them have sun and light in order that they may produce healthy cuttings. 


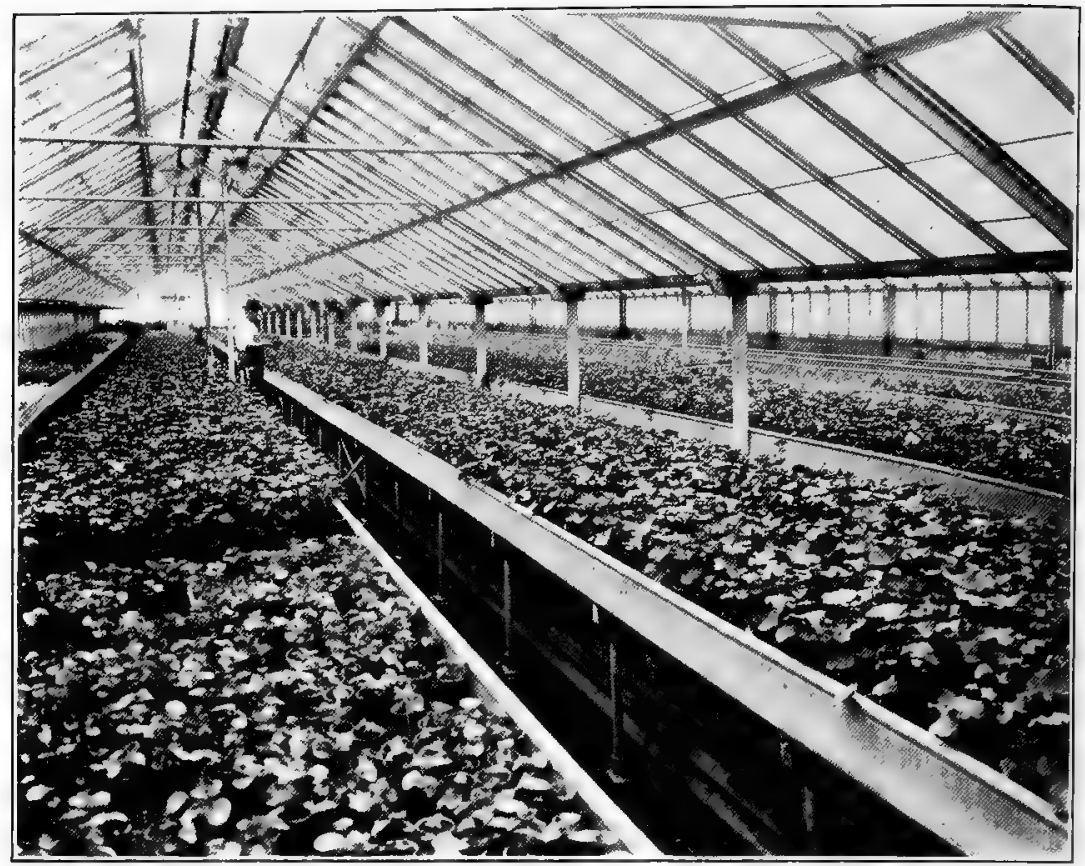

Fig. 8.-A Plant House in Winter. It isn't the good fortune of every retail grower to possess a beautiful house like this in which to grow on bedding stock during the Winter months. Notice the spacious walks; plenty of room here for a row of Vincas on either side. Note, too, the hot water return pipes under the benches, which space, especially with those whose room is limited, can be used for seed flats and for starting Cannas, tuberous-rooted Begonias, Caladiums and other stock

\section{Miscellaneous Materials}

Poinsettias and Bouvardia Stock Plants.-The cut-down Poinsettias and Bouvardia Humboldtii, require a dry place underneath some bench. The Poinsettias can remain there until the following April. Carrying over the Bouvardia Humboldtii for the second year is an easy matter, and pays.

Bulв STоck.-Always have a sufficient number of flats of Narcissi, Tulips and Miniature Hyacinths brought in from the outside, ready to be placed in heat whenever wanted for forcing. By the end of the month Golden Spur and double Von Sion Narcissi can be had in flower from flats subjected to heat below a bench from the first of the month.

Seeds to Sow.- Vinca rosea and V. alba should be sown at once, and during the month you can sow Lobelia, Verbena, the bedding Begonias, Thunbergia, Shamrock, Petunias, Maurandias and Salvias. Place your order for whatever seeds you will need so as to have them on hand when wanted. 
GLadioli.--Don't overlook the planting of at least a few bulbs of Gladiolus. That you have no bench room is no excuse for not doing so; for the bulbs can be started in pots later on. Don't overlook the Primulinus hybrids, for they are especially good for forcing under glass.

Annuals for Early Spring Flowering.-You can make a sowing now of almost any of the annuals we grow under glass and have them come into flower from April on up to the middle of May, according to the variety. Annual Larkspur, Sweet Peas, Calendulas, Gypsophila, Stocks, Lupines, Schizanthus, Poppies, Hunnemannia, double Cornflower, Snapdragons, Mignonette and others can either be sown where they are to flower, or, which is better, started in flats, pricked off into other flats, and finally grown on in a solid bed.

Keep up a nice display in the show house and store. Leftover Cyclamens should have a 55-deg. house and Paperwhites and Roman Hyacinths in flats should be brought into a coldhouse, where they will keep in better shape.

Have you made a record of the business you did during the Christmas and New Years just past? Don't forget to do it. It will belp you greatly in preparing for another year, but unless you get at it soon while the data are handy and the facts fresh in your mind, you will find it a bothersome job.

Have you brought in a few clumps of hardy Phlox "Miss Lingard" and planted them on a bench in a 50-deg. house to propagate from?

Is there enough protection on the bulb stock outdoors to keep the frost out? Plant cold storage bulbs of Lilium speciosum rubrum. By the end of the month sow seed of Cleveland Cherries and some of the Peppers for next Christmas. Sow out Dracæna indivisa and Smilax.

Fresh seed of Asparagus plumosus can now be had. Order a good supply and sow the first batch in a warm house. Plan to use these as pot plants rather than as a source of long strings which can be more economically bought from specialists or large growers.

Root cuttings of hardy Phlox can now be placed in flats filled with sandy soil. Every piece about one inch long will break. Cover them one-half inch deep and place the flats in a cool house. You may be able to purchase 2- or 21/2-in. stock of Snapdragons or Calendulas, which is just the thing for benching.

Sow Pansies this month and they will give you fine blooming stock for late Summer. If you wish to be good to Carnations which are making an active growth, work into the surface of the benches a good dose of bonemeal. 


\section{FEBRUARY}

\section{General Cultural Notes}

WHILE weather conditions may be the same as they were during the previous month, the days are getting longer, and in almost everything new life appears, a sure sign we are making toward Spring. The Carnations show it; they can stand a light feeding if you haven't attended to this already last month. Maybe a mulch, half soil and half well-decomposed manure will be best. Watch the temperature and water carefully as before.

The Sweet Peas are making an active growth, and after the first crop is off, a light mulch and maybe a dose of sheep manure will benefit the plants and make for a fair second crop. The Snapdragons can stand $50 \mathrm{deg}$; keep the flowering stems free of lateral growth.

\section{EAster Stock}

You can judge best for yourself about the Lilium giganteums: being on time. Six weeks before Easter you should see the buds; this will get them in nicely, but there are many growers who do it in less time. It can be done if you can put on plenty of steam. Increase the temperature a little for the Ramblers in the pots; they should start into growth now. And the same with the Hydrangeas. Pot up a few Bleeding Hearts and variegated Funkias and place in a 45-deg. house; increasing the temperature later on. Spiræa japonica or S. astilbe potted up a few weeks ago can be kept underneath a bench until growth appears; the plants will come along all right in a 55-deg. house if wanted in flower by early April.

\section{Hybrid Tea Roses for Summer Flowering}

If you haven't already potted up a good number of Hybrid Teas for Spring sales and outdoor flowering, get at this work and place the plants after potting in a frame or coldhouse. Maybe you have two- or three-year-old bench plants on hand to be replaced by young stock. Withhold water from them gradually, and when in a dormant state, lift, cut back a little and pot up into $5 \mathrm{~s}$ or $6 \mathrm{~s}$. You might say that all the Roses we grow under glass today are fine for Summer flowering outdoors, but of course some are better than others, and few equal Columbia.

\section{Perennials and Bulb Stock}

Stock heeled in last Fall in frames should be potted up now. If you have plants of Aquilegia, Delphinium, Coreopsis, Gaillardia, Pyrethrum, Achillea, or others that are too large for 31/2-in. pots, they can be divided. After potting, place the new plants in a coldframe and give a good watering. A little frost won't hurt them. 
You can also pot hardy climbers and Ramblers now, and place them with the perennials in a frame.

With each week it becomes easier to bring Dutch bulb stock into flower. It is easier and there is less loss, because you are getting nearer its natural time of flowering. Be sure to provide a dark, cool place for the plants in bloom; it will give you better finished flowers and they will last longer.

From now on, you will have no trouble in forcing Lily of the Valley.

By the middle or end of this month your stock plants of Chrysanthemum should be brought from the coldhouse to a 50-deg. temperature. Plant them out if you have a sunny bench, where they will soon be full of cuttings. These, when rooted, can be planted out again as stock to take more cuttings from.

\section{Propagating Bench and Seed Bed}

With all kinds of bottom heat you can root almost anything from a Cincinnati Begonia to Parlor Ivy. Carnations root best in a house of $50 \mathrm{deg}$. with a little heat below the sand. Keep the sand full of cuttings of bedding stock. Salvias rooted in February and grown cool will make fine 4-in. stock by the end of May; the same holds good with Fuchsias.

Root variegated Vincas and English Ivies, of not too soft a growth, now. Also root Ivy Geraniums, Rose Geraniums and Lantanas and don't overlook the trailing Fuchsia for basket work.

Lobelia, early Aster, Begonia, Coleus, Petunia, Dusty Miller, Salvia, Ageratum, Thunbergia, Verbena, single Dahlia, Pansy, Forget-me-not, Pyrethrum and Coleus are only some of the many seeds of bedding stock to be sown in early February. Also for early flowering plants of Primula chinensis and P. obconica seed should be sown.

\section{Miscellaneous}

Get ready early with advertising for St. Valentine's Day, which each year grows more important. Watch your cut flower crops a little and do not cut too close the week before, so as to have a good supply on hand. Sweet Peas, Violets, Pansies, Forget-me-nots, Freesias and Mignonette are all desirable flowers for corsages. But push flowering plants as well - and that means that you must have a stock of them on hand.

Start tuberous-rooted Begonias, fancy-leaved Caladiums and Gloxinias this month. Keep the Pelargoniums shifted. Place a few Genistas in a Carnation house by the end of the month. It is time to sow Asparagus plumosus and A. Sprengeri.

Sweet Peas sown by the middle of the month will give you a fine crop during May. 


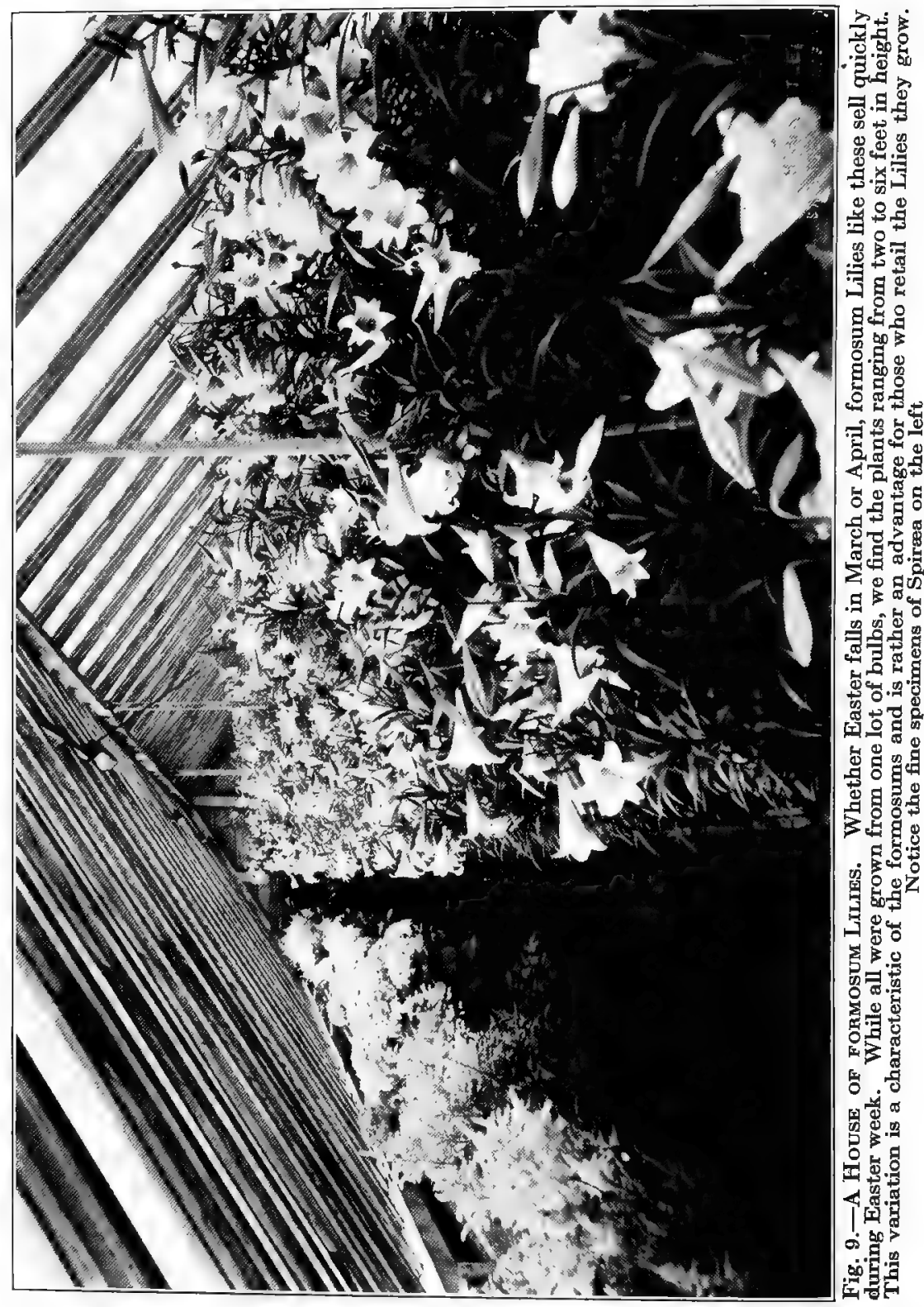


Give Calceolarias the final shift. Marguerite cuttings rooted during February will make good 4-in. pot plants by May and June for use in veranda boxes. Feed the Callas in pots with weak doses of liquid cow manure.

The heavier roots of the small flowering Bouvardias cut up into 1-in. long pieces and placed in sand with bottom heat will soon break into new growth, while the best way to root B. Humboldtii is by means of softwood cuttings.

The small shoots at the base of the larger plants of Pandanus Veitchii will easily root in warm sand now; Dracæna terminalis canes cut up into 2-in. lengths will also root and break, and the tops of this variety can be removed from old plants and rooted now. The same holds good with Ficus. Place the stock plants of Coleus in a 60-deg. house if you want material in the way of cuttings for propagating. Quite a number of perennials can be sown indoors now and grown on for planting out in May. Among these just a few are Oriental Poppies, Larkspur, Columbine, Gaillardia, Lychnis, Shasta Daisy, Polyanthus Primulas, Pyrethrum, hardy Pinks, Rudbeckia, Anchusa and Valeriana:

\section{MARCH}

\section{Easter and Other Bulb Stock}

THE Lilies, perhaps, head the list of the many Easter plants. They may need extra pushing in order to get them in on time. Hardly ever, with Easter falling around the end of March, is there much holding back to do when giganteums are made use of. The same holds good with the Ramblers and Hydrangeas; with the latter a week or so in a cool house before Easter will not only harden off the plants, but also bring out the coloring of the flowers better.

Deutzia gracilis, Bougainvillea, Rhododendron, Azalea, Spiræa -in fact, almost any plant-can, by the middle or end of March, be subjected to a high temperature without bad results. If found a little late, there is no alternative but to resort to forcing. The hothouse is, however, of no greater importance than the cold one in which, if necessary, things can be kept back or at a standstill for a few days.

Whatever is being placed in strong heat must be given extra attention in regard to spraying and watering. To apply ice-cold water to a Lily or anything else to be forced, and in an 80-deg. or 90-deg. house is a foolish thing to do, and you are bound to hurt the plants by allowing the soil in the pots to dry out. The more you force, the more it becomes a necessity to harden the stock off a little before it is placed on sale.

To have double Tulips in flower by the end of March will require close on to twenty-five days in a 55-deg. house, allowing a 


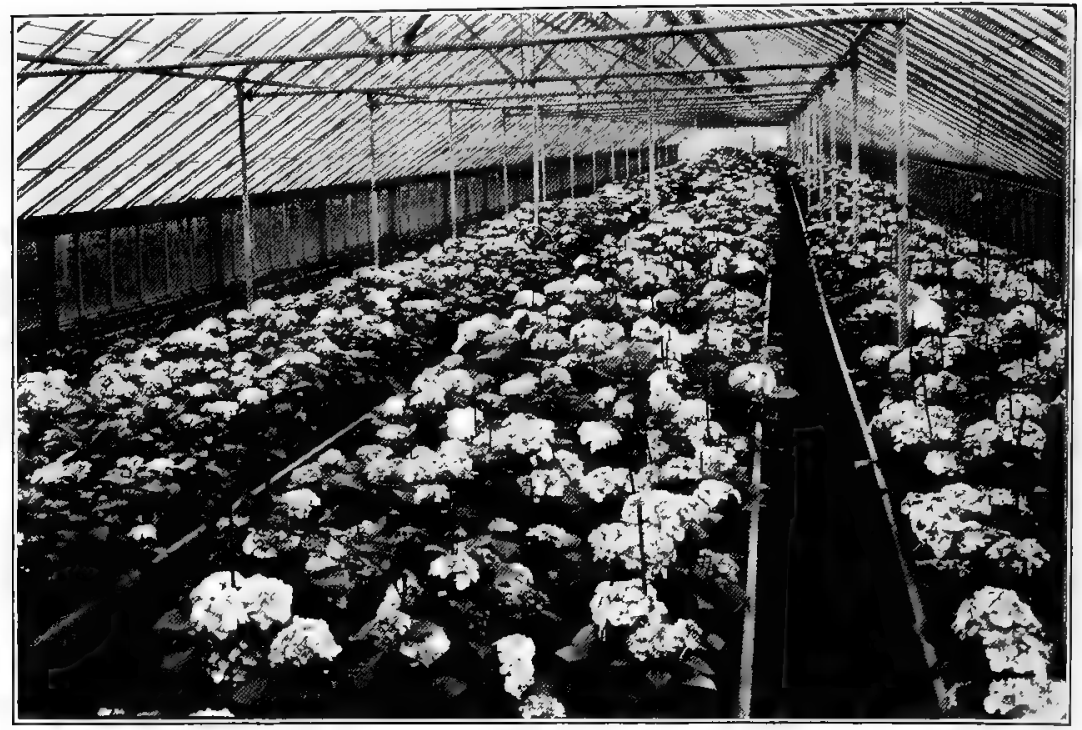

Fig. 10.-A House of Hydrangeas. With proper heating facilities and a whole house devoted to Hydrangeas, it is far easier to time the plants so they will come in just right for Easter than when only a few plants are carried in a house of mixed stock

few days in cooler quarters toward the end. Darwins will require a few days longer, Narcissi a few days less, and the same with Hyacinths. If you have proper quarters in which to place the open flowers, always give them enough time.

\section{In the Gut Flower Houses}

No matter how wintry the weather on March the first, we are, for sure, on the way to Spring. The sun again plays an important part in warming things up during the daytime and the plants show the beneficial effects of it. There is less care needed in the houses for Nature is helping along and young, healthy growth can be noticed everywhere. Stock which has stood still is beginning to make headway, especially in the case of the Sweet Peas; you should be cutting, toward the end of March, your best flowers from those sown just after the Chrysanthemums. The same holds good with the Calendulas and the Lupines. The Canterbury Bells can go into a 50-deg. house now and the Snapdragons can stand even more.

\section{For Memorial and Mother's Days}

For a crop to cut from by the middle or end of May, double Feverfew benched in March is fine. Stocks sown out by the end of February or early March will be just right and the same with Snapdragons and Larkspur. Another good crop is ' Candytuft, 
which should be sown in early March. Schizanthus is an excellent cut flower; Gladioli planted in March will flower during May; and the double Cornflower can be had at its best under glass. Canterbury Bells make showy cut flowers if moved from the coldframes to a Carnation house temperature in March. Another splendid plant to cut from is hardy Larkspur; grow it on in solid beds in a 45-deg. house during March, increasing the temperature later on. Gypsophila elegans should be sown indoors from January on up to the middle of March, a little seed every ten days or so. Shirley Poppies sown in March make fine cut flowers during May and should be grown cool: Ageratum grown from seed furnishes desirable blue flowers during May; you can sow the seed out where the plants are to flower on solid beds, thinning 'them out to 3 or 4 in. apart in the row. The blue Lace Flower (Didiscus) is another good cut flower, and just the thing if you want something a little out of the ordinary. Calendulas will produce large flowers and long stems if sown about the first of March and planted on a solid bed in welldrained, rich soil.

Almost any of the above, if sown during the latter part of February or early March, will flower for Mother's Day. A great deal depends, of course, on weather conditions. Besides these plants you should set apart a good number of flats with bulbous stock to be brought inside about the middle of April. As important as any are the Darwin Tulips of the lighter shades, not overlooking "Rev. Ewbank" with its beautiful soft shade of heliotrope.

\section{Bedding Stock and Miscellaneous}

Make another sowing of practically all the seeds sown in February. Be sure of enough Rosy Morn Petunias, and don't overlook the giant California ruffled and fringed singles and Balcony Queen. Sow out a package each of Musk Plant and Sensitive Plant as these always attract attention.

Start the Cannas, the Caladiums (C. esculentum) and a few Tuberoses. Put in a good batch of Impatiens, it is always desirable for shady positions. Also more Salvia. Heliotrope from cuttings rooted in March will make the best plants. So with Cuphea and double Alyssum.

Get the hotbed sashes in shape as well as the frames. You will want them soon. Prepare enough transplanting flats, provide potting soil, and order what bedding plants you are short of to be delivered right after Easter. Have you enough pots on hand?

Keep on planting Gladioli, sow Sweet Peas in pots to be planted in the field later on, and pot up the Carnation cuttings as soon as they are rooted. They suffer if left in the sand too long. Give the variegated Vincas their last shift; they need a rich soil. 
Order fertilizer and let your patrons know you have on hand what they need for their lawns and gardens. The same with grass seed. Order the shrubs you will need for Spring planting.

The little Gyclamen most likely will need a shift, but don't overpot them. They should have a 55-deg. house and a sunny bench. Start to root 'Mum cuttings of the early sorts.

Sow out Tomatoes, Eggplants, Bullnose Peppers, Early Cabbage, Cauliflower and Parsley. There are always some among your patrons who are willing to pay a fair price for large Tomatoes, Eggplants and Sweet Peppers in pots during May and June.

Propagate Stevia this month and include the dwarf double sort. Root Genista cuttings with a little bottom heat.

\section{APRIL}

\section{BEDDING Stock}

SPRING is here for sure now, and in the plant houses we have to $S$ step lively in order to keep up with things. With Easter out of the way, the Geraniums want their final shift. Strong $21 / 2 \mathrm{~s}$ can be shifted at once into $4 \mathrm{~s}$, and the same holds good with Salvias, Petunias and Heliotropes. For the Geraniums, make use of a heavy soil and pot firmly.

There is still time to root cuttings of many plants which, in from eight to ten weeks at this time of year, will grow into salable stock. Among these there are the Salvias, Petunias, Ageratum, Heliotrope, Lantanas, Abutilon, and others. Make your main batch of Coleus cuttings toward the end of this month; in a month from the time you place the cuttings in the sand you will have salable plants in a $2-$ or $21 / 2$-in. pot.

Have you a good stock of Mme. Salleroi Geraniums? You will need this old favorite as it is still used a great deal for bordering. Then you most likely will have call for some of the other variegated leaf sorts such as "Happy Thought," "Mountain of Snow," or "Bronze Bedder." Look over your stock and make note of what you may be short of; your assortment should be complete. See if you have all of the following: Rose Geraniums, Lemon Verbenas, Lantanas, double and single Lobelias, double and single Sweet Alyssum, Cupheas, variegated Glechomas, German Ivies, Impatiens, Achyranthes, Abutilon for bordering (such as "Eclipse," or "Savitzii"), small Bostons for veranda boxes and vases, Asparagus Sprengeri for the same purpose, Alternantheras, Fuchsias, Ivy Geraniums, Pelargoniums, Dahlias, Cannas, Ageratums, Heliotropes, English Ivy and bedding Begonias. If short you will have no trouble in obtaining either rooted cuttings or $21 / 2$-in. stock of most of these items. Don't carry just Geraniums, Cannas and Salvias. You need more of an assortment-in fact, the larger it is, the better. 


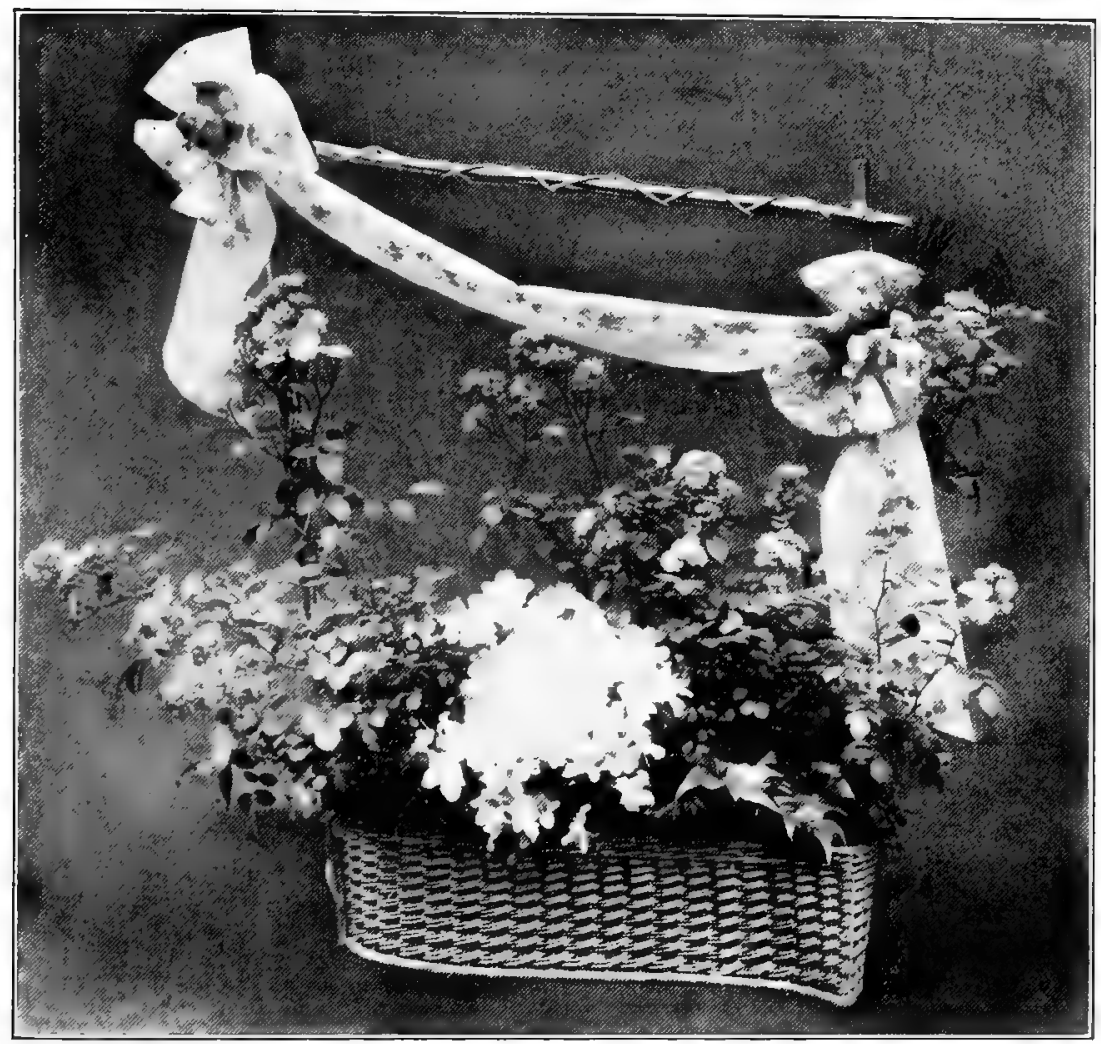

Fig. 11.--Av Azalea Basket for Easter. Pink Baby Rambler Roses and a white Azalea in a gilded wicker basket make a good combination for patrons who want something really showy irrespective of price

\section{USING THE HotBeds}

Why not make good use of the hotbeds during this month? A lot of bedding stock can be grown to perfection in frames with just a little bottom heat. There is no better place for Alternantheras, Fuchsias, Lobelias, Begonias, Geraniums, Cannas, Heliotropes, etc.

About the middle of the month sow annuals to be sold for planting out by the end of May. Your patrons will want them. The ones which have, perhaps, the most call are the Asters, Zinnias, Marigolds, Calendulas, Snapdragons, Scabiosas, Everlastings, Cosmos, Verbenas, Balsam, Salpiglossis and annual Larkspur.

There is always a demand for 21/2-in. annuals of the above mentioned sorts and seed sown by the last of March or first of April will give you seedlings ready to be potted up by the first of May in plenty of time to make fair stock by first of June. Snapdragons and Salpiglossis will take a little longer. Don't neglect to have a nice lot of early flowering, outdoor Chrysanthemums to offer in May. 


\section{Flowering Plants for Next Winter}

The largest of the Cyclamens should go into $3 \frac{1}{2} \mathrm{~s}$ now; they will do nicely in the house where your best Geraniums are; that is, for the next eight weeks.

The first sown Primula obconica will be in $2 \frac{1}{2} \mathrm{~s}$, and well established by this time, so make a second sowing. Primula chinensis, if wanted for December flowering, should be sown now. By the end of the month make the first sowing of Cinerarias if you want flowering plants next November. Get the dormant Poinsettias up and after potting them, place them into a $60-\mathrm{deg}$. house. They will furnish you cuttings byJune.

Propagate a good batch of the old favorites in Begonias and include a good number of Chatelaine; they will come in handy next Fall and Winter. Cincinnati Begonias can, from the end of April on, be handled in the average establishment without much trouble; you will want well-established 2-in. stock to start with.

While not used as flowering plants, the Cleveland Cherries are of no less importance to the average florist; if you have no small stock you can purchase some now-and the same with the various Peppers.

The small shoots from the base of the Hydrangea plants will furnish good cuttings now; these root easily, to be planted out later on or grown on in pots.

\section{The First Outdoor Work}

Work the ground as soon as possible to get things ready for planting out, but don't handle heavy soil while in a wet state. Sow Sweet Peas as early as possible. Lining out stock of shrubs should also be planted as soon as weather conditions permit. Small conifers are best transplanted when the ground has warmed up a little. Push the sale of shrubs; get into this profitable side line. Gradually remove the covering from the perennials and the bulbous stock.

The 21/2-in. Carnations can now be brought in to a coldframe to harden off a little. Protect them with sash during cold weather. The Sweet Peas in pots can also be brought out into a frame. Plant a nice batch of Gladioli in a frame. Sow double Cornflowers in a frame, also Gypsophila elegans.

Dormant bench-grown Roses can still be potted up for Spring sales. Don't overlook Killarney and Butterfly. Pot up some more cold storage Lilium giganteums and $\mathbf{L}$. speciosum rubrums. Pot up, in early April, the dormant Bouvardia Humboldtii plants and cut them back a little. Pot up dormant Ampelopsis Veitchii, Glimbing Honeysuckles, Wistarias and other climbers to be sold during Spring and Summer out of 5-in. and 6-in. pots. Get ready to plant Roses out of 2 -in. or 21/2-in. pots for indoor flowering. The early Chrysanthemums should be benched by the end of this month. 


\section{MAY}

\section{The Bedding Stock}

THERE are still thousands of plants to be shifted and many more to be transplanted; in fact, there's no end of work to do. The last lot of plants isn't nearly ready before the first is ready to go out. Try to manage to have stock coming along up to the middle of July, for while a lot of business is done before Memorial Day, with many bedding out doesn't really start until June is under way.

Keep on propagating, transplanting, sowing, and don't let up. Start the filling of veranda boxes and hanging baskets early. There is nothing like having a good sample on hand for visitors to look at.

Space the large Geraniums a little to give them room for proper development. Keep the large Petunias tied up, and the same with the Cobæas. It's cheaper to do that than to ruin the plants, which means a total loss and waste. Watch the hotbeds and the coldframes; proper watering and ventilating mean everything. Don't get caught napping during a cold night. The potted Hybrid Tea Roses, however, have had no sash over them for the past month and don't need any; you don't want them to make much of a growth or get soft.

\section{More Work Outdoons}

Here, as well as inside, there is no end of work. The Carnations should be planted and a little frost won't hurt them if they have had a chance to harden off a little in a coldframe.

Plant the Dahlias and Gladioli. Start to cultivate the herbaceous plants, which were overwintered outdoors. A little manure worked in between the Peonies won't hurt. Plant out the young Phlox you propagated during the Winter months and the perennials grown from seed sown during the latter part of January and in February.

You can still divide Shasta Daisies, Iris and other hardy plants if short on stock, but the earlier in the season this is done, the better. Get a seed bed ready now and sow more biennials and perennials such as Canterbury Bells, Foxglove, Larkspur, Columbines and others which take rather a long time to develop.

If you are short on Phloxes, purchase some now and get the benefit of a season's growth. This holds good with many other perennials you may wish to work up a stock from. Why not plant out a few long rows of small Spruces, Pines, Arborvitæ and Cedars? They will grow into money while you sleep and are bound to come in handy some day. The same is true of Berberis Thunbergii, Lilacs, Bush Honeysuckle, Weigela, Red-Twigged Dogwood, Forsythia, Philadelphus, Hydrangeas-in fact, almost 


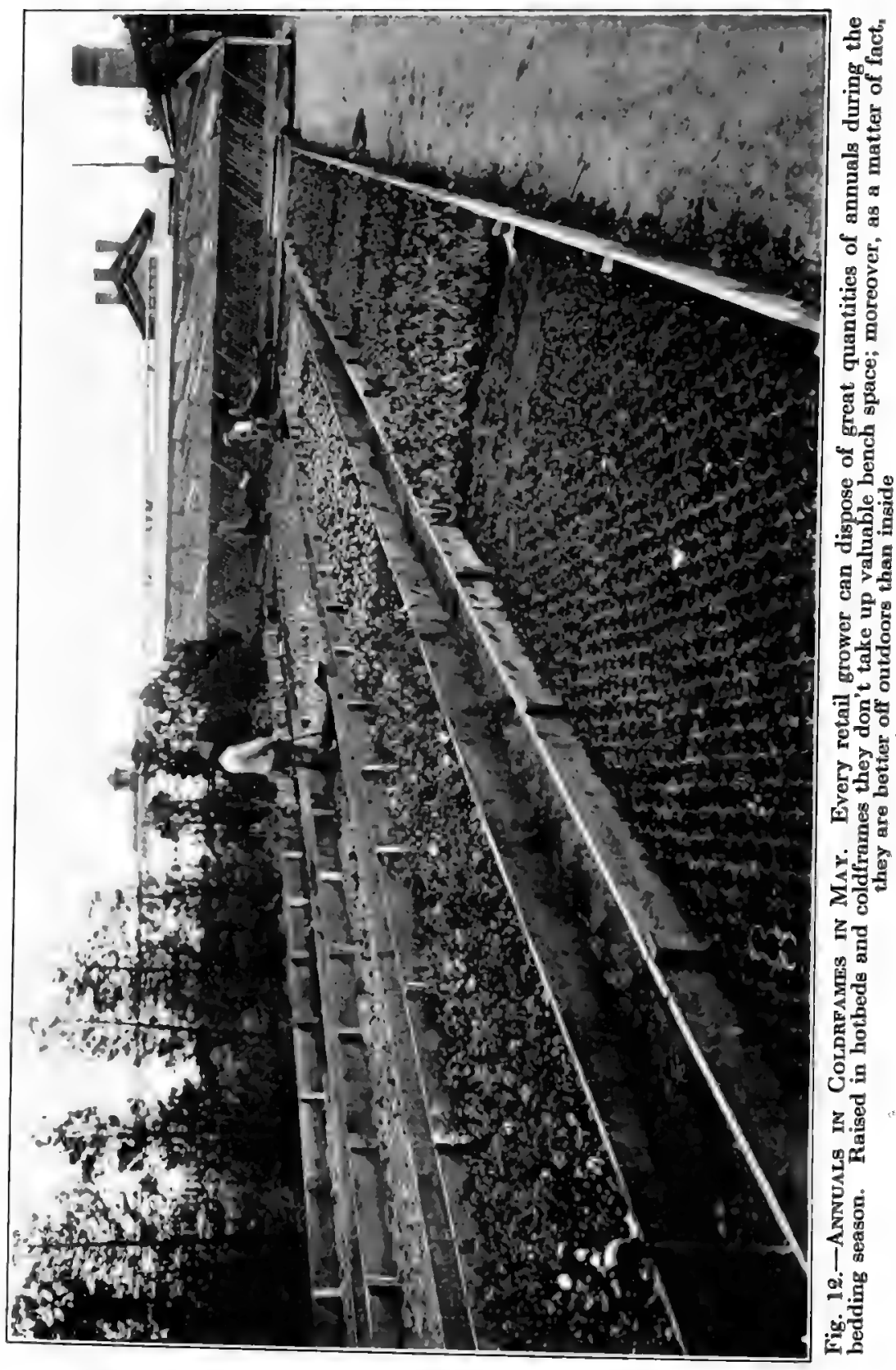


anything in the way of shrubs. You can purchase lining-out stock in the neighborhood of $\$ 25$ to $\$ 30$ per 1000 and, if you have space, what about planting out a few Red Leaf and Cutleaf Maples, Horse Chestnuts, Elms, Ashes, or other small trees? They will all grow into money.

\section{Sow Summer Flowering Annuals}

Sow this month outdoors where they are to flower, seeds of annuals. Among such we have the Centaureas, Gypsophila, Candytuft, Eyerlastings, Zinnia, Larkspur, miniature Sunflowers, Schizanthus, Celosias, Scabiosa, Snapdragons, Salpiglossis, Calliopsis, Marigolds, Cosmos, Calendulas, Poppies, Nasturtiums, Clarkia and others. Asters are better when transplanted from the frames. For the late ones seed should be sown by the end of this month outdoors; later, transplant the seedlings where they are to flower.

\section{The Chrysanthemums and Their Care}

With most florists the Chrysanthemums are one of the important crops. May first should find us well under way with a nice lot of $21 / 2$ s on hand of the early and midseason varieties and such as are to be grown on as pot plants. Keep the sand full of rooting cuttings and keep more coming along on the stock plants. You will need shade on the cuttings now. By all means make a note of what young stock you have on hand, map out exactly what benches are to be planted, and, if short on certain varieties, order without delay.

Are you going to grow a few of the very early Pompons outdoors to be protected with temporary frames and sashes next Fall? It will pay you.

\section{Miscelilaneous}

In early May, sow out another lot of annuals in coldframes. They may come in handy when the earlier hotbed-sown ones are sold out. A few rows of Zinnias, Cosmos or Scabiosas don't take up much space, but, even when sold at a low price, they will bring in more money for the space they take up and the work you have with them than almost anything else. If you are going to have an empty house with solid beds which are not going to be used until Fall, consider planting it with a good strain of Asters. Snapdragon will also make a paying crop.

Carnations out of 3 - or $3 \frac{1}{2}-$ in. pots can be benched in May or planted on solid beds. Some growers are very successful with this method of culture.

Cold storage speciosum Lilies started in February or March, can also be planted out under glass. You can also plunge a few of them in pots out in a coldframe. Shift a few of your tuberous-rooted 
Begonias into larger pots. Don't wet the foliage of the Gloxinias too much; you want them for show during the Summer months, and the same is true of the fancy-leaved Caladiums.

\section{JUNE}

\section{Bedding Stock Progress}

TO plant out a bench of your best Geraniums for stock is always a good investment when you use many thousands of them each Spring. No good grower will wait to select his stock plants until the end of the bedding season and take what is left.

When things begin to thin out in the plant houses is the time to keep on moving the remainders together. Your stock will look better and is easier to take care of that way. Plant out enough Cannas for stock, but only the very best varieties, such as The President, Mrs. F. Conard, Hungaria and King Humbert, which are among the most desirable of bedders today.

Don't wait until the last variegated and green Vinca and English Ivy are gone before you order more. You are not through with your bedding plant season when your own stock is gone; keep on preparing until there is no more demand. If you have grown on enough Petunias from seed sown at different times and kept the stock transplanted and shifted, you can always do business away into July.

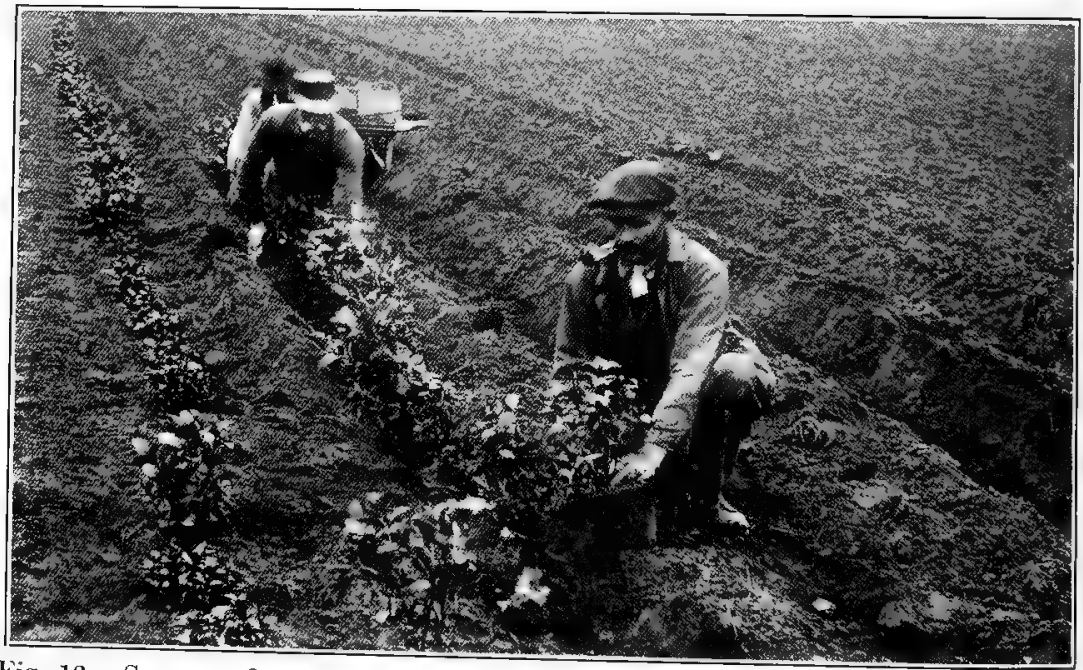

Fig. 13.-Setrting Out Hydrangens from Pots. No matter how much bedding out you have to do for your patrons-for ornamental effect, of course- - you cannot
afford to neglect setting out your own stock plants when it is time to do it 


\section{OUtdoors and Indoors}

Resow where the seed of any annuals failed to grow; transplant Asters; plant a few more Gladioli or Dahlias out of pots; plant out a part of your Cleveland Cherries, and let the others grow on in pots. Plant out either rooted cuttings or 2-in. stock of variegated and green Vincas and English Ivies. Small Dracæna indivisa plants can also be planted out in the field; the same with Hydrangeas. Plant out Stevia, too.

Finish planting Roses and Chrysanthemums and start repairing benches in the Carnation houses. Clean up on top of and below the benches, whitewash, paint, scrub, do everything to make things clean and sweet.

Get the soil ready for filling the Carnation benches. Shade the fern and palm house, but don't get things too dark for the Bostons; they don't need it. A little shade on the Carnation houses will help along, that is, for the old plants still giving you fair flowers. The young stock doesn't need shade, in fact, it must have all the sun possible, as well as plenty of ventilation.

A good, heavy soil is necessary for the Rose benches and it won't hurt the Chrysanthemums. Don't forget that October and even November varieties can be flowered outdoors in normal seasons over much of the country. Handle and support like those indoors and protect with sash top and cloth sides in late Fall. Plant Smilax out of 21/2-in. pots this month, and put up the wires and strings at the same time. For November and early December flowering, plant now, out of cold storage, Lilium speciosum vars. rubrum and album. You can also plant to advantage cold storage Lilium giganteum. Start to dry off the Callas if not already done; but keep on shifting small plants of Godfrey Calla into larger pots. Start to root Poinsettias now; the early ones are best for benching, and will give you the largest stems and bracts. Go over the palm house, shift plants, clean leaves, apply a mulch to some, and throw out what are no good.

\section{Looking Ahead a Littue}

Put away nicely the hotbed sashes not wanted any longer; the same with the flower pots, keeping each size by itself. Order the Bamboo stakes, the wire, and the twine that will be wanted later on for the Chrysanthemums and the Carnations. Stock up with insecticides, which you will need right along. Buy paint and putty, as well as glass for repairing the roofs later on. Don't put off whatever changes or alterations you intend making on the place; June, while only the beginning of Summer, is the time to start such work if you want to get through before Fall. Plant out a few Buddleias, they give fine cut flowers. 


\section{JULY}

\section{Outdoor and Indoor ACtivities}

KEEP the cultivator working overtime. There is nothing quite I as beneficial as cultivation; it beats manure and rain. Keep the soil stirred up and let it breathe. The drier the season the more cultivation becomes a necessity. In early July, sow Hollyhocks, Gaillardia, Coreopsis, Pyrethrum, hardy Pinks, Shasta Daisies, Columbine, Helenium, Delphinium, Anchusa, Sweet William, Rudbeckia, hardy Primulas, Achillea, Heliopsis, Hibiscus and others.

A planting of Gladiolus about the tenth will result in a late crop of flowers. Sow another lot of annuals such as Zinnia, Larkspur, Cosmos, Schizanthus, Calliopsis, Scabiosa, Candytuft, Salpiglossis and Calendulas.

Sow Cinerarias and Calceolarias, more Primula chinensis and P. obconica, also P. malacoides. Attend to the shifting of the $\mathrm{Cy}$ clamens and Begonias, but do not overpot. It is time now to obtain small table fern seedlings and pot them up into $21 / 2 \mathrm{~s}$ for next Fall. If you can spare the bench room, you cannot devote it to anything better than Boston Ferns. Small stock planted out now will result in salable 5-in. and 6-in. pot plants by October. Plant Asparagus Sprengeri in a deep bench or in large-sized hanging baskets; you will need the green during the Winter months. Bench Bouvardia Humboldtii now. Sow seed of a good strain of pink Snapdragon for Winter flowering.

\section{Carnations and Ghrysanthemums}

Get the benches filled with soil and start to plant by the middle of the month. Select cloudy days if you can, but do not wait a month for them. Stock left in the field should be kept cultivated and pinched back if you want to sell the plants for housing. If not, let them flower; they will keep it up until frost, and will pay well for themselves if you are in a position to retail the flowers.

Keep the newly housed plants pinched; don't overwater; and cultivate the surface of the soil lightly, the oftener the better. Any plant with the least sign of stem rot should be removed at once, and a little of the soil surrounding it as well. Don't have shade on top of the house any longer than is necessary, and spray the plants rather lightly several times during the day.

Shift and pinch the pot plants and pinch the Pompons. If the plants in the benches are once well established there isn't much danger of overwatering, but be careful just the same.

Keep the stock sprayed regularly. Do not miss this, it will help more than anything else to keep away trouble, not only in the way of bugs, but of disease also. There is still time to bench very late 
varieties, for which purpose rooted cuttings often answer, especially if they consist of Pompons. Small Poinsettia stock can be benched now.

\section{Repains and Preparations}

Keep the hammer and the paint brush busy. Look over the heating plant. Clean the boilers, inside and out, below and on top, and the smoke stack as well. Look out for coal. Get busy on the roofs. Keep the show house attractive. If you haven't ordered all your requirements in Freesias, Paperwhites, Lilies and Dutch bulbs, do so now. You will want bulb flats soon; do not have them less than 3 in. in depth nor too large in size.

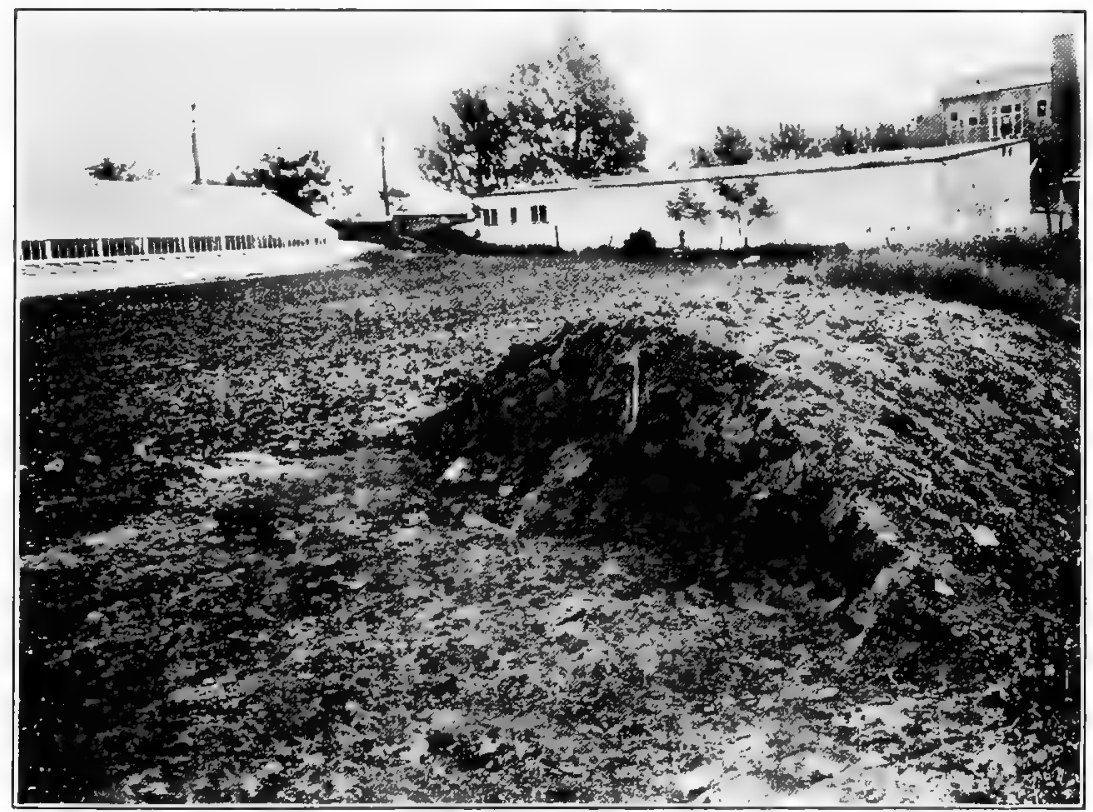

Fig. 14.-SoIl Ready for Summer Benching. It is always a great advantage to have a good-sized pile of soil near the greenhouses and easy to get to. It will save worry and delay

\section{AUGUST}

\section{Conventions and Cultural Notes}

I $F$ there is not any new building or any extensive repair work going on, August is usually the quietest of the twelve months in the year. It has always been so and was therefore selected as the best month in which to hold the annual S. A. F. and O. H. Convention. Attend, by all means, if there is any way to do it.

The Carnations should be all housed before the tenth, and the whole establishment be in first-class shape, ready for Fall, which will soon be with us again. 
The Roses, Carnations, and Chrysanthemums in the benches need their usual amount of attention in the way of watering, cultivating and spraying. With just ordinary care they will make good headway. Everything is now in favor of plant growth-light, heat, and fresh air; and with normal conditions, things usually move along nicely.

Watch your Cyclamens. They and the Begonias all need a little shade, plenty of moisture in the houses they are in, and liberal sized pots. With the approach of cool nights they all seem to grow better and make more headway.

There is not a great deal that's new to be done outdoors. Cultivating and cutting flowers so as to not let them go to seed are the main items of the daily work. By the end of the month Iris and Peonies can be lifted and divided, and one can do this with quite a number of other kinds of hardy stock. All of the biennials and perennials sown a month or two ago are now ready for transplanting, and more may be sown. A first sowing of Pansies can be made about the first of August, followed by a second toward the end of this month. The same with English Daisies and Forget-me-nots.

Hydrangeas, Genistas, Bougainvilleas, Roses and other stock grown on during the Summer months in pots demand careful attention in regard to watering. If out in the open, always plunge the pots up to their rims in the soil, and help along with a light mulch.

\section{Start Gychamens and Freesias}

For extra strong Cyclamens you should sow seed by the end of July or early in August. It takes in the neighborhood of sixteen months to grow Christmas-flowering stock.

A first planting of Freesias may be made in early August. Make use of the larger-sized bulbs for the purpose. If done on a small scale, it is as well to start them in pots outdoors in a frame. Do not cover the pots over with soil, as you would with Dutch bulbs, but place a shade frame over them to prevent the sun from drying the soil out. Five good sized bulbs are sufficient for a 4-in. pot.

\section{Sowing and Rooting Future Stocks}

Pinch back the Stevias, the Gleveland Gherries and the Bouvardias. Of the latter, the small flowering varieties are just as well planted outdoors during Summer, and the plants carefully lifted during August and planted on a bench. You can treat Bouvardia Humboldtii in the same way, but it is just as well to plant the stock under glass in May or June.

For next Spring's use for the filling of window boxes sow, by the end of July or early in August, Grevillea robusta. This is a most useful plant for the retail grower. Plant out a few leftover double 
Sweet Alyssums along the Carnation bench. Grow on a few Mrs. F. Sanders Marguerites in pots for Winter flowering, to be planted on a bench or solid bed next month.

The buds of the early Chrysanthemums may be selected this month; do not neglect to pinch the outdoor ones back, but not later than the early part of August, so as to obtain fair-sized stems on the flowers to be cut later. Keep on sowing Gypsophila, you will need the flowers right along. Order now what you may be short of in pots; you will most likely need quite a few of the larger sizes next month.

For Midwinter flowering sow a good strain of Calendula now. This can just as well be done outdoors in a coldframe, and the seedlings potted up into $2 \frac{1}{2} \mathrm{~s}$ later on.

Sow your first batch of Lupines to be benched later on to follow the 'Mums. If you have a good strain of Snapdragons in the field, why not root a good batch of cuttings and pot them up later? You may have occasion to use them this Fall. Make another sowing of Cinerarias and Calceolarias, also of Primula malacoides for late Spring flowering.

This is a good month to root Alternantheras. You can root them in shallow flats by the end of the month, making use of a sandy soil mixture. Give them plenty of space so you can let them remain in these flats over Winter when rooted. They will be practically at a standstill during cold weather. Also root some Coleus; these, if grown on and kept shifted, will make fine stock plants to propagate from during next Winter and Spring. If you use the variegated Glechoma for boxes and baskets in Spring, cut some of the stems now into 4-in. long pieces, put three or four together and pot up into $31 / 2 \mathrm{~s}$. They will root in a few days and can remain in these pots in a coldframe until wanted next March, when they can be divided, repotted and grown on in a Carnation house. Sow Mignonette seed now in 21/2-in. pots for December flowering. If you want to grow on candidum Lilies this is the time to plant them, either outdoors or in pots. Begin to take cuttings of Geraniums from plants in the field. They can be rooted in a coldframe and, if given plenty of room, can remain there up to November.

\section{SEPTEMBER}

\section{In the 'Mum and Carnation Houses}

TYING up, cultivating, disbudding, watering and keeping the plants free from insects-all these tasks keep us busy this month among the Chrysanthemums.

Whatever you do, see to it that the stock is kept clean. The plants, especially the midseason and late varieties, are making their best growth now. If there is room, apply a mulch of three parts 


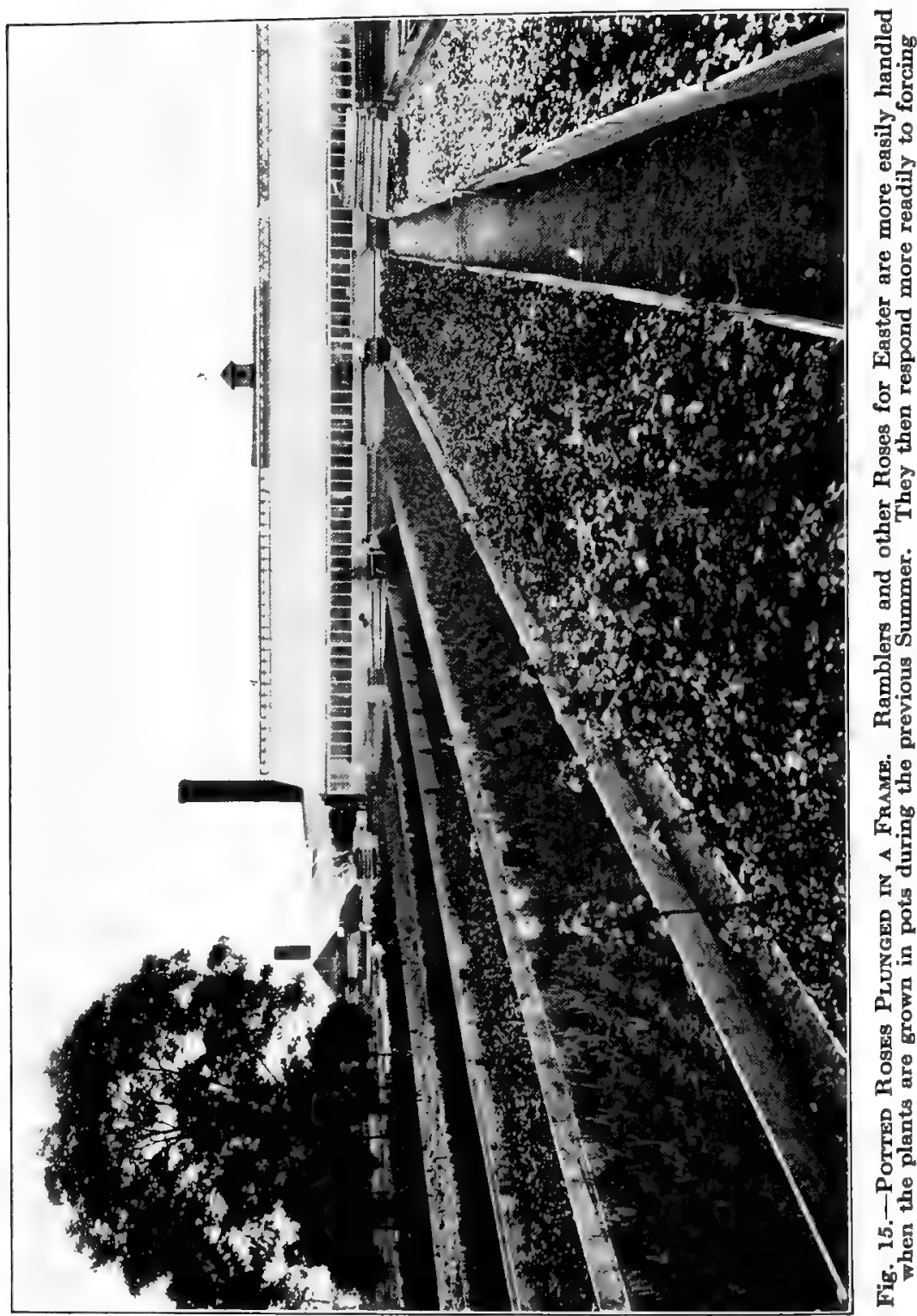


well decomposed manure and one part soil. The single stem sorts should be kept clean of all lateral growth, and always see to it that there is sufficient moisture in the houses. The pot plants need feeding with liquid cow manure; that is better than to keep on shifting them too often, for the object is to obtain a good-sized plant in a small pot. You cannot do much pinching back on any of them after August.

While a wetting down of the walks in the houses is a fine thing during the hot Summer evenings, let up a little on that as you go along in September. In other words, avoid an excess of moisture over night, but always keep the soil in the benches as well as in the pots in a moist state. Drying out will not help plants that are making a fine growth.

You should have no trouble in the Carnation houses during this month. Growing conditions are just ideal, sunny days, plenty of ventilation and cool nights being just what Carnations want. They are well established by this time and the first planted ones are producing fair-sized stems with good flowers, which may come in very useful even with the appearance of the early Chrysanthemums. Watch the soil; if a bench does not dry out in certain spots as fast as in others, find out the reason for it. Keep on cultivating and of there should happen to be any yellow leaves at the base of some if the plants, remove them.

Have all the supports in place long before the plants are in need of them.

\section{Poinsetrias and Roses}

This is fine growing weather for the plants. They can stand almost any temperature with the sun shining, but they seem to enjoy cool nights as much as the Chrysanthemums and the Carnations. Stake the single stem ones, and with the later propagated 21/2-in. stock, make up a good number of pans. Do not put this off until October; have a good number under way at least by the middle of this month. It is getting late for propagating, but early Septemberrooted cuttings often make useful little plants for retailing in madeup basket arrangements for the holidays.

With the young stock benched in May or June, there has not been much special care or watching needed up to the present; here, as with the Chrysanthemums, weather conditions have helped to do most of the work. The plants, in a good, stiff soil with proper watering, have made a fine growth, and while it will be some time yet before you cut fancy flowers and stems, with the approach of cooler weather as the plants get well under way, the new wood becomes stronger and stronger.

What is perhaps of the greatest importance from now on, is careful ventilation. Cold winds striking the young, soft growth 


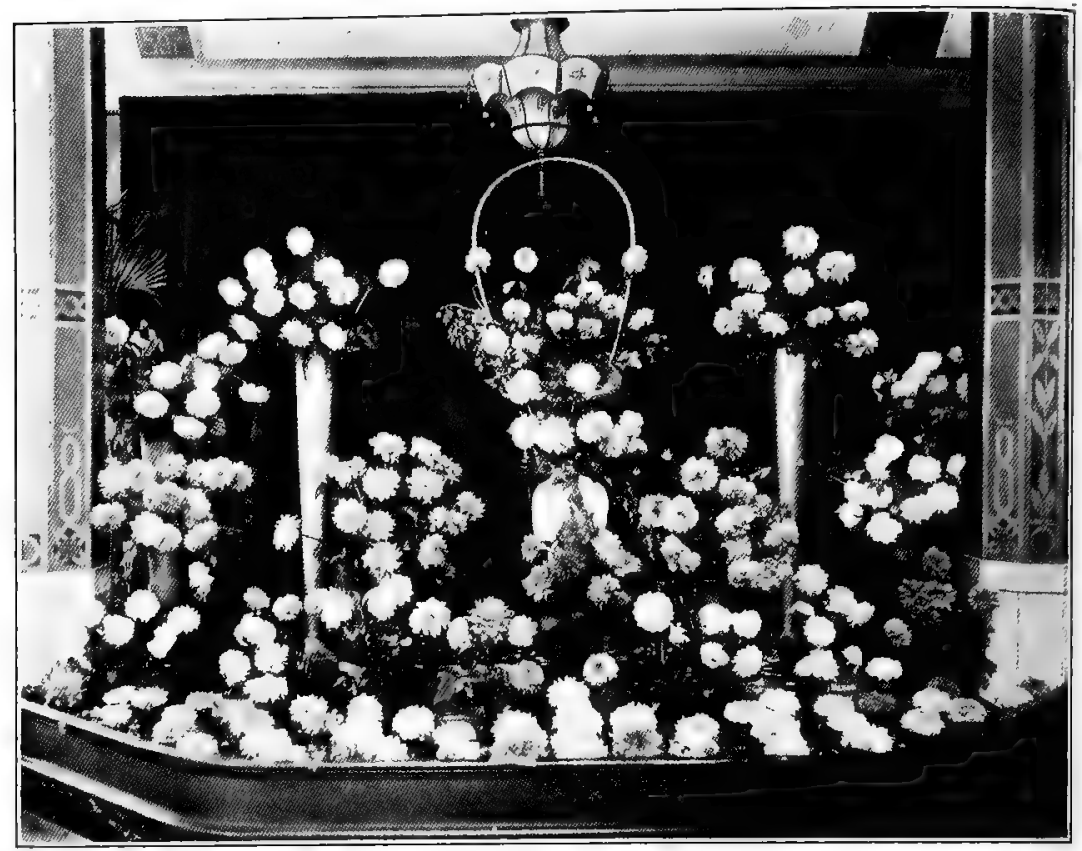

Fig 16-A Prize Show of Darrias. You needn't wait for Ghrysanthemum time to arrange a show window or make a display. Dahlias will produce fine effects and almost equal the 'Mums in size and wealth of varieties

of the plant is the very worst thing that could happen. It is the easiest thing in the world to invite a dose of mildew, right now, and while it is not always in your power to prevent this, it can often be traced directly to improper ventilation. With Roses, it is, more than anything, a matter of constant watching; open and shut your ventilators twenty times a day if necessary. That is the only way right now when we are gradua ly changing from Summer to Winter conditions.

You will never be successful if you merely open the ventilators when things warm up in the early forenoon and leave them open until late in the afternoon The man who brings his plants from Summer into Winter without the least check will have the best results. A touch of fire during chilly nights, proper ventilation, and careful watering are what you want to provide from now on.

\section{Cyclamen and Begonias}

Plants that made but little headway during the early Summer, are now, and from the middle of August have been, making up for lost time, that is, if they were not in a stunted condition. They need a shift as soon as you find the roots are starting to form a mat, and 
with ordinary care, they will spread out and expand their beautiful leaves which mean so much in making a specimen plant. If you have had your plants out in a frame during the Summer (as practiced by many successful growers) get them now into an airy house on a sunny bench, with plenty of ventilation: They do not require any further shading; if you find that during extremely hot weather the plants start to wilt, spray a little. The young seedlings should be removed from the seed flats and transplanted into other flats as soon as they are large enough to handle, making use of a light soil with a liberal admixture of sand.

Even those who do not want the bother of growing on Cincinnati Begonias, those ideal Christmas specimens, from cuttings, can now obtain well established plants out of $31 / 2 \mathrm{~s}$ or $4 \mathrm{~s}$, and will have but little trouble in growing them on further in a 55 -deg. house.

\section{Potted Plants, Bulbs and Other Stock}

Keep shifting the Cinerarias, the Primulas, the Cherries; and Begonias; most all of them do nicely in a cool, airy house. If short, stock up now with smal specimens. All of these plants are more easily handled than was possible earlier in the season. Pot up more seedling ferns for dishes and a good stock of Asparagus plumosus. You will want them next Christmas. "It is a good month to stock up with palms and other decorative stock.

The first Paperwhites are arriving. Plant a few in flats and place in a frame outdoors. Plant more Freesias. Roman Hyacinths and Grand Soleil d'Or Narcissi are indispensable for the Midwinter holidays. There is nothing finer for dishes and baskets. Order a few French-grown Trumpet Major Narcissi for early forcing. In early September is a good time to start Callas into growth again.

Start to root Geranium cuttings. Get the roofs in shape. Have you painted the gutters? Is the boiler in good order?

With each day, from now on, you will become more busy. Do what you can each day to catch up, there is hardly ever any chance to get ahead of your work. If there is a chance, arrange for a good supply of potting soil for next Winter and Spring. Transplant all your perennial seedlings into their Winter quarters. There is no better time than right now to divide Peonies and Iris, and, in fact, almost anything in herbaceous stock that needs dividing. If this is done now and the stock replanted, it will have a chance to become re-established before Winter sets in.

If you are going to plant more Peonies in such varieties as you are short of, do so now. Transplant all of your Pansies where they are to remain until in flower next Spring. Always select a few of the strongest, and plant them by themselves in a frame where you can get hold of them later on when wanted for benching. The same holds good with Forget-me-nots and Bellis. 
You may consider sowing out a few Pansies by the middle of September in a frame where they can remain all Winter and be transplanted the following Spring.

Keep up the cultivating outdoors; do not let Winter find you with a lot of weeds among the hardy stock or the conifers. Are you pushing Fall planting and outdoor work? Let folks know about it. Call their attention to the fact that you are in the ring. There is always more or less of such work to be done, and frequently people do not think about it until reminded of it. Every florist located in a country town can and should work up this branch. There is money in it, and so there is in Fall bulbs.

Start to make an attractive display right now and keep on adding to it, as more bulbs come in. Advertise in your local paper and keep it up. You needn't lose a single one of the bulbs you have on display; what is left over you can use yourself later on. Who is there better fitted to handle bulbs for Winter and Spring flowering than the local florist of a town? Who is there better able to talk to people about the different varieties and what they are best adapted for than he? We haven't started yet to take advantage of the great money making possibilities there are in retailing bulbs in Fall. Millions more of them could be disposed of if they were pushed. A lot more people could enjoy their beautiful flowers, and a lot more florists gain much by handling them.

\section{OCTOBER}

\section{Fall Work Outdoors}

YOU may have lifted some of your Gleveland Cherries already, and brought them into a frame or indoors; if there are any more to be lifted do it at once. September really is the best month to lift and pot these Cherries, Dracænas and Stevias; they seem to become re-established so much quicker.

From the end of September on, there is no telling how soon a heavy frost may come along to cut everything down or check things. Whatever there is to be brought indoors that will suffer in the least from frost, should, therefore, be brought in at once.

Pot up the Hydrangeas. If lifted carefully they will not lose their leaves, and if placed in a coldframe they will keep on making roots and become nicely potbound before Winter sets in. Roses outdoors in pots intended for forcing should be gradually hardened and gotten into a dormant condition. You do not want soft growth; the better ripened the wood is, the easier and better they force, and the more flowers they bear. Gradually withhold water and keep them a little on the dry side. You can do this with the pot plants which, if necessary, can be laid on their side toward the end of the 
month; but over the stock planted out in the field you have no such control, and it is much better left alone as long as good weather prevails.

If you have heavy plants of hardy Phlox (such varieties as Elizabeth Campbell, Rynstrom, W. C. Egan or others, outside of Miss Lingard) and wish to increase your stock rapidly, lift the plants, remove all of the heavier roots and spread in a coldframe with a layer of sand below and one on top of them. These roots can be cut up into 1-in. long pieces and started into growth inside in sand next February; every piece will give you a new plant. The old plants can be divided and replanted and will come out fine next Spring; a little protection should be given to prevent the frost lifting the plants out of the ground.

Pot up a good number of Canterbury Bells and English Wallflowers and place in a frame. Lift Shasta Daisies, Coreopsis and, by all means, a good number of Delphiniums. There is nothing finer than Delphiniums, and especially the belladonna hybrids when slowly forced under glass for Spring flowering. Good one-year-old plants will do for forcing, but two- or three-year clumps are better. Aquilegia or Columbine makes another good perennial for late forcing. All these plants, when lifted, can go into a coldframe. You do not want any of them inside much before February and March, and should never expose any of them to a high temperature.

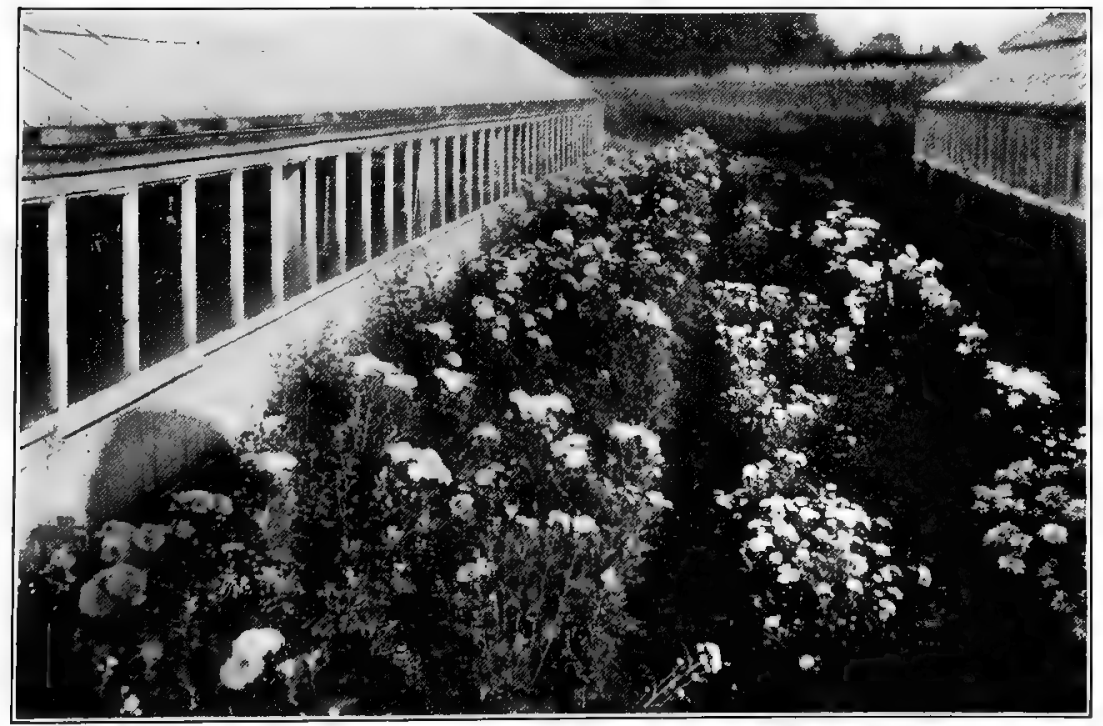

Fig. 17.-Outdoon Ghrysanthemums Here is a good way to make use of the space between the greenhouses. With just a little protection many fine varieties will do well here when they would prove a failure in the open field 
Lift some Polyanthus Primulas; they should go into the Violet house. Lift your English Ivies and pot them up. The green and variegated Vincas should also come in; cut them well back and either pot them up after they have been divided, or place the clumps in a frame until you get room on the benches later on.

It is at this time of the year that you appreciate your coldframes. There is no better place for many kinds of plants, either to overwinter in or to be kept in for a few months.

If you want to have stock of herbaceous plants in pots for next Spring and Summer (there is always a demand for such plants, and this demand is sure to become greater as we go along), you had better lift a good number of the different varieties you carry or have out in the field now. Heel them in a frame so you can get at them next February or March when ready to pot them.

Have you labeled all of the Dahlias and Cannas? The first good frost will make this impossible, so get at it in good time.

Lift your Gladioli and dry the bulbs off nicely outdoors before they are brought under cover. Whenever possible, keep the varieties separate.

Whenever the tops of the Dahlias or Cannas have been cut down by frost, lift them before a spell of bad weather sets in. This holds good with all outdoor operations: do what you can, and do it quickly.

There is nothing like turning soil over deeply in Fall, and letting it lie rough over Winter so the frost will go through it and sweeten it. If there is transplanting to be done, get at it. Move your stock together; have the beds and rows of perennials filled up properly, and turn over what empty space you have, so as to be able to get at the Spring planting early next year. There is always a rush during Spring; work piles up and, at best, you have only a few weeks in which to do the planting of hardy stock. Therefore, if for no other reason, do what you can in the Fall. Get whatever you can in the line of outdoor work out of the way.

\section{Watchful WaIting Indoons}

We are making toward Winter. We may experience ice one day and $60 \mathrm{deg}$. the next, and a rainy week may be followed by warm, sunny days. All this means that we must watch out with the firing and ventilating to maintain under glass the right temperature and growing atmosphere.

Nothing hurts Roses, Carnations, or Chrysanthemums-the three main crops with so many florists-more than sudden changes of temperature, particularly when they are once used to indoor conditions. It is really harder to run a greenhouse now than when Winter has once set in. 
A little feeding will do the Chrysanthemums good as soon as the buds are formed. Keep yourur houses well ventilated and let a rather dry atmosphere prevail over night. As soon as the first Chrysanthemums leave, have the benches cleared and follow up with something else. If you retail your stock do not cut too close. Keep up a show all through the Chrysanthemum season.

As a crop to follow Chrysanthemums, which are through flowering by the middle of October, you might consider single Violets. Others are Sweet Peas, Snapdragon, Calendulas, Stocks, Pansies, Marguerites, Schizanthus, Paperwhites, Freesias out of pots, Callas, formosum Lilies or Carnations which were lifted in August, potted up and kept in a frame up to the present

Usually in the smaller establishments where a great variety of stock is handled, there is no trouble in quickly filling up every available inch of space. It is more a matter of finding or figuring out what to fill up with in order to get the biggest returns.

\section{Bulbous and Other Stock}

With each day something else will be arriving in the way of bulbs. Whether Tulips, Narcissi, Hyacinths, Iris or something else, plant as soon as you can-that is, all those you want to force under glass the coming Winter. For outdoor planting you have plenty of time.

Have you piled up enough soil for this Winter, and in a place where you can get hold of it no matter what the weather? Put a good number of Stevias in a cool house to be brought into warmer quarters as needed later on. Do not plant all of your Paperwhites at one time, for you do not want the flowers all to come inside of a week. Keep 60 deg. in the Poinsettia house; the plants grown on benches can get along with a little less. Light doses of liquid cow manure are of benefit to the pot 'Mums up to the time the buds show color.

The Carnations should be disbudded and still lightly cultivated. Keep the flowering stems clean of the small lateral growth which usually appears in Fall. The outdoor 'Mums need sashes over them. It is not frost alone that hurts them; rainy weather is fully as bad for the flowers while opening up.

Keep the propagating bench busy this month. Your main crop of Geraniums, rooting now, will be ready for potting in November.

\section{NOVEMBER}

\section{Thanksgiving Preparations}

YOU can cut Pompons ten days before Thanksgiving and have them in good shape for that day; the flowers will answer nicely. You will need a cool, dry and rather dark place in which to keep 
them and a lot of fresh, clean water. It is a mistake to cut 'Mums too close a couple of weeks before Thanksgiving, and the same holds good with the Carnations. Of course, on the other hand, you do not want to allow the flowers to go to sleep on the plants. Be prepared with a good supply of Cyclamen and other flowering stock and even a few plant baskets.

\section{Cultural Notes}

With each day there will be more flowers on the Cyclamens. Those intended for late November and December flowering need a house of $55 \mathrm{deg}$.; the others can stand a little less. Do not try to force into flower plants that are not far enough advanced, for it cannot be done. Plants with buds well advanced can be hustled along in a 60-deg. house, but it is bound to result in a soft growth so that you will need stakes to hold the flowers up.

Select the most forward plants and place them in pots on a sunny bench allowing plenty of room between them. Early sown Primula obconica can stand a 55 -deg. house; when the plants start to flower they can stand just a little protection against the noon sun; it will help the flowers. Chinese Primula do nicely in a 50-deg. house and, by the end of the month, should be a mass of flowers. Stake the Cincinnati Begonias; they want at least $55 \mathrm{deg}$. Do not keep the Gleveland Cherries too warm and never let them suffer for lack of water.

It is a good time now to purchase a nice lot of Ericas. They can be carried along in a house of $45 \mathrm{deg}$.; a few can be given a slightly warmer house if well advanced and wanted for December flowering. Carry the Ghatelaine Begonias in a 55-deg. house. If you have any Buddleia asiatica in pots, plant them into the Carnation house on a bench. They are most useful when in flower during late December and January.

Bouvardia Humboldtii is at its best now. Always place the cut flowers in water for from ten to twelve hours before offering them for sale. Watch out for new varieties of Chrysanthemums and place your order for such as look promising to you. Select your own stock plants and plant them in a frame, or in a deep flat where they can remain in a cool house till next February. Do not forget the labels on the flats.

Sow Penstemon and grow it on in a cool house; this sowing will give you fine flowering plants for next Summer. Sow Schizanthus now for early March flowering, also Calendulas. If you can spare the room, by all means sow Sweet Peas to follow 'Mums. A solid bed is far better for them than a raised bench.

Make up a correct list of all the bulbs you planted in flats, pans and pots, and look it over. If you are short on certain varieties, there is still time to obtain more. 
Bring in what Paperwhite flats you have outdoors in frames; they cannot stand freezing. The same holds good with the Freesias. Give the flats of Roman Hyacinths a little bottom heat if they are slow. You should see the buds by the end of this month in order to have them in flower by Christmas in a 50-deg. house in which they will be short and stocky and just right for dishes.

Stock up with palms and ferns before it gets too cold. Bulb pans and low dishes are always used a great deal during the late Fall and Winter months. See to it that you have enough of them on hand. Get ready to plant Lilium giganteum and other Lilies such as auratum and rubrum, which will be here soon.

\section{Looking Ahead in Good Season}

Have you lifted a few Bleeding Hearts and variegated Funkias for Easter? These should be lifted now, potted up and placed in a deep frame. Spiræa Vanhouttei, Lilacs, Snowball, Forsythia and others can be forced easily for early April.

Are you pushing conifers for window boxes and vases? You should do so, and for the purpose secure a good supply of plants from your nurseryman. They can be heeled into a frame and easily kept in good shape. Keep on rooting Geraniums, Marguerites and other bedding stock. Half-ripened canes of climbing Roses cut in pieces containing about three eyes will root in a few weeks in a Carnation house in sand with a little bottom heat and can be carried along over Winter for planting out the following Spring.

Be sure to plant a good number of Darwin Tulips in pans for next Mother's Day. Right now is the time to do this and this lot should be marked and kept separate from your other stock outside. Also plant a few thousand bulbs outdoors in 5 -ft. beds, so you can cut flowers when your others in flats and pans are gone.

Do not let the Cinerarias suffer for want of a shift; they are making their main growth now, and need room to spread. The Calceolarias also are getting busy and, like the Cinerarias, need a cool, airy house.

The Primula malacoides do not need a house over 48 deg.; the larger ones want liberal sized pots.

\section{DECEMBER}

\section{Gultural Notes for Midwinter}

WE are entering into dark weather and steady firing has to be depended on in order to maintain a desired degree of temperature. What is foremost with us this month is Christmas. At the beginning of the month things may be slow in regard to business but the rush is bound to come. While you want to be able to cut every Carnation possible and, with the high prices prevailing around 


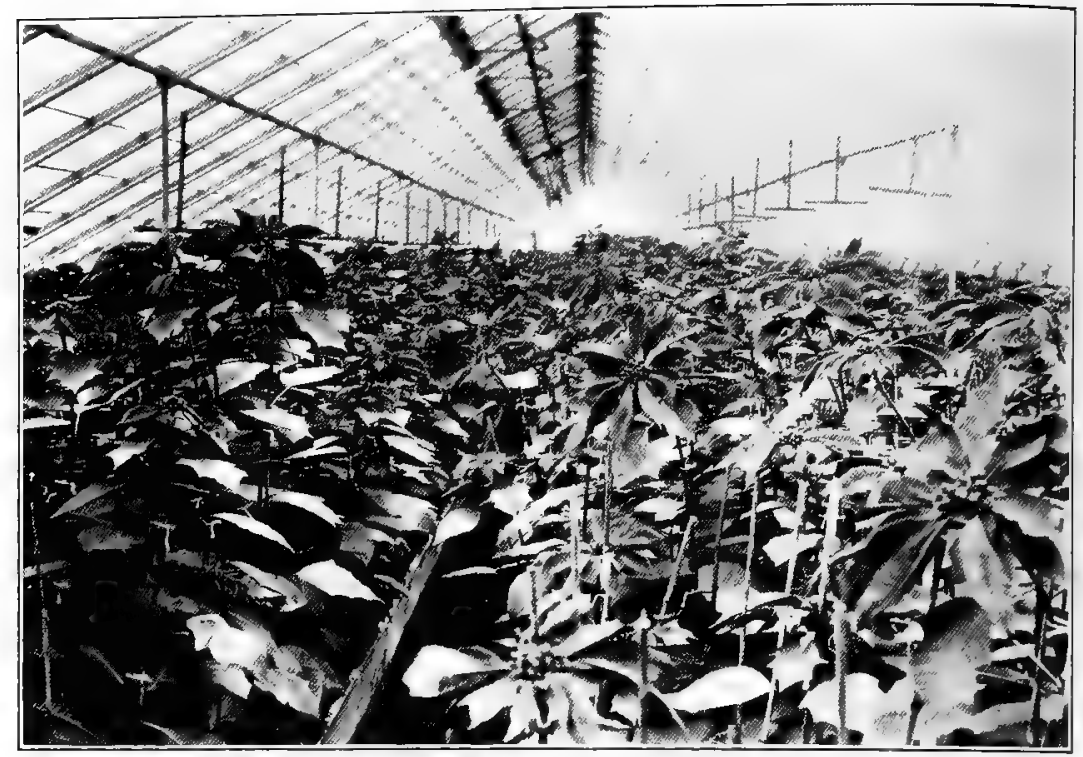

Fig. 18.-Poinsettias in December. By planting them out on benches in a house by themselves we can obtain the best results with these favorite Christmas plants

the holidays get all you can out of them, it is a great mistake to subject the plants to a hothouse in order to obtain more flowers. Increase the temperature 3 or $4 \mathrm{deg}$. overnight and do not open the ventilators quite so soon on sunny days a week or so before Ghristmas, but let it go at that.

The safest way, if you have a healthy lot of plants on hand, is to maintain the same temperature as the plants have been used to, cut what flawers you can for Christmas and be satisfied. You will be money ahead in the end. There will not be such a great drop in prices right after the holidays, while, on the other hand, plants which have been abused may require weeks in order to get into shape again.

Feed the Poinsettias in pans a little and do not let them have ice-cold water Time your Paperwhites, Roman Hyacinths and Grand Soleil d'Or Narcissi just right. Often this means carrying them back and forth from hot to cold quarters, so much depends on weather conditions. A few flats grown along with other stock in the same bench make as much trouble as a whole house full would.

If you have to purchase Cyclamen, Begonias or Poinsettias in pots and pans, do not wait until the last minute to have them delivered. One can never depend on the weather, and a few days in your own houses-as long as you can keep a temperature of $55 \mathrm{deg}$. for the Cyclamen and $60 \mathrm{deg}$. for the others-will do the plants good. 
Plant more Freesias now for late Spring flowering and grow them on in a cool house.

Empty the propagating bench of all rooted cuttings and fill it up again, for if your stock plants-of Geraniums for instance-have a lot of cuttings on them large enough for the sand, it is waste of time to let them remain on the plants any longer.

The Christmas and New Year's business will take up most of our time now. With the benches occupied with stock for these great days almost up to the end of the month, and busy as we are with the wreaths, greens, and the making up of baskets and centerpieces, there is not usually time for any great accomplishments in the way of refilling benches. But right after Christmas, if you have the bench space, such stock as Calendulas, Snapdragons, Lupines, Stocks and others may be planted out; a house below 50 deg. is sufficient for them.

None of these plants will make a great deal of headway for the next few weeks, but they will get ready for active growth and more than grow when the sun coaxes them on a couple of months from now.

\section{Stakting Stock into Growth}

Bring in the first flats of Trumpet Major and Golden Spur Narcissi in early December, also La Reine Tulips. If you planted. any prepared Hyacinths last October and if the bulbs are thoroughly rooted, they can also be brought in and started slowly into growth. Cold storage Lily of the Valley can be planted in pots or 7-in. halfpots and placed in a frame over a bench with 75 deg. bottom heat. It will take approximately from twenty-two to twenty-five days (allowing a few days to harden the flowers off a little) to have the plants in bloom.

Apply a good top dressing of manure and soil on the Asparagus benches, and the same in the case of the baskets.

If you have Cannas under the Carnation benches, examine them to see if they are too wet or too dry; either is bad. The first Freesias will come into flower around Christmas; see to it that the plants are properly supported. Start the first batch of America Gladiolus in pots to be planted out later on. Place them below a bench in the Carnation house until they start to grow: Plant giganteum Lilies if you have not already done so. Take advantage of every day you can. The earlier you plant them the more time you can allow them to become well rooted before you place them in heat. If you have Carnation sorts of which you wish to work up a goodsized stock, you can start to propagate now. There are usually fine cuttings on the plants at this time of year which will root even without bottom heat. Protect your bulbs outdoors well; they can stand frost but do not actually need it. 


\section{Late Bulb Purchases}

Sometimes, during early December, one can pick up a bargain in Dutch bulb stock which can be made to pay by late forcing or outdoor planting. But it is a mistake to put off the ordering of bulbs such as you need for your forcing demands. Waiting for such bargains in planting bulbs as late as December makes their forcing impossible for February, March, or early April; but you have good use for Tulips and Narcissi after Easter, and if you can buy sound bulbs at a low price after you have your regular requirements all planted, it is well to consider doing so.

If you intend forcing Valley during the next few months, stock up with pips now. They can easily be kept in fine shape in a cold: frame, and when well heeled in sand, a little frost won't hurt them. While you want cold storage pips right now for forcing, a little later the freshly imported ones will be just as good. In hardy Lilies you can now pot up Lilium magnificum, auratum, speciosum rubrum and album. The best way to handle them is to place the pots after a good watering below a bench in the Violet house. If you have a coldhouse with room to spare in it, the Hydrangeas and pot Roses should go there. The plants are better off if they don't freeze, and, with the Hydrangeas in particular, you want to be careful not to have the end buds get hurt through severe freezing. It will ruin the flower buds. For those who like to grow on palms from seed, this is a good time to get started; but bear in mind that while it is interesting to grow on a Kentia, a Latania, or a Phonix from seed and watch it develop into a beautiful specimen, you cannot ever expect to make money by doing this on a small scale. Heat and a moist house are the first things to be considered in palm culture-and a lot of time comes next. In the case of the average florist retailing his stock, that time can usually be devoted to something else that will result in better returns.

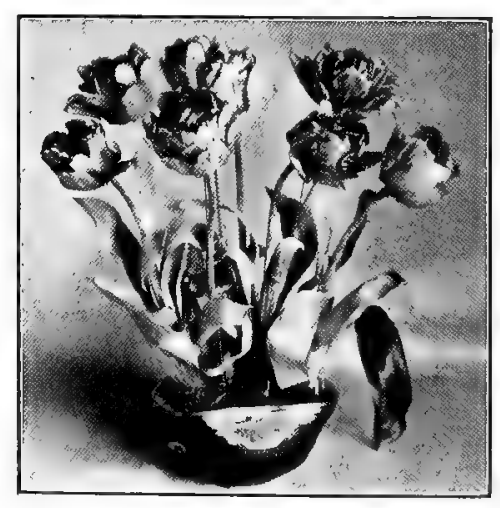




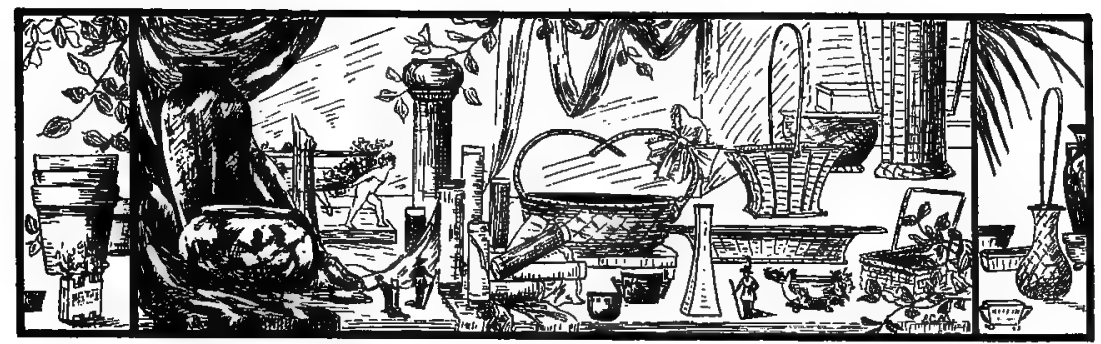

CHAPTER III

\section{THE RETAIL GROWER AND HIS EQUIPMENT}

\section{THE RETAIL GROWER'S ESTABLISHMENT}

T $\mathrm{N}$ most cases the establishment of a retail grower in the smaller city or town consists of a range of one or more greenhouses, and 1 a store in connection with it. This, if the establishment is not too far away from the center of business section of the town, is a great advantage, for in every instance where the store is separate from the greenhouses it means more overhead expense and more or less waste. The little extra business due to the store being on the main street doesn't always pay for the additional expense involved, and those located a few blocks farther out yet on a good street, by being able to do everything under one roof, are the gainers.

\section{Selecting a Building Site}

For those wanting to start into business, location is the first thing to consider. If you can obtain reasonably a lot, with say, $100 \mathrm{ft}$. of frontage and $150 \mathrm{ft}$. deep (one on a corner or with an alley to be preferred), there is no limit to the amount of business you can and should do later on when once established. If it is found necessary to acquire more space for houses, or more land, a few acres can be bought farther out-perhaps enough to grow hardy stock and start a small nursery. Never buy a lot without a future to it, no matter how cheap it is. A town may grow and spread out in an entirely different direction from that predicted by the leading real estate men, but if you are on a good street just a few blocks away from where things are alive, you cannot go very wrong. Quite a 
number of florists comfortably fixed today made their money, not in flowers, but in the land they bought with no idea that it would ever become so valuable. But we don't all live that long.

For the retail grower a lot facing north is best. This will give him a chance to locate the store and the palm house, fern house, or show house (none of which requires afternoon sun) along the street and the growing houses where they will get the morning sun. Three hours of morning sun is worth six in the afternoon. Of course, no one will select land surrounded by large trees or buildings, and if in later years buildings become so large and high that they take the sun away from the Geraniums, the place has most likely become too valuable to grow Geraniums on; it is then time to sell and move.

The man who wants to start but has only a limited amount of money and cannot afford to buy a lot $100 \mathrm{ft}$. x $150 \mathrm{ft}$. or $200 \mathrm{ft}$. without moving out where he can only be reached by the R. F. D., had better purchase a $50 \mathrm{ft}$. $\times 100 \mathrm{ft}$. plot nearer the pulse of life of the community. You can build a very attractive store and show house on a 50 -ft. front and have room for a driveway and a good plant house in the rear. It would simply mean that you would have to purchase more of the stock you sell-which a lot of the most successful men do today anyway, making more money by so doing than if they tried to grow it on themselves. You may be a good grower if given a chance to grow stock with proper facilities and with nothing else to do, but the retail grower of today is an awfully busy man. The time he can devote to the potting bench or in the Rose house is limited. Here it is truly a case where the man who uses the hammer isn't the one who makes the money.

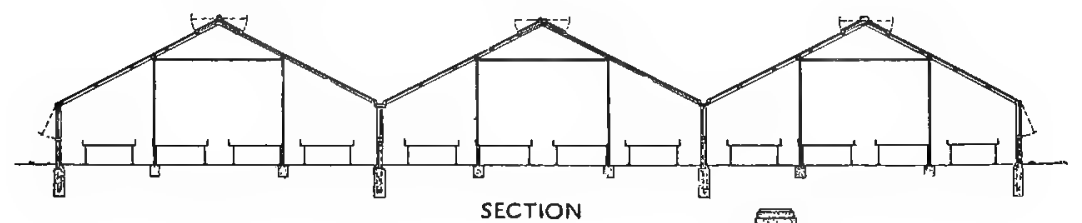

SECTION

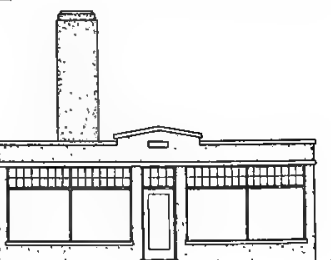

FRONT ELEVATION

Fig. 19.-A Practical Establishment of Three Houses and Store. See opposite page for description and page 76 for a partial plan of this convenient layout designed by the Lord \& Burnham Go. Note its compact arrangement and the splendid opportunity for a striking display in the shop windows and in front of the two greenhouses at the left. 
The time devoted to keeping up your own appearance and that of the store and the show house, counts for far more than that employed in pulling weeds. There are times when one may buy one or two lots and by paying a small sum, obtain an option on another lot next to his own for a year or so. Never let a chance like that go by. Buy only a small piece, and take an option on more. In the meantime, make the best use of what is your own, and by the time you near the end of the option you will know-whether you want to take advantage of it or not.

Many have failed because they started out on too big a scale; they couldn't carry the load long enough. There is nothing in the statement that "almost any piece of property is good enough if the right man is on it." It takes the right man on the right piece of property in order to succeed, and of the two the poor man on a good piece stands a better chance than the good man on a poor piece.

To sum up, get near to where others are doing business; face north, if you have your choice; and don't buy too much.

\section{Two Establishments for Small Retail Growers}

The accompanying illustrations (Figs. 19 and 20), show the ground plan, front elevation and cross section of three houses and store designed by the Lord \& Burnham Co., and give a splendid idea of what can be done on a $100 \mathrm{ft}$. $\times 150 \mathrm{ft}$. lot. This would make an attractive and useful layout which any retail grower could be proud to possess and do business in. It comprises a goodsized store with office, workroom, cool room and neat, pleasing front; a boiler room in the basement; connecting with the store, three modern, uptodate houses, fit for almost anything you might want to grow under glass; and, next to the store, an open space for a show house to be added some day, but at present well suited for a little formal display garden.

To erect such an establishment one ought to have a capital of about $\$ 10,000$ - or know where to get it. But what you really need far more than the land to build on, is a thorough knowledge of what you are about to undertake, and of the business itself. The three absolute essentials are: A conviction that there is a demand for a florist (or another one) in the town; a will that you are going to succeed and ignorance of the word failure; and about $\$ 3000$ in cash. I realize that the builder won't agree with me on that point, but I would put my money even on a man with only half that amount if he had all the other qualifications. Everything depends on the man himself. I could name one hundred men who are well known florists today, who have made names for themselves as good growers and been successful in business who didn't have $\$ 500$ when they started nor a layout like this to start with. Perhaps you know of some with better lavouts and lots of money who have failed. 
You may say that there is no use in showing illustrations of a place requiring $\$ 10,000$ capital, but there is. The writer for one,
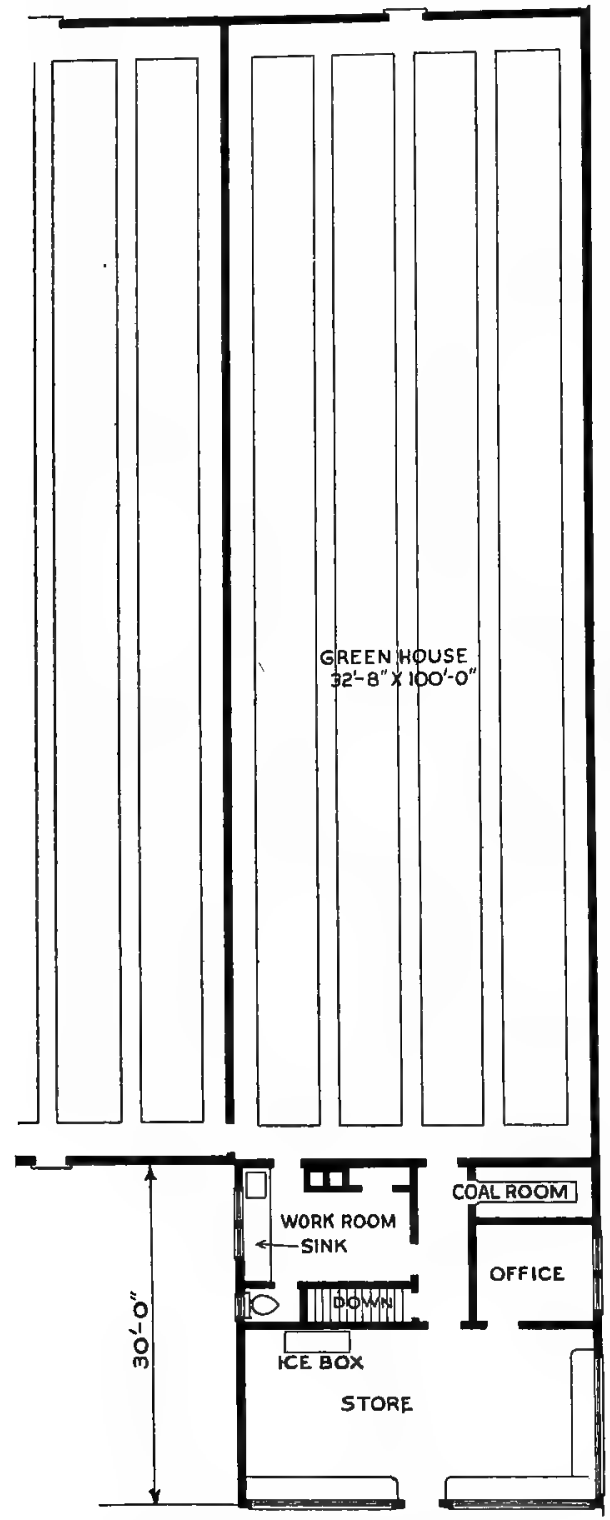

Fig. 20.-Economical Use of Space on A $100 \times 150$ FT. Lot. This is the righthand half of the layout shown in Fig. 19, all three houses being alike. Note the fine space $(30 \times 66 \mathrm{ft}$.) for a show ground in front of the houses and beside the store would have been awfully glad had he, at the time he started, had such a plan, which represents the last word in construction and arrangement. If this layout happens to meet with your approval, but if you haven't got the money to erect it, why not erect what you can to start with and then keep on going? You could build the store and just a little plant house back of it at first. To my mind the store with a neat front is the most important part to consider first, even if it means that only a $10-\mathrm{ft}$. wide sash house can be hung onto the back of it. Ability to show stock comes first and always with the retail grower. If, to your mind, it is of more importance to grow stock for the local demand, let the store go and erect one of the houses first, just as they are planned, with the idea of a store to come later on. If you cannot erect one house its entire length, put up half of it, but have the whole plan in mind and work according to it. A good many expensive mistakes could be avoided by the beginner had he a definite plan to work by instead of erecting a house or several houses any old way only to tear them down in a few years to make room for good ones.

The other illustration (Fig. 21) from the Foley Greenhouse Mfg. Co., gives a good idea of how to lay out a $100-\mathrm{ft}$. long 


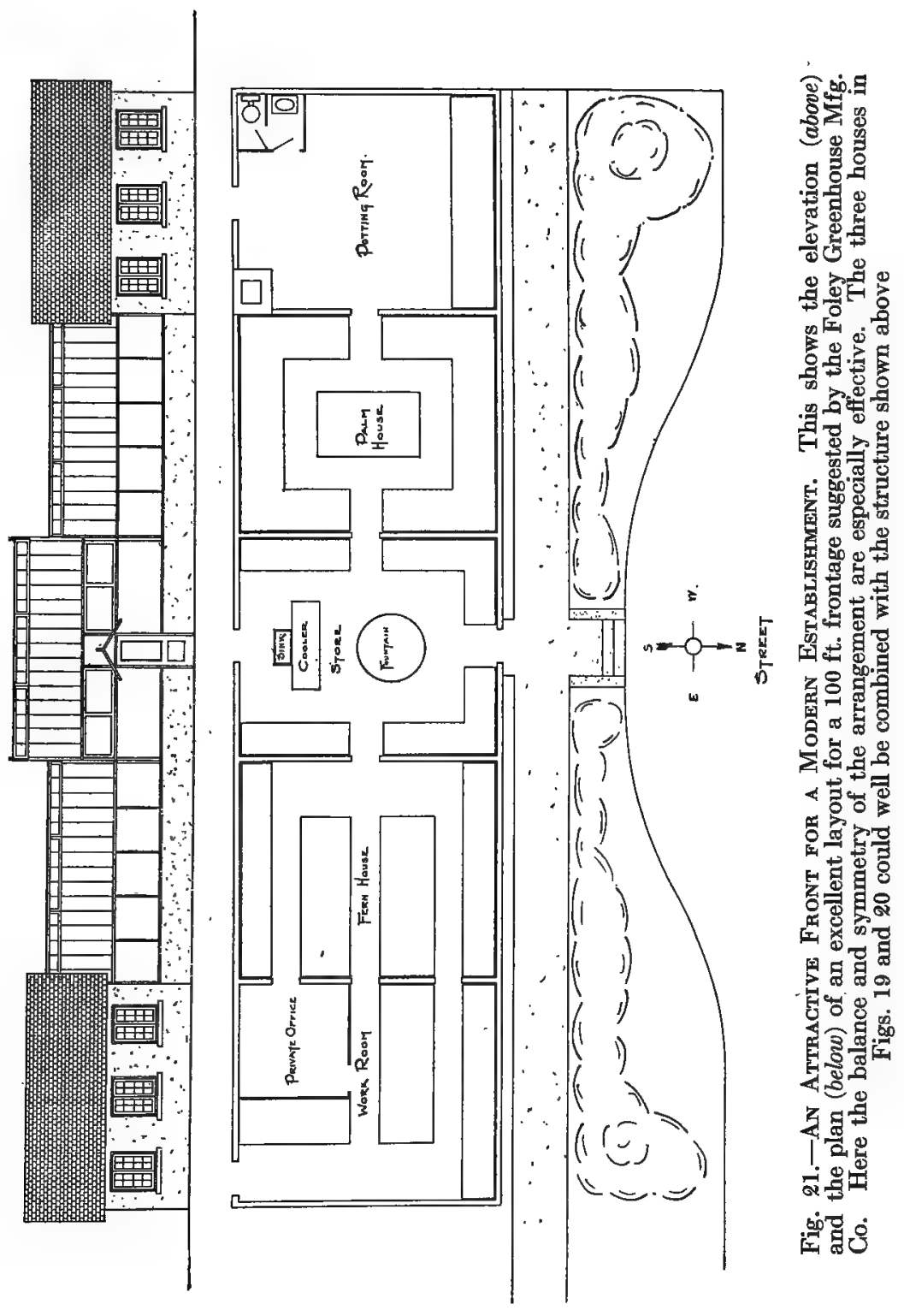


north frontage. If this should happen to face a street with a $20-\mathrm{ft}$. wide parkway (as is apt to be the case in the Middle Western and Western parts of the country) an attractive drive approach is possible. The $100-\mathrm{ft}$. front is divided into five equal parts, each $20 x 24 \mathrm{ft}$., namely: The potting room with boiler room and coal cellar below; a palm or show house; a store; a fern or another show house, and a workroom and private office. Houses for growing stock can be built on, running either north and south or east and west; but were it desirable,' one could conduct a mighty fine retail business in the first section alone. Or, if a man wanted to, he could build just a portion of that section to begin with. The store part might be shingled or have frosted glass in the top. The front elevation of the workroom and potting room might be brought up higher and a flat roof used. If the lot has just $100 \mathrm{ft}$. frontage and the whole of this is used, it should be located on a corner or have a driveway or alley in the rear. That much is certain.

With this layout one could create a very attractive front, and one not only attractive, but convenient too. The potting room is nicely located and away from view. The workroom at the other end is used mainly for making up floral designs, and for storing paper, boxes and other material. In these instances, as well as in the others, it isn't claimed that such an arrangement will suit all purposes. But a good part of it might be adapted; or the study of the plans may lead to other useful ideas. There wouldn't be much difference in cost if this section with a couple of more houses were erected.

\section{THE SHOW GROUND}

The show ground is as important to the florist in the country as the show window is to the flower shop in the city. The name doesn't apply only to a five-acre display, for a 50-ft. lot can often be transformed into an attractive show ground and made beautiful with no outlay worth mentioning for the stock required.

PRACTICALLY every florist located out of town has a piece of land in connection with his greenhouses. Usually such land is not only near the greenhouses, but actually part of them, facing on a street or highway, and affording a splendid opportunity as a place in which to set out stock plants of Geraniums, Cannas, etc., so as to create a real display.

\section{The Formal Show Ground}

Why plant any old way just so as to get the stock outdoors when, with very little more work, you can lay out a piece of ground in beds and sod paths in a sort of formal garden and thereby transform that piece of your garden or field into a show ground? 


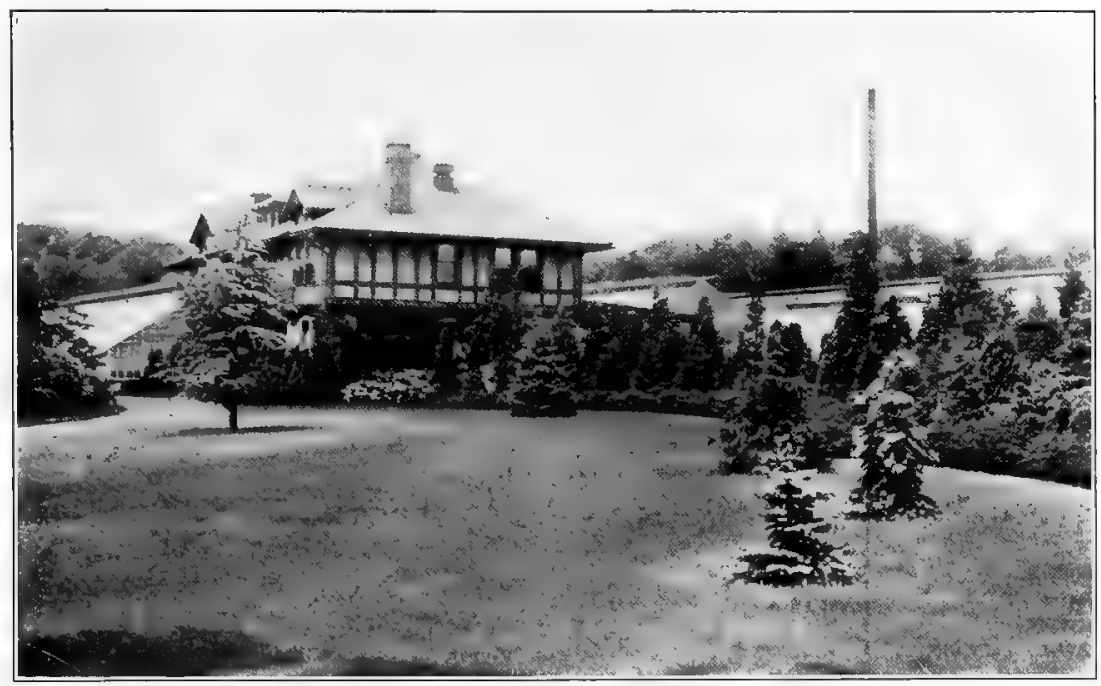

Fig. 22.-Your OwN Home Grounos. If you are located in the country where things are usually less crowded than in or around the larger cities, you cannot do better than to set an example of how home grounds should be laid out and kept up. They are always a good advertisement for your business

Don't be afraid of tackling the job; you can do it easily if you want to. Get your four corners and then put a stake in the middle or center of the square or oblong as the case may be. From it locate your beds using a good line, a tape measure, a few stakes and a hand axe to drive them with. If this is all new to you, start out by drawing a 6- or 8-ft. circle with the line for the center bed and placing stakes every 2 or $3 \mathrm{ft}$ along that line. Another row of stakes 3 or $4 \mathrm{ft}$. away from the first stakes and parallel with them marks the outer edge of a sod or gravel path. Another row, 3 or $4 \mathrm{ft}$. away, will be the inside limit of a flower border running parallel to the walk, which, again, is followed by a sod path and so on.

Or a sod path may be laid out by stretching a line so as to divide the whole square into four equal parts, the line forming the center of a path running from the center bed to the outside of the plat. Each of the four smaller squares can then be laid out in straight beds or other shapes-anyway to obtain a good layout, and give an attractive setting. If you haven't enough Cannas, Geraniums, Petunias or Salvias, with Coleus or Mme. Salleroi Geranium borders, make use of annuals. After you have looked at the layout all Summer, you may want to change it for another year. Maybe that Fall you will even want to plant part of it to Spring-flowering bulbs, Pansies, Forget-me-nots, and English Daisies. You may still further improve your layout with a sundial, gazing globe, concrete benches, fountain, arches, pergolas, Rose trellises or other garden furniture. 
What better ad could you have than such a show ground, or what better setting for a "Say it with Flowers" sign? Such signs don't belong on the side of stables or barns, where we see them sometimes displayed, or in an empty lot with weeds of every description growing all around them. How much more impressive and attractive with a background of conifers or evergreens and a foreground of flowers!

\section{Making Use of HaRdy Stock}

Though it is important for the florist to have a show ground, it is still more so for those who handle hardy stock and do landscape work. Here a formal layout isn't as appropriate as an open sweep of lawn, with perhaps a small fountain or sundial in the center and the lawn running into an irregular perennial border with a background of shrubs and conifers. This does not mean that a small formal garden may not be used to advantage when surrounded by irregular borders of hardy stock, with at least three sides giving an open view from the street. A perennial or hardy plant border, even one of shrubs, usually looks best when a sweep of open lawn leads to it. These irregular borders don't need to be filled. with perennials alone. Annuals may be used to great advantage in connection with them as long as you obtain a show, for that is the object sought.

Again, there are occasions when it isn't always possible to obtain an ideal piece of land to be used for a show ground. In such a case even a narrow strip of ground or sometimes a parkway will be all that is available. But even here, with just a little figuring and planning, an attractive showing can be made. You owe it to your business to help make this possible. You should have on hand a fair sample of what can be done with flowers and plants for the beautification of the home ground. You should be able to have a display of Geraniums, Cannas, Begonias and other bedding stock for the passerby to admire. Nothing will help you more to take orders, or do more to make people appreciate flowers, or to create a wish to possess the plants in their homes and on their grounds than the chance to admire them as displayed to best advantage by you.

\section{THE RETAIL GROWER'S BENGHES}

I WISH I were able to recommend to the retail grower something in the way of a bench to replace wood, of a more permanent nature, and not too expensive, but I cannot.

A lot of concrete benches built during the past ten years have since been replaced with wood, with the exception, perhaps, of the legs, which, when made of concrete and heavy enough, will remain forever; but a thin layer of concrete, even reinforced, for the bot- 


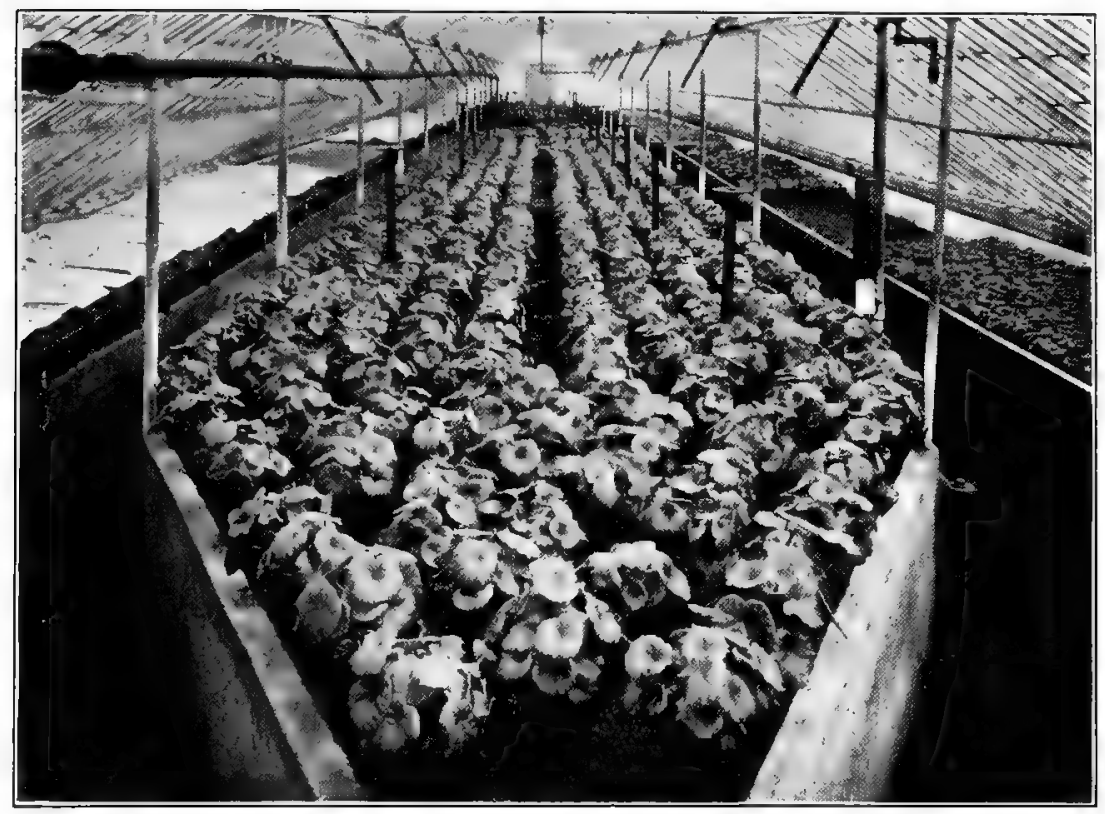

Fig. 24.-Weil-made Benchess and Beds. Concrete successfully used in one of the Begonia houses of J. A. Peterson, Westwood, Cincinnati, O. Whether you use wood, concrete or tile in making your benches, build primarily for convenience, durability, cleanliness and economy of space

tom and sides of benches has as yet not proven satisfactory in every case and to answer all purposes. At present heavy Cypress lumber is considered the best even by the largest growers. This is not to say that there are not some good concrete benches, and other good ones made of tile, but they certainly have not been found practical enough to appeal to the great majority.

For convenience, a bench $4 \mathrm{ft}$. in width is the best if you grow Roses, Carnations or Ghrysanthemums. When a bench gets over $5 \mathrm{ft}$. it is no longer practical for the growing of cut flowers. You cannot attend to the plants properly, nor will they dọ as.well. In depth a 6-in. board nailed on the side of the benches will answer for most plants grown. Instead of using tins or triangular pieces, of wood to be nailed on the inside to hold the sides in position, we make use of angle irons screwed to the crosspiece holding up the bottom of the bench, and to the sides, holding the sides in perfect shape, no matter what the weight of the soil inside of the bench.

Every bench should be provided with proper drainage and at least a $1 / 2$-in. space should be allowed between the bottom boards for that purpose. Laying the bottom boards lengthwise will make the removal of the soil when emptying the bench much easier. 


\section{Benches or Solid Beds}

With large houses and for certain crops such as will do as well on a solid bed as on a raised bench, it would be folly to erect expensive benches. In small establishments this is different, and there is always good use for both. It is well to have a house with benches where mostly pot plants are carried, while in one where a crop of Chrysanthemums is grown, followed by, say, Snapdragons and this crop later on succeeded by Sweet Peas or Asters, it would be a waste of labor and material to build benches. Many successful growers don't change the soil in beds, any more than the gardener would in the beds outdoors; he simply spreads a layer of lime in Summer, and then adds a good dose of manure. The beds are dug over deeply, and perhaps left rough for a few days, and then are ready for the new crop. Some men don't know what failure means who practice this method year in, year out. This much is certain it means a lot less work in building, keeping in repair and filling and emptying the benches. And except perhaps during the dark, Midwinter days, almost all plants do better in such beds than in a shallow bench. Some of the best Carnations I have ever seen were grown in solid beds; the same with Chrysanthemums and Callas.

However, for the retail grower, besides the fact that pot plants are better off on a bench than when placed on top of a solid bed, still other advantages in having benches are: It will do away with having heating pipes hanging all over the houses, along the gutter or purlin supports; it will provide bottom heat for cuttings to be rooted, or seeds and bulbs to be started into growth; and the space, or at least some of it, often can be used for the storing of plants not needing bench space; again, while not exactly the right place for pots, they can go under a bench. So, as already stated, I think any establishment with three or more houses can use both the solid beds and the raised benches to advantage.

\section{THE PROPAGATING BENGH}

For general use a bench with $3 \frac{1}{2}$-in. sides, filled up to within $1 / 2$-in. of the top with clean, sharp sand will answer nicely for the retail grower to propagate his bedding stock, his Carnations and his Chrysanthemums in.

While, as a rule, heating pipes located directly under the bottom of a bench planted with Carnations, Roses, Violets, or, for that matter, almost anything else, are anything but beneficial to the plants, due to such heat drying the soil or warming it up too much, bottom heat, when properly used, is a blessing for a number of purposes.

Therefore, if possible, always have a few extra pipes provided with a shutoff about $1 \mathrm{ft}$. or so below the bottom of the bench. Bottom 


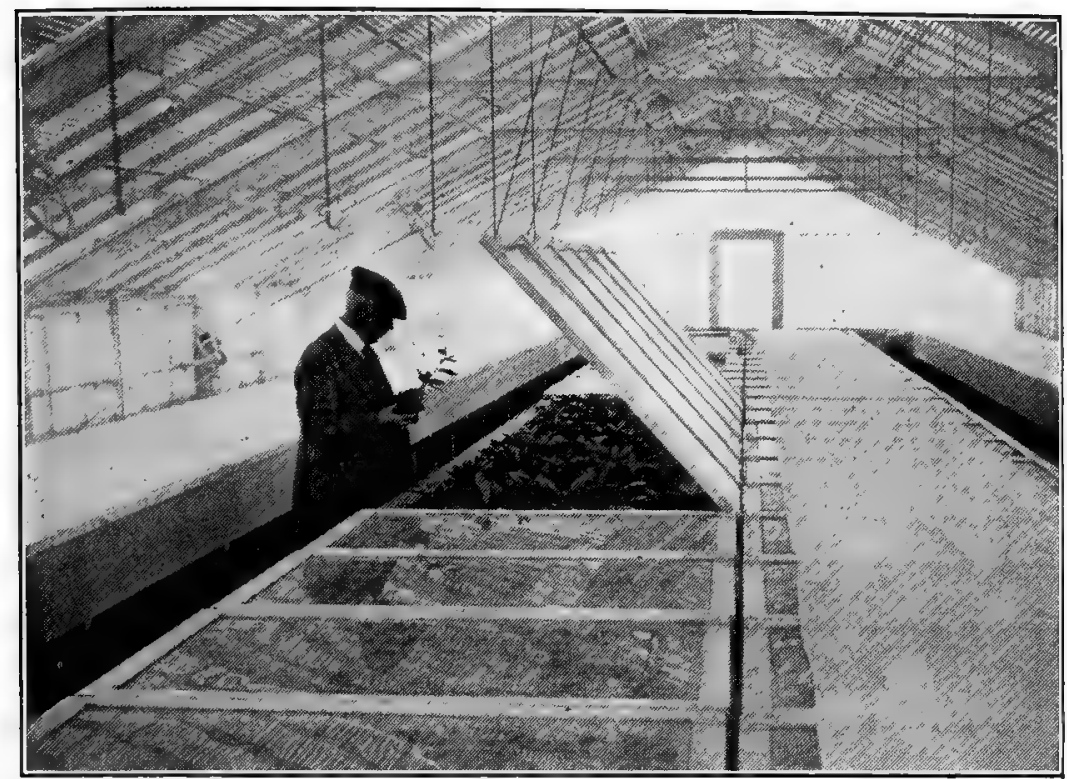

Fig. 25.--Inside an Ideax Propagating House designed by and built for P. $M$. Koster, Bridgeton, N. J. Note the flat benches and sashes, the hanging sash supports, the cloth bench screens and the slat screens outside the glass. No retail grower will need such an elaborate house, but it has some good features that many could adapt to their needs

heat is the thing that coaxes most cuttings to root quickly, and with most softwooded stock it is essential. For example, you can root a Coleus cutting in less than a week in warm sand, say of 70 deg. or a little over; but with a cold bottom the same cutting might stay a month without a sign of root, and would finally damp off. The results are practically the same with Heliotropes, Salvias or Fuchsias during the Winter or early Spring months.

Just a little bottom heat for Carnation cuttings in January will root ninety-nine per cent of them; they don't want 70 deg., but should have about $10 \mathrm{deg}$. more than the temperature of the house the plants are in. Usually the smaller grower will root his cuttings in the Carnation house.

Chrysanthemums also root more freely with just a little bottom heat. When it comes to rooting Dracænas, Ficus or Begonia Cincinnati, not only should you have sufficient bottom heat, but the lower part of the bench should be properly enclosed to keep a steady heat above 70 deg. In many establishments the grower will have this enclosure built in sections so as to take a section out whenever he wants to place bulb flats underneath for forcing.

In order to maintain a certain temperature not only in the sand but also in the air surrounding the cuttings above the sand, a frame 


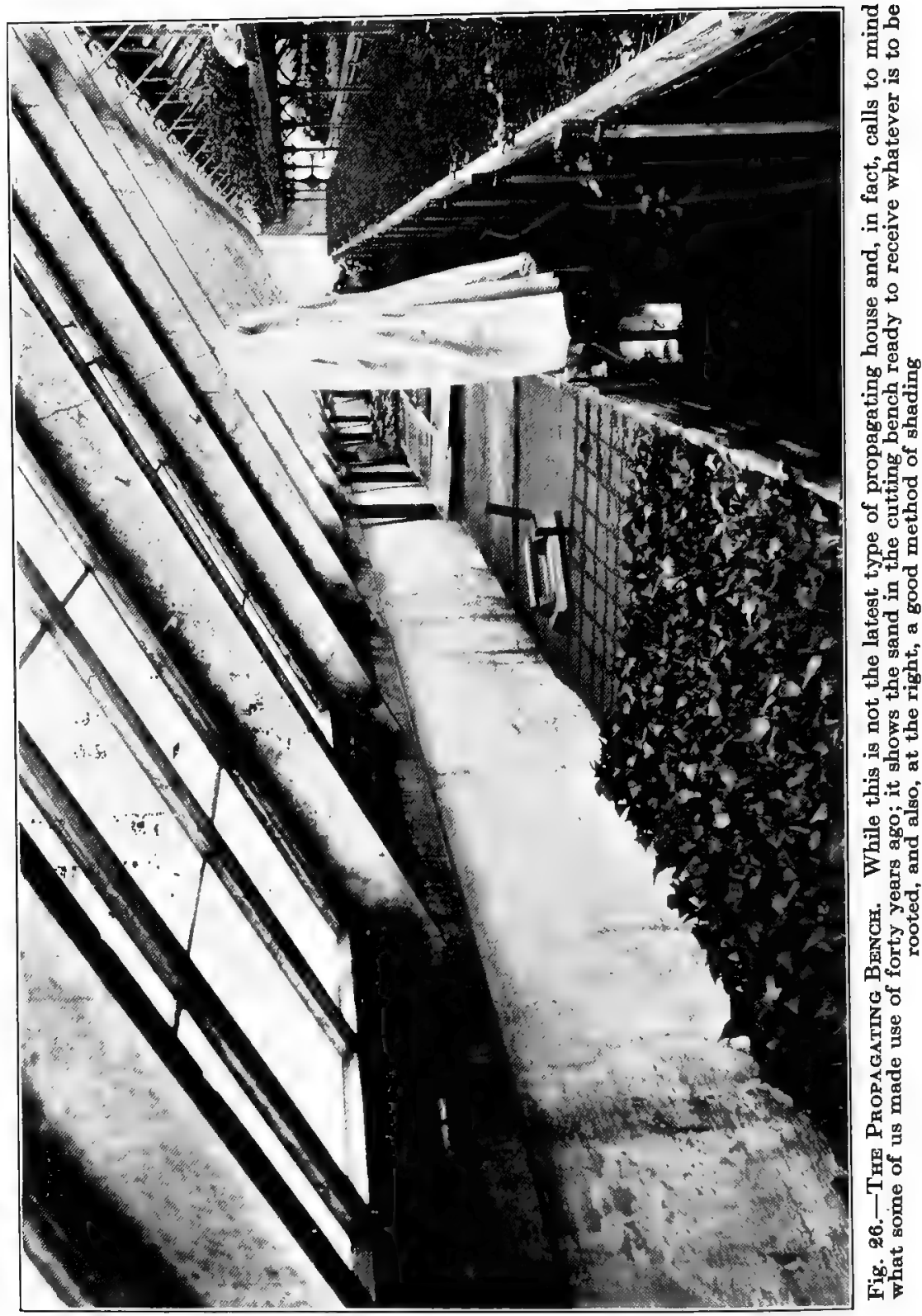


from 6- to 8- or $10 \mathrm{in}$. in height, according to what you want it for, is built over the bench and provided with a sash or large pane of glass. Such a well-constructed propagating frame is the proper thing for Ficus cuttings in pots, or the forcing of Valley. You can also use it for pot plants.

Just as almost everything in the way of cuttings needs a little bottom heat during dark Winter weather the same is true of seeds; if you want the greatest percentage of the seeds to germinate quickly, apply bottom heat. But with most plants the minute they become seedlings you want to move them according to their requirements to either a cool- or a coldhouse. The return pipes of your hot water system are a blessing for your Salvia seed flats, but leave these just twenty-four hours under the dark bench after the plants are up, and you ruin them for good.

Next to bottom heat, cleanliness is the most important thing. If the frame is constructed of wood, the oftener you change the sand the better. Don't keep on propagating all Winter in the same sand. Every time you root a batch of cuttings and remove them, no.matter how careful you are, particles of decayed foliage or pieces of root will be left in the sand. These are likely, sooner or later, to cause trouble in the way of fungus or disease. Remove the sand every so often, wash the bench clean and apply a good Naghot whitewash after the boards are dry.

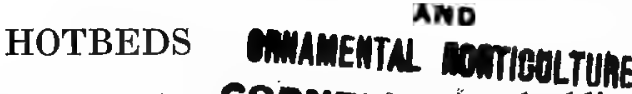

No greenhouse affords more ideal growing conuurs tonyint bedfling stock during Spring than a hotbed. With a whrm fogting and close atmosphere, and near to the glass, everything seems to thrive and flourish. No retail grower's establishment is complete without a good number of sash-covered hotbeds.

HOTBEDS like coldframes are of great value to the florist and while, each year, the problem of obtaining suitable material with which to prepare a hotbed becomes more difficult to solve, those who have a chance to secure manure or leaves should do so and make use of hotbeds for growing a part of their stock. This is especially to be recommended to those growing on large quantities of bedding stock.

Usually, frames which have been used for the overwintering of stock can, in early Spring, be made over into hotbeds. A layer of hot manure about 12 in. in thickness tamped down well and covered with 3 or 4 in. of soil, provides an ideal place for almost anything in the way of bedding stock, from the middle of April on. 


\section{Hotbeds vs. The Greenhouse}

No greenhouse, no matter how well built, will grow better plants in the way of Alternantheras, Heliotropes, Begonias, Coleus, Geraniums, Fuchsias, etc. For the man with a limited amount of glass in the form of greenhouses, hotbeds are almost a necessity during the Spring season. With enough of them on hand, he can devote some of his benches to cut flowers such as Snapdragons, Gladioli, double Cornflowers, Candytuft, Larkspurs, Stocks, double Feverfew, Lupines, Schizanthus and others; or he can hold on to several benches of Carnations which are producing a good crop of flowers instead of having to use these benches for bedding plants.

Greenhouses cost money not only to build, but also to run; not only will coldframes and hotbeds frequently take their place, but also their cost and maintainance are comparatively little.

It may be news to some to learn that dry leaves gathered in late Fall and piled up somewhere over Winter, wetted and packed down

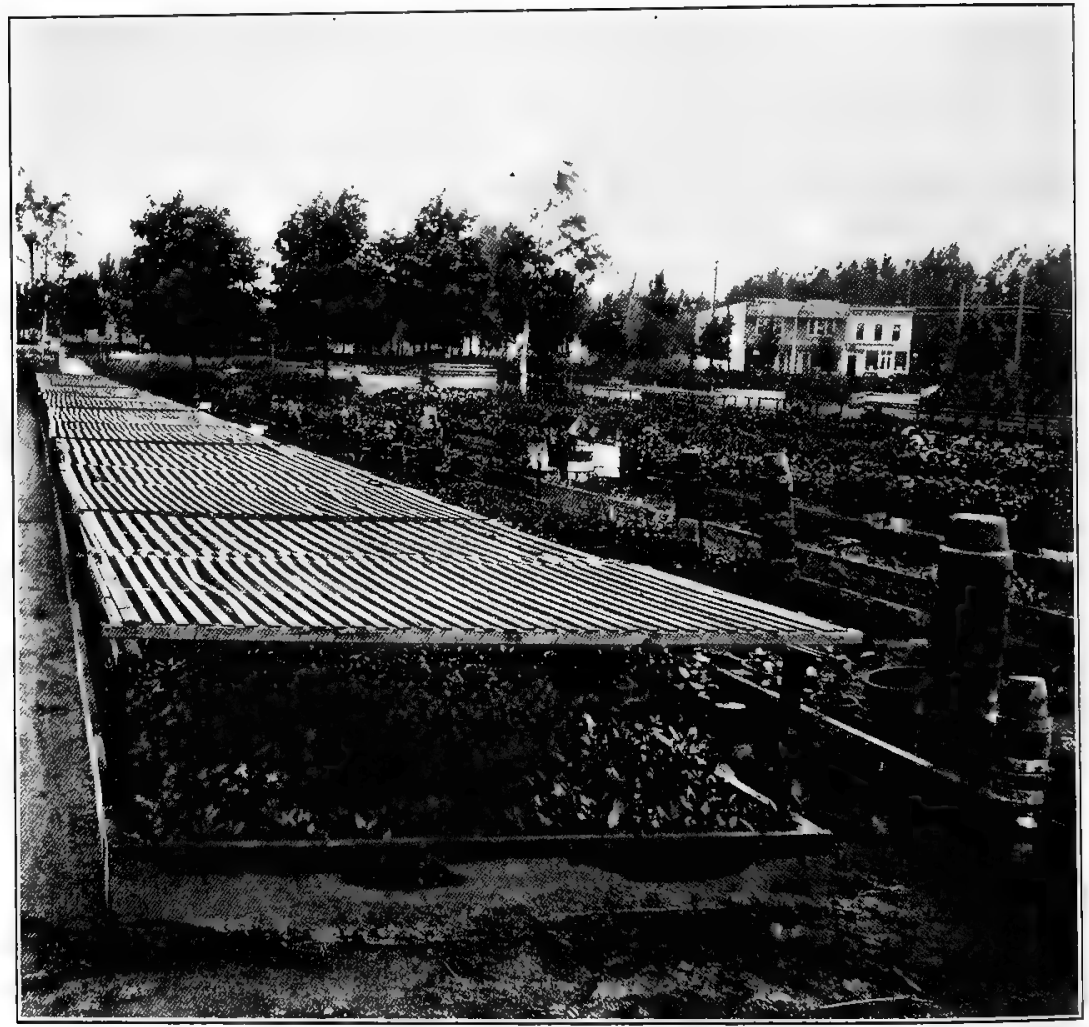

Fig. 27.-Shade Coldframes. Made, as illustrated here, out of laths and 1-by 2-in. strips, shades for coldframes are of no small use to the florist. Such a combination affords ideal protection, especially for small stock outdoors 
in a deep frame in late March, and covered with a layer of soil will make an excellent hotbed. While they will not heat up to as high a temperature as fresh horse manure, the heat will stay in them longer. Another good way is to use part leaves and part manure.

Aside from the usefulness of a hotbed, one should take into consideration the fact that even though you have to pay a high price for manure, every bit of it will come in handy after you are through with the hotbed. You can mix it with your potting soil, or that which you are going to use for the filling of benches. However, this, of course, is only a second consideration, the most important being the fact that a hotbed will give you relief in early Spring when every inch of bench space is taken up and when stock is in need of a shift and more room. There are a lot of different softwooded plants that cannot be placed in a coldframe, but which in a hotbed, or one with just a little bottom heat, will do as well as on benches in a greenhouse, or better. This is the case with Coleus, Alternantheras and tuberous-rooted Begonias. In a frame you have a chance to harden the plants off a bit before you plant them out. Always plunge the pots half way, or better still up to their rims, into the soil as it helps retain the moisture in them. When you remove the plants later on, give each pot a twist a quarter way around, and it will come out clean, while if it is lifted out straight, some of the wet soil is apt to cling to it.

\section{GOLDFRAMES}

Build all the best and most modern greenhouses you can afford; they will help you produce good stock and save you money. But don't, on that account, overlook the great importance of coldframes. Every foot outdoors covered with coldframes is fully as valuable-especially to the retail grower-as bench space inside; in fact there are times when you can use the coldframes to even better advantage.

THE more it costs to erect a greenhouse, the more valuable coldframes are, for it would be wrong to make use of bench room in a coldhouse when the plants could be just as well off in a coldframe leaving the bench to be used for another crop which couldn't be handled in a frame.

With an apparently constant increase in the overhead expense of running a greenhouse, and the ever-increasing price of erecting a modern structure, it becomes more and more necessary to plan on getting the utmost out of an establishment. You can no longer afford, for instance, to overwinter a lot of Chrysanthemums in flats on a bench in a cool house, when they are just as well off-in fact, better off-in a coldframe; you might better be devoting the bench space to something which would bring in money at the same,time. 


\section{Coldframes in Fall and Winter}

The retail grower, during Fall, can keep a lot of so-called stock plants and even a small stock of bedding plants in a coldframe until the early 'Mums are gone. He can start his Freesias in pots and keep them nicely in a frame until, perhaps, the end of October or early November, when he wants them for benching. Harrisii, candidum and formosum Lilies, instead of using up bench space needed for Hydrangeas, Azaleas, Rambler Roses or potted shrubs for early flowering, all can be kept in a frame until some crop is through flowering indoors, or until they are wanted for forcing.

Plants of Delphinium, Shasta Daisy, Coreopsis, Aquilegia, Polyanthus Primula, Canterbury Bells, Pansy, English Daisy, and Forget-me-not are better off kept in frames until wanted for Spring forcing under glass, than if kept in a coldhouse where they take up valuable room.

Paperwhite Narcissi, Roman Hyacinths, Dutch Hyacinths and other bulb stock to be used for extra early forcing, all should be kept in a coldframe rather than outdoors, so they can be gotten at any time. A lot of Paperwhites, planted in flats and allowed to come along slowly, can be kept in a good frame up to December, a few flats being brought indoors as wanted.

Again, we can use a coldframe for storing our cut Boxwood and Winterberries for Christmas; perennials potted up in late Fall are best kept in a coldframe; Roses for outdoor flowering to be sold during Spring in pots can be potted up and kept in frames, and many of your more tender perennials, which often suffer outdoors even when protected, overwinter nicely when heeled in in a frame and covered with glass sash.

\section{Coldframes in Spring}

If you have a limited glass area and are crowded up to the rim, it is a "grand and glorious feeling" to be able to empty a bench of $21 / 2^{-i n}$. Carnations and place them in a coldframe by the end of March or early April, to empty the shelves of the Pansy flats and take them outdoors, and to get out the Sweet Peas and Gladioli in pots, so as to make room for other things which need a shift and more space. Beds of planted out candidum Lilies, Darwin Tulips or Narcissi can be hustled along quite a bit by placing frames and sash over them. Others in the bulb stock group can be held back or protected in frames with shade on top.

A lot of seeds can be sown in a coldframe in early Spring, where with the protection of the glass, you can gain weeks over those sown out in the open. Quite a number of annuals sown indoors can be transplanted into coldframes and will get along there as well as, if not better than inside. The same holds good with small perennials. 
You can also, by the first week in May or in some years earlier, bring out into a frame bedding stock such as Geraniums, Gannas, Salvias and others which don't need a hotbed-and thus make more room inside.

Around Easter a coldframe is often the best place in which to keep the bulb stock you want for that date. You can keep it cool and shaded better than in the greenhouse; and, if need be, you can maintain a high temperature during the day time.

\section{Coldframes in Summer}

Every coldframe you have can be used to good advantage even during Summer. For early use, you can plant out some of the Gladioli started in pots indoors and get them into flower long before those planted outdoors; or, if you merely plant the bulbs right in a frame during the latter part of March, you will get earlier flowers.

The same holds good with double Cornflower. Sow the seed, say, in early March and plant the seedlings later on in a frame; or sow in the frame and let them flower there. Calendulas, annual Gypsophila, annual Larkspur, Salpiglossis, Zinnias and a lot of other useful cut flowers can be treated that way during Summer. Any frame not used for such pot stock as Roses, Solanums, Bougainvilleas, Cytisus, Ericas and others can be planted to annuals.

In Fall, in a deep coldframe, you can protect a lot of Calendulas (sown in July) and keep on cutting from the plants away into November. The same holds good with the early outdoor flowering Chrysanthemums, which, if wanted for cut flowers, or naturally late flowering, are always better off protected with frames and sashes. Even most of the early Pompons that we grow under glass and that come into flower around the end of October can be grown nicely outdoors if protected in this manner.

\section{The Construction of Coldframes}

There are a dozen different ways of constructing coldframes: You can make them out of 1-in. Itumber for temporary protection, or of any other dimensions up to those of a miniature equal-span greenhouse with 4-in. concrete walls. Where a permanent frame is wanted, 2-in. planks are more used, perhaps, than anything else. Really all there is to it, is to plan on getting as tight a job as possible and having the standard 3 by $6 \mathrm{ft}$. sashes fit properly. The use of a 12-in. plank for one side and an 8-in. one for the other will give you a good pitch. The heaviest sash with well-puttied, double thick A glass is none too good; all this helps to make a warm frame.

If you divide your frames, place a $2 \times 4$ where the sashes come together; it will not cast much shade, but will keep out cold and drip 
in case of rain. For a permanent frame, use good Cedar posts and always be sure that you have plenty of drainage.

Often it is found advisable to construct frames which can be moved about and for such, 12-ft. planks are best. This length will give you room for four sashes.

Every man should figure out for himself just what will meet his own requirements best and work accordingly. Those located in southern sections won't need as heavy frames as are necessary in the North; yet in either case the more substantially they are constructed, the better. There isn't a retail grower anywhere who cannot use frames to good advantage, almost, one might say, nine months out of every twelve.

\section{THE SOIL}

The smaller and more delicate the roots of a plant, the finer and more mellow should be the soil you use for potting. Heavy roots usually like a strong or heavy soil, but in all cases, perfect drainage is essential in order to promote a healthy growth. Good soil and perfect drainage must go together if you want results. As long as you have perfect drainage, you can feed plants in poor soil, and have success, but the best soil without good drainage will soon become sour and useless.

FOR general purposes a soil on which you can grow a good crop of Timothy, Clover or Red Top will do nicely. If it is heavy enough it will also grow good Roses and answer for your palms.

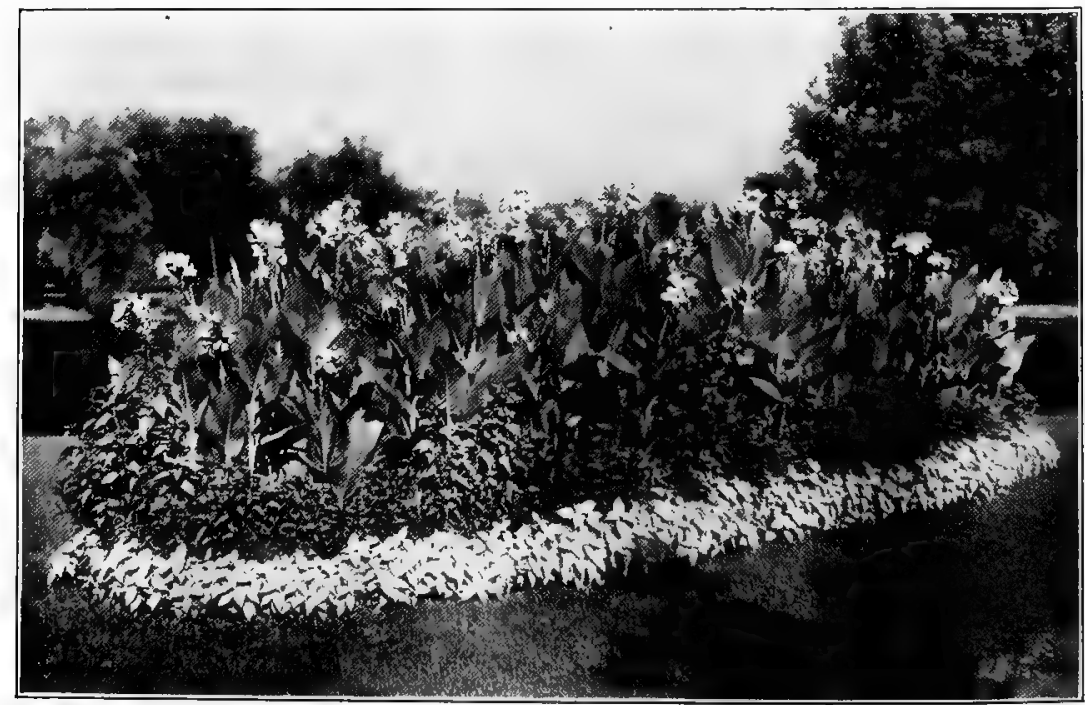

Fig. 28.-A Canna Bed Bordered with Celosta and Golden Bedder Goleus. Even though to some it appears a little too formal, a proper border around a Canna bed is almost essential to a proper finish or suitable setting 
Heavy soil is used for Roses principally because such soil is best suited to remain in the benches for two or more years; there is more body to it, and by mulching and feeding from time to time, one is able to replace the nutrient elements taken out by the plants. You might apply this principle also to the palms which do best for the longest period in a so-called heavy or strong soil. This is not to say that Roses and palms cannot be grown in a light soil, but experience has taught us that a heavier soil is preferable. If it consists of loam, rather than clay, so much the better.

Short-lived plants usually are most easily handled in lighter soil, yet a good, mellow loam with a liberal amount of well-decomposed manure and sand suits almost everything. You can grow to perfection in such soil Cinerarias, Primulas, Cyclamen, Begonias, ferns and bedding stock of every description.

A light and rather heavily manured soil is always apt to produce a rank growth, while a heavy soil makes for a short, stocky growth. As in the case of Geraniums, it gives you not only short-jointed plants, but also better flowers.

The heavier the soil you use, the more particular you should be in providing proper drainage. Whenever possible mix a liberal amount of sand with it. Without proper drainage the best kind of soil soon becomes worthless; with it, even a soil lacking in humus will grow fair stock if this is helped along a little with food from time to time.

\section{Success Without Soll Renewal}

It has been demonstrated that Roses in the same soil in benches can do well for three years and more, and that Carnations grown in the same soil in beds for five years and over have paid. All that was done to the Roses was to apply from time to time a fresh mulch of manure on top; with the Carnations, each Spring or early Summer the young stock was planted in the same soil the old plants had come out of after a good dose of lime and manure had been spaded in.

Soil in a solid bed, with-good drainage below, doesn't seem to give out or wear out nearly as quickly as that in benches. This is easily accounted for, as with almost daily watering, a good deal of the humus or organic plant food is soon washed out. Many growers make use of every bit of the old soil that comes out of their Chrysanthemum or Carnation benches for their bedding stock. There isn't any reason for wasting such soil.

Personally, I much prefer new soil for benching Ghrysanthemums or Carnations, for I don't believe there is any fertilizer known today that will replace the food that is taken out of the soil by growing Carnations in it for eight months. That is the case with 
bench soil, but, on the other hand, such soil spread broadcast outdoors, and plowed under with the field soil, after a good crop of Clover or grass has been grown on it, will, the second year, be as good as any soil you can secure.

I call ideal soil for benching that which you obtain by plowing up good sod about 6 or 8 in. deep and piling it up for three months or so. Three months isn't enough if the ground was dry when you plowed it, but if the soil and sod were fairly moist or received a good soaking as you piled them, except in the case of a very heavy sod, it will break up nicely after three months. Use the small lumps or pieces of sod in the bottom of the bench for drainage, and before bringing the soil in, mix with it one-third as much well-decomposed manure. Or the manure can be incorporated at the time you pile the sod.

If such soil consists of rather heavy loam, or especially, if it appears somewhat like a clay in nature, you can mix with every six yards at one yard of sharp sand. This will give you about as ideal a soil for Carnations, 'Mums, and the general run of florist's stock as you can wish for. I call such a soil "live, sweet, full of plant food and fiber," and would much prefer it to that which has been piled up for two or three years.

It is easy to say to a man: "You should have such and such a soil for certain things," but to always be able to get it is quite another matter. There are Cyclamens being grown in soft leafmold with rotted cow manure and sand, the mixture being finely sifted before it is used for potting, that are giving beautiful plants; and there are just as good plants being grown in heavy loam. This holds good with other stock as well.

\section{What a Good Soll Must Be}

What is of greatest importance, especially in pot culture, is a sweet, porous soil; the heavier its nature, the less you want to think about using a sieve. Finely sifted heavy soil will always pack more than that which contains small lumps and grass rootlets. Of course this doesn't mean not to work the soil over so as to have it fine enough to work or pot with. Also I wouldn't want to use such soil for small Begonia, Petunia or Primula seedlings. A lighter soil is better to work with and for such plants to grow in.

It doesn't-take a man long to find out what suits his stock best, but in most cases a florist can obtain what he needs for ordinary purposes near his neighborhood.

Soil to be avoided is such as lacks fiber and is mucky and sticky; this kind of soil will remind you of putty when in a moist state and moulded into a ball. You can grow certain things in such material 
outdoors, but you can do nothing with it under glass, no matter how much manure or sand you mix with it.

Soil which you obtain from the compost heap will usually grow anything in the way of bedding stock. The man who has the space should save everything in the way of so-called sweepings, thrown out bulb flats, old plants, etc., etc. When left long enough in the compost heap or pile they will all come in useful some day.

\section{COMPOSTS}

In the modern slaughter house not a single thing is wasted, but exactly the opposite is true with the average florist. If we today ran our business the way we will some day, the only things we would actually have to find a dumping place for would be broken glass and clinkers -and both of these make excellent material in a concrete mixture.

A GOOD sized space covered with a compost pile is a paying A investment for every retail grower. Such a pile consists of, or is composed of, so-called wastes of the greenhouses, corresponding to what the slaughter house sells as tankage, which is simply a. mixture of waste scraps of meat, blood and bone. As this makes an excellent fertilizer, so can the compost pile be used to great advantage.

There is hardly a day in the year when the florist hasn't something to throw out, if it is only the sweepings of the potting shed. Everything outside of coal ashes, clinkers, broken pots and glassanything that in time will decay and turn into soil or help to create a porous soil-should go toward making up a compost pile.

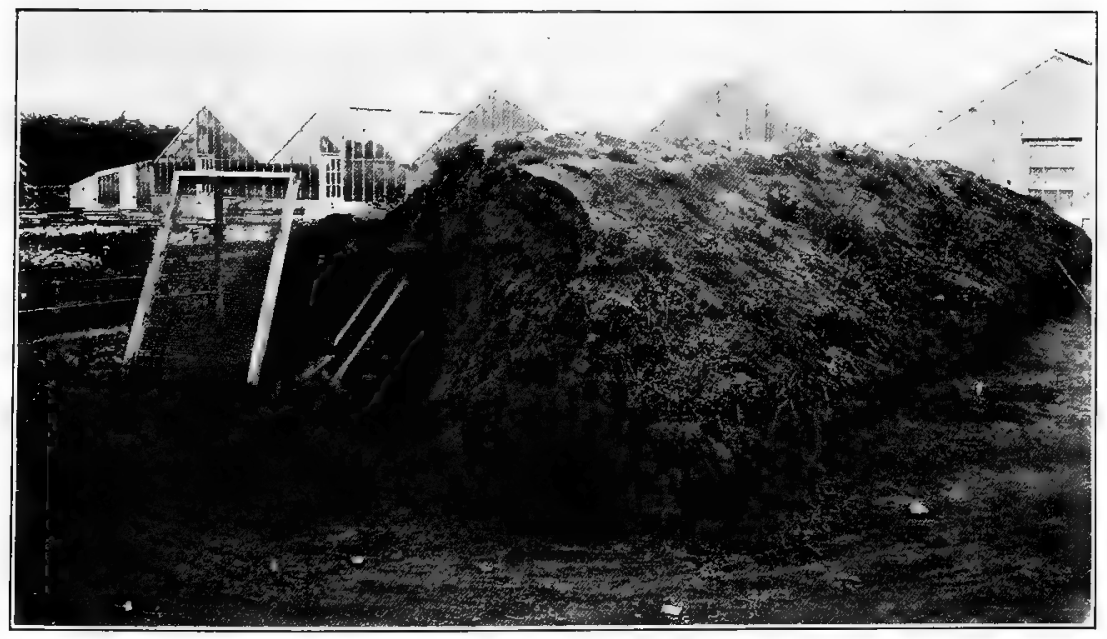

Fig. 29.-A Well-made Compost Pine. Good potting soil is necessary no matter what kind of stock you grow, and a fair-sized pile should always be on hand to draw from 
While the Rose or Carnation grower wouldn't want to use such soil for filling his benches, even he can use it to advantage for mulching or top dressing. It is the retail grower, however, who can best use such soil for potting, especially for potting bedding stock. If only utilized by being mixed in with some other soil, it will afford a great saving.

The compost pile should not be confused with the soil pile, put up for the filling of benches for Roses, Chrysanthemums or Carnations. When making up such a soil pile you should know exactly what goes into it, and that it is suitable for the purpose for which you want it; a compost pile may contain everything. It is, for instance, the proper place to dump the cut-down flats of Paperwhites and Dutch bulb stock, all the pot plants either cut down or such as are left over and cannot be carried over, the old soil out of seed flats, the sand from the propagating bench, manure which has been used around the greenhouses, or between the hotbeds over Winter, leaves, sweepings of the houses and walks-any and everything which, as stated above, will go toward making a good compost later on. If you wish to add some sod and soil from the field and some manure, so much the better, but the principal object should be to use material which, if not used up in this manner, would go to waste. It might even mean additional expense to dispose of it, whereas, if given time to turn into soil, it can be utilized to advantage.

In starting a compost pile, a good way to do is first to select a place, high and dry and with sufficient room to get around with a wagon or truck in loading and unloading. The retail grower can well start a pile 6 or $8 \mathrm{ft}$. in width and make it 4 to $5 \mathrm{ft}$. high. Keep on adding at one end and give the part put down first a chance to decay. Forking or spading and turning the pile over will help matters.

Even in a small establishment where a variety of stock is grown, where benches are filled and emptied every year and a lot of pot plants raised, it is surprising how much material can be gathered that is fit for the compost pile and which will, in time, become valuable potting soil. We all know that it costs more and more each year if you have to buy such soil by the load-as many have to do.

\section{MANURES AND FERTILIZERS}

There is no subject in connection with the florist business more deserving of consideration and careful study than that of fertilizers and other forms of plant food.

UCKY indeed is the florist who keeps a couple of cows, more or less, to supply him with the manure needed for his crops. I say
lucky, for the reason that, if necessary, one can get along nicely with 
cow manure alone, and doesn't have to pay much attention to socalled commercial fertilizers or chemical salts as plant foods. With cow manure on hand-whether fresh and used in liquid form, or well decomposed and mixed in with the soil in the benches or for potting-we hardly need spoil a single crop.

Conditions, however, have changed and are changing rapidly, and it seems almost as if the automobile has not only done away with the horse, but had also driven the cows away from the neighborhood wherever a florist is located. There are really more cows in the country than ever, only they are distributed differently, and for the florist the cost of manure, if bought, is almost prohibitive.

Gradually some of us are beginning to realize that we have to find substitutes with which to supply the essential plant foods, such as nitrogen, phosphoric acid and potash, one or the other of which-or all three-are usually lacking in most soils.

We are beginning to realize that we are creeping in the dark as far as knowing the first thing about what the soil in our particular section lacks in essential plant food requirements. Nor do we intelligently go about applying fertilizer. We look upon a bag of 2-12-1 fertilizer with suspicion, just because it doesn't look like a yard of manure, and we don't realize that the food values in that bag are far greater than what is actually available in that yard of manure. Or we will use bonemeal, which contains a high percentage of phosphoric acid when the soil really is in need of potash; or we apply nitrogen in the shape of nitrate of soda when the soil is really in need of available phosphoric acid, and so on. Even those who do use fertilizers and salts to promote growth or flower development, far too often take the stand that because the dose applied hasn't killed the plants in the bench or made them look sick it naturally must have done them a lot of good; whereas, if the truth were known, it was just money thrown away.

\section{Organic or Animal Manures}

I don't blame any man who can get all the cow and horse manure he wants and obtains good success with his methods of applying it, for sticking to what he may term "the safest way and the easiest." However, the number of florists finding it more difficult to obtain manure is increasing greatly each year, and as there is no set rule to go by in applying fertilizer, it is surely of enough importance for every florist to try and get better acquainted with his own particular requirements. You cannot obtain satisfactory results by experimenting for just one season; it takes more than that, and each class of plants we grow requires different treatment. Even those who at present have all the stable manure they need, often can use commercial fertilizers and chemical salts in connection 
with it to the greatest advantage. After all, we don't differ a great deal from the farmer, only that our farming is done under glass. In regard to obtaining better results with a crop and securing the highest possible yield from a given space, both have to depend to a large extent on the available plant food the soil contains.

Bonemeal is, of all fertilizers, the most used by the florist. Being slow to act and the actually available phosphoric acid being produced only as it slowly decays, we hear of very little damage being done by it. The Rose grower has used bone for many years and finds it better than anything else for restoring that which the plants in the bench for several years have used up and that which has been washed out of the soil by constant watering. We find that mixing into the potting soil for our bedding stock about an 8-in. pot full of bonemeal to a barrowful of soil, will provide food for the plants in the small pots and make them do better than those which have no bone.

Sheep manure we also are well acquainted with, but under glass don't use it too heavily, or as extensively as bonemeal. It acts quicker, but of course hasn't the lasting qualities of bone, being only a manure.

The Carnation grower uses bone and sheep manure as a top dressing during the Winter months; the Sweet Pea grower, after his

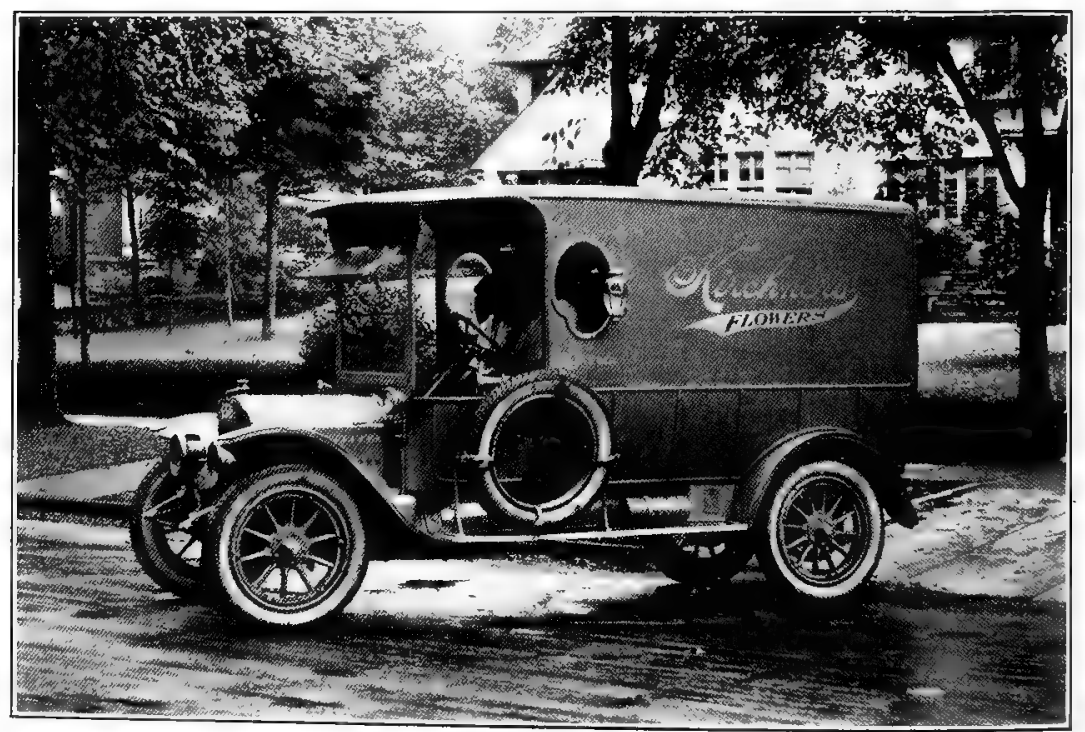

Fig. 30.-The Usegul Delivery Gar. Here is indeed a "nifty" delivery outfit. Just what make of car you use is of less importance than to have a neat body attractively painted and always kept in good order 
plants have yielded their first crop, works in a fairly heavy layer of sheep manure and gets good afterresults.

Horn shavings is next in importance to bonemeal and, like bone, represents valuable plant food in a highly concentrated form. For the final shift of the Geraniums there is nothing quite like a liberal dose of horn shavings; a 10-in. potful to a barrowful of soi] will do a lot of good. For Ghrysanthemums in light soil a liberal amount of bonemeal and horn shavings is always to be recommended mixed with the soil after it is in the benches, but before the plants are set. And there is nothing better for Cinerarias.

Chicken manure contains a lot of plant food, but it is far safer to use it outdoors than under glass as long as bone or -sheep manure are to be had-and usually they can be obtained.

Horse manure, when well rotted (which is the only state in which it should be used under glass), doesn't differ greatly from cow manure, but hasn't quite the same food value. If not applied too heavily it will always be of benefit as a top dressing or for giving a bench a mulching, as well as mixed into the soil. There is one thing in favor of using manure, namely, in the case of a heavy soil outdoors a good layer of either horse or cow manure worked in will help to make it porous and on that account alone be of great benefit. This holds good also in benches containing heavy soil.

Tankage is getting to be quite popular with many growers. It derives its name from the fact that in the slaughter houses, pieces of bone waste, blood and scraps of meat are all dumped into huge tanks. They are cooked, the fats and grease are skimmed off and the contents afterward dried. This naturally makes a good, allround fertilizer and in the lack of stable manure is used today by many successful large growers.

Blood in a dried state is one of the most valuable fertilizers. Containing a high percentage of nitrogen it is to be recommended whenever a stimulant is required. If you want to change the color of a starved Boston into a dark green, apply blood; and the same with Carnations in January.

\section{Wood Ashes AND LIME}

Wood ashes are of great value. It stands to reason that they are bound to contain a lot of valuable plant food in one form or other, coming as they do from wood, which took years to develop, requiring and absorbing food during all those years, of which a lot is contained in mineral form in the ashes. Spreading wood ashes over land and plowing them under cannot help but be of benefit. For lightening a heavy soil outdoors there is nothing finer than coal ashes, which, however, contain practically no available plant food. They are much made use of in Europe, but here we waste them. 


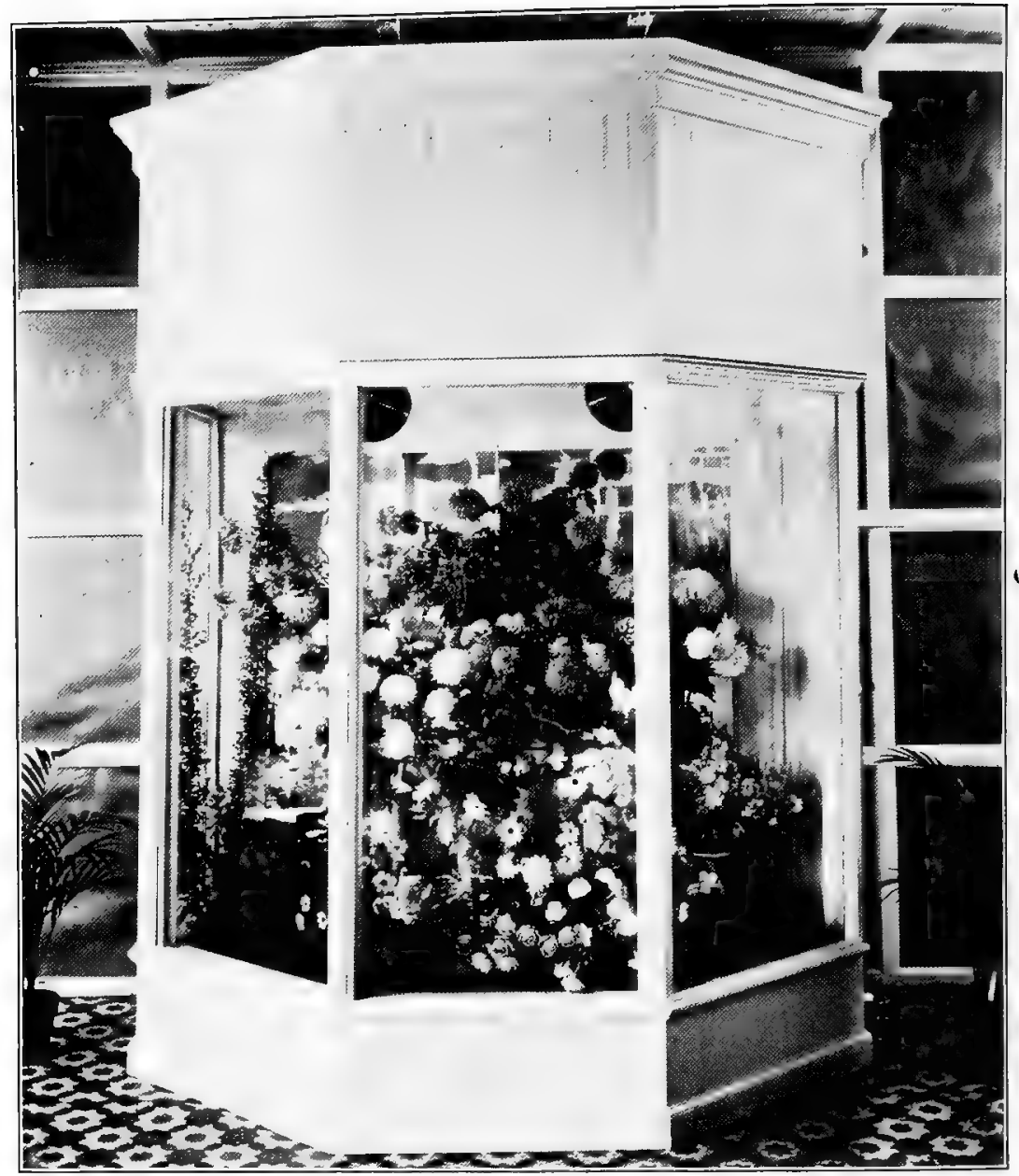

Fig. 31.-A Convenient Display Cooler. This is quite different from the usual square, corner cooler found in many florist shops, but it should prove especially well adapted for the center of a store of medium size

There is no better way to tell all about the value of lime than to quote from Wisconsin Bulletin No. 225 as follows: "Lime has a definite market value as a fertilizer only when purchased in the form of compounds like carbonates (limestone and marl), sulphate (land plaster), or as quicklime or slaked lime. It should not be considered as a fertilizer, but as a soil corrective, having as it does a very important and beneficial action on acid soil and the living processes going on therein. It may also improve the mechanical properties of such soil.

"Applications of lime in the form of carbonates, quick lime, or slaked lime are necessary to correct soil acidity and will prove es- 
pecially beneficial in growing legumes such as Alfalfa or Clover, or in the raising of Sugar Beets."

\section{Nitrate of Soda}

Nitrate of soda, which we obtain from Chili, is a great stimulant. If you want to convince yourself of its value, take a flat of stunted Tomato seedlings, dissolve a level tablespoonful of nitrate of soda in a five-gallon can of water and apply to the plants. Place another flat alongisde, but do not treat it and in just ten days you will notice the greatest difference. However, nitrate of soda is good only to develop and encourage leaf growth. If used during the growing period of Chrysanthemums or other plants, and used carefully, it is always beneficial, but you cannot be too careful and must feel your way. There is no better method of telling what is best for your soil than to start in with weak doses. This much, however, is certain, that by using fertilizers, you can increase the production of the soil. The result of eighteen years of experimental work done by the Ohio Experiment Station showed an increase of fourteen bushels of Wheat per acre, and thirty-one years' of experiments carried on by the Pennsylvania station, showed thirteen and six-tenths bushels increase per acre as the result of the use of fertilizer.

All so-called commercial fertilizers are now sold under different state licenses, according to the amount of available nitrogen, phosphoric acid and actual potash they contain. For example, a 2-10-6 fertilizer contains 2 per cent nitrogen, 10 per cent phosphoric acid, and 6 per cent potash.

\section{What Kind of Plant Food to Use}

The next, and perhaps most important matter, we arrive at is how are we to find out or know what is best to use for the crops we are growing? When do we know we are using the right kind of mixture to do our soil good, and when do we do more harm than good? Well, as far as has been found out, a safe rule to go by is this: Heavy soils are usually richest in potash, but usually lack nitrogen as a stimulant to promote growth, and also are apt to be short on available phosphoric acid. Sandy soils are always benefited by heavy doses of tankage which will improve the soil and give it more body. Whenever possible, stable manure should be applied to such soil; it benefits it more than any other food. Black soils usually are benefited by a fertilizer sold as a 3-8-6 or 2-10-4 mixture.

Next comes the question, how is one to ascertain exactly what a certain soil lacks in the way of plant food? I can answer this no better than by quoting an Indiana Agricultural Experiment Station report: "Soil analysis is of little value in showing fertilizer requirements, for there is no chemical method known that will show reliably 
the availability of the plant food elements present in the soil." This means that in order to find out just what is best for your soil, you must conduct experiments yourself. Whether now or later on, the day is bound to come to most of us when we will have to do this -and the sooner we get at it, the better it will be.

\section{Fertilizer Experiments at Home}

As an example of how one can determine in a simple way just what benefits a certain soil, take, for instance, a bench of Carnations which up to December first has received no feeding of any sort, and is in a healthy condition. Say the bench is $4 \mathrm{ft}$. by $100 \mathrm{ft}$. Divide the length into six equal parts, and on the first, starting from one end put on a layer of tankage about $1 / 4$-in. in thickness; on the second put a layer-not quite so heavy - of bonemeal and sheep manure mixed; on the third, blood and bone; then skip one section. On the fifth, apply a layer of a 12-2 fertilizer; and on the sixth, or last, a 2-10-4 mixture. Work them all into the soil and follow with a good watering. Of course you can divide into smaller spaces and use still other mixtures, so long as you have division lines and keep each plat properly labeled. Keep a careful record of the results. It isn't likely that you will hurt anything, and if inside of six weeks you notice no apparent change, you might apply a second dose of the same sort. Then in six weeks more you should be able to tell exactly what has benefited the plants most, though it may take a little longer.

Another way is to use different fertilizers in the potting of plants and keep a record of their growth; still another is to apply some of the plant foods to the compost pile.

There are still some who cannot make themselves believe that fertilizer can possibly be as good as manure. But each year more people have to get along with less and less manure and while it may seem foolish to predict it, the day when plants, fruits, cereals, vegetables and flowers all will be grown to greater perfection than ever before, without animal manure or anything of the animal in the way of blood or bone, but merely chemicals and minerals scientifically prepared and applied-yet this day may come, and for no other reason than that man will have no more use for animals.

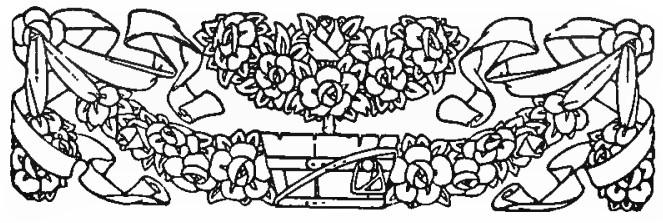




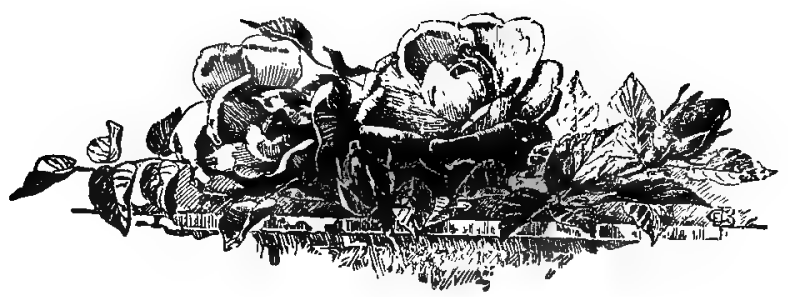

CHAPTER IV

\section{PRACTICAL OPERATIONS IN THE GROWING END OF THE BUSINESS}

\section{GREENHOUSE HEATING}

7 HE heating of greenhouses is surely a most important subject, and although great improvements have taken place since we

1 substituted hot water pipes for the old-time brick and tile flues, it seems to take as much coal as ever. Even firing with oil doesn't bring the cost down.

The florist grower erecting a new range of houses today usually leaves the system of heating to the builder. All the best firms have expert men in charge of the heating end, and there is little use taking up time here for the discussion of the subject, as it couldn't be treated so as to apply to all sections of the country, nor could one go into it deeply enough. Still, for the beginner and the smaller established florist it may be of interest to mention a few things which, to my mind, are worth considering as they are the result of my observations and experience during more than forty winters spent in greenhouses.

No matter what kind of boiler you use, what coal you burn, nor how large or small your establishment, always separate the greenhouses from the boiler pit. Many failures-with flowering pot plants in particular-have been traced to gases escaping from the boiler pit. For small establishments, hot water is always better than steam, as it doesn't need quite so much attention, which means a lot to the man who does not employ a regular fireman. Always get acquainted with the grade of coal you use; the cheapest is not always the best or the most economical, especially when used with a small smokestack.

If you figure on fourteen 2-in. pipes heating a certain sized house, put in six extra ones. More pipes and less heat in them gives you better results than to force your boiler and be obliged to keep the pipes red hot in order to keep frost out or maintain a certain temperature. 
The farther you keep pipes away from the bottom or sides of benches the better for the plants in them.

You can never have too many shutoff valves in your pipes. They will be appreciated in case of a breakdown, or if the pipes are not all required during a warm spell they can be partly cut out, to be turned on again when it gets cold.

A too large boiler may eat up more coal than necessary, but you are out more money by having to force a boiler that is too small. With most plants it isn't nearly as important just how hot or cold you keep them, as it is how evenly you can maintain the temperature they require.

There is always a way to find out just what heating system, what kind of boiler, and the amount of piping one requires in order to maintain a certain temperature. The man who starts into business today makes a big mistake in going ahead without knowing just what he is doing.

\section{WATERING PLANTS INDOORS}

WATERING plants growing in pots or in a bench requires careful attention, for the plants are entirely dependent upon you for the right amount necessary to encourage a healthy growth. When out in the open the roots have a chance to go down into the soil and look for moisture if necessary, and they usually do it. You can lift a tender annual and find that its hair-like roots have grown right into a hard, rock-like clay soil and wonder how it was possible. That same plant in a 4-in. pot on a bench has no chance to do so. It is absolutely dependent on some one to supply the moisture. necessary, as the roots are confined within the sides of the little pot. And the same almost holds good with the plants in a bench with only four or five inches of soil.

Now with most plants grown by the average retail grower it is just a matter of keeping the soil fairly moist at all times and when applying the water of disturbing the plants as little as possible. Just how to do this, one has to find out for himself. You can show a man how to hold the hose, how to place the forefinger over the opening, how to move himself and the arm that holds the hose so as to distribute the water evenly, instead of squirting it twenty feet from where he stands. But in order to do all this rightly the man has to learn through experience.

You can tell when a bench of Carnations is in want of water by examining it. Get your fingers down into the soil and find out its exact condition; you cannot always tell by the appearance of the surface. Don't water soil that is wet nor ever let a lot of stock suffer in soil that is dry. To give soil in pots or in a bench a chance 
to dry out well every once in awhile is wrong. The plants suffer every time you do it; you stunt their growth. Plants which have been grown under glass in pots or in a shallow bench with artificial watering are different from those in the open field and can't stand a dry soil without showing bad effects. On the other hand, if you have poor drainage and the water you apply remains in the soil too long, you will get the same bad effects.

Take a Boston Fern. No plant loves water more and as long as you have plenty of drainage in the pot it can stand watering practically every day. But in a sour soil resulting from improper drainage, it will soon go. And this really holds good with all other plants.

No man who does just a little thinking for himself will use the hose on a seed flat or pan or on small delicate seedlings. It is being done, of course, in some places, but the gardener who uses the water ing can is very apt to have better success. There are men who can hit a Gloxinia plant every time with the hose when ten feet away, but it won't be a Gloxinia long. With a little judgment and common sense, the man who wants to do the right thing for his plants won't be long in finding out how best to water. The man who will keep his elbow tight a-

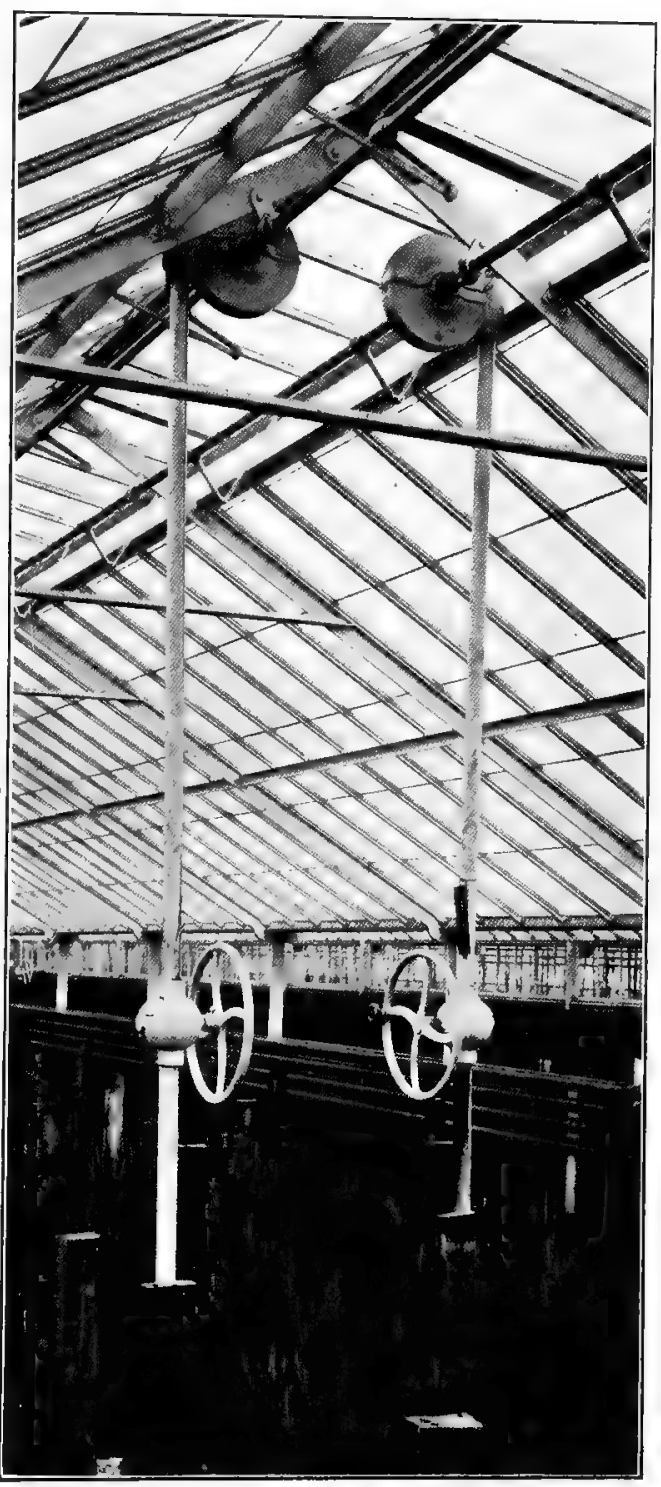

Fig. 32.-Ventilation Helps. What we expect from a ventilating apparatus is that it will open all the ventilators evenly and with ease, and when they are closed, hold them tightly in place. The type shown does these things and is considered one of the best on the market 
gainst his body when watering a bench never will make a gardener.

Every plant when freshly transplanted or shifted should have a thorough watering. Only by so doing can you hope to settle the soil evenly and firmly around the roots. The same thing should always be done when placing cuttings in a sand bed to be rooted. One good soaking is sufficient for many quick-rooting cuttings, and a fairly moist sand is usually better than one that is too wet.

The more firing that has to be done to keep the temperature up in a house, the more attention you must pay to watering, especially when heating pipes are just below the bottom of a bench or close to its sides. Watering includes not only watering the plants themselves, but also the use of the hose as often as is necessary during the Winter months (or the Summer for that matter) in applying water on the walks and below the benches in order to maintain a moist growing atmosphere, This is often necessary when a lot of heating pipes underneath the benches are drying things out. During a hot, dry Summer you are also liable to have too dry an atmosphere prevailing.

\section{VENTILATING}

Unless a suitable atmosphere prevails in your houses, no matter how wet or dry you keep the soil, nor how high or low the temperature is, your stock will never do its best. To my mind the atmospheric conditions surrounding a plant under glass have far more to do with its success or failure than the soil it is planted in.

NE of the essentials in successfully handling plants under glass is to create and maintain a healthy growing atmosphere; without such an atmosphere, there is bound to be trouble somewhere.

We often hear of a man making use of the best kind of soil, providing perfect drainage, maintaining the proper temperature, and keeping his stock clean-and yet a certain crop simply will not do with him. In most of such cases one would have no trouble in tracing his failure to the lack of a proper atmosphere in his houses.

One of the reasons the smaller grower, or the one who conducts a retail establishment, is not always successful with Roses, Carnations, Sweet Peas, Lilies or pot plants such as Begonias of the Cincinnati type, is that he has to handle the stock with fifty-seven other varieties all in one house, which means about the same temperature and atmosphere for all. On the other hand, the specialist in Roses, Cyclamens, Lilies or Carnations, devotes a solid house or several houses to each individual kind of plant and, through experience, has found out just how to run the houses and what kind of atmosphere best suits each class of stock. This is not to 
say that a number of different varieties of plants cannot be successfully grown in one house, but only that in order to grow them to the highest state of perfection-to grow "fancy stock" as the florist would call it-you want each by itself so you can study its requirements and provide as nearly ideal growing conditions for it as possible.

Because a beginner happens to have so-called "good luck"and, by the way, there is really no such thing-doesn't prove anything. You will always travel more safely with the experienced man, and it is the latter who will at once know what to do in case of trouble.

\section{The Importance of Moisture}

Perhaps no other plant better illustrates the part that the right kind of atmosphere plays in its development than the Cyclamen. We all know the type of grower from whom the Cyclamens receive no particular attention, but "jes' grow." He may have them in old houses where you must wear rubbers walking between the benches if you don't want to get your shoes covered with mud. That same grower is fully as successful with his Ginerarias and obconica Primulas. Again, you may notice the fellow with a brand new house where everything is uptodate and convenient with concrete walks and perfect ventilation and not a leak in the roof, whose Cylamens stand still, don't move at all. What is the trouble? What is the cause of the dose of red spider and the sickly growth? Simply this, the house is too dry; he hasn't the moisture in the atmosphere that the plants require in order to produce a healthy crop of fat leaves. It is not, necessarily, that he can't provide these conditions, but thus far he hasn't. His Cyclamens are in good soil and liberal sized pots and the soil is always kept moist; but the pots are sitting on a dry bench and it is dry below and on top. Such conditions may not do much harm during November when the plants are through growing and are ready to flower, but you can't grow them on that way.

You can grow good stock in an old house and better stock in a new one; but in either case you need a certain amount of moisture if you want to grow anything really well.

Here is another illustration. Frequently we find cases where everything in an establishment does finely all through the Summer, but as soon as firing starts and the ventilators are shut down, there is trouble. Some of the causes for this are the following: A man may shut down his ventilators early in the afternoon in October in order to save coal and still maintain a certain degree of temperature over night. When he enters the next morning there prevails in the house a cold, damp atmosphere - the worst thing in the.world for Poinsettias, Roses, Chrysanthemums just opening up, Car- 
nations, or, in fact, almost anything. From the daily waterings given all Fall, there results an excess of moisture which, with ventilators shut down, will transform the greenhouse into a wet cellar over night, which a crack of air and a little fire would easily prevent. As bad, only the other way about, is to fire heavily and dry out the houses. The plants that have become used to moisture in the atmosphere-or at least many of them-will object to this. Wetting below the benches and the walks is usually necessary in maintaining a certain degree of moisture. Plants differ, of course, but watering the pots is not always enough. This, however, is not to say that you cannot overdo things in this connection.

\section{Ventilation and Disease Control}

With a well-ventilated house, you can, to a great extent, check stem rot in Carnations or hold in check mildew on Chrysanthemums. You are not bothered with mildew during Summer because the plants have more resistance and atmospheric conditions are not favorable to it. The man who wets the foliage of the Chrysanthemums late on an October day, invites trouble and the same in the case of Carnations. The closer we get to Winter, the more careful we have to be to avoid a stuffy atmosphere in the houses. While you must provide a certain amount of moisture, at the same time avoid wet foliage over night. The harder we fire the more important a part the hose plays in preventing a dry house. Heat itself, whether from steam or hot water pipes, is heat pure and simple, but if this heat is allowed to dry everything out in a greenhouse, it will interfere with a healthy plant growth.

Even in the houses kept at 50 or $40 \mathrm{deg}$. there should always be attention paid to the moisture of the atmosphere as well as that of the soil in which the plants are growing.

In connection with the application of water, ventilation to a great degree controls the atmospheric conditions of a greenhouse. It also helps us to maintain under glass the desired temperature. Good ventilation is such as will permit a circulation of air in a house without letting cold draughts strike the plants. While some plants are not as particular as others nor as sensitive, any plant grown in a greenhouse and sheltered from the wind and weather to which outdoor stock is subjected, will feel sudden changes of temperature as well as of the air. It is of the greatest importance to prevent any such variations.

The larger a house, the easier it is to ventilate it properly and the less chance there is of chilly air coming in contact with the plants. The smaller the house, the more attention should be given to opening and closing the ventilators. You cannot hope ever 


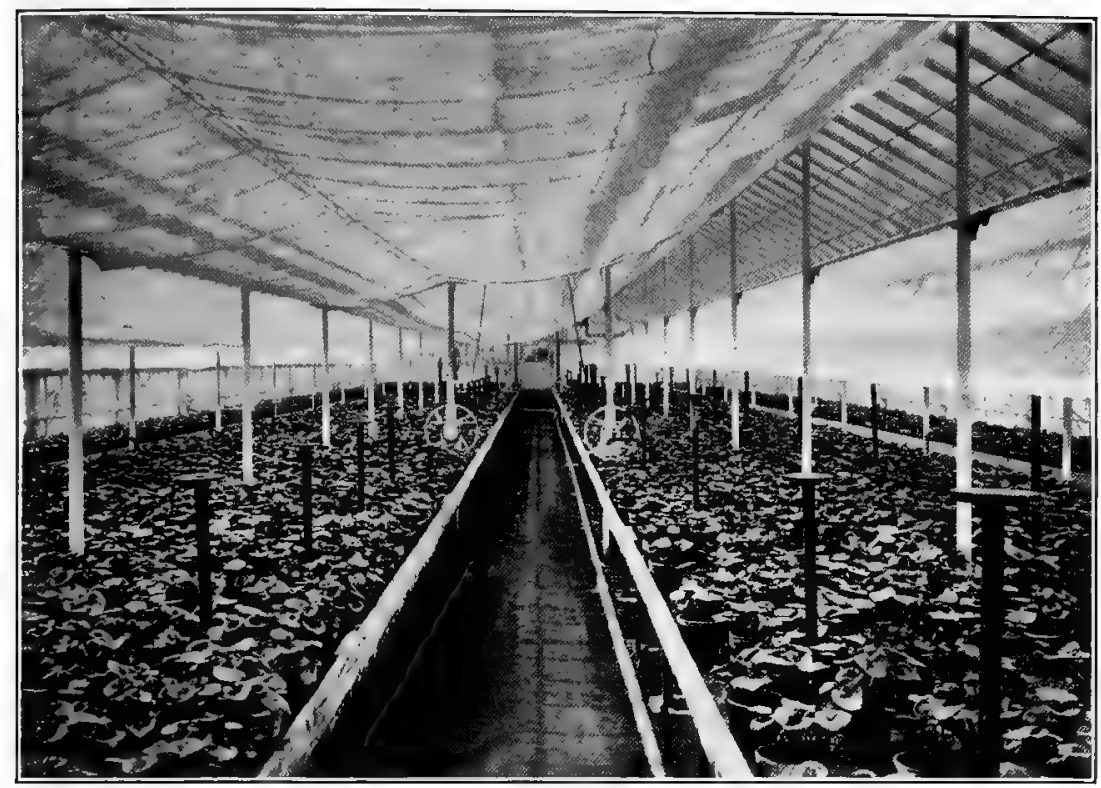

Fig. 33.-Shading Crclamen. Proper shading during the hot Summer months is an important feature of Cyclamen culture. Too much or too dense shade is worse than none at all. Just enough to prevent the plants from wilting is the thing and if, whatever method you use, you can remove it easily, so much the better

to open or close up at any certain time of the day. It all depends on the weather conditions.

\section{Special Problems in the Fall}

At no other time of the year do the ventilators play as important a part as during Fall, when you gradually change from Summer to Winter conditions. That is when the eyes of the man in charge of the Rose or Poinsettia house should be open and his hand be on the wheel all day long. Many a dose of mildew on Roses could be avoided if the ventilators were watched more closely and the same with yellow leaves on the Poinsettias or tender Begonias. Too many growers open their ventilators when the sun warms things up above a certain degree and leave them open until the sun goes down or even long after it has gone down, whereas they should have partly shut them or opened them up more and then shut them again several times during the day. Or, in the case of ventilators on both sides of the roof, the north ones should have been opened and the south ones closed, or vice versa, according to the shifting of the winds. There is no "best way" to have ventilators stationed, and it is impossible to say whether they should open at the top or at the bottom. A good way, however, is to have them on both sides of the ridge so you can open the ones best suited to 
the conditions on a windy day. Side ventilation is excellent, especially during Summer or at times when you need all the ventilation you can get. The better ventilated your houses are, the better stock you can grow and it all sifts down to the question of "getting the maximum amount of circulation of air without exposing your plants to cold."

\section{SHADING}

THERE is one thing we haven't as yet got to quite suit us and that is a method of shading that can be used for most purposes. Nor can we hope for much in this direction, as almost everything that needs shade while under glass needs a different kind.

Each grower, almost, has a different way of supplying shade. With all of them, whitewashing the glass either lightly or heavily is found most suitable for certain crops. Cheesecloth on wires over the cutting bench, and shade frames made out of laths and 1- by 2-in. strips for small houses or frames, still lead. Some growers use effectively whiting and oil for a more permanent mixture or frosted glass for palm houses. But you can't mention any one kind of shading that will do for all kinds of plants, or for any one class of plants at all times of the year.

A light whitewash is easily applied to a roof with a sprayer and is almost as easily removed. That is what makes it a most desirable shade for the retail grower; if removed by a heavy rain, it is but little trouble to put on another coat.

Cuttings in the sand don't ever want to be kept dark, yet the sun must be kept away from them until they are rooted. Cheesecloth or other lightweight cloth seems to do this to perfection, and if you can fasten small rings along the edge of the goods and stretch wires just over the bench or right under the glass, you will find this far better than laying papers over the cuttings, and having them fly all over. Few flowering plants need shade during Winter but bulb stock, of course, not only needs shade, but also should go into a cool place. Primula obconica is a plant that needs moderate shade to be at its best, but Cyclamen, Chinese Primulas and Cinerarias don't need shade as long as proper ventilation is given. Any of these plants during Midsummer cannot stand full sunlight, but heavy shading would be just as wrong. Just enough shade to keep the foliage from wilting is the thing.

Palms can stand a fair amount of shade practically all the year around. Ferns like shade, but not so much as to produce a soft, weak growth.

A little shade for small seedlings is nearly always of benefit, but with most flowering plants, it should be given only until the plants are hardened off a little. With the seedling small table 
ferns, sunlight need never strike them and they will be all the better for its absence.

Roses, Carnations, Poinsettias and Chrysanthemums don't ever want shade while growing in a bench, unless you want to shade the flowers a little to make them last longer or to get a better finish on them as you might with 'Mums for the exhibition table or Carnations during a hot May.

Just a little experience will soon teach a man when a plant is benefited by a little shade; when there is too little shade; or when there is too much of it to do the stock good.

\section{SOIL DRAINAGE PRINGIPLES}

WITH the possible exception of aquatics, most everything the florist grows needs drainage in order to do well. We often overlook this fact in the case of plants requiring moisture, and have them go back on us. Even the greenhouse should be provided with proper drainage the same as the basement of a dwelling, and the heavier the subsoil, the more drainage is necessary in order to keep things sweet. A few 4-in. drain tiles, with a covering of cinders and provided with a proper outlet will in a short time pay many times over for the cost of installation.

The solid beds in the greenhouse need drainage. You cannot water daily without having drainage to take the surplus moisture away. The more you water the more drainage becomes a necessity. I have seen many acres of orchard ruined by overirrigation which really wasn't due to irrigation at all, but rather to lack of drainage. The very same thing happens in the pot or in the garden on a smaller scale. Soil not properly drained causes sourness and the roots growing in it will decay in time.

Sour soil is like a sour stomach. Lime in one form or other may give relief, but it takes more than that to cure the trouble. In heavy soil in the field you can, during a hot spell, easily overwater and notice the stock going back in consequence, while other stock, not watered, but faithfully and persistently cultivated, will flourish.

Water is a great blessing, but perfect drainage has to go with it. Always see to it that there is plenty of drainage in the bottom of the benches. Allow at least a 1/2-in. space between the boards and cover the bottom with a layer of long strawy manure or rotted sod before you put in the soil.

When shifting plants from $2 \mathrm{~s}$ or $21 / 2 \mathrm{~s}$ into larger pots, if you make use of a heavy soil, it is always well to lay a small piece of broken pot, or several of them, archways over the hole in the bottom of the pot. This will insure better drainage, and the larger the pots you make use of, the more it is necessary. 


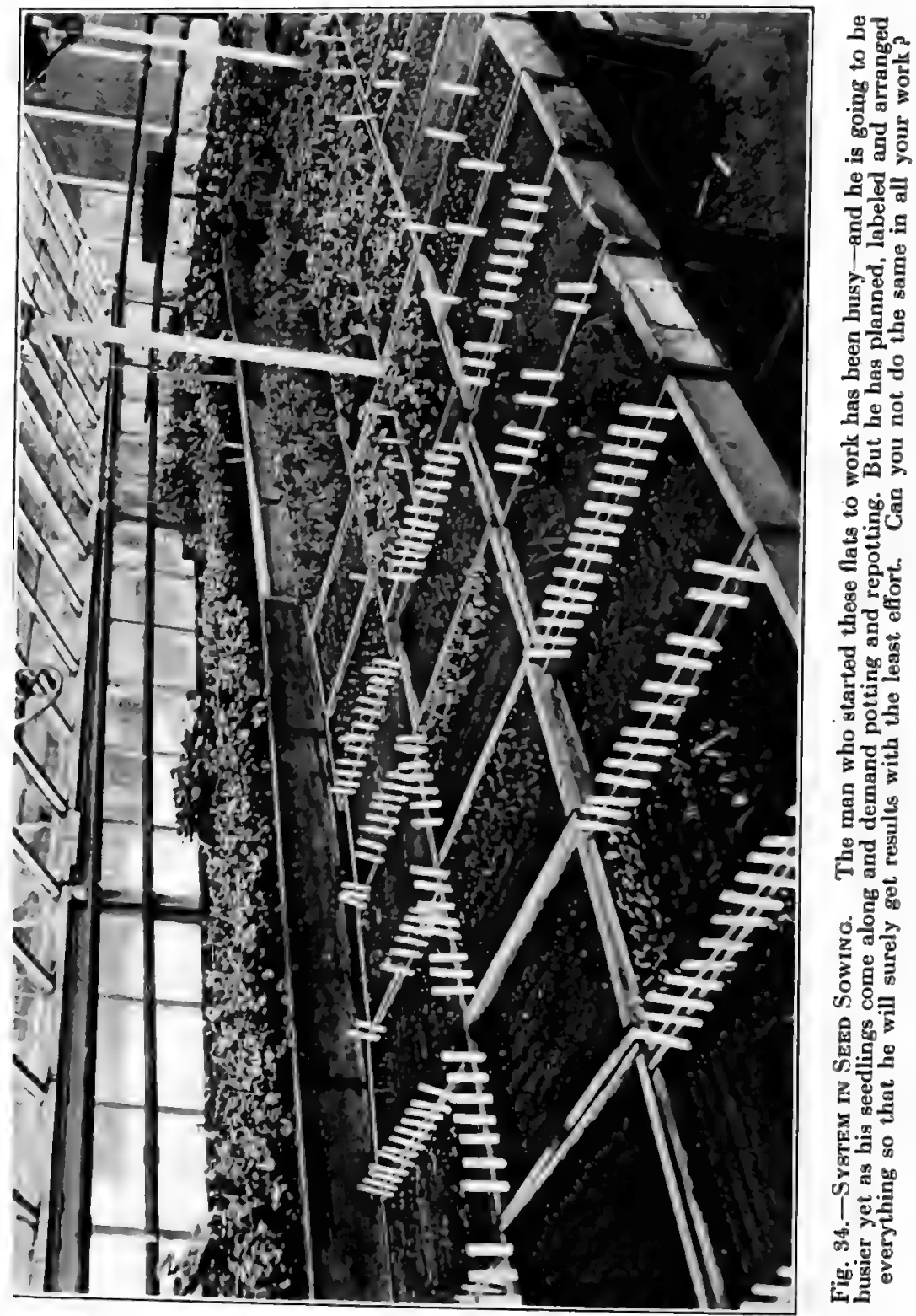


In Chrysanthemum or Carnation benches, it is always a safe plan to examine the condition of the soil once in awhile. Instead of applying water all over the bench just because one spot is dry, find out first, in what condition the rest of it. is, and water only such spots as dry out faster than the others. Find out the cause, it is most likely a lack of proper drainage.

Yes, you can also have too much drainage. By not pressing the soil down firmly along the edges you may let a bench filled with rather heavy soil dry out to such an extent as to create cracks. Any water you apply will then run through these cracks or down the inside of the bench without doing much good. But there are many more times when we lack proper drainage for the promotion of healthy plant growth and good crops, both indoors and out.

\section{SEED SOWING}

WE will take this subject up quite fully in Part II under

Petunias, a class of plants in which not only is the seed expensive (if you want the best) but in which the most delicate of the seedlings often have the largest and best flowers.

When sowing any seed, it is always well to take into consideration their size. This usually will indicate how deeply they should be covered, or, in the case of very small seed, whether covering is needed at all. Sometimes far better results can be obtained merely by gently pressing the seeds into a finely sifted surface and covering the pan or flat with shaded glass to keep the soil moist until germination sets in. There is much seed wasted as the result of careless handling, for which there really is no good excuse; and with seeds we sow under glass more trouble is due to too heavy covering than to anything else.

\section{THE ART OF POTTING}

THE main thing about potting is to do it quickly. At least, that holds good when many thousands of small plants are to be shifted into larger pots or potted up from the cutting bench. If there is ever any chance of becoming efficient through actual practice, it is in potting. No matter how carefully you show the beginner what to do, how to hold the plant, how to put the soil around it and do the potting, only actual experience can ever make him an efficient potter. If he is a young man and does enough of it, it may not be long before he will out-pot you and do it better. The writer has had that happen.

I am sure there isn't nearly as much fuss made today about potting as there was years ago; yet just as good and even better Cyclamens are being produced at present and, after all, it is results 
that count. To begin with, the main things about potting are (1) to get the roots down; (2) to press the soil firmly around them;

(3) to leave an even surface when the job is finished, with the plant in the center of the pot and the soil level a little below the edge of the pot. This would hold good with almost any rooted cutting taken from the sand bed or with seedlings, so long as you have the plants about as deep in the pots as they were in the sand or soil they came out of. Just which way suits you best in doing the actual work so as to do it in the shortest possible time and with the least exertion, so as to keep at it all day if necessary-that must be left entirely to yourself.

I respect the man who takes pains in doing his work right; but if he is too slow it becomes painful to have him around. At least, that holds good when it comes to potting ordinary stock. With such, speed means almost everything-yet it isn't to be said that on that account poor potting has to be done.

I have seen bedding stock turned out by men who had but little experience and some hardly any, men who had no one to show or tell them how to go about it, yet their plants were as good as any. Then again, we find men who have had many years of experience in the potting shed doing miserable work.

I am sure that the beginner or the man who wants to find out just how to pot, will have no trouble in getting someone to show him. Or he can pay a visit to a large concern somewhere nearby, where potting and re-potting goes on every week day of the year.

\section{Drainage Essential in Potting}

For the benefit of those starting out, it may be well to state that you can never make a mistake by providing drainage when potting or shifting plants from one size pot to another. No matter what the stock consists of, proper drainage is, to my mind, the most important thing about growing any plant in a pot. It is provided usually by laying a piece of broken pot, with the hollow side down, over the hole in the bottom of the pot. In using small pots, a little charcoal or cinders may answer better. The heavier your soil, the more attention you should pay to proper drainage.

It is an easy matter to apply water to a plant in need of it, but it is perdition when the surplus water can't get out of the pot. The effect will soon be noticed.

The man who buys Begonias, Cyclamens, palms or, for that matter, anything else from the specialist, need have but little trouble finding out the proper way to pot by looking at the surface of the soil in the pots he buys, and also below it.

The firmer you pot, the better; yet more care is needed with the tender roots of a Begonia, Primula or Poinsettia, than when 
you shift Geraniums which thrive best in a heavy soil. A dormant Rose can stand all the pounding the pot will allow, as well as a heavy soil or loam, and the same pounding is in order in shifting a palm. But tender-rooted cuttings require a rather light sandy soil and more careful handling.

Common sense is always a good thing to employ in potting.

\section{CROP ROTATION AND ITS RESULTS}

You cannot pay too much attention to crop rotation in greenhouse management. There, with the steady increase in cost of production, it becomes more necessary than ever to make every foot of space count.

FOR the average retail grower, there are two principal crops that can be produced in an establishment. The main one is Spring stock which, to a large extent, consists of bedding plants and all that goes with them. The other is the late Fall crop consisting of Chrysanthemums, Christmas plants and Carnations, all of which are out of the way again in time for the Spring stock. However, there are also catch or fill-in crops, which, if properly handled, will bring in returns without interfering much with the others. It is these that deserve careful planning.

The object should be to avoid empty bench space and also to have the benches filled with plants which either do not really require so much space or which don't bring in returns. For instance, you cannot afford to have a cut-down bench of Chrysanthemums lie empty until wanted, two or three months afterward, for small Geraniums; nor should such a bench be filled with a crop that will be in the way of bedding plants later on. You cannot set down a rule suitable for all. In fact, there are hardly ever two establishments which could to best advantage be treated alike. It means that each grower must figure out a method best suited to the running of his own affairs; but we can, at least, suggest methods which will help to properly arrange matters.

\section{The Use of a Goldhouse}

Those who have sufficient bench space to avoid carrying a lot of stock below the benches are well off. The smaller retail grower, however, can often use the latter space to great advantage. Next of importance is a coldhouse where plants may be kept in a dormant state ready to follow a crop that is getting through in another house; or in which such stock as potted Roses, Hydrangeas and the like can be allowed to come along slowly and are better off than in warmer quarters. Frames outdoors with glass protection are of great value, especially in the Fall and early Spring, for the reason that you can keep there stock that does not require a bench, or 


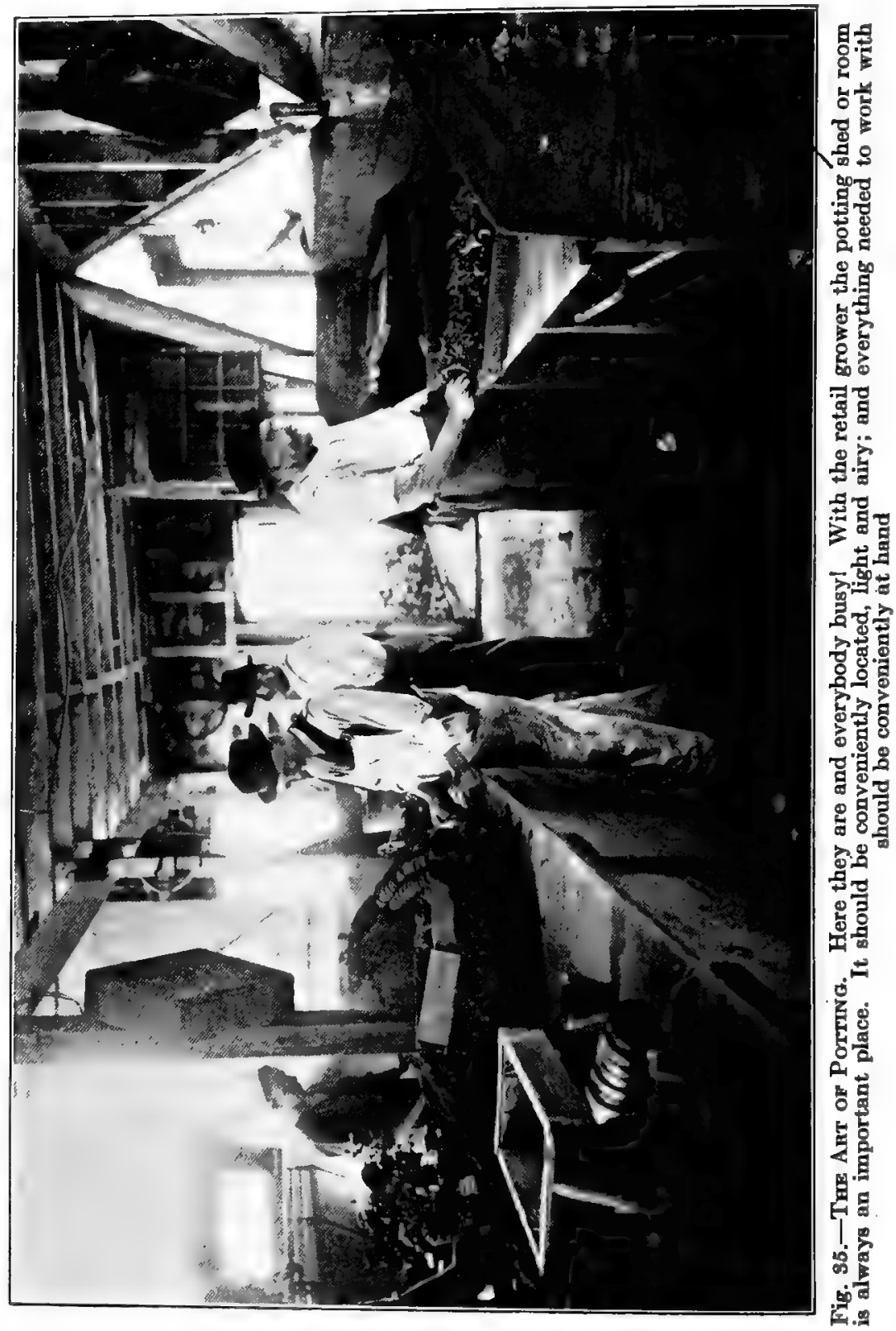


hold plants there until the harvesting of another crop makes room inside.

Both a coldhouse and frames are essential for the retail grower, no matter how small his establishment, if he wants to get the most out of it. With their help it is easier for him to figure out ways of keeping his house or houses which can be kept at 50 or 60 deg., busy all the time and thereby bringing in results.

\section{Getting Four Grops a Year}

As an example, let us take a bench of Geraniums, which by June is emptied. Chrysanthemums, consisting of early varieties, can be planted out of $21 / 2 \mathrm{~s}$ and will be out of the way by the first of November. These can be followed by Freesias, started in pots in August and kept up to that time, properly protected, in a coldframe. These Freesias will flower starting toward the end of December and are ready to be thrown out by the end of January. It would hardly pay to keep them any longer for the sake of the few buds remaining. By that time another lot of Freesias, grown on in a cool house from bulbs planted the first of November, can be planted out to flower in early March, after which you will want the bench for bedding plants. Or the bench, after the Chrysanthemums are through, may be planted with 4-in. pot plants of Snapdragon which have been kept in a frame. These Snapdragons won't be quite through by the time you give your Geraniums their final shift, but if you have good luck, they will have paid for themselves and you won't be justified in letting them take up any longer the space the Geraniums should have.

Another way would be to empty the soil out of the bench when through with the Chrysanthemums and bring in flats of Paperwhites from the frames, Stevias in pots from the coldhouse, Cinerarias, Primulas, Freesias to be grown on and flowered in pots, formosum Lilies kept under the bench up to that time, or Geraniums which have been rooted during September and carried in a frame.

Field-grown Carnations potted up in September into $5 \mathrm{~s}$ and carried in a frame, can follow early or even midseason Chrysanthemums and bring returns from the end of January up to the time you need the space.

Pansies and Forget-me-nots are two useful flowers for the retail grower and might be planted on the bench after the Chrysanthemums where they will flower all Winter-not much before Christmas, but heavily during February and March.

For those who plant Carnations for Winter flowering and have to use the benches for bedding stock, the sooner the plants are benched after the first of July the better, for you want them to be well enough established by September to produce good sized flowers 
on large stems. These plants should have paid for themselves by March.

\section{Making the Most of Your Spage}

For the man with limited space who needs every available foot for Spring stock, most of the so-called early Spring-flowering annuals come too late to make room. Calendulas, planted out from 21/2s following Chrysanthemums, will be through by March and can be followed with Gladioli started in pots. They can also follow the second crop of Freesias; or, if the Calendulas are grown in a solid bed, you can plant field-grown Delphiniums, Shasta Daisies, Coreopsis or Columbines to follow. Sweet Peas of the early Midwinter flowering sorts can be grown on in pots from seed sown about the end of September, and planted in the emptied Chrysanthemum benches. Or Chrysanthemums of the late sorts, grown in solid beds, can be followed by a sowing of Sweet Pea seed to flower in Spring; but only when you can spare the space.

While you can grow only one thing at a time, and while most retail growers find it advantageous to grow on as many as possible of the bedding plants they require rather than to purchase them, it is easier, if you cannot grow both the cut flowers and the bedding stock you need, to buy the cut flowers.

The smaller an establishment, the greater the consideration that has to be given to crop rotation, how best to handle each one so as to take up bench space for the least possible time, so that one will not interfere with the other, etc. You have to plan weeks and months ahead, lay out your work, get ready the plants to follow up and keep the benches working full speed. We realize that quite frequently things don't turn out the way we plan, conditions arise beyond our control which change everything, but we should figure even on that to some extent. We should be able without much trouble to make different arrangements so as to obtain the maximum returns from the minimum space.

\section{FUMIGATING AND SPRAYING}

IF YOU are in need of a good article on plant diseases and how to fight them, I cannot do better than refer you to Chapter 5 on Plant Enemies in "Plant Culture," by Geo. W. Oliver. What I want to call attention to here, is mainly the necessity of keeping clean the houses, or the stock in them, by fumigating and spraying with nicotine solutions. This is, to my mind, the most effective way to fight ordinary troubles and prevent the appearance of the green and white fly and the thrips among the general run of stock found in the retail grower's establishment.

I don't wish to be understood to say that nicotine in one form or another will overcome all troubles, but let a plant once get in- 
fested with green fly or aphis and you will have it in the right condition to get almost anything else going, for the insects stunt its growth and weaken it. I claim that stock in a greenhouse faithfully sprayed lightly once a week can be kept clean if it is clean when you start out. But this must be kept up. Let a Calceolaria, a Cineraria or a Carnation once get full of green fly and you will have real trouble in getting the plants clean again. It is not that this cannot be done, but why permit the condition in the first place?

The good grower never allows green fly or aphis to appear. By so doing, he keeps other pests away. Consider just for a moment the loss of money due to crippled Carnation flowers where green fly has done its work. Isn't it a crime to permit it, when you have to depend on the dollars and cents you get out of the plants? Yet each year a lot of growers will not pay proper attention to their stock in this respect. With each year spraying becomes more necessary, and the older the houses and the longer they have been in use the more so. If you fumigate rather than spray, the same is true. Light doses, but often, is the thing, rather than to start only when you see signs of trouble-and then maybe overdo it.

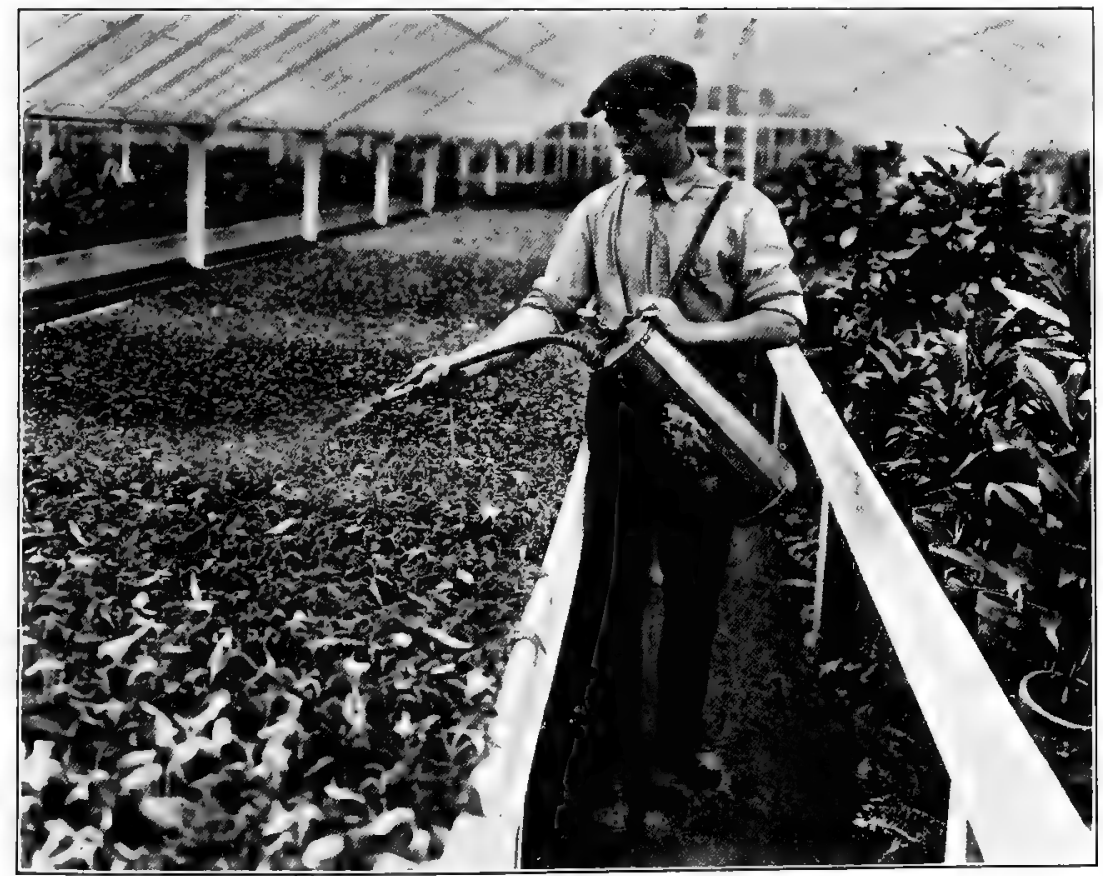

Fig. 36.-SPRAYING. The good grower will everlastingly keep on fighting insects and plant diseases. He doesn't wait until there are signs of aphis, midge or green fly, but by spraying regularly once a week or so prevents their appearance 
What is as important as fumigating or spraying regularly is keeping the houses clean. Benches were never intended to carry rubbish below them. They should be as clean underneath as they are on top. I realize that, with the retail grower, it is often necessary to use the space below for the storage of all sorts of things. Well, that cannot be helped, and the smaller the establishment, the more often it has to be practiced. But there is no good reason why there shouldn't be, every so often, a thorough house cleaning, especially of the corners. Keep things clean if you don't like bugs.

Don't throw out cut-down Chrysanthemums and place potted plants right on top of the soil in the benches because you are so very busy. By so doing, you invite trouble. Clean out the soil first, scrub the bench, whitewash it and then use it again. Make up your mind that green fly and aphis are only the forerunners of other, more serious troubles. Where these two are permitted to eat off the family table, they invite others to come that soon eat you out of house and home. Keep them away and you will, at least to a large extent, keep the others away. For it shows you have your eyes open and are ready to nip anything in the bud before it has a chance to get the best of you.

\section{NOTES ON DISEASES OF PLANTS}

Keep on getting all the information possible on diseases to which plants are subject but spend more time trying to avoid them instead of waiting until you are obliged to fight them. At its best, a commercial greenhouse doesn't pay when turned into a hospital.

JSUALLY when softwooded plants, or such as you carry in the greenhouses only for a few months, get sick to such an extent that they show bad effects of the illness in growth or flower, the best remedy is to fire them out and forget about them.

Such treatment may perhaps appear too radical, yet I am convinced that in most cases it will be found far better than trying to nurse the plants back into health.

I have yet to hear of a case in which a man had a sickly lot of Carnations in Midwinter-no matter what the cause of the trouble -nursed them along, got the plants back into good shape and made them pay by Spring. I don't say that it cannot be done, but I claim that in most instances one is better off throwing out his sick plants and filling his benches or beds with something else.

\section{Prevention More Important Than Gure}

In nine cases out of every ten, by the time a man finds out just what is wrong with his Cyclamen, Chrysanthemums, Cinerarias; or Carnations, the plants really are worthless. Here, as with human troubles, you can often do more in preventing them from 
getting sick than in finding a cure afterward-or rather, finding a cure that will bring the plants back into a healthy growing condition quickly enough to make it worth while.

Given clean houses, proper ventilation, the right kind of atmosphere, temperature and watering, and regular spraying or fumigating to keep out aphis and green fly, you are well on the way toward healthy stock.

The growers who let aphis and green fly get a foothold, always invite other troubles, and so does he who keeps the soil in the pots or benches too dry or too wet; whose steam or hot water pipes run too close to the benches; who maintains a temperature that is too high and sometimes, but not frequently, too low; who keeps a stuffy house or one in which, for some reason, the atmosphere is too dry. These, to my mind, are some of the principal causes of plants getting sick, and only through experience will one be enabled to know just what his crops require in order to do well.

Many of us know of instances where a beginner-often with little or no experience-has turned out a splendid lot of plants or cut flowers. One case in particular is fresh in my mind in which a man bought, in June, 300 Cyclamen out of $31 / 2$-in. pots. He offered them the following December in $6 \mathrm{~s}$ in full bloom! They were wonderful plants, yet some of the pots were hardly threequarters full of soil, for the man had never potted much of anything before in his life. A few blocks away at a Cyclamen grower's establishment where the owner had been making this crop a specialty, there were, in December, almost 4000 plants as fine as you would want to see; but all of the buds dried up. None knew what the trouble was so we called it the Cyclamen mite. This you cannot see, but it was there somewhere - at least we thought it was.

I don't want to be understood to say that scientifically prepared insecticides and fungicides are of no use, for I am firmly convinced they are a blessing. Each year we find out more about effective remedies with which to fight plant diseases. On the other hand, I claim that if by experience you find out what your plants need in the way of care and a proper environment in order to grow and thrive, and if you keep them clean with nicotine in one form or other, you will have gone a long way toward rendering it unnecessary to use other remedies in treating sick plants.

\section{THE WINTER PROTEGTION OF HARDY PLANTS}

HARM is more often done by covering hardy stock too early or too heavily than by not covering it at all.

If you are located in a section where severe Winter conditions make necessary the protection of perennials or biennials, it is always well to delay the covering until the ground is frozen. To pile manure, 


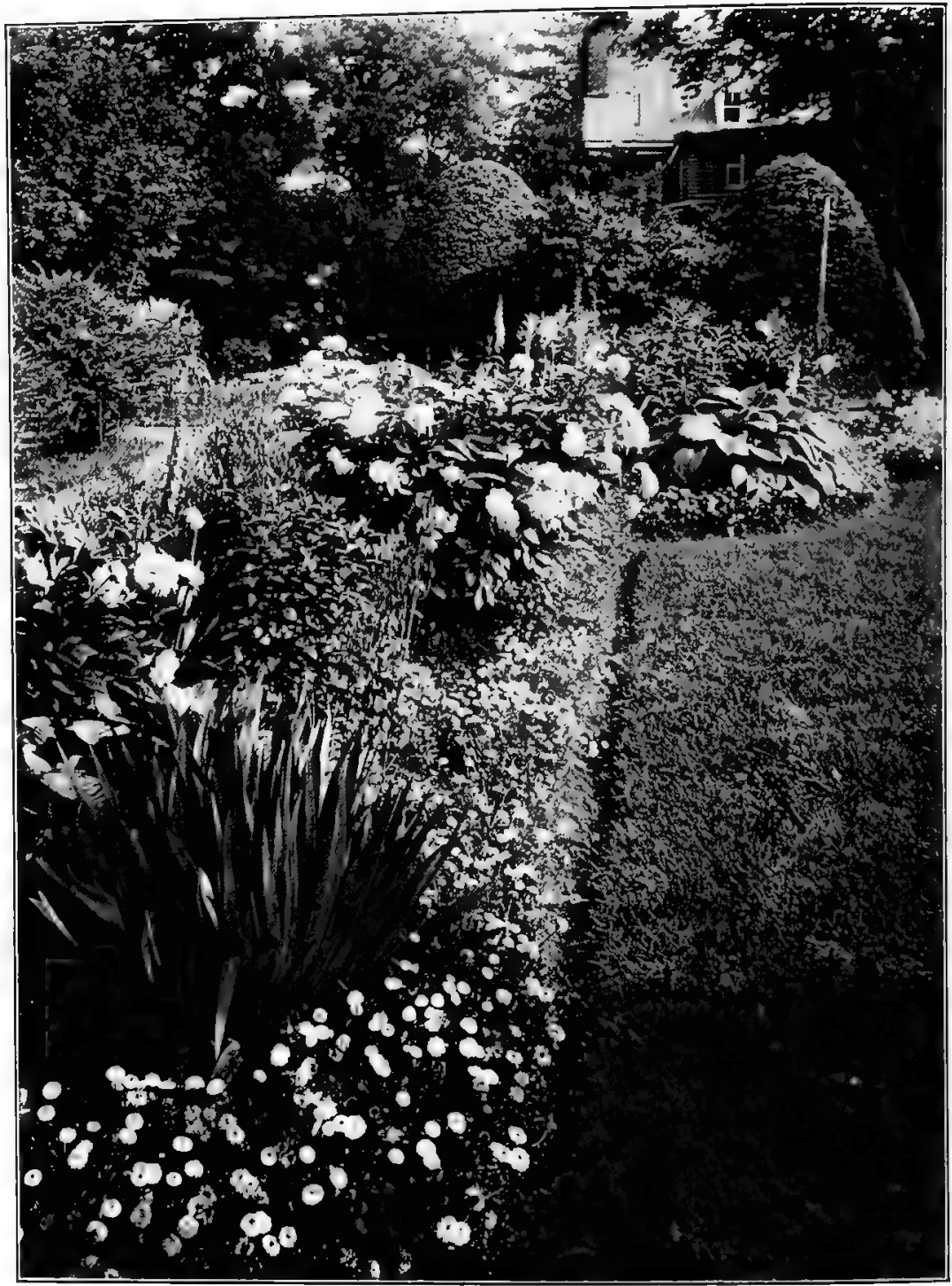

Fig. 37.-The Flonist's Ideal Showground. Here is shown a rather elaborate outlay representing one corner of a formal garden. Its owner must feel well repaid, however, because every passerby stops to admire the charming setting 
straw, or leaves on top of such plants as Foxgloves, Canterbury Bells, Shasta Daisies, Coreopsis or others before the ground is frozen and while their tops are still in a growing condition, is to invite trouble. Not only are the tops of some plants likely to rot off before Spring, but there is much danger of field mice destroying those that don't suffer in that way.

While it doesn't matter how heavily or how early you cover a Peony, a Phlox, or a hardy Aster, all plants that retain all or a part of their foliage should be treated more carefully. Always avoid placing even well decomposed manure directly on top of such stock; it is too heavy. A light but thick covering to keep the sun, light and raw winds away from the top of the plants is best. Always wait until regular Winter conditions have set in before you really cover.

It isn't during November and December that much harm is usually done. The plants not protected during the following three months suffer most. Under a few inches of snow from the end of November on up to the middle of March, almost anything in the perennial line will come out all right. An open Winter without snow, even through the temperature does not go down as low as zero, with alternate freezing and thawing, is usually what makes the beds look sick in early Spring. Freezing itself doesn't do as much harm as the exposure of the plants to dry winds and changeable weather conditions. You don't keep Jack Frost out with a light covering but rather render the plants less exposed to the weather and in the best possible dormant state until Spring.

As soon as hard freezing sets in, apply the covering; be sure the surface of the ground is frozen first. If you use manure, shake the heavy part out with the fork as you go along; it is just the thing for between the plants. Then use the lighter part, that is, the straw in the manure to cover the plants themselves. The lighter and more airy this covering, the better; it doesn't hurt if it is six inches or more thick, if loose enough. Or you can apply a light dose first to be followed by another later on. Dry leaves make a good covering if held down by straw manure or brush. In the case of small transplanted seedlings such as Pansies or Myosotis, short pieces of brush laid over the plants first and filled in between with leaves make an ideal protection.

In any case, when once the ground is frozen toward the end of November or early in December, it is usually safe to start covering. In severe sections the more protection given during December and up to the end of February, the better; but by early March, if mild weather prevails, you can begin to remove a part of the covering. Don't take it all off until actual growth begins. One can uncover plants too soon-but there is as much danger in leaving the covering on 
too long. You have no date to go by, but must examine things from time to time. Canterbury Bells and Foxgloves in particular are very sensitive, and at times a plant will come through the Winter in fine shape only to be ruined by a severe cold spell the latter part of March or early in April after all covering has been removed.

It is always a good plan for those with a limited amount of stock to heel in a certain number of their plants in a frame in late Fall, protecting them with dry leaves and later on with sashes in case stock in the open field is winterkilled. It is also well to sow each Winter seed of such species as Shasta Daisies, Gaillardias, Coreopsis and others, no matter how many old plants you have in the field. Keep on sowing more each year and get rid of the field clumps or plants. A Gaillardia, Daisy or Delphinium sown during January and carried in a cool house will bloom freely the first year.

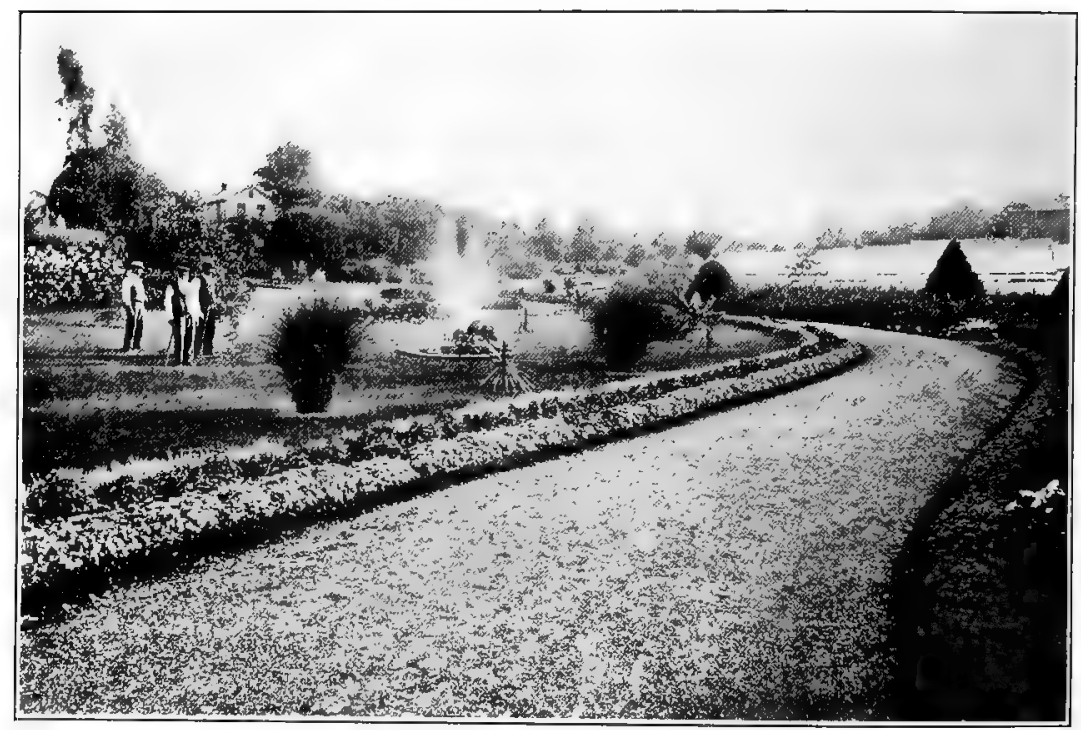

Fig. 38.-A Florist's Show Ground of Thirty-five Yenrs Ago. This is a view of the entrance to the establishment of the late Valentin Burgevin, Kingston, N. Y., showing Mr. Burgevin and his two sons and successors, George (who lent the photograph) and David. This layout, he says was hardly typical of average conditions in those days, but it shows the result of skill, taste and progressiveness. 


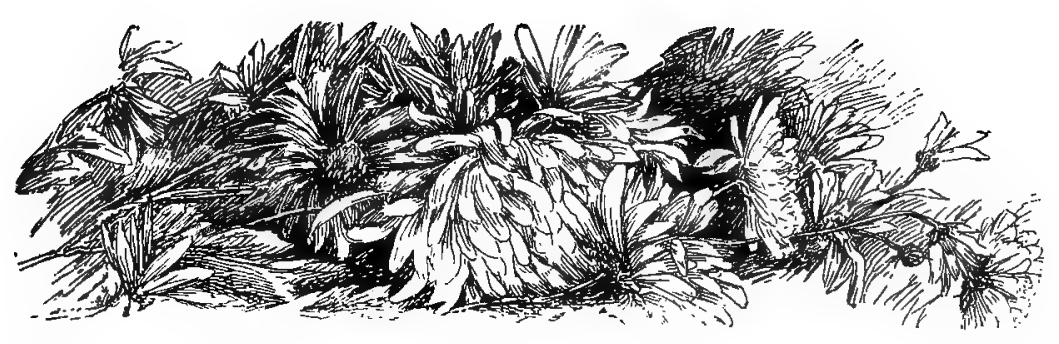

CHAPTER V

\section{SIDE LINE POSSIBILITIES FOR THE RETAIL GROWER}

\section{LANDSCAPE GARDENING-IS IT WORTH CONSIDERING?}

70 become an efficient landscape gardener takes years of study, hard work and experience; a college education should go with it, too. When I mention landscape gardening as a florist's side line, I do not wish it to be understood that I claim to be myself an efficient landscape gardener, or hope ever to be one competent to compete with professional men in that line. But as a result of personal observation and experience in what a florist would term "outside work" extending over thirty-five years, I claim that there are a lot of opportunities awaiting every progressive florist or retail grower in the smaller cities and towns, especially the suburban towns, to get acquainted with, and to do work pertaining to, the laying out of the small home grounds. Such work starts at the very beginning with the selection of the site for the residence and continues up to the time the grounds are completed in every detail. It will often include the excavation of the basement, draining, rough grading, the making of the lawn, the planting of trees and shrubs, the building of a terrace, the laying out of a formal, a Rose, or a sunken garden, the building of pergolas, the construction of driveways and concrete walks, brick walks or walks made out of stones, the building of water gardens or Lily ponds, swimming pools, septic tanks, concrete curbing or gutters for a drive, the laying out of a perennial border, and everything pertaining to work on the home grounds.

I realize fully that no one man is capable of doing all these things perfectly, who does them as a side line of his main business; or even of doing them as well as if done by the man who is devoting his entire time to it and always has. But there are only too often occasions when such a man can't be had; when there is 
124 FRITZ BAHR'S COMMERGIAL FLORICULTURE

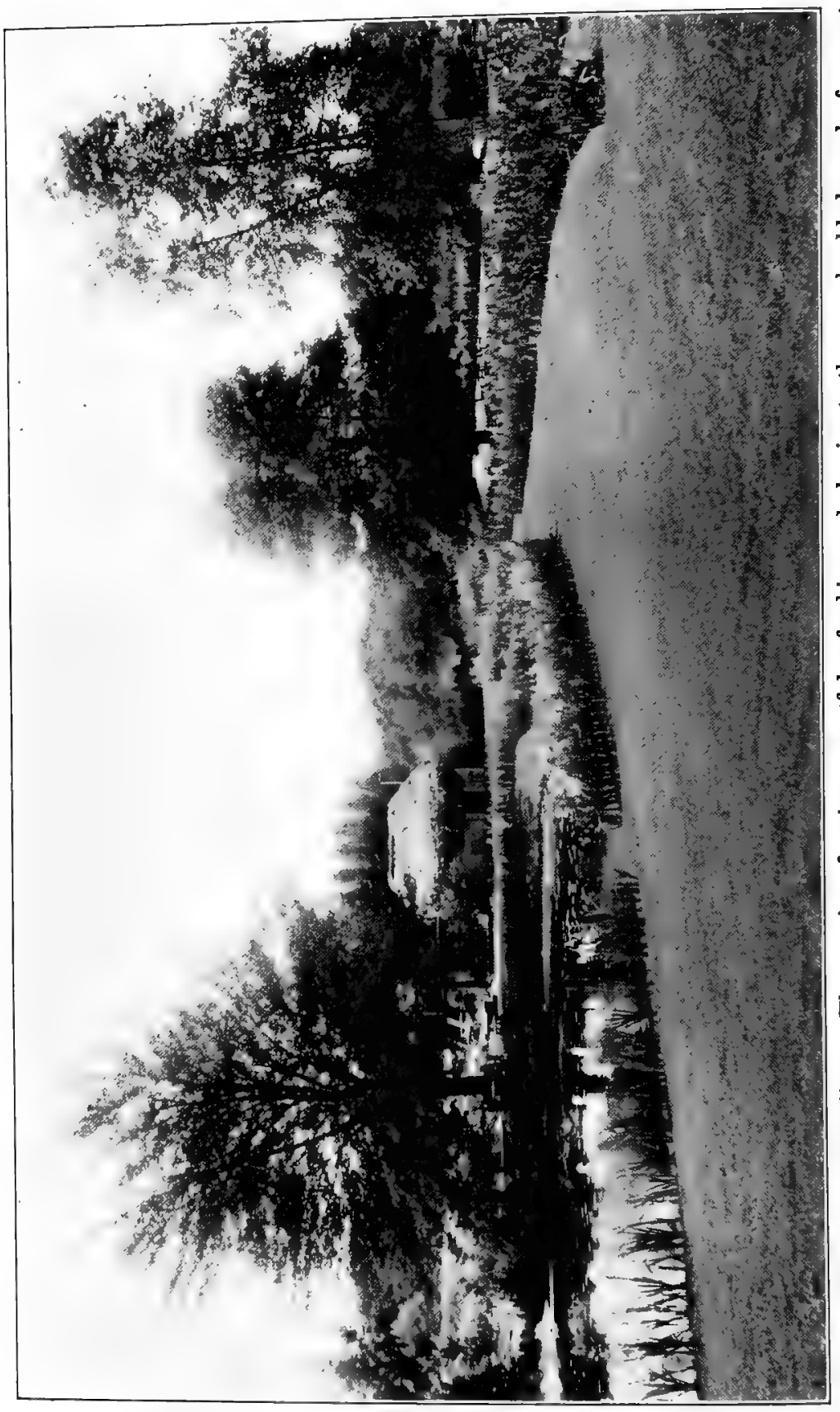

巻骂卷

웅

4

.

?

을

ธี 영

눙

응 잉

के

둥

एक

욜

$\circ$ क

$\infty$ 요예

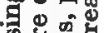

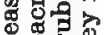

숭ㅎㅁ

영

5

$\infty \frac{1}{5}$

긍형

논으멱

도웡

उ년

곤연

蛴

월영

5.

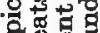

๘

ㄴㅇㅇ

명년현

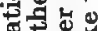

$\Phi$.

흘을

वैं

-

웜 쿵

토용

$>0$

$<$ 察

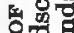

a

궁

\$

동영

부웜

.

通

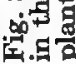


none for miles around. And all the time there are any number of neglected home grounds or such. as could with very little work be made much more attractive. Other grounds were laid out many years ago and are in need of being remodeled. Driveways of the old type, constructed of cinders with a little top dressing of gravel, need to be made over. Or an owner may wish to have his grounds made to look like others he has seen elsewhere.

Who but the local florist is the logical man to call upon to do such work in the absence of a professional landscape gardener? Particularly if that florist has his own grounds attractively laid out, as he should have.

I claim that almost every florist, with just a little experience and exercise of will power, is capable of becoming a practical and efficient man for such work, that is, on small grounds at least. And I am sure this subject is well worthy of consideration by every florist who conducts an establishment in a neighborhood where the average home is surrounded by from a few square yards of ground up to a one-acre lot or larger.

\section{A Great Field and Future in Landscape Work}

There were great landscape gardeners before Napoleon's time, but even our country hasn't always been so wealthy that those other than the very rich could afford to employ them. During the past thirty or forty years with people prosperous all over the land, the desire came not only for a higher standard of living but also for better homes and home grounds. This created a demand for trees, shrubs and other hardy stock and for garden literature, all of which in turn helped to create a greater demand for more stock and men capable of laying out grounds, and others able to maintain them. With all that has been accomplished, it is still only the beginning and always will be. As long as the nation increases in population and new houses are being built, there is no end and can be none. No matter how many landscape gardeners may appear there will always be all kinds of opportunities for the local florist of a town to develop landscape gardening into a paying side line. There are today many examples of florists who have been in the greenhouse business all their lives, but never made as much money as they have since they went into outside work. Most of themthe writer of these notes included-didn't know the first thing about it at first. They couldn't have named four different shrubs by their right names, or told what they were good for if you had paid them for it.

I claim that you cannot learn landscape gardening out of the best book ever written by the best authority. You must start the same way that practically all great landscape gardeners started, 


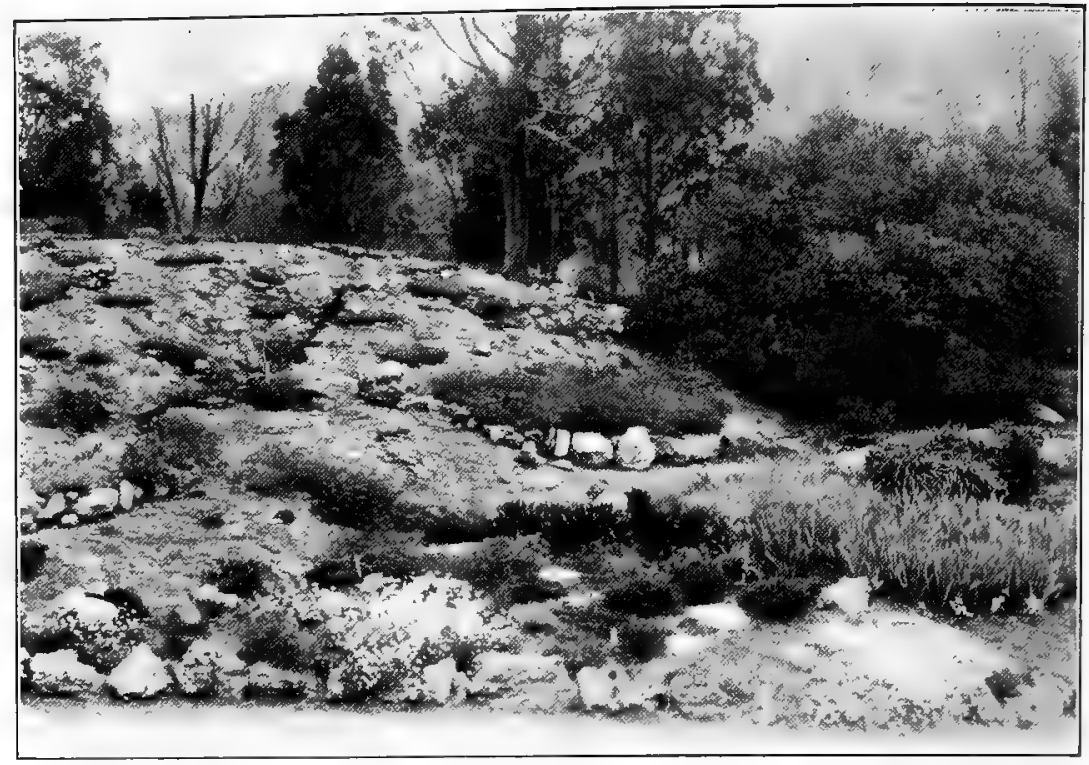

Fig. 40.-A View in a Rock Garden. The average florist, even though he does landscape work, isn't often called upon to lay out a rock garden. Yet this can be made a most attractive feature of even the small home grounds. We have a complete list of interesting as well as showy plants to select from in making one. (See Chapter VII, page 221.)

that is, by practicing the profession, by doing the actual work with your eyes and mind open. It is only after you have started to do this that books are of value to you and then you cannot read too many good ones-not so much to find out how to do things, as to get the different ideas of efficient men, which will help you to formulate your own.

This much is certain: no grounds are ever finished. They are no more done or finished than when new work opens up, and this is especially true of the smaller ones. Large grounds or estates often require many years before they develop into the picture the landscape artist had in mind when he laid out the place, while on the oneor two-hundred-foot lot the planting usually is done to create an immediate effect. This, to an extent, is a bad feature, yet it is the spirit of the times. An owner wants his home built in a week and will often pay a premium to the contractor who can do it quickest. There are even cases in which the home hasn't a roof on it before the owner is ready to sell and build another one. The planting of the grounds in all such cases doesn't differ much. Big trees, large conifers, specimen shrubs, Lilacs to bloom the first season, anything to create an immediate effect. This usually means planting too close, or using overgrown stock or else in a short time a regular wilderness of what has been planted. Sometimes improper care of 
what has been planted necessitates the replanting of the whole layout in a few years. Again the grounds may change hands and the new owner has everything ripped out and laid out differently, only to sell in turn, when all is done over again. All this means more work to be done-in fact, there is no end to it.

\section{Where the Greatest Opportunities Lie}

It has always been my experience that in localities where there is the greatest field for landscape gardeners and where no end of competent men have the laying out and planting of new grounds, there are the most and the greatest opportunities for work on those same grounds afterward, for the local florist or florists if they have established any reputation at all for being able to do work in that line. The more planting there is done originally the more work there will be needed to take care of it, add new features, change things, replant, etc.

The laying out of new grounds and their planting is, after all, only the beginning. We will keep on building new homes and keep on selling others and there isn't a city or town, no matter how well laid out nor how well the home grounds are planted, where there are not all kinds of opportunities for the local florist to get his full share and more of landscape work, if he goes after it.

If you get plans from fifty different landscape gardeners for the layout of a small home ground, let us say $100 \mathrm{ft}$. by $150 \mathrm{ft}$. in size with a residence about $\mathbf{5 0} \mathrm{ft}$. from the sidewalk, you will most likely obtain fifty different ideas as to treating the property. Yet most of them will include the features treated in this chapter, all of which are necessary in order to obtain a harmonious setting and give character to the grounds. It is these things that you should have in mind whenever called upon to treat small grounds, and to quite an extent the treatment of larger grounds doesn't differ greatly. When a man once has practical experience in laying out small grounds, he will have no trouble in taking bigger jobs and growing with his work. It is right here that he can make good use of the ideas of others who have written books on the subject.

\section{Drainage Work and Grading}

Whenever I have to submit sketches, specifications and an estimate on the laying out of new work, which is usually about the time the residence nears completion, I take up the grading and drainage first, for these form the foundation of all the rest. Uusually the soil excavated from the basement is all needed to fill up to what is called the water table of the building, and from there help to form a gentle slope toward the lot lines. Wherever this can be done, it usually takes care of the surface drainage at the same time and does 
away with the necessity of installing a tile drain for which an outlet has to be provided. But if you do have to put in a drain, a 3-in. farm tile will carry a great amount of water. Don't lay it over $2 \mathrm{ft}$. deep if you can help it and put a 6 -in. covering of cinders over the tiles. If you have 75 or $100 \mathrm{ft}$. from the residence to the lot line, a slight dip or depression about half way will give a better effect than an uninterrupted, even fall all the way. Sometimes, with a surplus of soil on hand and the water table considerably higher than the surrounding level of the grounds, a 12- or 15-ft.wide terrace may be suggested, if agreeable to the owner or the architect. By the way, always try to be on the right side of the architect; compliment him on the residence and obtain his ideas (and he usually has some of his own) on treating the planting of the grounds.

Never spread excavated soil from a cellar or basement without first removing the top soil of the area to be covered. Then top dress with the good soil again later. If there happens to be a shortage of material with which to get a desired grade, it means that you must buy some, or in case a drive or walks are to be built, the excavated material from these might be figured on.

As to estimating the cost of rough grading, if you have to hire a teamster to do it he can most likely figure the job for you. Or by keeping a correct record of the actual cost of everything when doing your first and second jobs you will be able to estimate fairly closely the cost of the third job you take up, and with very little figuring. In time you will find yourself able to walk over a place once and tell in three minutes what the grading job is worth. That, however, is not to say that it doesn't pay to be careful, nor that the grading on all jobs is alike.

\section{Laying Out Drives and Walks}

The driveway in small grounds is usually not a thing of beauty, for it takes practically $60 \mathrm{ft}$. to provide a turn-around or drive circle to accommodate a large machine. This is out of the question on a 100-ft. lot without cutting up the entire front, so we usually find a straight drive leading to the garage along which the car is backed out to the street. Or a square space for backing up and turning around may be provided directly in front of the garage. Still another way is to enter the grounds on one side of the lot, swing up to the front entrance of the residence with a graceful curve, and swing out again on the other side, with a stub end leading to the garage.

In considering a driveway, always keep in mind, first, having it of practical use. Next avoid as much as possible the cutting up of the grounds. Then comes the construction. The most sensible solution is to use concrete; this is by far the most satisfactory way. 
For those demanding a cheap construction cinders with a top dressing of crushed stone and screenings can be suggested, but let's take up the concrete construction first.

An 8-ft. wide driveway will answer in most cases, in fact, less width can be made to do, especially if it is a straight runway, as the base of the wheels take up only $5 \mathrm{ft}$. no matter how large the car may be. A 6-in. layer of cinders should form the foundation. These should be wetted, tamped and followed by a layer of concrete ranging from 6 in. deep in the center to about 4 or 5 in. at the sides. For a good mixture you should use three bags of cement to every yard of mixed stone or large gravel and coarse sand. The mixing can be done by hand, but a little batch mixer is not expensive and does the mixing quicker, better and with less effort.

Every 9 or $10 \mathrm{ft}$. have an expansion joint in the drive. If the owner objects to the cold, uninviting appearance of the concrete (to which objection I fully subscribe), leave the surface of the drive rough and when it is dried out, put on a coating of Tarvia $\mathrm{X}$ followed by a thin layer of roofing gravel or small granite chips. This will give you as fine a roadway as anybody can wish for, and what is best of all, a permanent one. In localities with a sandy, well-drained subsoil, 3 in. of cinders well tamped can be made to do and 4 in. of

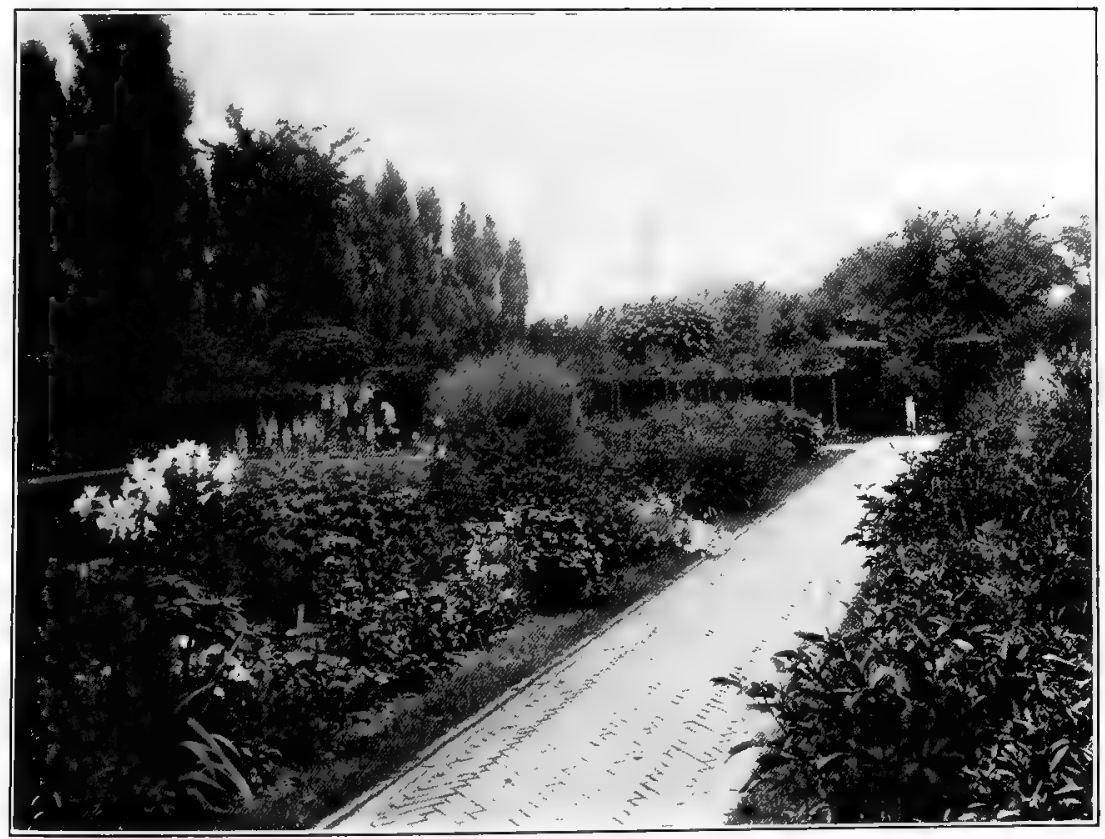

Fig. 41.-A Brick Walk Bordered with Perennials. Stiff, cold concrete never made a really inviting or attractive walk. How different with one of brick, especially when there is a chance to border it with perennials, as in this case 
concrete will be sufficient. In a heavy soil you cannot provide too much drainage and, in addition to the cinders, it won't hurt to lay a 3-in. tile drain $18 \mathrm{in}$. below the finished side grade of the drive filling the ditch up with cinders.

You may want to hire a concrete man to do your first job, but there is no reason why in time your own men cannot do that work and also the resurfacing of old driveways with Tarvia and screenings. A tar heating outfit will soon pay for itself and as long as there are drives there will be work to do on them. You don't need all those things to start out with, but if you go on and find not only that there is good money in this kind of work, but that it is becoming interesting, as all constructive work is, you will soon get everything necessary in order to do efficient work, and do it with the least effort.

\section{Cinder and Crushed Stone Construction}

In order to hold up an automobile (and there is no use building a drive for anything less heavy today) you need at least a 4-in. layer of cinders and 6 or 7 in. of coarse stone with enough limestone screenings to bind all of the interstices. After these are spread the whole should be flushed with water and rolled with a roller heavy enough to produce a firm and even surface. To be finished properly such a road should have a good coating of Tarvia and screenings. This will keep the water out, but, after all, the cost is not much less than that of a concrete one.

The main walk leading from the street to the entrance of a residence is next in importance, and if laid out to run up straight from the street sidewalk, it usually means cutting the front lawn in half, which should never be done with a walk straight through the center of the lot. If a walk is wanted-and this is necessary in the case of the absence of a drive-suggest one with a long, graceful curve, but never with a reversed curve in the shape of a letter $\mathrm{S}$. The walk should enter at one side, run for a little way almost at right angles to the street sidewalk and then curve gently toward the front entrance with a group of shrubs or conifers near the point where it starts to lead to the entrance. This planting should mask either end if viewed from the other. Never have such a walk so that you can see both ends of it at the same time.

\section{The Elements of a Lawn}

While the planting of trees and shrubs is, perhaps, next in order after the grading has been completed and the drive and walks have been located, we will take up the lawn for a few minutes for it comes next in importance and consideration. What would all the trees, shrubbery and flowers on a place amount to if there was no lawn as a background? To my mind, a fine sweep of turf is of the very first importance. 
An open sweep of lawn, no matter how large or how small the grounds, is needed to go with the home itself. Plant the shrubs as thickly as you want to along the outskirts of a lot, or at the front or rear, but have an open stretch of lawn somewhere. It helps give character to a place and supplies a proper setting for the planting you do. A lawn doesn't want to be dotted with trees and shrubs; it wants to be open. Get away from the big center bed of Geraniums or Cannas in the main lawn; you can find other places for them if you look around enough, but don't cut up a sweep of green turf. The smaller the grounds, the more the lawn means and the less one can afford to sacrifice it for other purposes. A shrubbery border, or one with flowers means nothing unless a lawn leads up to it.

\section{How to Make a New Lawn}

The florist located in the country where almost everyone of his patrons has, at least a good-sized yard, will often be called upon to take charge of making a lawn and should know how best to go about and doit. Usually it is a paying proposition and leads to more business, such as the planting of shrubs, perennials or other stock.

In order to obtain a good lawn, you should start out with welldrained and deeply worked over soil. These, to my mind, are the most essential requirements. You can ultimately establish a good turf on the stiffest clay, but it takes time, and this is true, to quite an extent of almost any lawn on heavy or light soil. In most cases where a lawn has run out, it is usually the owner's fault, for it takes proper attention to keep a lawn in good order.

I don't care how rough a piece of land may be or how stiff the clay from the basement or cellar excavation of a new residence, with a little work and by handling the soil at the right time, when it is not too wet nor too dry, you can not only obtain a fairly smooth surface, but also lay the foundations for a good lawn without going to a lot of expense as in top dressing the whole area with top soil, manure and sand. I do not mean to say that this would be wrong; if the owner wishes to go to this expense, well and good. However, you can get along nicely otherwise and still have success.

The deeper you can work the surface over, the better for the roots of the grass and the better will the soil retain moisture during the hot Summer months. In heavy soil, after it has been plowed, follow up with the disk or pulverizer and a polescraper or heavy planks to do the leveling. If you want to make an extra good job, go over it with the pulverizer again after leveling. Follow with a good fertilizer consisting of blood and bone at the rate, say, of one and onehalf tons per acre. Work this in with rakes and after the surface is all raked, sow the seed, either with a seeder or by hand. For ordinary purposes, as good a mixture as you can want will contain equal 


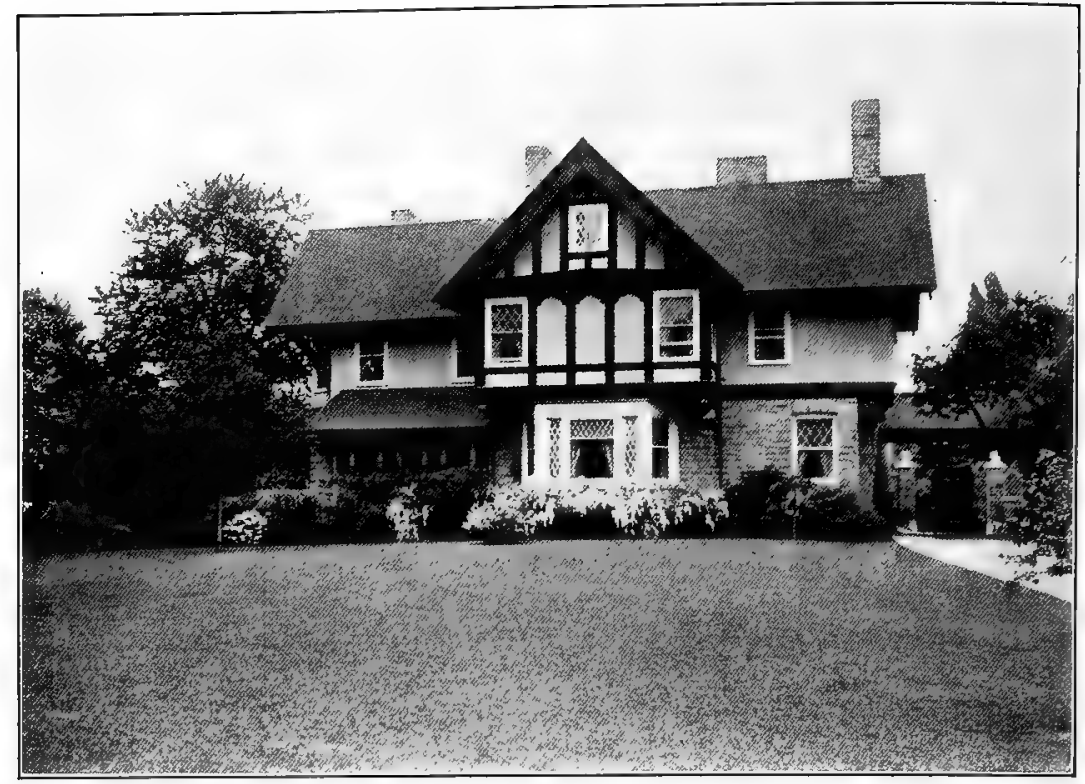

Fig. 42.-The Indispensable Lawn. A good lawn is as essential as anything connected with the home grounds. No matter whether large or small, nor how fine the trees and shrubs, nor how well proportioned the foundation planting, nor how beautiful the flowers - if there isn't an open sweep of green sward the grounds will be lacking in attractiveness

proportions of the best Kentucky Blue Grass and Red Top, with White Clover added at the rate of five or seven pounds per 100 pounds of grass seed.

As to quantities required, I should never use less than 100 pounds per acre. This is contrary to the average seed catalog or farmer's guide, but in the years I have used seed, I have never yet found a lawn that we made on which we put too much seed. Many times, on the other hand, after the grass was up, it required time, expensive labor, and a lot more seed to go over a lawn and reseed itand perhaps repeat this a second time. The heavier the soil the more seed you need, and it costs less to use enough the first time and obtain a heavy stand of grass than to have to reseed, which cannot be done without loosening up the surface.

\section{The Cost of Lawn Making}

Now about the cost of making a lawn. This depends to a large extent on the amount of grading one has to do, as labor is what costs. One has also to take into consideration whether a place is open, so as to permit using a team to advantage, or whether because of a lot of trees, all hand work is required. It shouldn't take a man long to figure out approximately what it will cost for labor and ma- 
terial and add fifteen per cent for extra expense. A man starting out to do such work should keep a correct record of every item; it is the only way to be able to estimate future jobs.

For the benefit of the beginner the following is a sample of the specification we make use of here and which, we have found, appeals to the average customer wanting such work done. While not suitable for all cases, it may come in handy. Such a specification, typed on $8 \times 10$ in. paper with a neat letter head will always make a good impression, even if your estimate is considerably higher than those submitted by others; it may land the order because it means more than a mere written estimate without detailed specifications.

SPECIFICATION AND ESTIMATE FOR WORK TO BE DONE, AND

MATERIAL TO BE FURNISHED FOR THE HOME GROUNDS OF

MR. D, BRUNDAGE

AT

HIGHLAND, ILLINOIS

\section{LAWN.}

(Work on lawn is to begin after building contractor has removed his material, bricks, lumber and rubbish).

Area for lawn is to be graded so as to form a gentle slope from water table of residence toward lot lines, after which all is to be plowed, grubbed or spaded over deeply, is to be pulverized, and ........ pounds of fertilizer consisting of blood and bone are to be worked into surface, which is to be raked and seeded with the best lawn grass seed at the rate of 100 pounds of seed per acre. All is then to be rolled lightly and covered with long, strawy manure (to keep surface moist while seed is sprouting and to prevent washing). As soon as the grass is up, the manure is to be removed, and all bare spots in lawn are to be reseeded free of charge by contractor.

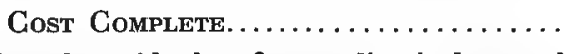

Eighty-five per cent of the amount is to be paid when first seeding is done and manure is spread; balance to be due when reseeding has been attended to, which is to complete this contract. The contractor further agrees to furnish ........ pounds of seed in addition, to be left with the owner to be used by him should weak or bare spots make a second reseeding necessary.

Whenever one has long strawy manure or any other material that can be used for covering, the raking in of grass seed is unnecessary. In fact, it makes a better job not to rake after seeding whether you have light or heavy ground to deal with. Much quicker and better results are obtained by putting a light covering over the seed. On the other hand, and in cases where manure cannot be obtained reasonably, or where the area to be sown is too large to be mulched, a light raking and rolling are the next best thing.

\section{Border and Shrub Planting}

When planning the planting of home grounds, I should consider first the surroundings or adjoining grounds at either side of the lot lines. Where objectionable sights are to be overcome, heavy, dense planting is necessary. This may consist of tall conifers, hardwood or tall-growing shrubs. The choice of what is best to use is 


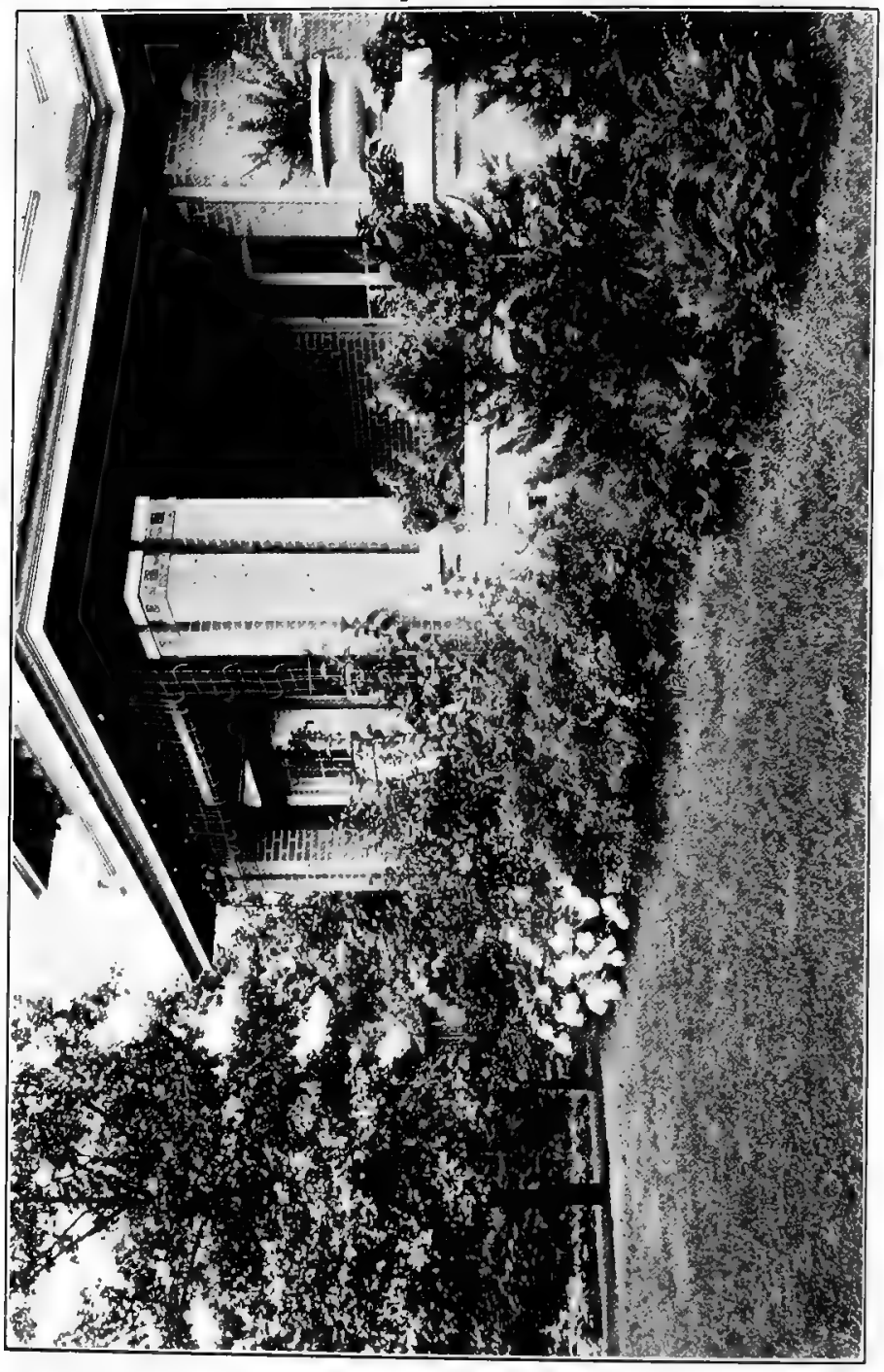

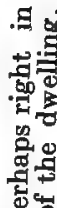

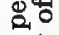

喜魯

范

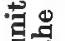

豆。

응

8.

范웜

옹

으요

동

की

흥흐

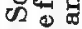

ํำ

瓷影

z

ง.

A

ᄂ

영

방

ใ

㲾

8

红

o 9

(2)

点

它

응

ธू'

4 을

$\stackrel{9}{9}$

空。 
governed by the amount of money the owner is willing to spend. Tall conifers are most effective and expensive; hardwood trees afford protection in Summer, but not much in Winter when one wants it most. This is to an extent true with most shrubs. But those who cannot afford evergreen trees have to use shrubs and at times are willing to have a small stock of these planted and wait for results.

In border planting always consider the land across the lot lines. If this is planted with shrubs, you may need but little planting, or just a little to form graceful lines. Whether the shrubs are planted on one silde of the lot line or the other doesn't matter as long as the outlines of such a planting are attractive. In planting a border to outline grounds, always have in mind what it will look like in a few years to come. To plant shrubs such as Spiræa Vanhouttei, Honeysuckle, Lilac, or Highbush Granberries 2 to 3 . ft. apart is a crime; the owner must expect to lift every other plant in two or three years to allow room for the others. Wherever you can, allow from 4 to $5 \mathrm{ft}$. of space. Never plant in straight rows or mix things up too much. Plant according to the height and habit of each variety and always in groups of from five to nine plants of each.

For instance, starting a border along the sidewalk on the lot line, a group of dwarf Barberry may be placed first, then a group of Spiræa Vanhouttei, then a group of Weigela, followed by Snowberry, Lilacs, Highbush Cranberry, Forsythia, another group of Spiræa, Honeysuckle and so on. Where a border is more than $6 \mathrm{ft}$. in width, carry your tall varieties to the back and keep such as Berberis Thunbergii, Kerria, Hydrangeas, Spiræa Thunbergii, Forsythia suspensa toward the front. Always bear in mind the desirability of obtaining a contrast in foliage and distributing your flowering sorts so as to obtain a touch of color all through. The same with those bearing berries or fruit; and, last but not least, plant for Winter effect. Consider the gray bark of the Loniceras, the brown of the Philadelphus, the red of Salix or Cornus, and the yellow of the Golden-Barked Cornus. For that matter Spiræa Vanhouttei or the dense growth of Berberis Thunbergii with a sprinkling of berries is fine for Winter. When everything is in a dormant state, here is where the conifers come in. They can and should be planted in groups in a shrubbery border to outline the grounds. These conifers don't need to consist of expensive Blue Spruce; almost anything will do so long as it provides the green Winter effect. Evergreens or conifers don't often grow all by themselves in their natural state; they like the company of trees and other shrubs, and look well with them.

\section{The Foundation Planting Is Important}

The foundation planting is another important matter. With very few exceptions, almost any home is greatly improved by a 
foundation planting of some sort. Usually soft or graceful shrubs of medium size, or such as can be kept at a medium height with the pruning shears are the best. Here again Barberry and Spiræa Thunbergii and S. Vanhouttei are among the best. So are the Snowberries and Indian Currants. Rugosa Roses, dwarf Philadelphus, Kerria and conifers such as Mugho Pine and Savin and other Junipers, can be used to advantage.

Care should always be exercised in treating the front of the grounds. Here and there is an owner who desires heavy planting in the way of a solid continuous border in order to get privacy. But more often it means simply a hedge or a few groups of shrubs with openings between the groups-which really gives the best effect. The larger the grounds the more heavily you must plant, and the bolder the curves and sweeps of a shrubbery border. The smaller the grounds, the more careful you must be to have your planting in proportion to the surroundings. Here also all too frequently, for the sake of the immediate effect, shrubs are planted too close together. In a group of dwarf Barberry which should contain say seven plants, we may find fourteen. Or the stock is planted so near the sidewalk that the branches will be in the way before the first season is over. All this can be and should be avoided.

The way for the beginner to get ideas in arranging the planting of shrubs in groups for the entrance of grounds, is to look at other plantings. That holds good also with border or hedge planting, or, for that matter, any landscape work.

In charging for the planting of shrubs a great deal depends on what preparations have to be made before one can start to plant. If the soil is so poor that it needs to be replaced, or enriched with manure, the work will run into money, but if such is not the case and it is just a matter of planting, govern yourself by the cost of the shrubs to you. Shrubs which cost you at the nursery, say, $\$ 25$ per 100 , by the time you have them planted will have cost you twice that much. Even if only a few are to be planted, a dollar per plant is not too much to charge for them.

Trees are of great value on the home ground. There are times, - as in the case of a wooded piece of ground, when a good many have to be taken out before you can even start to grade. Always open up well on the east and north sides of a residence; you want the morning sun and the light which trees keep out on the north side. On the south and west sides go more slowly. The afternoon sun of a Summer's day often makes things very uncomfortable. If there are no trees on the grounds, plan to plant some-but not too near the residence; and always allow plenty of space between them for proper future development. What good is a beautiful Maple or a stately Elm when crowded in with other trees? 


\section{Special Features in the Garden}

If you lay out small home grounds and plant them, avoid having them all look alike. Treat each place just a little differently from the others. This result can be considerably helped along by whatever additional work has to be done after the grading, lawn, drive, walks and lot line plantings have been completed.

Perennial and so-called hardy flower borders add a great deal and we will take them up separately a little farther on.

A little formal garden that can be laid out in an almost endless variety of designs is always attractive; then there is the Rose garden and the water garden or pool which can be made quite a feature. The rear of a residence can often be made to look even better than the front and often is used by the owner more than any other part of the grounds. A few specimen conifers are almost always in place somewhere; so are pergolas, gazing globes, fountains or bird baths and sun-dials.

Rustic or concrete benches may be used; the rockery can be made in endless shapes to harmonize with the surroundings; a Summer house can often be used to great advantage; a little ravine gives occasion for the building of a little bridge from which one can turn

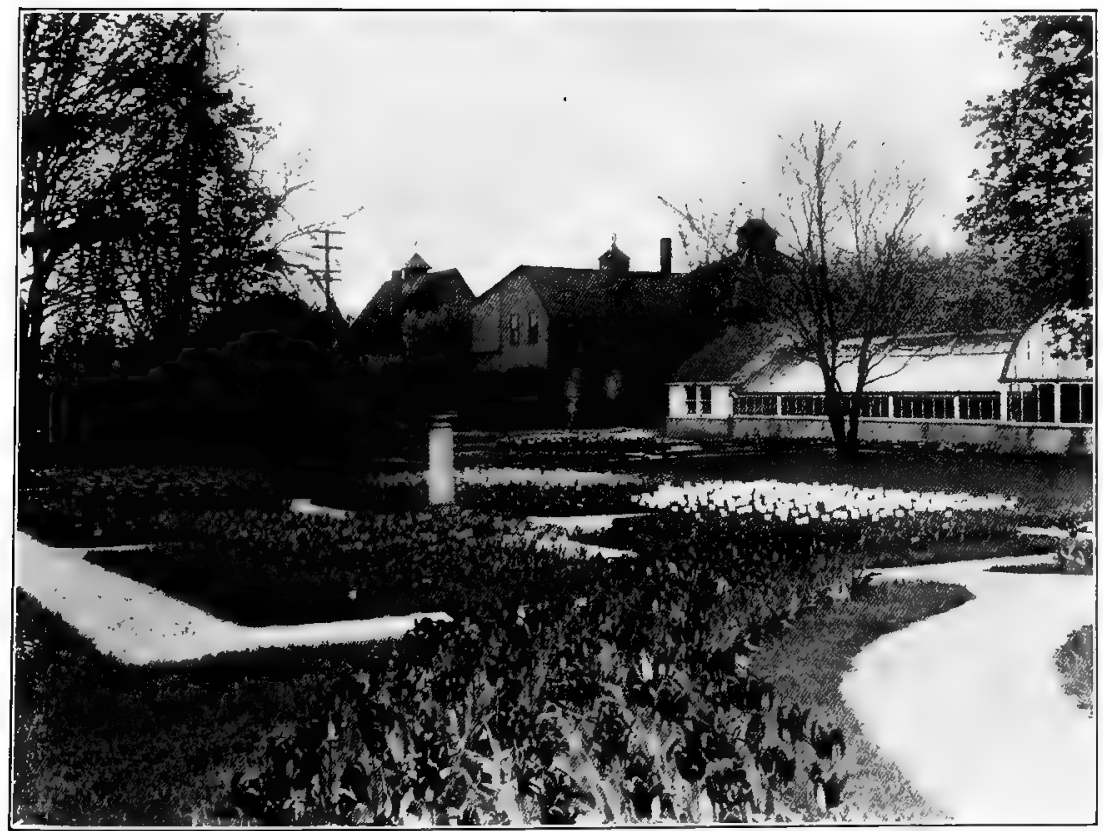

Fig. 44.-The Formal Garden Feature. Wherever space permits the formal garden can be made an attractive feature. It should always be considered in the laying out of a showground 
on the water of a miniature waterfall nearby. A sunken garden with a fountain in the center surrounded by a few narrow formal beds and with Boxwoods in concrete vases at the corners will help to make another feature of certain grounds. The vegetable garden may be screened off by a small thicket of native shrubs with a path winding through it and an arbor at the entrance, and you may suggest a wading pool for the "kiddies," or a swimming pool with an evergreen hedge for a screen. Bird houses and feeding places for birds, with a group of native trees to afford shade and plenty of ferns are in order, and so are a few of the many beautiful native, hardy plants, with a path made of stepping stones leading to an open space that is just the right spot for a camp fireplace and rustic seats. Not every ground requires or wants a terrace, but some do and it is here that the stone step and stone walk are in order. All of the above are only a few of many suggestions which might be offered in helping to make the home grounds attractive and the layout different from others in the same neighborhood or community.

\section{RAISING SHRUBS AS A SIDE LINE}

FOR the florist located near a nursery where he can quickly obtain whatever he needs in shrubs and trees, it may not pay to think about growing on some of this stock himself. But there are many florists who do more or less landscape work, and who must have the stock they need shipped great distances, and so find it convenient to devote a part of their grounds to the growing on of shrubs and small trees of the more popular varieties. Then there is still another class, and to my mind the largest, made up of those who have by years of experience found that, whether they are located one mile or 500 miles from the nearest nursery, it pays them best to buy what they want when it comes to well-grown, clean shrubs ranging from 2 to $4 \mathrm{ft}$. in height-and these are needed by the hundreds.

On the other hand, it is well to devote a little land to the growing on of specimens so as to have them on hand whenever a customer wants such material. There are times when from $\$ 10$ to $\$ 25$ is readily paid for a large specimen Lilac, Honeysuckle, Spiræa, Highbush Cranberry, Japan Quince, Philadelphus or Weigela. It is true that such specimens don't always do well, but there is a demand for them; there are people who simply cannot wait a couple of years for a Lilac 2 or $3 \mathrm{ft}$. in height to grow and develop into a flowering plant. They not only want an immediate effect and flowers the first year, no matter how poor they may be, but they are willing to pay for it. There are nurseries where such specimens are grown on to supply this kind of demand, but you cannot very well ship such stock with naked roots. That would require cutting it away back after planting, which is not necessary if a plant is lifted and delivered 
with a ball of soil. With enough soil around the roots you can lift and transplant a large Lilac or Spiræa Vanhouttei in full bloom and make it live. This is not to say that such a plant is as good as one which hasn't been disturbed, but the very fact that it can be done means a lot.

Most nurseries don't bother with such large stock. When a shrub gets to be from 4 to $5 \mathrm{ft}$. in height, they get rid of it one way or another. For them there is more money and less bother in growing on regular sized stock from rooted cuttings in the nursery row and every three years or so clearing the land for another lot to come on. But I am convinced that the local florist with room outdoors, who makes a side line of fixing up small grounds for his customers will find a good margin of profit in growing on specimens of the popular varieties, and in taking proper care of them.

\section{Growing on Specimen Shrubs}

The most important factor in growing shrubs into large specimens is to give the plants sufficient room for development. You cannot get results under crowded conditions. The next thing is to keep the soil well cultivated, keep the plants sprayed and give them each year a little pruning. Usually a Lilac, a Spiræa or a Bush Honeysuckle, if given plenty of space, will develop into a fine-shaped specimen even if left alone. But in the case with a Spiræa or a Honeysuckle, if you keep the inside of the plant cleaned out a little and after it is through flowering prune back some of the heavy growth, you help matters along.

Your nurseryman will supply you with 2- to 3-ft. or 3- to 4-ft. stock in early Spring. Order enough of it and line it out in nursery rows, allowing about $2 \mathrm{ft}$. between the rows. Prune back well and the following year you can lift every other plant in the rows and sell them. With $4 \mathrm{ft}$. of space each way the plants will be all right for at least two more seasons, or even three. After that, either sell more, to give the remainder more space, or transplant. In four years after planting you will have good specimens for sale and by planting a few plants each year, you can always have some coming along. If you wish, you don't need to have the plants in straight rows; the stock may be grown on in an irregular border along the lot lines of your property. Thus you can not only beautify your grounds, but also, by taking out a few of the large plants each year, and replacing them with others that will come along, make it.a paying proposition.

\section{Growing on Small Nursery Stock}

You are not butting in on the nursery business, nor interfering with it in any way by growing on a part of your own nursery stock. In fact, almost every nursery in the country today issues each Spring 


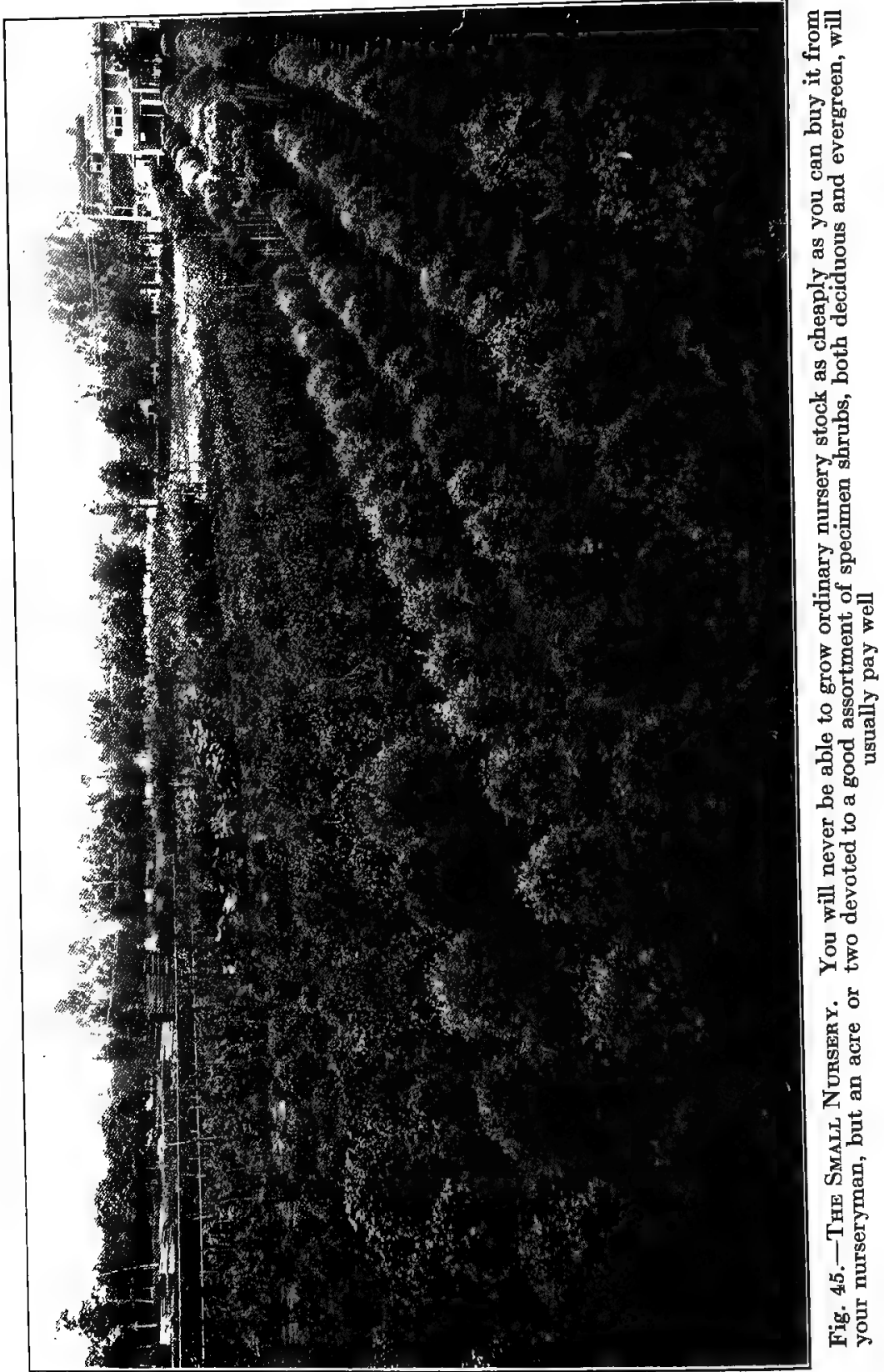


a list of so-called."lining-out stock," which it offers at from $\$ 25$ to $\$ 50$ per 1000 plants, according to the variety. These plants usually consist of rooted hardwood cuttings and the nurseries don't care whether another nurseryman or a florist buys them. They also realize that the more florists handle nursery stock, the more will be sold. The few shrubs a florist grows on are usually the smallest part of his requirements in nursery stock, so there is no reason why those who have the land shouldn't go into the growing on of a few of the shrubs they need.

Almost any rooted cutting planted out in fair soil and kept cultivated, will by the end of the second season, develop into bushy, salable 2- to 3-ft. stock. Some of the plants will be even larger. If you have use for such stock, why not grow it? It will pay better than a lot of other things that take up bench space and demand a lot of your time. To me anything that doesn't need coal during Winter looks good. Besides, there is an ever-increasing demand for shrubs and other hardy stock.

To the beginner I might say that there are among the shrubs certain varieties which everybody knows. It is these that you should consider first, and of which you should plant most as you go along. Then keep on adding to your assortment.

\section{Twenty Popular Shrubs}

The following is a list of what, to my mind, are twenty of the most widely used shrubs. They are arranged not so much according to their popularity as to the amount you need of each. For instance, the Lilac is far more popular than the Japanese Barberry, yet you will need ten Barberries to one Lilac on the average home ground; so it is with Japanese Quinces and Honeysuckles. In my experience with shrubs, they rank in importance and in the quantities most used about as follows: (1) Japanese Barberry; (2) Spiræa Vanhouttei; (3) Bush Honeysuckle; (4) Philadelphus; (5) Hydrangea; (6) Weigela; (7) Forsythia; (8) Red-twigged Dogwood; (9) Snowberry; (10) Lilac; (11) Rosa rugosa; (12) Persian Lilac; (13) Golden Dogwood; (14) Althæa; (15) Highbush Cranberry; (16) Snowball; (17) Kerria; (18) Japanese Quince; (19) Golden Elder; (20) Cutleaf Elder. I don't claim that this list will suit everybody, yet I am sure it will be a good guide for those starting out to go by. - I am also sure that hardly ever will anyone have a surplus of any one of the first twelve named, no matter how many of each he grows on; and even less often of the first six:-

Besides the above twenty varieties there are, of course, a great number of other good ones and still others that are used for hedges but are not mentioned here. But those who once get started, will soon find their way. 


\section{HOW ABOUT HEDGES?}

YOU can use almost any shrub, evergreen or conifer for hedge planting and obtain the desired effect if the plants are sheared or trimmed into shape. Yet certain varieties are more adapted for that purpose than others, and a great deal depends on what height hedge is wanted, what space is allowed for its spreading, and for what purpose it is intended.

There is hardly a florist doing business in a city or town of any size, who, even if he doesn't handle nursery stock, isn't called on ever so often to plant a hedge, whether it is intended merely to line a small lot, to screen an unsightly view or alley, or to be planted back of a wire fence.

It isn't a matter for discussion whether it is desirable to recommend hedges or whether they make a street more attractive, or in time become a nuisance. Rather is it for the florist to encourage his patrons whenever they happen to think about planting a hedge.

No matter what style of gardening may come into fashion, there will always be some who want a hedge in front, along the sides, or all around their home grounds, and the local florist should be able to talk hedge as well as bride's bouquet or Christmas basket. What is still better is to have a supply of the most popular plants used in the planting of hedges, or to be in position to show a well-kept hedge on his own grounds.

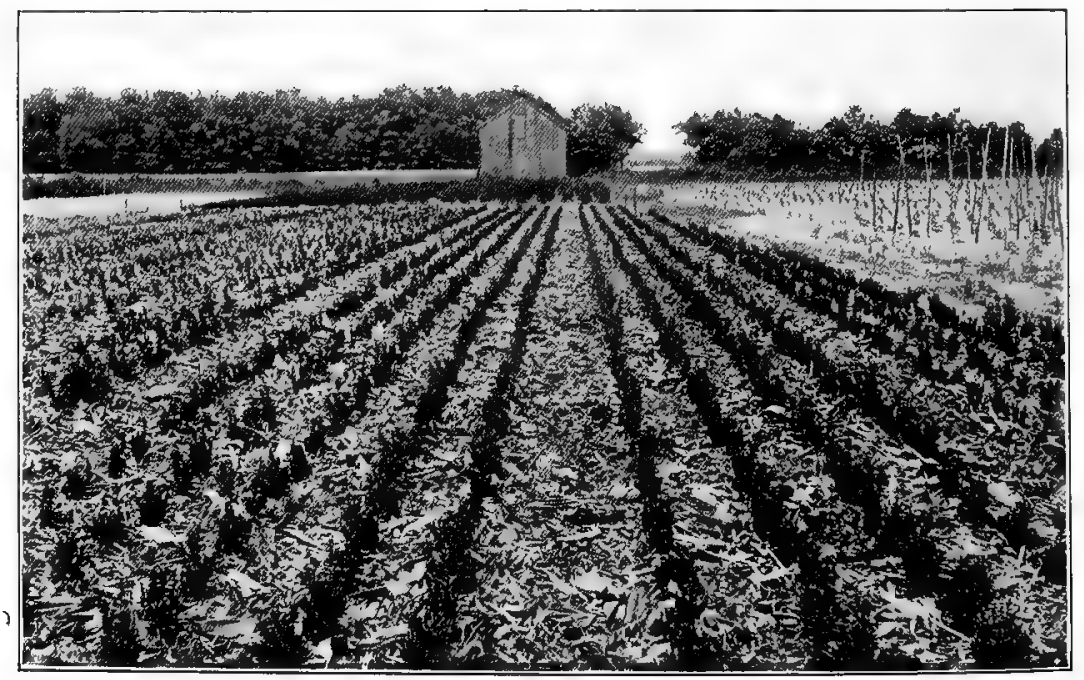

Fig. 46.-Boxwood IN THE NuRSERy Row. We have only recently begun to grow Boxwood in this country, but already we are "on our way." Here we behold twoyear-old plants well mulched with cornstalks to conserve moisture and keep down weeds. They have been growing in their present location in New Jersey one season and certainly look promising 
Any hedge confined within a limited area needs constant attention the same as a shrub border or anything else we plant. It is different with one used as a windbreak, but such are the only exceptions. As far as the florist is concerned, a hedge, in order to look attractive, has to be taken care of to the extent of keeping the plants in a healthy state and properly pruned to produce the best effect.

\section{Suitable Plants for Hedges}

I believe the Amoor River Privet (Ligustrum amurense) is one of the most desirable of hedge plants for ordinary purposes. In many localities it has replaced almost entirely the California Privet wherever the latter isn't quite hardy. Not only does this Privet make an ideal hedge plant, but it can be pruned or clipped into almost any desired shape or form, and planted at a moderate cost.

For the best effect a double row should be planted, allowing about 15 in. between the plants; if used near a walk don't plant closer to it than $3 \mathrm{ft}$. to allow for spreading.

Japanese Barberry (Berberis Thunbergii) is used for hedge planting perhaps even more than the Privets. It can be clipped so as to obtain a formal effect, but shows up at its best when pruned just once in Spring, and after that allowed to develop its graceful branches usually covered with berries which hang on all Winter, and at least long after the brown and red colored foliage has disappeared. The only person I ever found objecting to a Barberry hedge was the man in charge of one who had to clean it, in Spring, of the leaves gathered there during the Winter months. Such a hedge will, in time, grow to a height of $6 \mathrm{ft}$. and make as wide a spread; yet for years it can, with proper pruning, be confined to dimensions of $2 \mathrm{ft}$. or so each way.

Rugosa Roses make a showy hedge and so will Spiræa Vanhouttei, Kerria, Bush Honeysuckle and the Red-twigged Dogwood, but none of these adapts itself where a formal affair is desired. In evergreens we have Boxwood where this plant is hardy; Rhododendrons also make grand hedges but are out of the question with most of us. In conifers the Arborvitæ heads the list, remaining in good shape longer than Spruce or Cedar. For bordering a formal garden or lining out the walks, the nearest to Boxwood and, by the way, a good substitute for it, is the new Box Barberry or dwarf form of Berberis Thunbergii.

Whenever space permits and there is no limit set as to height, the Bush Honeysuckle, the Lilac and the Mock Orange are all desirable. If four feet of space can be given between the plants, so much better will be the final results. By planting too close you may obtain an immediate effect but not a lasting one; it will, before long, mean bare stems below. The same holds good with 
Spiræa which not only becomes bare below but, if not pruned properly each year, right after it is through flowering, becomes top heavy and resembles anything but a hedge.

\section{How to Gharge for Hedge Planting}

There are times when a customer hasn't the means or is not willing to go to great expense in having a hedge planted. In such cases, and particularly when you have to purchase the stock from your nurseryman, you will do best to sell him the necessary number of plants at a fair profit and do the same if you have to plant them. There are other times when you are called upon to prepare the soil, plant and do a good complete job and most likely you are expected also to make good should any plants die the first season. This, by the way, is not unreasonable as long as your customer wants a good hedge and is willing to pay for it. In such cases it is best to charge by the linear foot and, outside of evergreens and conifers, a charge of from one to two dollars per linear foot is not too high, depending, of course, on the size of the shrubs you use, what they consist of, and the number of linear feet to be planted. It takes pretty nearly as long to get ready, prepare and plant fifty feet as seventy-five or one hundred feet, and while under ordinary

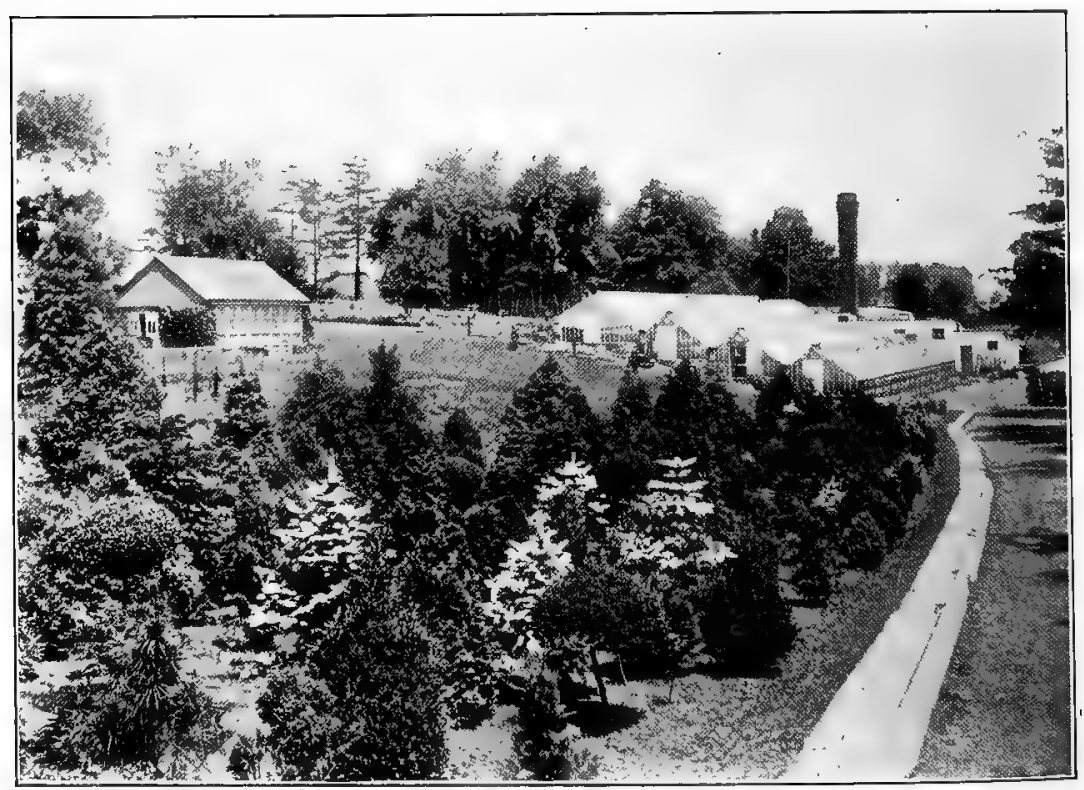

Fig 47.-The Valie of a Display of Conifens. Even though you don't grow on your own stock of conifers, you doubtless have call for (them if you do land scape work as a side line. You can greatly increase your sales by maintaining a well arranged display on your grounds where people can see their grace and beauty 
conditions and with just a little care, it isn't likely that you should have to replace many plants, it is a gamble nevertheless for which someone has to pay. Even if every plant lives and does well you should be paid for taking the risk, and if called upon to replace, do so cheerfully. You can't very well overcharge for planting a good hedge, and for those who want a satisfactory hedge the money is well spent.

\section{HANDLING CONIFERS AND OTHER TREES}

WHILE you can easily handle a specimen shrub, even when of large size, things are different when it comes to large trees. One has to be properly equipped to move trees when they have a trunk six or more inches in diameter. It takes a regular tree wagon to move them, but for all of that it doesn't hurt, if you have the space, to plant each year a few small Elms, Maples-Hard, Redleaf and Cutleaf-Ashes or Lindens. They will all grow into money, and the same is true with conifers. You couldn't use an empty lot provided with half decent soil to better advantage than by filling it with small Spruce, Pine or Arborvitæ. In a few years you can start selling plants, giving the remaining stock more space in which to develop into large specimens.

There are many sections of our land where much good could be accomplished by the local florist encouraging the planting of more trees, especially conifers; localities where Spruce and Pine would do well and help to create a charming Winter effect; where streets and highways are bare and could be made beautiful with rows of trees. There are many instances where, a florist established in a small city or town could acquire land on the outskirts at very small cost. He would hardly feel the loss of the money it would require to plant, as a starter, an acre or so with small trees. and conifers; yet in the course of a few years this would yield him a better income than any other crop he could possibly plant. I know this can't be done everywhere, as in many places nurseries are already established, but this country of ours covers an awfully big area and there are all kinds of opportunities for future development.

A man cannot very well start a small nursery and wait for a number of years for returns. He has to have an income in the meantime, and in localities where there is a florist but no nurseryman, that florist cannot do better than to get busy, no matter if he starts on only a small lot and keeps on adding. a little each year. Besides all that, I am sure that every florist who conducts a local trade and does landscape work will find a little nursery where he can at any time go and dig a few shrubs, conifers, or trees a mighty convenient thing to have. If he hasn't such stock on hand he is 
badly handicapped. I don't mean that he should make an attempt to grow on everything that is needed and so get away from buying. I know it would be folly to attempt this. For I am sure that the more you grow on, the more you will sell and the more you will buy from others. But if you do landscape work and have to depend year in and year out on stock that has to be shipped great distances in wooden boxes, you are working at a great disadvantage.

For a descriptive list of twelve desirable conifers for the florist to grow on, see Chapter VII, page 203.

\section{RAISING FRUIT TREES AND WHAT IT OFFERS}

Retail growers located in the smaller towns and in sections where fruit trees can be grown for retailing, no matter how limited the varieties, can make the selling of such stock a profitable side line.

IF THERE is anyone who should encourage the planting of fruit trees, such as Apples, Pears, Cherries, Plums, and Peaches, it is the local florist or florists of a town. I realize that in order to make such trees really pay, expert care and attention must be given, the same as with anything else. But there are many hundreds of thousands of such trees all over the land on small home grounds, which are giving pleasure and delight to the owners-and there is room for millions more to be planted.

Let us take, for example, the so-called common Keifer Pear. This variety will grow where other better ones cannot be grown or rather won't amount to much. But see what a beautiful tree it will develop into in a short time with its upright habit, covered all Summer long with deep green glossy foliage, hardly ever infested with insect pests, loaded almost every Spring with thousands of flowers and bearing an abundance of fruit which cannot be beat for preserving even if not as palatable as other varieties for eating! Why cannot we recommend such material to a customer who is in want of trees? When once established, it will get along and thrive with almost no care.

"More Fruit Trees for the Home Grounds" should be the motto of every retail grower. Encourage it, push it; plant some trees on your own grounds. It takes many years to grow a good sized Apple tree, but so it does to grow a Maple or an Elm, so why not have all three? What better shade tree could you wish than an Apple? And often where Apples won't do, Grabs will. Where is the family that doesn't use Crab apples in Fall for putting up? Let the nurseryman advertise and canvass your town from one end to the other; so much more will be planted for the good of everybody, and there will still be plenty of chance for you to sell some. So far, we have only begun planting fruit trees in the home grounds, and in the great majority of cases you don't see them. 


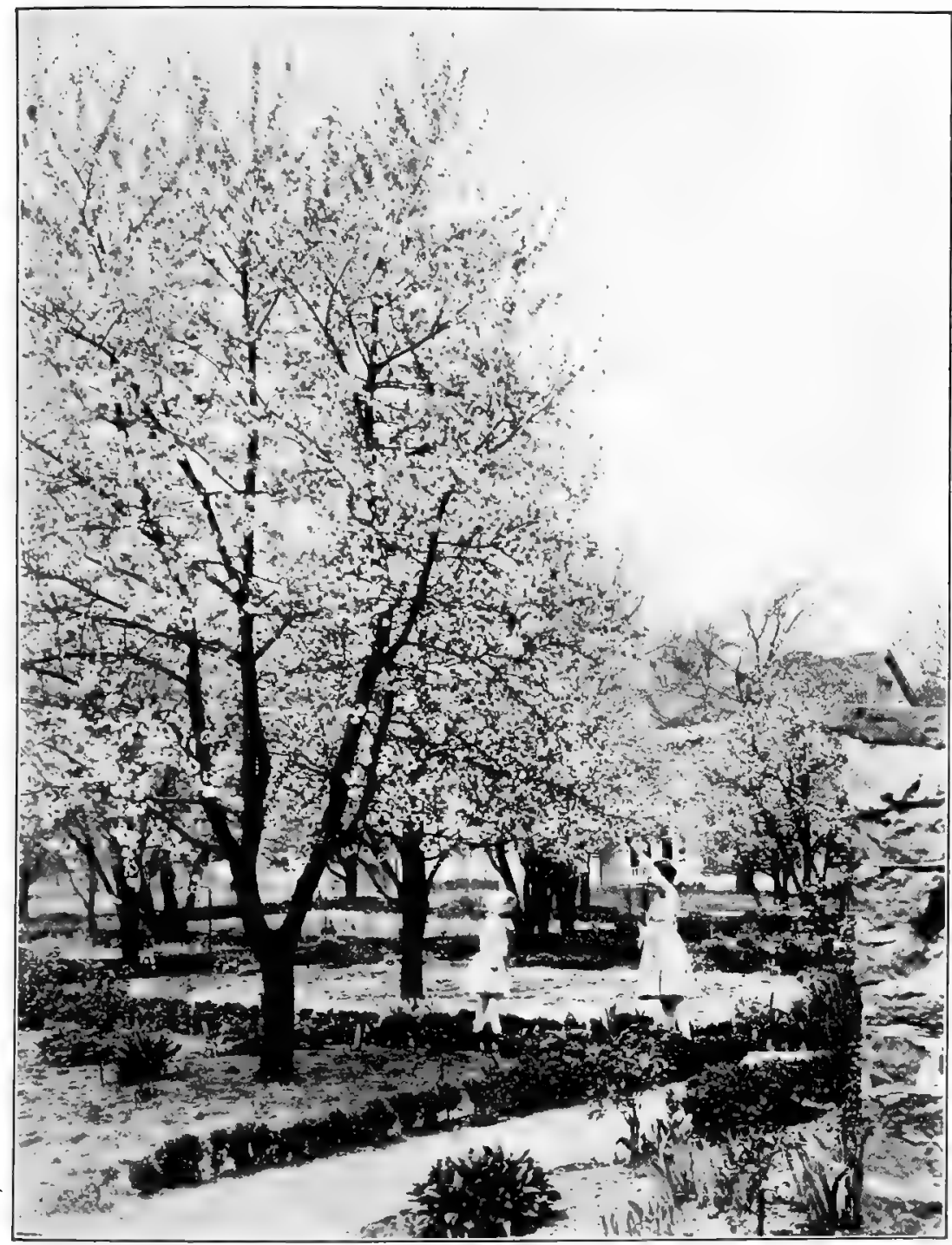

Fig. 48.-Why Not Handle Frutr Trees? Don't let the slogan be merely "Plan to Plant Another Tree;" add to it "Another Fruit Tree." Without considering the value of the fruit, what could be more desirable as a shade or flowering tree? The country florist in particular should encourage fruit-tree planting

Plant Cherries and Plums or Peaches in with the stock for an irregular border of shrubs along the lot lines. Even if they bear fruit fit to eat not oftener than one year in every five or six, they look as well as any other tall-growing foliage shrub and are beautiful when in bloom. 
Get the principal of your public school interested in the planting of more fruit trees and let him get the "kids" interested. Furnish some small trees each Spring for the children at cost, and let them plant them. It helps you in business; it helps the children who plant them; and it helps the whole community you live in.

Every little home with a 50-ft. front has room for three or four fruit trees, and there is hardly a spot East or West, South or North where, if given just a little attention, fruit of some kind cannot be grown.

Your nurseryman will supply you in Spring with small trees, ranging from $1 / 2$-in. in diameter or thereabouts, upward. The smaller the better, really, as long as they have good roots. The branches should be cut to one or two eyes from the little trunk at planting time and during the first year about six shoots should be allowed to grow. What you don't sell, plant out four feet apart in rows on your own grounds where you can lift them again the following year or later. Don't bother with doubtful varieties; you cannot grow everywhere a Delicious Apple or a Bartlett Pear or an Elberta Peach. The fancy fruits will always be grown only by experts, but there are usually varieties which are known to do well in a section which may be not the best for eating and yet be valuable for cooking, preserving or canning. And that, in most cases, is recommendation enough.

\section{SEED SELLING} HIS could be made a profitable side line by the average florist
in many a town.

There are ever so many communities all over the country where a florist is conducting a retail establishment in connection with his greenhouses where a side line could be worked up with seeds. It is just a matter of going after the business.

Many of the larger seed houses place cases of seed packets in grocery and hardware stores, and while a little is sold in that way, no one has a better chance than the local florist to make a real business of it and handle and sell not only flower seeds but vegetable, grass, and perhaps farm seeds, too, according to his locality.

Is there money in doing so? Of course there is. The very fact that you have people come in to get a five-cent packet of Lettuce seed means a prospective buyer of something else. Anything that tends to make people come into your establishment pays. But there is more to it than that; wherever there are homes and home grounds seeds of every description are, wanted and a fair margin of profit can be made by handling them.

It isn't hard for a florist who uses and sows seeds of all kinds himself to take up the retailing of seeds. From a small beginning 
a good paying business can gradually be worked up in time, and it will help sell your greenhouse plants and other stock. Get away from the idea that handling seeds isn't in your line. It wouldn't be if you were located in a city with good seed houses all around you and your hands full of other things; but if there isn't any regular seed store in your town, there is a mighty good opportunity waiting to be taken advantage of.

\section{SELLING FERTILIZERS}

WHEN Spring comes and the man with the little home grounds starts to rake leaves, begins to lay out his little garden plot and get the annual planting fever, he thinks of the dark, rich looking manure that he wants for either the lawn or garden; he feels as if that was the proper thing to use. For that matter any manure or soil, if it is of a rich, black color, appeals to any one who has either a light sandy soil or a heavy clay to work with.

While it was comparatively easy in years gone by to obtain all the manure one wanted in the smaller cities and towns, the auto

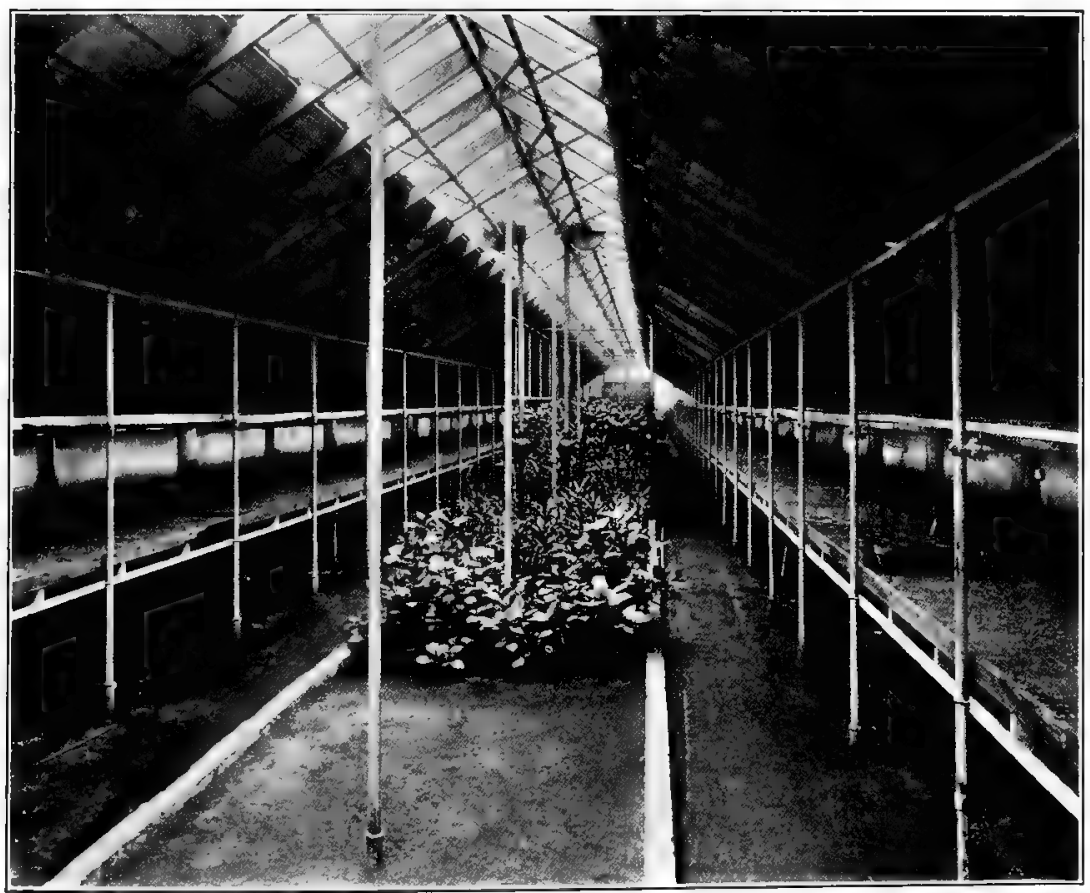

Fig. 49.--Inside the Modern Storage Shed which makes it possible to overwinter a great variety of stock until time to force it or put it outdoors again. Often patrons will want you to keep plants for them. This view shows excellent construction that could be carried out on a smaller scale if desired 
has put the manure box out of commission. It is empty, never to be refilled, and with it has disappeared to a great extent the house fly.

While stable manure will keep on getting less and less, the demand for fertilizer will keep on increasing from year to year and there is the best of chances for the florist of a town or city to work up a paying side line in the handling of it. There may at this time be no one in particular handling fertilizer in your town, but there is bound to be some one who will, sooner or later. You may at first object to the idea of a florist with a nice retail establishment handling fertilizer, but there is nothing in that; all you need is a shed or storehouse, to keep the bags dry; and during early Spring, if orders are taken in time, you can haul direct from the freight car to your customers' grounds and save extra handling. No store is too good to take orders for fertilizer in, as long as you haven't got to handle it there, and the very fact that you use it yourself in the growing of your plants is the best recommendation for others to do the same. It should be as easy again for you as for a feed or hardware store to land an order for fertilizer. Let me here give the contents of a good letter to send out about the middle of February to those who have a lawn or a garden.

Mr. J. JoNES,

Lake View Place,

Chicago, Ill.

Dear Sir:

Every lawn, in order to maintain a healthy growth and good color, requires food of some kind. Stable manure is not only unsightly and always contains a lot of weed seeds, but also is almost prohibitive in price. Practically every golf club uses so-called commercial fertilizer for best results, for it is clean and contains more actual, available plant food than most manure, besides being far less expensive.

Our first car will be in about ten days from now and as the hauling direct from the car to your grounds will save handling, we would be glad to make you a special price. We will be pleased to give you an estimate on your requirements including the spreading of the fertilizer. We might further state that the sooner this fertilizer is put on the lawn after the snow has gone, the more effective it will be. May we hear from you?

$$
\text { Yours truly, }
$$

You can have fertilizer put up in almost any size bags and you should go after the small orders, calling for 25 -lb. bags, as well as big ones requiring ton lots. There is good money in both.

\section{STORING PLANTS FOR YOUR GUSTOMERS}

YOU will always find it best to take thorough care of the plants intrusted to you and no plants should be accepted in the Fall so far gone as to be hopeless. If plants received at the greenhouses don't look good, make it your business to let the owner know about it at once. It is not unusual for a customer to send almost any old 
dried-up or dead plant to you and expect a good one in return the following Spring.

The time to attend to such trouble is when the plants come to you in Fall, for you are money ahead by not taking in such stock; or at least let your customer know the condition of the plants, and what to expect from them. Even if he is disappointed and your competitor is foolish enough to take them in, you are still ahead.

There is often a question as to the proper charge for storing Boxwoods, but it is really easy to figure. No one can store any kind of plant, no matter how small, for less than fifty cents per month, and that for not less than a period of six months. It is well worth that for a Boxwood two or three feet in height, and there should be a charge of at least one dollar per pair for cartage each way, if you don't have to go too far. Larger stock should be charged for accordingly. It is always better to charge enough, so you can take the best possible care of the stock, than to be satisfied with almost anything and not take care of the plants.

\section{How to Avoid Difficulties}

Storing any kind of plants can be made a most disagreeable feature of the retail grower's business." At best it isn't always pleasant, but you can't very well get along without it. You have to do it in order to oblige your customers and they have no one else to go to, so it is for you to make the best of it and adopt a system whereby you can avoid unpleasant feelings. To begin with, no one should be allowed to bring a plant in until either yourself or the man in charge of the place has had a chance to examine it as to its condition. Many a dose of white fly has been introduced and given a new home by being brought in along with an old fern or some other pet; and so with scale and other troubles. Or a good lady will come in and want to know "What became of the beautiful palm I left here three months ago?" and no one will know anything about it. Or you may hunt for two hours all through the palm house for a Rubber Plant, bigger and better than any you have on hand, only to have the delivery boy recall a week later that he brought the plant in, that it was in an 8-in. pot, seven feet tall with three leaves at the very top-and that "Billy threw it out."

No one need say that there is no way to prevent such poor management; it is a simple matter to avoid it. You cannot possibly invite trouble easier than to store old Boston Ferns and the easiest way to avoid doing so is not to accept them. There are, of course, exceptions. You may have a good customer and one you can reason with who wants you to store a good fern; but between it and one 
with fronds on it six feet long full of scale, which has been in a dark place undisturbed for the past four years, there is a big difference.

When you know that an old Kentia with two crippled leaves would, with the very best of care, require five years to make a good plant; why not tell the owner about it?

It isn't much trouble to properly label every plant received for storing, but think what a lot of trouble it may avoid later on if each plant is labeled at once.

Take a few pages in the back of the cash book or journal and mark down the date of arrival of each plant and the condition it was in; and if you have to write a letter about the plant, file away a copy.

\section{THE IMPORTANGE OF GUT FLOWER ARRANGEMENTS}

FLORAL designs and arrangements play an important part in the business of the retail grower. The wholesale grower in bringing his cut Roses, Carnations or other stock to the market, gets out of them just the actual value they represent, while the retailer or florist who displays them to best advantage or uses them in making up a floral design, basket or spray has a chance to make a fair margin of profit not only on the flowers themselves, but also on the labor and skill involved in arrangement.

Real art in a flower arrangement is never based on the amount of stock used in it, but always on the way it is arranged. The day of the floral pillow or wreath with a solid mass of short-stemmed Carnations, Hollyhocks or Candytuft as a base passed long ago, and that of the light, artistically arranged effect has taken its place.

Every retail grower has to depend more or less on disposing of part of his flowers in the form of floral arrangements in order to make money. With the unavoidable loss there is in perishable flowers, one has to have more of an outlet than just the selling of Roses or Carnations by the dozen. It is for this reason that every effort should be made to encourage your patrons to use cut flower basket effects, centerpieces for their dining tables, corsages, arm bouquets or other arrangements. Not only will you find this more profitable, but your patrons will get greater value for the money they spend.

Take an expensive wedding shower bouquet. By themselves the flowers don't look like much, yet their cash value, when properly arranged may be only one-third of that of the bouquet. The same holds good, though maybe to not quite such an extent, with a spray, a basket or any floral design. In all such cases you really get paid for what you know and are able to do. 
Practice Is Essential in Floral Designing

There are enough design books on the market today and enough illustrations appearing from time to time in the trade papers to give one an idea of floral arrangements. As in many another accomplishment, to some the artistic arrangement of flowers seems like a natural gift while others find it impossible to acquire it no matter how long they stick at it. Of course, in any case, it requires experience and practice to become efficient. And not only that, as important as anything is to learn how to accomplish the most with the minimum of material. This should not be confused with giving as little as possible for the money, but means rather the avoidance of waste.

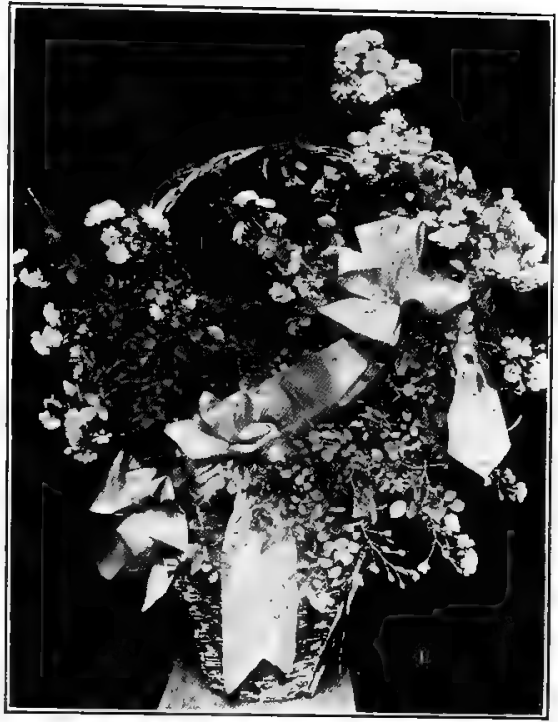

Fig. 50.-The Sort of Rose Basket that Pays. No one would have paid more than two dollars and a half for this Dorothy Perkins Rose in a 5-in. pot; but with the dollar basket and the fifty: cent ribbon added, it sold for six dollars

It is not possible here to dwell at length on this subject. Not that it isn't as important, perhaps, as any connected with the florist business, but men and women will have to find their own way themselves. Those who start into business with just a little knowledge of what pleases the eye, a will to learn, and open minds will soon get on their feet. The first design or spray arrangement turned out may not come up to what it should be, but is there anyone who ever had a different experience?

Feel your way. Watch what others do. Do not try only to imitate them, but try to improve on their work. Keep on thinking of something a little out of the ordinary and keep on perfecting yourself. There is room for that improvement in the methods of even the most uptodate florist living. You could explain things to a man for a year, but unless he actually had a hand in the work, it would be of but little good to him. The minute you begin to have the least to do with such work, it comes perfectly natural to take an interest in it; and it is equally natural to keep on improving as you go along.

Strive to please those you serve. That, after all, is the main thing. If you can turn out work that will please your patrons who pay for it, you are on the right road even if you never acquire 


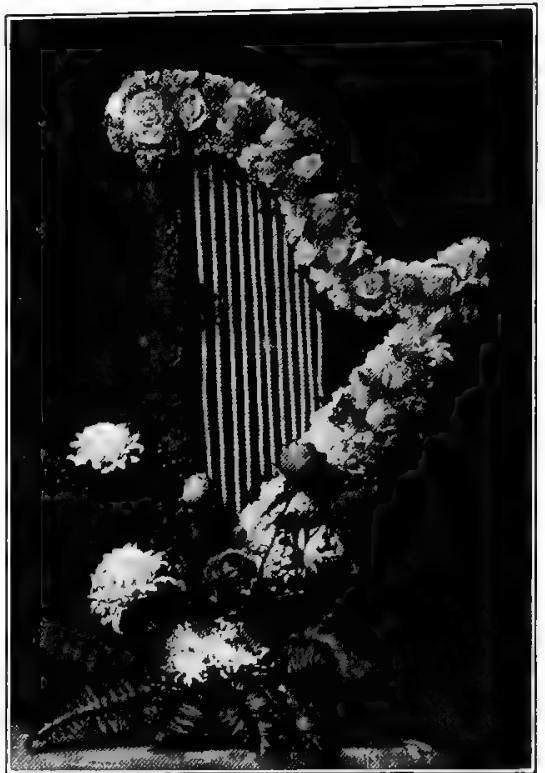

Fig. 51.-A Floral Destgn Properly OUTLINED. As important as anything well proportioned outlines so that one doesn't (as is often the case) have to guess at what it is supposed to represent about a set floral design are correct and

the artistic touch of the large city florist. At the same time, in order to keep up to date, meet competition and keep on going ahead. You can't do better than to take advantage of every possible opportunity to find out what is going on in the big cities, where, usually, the new ideas in flower use and floral arrangement originate.

\section{Materials Useful in Design WORK}

The farther away from a big city you are located, the more prepared you should be to fill all kinds of orders, but especially such as you are apt to receive for funerals. It is always well to have a stock of different sized wire designs in wreaths, pillows, crosses or lodge emblems. There used to be a time when these designs, nicely lined with tinfoil, served as suitable wall decorations for the flower store, but it didn't last long and today no first class shop displays anything to remind a visitor of funerals. Store your designs out of sight where they won't rust. Have at hand an uptodate design book of floral arrangements to show to those interested and always carry a good supply of green and brown Magnolia wreaths.

Personally, I don't approve of set designs in which the flowers in order to show up have to be wired on toothpicks. No matter how well arranged they are, there can be nothing really artistic about such pieces and the sooner we get away from them the better. While funeral work means much to us today in the way of business, let us keep on educating the public to use flowers for themselves and their friends while alive. The day will come when we won't have to wait for them to die in order to get orders. We are getting away from set and stiff designs as the use of baskets filled with flowers is becoming more popular for funerals. A spray of loosely arranged flowers is also more becoming, but of all formal pieces the wreath is, to my mind, the most appropriate.

To come back to Magnolia leaves and wreaths made from them, these are among the most popular designs used today. It 
is for us to be prepared to furnish them, and on short notice, too. It is well not only to carry these leaves always in stock and moss and hairpins as well, but also to have a few wreaths made up, ready for the addition of a cluster of flowers and some soft green. Thus you are enabled to deliver one at a few minutes' notice, especially' during Winter time when a shortage of flowers may prevail. Magnolia wreaths can easily be carried for a long time if properly put away from dust, dirt and dampness.

Cycas and Galax leaves, Statice, wire, tinfoil, Wood Ferns, Boxwood, Leucothoë, ribbon, cut flower baskets, lettering, cut asparagus, toothpicks, chenille and design boxes are just some of the items one should always be supplied with.

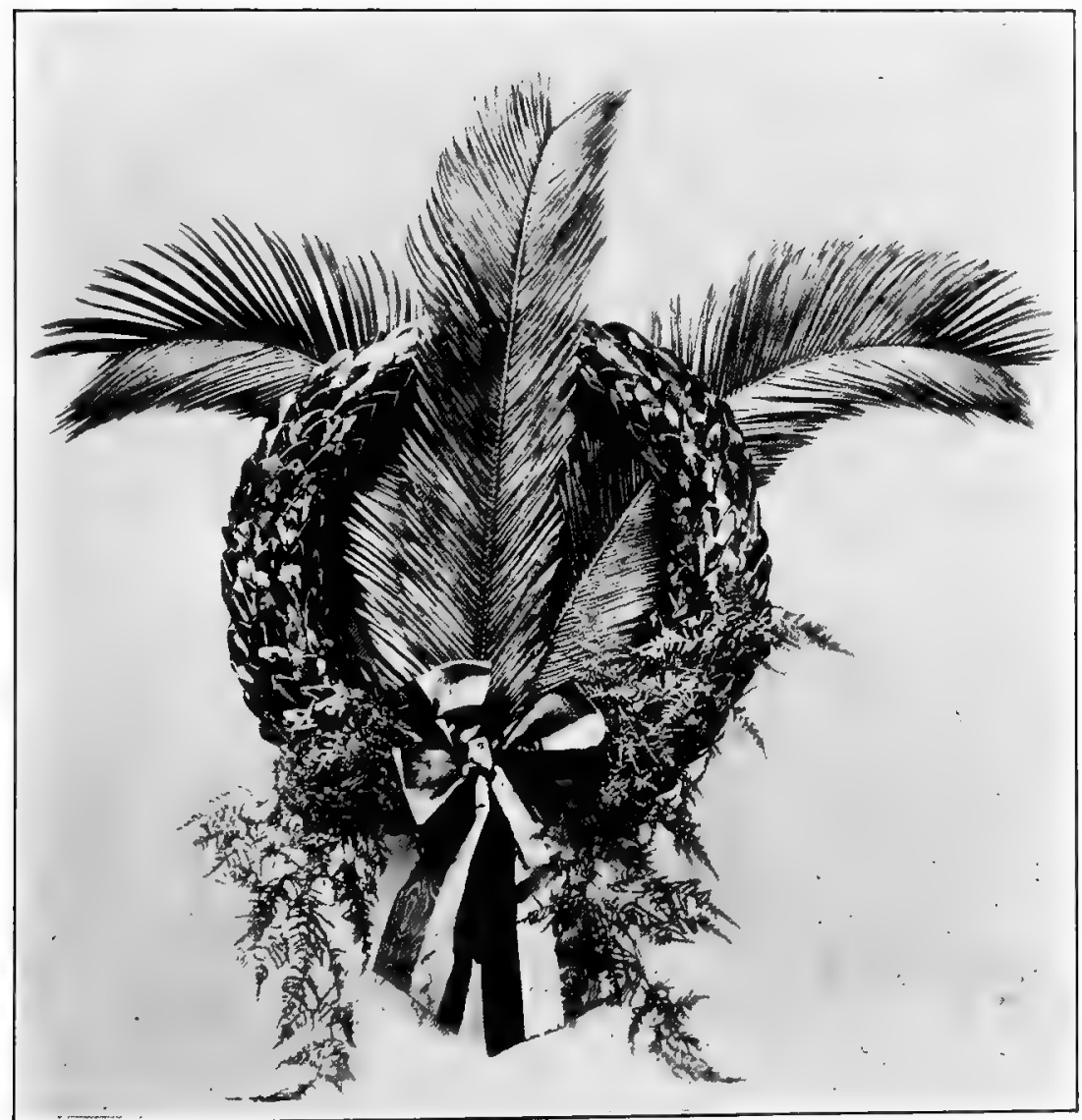

Fig. 52.-A Digntfifed Wreath Without Flowers. There are occasions when a wreath like this will not only prove a pleasant change from the average but, with a scarcity of flowers in Winter time, will appeal to those located far away from the cities. I doubt whether one could add anything to this design by using flowers in connection with it 
Since you are in business try to be ready to fill any and every order received, whether it calls for a floral clock, a broken wheel or a blazing star. The investment required for the wire designs doesn't amount to much, but their possession may mean much to you in cash returns as well as the good will of a patron when you have a hurry-up order to fill.

\section{What About Artificial Flowers?}

Why not? There is a place for them, in the case of the outof-town florist especially, and occasionally they can be used to advantage. It isn't natural for a florist with houses full of stock ready to cut and use in design work to prefer paper or waxed flowers instead, but there are times when flowers are at a premium and when artificial flowers will answer every bit as well. And there are cases in which wreaths are to be used for grave decorations, when a patron will actually prefer the artificial to the fresh cut flowers.

Floral decorations for a store, hall or church can often consist partly of artificial flowers, and answer the purpose every bit as well as the best Roses or Carnations you could cut. It isn't that I want to advocate the use of artificial flowers whenever and wherever it is possible. But I am sure the florist who insists that it is unprofessional to consider them and that they have noplace in a firstclass establishment, is making a mistake. A few dollars invested in a few boxes of such flowers kept handy, might easily prove a mighty good thing. And I don't know that there is much difference between such material and a lifeless, preserved Magnolia leaf, to the use of which I am sure no florist would object.

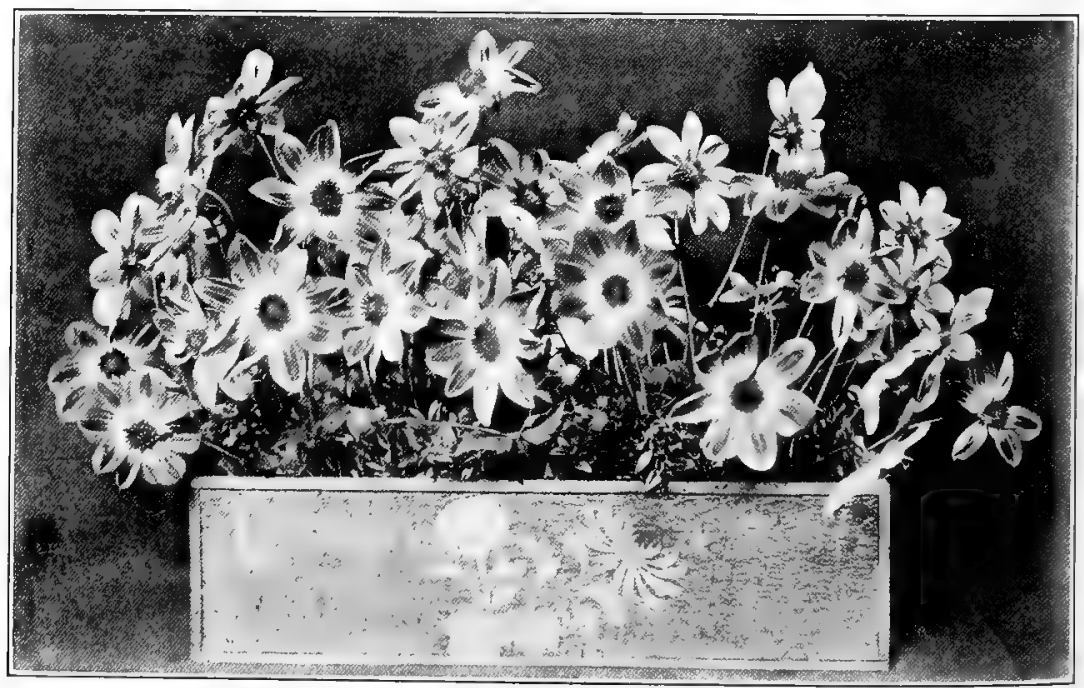




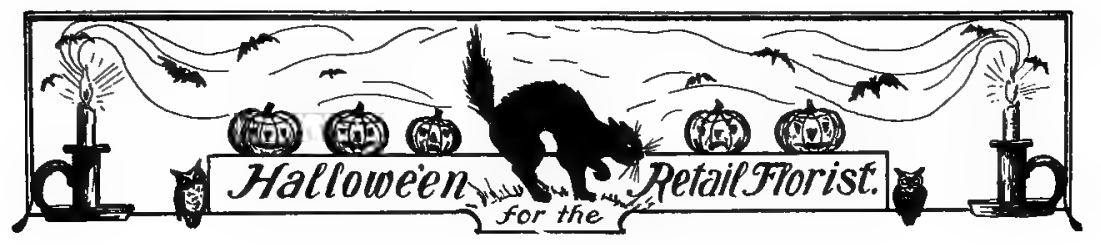

CHAPTER VI

\section{IMPORTANT FLOWER DAYS OF THE YEAR}

\section{CHRISTMAS AND ITS INGREASING IMPORTANGE}

$\mathrm{A}^{\mathrm{T}}$

T no other period of the whole year do people go more out of their way to make others glad, forget more completely that one day is practically like the other, and realize more fully that there is no happiness compared with that of making others happy-than at Christmas. Each year we all give and receive more tokens of kind thoughts and thereby come nearer living and celebrating Christmas in the true spirit the day stands for; and so the florist, today more than ever, plays an important part in it all, not only measured by the amount of business he does, but also because by doing it he helps to spread cheerfulness to many a home, fireside and sick room.

With hardly any exception, the established florist has been. doing a greatly increased business with each succeeding year; there is every reason to believe that this will keep on, especially if we do our part in preparing the stock, advertising it and delivering the goods.

\section{Christmas Business Is What We Make It}

If we sit down contented with the way things are, Christmas will pass the same as every other weekday. Push and keep on pushing a little harder each year, and it can be made one of the most important flower days of the whole year. And why shouldn't 


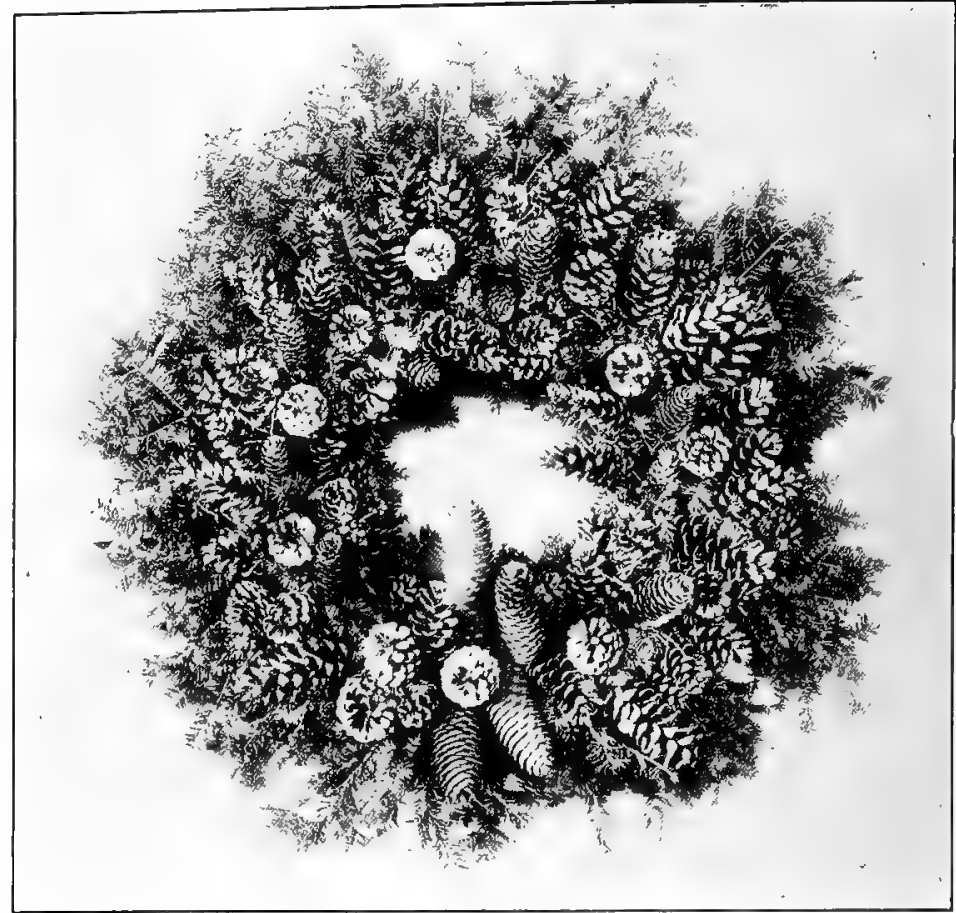

Fig. 53.-A Wreath of Hemlock and Pine Cones. There is always a demand for the unusual. That is why some of your patrons will appreciate an arrangement like this around Christmas time

it be? One can hardly imagine a single instance where flowers in some shape or another would be out of place if tendered as a gift; in fact, if greater efforts were made on the part of the florist to advertise sufficiently, many more could be made to think of and choose flowers in preference to other things.

In other words, the Christmas business is exactly what you make it. You can have your patrons satisfied with twelve fifteencent grocery store wreaths, or you can educate them to demand fewer wreaths but better ones.

You can handle a lot of plants and sell them as they are with but little profit, considering what they cost you; or you can use these plants in inexpensive baskets with a little ribbon and double your output. You may not be able to sell a lot of so-called everyday stock but if you use taste in basket arrangements and display it properly you will get well paid for it. 


\section{Christmas Advertising}

For the florist located out of town, or rather in a moderatesized town or small city where he depends on a local trade, even if he is the only florist in that locality, advertising, and a whole lot of it, is absolutely necessary if he wants to get the most out of his Christmas business.

During the holiday season even folks who don't do much for the rest of the year are usually busy, and often too busy to think of what they might need or could use in the way of flowers or plants and particularly Holly wreaths and greens. If left to themselves they will usually order their requirements a day or two before Christmas - at a time when you don't know what to do first.

For years we have made it a practice to mark down, if at all possible, the names of all patrons who come in at the last minute and are unable to obtain wreaths or Holly; a list is also made of all who buy wreaths. Starting about the fifth or sixth of December the following year, everyone on the list is called up over the telephone, and in a nice way informed that we are anxious to fill their orders this year and would appreciate early booking so as to be able to give them the best attention. In that way most of our orders for wreaths, loose Holly, Mistletoe, Winterberries, Boxwood balls, wild Smilax and wreathing are in by the tenth of the month, and all wreaths, with a good number of extra ones, are made up before the twenty-first.

We have yet to hear of a customer being put out by our calling up; in fact, most of them depend on us to do it, and some would feel slighted if we neglected to. They will come personally to select what they wish in plants or cut flowers, or will call up about it; but for the Holly wreaths and decorative greens it is up to us to book the order early.

\section{Preliminary Publicity}

The first reminder of Ghristmas can be made in the form of a neat card inserted with the statements going out on the first of December. Liberal space in the local newspapers from that time on is always money well spent; an appropriate Christmas folder sent out about December tenth is timely, and another one, the last reminder, about a week later, calls attention to the complete Christmas display as a finishing touch. An attractive slide in the movies, the putting of a few of the main Christmas plants in the windows of the local Western Union telegraph office, and a neatly printed sign, "Orders Taken for Flowers by Wire for Xmas," will often do a lot of good. If you belong to the F. T. D. the agent of the telegraph office will direct inquirers your way. For those located just outside 
of the business section of a town, a part of a store or a window may be rented for two weeks or so and used for a Christmas display where the heaviest traffic of the town will notice it. "Say it with Flowers This Christmas" and other attractive folders may be left at the drugstore, hotel or other prominent places of the town; do everything and in every way to let people know that flowers are the only thing for Christmas.

Your preparations for Christmas are never completed if you neglect to let everybody know about it, and often the last-minute call in the way of folders, sent December twenty-second or twentythird does more good than anything mailed previously; yet you want to do the other things as well.

\section{Preparing for Ghristmas}

You may take orders for Christmas delivery right after Thanksgiving; yet the real ordering often does not start until after the middle of December. This is followed by the Christmas rush of the last four or five days, during which you should do more business than in the six weeks following. This means that you must get ready in good time, prepare, plan and work out a way to conduct that brief, unavoidable rush with the minimum of confusion, to accomplish the most, and to take and fill orders in the shortest possible time without mistakes.

The beginner should always bear in mind that while practically all of the stock he handles is more or less perishable, some of it is more so than the rest. To have left on hand after Christmas a lot of Poinsettias or tender Begonias may mean quite a loss, while left-over palms, ferns and other decorative stock such as Araucarias, Dracænas, Pandanus and the like form a good asset all through the year; we will come to that later.

To start with the preparations: Baskets, pot-covers, ribbon, crêpe, tissue, wax and wrapping paper, boxes and other accessories all can be purchased weeks or even months ahead for future delivery. No one who has ever gone through a real rush, or found himself sold out before the twenty-fifth of December, or who has tried to purchase flowering stock the week before Christmas and failed to obtain it, will let the ordering of such stock go until the want of it is felt.

Locate the stock you need weeks ahead and place your order to be shipped at a certain time. As soon as Thanksgiving is over the store or show house should begin to put on its holiday dress, even if this consists only of a few bright Cyclamens with pot-covers or in baskets with suitable ribbons on the handle, a few samples of moderate-priced made-up baskets and some more expensive ones, a vase of red Winterberries and Boxwood, and a well-made wreath 


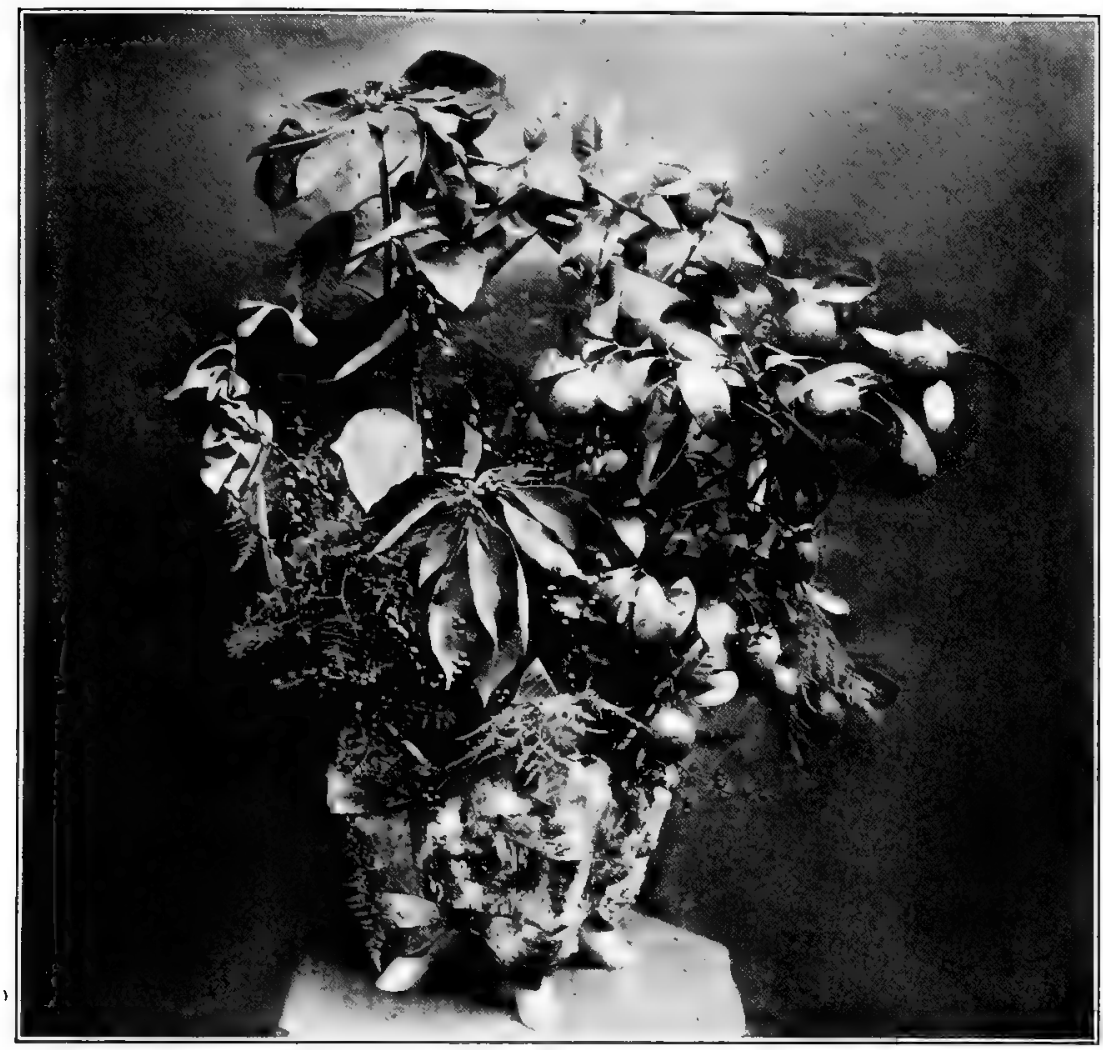

Fig. 51.-A Satisfying Ghristmas Basket. This pleasing arrangement for the holiday season consists of a Birch bark basket filled with Poinsettias, Oranges, Pussywillow, Winterberries and Asparagus

of Boxwood or Holly with red berries and red ribbon properly displayed. Red and green are your decorations from now on; if you remind the passersby and the visitors to your establishment of the coming Christmas they will help-by giving you orders.

\section{Get Your Supplies Early}

If you use waterproof crêpe paper for inexpensive pot-covers, have a number of these cut to fit 4-in., 5-in., 6-in. and larger pots. Red, white and green are made use of, but a deep green is the most desirable. If these papers are cut, it will save a lot of time later on; and so with the cut flower boxes; make up some and have them handy when wanted.

Make out a list of whatever you want from your wholesale or supply house and have everything on hand long before you need it. Spare no effort to be prepared to do business. The farther 
you are located from the large city the more attention you must pay to details. See to it that there is a good supply of wrapping paper, twine, sheet and sphagnum moss, corsage pins, shields and boxes, plain cards, card envelopes, delivery tags, the different sizes of fern dishes and bulb pans, wire and wire rings for wreaths, various sizes of wired toothpicks, tinfoil, narrow fiber, chiffon, and a better grade of red ribbon; these are just a few of the things almost every florist, no matter where he is located, needs for Christmas. The list would be as long again should we mention all the items made use of by the larger city florist.

\section{Displaying the Holiday Stock}

The chances of making a sale all depend on what you have in suitable Ghristmas stock and how it is presented to those who visit your establishment. For instance, a Winterberry centerpiece among a lot of baskets and pot plants doesn't make nearly as much impression as when set by itself on a small table with a white cover; in this way it will give one an idea how it would look on the diningtable. A Cleveland Cherry, no matter how fine the plant nor how full of berries, should not be placed alongside a Poinsettia pan; the color of the latter gives the Cherry anything but a Christmas effect, although alone or next to some white flowers it looks fine. There is never anything gained by crowding things in the store or show house and the florist with greenhouses in connection with his store should always put aside a bench in one of the houses where the main part of the Christmas stock can be kept to be drawn upon when needed. As this bench begins to empty, move up the remaining stock and use the space vacated for stock sold and to be delivered later.

If you should happen to have an oversupply of anything, whether it consists of Christmas Peppers, Gleveland Cherries, Primulas, Poinsettias or anything else, and you are anxious to dispose of the plants, you will never do it by crowding them into the show house, or having them predominate there. Rather display them to best advantage and in proportion to other stock. But push them, that is where you salesmanship comes in. If, for example, you have twelve Cleveland Cherries on a counter and just one each of Cyclamen and Poinsettia, it is a safe bet that no one will want the Cherries.

Stock once sold has no longer any business in the store or show house; it should be removed immediately and put out of sight. Last, but by no means least, maintain your display in the best possible shape until you close up. When the flowering plants begin to give out, keep on bringing palms, ferns or other decorative stock to take their place. Anything looks better than an empty or half- 
filled counter or bench. Try to make things as attractive as you can even for the late comer.

\section{Delivering Christmas Orders}

Always bear in mind that what you send out should reach its destination in the best possible condition even though you may be located in a section of the country where from a sunny, Spring-like twenty-third of December the weather may change overnight to a blizzard with the temperature around zero. The man who wraps up a flowering plant or basket and he who delivers it to the customer in the same shape in which he received it, are as valuable assistants as any you can have around you. Whether your territory is big or small, the orders to go out on the twenty-fourth and twenty-fifth should all be properly packed and set in lots going the same direction. The orders going farthest, particulary during cold weather, should receive special wrapping and attention. If the delivery man can have a good boy with him to get the orders ready and out of the car quickly it saves a great deal of time and more than pays for his services.

All the good you may have accomplished in growing on a good stock, preparing in every possible way for the rush and doing a big, profitable business, counts for nothing if your stock is not delivered properly. No one can conduct a Christmas rush and not have any complaints; but why not avoid them as far as this is possible?

You must adopt a proper system of conducting things. Every order, whether it is a cash sale or charged, should be booked with full instructions as to delivery. Wax paper envelopes will keep cards clean and dry and should be securely fastened. The larger your business grows the more necessary is a proper system of taking care of the filling of the orders, and each man has to work out for himself the way that is best for his own requirements.

\section{Keeping a Regord Afterward}

There is nothing you can do which will help you more to prepare and arrange for the next Christmas than to devote a little time to putting down approximately the business you did and the stock and material used for the one just past. You can easily look up just how many cases of Holly you used, how many wreaths were disposed of, how many pounds of Boxwood were bought, how many Cyclamens, Poinsettias, Begonias and other plants were used and how many Roses, Carnations, Violets, etc.; what you had too much of, and what you were short on. Make a complete record of every detail and place it where you can find it. Everything is fresh in your mind now, but it won't be long; you have to think of preparing for St. Valentine's Day, Easter and another Spring to come. 
So if you have a memorandum of all this year's details, it will be much easier to place your orders for next year, to prepare and grow on stock you were short of this season and perhaps to cut down on other items; you won't have to guess at how many cases of Holly, Winterberries or Wild Smilax to order or the number of wreaths to make up.

\section{Made-Up Ghristmas Baskets}

The illustrations in connection with these Christmas notes are not intended to show what elaborate and expensive arrangements can be created, but are rather to give an idea of what can be done with so-called inexpensive or ordinary stock with the help of baskets and pot-covers.

A single Roman Hyacinth doesn't mean much, nor do three of them planted in a pot; but when you add a few small table ferns, or Asparagus plumosus, a little Boxwood and Winterberries, and place the pot in an inexpensive basket with a touch of red ribbon, you behold a most attractive Christmas arrangement. The same holds good with a Chinese, obconica or malacoides Primula, a small Cyclamen, Celestial Pepper, Cleveland Cherry or anything else; any of these plants needs a holiday dress in order to be attractive, and often twenty per cent additional cost per plant in the matter of dressing it up will increase its retail value seventy-five or one hundred per cent.

Handle all the expensive and beautiful large specimen flowering and berried plants you can dispose of, and make up baskets to sell at a high price; use Begonias, Oranges, Ericas and large Cyclamens. But also cater to those who cannot afford to spend fifteen, twenty or fifty dollars for a basket. Every florist located in the country has to prepare for this kind of trade, and even with not the best facilities he can himself grow quite a variety of the plants which, while individually not perfect, are nevertheless nicely adapted for basket work.

Around Christmas the demand for made-up baskets is especially strong. Your patrons want more than just a plant; a basket, even if small, filled with an assortment of things appeals more strongly to them. They enter your establishment with the intention of spending a couple of dollars for what they want, but will spend twice that much if the right kind of basket looks good to them. That means that you must carry a good assortment. You often fill a basket which may not suit you exactly in regard to color scheme or arrangement, but, strange to say, it may be the first one a lady selects. You will find another patron choosing and finally deciding to take for five or six dollars a made-up basket consisting of a small Poinsettia, a white Primrose, a Bird's-eye Cherry and a few ferns, 


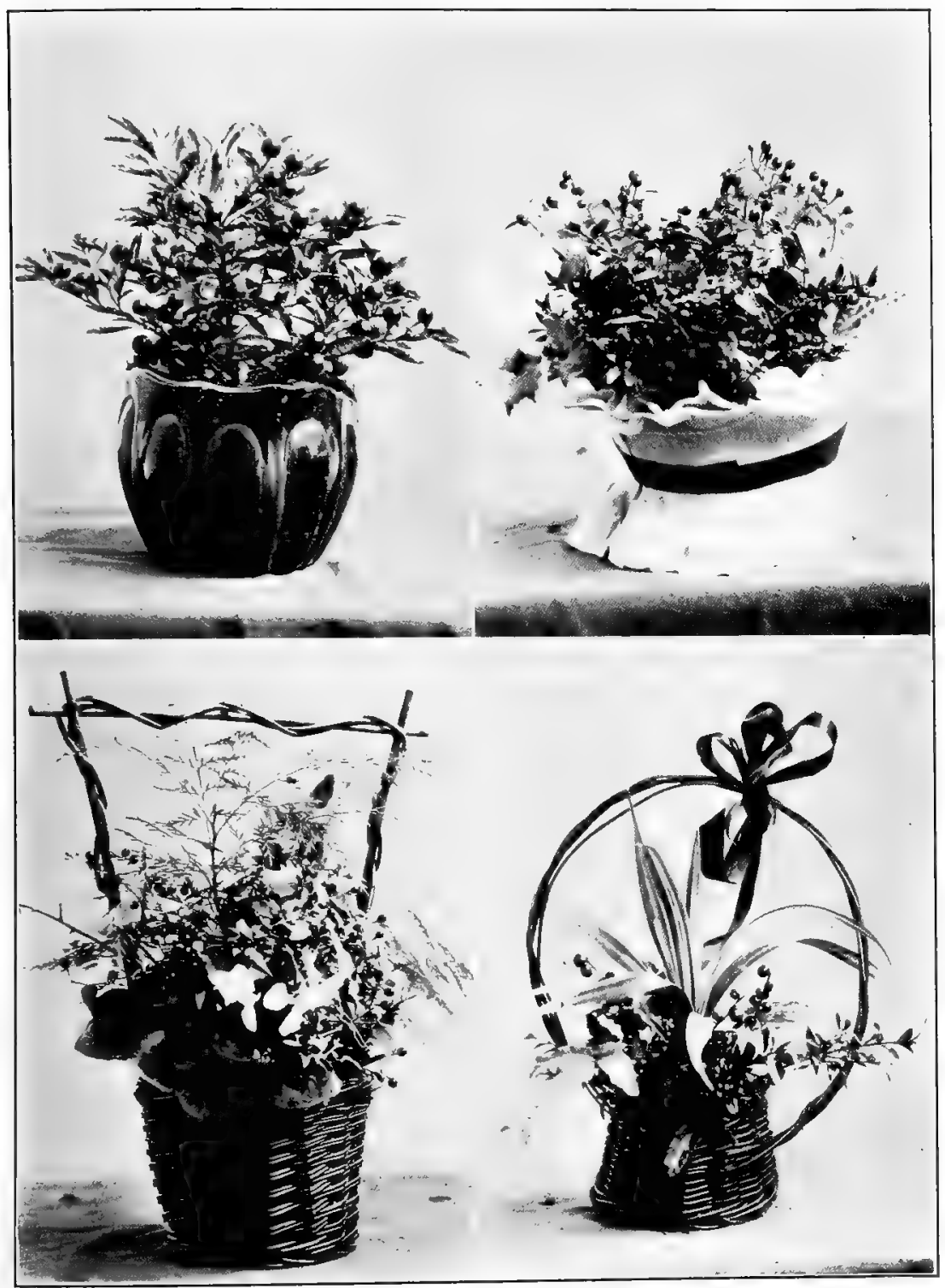

Fig. 55.-Four Christmas Offerings, simple and inexpensive, yet pleasing. Upper left, a well-grown 4-in. Cleveland Cherry in a fifty-cent dark-brown jardinière; upper right, 4-in. Birdseye Pepper in 5-in. half-pot, surrounded with small ferns, Boxwood and Winterberry, and finished off with white crêpe paper cover and green paper band; lower left, two Grevillea robusta, a Celestial Pepper, a 4-in. Cyclamen, three Asparagus plumosus, and some small ferns; lower right, a 5-in. red basket with fiber bow containing a 4-in. Pandanus Veitchï, three variegated Pteris, a little Boxwood and some Winterberries 
instead of a beautiful 7 -in. Gyclamen at its best. It is a good thing to have it that way, and a still better thing if you prepare for it.

One has no trouble hunting up country florists who, around Christmas time, will invest a lot of money in expensive plants, but make no effort whatever to use their own stock in connection with them. They are satisfied with selling a 4-in. Chinese Primula for fifty cents instead of adding twenty-five cents for trimmings in the way of green and berries and a pot-cover and making it a $\$ 1.50$ plant. And as yet they don't take advantage of what there is on hand so as to get the most out of it.

\section{Holly and Holly Wreaths}

The only time of the year when Holly is used by the florist is at Christmas. The man with just a store and no dark, cool place in which to keep his cut Holly often loses more money than he makes in the handling of it; but with the florist who has greenhouses, frames and proper facilities, Holly can play an important part. Not only does the handling of it pay, but usually a customer who buys a few wreaths or loose Holly will also buy other things.

You cannot afford to handle poor Holly. Your stock must be the very best there is obtainable. Let the local grocer or fruit stand handle the other kind. Place your order for Holly with a responsible firm and don't wait until the last minute to have it delivered. Try to have it on hand by the eighth or tenth of December; open and examine every case and give the contents a sprinkling of water, then close them and place them, if possible, in a cool, dark cellar. In that way Holly will keep perfectly for weeks if necessary; but expose it in a dry, hot or sunny place and it will go to pieces in a few hours. Those who have deep coldframes that can be kept free from frost couldn't find a better place for storing it, especially if shutters are placed over the frames to darken the inside.

If you ask your patrons to pay from seventy-five cents up to three, four, or five dollars for Holly wreaths, according to size, you must deliver goods of a superior quality as compared with those usually offered on the street. To do this you should procure the best Holly on the market and handle it in the right way. A good case of Holly will make about thirty-five seventy-five-cent wreaths, besides five or six dollars' worth of selected long branches of loose Holly; but to get such results one must use up everything. You will get some cases full of short branches fit only for wreaths, and others with nothing but long branches, but usually they run half and half. If you have call for selected loose Holly, as soon as you open a case put what good branches there are aside and just use the short stuff for the wreaths; when the case is empty, make up bundles to sell at fifty cents, seventy=five cents and a dollar each. 


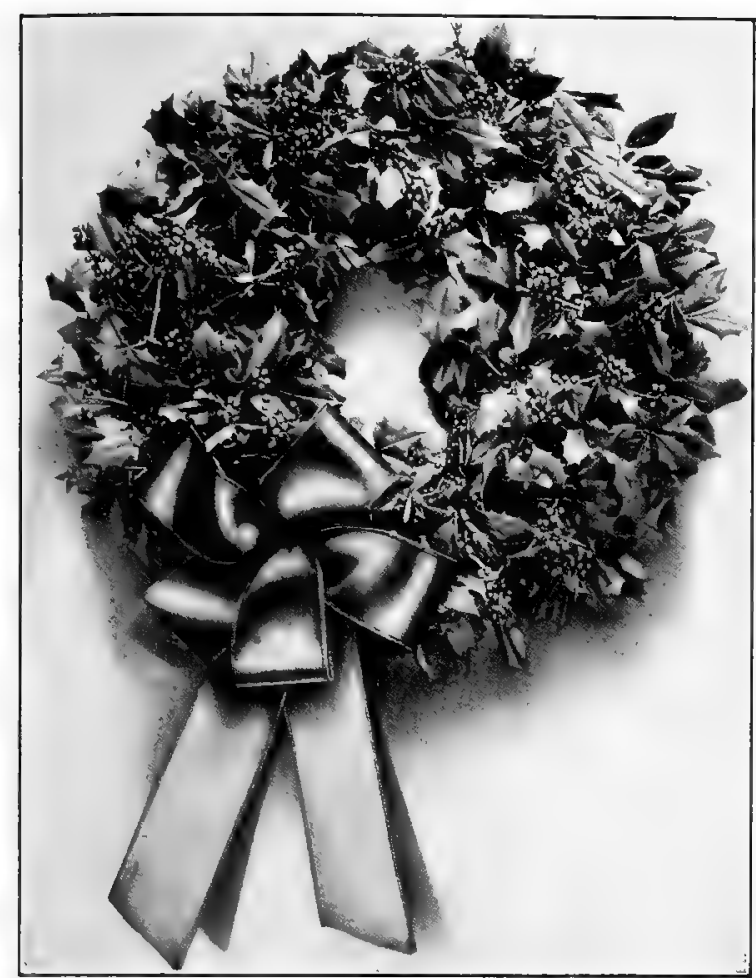

Fig. 56.-A Real Holly Wreath. Many people will prefer one good Holly wreath to a dozen poor ones and it is good policy for the florist to have on display a week or ten days before Christmas a few samples of "real" Holly wreaths to take orders from
Lay the branches all one way, face up, tie them with heavy twine and put them back in the case to be returned to the storage place. All made-up wreaths should also go back if possible, but in the absence of a better place they can go underneath some bench in a cool house where they should be covered with paper.

Twelve-inch wire rings are the right size for ordinary wreaths and No. 3 wire is used for making them. If your patrons are not used to paying more than twenty-five or thirty cents for a wreath, educate them to ask for better ones by showing them the difference. It doesn't take much more material to make a dollar wreath than it does to make one for fifty cents, and it is your business to push the better sort.

\section{Boxwood's InCREASING Importance}

Next in importance to Holly comes Boxwood, which from year to year is being used more extensively around Christmas and, in fact, all Winter long. If you have to buy it by the pound and pay a good price for it, you cannot afford to waste it. Let it lie around in a dry place for a few days and it will be ruined, but if you take proper care of it, stock which you receive about the first of December can be kept in perfect condition until April. As you receive it, take it out of the burlap bags, gather as much as you can in one hand with the stems all even below, and heel it close together in a coldframe; get the stems five or six inches down into the soil if possible, give a good watering and cover the frame either with glass 
on which boards are placed to keep the light out, or use mats and boards. Bring it in as you want it and no faster. In that way you will always have good Boxwood on hand.

Not only for wreaths do we use Boxwood, but often some of the short branches will come in handy as a sort of filler for plant baskets, where it will usually last as long as almost anything else in the arrangement. By its use you can often save expensive ferns or other plants.

\section{Boxwood Balls and Centerpieces}

A Boxwood centerpiece with Winterberries is not only a most appropriate thing for decorating the Christmas dinner table, but if you have several on display a week or so before Christmas some of your patrons will prefer them to cut flowers or flowering plants; while to you the profit will be at least double that on almost anything else you sell.

Make a moss pad about six inches in diameter and three inches high on stiff cardboard, cut the Boxwood in six-inch-long pieces and stick them into the moss pad, with a few nice branches of Winterberries in the center. On the lower side fasten with wire hairpins (such as you use for Magnolia wreaths) a double thickness of wax paper or set the centerpiece on an ordinary plate so that it will not soil the table-cloth. If such a centerpiece is kept in a cool place overnight and sprinkled once in awhile it will last until after New Year's.

Boxwood balls also will often take the place of cut flowers or plants to be offered as gifts. Either purchase the wire frame of a ball about five inches in diameter and fill it with sphagnum moss or make up a ball without the frame and stick it full of Boxwood about four inches in length. An easier way is to stem the Boxwood on toothpicks; after this is completed trim the whole into a perfect ball. But, before you put the green into the moss, attach a 12-in.-long wire so that you will be able to hang it up when finished. A few short Winterberries in the green and a red ribbon fastened onto the wire hanger will make it still more attractive.

\section{Wild Smilax and Other Greens}

It is always well to stock up with Southern or Wild Smilax, for the reason that there is nothing quite so graceful for decorative purposes. This you cannot say of Holly. This green should also be kept in a cool place; but frost will ruin it. If it should freeze -if not frozen too hard-it will come out all right if kept in a dark, cold place afterward and well watered.

There are times when one runs short of Holly-that is, good Holly for decorating-and usually there isn't much trouble in per- 
suading a patron to take Wild Smilax instead, rather than be disappointed.

Years ago Ground Pine was used in great quantites for wreaths and wreathing, and it is still employed for the latter purpose, but not so extensively. Unless you are called upon for extra heavy wreathing, it hardly pays to make it up. A better way is to purchase your requirements already made up. Long-needle Southern Pine tops are useful for decorative work; they often take the place of a valuable palm or fern in a church decoration and cost but a few cents. Almost anything that can be had in the way of decorative greens comes in useful at Christmas time. Every florist should be well stocked with Leucothoë leaves. Asparagus plumosus is of particular value; in small made-up baskets it can be used to fill in bare spots. This is not to say that one should make a practice of using either Boxwood or cut Asparagus in connection with a plant basket, but there are times when it is mighty handy to have both to fall back on.

\section{Handling Flowering and Berried Plants}

Whatever you have to offer in the way of flowering plants, each specimen should be at its very best on December twenty-fifth. It is fine if the plant will still be good for New Year's, but it is the impression it creates on Christmas Day that counts for more than anything else. On that account it is not advisable to have in your own greenhouse many days before you need them plants such as Cincinnati Begonias, Poinsettias and others which were grown by specialists in a temperature of nearly $60 \mathrm{deg}$. Order in good time and have a sample on hand by the middle of December; but bave the balance shipped so as to reach you four or five days before Christmas. Other stock, such as Ardisias, Peppers, Cyclamens, and Ericas, all of which get along in a temperature near the $50 \mathrm{deg}$. point, can be handled without loss and much more easily.

There is hardly any use in naming the few varieties of flowering stock to be had during the Christmas season. Your trade paper will furnish that information, but don't neglect to locate in good time what you will want.

\section{Palms, Fenns and Decorative Foliage Plants}

For a good many years past, growers of select stock in flowering plants have usually sold out clean for Christmas; in fact, the supply has not been equal to the demand-that is, for good stock. Nor does it seem as if in our time these conditions would change, no matter what they may be the rest of the year. The florist who has to purchase his specimen plants should on that account not confine his display to flowering plants alone, but should carry a complete 
assortment of palms, ferns and other so-called decorative foliage plants, stock which will, if not sold for Christmas, be just as valuable afterward.

Flowering and berried plants are not only expensive, but may be a loss if left over. You cannot say that of an Araucaria, a Kentia, a Pandanus Veitchii, or a pretty Dracæna; such plants well cared for, will grow more beautiful, if anything. On the other hand, you will always find among your customers many who may prefer such plants or a beautiful fern to almost anything else; your margin of profit in this case will be as great. Sometimes, when nearly everything in flowers is sold out and you have a nice lot of such plants on hand, there is no trouble in making a sale; but the thing to do from the beginning is to push them as much as your perishable stock. Here, again, a great deal can be done with the help of a few Winterberries, red ribbon and often a red crêpe paper pot-cover to make them still more attractive.

\section{Christmas Bulb Stock}

There are years when it is possible to have a few red and yellow Tulips, Freesias and Trumpet Major Narcissi in flower for Christmas, but Roman Hyacinths, Paperwhites and Grand Soleil d'Or Narcissi are the standbys. All three are not only valuable, but can be had in flower in even the smallest establishment. (See cultural notes in Part Two.) If you grow these plants cool, with plenty of space between them, they can be lifted with care and used in many plant arrangements. An 8-in. fern dish filled with Roman Hyacinths and a 2-in. Asparagus plumosus makes a fine centerpiece for the table

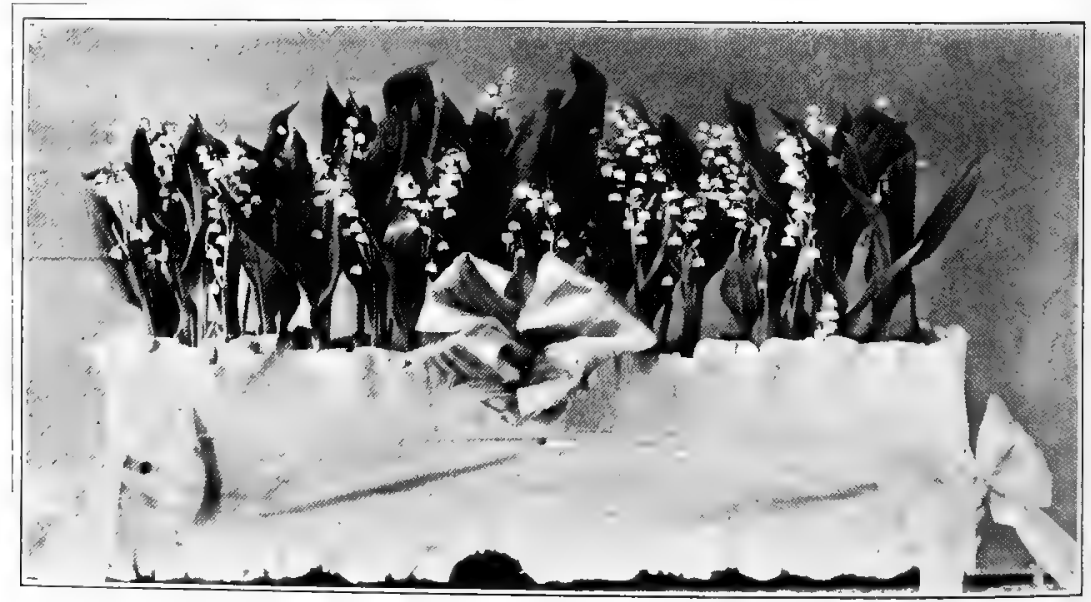

Fig. 57.-A Flower Gift For a Winter Holiday. Lilies of the Valley are always attractive and even without greens or other flowers in a box with crêpe paper cover and harmonizing ribbon they make a suitable Christmas or Easter offering 
and an endless assortment of small as well as large baskets can be made up with them used in connection with a few other plants. What more pleasing combination could you imagine than a pan or low basket filled with Cincinnati or Chatelaine Begonias, small Adiantums and Roman Hyacinths?

Not all of your patrons will want Paperwhite Narcissi in their baskets; many object to them because of their strong odor, but you can sell a lot of them in plant arrangements just the same. Fill even 6- and 8-in. bulb pans, and put a border of Adiantum or Asparagus around them. Do the same with the yellow Narcissi-Grand Soleil d'Or-or the double Romans. If you have them, you can sell them and make them pay; but obviously you cannot do so if you don't carry them in the first place,

\section{Cut Flowers at Christmas}

Cut flowers are the most perishable of all your Christmas stock and the out-of-town florist in particular has to be careful both in taking orders for them and in handling them. There is always more or less trouble and disappointment in shipping flowers a long distance, especially Carnations, and if stock is on the road for several days, it doesn't have to be "pickled" to start with in order to "go to sleep" by the time you deliver it.

I don't believe that you should discourage a demand for cut flowers, but it is better to disappoint a patron wishing to place an order, for say, red Carnations that you cannot supply than to take the order, and later on, disappoint him. It is easy to take an order for cut flowers for Christmas and quite another thing to fill that order properly. Never take an order for cut flowers unless you are reasonably sure that you can fill it; know beforehand where and how to get the flowers.

The man located near the large city where he can in a couple of hours obtain almost anything he wants, or whatever there is on the market, has the advantage over the out-of-town man. On the other hand, Christmas is a time when flowering plants and made-up baskets are more used in preference to cut flowers for gifts than for any other special occasion.

The high price of cut flowers around the holidays, their perishable nature and the difficulty in obtaining what is wanted, should make every country florist careful in taking and filling orders for them and in doing what he can to get his patrons to make use of plants if possible. You cannot fill an order calling for a Violet, Sweet Pea or Valley corsage with a Poinsettia plant, but there are times when a buyer is undecided whether to send as a gift red Roses, Carnations or a nice plant. That is the time for you to talk plants. 
Immortelles, Everlastings, Mistletoe, Etc.

The florist with a good stock of plants and flowers doesn't need to resort to artificial and dried materials, yet they are displayed around the holidays even by some of the better city florists, who will make up baskets of Ruscus, Statice and Everlastings because there are always some who will purchase them. If such an arrangement can be sold at a fair profit, why not do it? If your trade calls for Red Ruscus, and wreaths made of Frieze, Ruscus and Statice, by all means have them on hand. Again, it may happen that some of your patrons will want a few wreaths for decorating graves. Be prepared for them. A Boxwood, Magnolia or Frieze wreath will usually fill the bill, and if you have a limited number made up, a few bunches of Immortelles often come in very handy. You may run short on red berries for the decoration of a Boxwood wreath or something else, and in this case Immortelles will help out.

Mistletoe we must always carry. The best plan is to go over the contents of a box and make it up into bunches ranging in value from 50c. to $\$ 1$. Tie each neatly with a narrow red fiber ribbon and bow so it is ready to hang up. This again will save you valuable time when filling your orders.

\section{EASTER AND ITS ACTIVITIES}

To the average retail grower Easter, to some extent, means more than Christmas. Not only is it one of the greatest flower days we have, but also a good deal of the stock used then can be grown on even in a moderate sized establishment, and that is what counts.

FOR Easter, well-grown Marguerites-whether specimen plants in 6- or 8-in. pots or made-up pans of $21 / 2$ - or $31 / 2$-in. plants in bloom - are most attractive. You can get similar results with $31 / 2$-in. Geraniums, in either the white or the pink shades. Put five or six into an 8-in. pan and add a few Asparagus plumosus vines and a neat potcover. The same is true of Ageratum and Begonia Gloire de Chatelaine. There are times when your patrons will prefer such an arrangement to almost anything else.

Large Pansy plants brought in from a coldframe a month or so before and planted on a bench in a 50-deg. house, will be in full bloom Easter week, and if you had a good strain of seed, and kept the colors separate, you can make up stunning pans which will sell readily. Forget-me-nots can be treated the same way and even English Daisies (Polyanthus Primroses) kept in a frame or a coldhouse all Winter should also be a mass of flowers at Easter week, and can be potted up. Late-sown Primula obconica will usually be-loaded with flowers at that time and the same with Genistas, which should be kept in a coldhouse up to three weeks or so before Easter. 
Bleeding Hearts potted up during January, kept in a cool house and given $55 \mathrm{deg}$. about twenty-one days before Easter will be in full bloom, by then and the same with the variegated Funkia.

All the above-mentioned stock can be gotten ready by practically every florist. Besides these things and, with many, of even greater importance, is the bulbous stock. Easter week is the time to dispose of pans of single and double Tulips, miniature Hyacinths, Daffodils and the many other fine varieties of Narcissi. If Easter doesn't come too early the Darwins are at their best, not only in pans, but also to cut from, and this holds good with the Narcissi and all the other

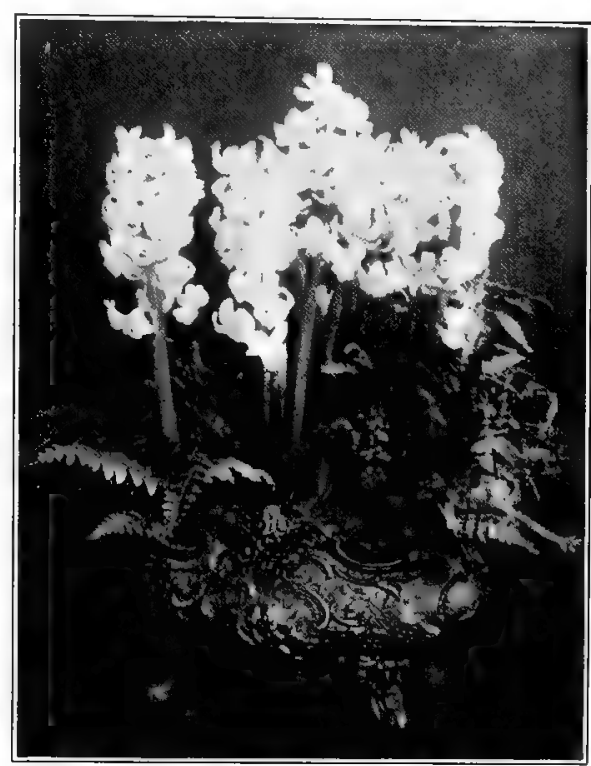

Fig. 58.-Hyacinths For Easter. You can sell more Hyacinths during Easter week than during the three months previous, but you should try to have them at their best just on Easter Sunday and not a week beforehand

Tulips. By planting Freesias in dishes during December and carrying them in a house just a little above freezing up to five weeks or so before Easter, you can have them all in flower.

- Dutch bulb stock, however, when timed properly can be had at its best and in greater variety than at any other time of the year. As I mention under Dutch bulb stock, elsewhere, it pays any retail grower who looks forward to a big Easter business to keep the flats and pans filled with Dutch bulb stock intended for that day separate from those that are going to be forced during Winter. You cannot afford to depend upon what is left being good enough for Easter, and of all the stock you purchase for that day, none is more subject to prevailing weather conditions, or will suffer more when on the road several days, than Hyacinths, Tulips or Narcissi in pots.

There are seașons when, with a forward Spring and Easter coming on, late date bulb stock is past its best, but as a rule it is among the most important of Easter plant materials. This is true not so much in the case of the large city florist, perhaps, who has just a store, is altogether dependent on the out-of-town grower to ship him the stock, and is without proper facilities for carrying it, as in the case of retail growers in the smaller cities and towns who 
hầ $\overline{\text { ways }}$ and means of properly caring for their plants so as to have them just at their best for Easter Sunday.

\section{Preparations for Easter}

Perhaps as important as anything, besides having an Easter display, is to provide proper facilities for keeping the flowering pot plants such as Roses, Rhododendrons, Azaleas, Hydrangeas, Lilies, etc., in good shape. You must have a place where plants can be kept, if' found necessary, in a cool, shaded position. There the flowers of in a hot, sunny house. I have yet to go through an Easter season in which it didn't happen that, just a few days or maybe a week or hóre before Easter; a hot, windy spell set in. That meant getting bits y and moving things to cooler quarters. It helps a batch of late Lilies perhaps, but other stock, if left unprotected, would surely

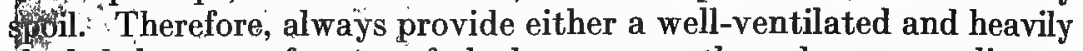
shaded house, a frostproof shed or some other place, according to your needs, to properly take care of your plants. For bulb stock a deep coldframe is usually an ideal place to keep the flats and pans in good condition; such a frame can be shaded and ventilated to best suit the stock.

What I have said about the Christmas rush is equally true in regard to preparing for Easter-you want to be well supplied with

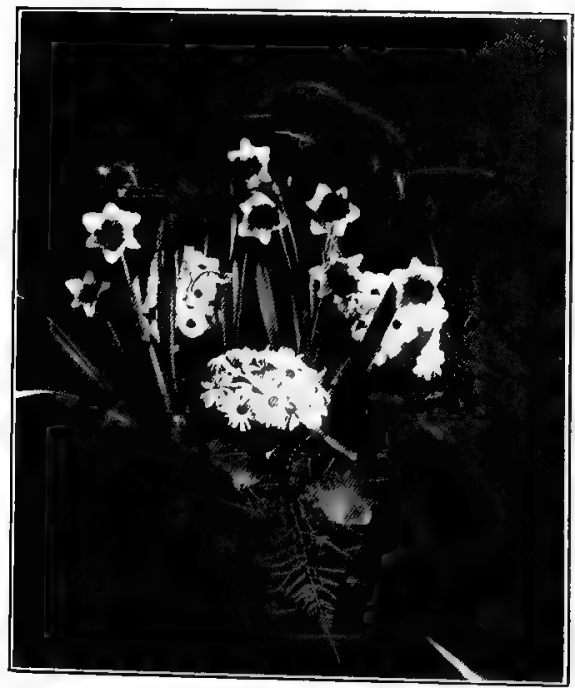

Fig. 59.-ANother TASTEFUL EASTER ARRangement. Narcissus Victoria and Cinerarias can both be grown for Easter by even the smallest grower and then used most effectively in such a basket arrangement as is illustrated here everything necessary for doing business. Baskets, hampers, pot-covers and ribbon play a more important part today than ever. It is the way some plants are dressed up that sells them. Seeing what the big fellow in the large city does is a good way to get new ideas, for people want something different, some new creation and these usually come from the large cities. Not that the city florist is so much smarter than his brother from the country, but competition and the fact that he devotes his entire time to the selling end of the business make the city florist naturally a leader when it comes to a floral arrangement or dressing up a plant for the counter. It is 
from him that we, located far away from the larger cities, can get the best and the newest ideas and keep ourselves up to date.

\section{Simplest Stock Holds Large Possibilities}

What one might look upon as the simplest or most common flowers, properly displayed, will sell now. Geraniums, Pansies, Forget-me-nots or anything else you couldn't sell the Sunday. after, will go like hot cakes on Easter, if properly displayed. Keep up the show until the last minute. Advertise. Let people know that Easter is "coming and that flowers and plants are the proper things to help celebrate the occasion with. Push pot plants, but also be well supplied with cut flowers, quite a few of which may be grown on at home. Hëre again Dutch bulb stock counts for a great deal.

The Darwin Tulips should be at their best and when we once have Rev. Ewbank and Clara Butt to offer, it is a hard task to move any of the early varieties of other Tulips, with the exception of the double sorts. Couronne d'Or and Murillo are among the finest of the eight or ten good ones available. Long-stemmed Daffodils and Emperor Narcissi are always good sellers, so are Poet's Narcissi or any of the other small-flowering varieties, some of which may be grown outdoors in frames, or in beds with temporary frames and sashes over them.

In coldhouse crops there may be had the Snapdragons, Sweet Peas, Calendulas, Lupines and Stocks. I have hardly mentioned the Lilies for the reason that, in my opinion, the average small florist is better off purchasing his requirements in bud and bloom from the specialist than trying to grow his own. The same holds good with the most popular of all Easter plants-the Rambler Roses, the Hydrangeas, the Bougainvilleas, the Ericas and other stock requiring special attention.

No man in the business of selling at retail the stock he grows can grow all he needs. There are enough other things to take up his time and with which he can succeed by giving them just ordinary treatment.

With every florist Easter should prove a greater flowèr day each year. It is well worth while to prepare for it monthis ahead and to keep a correct record of all that is sold each year in order to know just how to prepare for the next one.

\section{MEMORIẢL DAY}

MEMORIAL DAY has always been the most important of all holidays for the florist located near a cemetery and there is but little of value that can be said to him or that he doesn't already know. But this day, like all other flower days of the year, seems to become 


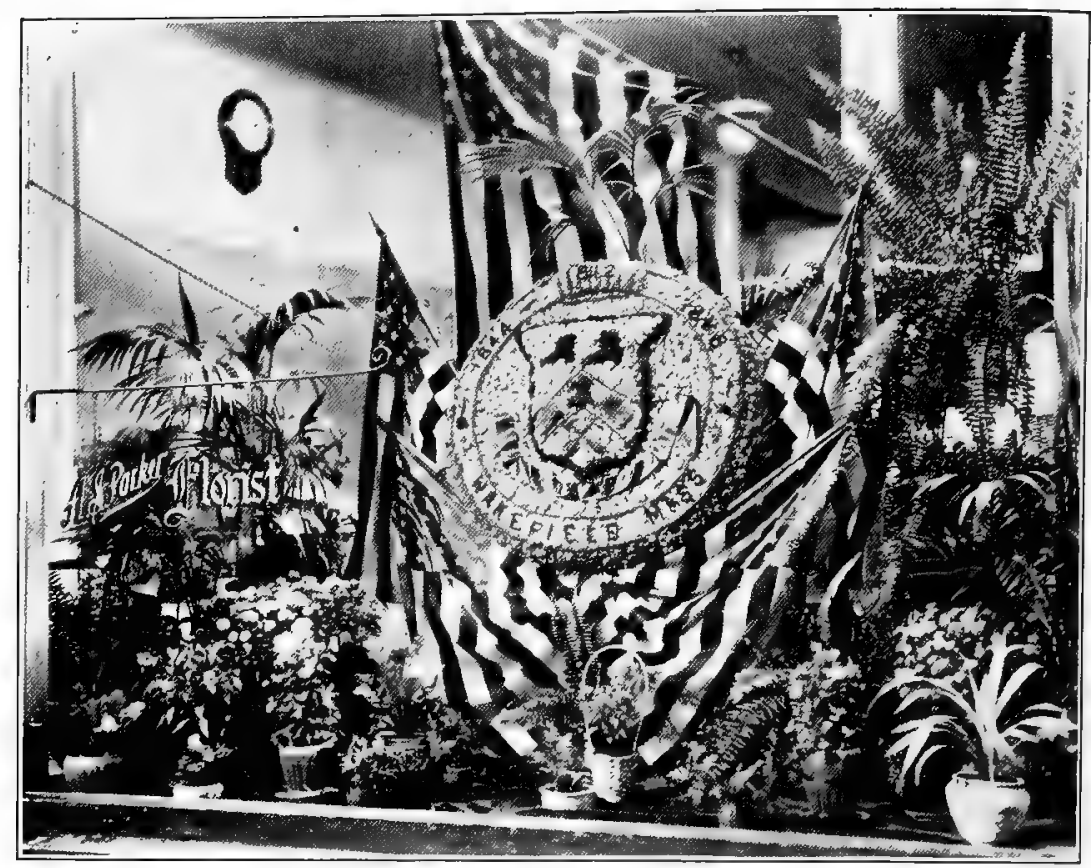

Fig. 60.-A Window for Memorial Day. Especially around Memorial Day will an appropriate window decoration prove a good investment. For it is bound to attract attention and constantly reminds the passerby to use flowers in honoring the dead and in remembering the living

of more importance each year even with those florists not located within miles of a cemetery.

The World War brought about not only a more patriotic way of observing Memorial Day, but also, as part of it, more general decorating of the graves of departed ones with flowers than ever before. More and more do we set the day aside to the memory of loved ones, and there is absolutely nothing that can take the place of flowers to help do this. At present it is up to the florist not only to keep this spirit alive, but to encourage it.

In every community there are naturally people who have graves to decorate, and cut flowers and plants are wanted to do it with. This means that you should let everybody know that you have them. It isn't enough that people know about you; you should let them know more about you. Call their attention to what Memorial Day really stands for and that you are ready to fill every order for plants, cut flowers, wreaths, sprays or anything else suitable for the occasion. Offer suggestions, and have a few neatly made-up Magnolia or Galax wreaths on hand. 
You don't want to take business away from the fellow across from the cemetery gate and you are not doing it by advertising. Rather are you helping him as well as yourself by making people buy flowers who hadn't thought of it until you called their attention to it. You don't need to live close to a cemetery in order to profit by Memorial Day. You can sell stock many miles away from one and have your customers take it with them. You can also take all kinds of orders for cut flowers or plants and have them filled by telegraph, that is, if you advertise your ability to do so. In other words, you can have Memorial Day go by the same as any other week day of the season, or you can make it one of the great flower days of the year. It is up to you.

There is hardly any use in going over the long list of desirable stock one should carry for Memorial Day. Every florist who carries bedding stock carries, at the same time, the right kind of stock to decorate a grave with. Only, as with Geraniums, Heliotropes, Fuchsias and Petunias, it pays to have extra large stock, commanding higher prices than ordinary stock. You will want big plants in full bloom; all foliage plants are suitable and in demand. The more people see of flowers and plants, the more they will buy and use them, and the greater May 30th will become as a flower day.

\section{MOTHER'S DAY}

IT IS hardly necessary to call attention to the importance of Mother's Day. Every one knows that this is the latest addition to the list of great flower days, yet in some instances it has already outstripped Christmas or Easter. Nevertheless, only a small percentage of the many millions of human beings in this world in which flowers are sold, each one of whom has a mother to remember, knows about the day and its real significance.

What we are doing today in the way of business for Mother's Day is only a starter. We have only just begun. Don't worry about stock being too high or people using artificial flowers. What is wanted at present and no doubt will be for a long time to come, is someone to produce the stock to supply the ever-increasing demand. Supply and demand will determine the price at which flowers for that day are sold. I am sure that every retailer is satisfied to sell for a fair price if he can obtain his flowers at a fair price. But if the supply isn't there and he has to pay a premium in order to obtain what he must have to fill his orders with, he has to charge accordingly.

Mother's Day coming in early May gives even the small retail grower a chance to grow on a good part of his requirements on his own place, and this means increased profits for him. 


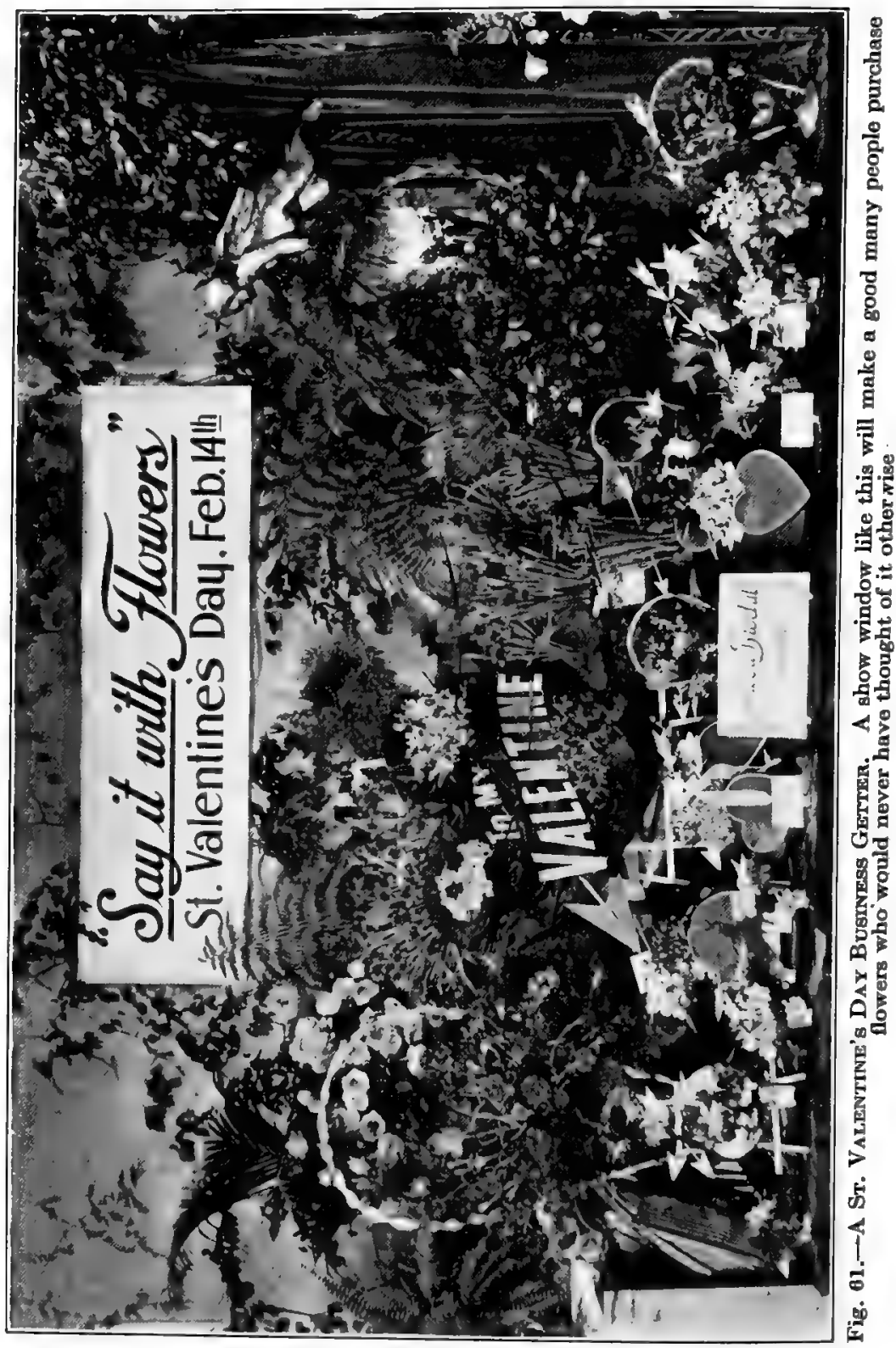




\section{Wide Range of Stock for the Segond Sunday in May}

Almost anything in the line of such stock as sells for Mother's Day-Sweet Peas, Snapdragons, Calendulas, annual Larkspur, Lupines, Stocks, Schizanthus, Gladioli, double Cornflowers, Darwin Tulips, Forget-me-nots, Pansies, etc.-can be had without much trouble. Not only that, but quite a number of bedding plants can be disposed of. Anything in flower will find a ready market and you can obtain twice as much for a well-grown Geranium in bloom that day as you can three weeks after. Many people will not object to paying $\$ 1.50$ for a pan with three Geraniums in it and a crêpe paper pot-cover, whereas they will refuse to pay that much for six Carnations, on which there is nothing like the same profit for the man who has to purchase his flowers in the wholesale market and pay fifteen or eighteen dollars per 100. You can make up attractive pans of Gloire de Chatelaine Begonias with plants out of your bedding stock in $31 / 2 \mathrm{~s}$ and the same holds good with dwarf Ageratums. There is no reason why you can't have tuberous-rooted Begonias in full bloom at that time from bulbs started in early February or even later. The large fringed Petunias are good and Fuchsias sell well. Hydrangeas kept in a 50-deg. house will not come in for Easter, but will be at their best in early May and are fine for those wanting a more expensive plant. The same holds good with Baby Rambler Roses. Instead of trying to get them in for Easter, with not the best of heating facilities, why not let them come along for Mother's Day when there is demand for them and a shortage of such stock. Overcome the shortage of cut flowers by working up a stock of flowering plants. People with limited means and who have little gardens will buy almost anything in the line of bedding stock for Mother's Day to be planted out later on. With houses that can be kept at 50 deg. during cold weather, formosum Lilies can be had in bloom by early May and will bring as good if not better prices than at Easter.

Pansies sell well, particularly if you make up inexpensive baskets with them. In fact; they are among the very best things to have. Get baskets of the proper shades and fill each one solid with just one color-yellow, blue, or white. Myosotis Victoria has a dwarf, compact habit of growth and large blue flowers and gives ideal pot plants. They will be in full bloom in the coldframes by the first of May and don't mind the lifting at all. The above doesn't nearly cover all the stock that sells readily at Mother's Day, but any retail grower can select and grow enough of it to keep him busy.

\section{OTHER FLOWER DAYS}

NEXT perhaps, in importance to Christmas, Easter, Mother's Day and Memorial Day, we have Thanksgiving, St. Valentine's Day and Armistice Day. And there are still other special 


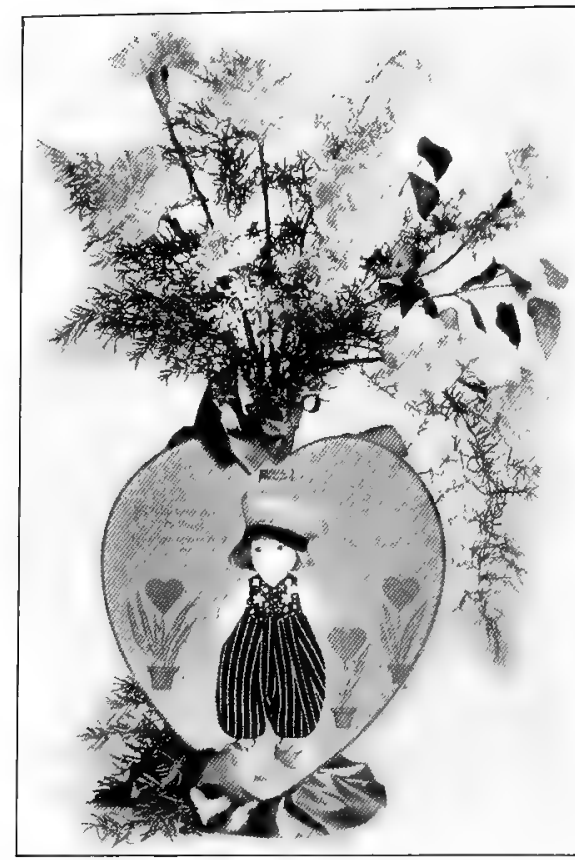

Fig. 62.-A Favor for February 14. St. Valentine's Day is a great flower day, but both country and city florists can make it still greater. Here is a simple, appropriate arrangement of white Carnations, Lilacs and Asparagus-and, of course, a red heart. It is by Max Schling of New York City occasions when flowers and flowering plants can be made to play an important part.

While we are in business there is only one thing to do and that is to keep right on going forward, to keep on doing more business. Each one of us individually and all of us collectively must help push by bringing what we have to offer to the attention of the public. The more we get the public into the habit of making use of flowers, not only for every day in their homes but also for every special occasion that may arise, the less we will need to depend upon funerals and the sadder occasions to supply illustrations of the usefulness of flowers.

To keep on adding more holidays to the calendar may or may not be the wisest thing in the world, but you and I will not be consulted about it. If occasions arise when there is a chance to help celebrate with flowers, it is our place to encourage that sort of observance. We should all do what we can to help celebrate any and every event that has to do with flowers; we should try to make people think of flowers. If possible we should each do something individually that will compare favorably with the idea of "Whose birthday comes this month? Say it with Flowers;" or that of the person who first thought of celebrating one's: own birthday best by sending one's mother a nice box of flowers.

No retail grower, no matter where he is located, should ever let a holiday of any kind pass by without making an effort to get a supply of suitable stock and to let everybody know that flowers and flowering plants are the things to most fittingly celebrate with. 


\section{ALL KINDS OF PLANT MATERIALS FOR THE RETAIL GROWER}

\section{ANNUALS-WHAT THEY ARE AND DO}

$\mathrm{U}$

NDER annuals we class those plants which we grow from seed, whether started in Spring for Summer flowering or later to be grown on to flower under glass during the Winter and Spring months. To the retail grower in particular annuals are of importance and greatly improved varieties are being sent out; as we find out more and more about their cultural requirements under glass, we can make them bring better returns than ever before.

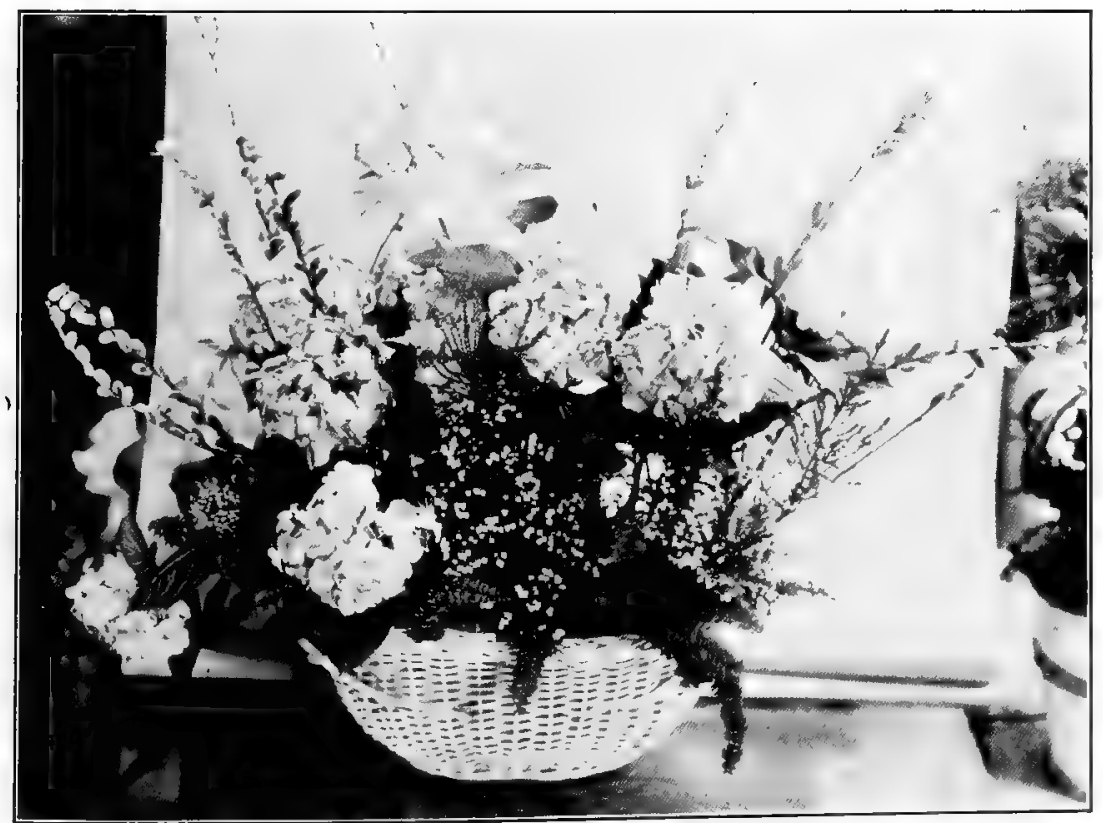

Fig. 63.-A Typicat Easter Combination of Popular Florist's Stock. It includes one blue and one pink French Hydrangea with Erica cupressina, ferns and Pussy Willows in a green and white oval basket trimmed with pink ribbon bows 


\section{Annuals for Summer Flowering}

It cannot always be said that to the retail grower depending on a local trade annuals bring much of a profit in dollars and cents when grown outdoors during Summer; yet, as there is a demand for cut flowers every day and as we no longer consider dull Summer months unavoidable for the man who keeps on pushing and carries a display, cooler full of fresh flowers during July, August and September, annuals ought to be grown.

Your customers don't want Roses and Carnations during Summer for every purpose. For table and house decorations so-called Summer flowers have the call. A basket or vase full of Summer Larkspur, Salpiglossis or Scabiosa is often preferred to the best Roses you carry, and either of these three can be made use of to good advantage in a spray or a floral wreath, if you add a few sprays of the annual Gypsophila. I fully realize that the country florist meets with cases where if he doesn't use Roses, Lilies or some other flowers grown under glass in a pillow or other design, some of his customers who have plenty of Summer flowers in their own gardens feel that they aren't getting their money's worth. But these cases, after all, are only exceptions.

Every florist should have a good-sized space on his grounds devoted to annuals and have it a mass of colors all Summer. It's a great way of advertising. It makes people passing by think of flowers and that is what you want. Make your establishment a show place, it doesn't matter so much what your annuals consist of so long as they make a show and are planted or arranged for the best effect.

At present we grow only a small portion of the many different varieties of desirable annuals and, at that, only the better known ones. The average florist again sifts them down to a very few, but of late years he has been adding more to the list which up to a few years ago usually consisted solely of Asters and Sweet Peas. There was a time when people didn't ask for anything else, but it is different now.

We will here mention some of the more important varieties best adapted for cut flowers: Acroclinium, Ageratum, Antirrhinum, Aster, Calendula, Calliopsis, Candytuft, Carnation (Marguerite), Centaurea, Clarkia, Cosmos, Eschscholtzia, Globe Amaranth, Gaillardia, Gypsophila, Helianthus, Helichrysum, Hunnemannia, Larkspur, Lupine, Marigold, Nasturtium, Salvia, Salpiglossis, Scabiosa, Schizanthus, Sweet Peas, Stocks, Zinnia. 


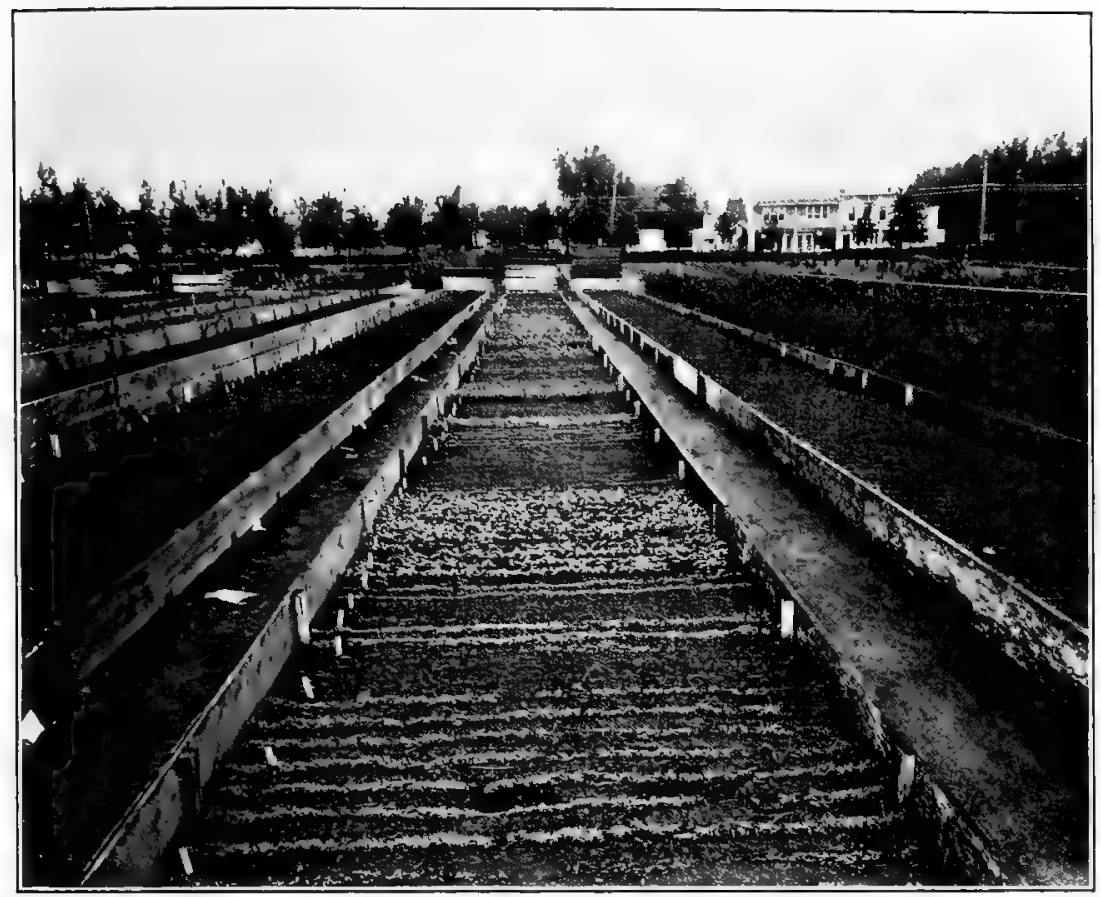

Fig. 64.-Annuals in the Hotbeds in April. When Spring arrives these annuals make as good-yes, better-headway here than they would in the most uptodate greenhouse. Hotbeds and coldframes with plenty of sash for protection are always good investments

\section{Annuals for Flowering Under Glass}

In many instances a florist will struggle along, trying to grow and make profitable a bench of Roses or perhaps giganteum Lilies for Easter, when the same space devoted to Calendulas, Schizanthus or some other annual would require but half the work or expense and bring him in good returns.

If you supply a retail trade you have found out that, as a rule, people during the Winter and Spring months not only don't object to, but often ask for, so-called old-fashioned flowers. They are apt to call them "old-fashioned," comparing them with the American Beauty or Columbia Rose or the latest in Carnations. The most valuable customers you have are not the ones you see around Christmas or at Easter buying $\$ 25$ baskets, but rather those to whom you send each month a statement which is paid promptly. Those who purchase flowers every week may not be a great many, but you can depend upon them. The man who has enough of 
such patronage really doesn't need worry about how good or bad his Christmas or Easter business turns out. A steady demand all through the year is what counts, and to supply this sort of demand you must grow on or carry as great a variety of stock as possible.

Your customers may get tired of Calendulas by August, but let a couple of months go by and they will be just as eager to get them as ever, and that holds good with almost any of the so-called annuals. The retail grower with a bench full of Sweet Peas starting to flower in December has as valuable crop as any Rose he could grow, and so with other things. Even on a small scale you can have Schizanthus in full flower for Christmas and sell them all with a margin of profit as great as, or greater than you could hope to realize out of a bench of red Carnations which you have tried to force by holding the house at $55 \mathrm{deg}$. And so it goes until Spring. You will have a hard job making a customer take Roses when by the end of February you can cut your Lupines grown in a house at 48 deg.; and when the Stocks come into flower in March, everybody wants them.

It isn't that any of these annuals ever can replace either Roses or Carnations, or that those growing Roses or Carnations successfully and making money at it should grow annuals instead; but it will pay those who cannot, for instance, very well handle Roses or ship them so they will arrive in good shape, to go more heavily into annuals. Let them be one of your main crops. Almost all of them can get along in a cool house, and even if you don't cut a great many flowers during Midwinter you are bound to make up for it later on.

\section{Annuals for Growing Under GlaAss}

Perhaps the list of annuals grown extensively under glass comprises only about a half dozen varieties, yet there are a good many more which can be grown successfully. The following list doesn't embrace even half of those available-only those that are best known. It is up to the florist who is interested in annuals to constantly keep on looking for something new or out of the ordinary and when he finds it to try it out. You cannot get too much of an assortment and it always pays to bring forward something the other fellow hasn't got. Never before was the public more anxious and ready to pay well for the unusual; it is just a matter for you to supply it. Let us start the list with the Antirrhinums (Snapdragons). Although they really belong to the perennials and are usually grown from cuttings, we treat them as annuals, and usually class them as such. Other annuals are: Ageratum, Calendula, Calliopsis, Candytuft, Centaurea (among these the double Cornflower, both the blue and the pink, Sweet Sultans and $G$. suaveolens), 
Clarkia, Didiscus, Dimorphotheca, Eschscholtzia, Gaillardia, Gypsophila, Hunnemannia, Larkspur, Lupine, Marigold, Nasturtium, Myosotis, Nemesia, Mignonette, Pansy, Poppy, Salpiglossis, Schizanthus, and Sweet Peas. That makes over two dozen-enough to hold the average florist for awhile.

Notes on the culture of all the above sorts, for both outdoor and indoor growing, will be found under their respective alphabetical headings in Part II of this book.

\section{AQUATIGS}

FOR those who desire to go into the interesting subject of aquatics or water plants more deeply, I cannot do better than refer them to the chapter that treats of it in "Plant Culture," by Geo. W. Oliver. The following notes pertaining to aquatics are written from my own experience and observation and are mainly intended to help the florist located in the smaller town, where most of his customers have either large or small grounds surrounding their homes, see the opportunities in talking Lily-pond, pool or water gardens. Any one of these opens up a paying side line.

The landscape gardener will hardly consider a planting plan fully developed without a water effect of some kind. It tends to make the picture complete and when you are called upon to make suggestions in regard to laying out even a $50-\mathrm{ft}$. lot, you should bear this in mind. Grounds are never too small to have a little water garden, even if it only consists of a half-barrel sunk into the lawn with a Water Lily in it. To my mind, there is nothing more restful than a rustic seat under a spreading tree, overlooking an open sweep of lawn and a pool with its surface partly covered with the leaves and different colored flowers of Nymphæas, with a background of rocks over which a small stream of water finds its way to the pool, and with stately conifers behind it and shrubs and perennials along its sides. This appeals to the tired business man and you should be able not only to describe such a picture to the owner of a home ground, but also to carry it out in reality.

Such pools should in size always be in accordance with the surroundings, but they can be made in endless shapes. The fact that you can successfully grow and flower a Nymphæa in ten inches of good soil in a half-barrel will really give a good idea of what is required in the construction of a pond, pool or water garden. While the so-called Lily pond in :a formal garden needs to be formal in outline to correspond with the garden itself, the average pool with water plants in it should have irregular outlines and be bowl-shaped inside. If constructed of a 6-in. layer of reinforced concrete on six inches of cinders and provided with a drain outlet, even a pool ten feet in. diameter won't crack over Winter. Larger pools, of 


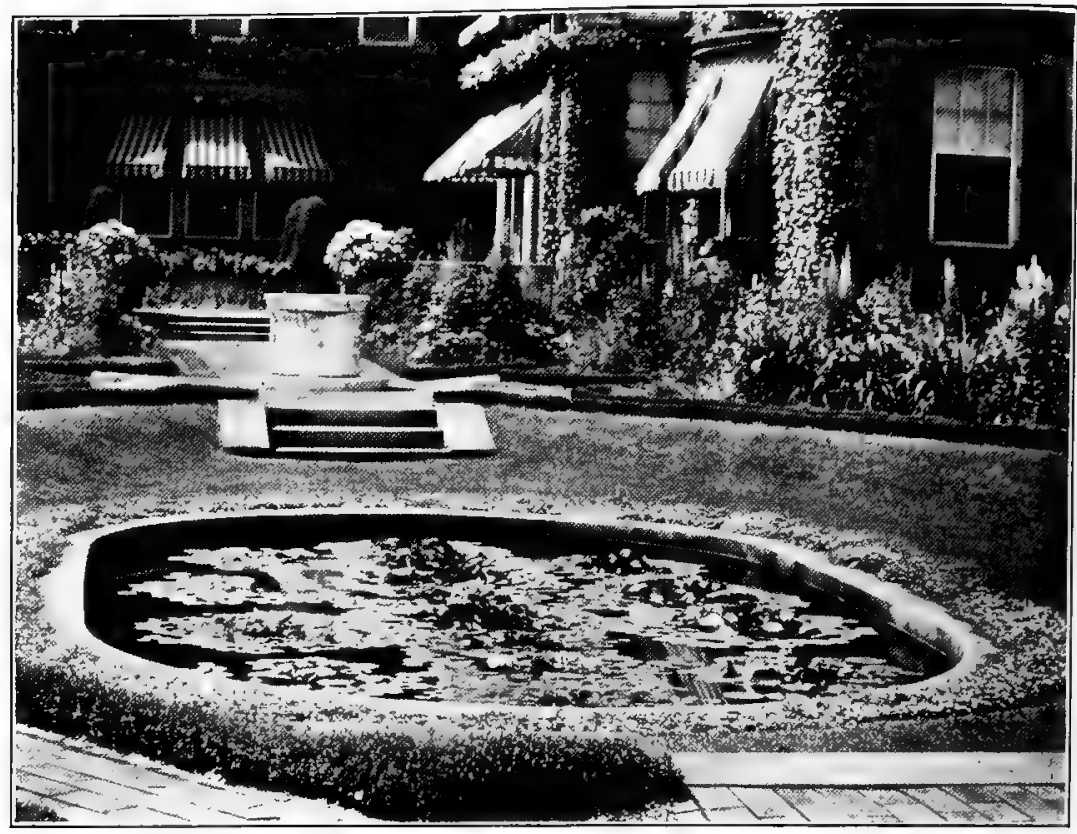

Fig. 65.-How Loveru Is A Lisy Poou! The only thing that could possibly add to this setting would be a light planting around the margin of the pond. Note the fine Hydrangeas in the rear and the Boston Ivy on the building

course, should be of heavier concrete. Draining such a pool in late Fall would mean the loss of whatever Lilies or other aquatics are planted. The only way to avoid this is to cover the entire pool with boards and other material so as to keep the frost out, and the following May. open up the drain, clean out the pool and refill it with fresh water. Usually a pool is made from eighteen to twentyfour inches deep in the center and contains a frame made of 2-in. plank twelve inches wide, ranging in diameter from eighteen inches up. This frame is filled with good soil and the Lilies or whatever else you wish are planted in it.

\section{Water Plants with but Little Water}

There are occasions-we have met them-when an owner will object to two feet of water on account of there being small children who might fall into it. If this difficulty confronts you, a good showing of Lilies can be had in eight or ten inches of water-if you provide a depression for the plants in the center of the pool. For instance, let us take a pool, oval-shaped, say ten feet long by five or six feet wide. When you have completed the excavation and are ready for the cinders, make another hole in the center twelve inches 
deep and large enough around to hold a 12- to 18-in. sewer pipe. Insert the pipe with the bell up; this will give you twelve inches of pipe above the sub-grade (that is, if the pipe is of the usual length, twenty-four inches), six inches of cinders and six inches of concrete. This, when your pool is finished will bring the upper edge of the pipe even with the bottom of the pool. If you put a 4-in. layer of concrete in the bottom of the pipe, it should be watertight. Later on put in ten inches of good soil and decomposed manure in which plant pink and white Nymphæas, one of each, then fill it up with water. You still can, if desired, place 1- by 2-in. wooden strips over the pipe, fitting them into the bell, to prevent any small child from falling into it.

If you have provided the pool with a drain, you can, if you like, let all the water out except what is in the sewer pipe. This can be left alone and whatever hardy Lilies you have planted in it will overwinter nicely as long as you place enough protection over the pipe and at the same time keep the drain of the pool open so that any rain or snow water overflowing the pipe will find a quick outlet.

It hardly pays the florist to try and overwinter tender Water Lilies. You can obtain started plants reasonably enough and when planted out by or around the first of June they will pay for themselves well the first season. There are two things Nymphæas enjoya good soil, as long as their roots are confined, and a warm spot. You cannot grow them in the shade. Always bear in mind that your water garden should be located in a sunny spot, and don't feed it with a constant stream of cold water.

In constructing a Lily pond of any size, you won't be successful with a sandy formation if 'you don't use concrete; but where there is a clay subsoil, by puddling or plastering the bottom and walls of the pond with the stiff clay, it can be made almost watertight as long as water is kept in the pond so as not to allow the sun to bake and crack the clay lining.

\section{A Short List of Water Plants}

The common hardy Water Lily is Nymphæa odorala, of which type there are several improved sorts; $N$. odorata W. B. Shaw, which has large pink, sweet-scented flowers, and $N$. odorata gigantea are among them. Nymphæa gloriosa has deep pink flowers. $N$. marliacea chromatella is a good yellow, and there are several others. If you can provide a Lily pond without too much expense it will pay to grow almost any of the above sorts for cut flowers.

Among the tender Nymphæas there are some beautiful blue and violet-blue kinds, such as $N$. daubenyana, $N$. zanzibariensis and N. pennsylvania. N. zanzibariensis rosea and N. Mrs. G. W. Ward 
are good pink ones. While these flower during the day there are ten or twelve night-blooming ones, among them, $N$. dentata superba, perhaps the largest white Nymphæa grown; $N$. rubra rosea, almost red; N. Geo. Huster, crimson, and $N$. kewensis, a light pink. For the permanent Lily pond the Egyptian Lotus (Nelumbium speciosum), with its yellow flowers, is beautiful.

For pond or pool, if you want a little more variety, fill a few bulb pans with the variegated Iris, or rather Sweet Flag (Acorus japonica variegata). This plant, with its green and white leaves, is always beautiful, hardy, and will do nicely in pots if you cannot plant it out; the same is true of the Umbrella Plant (Cyperus alternifolius) where you cannot use to advantage the taller and heavier growing sort, Cyperus Papyrus. For the shallow pool described above, by all means plant a few Water Poppies (Limnocharis Humboldtii) and a few Water Hyacinths (Eichhornia crassipes major). There are many other desirable plants, not alone those grown in the water, but such as might be planted to great advantage along the edge of a pool. There is no better place than that for the Japanese and German Irises, Pennisetum, Arundo, Myosotis, Ranunculus, Monarda and Eulalia. For those not acquainted with aquatics or the construction of a water garden, it won't be much of a job to find out all about it and then get busy. Get your customers started. A pool with water plants in it needs so little attention during the Summer months, and the day- and night-blooming Nymphæas make such a beautiful display and at the same time one so different from the Geranium or Salvia bed, that you will seldom find anybody disappointed.

You may make some mistakes-that happens even to those who have been at it for many years. But as you go on you will find that there are so many different ways of creating good effects that no two pools you lay out need be alike.

\section{BASKET AND WINDOW BOX PLANTS}

If there has been a decline in the demand for so-called bedding plants, this has been made up many times over in the ever-increasing call for the filling of window and porch boxes, hanging baskets and vases. The average retail grower can do much to make this feature of his work still more popular as well as more profitable.

THE older the residence section of a city or town, the less use our customers living there have for bedding stock, and for this reason: When they started to build there was usually a lack of shade and they planted trees and shrubs for immediate effect. This meant that in a few years the trees became so dense that there was no longer any chance for the flower beds in the lawn to do well and finally they were done away with. This, to an extent, 


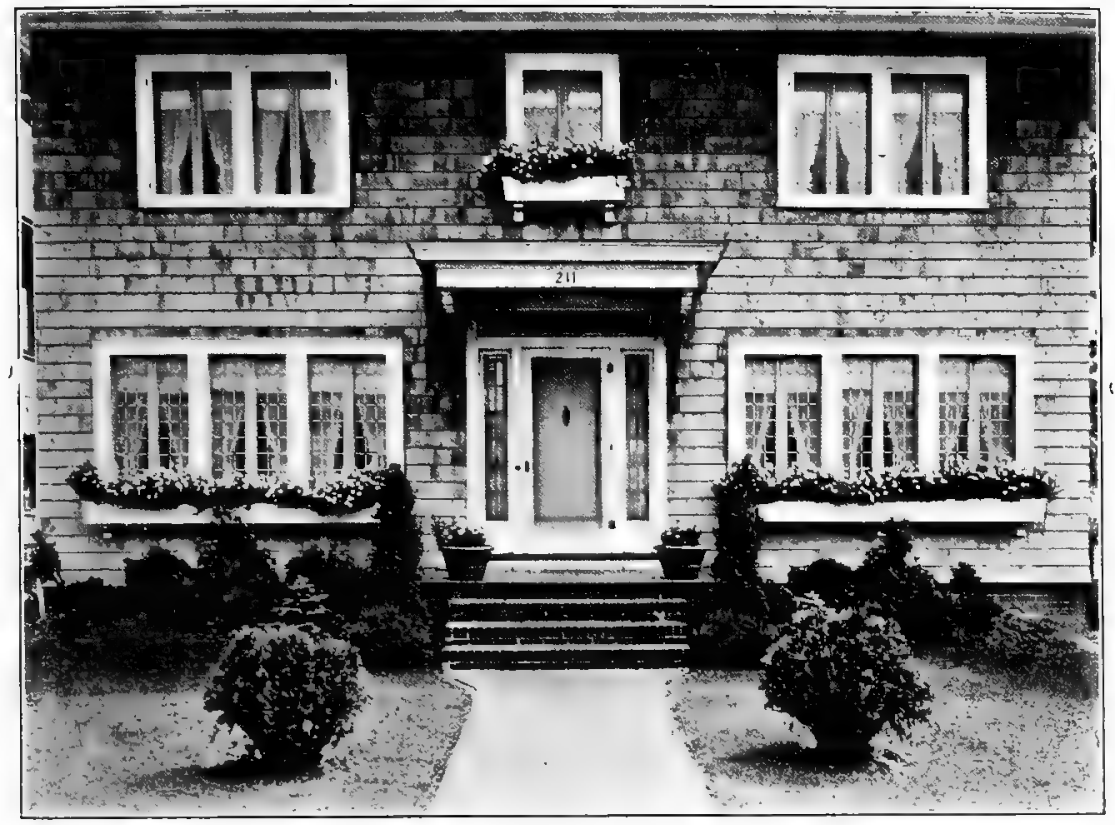

Fig. 66.-The Charm of the Window Box. Trailing plants usually form the most important part of a window or veranda box layout, but one can obtain a most pleasing effect by using Rosy Morn or some other variety of Petunia, which in a short time will completely cover the sides. Note the attractive setting of conifers

helped the demand for window and porch boxes, but far more entitled to credit is the modern architect, who hardly ever designs a country or suburban home without providing in his plan places for window boxes. Often these boxes are made part of the building, being stationary and fitted with liners. Or large concrete vases or urns filled with flowers and trailing plants adorn the terrace or front entrance. This idea was copied by the owner of larger grounds too shady perhaps for flower beds, and with each succeeding year the demand for the filling of window boxes or boxes used for porches increased so that today we are supplying more than ever; indeed, with many florists this demand forms the most important item during the so-called bedding season. It doesn't even stop here, for the demand for window boxes in the business district, not only of large but also of small cities, keeps on increasing from year to year.

This particular phase of the business, by the way, deserves to be pushed by the local florists. It provides a new outlet for stock, and not only that, but it helps more than anything else to beautify the town you live in. Have attractively filled boxes at your own home, at your store or in front of your establishment. Set an example of what can be done and others will follow. Display some 
well-filled baskets and boxes during the Spring months at your greenhouses and you will sell them.

A lot of people who wouldn't want their lawns cut up with beds are willing to have porch boxes filled; again, these can be used to advantage where there really isn't room for beds.

\section{Suitable Stock for Filling}

Whether it is a hanging basket or a porch or window box you have to fill, the main thing is to have large plants to do it with and these in as small pots as possible.

A porch box has to be good looking at the time you deliver it. Your customers don't want to be told that the plants in it may be small but that they soon will grow into big specimens; they want immediate effects, and it is that result, which to many means more than anything else, that must be kept in mind in preparing boxes.

Of heavy stock and bushy Vincas or Ivies, a few plants will fill a box and make it look the way it should; this result cannot be obtained with small plants, no matter how many you use. With hanging baskets it is the same way.

The man who has baskets and boxes to fill during Spring cannot do better than to grow on stock especially for that purpose; it pays him to do so. A large, bushy Geranium in a four-inch pot is worth three or four small ones. If you separate a batch of plants from the general run of stock and give them special attention and plenty of room so as to get them as bushy as possible, you will appreciate them later on.

There is hardly ever too much space in a basket or box and the plant out of the small pot is naturally the one best adapted to do the filling with. Frequently, by feeding your plants, you can prevent extra shifting; a Vinca, if allowed to root through the bottom of a 4-in. pot, doesn't need a shift. Whatever way you do it, avoid having plants in pots over four inches in diameter.

\section{How to Fill a Basket}

In filling hanging baskets for a porch, the main thing is to select plants that can stand the maximum of abuse. Hardly ever do you sell such baskets to a customer where at one time or other during the Summer months they don't get neglected, and with the little soil contained in a 12- or 14-in. wire basket it doesn't take much to ruin the plants. There is nothing quite as hardy for a basket in the way of a trailing plant as the English Ivy-that is, if you can . get enough for the basket, for this Ivy will make it more expensive than Vincas, Glechomas, Maurandias or almost anything else. 
What you use in the center of a basket is, after all, not nearly as important as to have the sides of the basket well covered.

A beautiful effect for a partly shaded porch can be created by filling a basket solid with Fuchsia "Trailing Queen." These Fuchsias will flower all Summer and completely cover the basket by the end of the season. Another good subject is the trailing or weeping Lantana, which is ideal for baskets. Still another is Rosy Morn Petunia, or the new purple one, Balcony Queen. Of course, any of these will prove a success only when properly taken care of.

Nemesia, Thunbergia, Maurandia, Lobelia, double Alyssum, Dusty Miller, Achyranthes, Coleus, Cuphea, and Nierembergiaall are among the general run of plants used for baskets and boxes.

No wire basket should ever be filled and delivered the same day. Do your filling a week or so before and go over your baskets once or twice. The sheet moss along the edges usually settles down with the soil after watering and more should be put on, or, in other words, a regular ridge made along the edge so as to hold the water that the plants may get some good out of it. To send out a basket with the rim above the moss is wrong and before long will cause trouble. Use plenty of moss for lining and only the best of soil, and don't crowd the plants too much. When filling a basket don't start in the center. Get the trailing plants in first-they mean more than anything else; no matter how well filled the center, if you are short on trailing plants, it won't be much of a basket. Be sure to get the sides well covered. You can, if necessary, make use of the bushy plants for the center and have a good looking basket.

In window or porch boxes we use about the same variety of stock as for baskets or vases. Of late years, however, many orders have called for just Ivies and pink or red Geraniums, or Vincas, variegated or green, and perhaps Petunias. A good many people object to a mixture of stock - they want either a red, pink, blue, or white effect, and there are times when it isn't very easy to get them to decide which. However, a box filled with English Ivies, Poitevine Geraniums and a few Boston Ferns or Grevilleas makes as attractive an arrangement as anything you can mention. Rosy Morn Petunias make a wonderful display if not exposed to the broiling. sun all day. It used to be all red Geraniums, but the people got tired of that; at present it is pretty much all pink, but no one can tell when things may change again.

\section{Variety in Window Box Filling}

Those who use only two or three porch boxes usually call for a variety of stock. This means the variegated Vinca along the edge, 
with a touch of blue, such as Lobelia speciosa, perhaps, and a few double Alyssums. The main planting consists of either pink or red Geraniums, some Ageratums, maybe a couple of Marguerites and the same of Dusty Miller. Coleus is not used as much as in former times yet, if given room and if the right colors are selected, it is all right. I doubt whether any plant can stand more and still look presentable than Geraniums, and usually when a customer has had her way for two or three years in selecting just what she wants to suit her taste and color scheme, she is very apt to come back to Geraniums and use them ever afterward.

When filling a box or vase always see to it that you get soil in between the rootballs of the plants. This is really necessary if you want the plants to do well; work it in with your fingers and get in all you can, but always leave the surface a little below the edges to allow for watering. Provide good drainage, use good soil and don't crowd, which is not necessary if you have bushy plants to fill with.

For the center of a vase there is nothing to beat Dracæna indivisa. K position Impatiens is excelloxt in order we have the tuberous Begonias, and even the fancy-reaved Caladiums can be used. As-

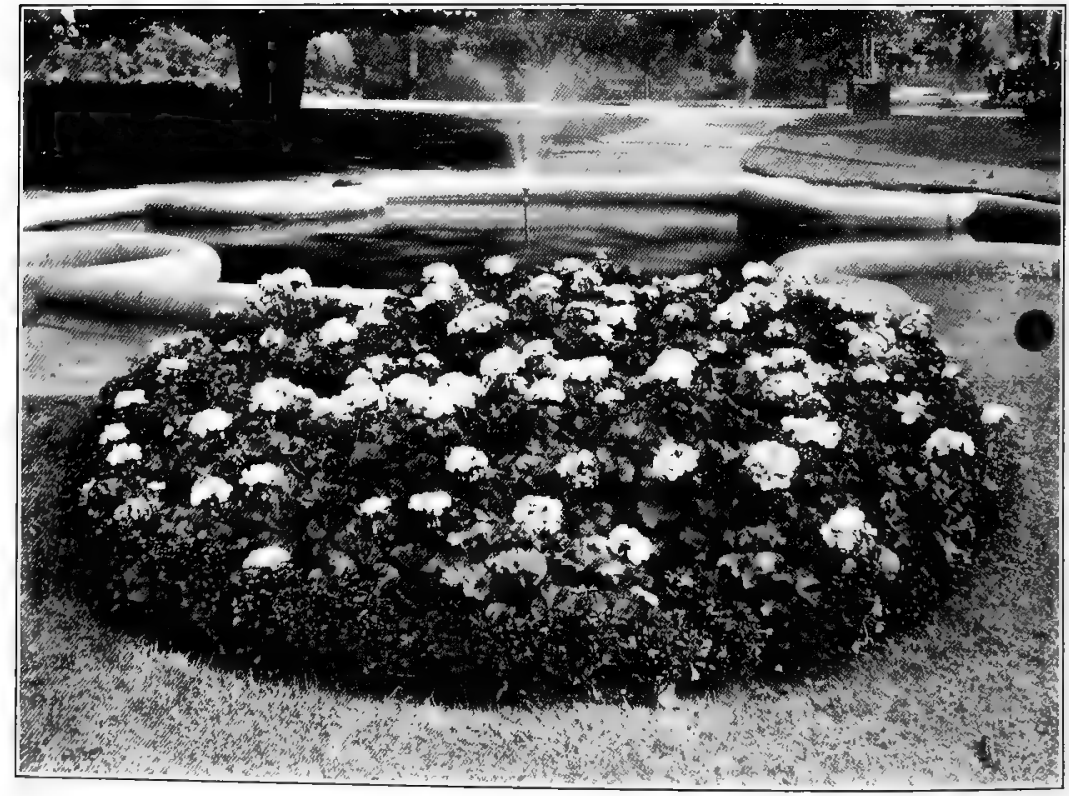

Fig. 67.-Perfection in a Bedonvg Plant. Geranium Jean Viaud is of dwarf habit and produces extra heavy trusses of large flowers of a soft mauve color all Summer long. So long as we can offer such Geraniums as this there will always be a demand for them for bedding, no matter how many other plants there are that might take their place 
paragus Sprengeri does well in the shade and can be used in boxes as well as in baskets.

\section{Evergreens for Window Boxes}

Here, as with all else, you have to get after your prospective customers early in order to land an order for the filling of the frozen window boxes with evergreens for Winter effect.

During the past few years one thing that has put a sort of damper on the taking of such orders has been the sharp advance in the price of such stock. But even more important, to my mind, has been the fact that we don't push hard enough, for there are always plenty of people who wouldn't mind the cost if they were only reminded at the right time, that is, when the boxes should be filled. Another thing, we notice but comparatively few florists who make an attempt to show their customers what can be accomplished, by having an attractive display of such boxes at the entrance of their places of business.

People with means are usually willing to spend a $\rightarrow$ dollars for evergreens or conifers rather than le at bare or empty window boxes until the following Spring; but one has to go after them if he is anxious to land an order. Among the many desirable plants one can make use of for the filling of such boxes we might mention Arborvitæ, Abies, Juniper, Pines, Retinispora, Yew, Gedar and Spruce. All of these are discussed in Part II as well as on pages 204 to 206.

\section{BEDDING STOGK}

UNDER bedding plants we class such stock as is used for the planting of flower beds and borders during the late Spring months. Years ago, planting used to be confined almost entirely to formal beds. It usually meant an open lawn and in the center a round bed filled with red Geraniums and a border of yellow Coleus; or a narrow border running parallel to the walk or graveled drive with red Geraniums down the center and Dusty Miller or Salleroi Geraniums along the edge. With the more extensive use of shrubs and perennials, however, the round bed 'gradually made way for the irregular border. The border along the porch which formerly had Cannas and Salvias in it, is now filled with Spiræa Vanhouttei or Thunberg's Barberry, the open sweep of lawn is no longer cut up with beds, but a planting of evergreens and flowering and ornamental shrubs marks the lines of the lot with maybe a border next to the lawn of Iris, Peonies, Phloxes and Larkspurs. The little beds filled with Vincas or Verbenas disappeared, and for a while it almost seemed as if whenever the modern landscape gardener had the laying out of new grounds, there wasn't a spot left anywhere 
for anything in the bedding plant line. However, that wasn't for long and while we don't use Geraniums as much as we used to, there are many more people who plant something than there were thirty years or more ago. Where there was then one window box there are now ten in the same block. The perennial border was foind to present anything but an attractive appearance at certain times during Summer without the help of so-called annuals or bedding plants'set between the hardy stock.

The formal carpet bedding disappeared, but the modern home ground has a place set aside for a sort of formal garden with narrow beds filled with flowers for cuttings. Here, in former years we used for bedding Verbenas, Heliotrope, Lantana, Ageratum, Alyssum, Candytuft, and Salvia. Even now once in awhile there is planted a border of Geraniums perhaps for no other reason than that they can be depended on to be in flower all through the Summer.

Again we find places where the owner, having had his grounds all made over a few years ago, is tired of so much green and no flowers. He wants us to pick out a spot for a bright Canna bed or one for Geraniums. He thinks he is entitled to a change. Consequently bedding plants are being sold each year in greater' numbers, besides the thousands and tens of thousands of perennials.

\section{The Best Bedding Plants}

For those wanting to start in growing bedding stock, Geraniums in pink and red, with a small proportion of whites, head the list of desirable plants to grow on. Well grown Geraniums in full bloom always sell and while we consider them the best bedders, I believe as many as are planted in beds - if not more - are used today for the filling of window and porch boxes, vases and hanging baskets.

Cannas, while not used as extensively as they should be, are becoming a close second to Geraniums and every retail grower should push them as bedders. Petunias, both double and single sorts; are more grown than ever and with their endless varieties and their usefulness not only as bedders, but also for the filling of boxes, and in the case of the smaller flowering sorts, along the edge of the perennial border, they always make good. Coleus with their highly colored leaves are still used extensively as a border for beds and even as small plants are showy. Every florist usually carries a stock of them during Spring and finds purchasers for all he grows before the bedding season ends.

As for Begonias for bedding, it is always well to have a stock of both the small ever-blooming sorts and the tuberous-rooted, largeflowering ones. Of Heliotrope, of which we have today some excellent sorts, you will want a limited number. Their, beautiful 
colors and the fragrance of the flowers make them desirable. Impatiens, especially in the light and deep salmon pink sorts, is always in demand where a plant is wanted for a shady position; and salable plants, when once you have a stock, are as quickly grown on as Coleus:

Lantanas are more grown for bedding than ever and even if the plants don't flower all Summer in every locality, when they are in full bloom during May and June, you can always sell them. Their colors and shades are quite different from those of anything else we have at that time.

Lobelias, the single as well as the double sorts, make fine border plants for small beds and are easily grown on.

While we should class all Geraniums as Pelargoniums, we don't, but use this name only for such sorts as are not used for bedding but which, while in flower, are by far the showiest. A few of these plants such as Easter Greeting and others always sell at good prices during the bedding season.

Pennisetum longistylum makes a fine border plant for the Canna bed and gives you a change from the usual Salvia or Coleus edging. Salvias are the thing where a glowing mass of red is wanted and you are bound to have customers who prefer them to anything else.

Centaurea gymnocarpa and Pyrethrum aureum are both old favorites as border plants and another is the little silver-leaved Geranium Mme. Salleroi.

Achyranthes and Perilla nankinensis are also old timers in foliage plants for borders and it is well to have a stock of them.

Fuchsias, if planted out in locations that are not too sunny, can be used to advantage for bedding, but you will be able to sell plants in bloom, just because they are so attractive during May and June.

Verbenas are fine bedders when you want low, free-flowering plants and little Vinca rosea and V. alba are a mass of color all Summer. Besides these you will want to carry a few Rose Geraniums, Lemon Verbenas, Cobæa scandens, Maurandias, Feverfews, and Torenias, a good stock of Alternantheras, a few Caladium esculentum, some started Tuberoses, Marguerites, both single and double, double Alyssum, Cuphea, Agefatums, Santolina and Mesembryanthemum. While these don't all belong to the bedding stock group you usually have call for them during the bedding season and often the customer who wants to look through your houses will purchase one or more of all of those plants before he is through, just because you have them on hand. During the bedding season is the only time of the year you will have a chance to sell such material and to my mind it takes but little more work and planning 


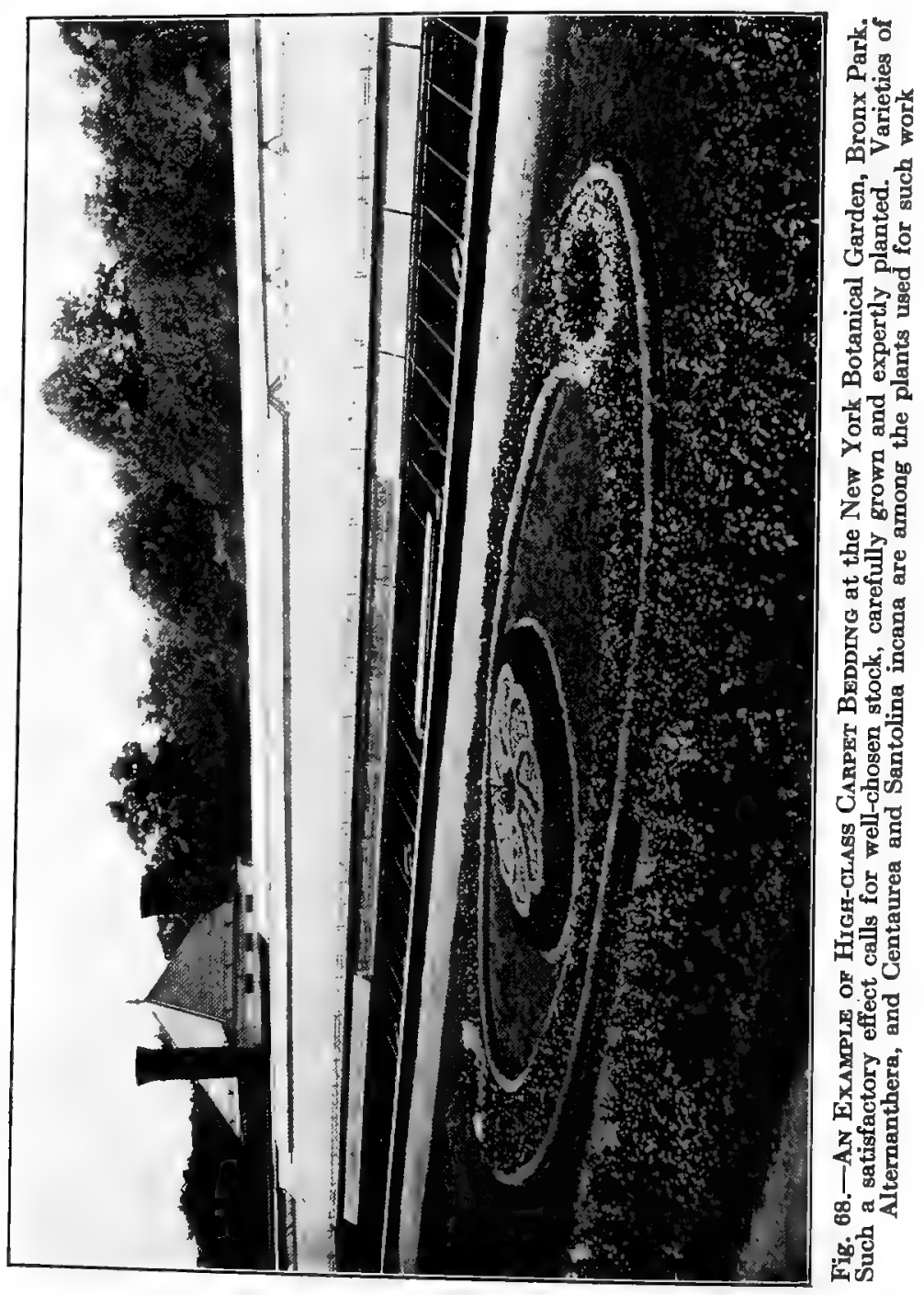


to include all of those plants in the stock you carry as they don't differ much as regards treatment during the Spring months.

\section{BULBS}

No matter how large or small your establishment, how good or poor your facilities for growing cut flowers, so-called Dutch bulb stock can always be made a profitable crop for those who retail what they grow. THE florist who can manage to have a supply of French-grown

Narcissi and Roman Hyacinths in flower from early December on, followed by English and Holland stock, home-grown Freesias, Japan Lilies and California or Florida Callas, can do business every day without much else. While actually not all of these grow from bulbs, the florist usually calls them such. The Dutch bulb stock to which some of the best belong is all grown from bulbs, such as Narcissi, Tulips and Hyacinths.

We no sooner get through with the last Ghrysanthemums than our patrons begin to ask if we haven't some Spring flowers; and they won't grow tired of them for the next six months to come.

\section{Upon What Bulb Success Depends}

With all the many varieties on hand and their easy culture, there isn't any good reason why even the small florist shouldn't make it a point to always have a supply on hand during the Winter months. The following are the main requirements if one would be successful: Plant as early as you can in order to have well-rooted plants before you bring them into heat for forcing. If you have no bulb cellar, bring the flats, pots and pans in which you planted the bulbs, in where you can cover them with 10 or 12 in. of soil. After they have been thoroughly watered put each variety by itself and provide a heavy wooden stake with the name of the variety and the number of bulbs (these stakes should be long enough so that they can be seen above the soil) and an additional heavy layer of strawy manure which should be placed on top of the soil as soon as Winter sets in. Examine the soil every once in awhile, for it should be kept moist at all times and during a dry Fall has to be watered. It is always well to place boards to set the flats or pans on, which will give you a clean bottom when bringing them in later on.

To attempt to force either Hyacinths, Tulips or Narcissi without their being thoroughly pot- or root-bound will always result in failure. For early forcing a dark place and high temperature are needed in order to obtain flowers with reasonably long stems; this condition is usually provided by using space below some bench darkened with boards, heavy paper or bags-the darker the betterand a steady heat of from 70 to $80 \mathrm{deg}$. Overhead heat is to be pre- 


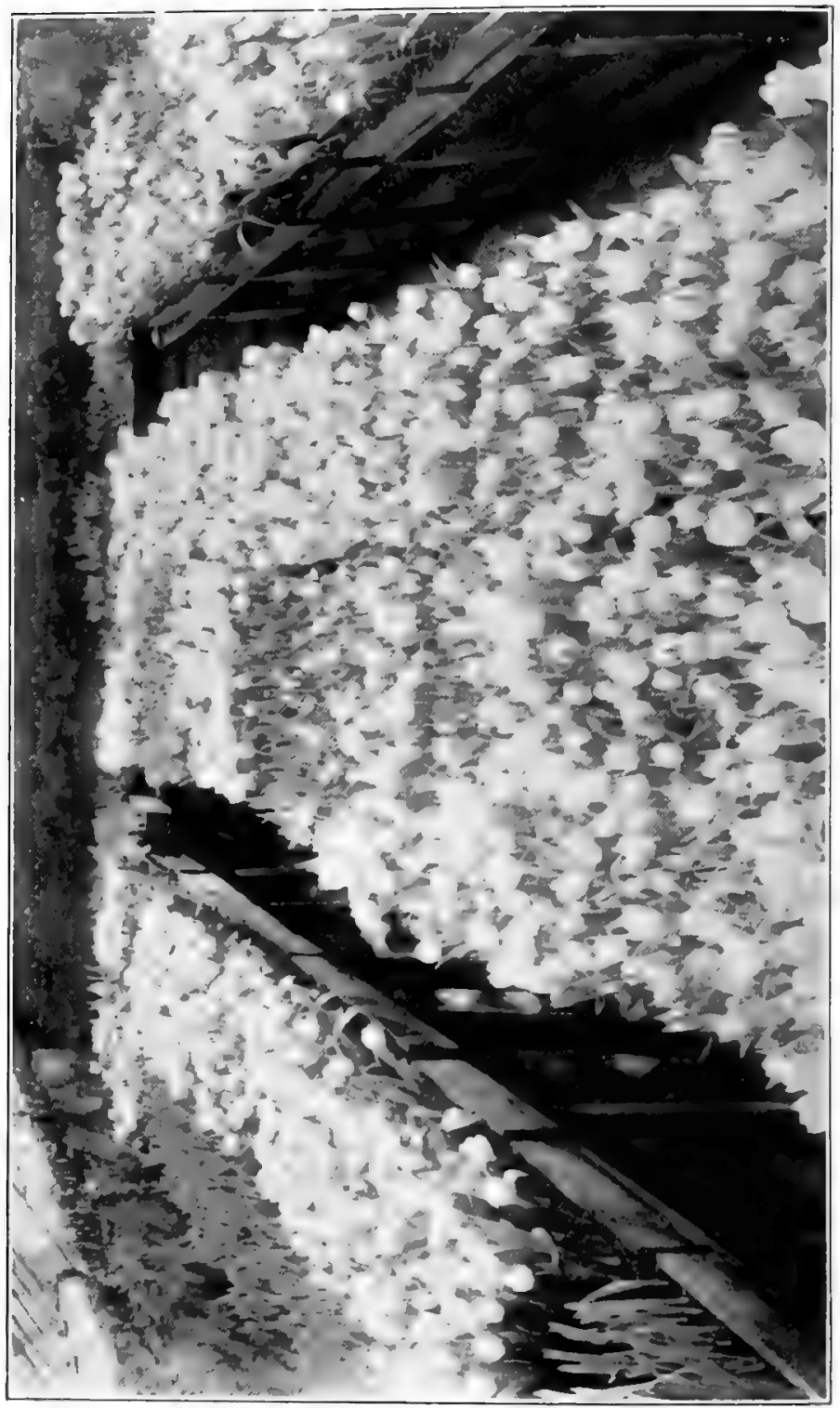


ferred; setting the flats on heating pipes often results in blind buds. Applying water heated to 80 or $90 \mathrm{deg}$. is also of benefit. While such treatment is necessary with stock for December and early January, for later use and as you approach the natural time of flowering, less shading and heat will give good results and the actual time required keeps on getting shorter.

It is always well to go slow in forcing extra early stock when you lack facilities; for example, it doesn't pay to get two dozen good salable flowers out of eighty bulbs planted in a flat, which is a thing that may easily happen with Tulips or Trumpet Major Narcissi; each succeeding week makes the forcing easier and gives you a greater percentage of perfect flowers, but after all, it isn't a hard matter to construct a small forcing frame or box even in the small establishment, and if you start out with well-rooted plants of the right sorts and attend to them properly you have as good a chance to succeed as the man who forces on a large scale.

\section{Making Dutch Bùlbs Pay}

From the time the first Trumpet Major Narcissi comes into bloom until the last Darwin Tulips are cut outdoors in June, the retail grower has use for such flowers every day; there is a demand for this stock and it is one of the crops he can and should grow on, himself, and make pay.

What the bulbs cost isn't of as great importance as the question of arranging matters so as to have a regular supply of flowers right along; this is the whole secret of success with bulb stock from the retail growers' standpoint. Try to avoid the oftmade mistake of having a dozen flats of La Reine Tulips or Golden Spur Narcissi one week and none for the next three weeks. Every time you let that happen you lose money, for in such cases you most likely have more flowers at one time than you know what to do with, and then again, have to buy them when you should cut your own. To have to buy cut bulb stock is a good thing only when you haven't enough of your own, when occasions arise calling for more than you can cut yourself; but not when this is due to poor management on your part in not timing your own properly. From the end of January on it requires in the neighborhood of three weeks to get a flat of Tulips or Narcissi into bloom, from the day it is brought into heat. That is enough to go by in planning at the time of ordering your supply how many of each variety you should plant, so as not to go too heavily into it to start with.

If you arrange it so that, for instance, you have a flat of La Reine. Tulips in good shape to cut from each week, but find weeks when you need three times as many, well and good; buy them. The more you sell the better for you, and you are justified in planting more another year. On the other hand, if some week you don't sell 
all you have of this regular supply, if you cannot make use of them in some way, you are but little out. But to bring in eight, ten, or twelve flats of one variety at a time and trust to good luck to get rid of them, is folly and poor management, and makes the forcing of bulbs unprofitable.

\section{The Gare of Bulb Stock in Flower}

The flowers of bulb stock coming out of the hot or dark forcing box or frame are not ready for the counter, but should be placed in a cool, shaded place for a few days to properly finish and harden off before they are put on display.

In a hot, sunny place almost any of these flowers are gone in a couple of days, but give them a cool, shaded house, a shed where there is no danger of frost, or a cellar with just a little light, and they will be good for a week or ten days. A place to finish the flowers in is as necessary as anything else. Take Murillo Tulips: Freshly brought from below the bench, colorless and soft, they don't mean much, but give them three or four days in a cool place and you have finecolored, beautiful flowers; and so with practically all the others.

\section{Bulb Stock for EAster}

Easter, whether it comes early or late, is a time which to the retail grower of bulb stock means a great deal; it is far too important to figure on using for that week whatever is left to bring in to be forced. If you have a nice lot of Narcissi and Tulips coming in for Easter to cut from, they sell. Pans of Hyacinths, Darwins, double and single Tulips, single and double Narcissi, all in pots and pans, find a ready sale and will make up for other items you may be short of.

Make it a point to push bulb stock for Easter; have enough of it and provide a proper place to keep it in good shape. Instead of working in the dark, plan the previous Fall, mark down just how many miniature Hyacinths are to be grown in pans for Easter, how many large Hyacinths in pots, how many pans of double yellow, pink, and white Tulips, how many pans of different sizes of some of the many beautiful large flowering Narcissi, how many flats of Tulips and Narcissi to cut from, and then plant accordingly. Don't stop there, but separate this stock from your bulbs to be forced during Winter and put them by themselues outdoors; reserve them just for Easter forcing. No matter what happens or how short you may be of stock before that time, for Easter-one of the great flower days of the year-you should certainly be prepared.

You may not be able to grow your own Lilies, Rambler Roses or Ericas, but you can and should grow your own bulb stock for that 


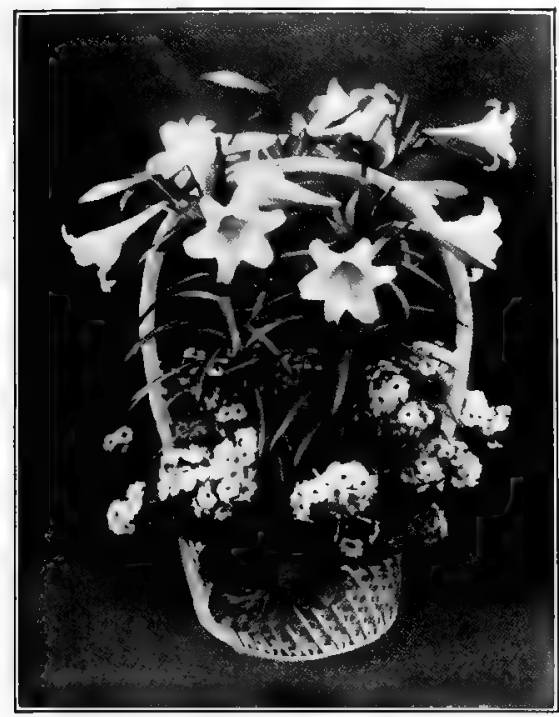

Fig. 70.-An Easter Lily Basket. Such an arrangement will always find plenty of admirers around Easter, for Lilies and Primroses in a graceful basket make a thoroughly pleasing combination

day-that is, if you want to make money. You can ship a Hydrangea, Rose, Lily or Bougainvillea, but you cannot nearly so well ship bulb stock in flower any distance. And it requires so little trouble to bring such stock into bloom for Easter -it might be done even without the help of a greenhouse-that every florist should be found well prepared with a full assortment for that date. With Easter coming around the first of April and no room to spare, if the weather isn't too cold, a good way is to let the plants, whether in pans or flats, come along in a deep coldframe, outdoors; here, with sashes and plenty of shade on top, they can be kept perfectly, much better, even, than in a cool greenhouse. Any frame is good enough so long as you can keep the frost out of it. During a hot spell such as we often experience during the Easter week, with cool nights and shade you can keep a deep coldframe down to $45 \mathrm{deg}$. without trouble.

\section{The Retailing of Bulbs By the Florist}

This is merely a side line as yet and is almost entirely overlooked by the average retail grower.

If you supply the plants in Spring for the filling of flower beds and borders, you have the best of chances to land the order for bulbs to be planted in Fall for Spring flowering. We know there are seed houses all over the country specializing in that line and sending out attractive catalogs, but in spite of that, you can get your share of orders if you only go after them. The great majority of people will not think of a bed of Tulips except when they see them in full bloom, and, strange to say, we have folks come into the store in May, wanting to know if they can have a bed planted. If you want to have your customers buy bulbs from you, advertise, send out an attractive folder, call them up, remind them of the fact that the Fall is the time for planting if they desire a show the follow ng Spring.

I always look at the selling of bulbs to one's customers in this light: There may not be a great deal of profit in handling them, 
but as long as you have to buy for your own use, whatever you retail will help pay for what you use yourself. I think that is a good way to look at it, and if you have to send a man to plant the bulbs, there again is a margin of profit, or should be, and you also are reasonably sure that your customer will be well pleased with the show of flowers for the money spent.

\section{Special Schemes for Boosting the Bulb Business}

In every town, no matter how many bulbs are shipped in from the large cities, there is always a chance for the local florist to sell more and make it a paying side line. It is just a matter of going out after orders, and not sitting down until they happen to come in. Every retail grower with a little store for the selling of cut flowers and plants should make it his business, when the first Freesias and Paperwhites arrives to start his display of bulbs and, as the Dutch bulbs arrive, to keep on adding to the assortment. Even if you can display them only in new, clean, 10- or 12-in. bulb pans, each nicely labeled, you can make them attractive. Get a few colored photos or pictures of some of the different sorts, have some low dishes filled with pebbles and Paperwhite Narcissi, a basket of Chinese Sacred Lilies, a few extra-size Dutch Hyacinths in glasses; get a few photographs of beds of Tulips or Hyacinths in bloom; put a weekly ad in your home town newspaper; enclose with your monthly statements a neat folder; have the clerk in the store call attention to the display of bulbs on hand; talk bulbs to those who buy flowers, and you cannot help but take orders and sell stock.

The more bulbs are planted in your town, no matter where they come from, the more will be sold the following year, and if you are in the retail business you should sell them. What is the difference, whether you grow them on yourself and sell the flowers, or sell the bulbs, as long as you make a fair margin of profit, provided the one doesn't interfere with the other? Don't be under the impression that a customer who purchases three dozen Paperwhite bulbs for inside flowering will buy just that many less flowers from you during December; no, it is usually just the opposite-she will buy more. And if she wants Paperwhites and you don't sell them to her, somebody else will. Sell where there is a chance to sell; the man who hangs his head and finds fault because so many bulbs are shipped into his town from the outside, usually has himself to blame.

Forget about the other fellow; make a display, advertise and back it up with good bulbs, and a reasonable price; push and then push some more. Do that and before long the result will be that more bulbs than ever will be sold in your town, more people-will be wanting them, and you will, as I have, come to the conclusion that there is money in handling them. 


\section{Dutah Bulbs for Late Flowering}

With so many fine Tulips especially adapted for late flowering, those who consider Easter the closing season for bulb stock, as far as the florist is concerned, miss a good deal. Usually a few flats of bulbs come in after that date, such as perhaps have been overlooked outdoors, or were planted very late, but no special effort is made to supply the demand for May and early June. Almost all such stock, whether Tulips or Narcissi, can be handled either outdoors in the open or in frames and can be made to pay well if properly handled. With the help of a frame, glass, and shade sash, you can bring a planting of bulbs into flower several weeks ahead of those left to themselves, or you can hold them back a few days; this to the florist means a better chance to make them pay. It will prove a good investment for any florist to plant some Narcissi or late flowering Tulips in beds $5 \mathrm{ft}$. in diameter outdoors; cover some in early Spring with frames and sashes and so have them come in ahead of those not covered; and have another lot which with temporary frames, shutters or other shading, are protected from the sun and thereby kept back.

Another way to use late flowering bulbs to advantage is to recommend them for planting in groups along the shrub borders and in the perennial bed. We have seasons when some of the Darwin or Cottage Tulips will bloom as late as June, a time when there is but little in the way of perennials and when what there is of Iris, Columbines, etc., will not be interfered with; the same is true in the shrub border.

If perchance you have to submit to a customer during Fall a specification and estimate for the planting of such borders, always include the planting of a certain amount of such bulbs. It pays.

\section{TWELVE DESIRABLE GONIFERS FOR THE FLORIST TO GROW ON}

IT TAKES years to grow conifers from seed until you have stock of any size to sell, but, on the other hand, if you should happen to have suitable land and let your nurseryman supply you each year with a few transplanted seedlings for planting out in rows, before you know it you will have suitable stock for the filling of window boxes. A little later there will be $2-, 3-$, and 4 -ft. stock to offer, and I don't know to what the average florist located near a city or in a town could possibly devote his land to better advantage. This is especially so in the case of the young man who, in a growing neighborhood, has a chance to purchase a few building lots, maybe located a little outside of town; lots which can be bought cheap. If he were to plant these with nothing but Norway Spruce, it would be well worth while and would bring good returns in a short time. 


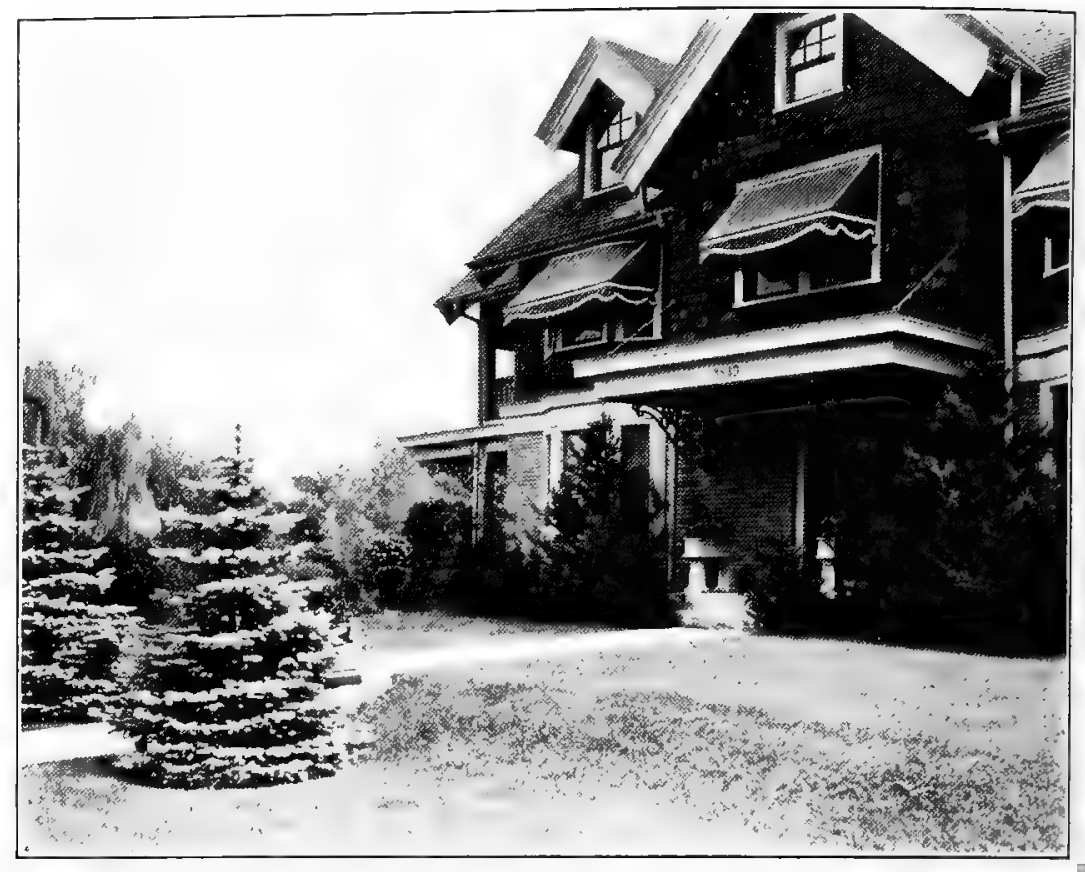

Fig. 71.-The Useful Conifens. The Blue Spruce makes one of the finest of specimen conifers for lawn planting. It never shows at its best when crowded in with other stock, but wants to be alone with plenty of room for development. All too often we find it planted too close to the drive or walk

Wherever home grounds are being laid out, whether large or small, there is always a place for conifers, and plants not sold this year simply grow into more money if left in the nursery or transplanted so that they can become specimens. You cannot afford to crowd them, no matter what the variety, if you want perfectly shaped plants, and that, of course, is what counts with conifers.

\section{Norway Spruce (Picea excelsa)}

I start the list with the Norway Spruce, not because it can be compared with many other beautiful varieties there are, but because it is one of the most useful of all. It is a fast grower, which means that from small, transplanted seedlings, eight to ten inches high, you can get suitable plants for the filling of window boxes the second year. Later on you can offer the larger stock at a more reasonable price than is possible with almost any of the other sorts. There are times when you have to fill an order calling for the largest evergreens for massing in a screen at the smallest possible price and that is when you want Norway Spruce. Also bear in mind that each year more and more specimens of this plant are wanted for Christmas, either in or out of tubs. 


\section{Аrborvitas (Thuja occidentalis)}

While not suitable for quite so many purposes, the Arborvitæ comes next in usefulness as an inexpensive evergreen. It is good in the form of small plants in window boxes for Winter effects; it is good for hedges a little later, and it is good as a specimen still later.

\section{Red Cedar (Juniperus virginiana)}

There are many sections where you cannot keep Boxwoods outdoors all Winter, which really is the time you want them most. A good substitute, hardy almost anywhere, is the Red Cedar. It makes a splendid specimen plant even in a small state and when from four to six feet high it is ideal for planting at either side of a front entrance of a residence, on a terrace, or on the open lawn.

\section{Golorado Blue Spruge (Picea pungens)}

The Blue Spruce is one of the most stately of conifers and as expensive as any. You will sell but one as against a hundred or more of Norway Spruce. Yet it always pays to have at least a few on hand and to my mind it is better to have your nurseryman supply you with plants about eighteen inches or so in height of the true blue color than to buy hundreds of small seedlings of which only a very small percentage will turn out blue.

\section{Balsam Fir (Abies balsamea)}

The Balsam, with its graceful branches, you can use to advantage both when small and later on for mass planting. Like all others, when the plants get to be $3 \mathrm{ft}$. and over in height, they need room if you want them good all the way around.

\section{HEMLOCK (Tsuga canadensis)}

Since it is as useful as the Balsam, it is always well to have a stock of different sizes on hand.

\section{Sabine Juniper (Juniperus Sabina)}

The Sabine Juniper, with its graceful habit, is one of the showiest of all conifers. It is especially adapted for planting in the foreground of taller growing sorts, but it is equally as good treated as a single specimen.

\section{Dwarf Mountain Pine (Pinus Mugho)}

The Mugho Pine, while not as graceful as the Sabine Juniper, is every bit as useful. There are plenty of occasions where you can use it to advantage. 


\section{Scotch Pine (Pinus sylvestris)}

The Scotch Pine should be far more extensively grown. $:$ It is a splendid evergreen and grows more beautiful the larger it gets.

\section{White Pine (Pinus Strobus)}

In many sections of the East and Middle West there is room for thousands of White Pines to help. beautify our Winter landscapes. Even those who grow on conifers on a small scale should. do their part to encourage the planting of this Pine. Even in the smaller sizes you want it for variety's sake if for nothing else.

\section{American YEW (Taxus canadensis)}

Try to grow a few Taxus to round out the assortment for your patrons to choose from. They are hardy and showy and would become more popular if people could see more of them.

\section{Góncolor Fin (Abies concolor)}

- 'For windbreaks or places where the owner doesn't care how high his evergreens will ultimately grow, these Firs will fill the bill. But you can also use them to advantage when in a small state.

\section{FIFTEEN DESIRABLE HARDY FERNS}

THE florist depending on a local trade and making bedding stock a specialty is bound to have calls for hardy ferns and should get acquainted with a dozen or so varieties that he can recommend to his patrons.

Hardly ever have we call for hardy ferns to be planted on the smaller new grounds, particularly building sites where there is a lack of trees. There the question of lawn, trees and suitable shrubs comes first; but as the trees and shrubs keep on growing and developing, and shady spots and nooks are created, the owner begins to think about hardy ferns to take the place of flower beds or borders where, for want of sunlight, Geraniums and other bedding plants don't do as well as they once did. Or the owner may feel like making changes. There are, of course, places where the natural conditions in the beginning are ideal for ferns and flowering hardy plants adapted for shady positions.

Anyway, it usually doesn't take much to create a spot where hardy ferns can be used to good advantage. There is, of course, this disadvantage about a fern bed: that many varieties, including some beautiful ones, begin to look anything but attractive toward the end of Summer. But there are many others that are evergreen; and again there are plants such as Sedums, Hypericums, Lilies and others which, if necessary, can be used in connection with ferns to 


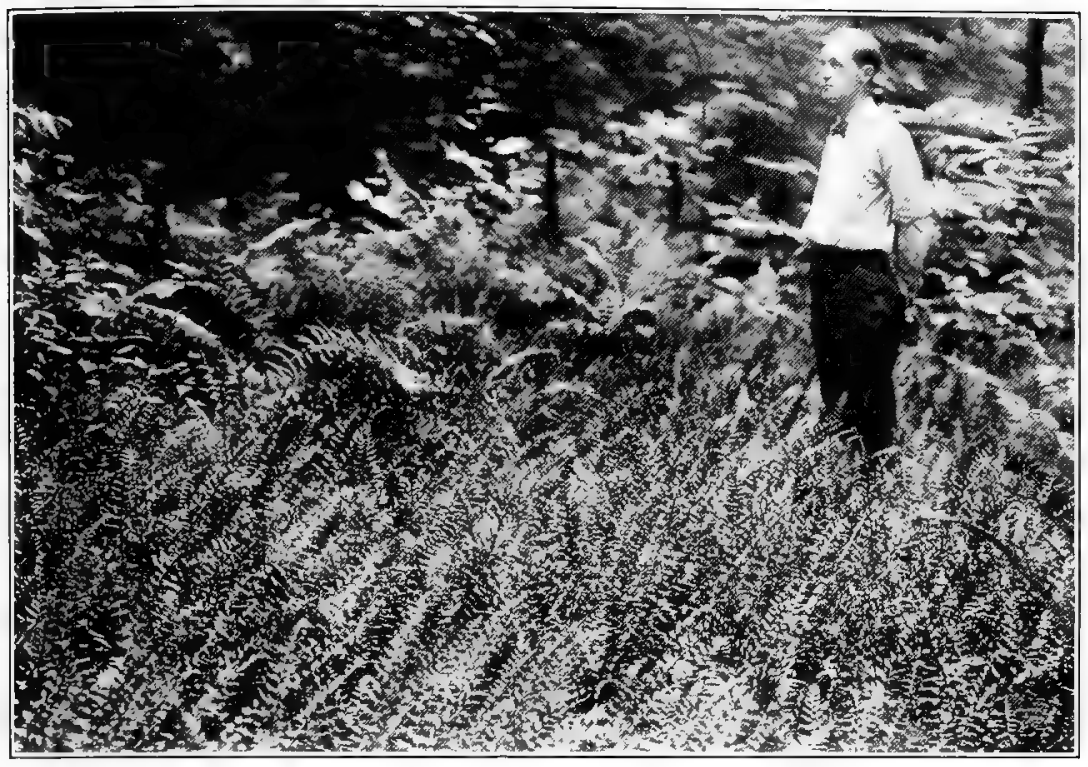

Fig. 72.-A Well-known Native Hardy Fern. The Christmas fern is really a Polystichum, but it is usually called Aspidium acrostichoides by florists who sell tons of it for holiday decorations. It is truly hardy, remaining green under the snow all Winter

make a showy bed possible all Summer. I don't mean on grounds where extensive plantings and mass effects are being carried out. But on the smaller home grounds with which the florist is apt to come in contact such combinations might well be considered. Where there isn't too much shade you can use, for instance, Aquilegias, ferns, and Iris. This is not to say that all three will do their best under the same conditions, but they can be made to present an attractive combination in partial shade.

\section{Gonditions that Suit Ferns}

Whether you go East, South, North, or along the Northwest or West you will find magnificent ferns in their natural environment. There are but few of the most desirable ones that do not appreciate the company of trees, and the leafmold which for centuries has been forming at their base. That alone is sufficient to tell anyone what ferns require in order to do well. Give them the best soil, and the mellowest, you can; a liberal amount of sand never hurts any of them, and some of the taller growing varieties don't object in the least to manure to feed on.

In many sections, maybe right in your own neighborhood, at one time there were beautiful native ferns growing. Usually, as sewers, streets, concrete sidewalks and a residence district take the 
place of the meadow and the woods, the hardy ferns, $\infty$ Trilliums, Anemones, May Apples, and Hepaticas have to go. But there are quite a few of us who after awhile are no longer satisfied with socalled cultivated things, and even on a small place and with just a little work, hardy ferns and other so-called native favorites can be made not only to feel at home, but also to add a great deal to the beauty of the grounds themselves.

Again, frequently a patron will ask your advice as to what to do in order to cover up a bare spot on the north side of a residence where it is impossible to grow anything in the way of flowers, or there may be shady places under trees where no grass will grow. It may be that it is desired to retain a part of the grounds in their natural state where a few Hazels, Thorns and native Crab Apples thrive; for such effects the native Cherry, Plum, Dogwood and Elder are as much thought of as all else on the grounds.

In all such locations ferns may be used to advantage for ground covering and what will do well with them are some of the Springflowering bulbs-Narcissi, Scillas, Snowdrops, and Iris and Mertensias as well, which while not grown from bulbs, are appropriate because of their early Spring flowering character.

The following list is of course not a complete one, but it will help the beginner get busy. With the fifteen varieties named a great showing can be made. Here again, of course, the size of the grounds, the location, the money to be expended, and the effect desired, all play an important part. Furthermore, I don't mean to say that a florist should bother about trying to grow on any of these ferns himself. It can be done of course, just as we grow on other ferns, but there are specialists in the country from whom you can obtain good heavy plants of just what you want and some even carry potted stock. Let them furnish you with what you need each Spring and Fall.

Personally I prefer Spring planting, but good results can be had with most ferns by planting them in Fall. There are times when you must fill an order whenever your patron is ready or not fill it at all; that may mean to do it almost at any time, and if you have potted plants so much the better. However, others moved in early Spring, or just before they start to grow will do nicely also.

\section{Adiantum Pedatum (Hardy Maidenhair Fern)}

The hardy Adiantum or Maidenhair Fern is one of the most desirable in the long list of good ones to select from. We find it in shady places and often in soil where even the much coarser varieties and those that form heavy crowns, such as Aspidium Goldieanum, are hardly ever seen. 
It hardly ever grows more than fifteen inches in height but when once established it will remain and spread for years. Its graceful habit makes it as popular outdoors as Adiantum cuneatum is under glass. The best time to plant this fern is in the Spring and while, as stated above, we find it in stiff soil, you will have better results by using as much leafmold as you can in planting. And don't plant it too deep.

\section{Aspidium (Hardy Varieties)}

There are a number of most desirable forms or rather varieties of Aspidium, of which we are best acquainted with the so-called Wood Fern. All Aspidiums form crowns and when you plant one it is always well to set the top of the crown just about even with the surface of the loose soil so that it will project just a little after the first good watering. A. cristatum Clintonianum is the Crested Wood Fern, growing 30 inches or more in height and almost an evergreen, even in cold sections. A. Filix-mas, the Male Fern, is another strong grower and a most valuable fern, especially for moist situations. A. Goldieanum or Goldie's Wood Fern grows three feet and more in deep, moist soil and a shady position. A. marginale, the Evergreen Wood Fern, is the best for mass effects and ground covering and can stand quite a lot of shade.

\section{Asplenium (Hardy Varieties)}

Among the Aspleniums there are not only fine varieities for greenhouse culture, but some for outdoor planting as well. While we will here name but two, there are a half dozen or more all beautiful and useful wherever there is a fern bed or border to be planted or arranged. Asplenium angustifolium (Narrow-leaved Spleenwort) grows about two feet in height and has light green, narrow, graceful fronds. A. Filix-fomina is the botanical name for the well known Lady Fern with the finely cut leaflets of its graceful fronds which are sometimes fully three feet in length. Shade, moisture and good drainage are what it wants in order to do well.

Asplenium Trichomanes, the Maidenhair Spleenwort, is a beautiful little fern hardly ever growing over five or six inches in height. . It is just the thing for small fern plantings or rockeries. As it is small and delicate, you should plant it in a well-prepared bed of leafmold and sand. When once established it will take care of itself, but you have to give it a fair chance to become established first. Watch the little crowns so you don't get them covered with too much soil. Have them even with or just a little above the surface.

Dicksonia punctilobula (Hay-scented Fern)

There are cases in which the hardy fern bed or border is partially exposed to sunlight at one time or other during the day?" this is 
most likely to affect particularly the outer edge of the planting. There is no better fern to use in such locations than this Dicksonia which will thrive not only in the shade, but in sunny positions as well. It hardly ever grows over twelve inches in height and does not form crowns as do the Aspidiums. It increases by means of underground root stalks, and the more mellow the soil (made so by mixing in a liberal amount of sand), the more you encourage it to grow and spread.

\section{Onoclea Struthiopteris (Hardy Ostrich Fern)}

As the name indicates this is one of the tallest ferns we grow. We find it not only in the New England States, but also, in splendid form, away up in Minnesota as a partner to Goldie's Wood Fern. The sterile fronds may attain a height of four feet and become eight inches and more across. Plenty of humus in the soil where you plant it will be appreciated by this variety. We find it in the shade and again exposed to partial sunlight, doing almost equally well in both locations. If you have a large planting to make, use the Ostrich Fern in the center or as a background allowing not less than from eighteen inches to two feet between the individual plants. Its graceful, large fronds are most effective when given plenty of room for development.

\section{Osmunda cinnamomea (Hardy Cinnamon Fern)}

If you have a wet spot, perhaps without drainage enough to permit other ferns to'do well, you can have good success with the Cinnamon Fern which likes plenty of moisture. In fact it must have it in order to do well. There are other more desirable ferns, especially among the Aspidiums and Aspleniums, yet there is a place for it if you have an order calling for an assortment, especially in cases where you are not sure of perfect soil drainage which most other varieties require to produce a permanent or lasting effect.

\section{Polypodium vulgare (Hardy Gliff Fern)}

This evergreen fern is what you want if a low effect is desired. It will form a dense mat with green fronds averaging about eight inches long and if ferns are wanted for planting a rockery, Polypodium vulgare should be included. It is especially fine for that purpose and quite hardy almost anywhere-but don't plant it in the Fall. If not established before Winter sets in, the plants usually die out before Spring even if protected and even though you may have no trouble with other varieties.

\section{Phegopteris hexagonoptera}

This fern is a good one to use in shady places where it will grow fully twelve inches in height. For effectiveness it is well to 
plant it along with others of dwarfer habit such as Polypodium vulgare, for the Phegopteri, of which there are several varieties, all develop more or less of a stem before the leaflets of the fronds start, and this makes them rather long-legged.

\section{WOODSIA ILVENSIES}

Woodsia ilvensis or Rusty Woodsia, is a splendid dwarf-growing fern which can be used in planting rockeries, whether around the bottom or away up on top where there is usually more or less of a lack of moisture at times. It grows about six inches in height and makes a good companion for Polypodium vulgare. While it will do well in the shade, it is equally at home in sunny positions. Plant it in the Spring.

\section{Woodwardia angustifolia (Hardy Chain Fern)}

The Woodwardias grow about a foot in height and their fronds are about three inches wide. They love a deep, cultivated soil where they always have an abundance of moisture about their roots. In a shallow dry soil they don't amount to much, but give their roots a chance to draw up moisture and they certainly will thrive. If you have wet spots, plant Woodwardias in them in preference to other ferns; however, they will do equally well in a rockery if you have plenty of good soil in it.

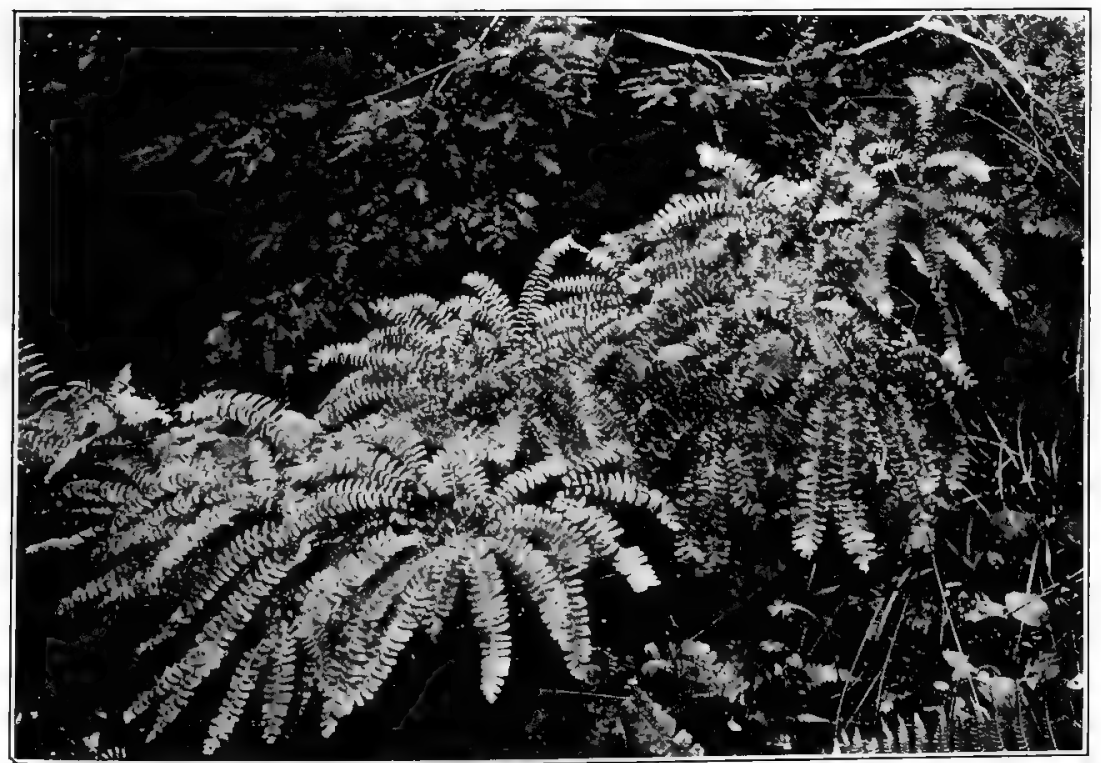

Fig. 73. - The Popular Hardy Maidenhair Fern. Modest, graceful and delicate, it is also hardy and easily grown. It can be collected in its native woods in late Summer, but the retail grower will do better to buy small stock from a specialist 


\section{PERENNIALS AND BIENNIALS AND HOW TO USE THEM}

I DON'T know of anything that, from the standpoint of floristsespecially the retail growers throughout the country-deserves more attention than the growing on and handling of so-called hardy flowering plants. Never before has there been a greater demand for this class of stock nor higher prices paid for it. And when you consider that most of the best known varieties and the showiest and finest of cut flower sorts are easily grown on or propagated either by division, cuttings or seed; that with the help of a greenhouse the work is made still easier; and that the great majority of the plants will thrive in ordinary soil and overwinter in the open even in severe sections, it seems that there cannot possibly be a crop which will bring greater returns for the space it occupies or for the outlay required in caring for it.

It is a fact that today there are not hundreds, but thousands of localities whence lovers of the hardy border send hundreds of miles each year to obtain their requirements in biennials and perennials for no other reason than that the local florist doesn't carry them. He may, perchance, have a few Peonies (half of which never flower), clumps of long-discarded varieties of Iris, or small-flowering, pinkishpurple Phlox-and none of these taken care of-but there are only very few who go into this branch the way they should. Yet who can do it better and to more advantage, who has a better chance to dispose of plants each Spring and Fall, who can make better use of the cut flowers, than the local florist?

\section{Don't Neglect the Perennials}

You will never be able to make money out of perennials by carrying just a few sorts and making people hunt you up in order to get them. You can never make them pay by having only a few rows, and those not taken care of, or of poor varieties. They should mean to you more than a side line. If you do business where people have gardens, the growing of hardy stock should be pushed to the limit. It should be developed into one of the main branches, for the demand is there and will keep on growing from year to year. What has been accomplished so far in creating this demand has been done by just a few large firms. The florist himself has done but very, very little. It may be that he has been kept too busy with other things, but that won't always be so. Your greenhouse stock will not suffer for want of buyers if you push perennials; nor will the large firms, which at present ship into your town, sell any less. But you will sell more, do more business, and make more money.

You are not through with a customer when he or she has bought of you $\$ 10$ or $\$ 20$ worth of choice Peonies or some of the 
latest varieties of hardy Phlox. It is more probable that the same customer will buy twice as much before six months are over, and keep up such purchases and want just as many porch boxes filled as before.

Consider for a moment the cost to you of producing a good 4-in. Geranium-the time, the labor and the bench space it takes to do it and remember that you can sell Geraniums only once a year. Then consider growing a Delphinium from seed sown outdoors, and transplanted once. What isn't sold keeps on growing into money; you cut the flowers and a year later the plant will be worth twice as much, whether you sell it or keep it, in which case you cut more flowers. The third year you can use it for flowering under glass, where one flower stalk will bring as much as an 8months' old Geranium plant. No, the Delphiniums are not the exception. Many other perennials do the same thing in proportion.

Grow on a good stock of biennials and perennials; advertise and keep on advertising; make a display on your own grounds; let your customers know when it is Iris, Peony or Phlox time. What you can't sell at home, dispose of wholesale. If you carry good varieties and let the trade know what surplus you have, there will be no trouble in disposing of it. What the trade is mostly interested in are those varieties which furnish good cut flowers or can be flowered under glass.

\section{How to Work Up a Stock of Perennials}

If you realize the importance and the possibilities of handling biennials and perennials and are considering going into the work, let me offer a few suggestions that will be of help in getting started and under way; after that you will be able to help yourself.

According to your requirements and pocketbook, begin by investing in the three leaders: Peonies, Iris and Phlox. The most expensive of these are Peonies, and I wouldn't plant more than six varieties. You might consider the following: Festiva maxima for white; Jules Elle, light rose; Duke of Wellington, creamy white; Golden Harvest, peach-blossom pink; Louis Van Houtte, dark red; and Felix Grousse, another red. Plant twenty-five, fifty, or one hundred of each in nursery rows, allowing about one foot between the plants and three feet between the rows. Don't go to the trouble of digging the soil over several feet deep and manuring heavily. Deep cultivation is fine, but too deep tillage is waste, and so is an overdose of manure. Cultivation after planting is what counts. If you plant one foot apart you can, if you like, take up every other plant and sell it.

Iris are not expensive, even the good new varieties. Of these you also want not over six varieties to start with, that is, if your 
working capital is limited. Here are a few splendid uptodate sorts: Pallida dalmatica, Sherwin Wright, Mme. Chereau, Lorelei, Lohengren, Princess Victoria Louise and Lord Salisbury. Plant the Iris the same as the Peonies and always provide each variety with a substantial label properly marked.

Among the Phloxes are many showy varieties and yet to start out with, six good ones of as many colors will do, for you can always add more. Miss Lingard is at the head of all white Phloxes, especially the early ones and Mrs. Jenkins is still one of the most popular late whites, even if not as large as Van Lassburg. W. C. Egan is the best soft lavender pink; Elizabeth Campbell, the best deep salmon pink; Rynstrom, a fine improved Phanteon of a deep cerise pink; and Mauve Queen is very attractive.

If you purchase field plants of Phlox in Fall, all with the exception of Miss Lingard can have two-thirds of their larger roots removed before you plant them into the field; these roots can be used for propagating (see page 473). Miss Lingard is best propagated by means of cuttings, which method is also described elsewhere (page 47\%.)

With a stock of any of these leaders on hand you can keep on increasing the number of plants from year to year. With the Phloxes you will have plants to sell the second season and the same with the Iris. The Peonies will take a little longer before you can start dividing the clumps, but when this time once arrives you can soon work up great numbers.

If you wish you can add to this list other important subjects such as: Delphiniums, Columbines, Shasta Daisies, Gaillardias, Achillea and Anchusa. But all of these are easily grown on from seed, which if sown during February and March and if the little plants are carried along inside until April and then planted out, will give the finest kind of salable stock that Fall. As with the Delphiniums, Shasta Daisies and Gaillardias will give you flowers the first Summer.

\section{Laying Out a Perennial Border}

There are many ways in which perennials can be used to advantage on the home grounds, but while Peonies or Iris, or for that matter, any other sort can be planted in groups, beds or long, narrow borders, whenever one variety occupies a bed by itself, you need annuals with it in order to obtain a showy effect all Summer. The Peony, while gorgeous when in flower, lasts but a few days; the same is true of Iris or Columbines. When you think of Hollyhocks or Golden Glow you have in mind the plants at the height of their beauty; two or three weeks after that they look sad. And not 


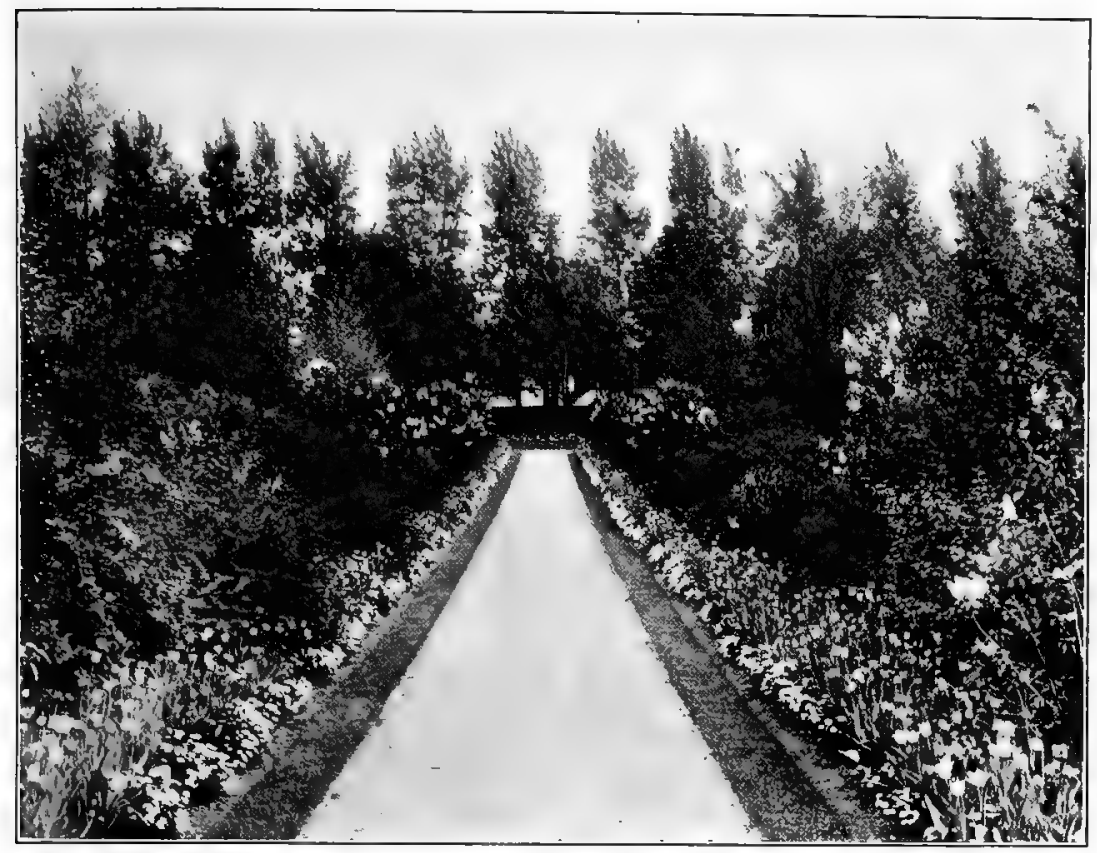

Fig. 74.-The Hardy Plant Bormer. The irregular perennial border is best placed on the outskirts of the lawn, but an equally pleasing effect can be produced along a straight walk bordered with hardy flowering plants set against a background of shrubs

all of these perennial plants have attractive foliage or are good to look at when out of flower. If a customer insists on having a long, narrow border filled with a row of Peonies, give it to her, but call attention to the fact that something else should go with the Peonies. For such a border a display of bulbous stock in Spring, followed by Gladioli, Snapdragons or other annuals might be suggested. The foliage of Peonies stays good almost all Summer, but that is about all that can be said about it.

On the smaller home grounds the most satisfactory way to get the most out of perennials or biennials is to plant them in an irregular border, maybe with a background of shrubs. If the border is six feet or so in width, you can plant them in groups and arrange things so as to have flowers coming along over the greater part of the season. But even here, you won't make a mistake by leaving spaces for annuals between the clumps or groups.

You cannot afford to take an acre of your own and spend a lot of money preparing the soil for the planting of perennials; but if there is a chance and if the owner is willing to pay for it, always work the beds and borders over deeply and put enough manure in them. If the soil is very poor, put good loam in its place; you will 
get better results. If you are asked to lay out a perennial garden, don't get into fancy designs and try to make beds of fantastic shapes. Straight beds four feet wide and as long as you want them, with 4-ft. sod paths between look better and answer better in such a garden. If these beds are properly filled with groups of plants, taking into consideration their flowering periods and their colors, and if a few annuals are 'used in connection with them, you can have them look good all season.

On small grounds where it is not possible to allow for a perennial or hardy flowering plant garden, it is often an easy matter to widen out a shrubbery border 2 feet or so and plant perennials along the edge. This may also be done with shrubbery beds of which the side facing the lawn or residence can be widened out and used. With a background of conifers or shrubs, you overcome, to some extent, the naked appearance of hardy stock which happens to be out of bloom.

\section{Potted Perennials for Spring and Summer Trade}

If you sell your perennials at retail in your immediate neighborhood, your patrons are bound to appreciate the fact that they obtain better stock than is possible when the plants have to travel long distances. A plant with naked roots is not to be compared with one delivered with a nice ball of earth around its roots and the latter is out of the question when you ship the stock. But even such plants can be lifted only during a comparatively short time in Spring. After they start into growth, it isn't long before you hurt them too much by lifting them. To overcome this difficulty and to make it possible to sell certain varieties practically all Summer, plants in pots are made use of.

It cannot always be said that when, in Spring, the plants in the field are ready; the people who want them are. Many of your customers overlook the ordering of what they need until too late; or, as is often the case with new grounds, the beds or borders where they are to be planted are not ready. With a good batch of plants in pots, you can prolong the planting season for weeks and even if such stock as has been planted in Midsummer doesn't make much of a showing that season, one still gains by planting it, for the plants will get so -well established before Winter sets in that they become far superior to those planted out from the field in the Fall. When you once get your customers to realize that you carry perennials, you will have plenty of calls for them long after the regular bedding season is over.

In order to have plants in $3 \frac{1}{2}$-in. or 4 -in. pots by May, you should lift field plants in Fall, heel them into a frame and leave them there until about the end of February, after which bring them 
to the potting shed. In the case of Shasta Daisies, Achillea, Physostegia and many others of which good sized plants can be had, these can be divided into small pieces, just large enough to be potted up in $31 / 2$-in. pots. After this they can again be brought in to a coldframe, given a thorough watering and protected with sashes to keep heavy frost out. By the middle of March or so, according to weather conditions, remove the sashes altogether, for you don't want to encourage growth but rather to retard it.

Don't draw on these plants, except for shipping, until it gets too late to lift field plants When that time draws near is the time to push the potted stock. Let the people know about it, advertise it, make people think of it. Call attention to the advantage derived from planting such stock and you will surely find sale for it.

\section{Twenty-five Biennial and Perennial Flowering Plants}

Arranged According to Their Importange to the Florist

From the florist's point of view, all such plants as come under the head of biennials, perennials, and herbaceous or hardy flowering sorts, have to be judged first by their individual value as cut flowers, for this is of greatest importance to most of us. A variety which will produce desirable cut flowers over the longest period should come first, especially if it furnishes flowers which adapt themselves to many purposes. Next in importance we have to consider its hardiness, then its ease of culture and next, for the retail grower, the ability to dispose of the plants themselves not only at retail to his patrons during Spring and Fall, but also, in the case of any surplus, at wholesale to the trade for growing on.

Every retail grower with space outdoors in connection with his greenhouises should have a stock of the following sorts always on hand. Most of them are easily grown on, either from seed or divisions of the field plants or clumps, and with just a little attention they will bring as good, if not better, returns than almost anything handled in or outdoors. The botanical or common name, according to which the plant is best known by, is used in each case.

Achillea Ptarmica Flore Pleno, "The Pearl." You cannot ask for anything more useful for sprays or in a basket arrangement of flowers than this Achillea. Small divisions planted one foot apart each way in September, will flower for three months the following Summer. (See page 243.)

Anemone Japonica. If these Anemones were just a little more hardy, they would become as popular as any perennial grown, for their beautiful flowers are at their best when we need flowers outdoors the most. (See page 253.) 


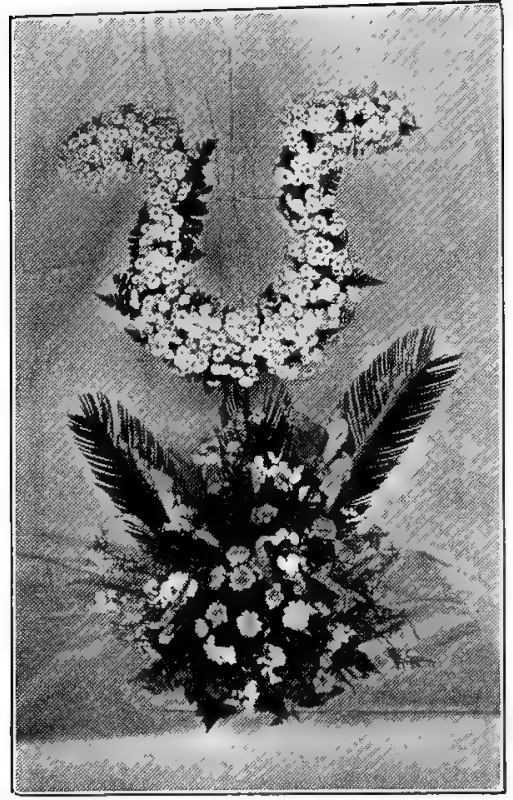

Fig. 75.-Perennials Effectively USED IN Design Work. This lyre is of Feverfew, Dorothy Perkins Roses and pink Veronica with Cycas and fern trimming

Canterbury yells (Campamula medium). We don't see many cut Canterbury Bells on 3to 4-ft. stems in early Summer for the reason that there are none to be seen. With a greenhouse you can have the plants in bloom from early April on. They make grand pot plants as well as cut flowers and are every bit as grand when massed in the hardy border. (See page 296.)

Ghrysanthemums (Early outdoor flowering). With each year new varieties are coming to the front, that come into flower the forepart of October and make it possible, even in cold sections, to enjoy outdoor flowers after most annuals have gone to sleep. Forget about their hardiness and lift enough field plants to be overwintered in a frame or used for propagating. Sell the small plants in Spring and plant enough for your own display as well as to cut from. (See page 324.)

Columbine (Aquilegia). The Columbines come in many different shapes and sizes and a still greater variety of most beautiful shades and colorings. They are hardy as an Oak, among the first to bloom outdoors, fine for cutting and easily forced for early Spring. Why not pay more attention to them? (See page 257.)

CoReopsis lance olata grandiflora. There is nothing quite so golden during June as a bunch of long-stemmed Coreopsis. The trouble with a bedful is keeping it picked. Give the plants room and they will flower all Summer long. Few florists as yet use the Coreopsis for flowering under glass for early Spring, but this is easily done and can be made to pay. (See page 331.)

Delphinium (Hardy Larkspur). The Belladonna hybrids, easily grown from seed, furnish most desirable cut flowers all Summer and are as goód under glass for forcing. (See page 347.)

Foxglove (Digitalis). This biennial, like the Hollyhock, is a great show plant when in flower and is used a great deal for massing. As it is one of the best known and most popular border plants, it is always well to carry a stock in frames over Winter with which to supply your patrons in Spring after they have lost their own through lack of proper protection. (See page 355.) 
Gatilardia. A vase full of long-stemmed Gaillardias in your display cooler will help make all the other flowers look better. The plants are constant bloomers, fine keepers, attractive singly or when massed, equally good during the dryest Summer or a wet Fall, and enable you to cut flowers until the snow flies. (See page 376.)

Hardy Asters (Michælmas Daisy). With their masses of delicately tinted Daisy-shaped flowers of light lavender, mauve, and heliotrope, borne on good stems, these hardy Asters are not only splendid for the hardy border, but equally good for cutting, whether you want to use them to go with other flowers or in vases by themselves. (See page 268.)

Hardy Pinks. This list would hardly be complete without mentioning these charming little border plants. As far as the flowers are concerned, they will pay best in the admiration and enjoyment you yourself get. As for the plants, don't ever let a patron go away saying "He talks about hardy plants but doesn't carry even a border Pink." (See page 351.)

HeLianthus (Hardy Sunflower). Among the Helianthus are varieties which will flower during October and grow into 6- or 7-ft. plants. The fact that they are also good decorative cut flowers makes them desirable perennials. (See page 393.)

HoLl yноскs. The cut flowers of Hollyhocks have but little value to us, but the plants when in bloom make a grand display. They help advertise your business if planted in the right spot and, as with the Poppies, quite a number of your patrons will call on you for plants for their gardens. (See page 249.)

ICELAND Poppy (Papaver nudicaule). The Icela id Poppies are well named and deserve more attention at the hands of the florist. Grown from seed sown indoors in February, they will flower all through the first Summer; the following Spring they will be the first to bloom of all of the perennials you cut flowers from. (See page 461.)

IrIs. While near the top of the list as a perennial for the hardy border and outdoor planting in general, the Iris isn't nearly as important as any of the foregoing; yet of course it deserves a prominent place in every assortment. (See page 410.)

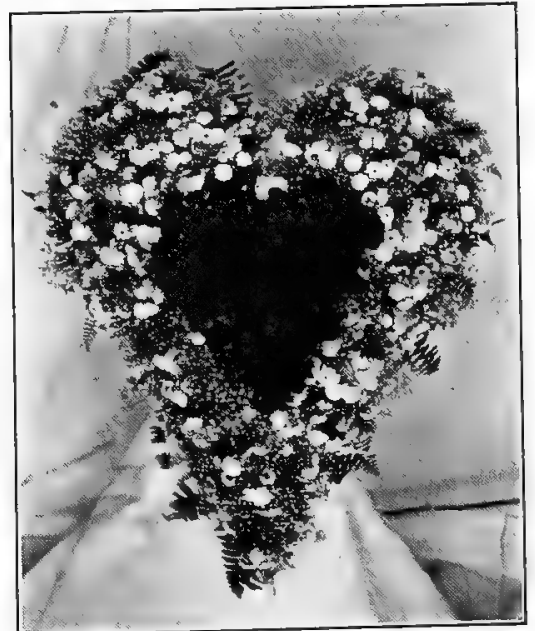

Fig. 76.-Another Perennial ProdUCT. The center of the heart is of double red Sweet William, and the border of Feverfew. Ferns and Gypsophila paniculata give lightness 
Lily of the Valley. You may just strike it right with the Valley you have in bloom on your own plants outdoors for a comingout party, a wedding or a funeral, as the case may be; but usually all such events happen either a few days before or a few days after, so that you don't get much out of the plants. But for all that, have somewhere a batch of Valley from which to supply your patrons with plants or pips whenever they want them. (See page 426.)

Oriental Poppies (Papaver orientale). You should carry the different colored Oriental Poppies not because they make good cut flowers, but because you are bound to have call for the plants. However, if you cut just as the bud begins to show color, you can keep the flowers in good shape for several days, in fact, longer than they would last on the plant. (See page 460.)

Peonies. Like the single-stemmed, large Ghrysanthemums, the Peonies are with us for only a short time each year, but while their gorgeous display is on everybody wants them. You not only have good use for the flowers, but the plants will grow into money from year to year. (See page 463.)

PhLox. The different varieties of the hardy Phlox are not only showy perennial border plants, but (as in the case of Miss Lingard) are of great usefulness as cut flowers. However; you don't want to carry clumps for five or six seasons, but should keep working up young stock each year. This will give you the first and second season flower heads that are really worth while. (See page 471.)

Physostegra vinginiana. Physostegias, with their white and pinkish flower spikes during late Summer, make showy plants and are fine for cutting. Like Helianthus, they don't much care how poor the soil they are in, or how severe the Winter weather. (See page 476.)

Primula veris (elatior) Polyanthus. The Polyanthus Primula by many would be classed nearer the top of the list. The plants are not only old favorites and considered among the earliest of Spring bloomers outdoors, but for the florist they make paying plants to grow under glass during the Winter months. They are especially fine for pans around Easter time. (See page 485.)

Pyrethrum roseum hybridum. The single Pyrethrums with their lively colored Daisy-like flowers on long stems are fine for cutting in early Summer. Like the Columbines, even when out of bloom they make good looking plants among other perennials in a border. (See page 488.)

Rudbeckia (Golden Glow). We have hardly anything else as tall and stately in the way of yellow flowers as the Rudbeckia when in bloom and it is on that account that we like it. It also can stand neglect without showing bad effects, but if you want real Golden Glow, divide the clumps each Spring. (See page 514.) 
Shasta Daisy (Leucanthemum and Chrysanthemum maximum). The florist can always sell Daisy-shaped flowers, particularly when they consist of a good strain of Shasta Daisy "Alaska." Plants of this sort flower freely all Summer and can be gently forced under glass. (See page 520.)

Sweet William (Dianthus barbatus). Every so-called “oldfashioned flower border" should have a few plants of Sweet William. You will always have call for them during the Spring season as well as in Fall and frequently can make good use of the flowers in a cut state. (See page 351.)

\section{Fifty Other Hardy Flowering Plants}

The following are all of value to the florist who handles this class of stock. While each of them can be used to advantage in the planting of perennial or hardy borders, many are of but little use as cut flowers. Practically all of them are fully described in Part II (pages 235 to 554) in alphabetical order.

\begin{tabular}{|c|c|c|}
\hline $\begin{array}{l}\text { AGANTHUS MOLLIS LATI- } \\
\text { FOLIUS }\end{array}$ & $\begin{array}{l}\text { DICTAMNUS FRAXINELLA } \\
\text { DIELYTRA SPEGTABILIS }\end{array}$ & $\begin{array}{l}\text { Myosotis } \\
\text { Physalis FranchetiI }\end{array}$ \\
\hline AconITUM (Sparks'var.) & Eupatorium AgERATOI- & Pentstemon \\
\hline MILLEFOLIUM & DES & Platycodon \\
\hline ROSEUM & UNKKIA & BAGO LARPENTA \\
\hline AgROSTEMMA & GYPSOPHILA PANICULATA & INTILLA \\
\hline ANTHEMTS TINGTORIA & HELENIUM & HRUM ULI \\
\hline $\begin{array}{l}\text { ANCHUSA ITALICA (Drop- } \\
\text { more variety) }\end{array}$ & $\begin{array}{c}\text { Gem" } \\
\text { HELIOPSIS }\end{array}$ & $\begin{array}{l}\text { GULUS } \\
\text { GKIA PU }\end{array}$ \\
\hline ARABIS ALPINA & Heuchera sangu & 4. AZUREA \\
\hline $\begin{array}{l}\text { ARTEMISIA LACTIFOLIA } \\
\text { ASTILBE }\end{array}$ & $\begin{array}{l}\text { HEMEROCALLIS } \\
\text { HIBISCUS (Mallow }\end{array}$ & OSA GAUGASICA \\
\hline IA AUSTRALIS & $\mathrm{HY}$ & $\mathrm{SP}$ \\
\hline BOCCONIA GORDATA & Lav & CE LATIFOLIA \\
\hline VA LATISQUAMA & LXGHNIS & ESIA GYANEA \\
\hline VULA PYRAMIDALIS & Mertensia Virginica & VALERIANA OFFIGINALIS \\
\hline MARILANDICA & LOBELIA CARDINALIS & VERONICA LONGTFOLIA \\
\hline IUM TOMEN] & JUPINUS & VINGA MINOR \\
\hline BELO & & \\
\hline
\end{tabular}

\section{PLANTS FOR ROGKERIES AND ROGK GARDENS}

EXCEEDINGLY pleasing effects can be created with the rockery or rock garden and this is particularly so on the small home grounds. One needn't have great sweeps of lawn space or acres of land in order to make such a planting or type of gardening permissible. In fact, if you carry out the idea in not too large proportions, you may, with the help of a rock garden, add greatly to the apparent extent of the grounds, making them appear much larger than they really are. Grounds with a flat surfaced lawn and the usual border planting of shrubs are not nearly as attractive as those in which along the outskirts of the lawn, we find elevations created by raised borders or rock garden plantings. A few elevations and gentle depressions always help to make a landscape more picturesque. 


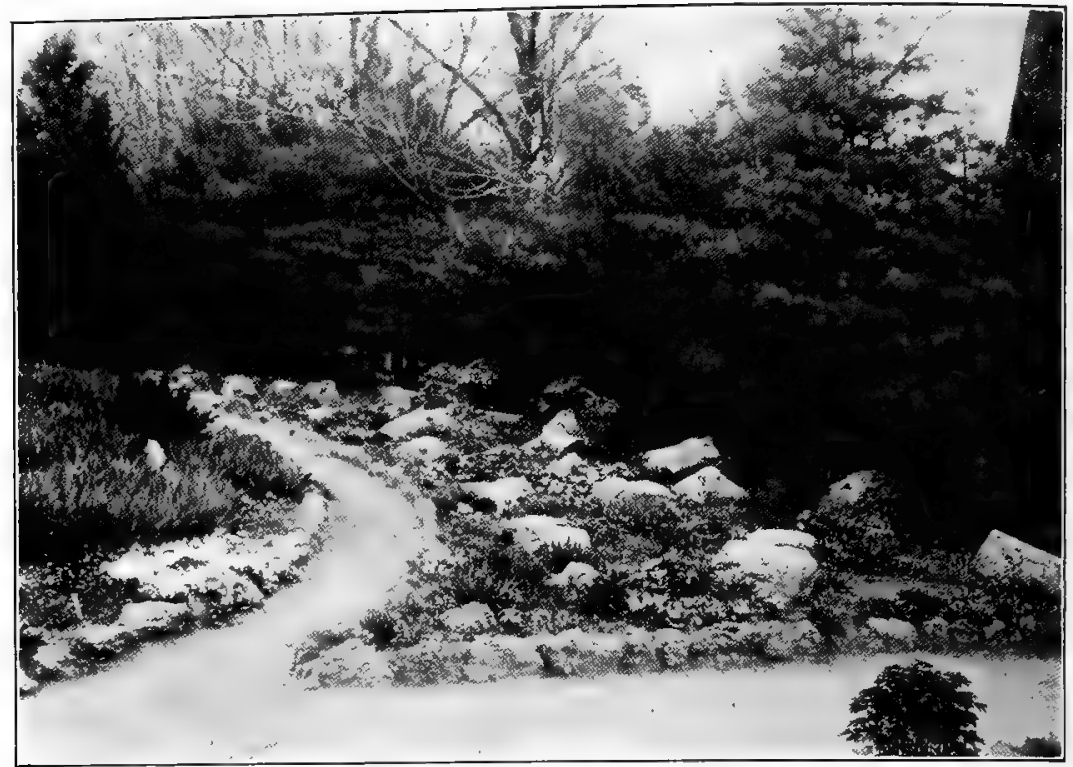

Fig. 77.-A Well-plannes Rock Garden, and in a good setting, too. Many of the typical Alpine plants are hard to grow in America, but there are plenty of satisfactory substitutes among our more common sorts

\section{What Is a Rogker y?}

A rockery is not merely a pile of rocks or boulders thrown in a heap with a few starved plants set among them; nor need a rockery be ten feet high in order to be effective. A rock garden may consist simply of a raised bed with a few good-sized boulders in it. It all depends on the effect wanted, the size of the grounds, and the extensiveness of the planting to be made.' For small grounds, a bed say five feet in diameter, elevated some twelve to fifteen inches above the surface of the lawn, with five or seven fair-sized boulders in it and planted with a few Iris, Aquilegias or other suitable plants and perhaps a few hardy Lilies, Santolinas and specimens of Vinca minor will add greatly to the attractiveness of the surroundings. Such a planting one may consider the beginning of a rockery or a rock garden in miniature, and really nothing more is needed than to extend the arrangement and size so as to make it correspond with the surroundings no matter how extensive.

Wonderful effects can be obtained, but each garden and planting requires a different treatment so that it will harmonize with the surroundings. At times a low effect is most desirable; at others the elevation may be many feet in height. But always you must have the width in porportion. An unsightly view may be hidden 
with a rockery, or a miniature ravine can be created with rock gardens forming the slopes. In connection with a pool for aquatics a rock garden can be so constructed as to give the pool a harmonious background or setting. Indeed, there are all kinds of possibilities, nor need the rock garden be planted strictly with dwarf-growing stock or such as is of doubtful hardiness.

The main thing to my mind is to create a pleasing effect. If the rockery or rock garden doesn't add to the beauty of a place, it is worse than useless. You don't have to confine yourself entirely to perennials in planting it. Nepeta or Glechoma variegata, Pennisetum longistylum, Thunbergia, Lobelia, Mesembryanthemum, Cuphea, Santolina, Alternanthera, trailing Lantana, Coleus, small single-flowering Petunias, Begonias, double Alyssum, dwarf Ageratum-all these are just a few of the so-called greenhouse materials that are suitable for such a planting.

\section{A Pragtical Planting Suggestion}

I realize that, in the opinion of an expert, such stock would hardly suit and that there are many other so-called rockery plants that should be used instead. On the other hand, one could arrange a raised bed of irregular outline with boulders or small rocks and make a wonderful display with nothing but annuals and bedding stock. What is there wrong, for instance, about a rock with its weather beaten, pointed top sticking out of the ground fifteen inches or so, and some plants at its base or sides? There could be a single plant of Rosy Morn Petunia, in the foreground a plant of Ageratum Fraserii, a double Alyssum, a little Thunbergia, and variegated Glechoma, and a background consisting of Pennisetum or a Grevillea robusta behind the Petunia.

Too artificial compared with real hardy rock plants? Maybe, but no Petunia, Alyssum, Ageratum, or even Pennisetum will show off as well as when displayed as a single specimen and planted just that way. To crowd things into a solid formal bed or border is all right if you want a mass effect, but to appreciate the full beauty of the plants themselves, you must give them a chance for individual development, and this can best be done when they are planted in a rock garden. It isn't likely that the average florist will be called upon to lay out rock gardens on a large scale, nor expected to draw plans and furnish lists of a hundred odd varieties of suitable plants. But he will be called upon at times to do such work on a small scale, and therefore should have some knowledge of what it means. No book or lengthy article ever written on rock gardening will make it possible for the beginner to carry out a job as well as one who has had actual experience, but any florist who can appreciate beauty in 
nature should have no trouble in planning a pleasing setting in this style of gardening and improving as he goes along. That holds good in all landscape work.

\section{Hardy Plants for the Rockery}

In the following short list of hardy stock suitable for rock gardening I have included varieties with which the average florist is most familiar, rather than a lot of stock which, perhaps, would be more important in carrying out a planting consisting solely of materials that are naturally found only in mountainous regions or in the crevices of rocks. While remarkable effects may be gained with such material, especially when carried out on a large scale, your patrons who either take care of their grounds themselves, or who put them in charge of inexperienced help, are not apt to be very successful with such plantings. Furthermore, we have to consider the hardiness of the plants themselves. So I have tried to make up a list of such as are best known and not only used for this purpose alone, but often found in the hardy border as well.

\begin{tabular}{|c|c|c|}
\hline AQUTLEGIA & LATHXRUS LATIFOLIUS & Primula polyanthus \\
\hline ARABIS ALPINA & LUPINUS & Ranunculus acRis fl. pl. \\
\hline Aster (dwarf sorts) & Heuchera SANGUINEA & SEDUM ACRE \\
\hline BeLLIS PERENINIS & HeLianthemum & SEDUM SPECTABILE \\
\hline GAMPANULA GARPATICA & LYCHNIS & SEDUM ATROSANGUINEUM \\
\hline CERASTIUM TOMENTOSUM & Mertensia & Shasta Daisy \\
\hline Dianthus (hardy Pinks) & Myosotis & STOKESIA CYANEA \\
\hline FUNKIA & PaPa VER NUDicaUle (Ice- & ThaIICTRUM DIPTEROCAR- \\
\hline $\begin{array}{l}\text { GEUM ATROSANGUINEUM } \\
\text { LILY OF THE VALLEY }\end{array}$ & $\begin{array}{l}\text { land Poppy) } \\
\text { Platycodon } \\
\text { PHLOX SUBULATA }\end{array}$ & $\begin{array}{l}\text { PUM } \\
\text { VINCA MTNOR }\end{array}$ \\
\hline
\end{tabular}

Most of the above are described elsewhere. With the exception of two or three, all of them will do for sunny positions, yet they can be successfully grown even in partial shade. In cases where a part of the garden is exposed to too much shade, one might consider gradually running it into hardy ferns and using Spring-flowering bulb stock such as Tulips, Narcissus, Scilla, Crocus, Snowdrops and Iris, and such plants as Aquilegias, Mertensias, Iceland Poppies, Funkia undulata, media picta and other early flowering perennials in connection with the ferns, and perhaps Vinca minor for a ground cover.

\section{DESIRABLE HYBRID TEA ROSES FOR OUTDOOR FLOWERING}

The average retail grower hasn't use for a great assortment of Roses in supplying his patrons with stock for planting out. A half dozen good sorts are often better to carry than twenty-five doubtful ones, yet there are times when more of an assortment is wanted.

In such a case a list made up by the florist or the Rose specialist isn't of as great value as one selected from varieties which have 
actually proved to be desirable, having been planted and grown outdoors for a number of years. The florist usually has facilities that enable him to take better care of his stock over Winter than the amateur, while those growing on plants for the market are generally located in sections where mild Winters are the rule.

At "Egandale," the beautiful estate of Mr. W. C. Egan at Highland Park, Illinois, 290 varieties of Teas and Hybrid Teas were growing in the open ground in the Spring of 1922, and the following list of thirty varieties was chosen from this assortment. With the exception of the extreme northern section of the United States, I doubt whether there are any other localities with more severe climatic conditions than prevail in northern Illinois. It is safe to say that any Rose that does well there, and which, with a little protection, will pull through Winters when the thermometer is likely to go down to 20 deg. below zero, will do well elsewhere.

I have watched the Roses at Egandale and feel satisfied that the following list, compiled by Mr. Egan at my request, consists of varieties all of which belong to the Honor Class, such as every florist can recommend to his patrons. This is not to say that these are the only good sorts; there are plenty of others and some of the new excellent varieties, especially such as Columbia, Butterfly and Hoosier Beauty, are among them.

\section{Thirty Roses That Have Made Good}

Mr. Egan says: "The following thirty Tea Roses were planted March 31, 1915 at Egandale and were still in good condition in the Spring of 1922 - ready to produce their eighth season's blooms. Three plants of each of forty-two varieties were originally planted, and the list shows the survivors. The remaining twelve were discarded on account of weakness and a tendency to mildew or black spot, or just because they would not do well; some of them would not last over Winter although protected.

"The figures opposite the variety names indicate the average number of blooms each plant gave in the Summer of 1916:"

\begin{tabular}{|c|c|}
\hline Garoline Testout. ........ & Lieutenant Garle... \\
\hline Dughess OF WELLINGTON. & Lieutenant Chaure. \\
\hline EARL OF WARWICK. & Loutse C. Breslau . . \\
\hline Ecarlate. ........ & Madame E. Rostand. \\
\hline Farbinkonigin. . & Madame Jules Bouche. \\
\hline Florence Pemberton. & Madame Leon Pain.... . \\
\hline GENERAL McArthuR. . & Madame Melaine Soupert. \\
\hline Grosherzog Frederick. & MRS. Aaron WARD... \\
\hline Gustay GRUNNEWATD . . . & MrS. A. R. WADDELL. \\
\hline KILLaRNEY. . . . . . . . . & Mrs. W. C. Miller. \\
\hline LA Tosca.. & Ophelia.... \\
\hline Lady Alice Stanley. & Phariseer. \\
\hline LADY AshTON. . . . . . . & ANCE. . \\
\hline Ladx Pirrie. . & VISGOUNTESS FOLKSTONE \\
\hline ADY UI & IILLOWMERE. . . . . . . . . . \\
\hline
\end{tabular}




\section{DESIRABLE TREES FOR LAWN AND STREET PLANTING}

$\Lambda \mathrm{T}$ a first glance, it may seem somewhat out of place to treat A trees here, and also to mention only sixteen of the many kinds there are to choose from. There are occasions, however, where it is well for the florist, especially if he is interested in outdoor work, to be acquainted with at least a few of the trees which, while not at home everywhere in the United States, are nevertheless among the most popular. There are beautiful trees in the South, both evergreen and deciduous, that we cannot do anything with in the North or Middle West, and the same holds good with many of the varieties grown along the Pacific and North Pacific Coasts. But for all that, the sixteen sorts described in the next few pages are grown on by nurserymen more than any others, and are used for lawn and street plantings in the same proportion.

\section{Growing vs. Buying Your Trees}

The smaller a tree, the more easily it will become re-established, and there is no good reason why the local florist shouldn't handle at least small trees, such as he can have easily shipped by freight from his nearest nurseryman. To handle large trees you must have proper equipment, and it isn't likely that you will ever compete in that line

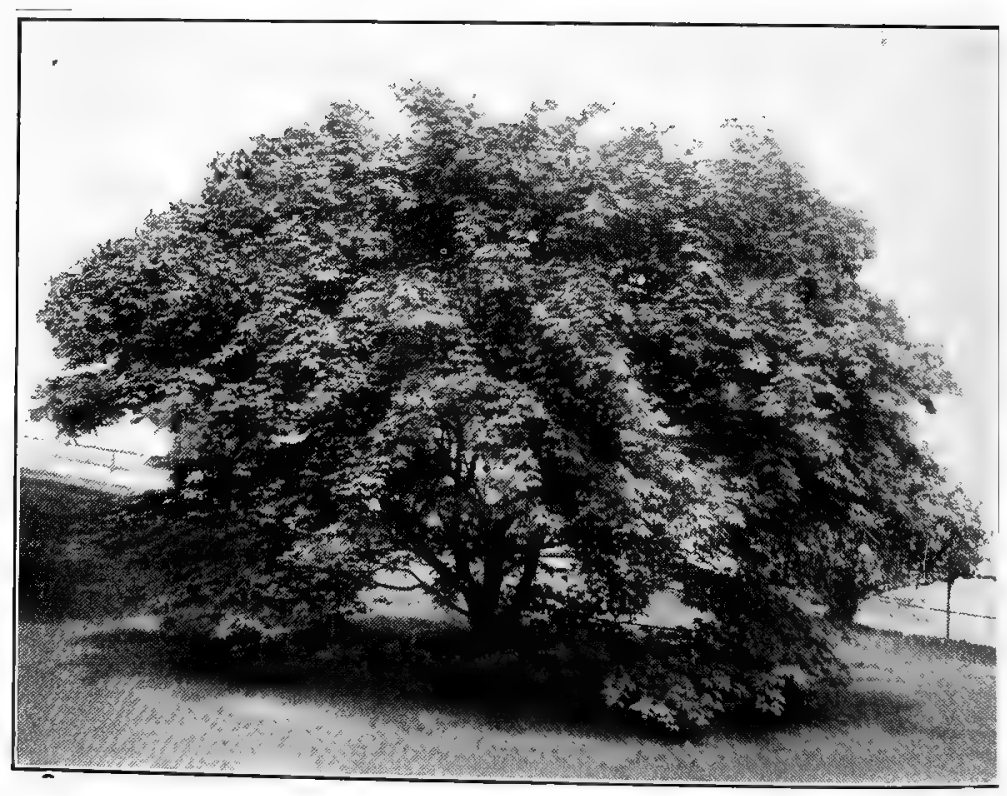

Fig. 78.-ONE OF THE Popular Mapues. Acer polymorphum, the Japanese Maple, is a favorite specimen for lawn planting on account of its rich coloring no less than its graceful form 
with the nurseryman. Nor will he, if he is at all liberal minded, feel bad about your selling small trees. As stated elsewhere, if you have the room to spare, plant a few of the varieties most popular in your section and let them grow into money. Up to 5- or 6-in. almost any tree can be handled without much machinery and yet will bring a good price.

Of course, a great deal depends upon how far a good nursery is located from you. If it is at all near, you may find it just as profitable to take the orders and have the nurseryman deliver the trees for you. You will have to decide that yourself, but in either case it won't hurt you to become acquainted with a few of the many good trees there are.

In planting trees of any kind bear in mind that the heavier the soil, the more liberal you should be in digging the holes for them. You can never overdo this-never. While you do want to pack the soil around a newly planted tree as solid and firm as you can get it, the deeper you have cultivated the soil in which the roots can go, the better success you will have. Good soil and a liberal amount of well decomposed manure mixed with it are things that every tree will appreciate.

Here are the sixteen trees I would suggest that every retail grower get familiar with and handle if the opportunity offers:

$\begin{array}{llll}\text { Ash } & \text { Ghestinut, Horse } & \text { Maple, Norway } & \text { Mountain Ash } \\ \text { BeEch } & \text { Ellm } & \text { Maple, Sugar } & \text { OAK } \\ \text { Birch } & \text { Linden } & \text { Maple, PuRpe-leaf } & \text { Plane } \\ \text { Gatalpa } & \text { Locust } & \text { Maple, Gut-leaf } & \text { Poplar }\end{array}$

\section{Ash (Fraxinus americana)}

The White Ash is one of the finest of our native trees and attains an enormous size. We often find it in low, marshy places, or, again, on high ground where it seems to thrive equally well, though growing more slowly. The thing that people often object to about both the White and the Black Ash is not that they have anything against the tree itself, but the fact that it may already. grow in its native state in the neighborhood they live in.

Ashes should always be planted where the trees will have plenty of chance to grow without being crowded. They will grow in time as tall as any tree we have, yet their shade is not so dense as that of Maples or other trees beneath which grass often cannot be made to grow.

\section{BEEGH (FAGUS)}

The Beeches make great trees, and where they do at all well, should be included in an assortment. One of the most showy is the Copper Beech (Fagus sylvatica purpurea) with its copper-colored leaves and spreading habit-an excellent lawn specimen. 
Fagus pendula is the name of the Weeping Beech. While not to be considered in the same class with Norway Maples, Elms, or Ashes, this Beech makes a beautiful, graceful specimen for the lawn. With its wavy, large leaves and the branches of a weeping habit, it is especially adapted for the smaller home ground.

You may experience a little trouble in getting the tree under way and a good way is to give it a severe pruning at the time of planting. But, really, that holds good with all trees.

\section{Birch (Betula)}

There are a number of fine Birches, but the most showy is the white-barked Birch, which we find native in many sections of the country. You don't want many of this sort on the home ground, but when properly placed a clump or group of them combined with other trees and with a group of evergreens or conifers in the foreground or background, always gives a picturesque setting for a Winter effect, which is what we in the Middle West need so badly. More attention should be given to the Winter landscape when we have so many beautiful evergreens and trees and shrubs with highly colored bark to choose from. The weeping white Birch makes one of the most beautiful and graceful of weeping lawn trees. It should be planted alone and given plenty of space for development.

\section{Gatalpa (Catalpa speciosa)}

The Catalpas are among the last trees to leaf out in Spring, and the first to drop their foliage in Fall; in a dry season they are past their best even before Fall sets in, yet they make fine trees, and are often planted for the flowers that load them down in July. As with some other trees, not as desirable as they might be, we often use Catalpas just for variety's sake. Catalpa Bungei makes an attractive lawn tree, especially when you have specimens with 8-ft. stems or trunks and perfect tops. We see them used on terraces, in formal gardens, and for lining driveways where, with just a little pruning, their heads can be trained into perfect globes, similar to those of Bay Trees.

\section{Elm (Ulmus)}

The Elm is, perhaps, the most stately of all our trees, and the older it grows, the more beautiful and majestic it becomes. This is not to say that even young trees 3- or 4-in. in diameter are any less desirable, for they are fast growers if planted in fair soil, doing equally well in low or high ground. But we notice that they suffer when passing through a hot, dry Summer. The Elm is one of the trees requiring careful pruning and thinning out when small, so as to lay the foundation for its future development. Of the eight or ten varieties none is more desirable than Ulmus americana, the American Elm. 


\section{HoNEY Locust (Gleditschia triacanthos)}

We use the Honey and other Locusts for bank and bluff plantings, or where slopes are to be held. Like the Willows and Russian Mulberries, they grow great root mats and so hold the soil in place. The Honey Locust, however, will also make a fine tree, and its wood is as hard as anything you want to saw. The tree not only has beautiful foliage, quite distinct from that of other trees such as Maples, Elms or Horse Chestnuts, but its beautiful white flowers make it still more desirable. You can use it for either lawn or street, and while it grows straight up when crowded, it makes a fine shade tree if given plenty of room.

\section{Horse Chestrut (AEsculus Hippocastanum)}

Why not grow more Horse Chestnuts? There are plenty of sections, especially throughout the great Middle West, where these fine trees will do well, both for lawn and street planting. Yet much less desirable ones are made use of. Like the Norway Maple, when once established, they will develop into magnificent specimens with but little care. They are ornamental, interesting, excellent shade trees, and a highway couldn't possibly be lined with anything more becoming. There are white flowering and red flowering sorts and even double varieties of both. The white flowering one is the best known and even as a small tree it is showy. The double white Horse Chestnut makes a most showy flowering tree, but, unlike the single form, produces no fruit.

\section{Linden, European (Tilia plalyphyllos)}

The European Linden is a fast grower, much valued for its delightfully fragrant flowers, and a most desirable subject for lawn planting. The tree is of pyramidal form and fine habit. Tilia americana, or American Linden (also called Basswood), also makes a fine permanent tree with leaves of a lighter green and somewhat smaller. There are also several other varieties, all good and well worth having either as lawn or street trees. The Silver Linden is another desirable tree on account of the silver grayish color of the underside of its leaves. Finally, the weeping or drooping Linden makes a handsome lawn tree.

\section{Mountain Ash (Sorbus)}

Both Sorbus americana, the American native Mountain Ash, and Sorbus Aucuparia, the European Mountain Ash, are handsome trees for the home grounds. They not only have fine foliage, desirable because it is different from that of the Oak, Basswood or Maple, but also are highly valued for the clusters of reddish berries with which the trees are loaded during the Summer and Fall months, 


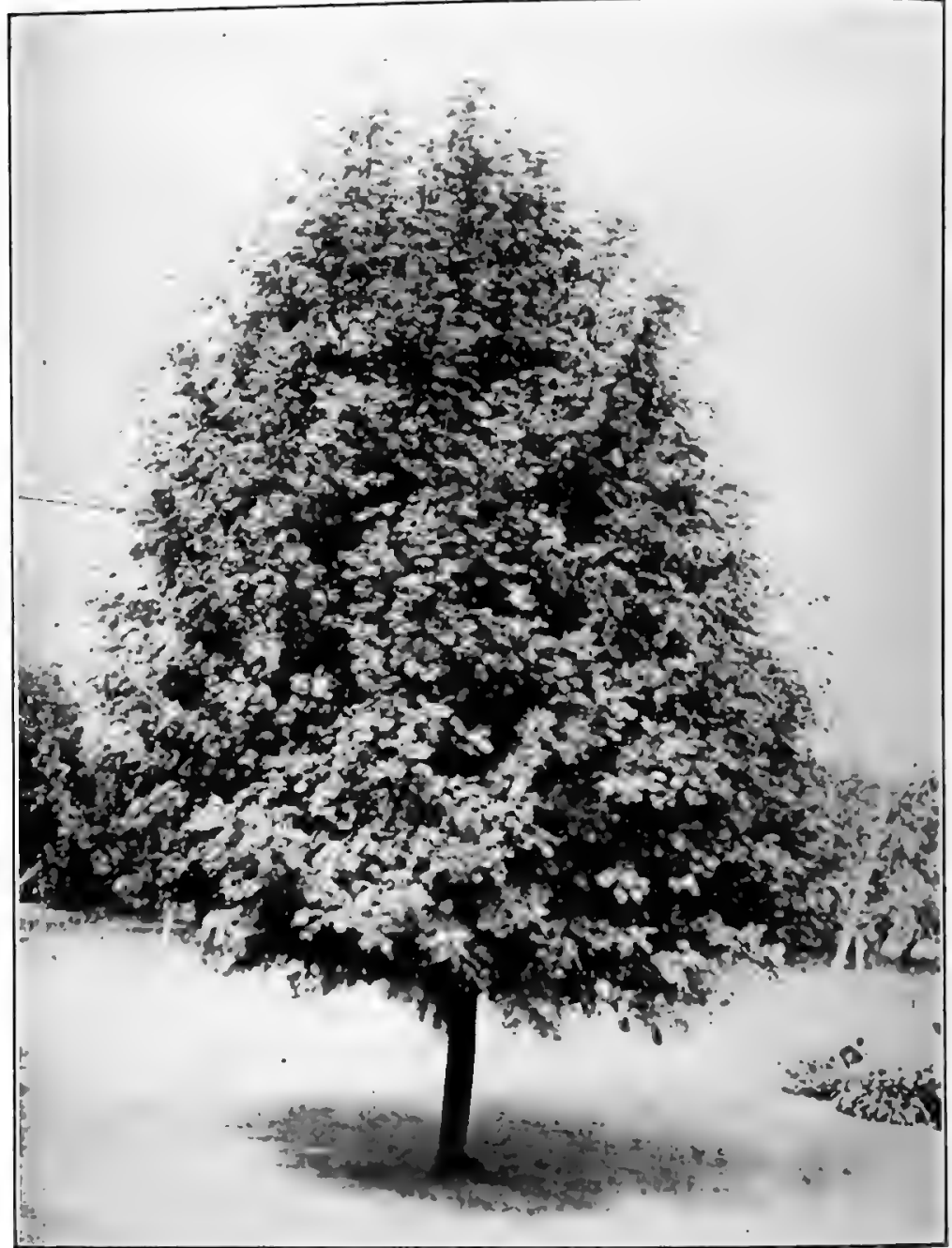

Fig. 79.-The Even-attractive Monntany Ash on Rowan Tree. A rather small tree and of slow growth but excellent for lawn planting, with its handsome foliage, brilliant yellow flower clusters and bright red berries lasting well into Winter

and which make them most attractive. All trees that have showy flowers, such as Horse Chestnuts, Catalpas, and Locusts, and the Mountain Ash with its berries have a place on the home grounds, and it is for the same reason that one should always consider fruit trees as well. Even if a Pear, Apple, or Plum never bears a fruit, the few days such trees are in bud and bloom well repay you for all they cost and the room they take up. By the same reasoning a Mountain Ash should be in every collection. 


\section{Norway Maple (Acer platanoides)}

It may take a lifetime for a Norway Maple to develop into a good sized specimen, yet even at that it is well worth planting, for it is one of the most beautiful of all trees. It is at its best when given room to grow, and if you have to crowd it in with other trees, its beauty can never be appreciated. Give one plenty of room to spread out in and a pruning knife will hardly ever be needed to get it into shape. When planting a Norway Maple, always start out with a straight tree, even if you have to pay extra for it; make the hole about five times as large as seems necessary; and fill it in with good soil.

\section{OAK (Quercus)}

When we speak of a "magnificent Oak" we have in mind a tree perhaps 100 years old, which has had a chance to develop and spread over a great area. Trees in the woods have no chance for that and too often we judge Oaks. in general by such specimens. This is wrong, for the White, Red, Pin and Scarlet Oaks are well worth careful consideration and frequent use in planting home grounds. It is a healthy sign that nurserymen all over the country are growing on some of the desirable Oaks by the thoussands. This makes it possible to obtain small and larger size trees with masses of fibrous roots which make their transplanting easy. This is not the case with native or field grown stock.

\section{Plane, Oriental (Platanus orientalis)}

The Plane, although a fine tree, does not interest those located in the country as much as those in the cities, for few other trees can stand more or thrive better in the narrow parkway of a city street and the environment that goes with it. It will do fairly well where a Maple or an Elm wouldn't amount to anything, and while there are other trees to be preferred for lawn planting the Plane is among the most desirable of all for streets and avenues. The creamy white color of the trunk and branches disclosed by the peeling off of the bark in late Fall makes this Plane a desirable tree for Winter effects, in which it forms a decided contrast to other trees in the landscape.

\section{Poplar (Populus)}

For quick results and immediate effects Poplars will always have a place among trees for the home grounds; moreover, we find Poplars of some variety grown over a wide area, even away up in Northern Alaska. The Carolina and Lombardy Poplars are often used where the space doesn't permit more spreading trees. The latter grow in the form of a column with branches all the way from the ground. It is also fine in a background planting, or to supply 
a skyline effect not possible with other trees. The Silver-leaf Poplar is desirable because its leaves are always in motion and are silvery underneath, while the Carolina Poplar is the most desirable for a border planting, or where you want to hide an unsightly outlook quickly.

\section{Purple-Leaf Maple (Acer platanoides Schwedleri)}

The red- or purple-leaf Maple is among the showiest of all the trees during early. Summer on account of the beautiful coloring of the leaves, which, however, don't retain this color all through the season. Although it is a hard Maple, so that the tree grows more beautiful the older it gets, even small trees $8 \mathrm{ft}$. in height and hardly over $1 \mathrm{in}$. in diameter are attractive because of the reddish-purple leaves. This is one of the trees which it will pay the florist with a small nursery to plant and grow on. Somebody in your neighborhood will some day want all you have.

\section{Sugar Maple (Acer saccharum)}

Those who don't want to wait for a Norway Maple to develop into a good-sized tree should plant the Sugar Maple. It grows faster, and if given a fair chance, will also grow into a fine specimen. There

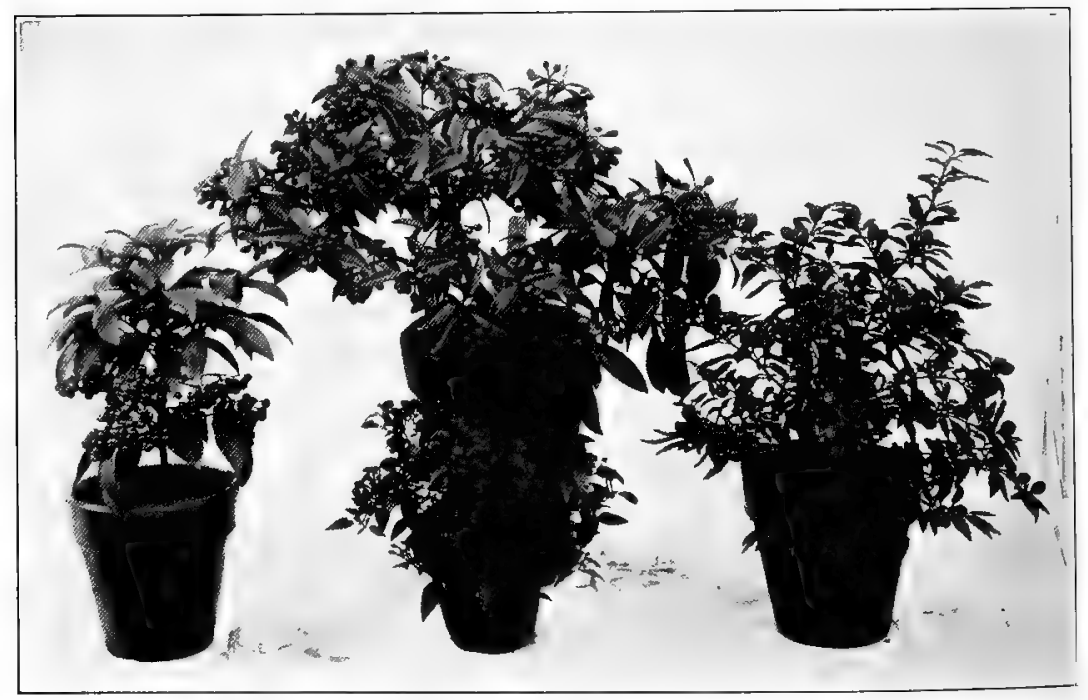

Fig. 80.-Four Popular and Reliarle Fruiting Plants for Winter Sales. At left, Ardisia crenulata; center rear, Skimmia japonica, sometimes grown outdoors; center front, one of the ornamental Peppers; at right, a well-grown Solanum 
are also times when Sugar Maples can be used to good advantage and help give variety, for the leaves are of a lighter green than those of the Norway Maple and have a silvery tint on the under side. Sugar Maples are among the finest trees for coloring in Fall, and for that reason, if for no other, deserve a prominent place in the home grounds, where well-colored Autumn foliage is as important and desirable as flowers are during the Summer time.

\section{Wier's Cut-leaf Maple \\ (Acer dasycarpum (saccharinum) Wierii)}

I like Wier's Cut-leaf. Maple as a lawn tree, because it grows fast. In five or six years from the time you plant a tree $1 \frac{1}{2}$ to 2 in. in diameter, you will have a beautiful specimen with graceful branches and cut leaves. It is quite different from any other tree we have. While considered a soft Maple and not having the lasting quality of the hard sorts, it is nevertheless most desirable-though not as a street or avenue tree, because of its weeping habit, and because the branches hang down too low.

\section{MISCELLANEOUS FLOWER AND PLANT LISTS}

\section{Desirable Gut Flowers for Mudwinter}

THE main object in making out a list of eighteen desirable Midwinter flowering plants is to assist the beginner in selecting such varieties as he may desire that are best adapted for flowering from December first on up to, say, the end of February. After this time a greater variety of cut flowers can be had each day, but it is during the three previous months that we are rather limited in our assortment. I have no doubt but what if twenty-five different growers were asked to arrange the list mentioned below according to the importance of each plant, we would obtain twenty-five different arrangements. But, after all, that is not as important as the fact that these plants represent the main varieties that all of us make use of.

Roses

Carnations

VIOLETS

Freesias

Sweet Peas

LILIES
Paperwhtte Narcissi

LILY OF THE VALLEY

STEvia

Bouvardia

Galendulas

Schizanthus

Mignonette
Calla lintes

Marguerites

SNAPDRAgON

Buddleia astatica

Prtmula malacoides

Roman Hyacinths 


\section{4 \\ FRITZ BAHR'S COMMERGIAL FLORICULTURE}

\section{Ten Flowering and Fruiting Pot Plants FOR MIDWINTER}

We have no great variety of flowering pot plants to choose from around the Midwinter holidays, but I very much doubt whether, if we did have, anything could usurp the present popularity of a good red Cyclamen or a pan of well grown Poinsettias for Christmas. On the other hand, there is no doubt but that if a grower can produce any or all of these ten plants in good shape, he won't have to go much out of his way in order to dispose of them at good prices. The list is arranged according to the popularity of the plants.

$\begin{array}{lll}\text { Gyclamen } & \text { Erica } & \text { Gineraria } \\ \text { Azajea } & \text { Poinsettia } & \text { Primula (in variety) } \\ \text { Begonias (in variety) } & \text { Ardisia } & \text { Solanum (in variety) }\end{array}$

\section{Desirable Degorative Plants to Be Carried Under Glass}

For the florist retailing his crops and depending on a local trade, decorative plants such as palms, ferns, etc., are fully as valuable as flowering stock. Among such plants the following are some of the principal ones which will prove good investments. Most of them, with just ordinary care, will thrive and increase in value rather than becone useless as is the case with leftover flowering plants. The most important ones head the list.

\author{
Kentia Forsteriana and $\mathbf{K}$. Bel- \\ MOREANA \\ Phoenix canariensts and P. Roebelenit \\ NePHROLEPIS in variety \\ AREGa LUTESCENS \\ LatanIa BoRBonica \\ Cocos Weddelliana \\ ASPIDISTRA LURIDA
}

\author{
Araucaria \\ Dracaenas in variety \\ Pandanus Veitchit \\ Crotons in variety \\ Euonymus \\ Aucuba \\ Ficus elastica \\ Cycas revoluta
}

\section{Ten Desirable Hardy Glimbers}

From the florist's point of view, such climbers as will in the shortest possible time make a showing are the most desirable. Even those who don't do landscape work are frequently called upon to furnish hardy climbers in preference to annual sorts such as Cobæa scandens and others.

Roses (Ramblers and other climbing sorts)

HONEYSUCKLE (Lonicera)

Glematis in variety

AMPELOPSIS in variety

BitTer SweET (Celastrus)
Dutchman's Pipe

Wistaria

Matrimony Vine

AKEBIA

Kudzu Vine (Pueraria) 


\section{PART TWO}

a CUltural MaNUAL FOR THE RETAIL GROWER 


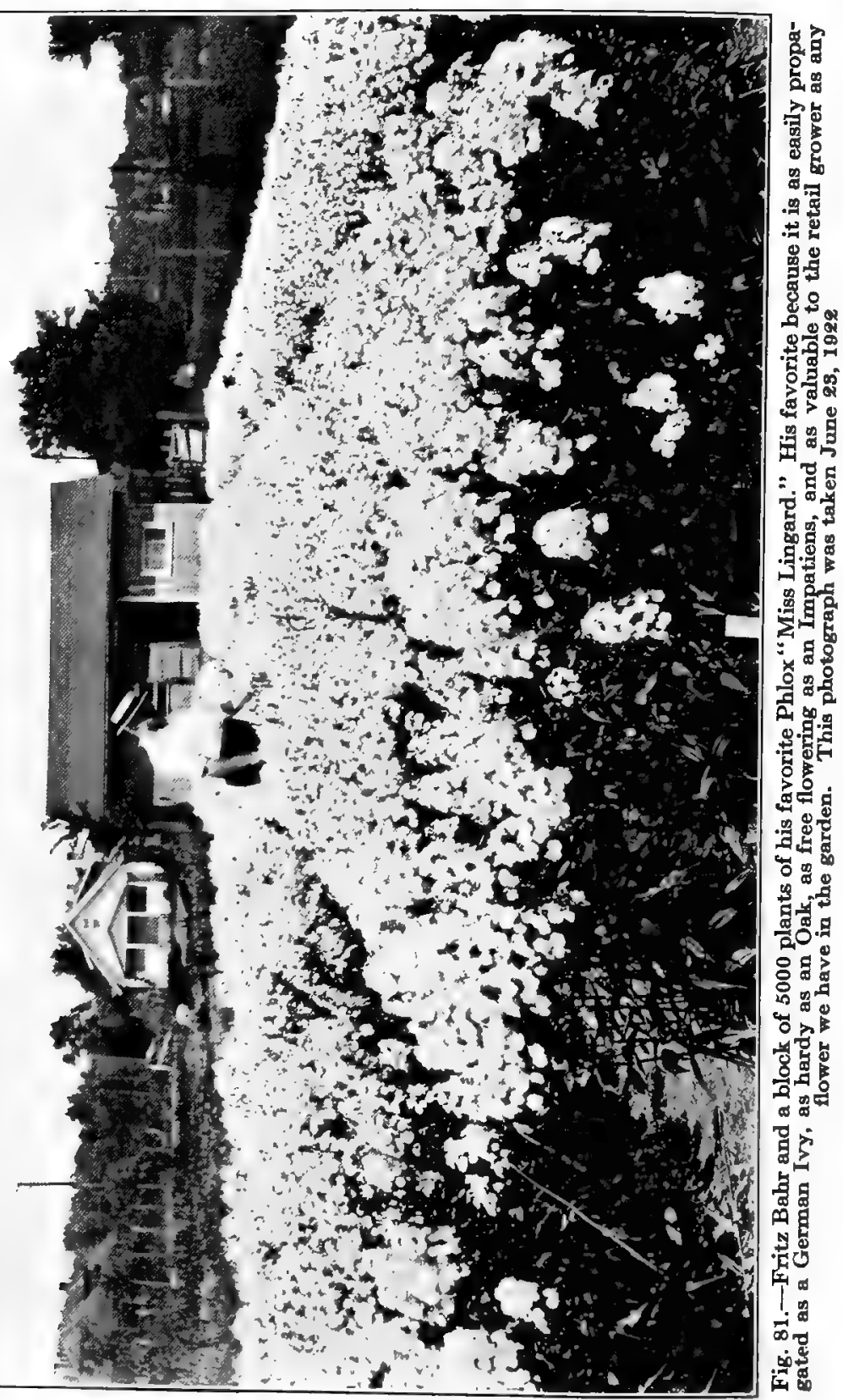




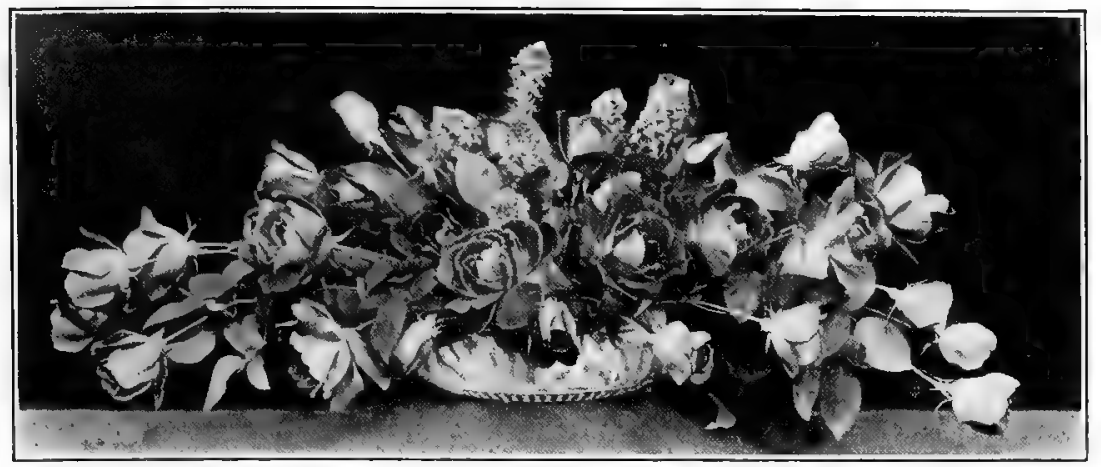

\section{PART TWO}

\section{A CULTURAL MANUAL FOR THE RETAIL GROWER}

TN the following pages will be found, alphabetically arranged, the different plants used by the florist. Except in a very few cases, I have written the descriptions and cultural notes from my own personal acquaintance with them, and have dwelt upon each according to its importance to the florist, pointing out just what its usefulness consists of, and how to handle it so as to obtain the best results.

Outside of a dictionary of gardening it is impossible to compile a list of plants in which every variety is represented, and after all, such a list wouldn't be of nearly as much value to the retail grower as one that makes him acquainted with the actual "bread-and-butter" sorts. This I have tried to supply, even going so far as to omit the names of quite a number of plants which, while desirable, are of but little interest to the average florist; some I have omitted because we have other more valuable plants which, to some extent, take their place and bring better returns.

I have also dwelt but briefly on the different and most uptodate sorts of, for instance, Roses, Carnations, Sweet Peas, Geraniums, Cannas, Peonies, Iris, Phlox and other plants, for the reason that while these plants themselves are among the most popular, they have long been so, and no doubt always will be. With each year the number of their varieties changes and increases. The most complete, uptodate list today is out of date tomorrow-which, by the way, is the best possible indication that we are going forward. 


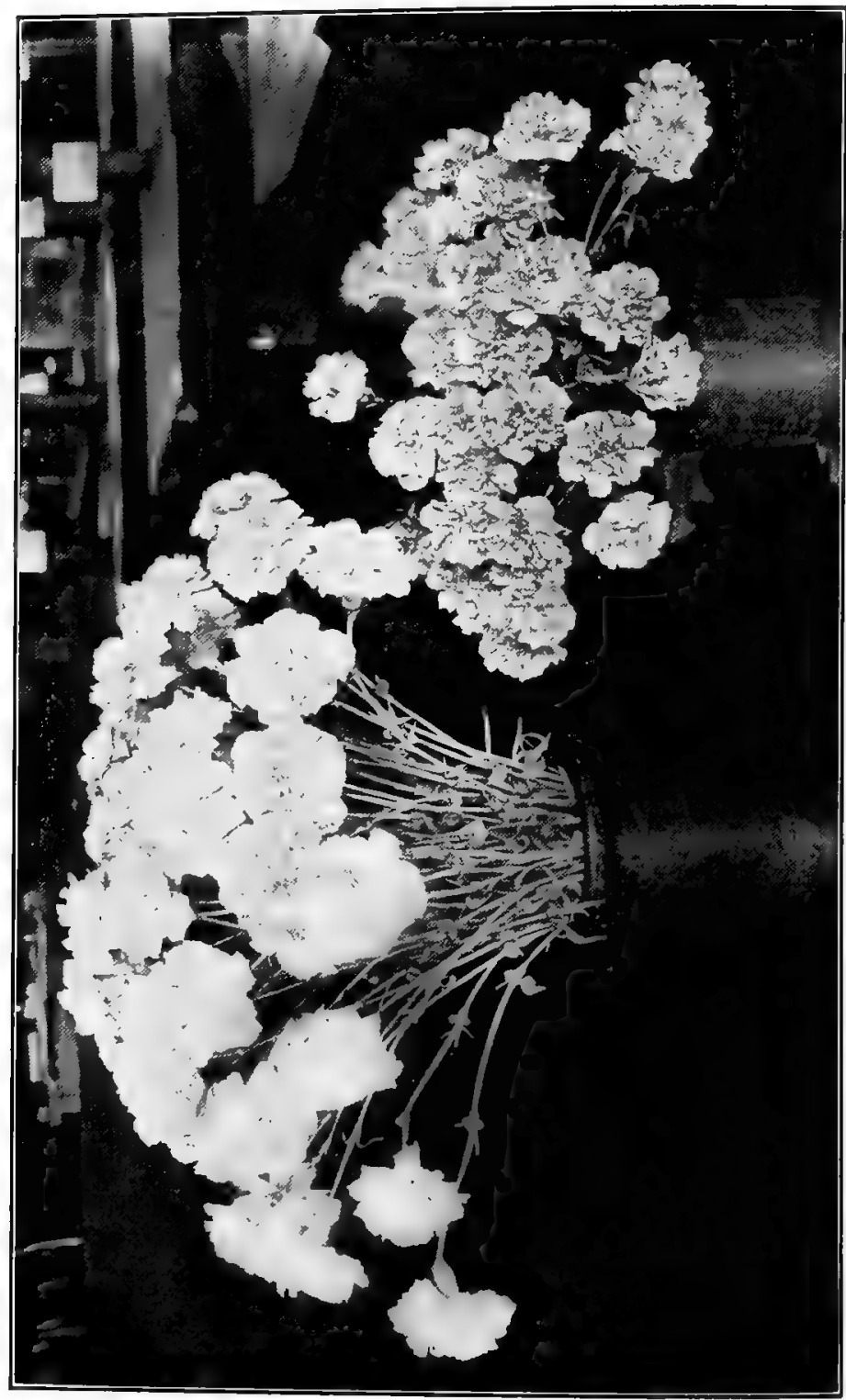

돌ํำ

동

员

ส

今.

$\sum \frac{\pi}{3}$

趂

영

$\frac{1}{8}$

变寒

要要

\%

ตี

是

y

훙

\%०。

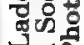

롱

पै

唍

Ф0

당

要递

最密

द

弯泀

苗年

3.

목.․․․

Z:

亩客

혀

4 요

옹용

볼

당

1.

oi:

뭉

空 
More hybridizing is going on than ever, which makes it possible for the florist to keep step, like the worker in other lines. True, many so-called novelties prove worthless, but that cannot be helped. We need only look back a few years in order to realize the progress made in the development of plants and flowers. Yet, as with all other things, we have only begun, just started on our way; the highest type of anything in the way of a flower now holding the center of the stage, is likely to be pushed aside overnight to make way for a still higher type, and this is going to keep on and on.

Here and there we come across a festiva maxima Peony, a S. A. Nutt Geranium, or an Enchantress Carnation; again, with all the many beautiful Roses coming along, we perhaps have none to equal the beauty of some of the oldtime favorites among the hybrid perpetual sorts. But as a general rule, only the latest and best and such varieties as are best adapted for present day methods of handling, will prove worth growing.

What has become of our list of favorite Sweet Peas of a few years back? Of Snapdragons, Carnations, Cannas, Petunias, Begonias and others? It is only in recent times that we have grown Chrysanthemums, Sweet Peas, Gladioli and Calendula under glass as we are doing today. What did yesterday's list of perennials or shrubs consist of compared with that of today? Yet the very lists that we are so proud of right now, will in turn soon be out of date!

Look at a vase of fifty well-grown, long-stemmed Columbia, Russell, Premier, or Ophelia Roses, and it is hard to believe that new varieties are on the way to replace them all. It seems only yesterday that Killarney was the most popular Rose grown under glass, and only a little earlier that Bridesmaid had replaced all other pink Roses; it is no less interesting for the Carnation grower or the Cyclamen specialist to look backward-he who thought his flower had reached a state of perfection forty years ago.

With so many beautiful and improved types of flowers on hand today, we can look forward to still greater developments in the introduction of new. sorts. The florist should keep posted on all such developments as may directly interest him. In order to get the most out of his business, he must keep step with the times.

There are beautiful plants that we don't grow today. What, for instance, would there be in it for the retail grower in particular, if he were to carry a house full of Camelias-a plant of which, thirtyfive years ago, every florist had a stock. Stephanotis and Asclepias used to be desirable plants for cut flowers under glass; both of them were beautiful as well as useful in their day. Even Pașsiflora, the Passion Flower, had a place. We thought the world of a Marechal Neil Rose under glass, running all over the house, and every retail grower handled Gloire de Dijon and Malmaison. But all these had to make way for others. 
We have to grow things that will bring the largest return per square foot of space taken up, and such as are most easily handled. We cannot afford to wait years before returns come in. The oldschool gardener regrets not seeing more attention paid to the things that were popular in his day, but the modern florist simply cannot afford to give it.

It isn't said that because you make every effort to get the most out of your establishment in dollars and cents you cannot enjoy the work, or find time to play. But if you lwant to stay in the ring, you must keep abreast of the times you live in. There are only two ways: Be uptodate or be outofdate. The man who leads in his particular line is the one who will always be ready to give a fair trial to everything new that comes out in the way of plants and flowers; he is the one who takes an interest in any and every movement making for the advance of floriculture. He himself profits most by doing so.

\section{PLANTS FOR THE RETAIL GROWER AND HOW TO GROW THEM}

\section{ABELIA GHINENSIS GRANDIFLORA}

The florist who handles shrubs and is located a little farther to the South than we are should find a place for Abelia chinensis among the desirable evergreen flowering sorts. Of medium height, it forms rather dense-growing specimens, starts to flower by the end of June, and keeps it up until late in the Fall. Its Heather-like blossoms practically cover the whole plant when in full bloom.

Being evergreen, a good way to handle the plants, especially when transplanting 3- to 4 -ft. stock, is to take them up with a ball of soil and burlap it. If this is done carefully the plants won't show any sign of a check.

\section{ABIES GONGOLOR (COLORADO WHITE FIR)}

There are a number of beautiful sorts of Abies which will grow into big specimens, and the florist who is called upon to make a planting of evergreens, or rather Conifers (to which group the Abies belong) should include some of them for the sake of variety. The White or Silver Fir (Abies concolor) is also known as Colorado Fir and grows into grand specimens. Balsam Fir is perhaps the best known of the Abies, and even as a small plant can be used to advantage when you have window boxes to fill with evergreens for Winter effect. We have customers who will choose the Balsam Fir instead of the Norway Spruce for a Christmas tree; they like the odor of the needles and think them more graceful. If you have the space, let your nurseryman supply you with a few plants. It doesn't 
take many years for them to develop into nice specimens. Abies Nordmanniana is another fine sort and Abies pectinata, the European Silver Fir, is one of the fastest growers, with dark green, glossy needles, silvery underneath.

\section{ABUTTILON}

With very little trouble one can grow an Abutilon in about six months from a rooted cutting, and have it in full bloom by Christmas. A plant with good foliage and full of pink, bell-shaped flowers such as Day Dawn will give you, is beautiful, but can hardly be compared with a Cyclamen or Cincinnati Begonia. Of interest to the florist of today are sorts such as Savitzii or Souvenir de Bonn, both of which, on account of their beautifully variegated leaves, make ideal border plants for a Canna bed; or they may be used to good advantage in bedding, as well as in window boxes. Take cuttings that are not too soft, and in September root them along with your other bedding plants, or lift a few plants, cut them back after they are potted up, carry along in a 52-deg. house, and, during February, use the young growth to propagate from. While Fall-taken cuttings may remain in the sand for three months before rooting, those taken in February and placed in sand with bottom heat will root in three weeks.

\section{ACACIA}

You cannot help but admire Acacia armata, $A$. Riceana, A. paradoxa and $A$. pubescens when in full bloom. They form a grand genus of broad-leaved ever-

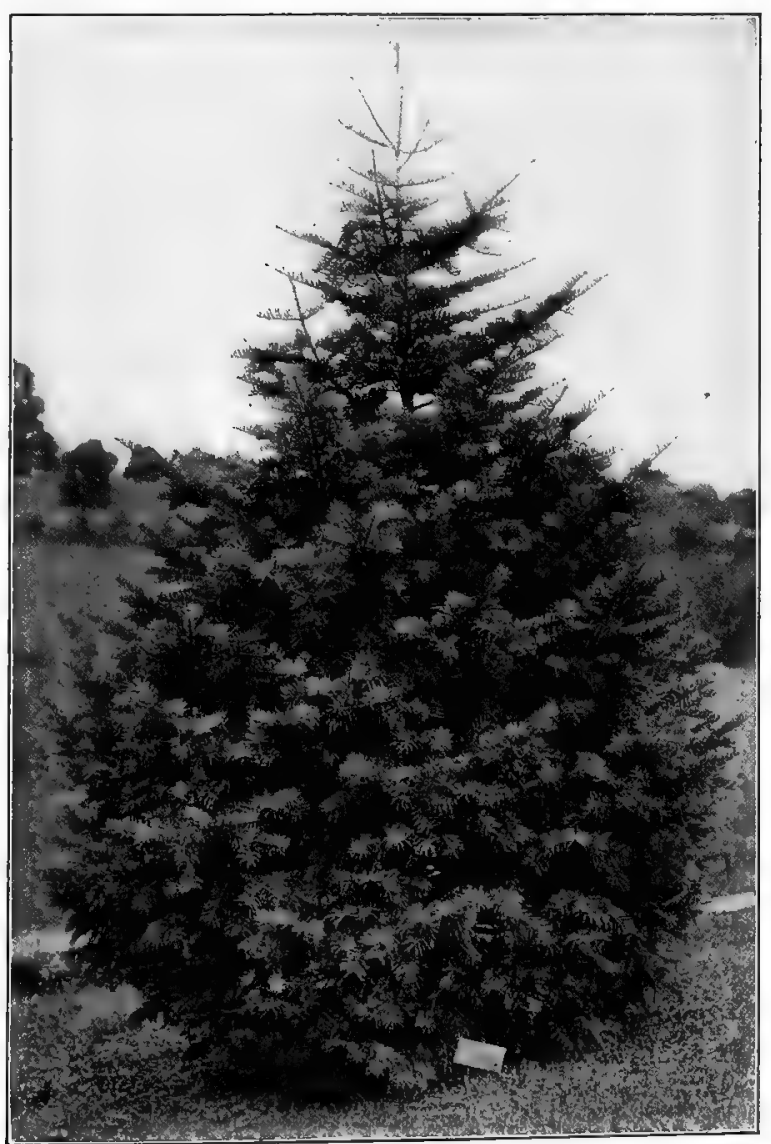

Fig. 83.-Abies congolor. The handsome, vigorous, popular White, Silver or Colorado Fir is one of the best conifers the retail grower can handle 


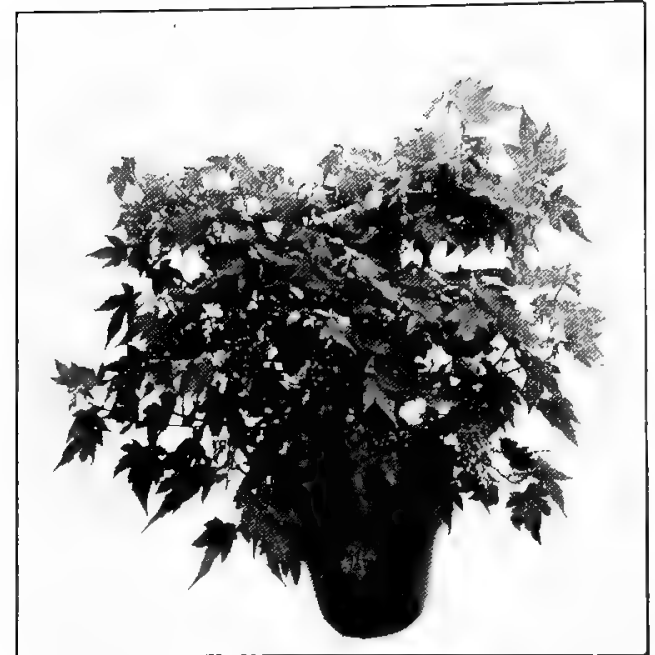

Fig. 84.-Airtilon Thompsonir. One of the many fine Abutilons that make desirable Midwinter flowering pot plants. It has orangecolored flowers and the leaves are mottled yellow and green greens; but even the sorts we grow on in pots, no matter how well done, do not compare with the beauty of Acacia trees and shrubs in flower as seen outdoors in California. To the lover of flowers having a chance to behold them there during Winter, it is worth the price of a trip, no matter how extensive.

Acacias are strictly coldhouse plants. They can even stand a light frost and never during the Winter months should they be exposed to a high temperature. While the cuttings root easily from half-ripened wood, in either Summer or Winter, it hardly pays the florist to grow them on from small plants. Let him buy a few well-established plants in 6-in. pots or over, keep them in a coldhouse, and allow them to come along slowly during February. Cut sprays of Acacias are now being shipped successfully by express from the Coast in January and later, and arrive almost anywhere in good shape. It pays even the little florist in the small town to have his wholesaler in the large city send him some, and thereby let his patrons know he is thoroughly uptodate.

Or, if you have a coldhouse with enough headroom, plant out a few good-sized plants of Acacia pubescens; you will find good use for the cut sprays. Left-over plants

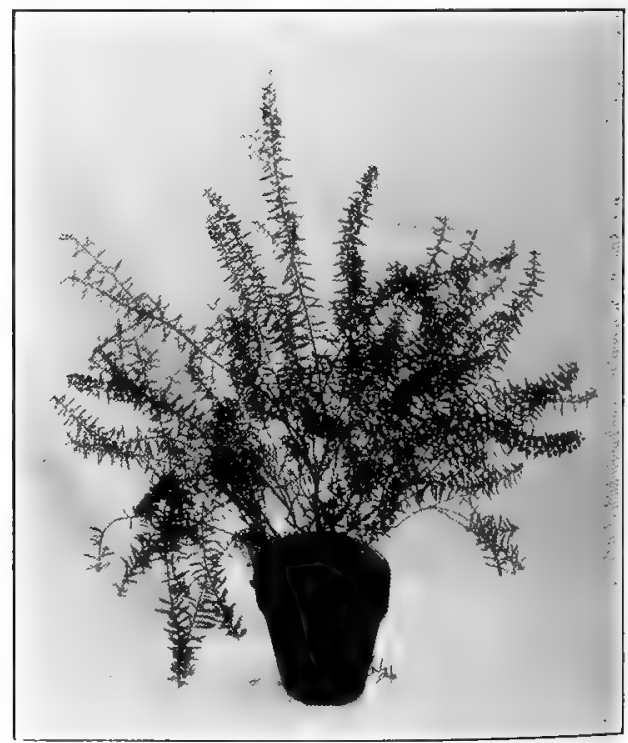

Fig. 85.-Acacia haRPophylla. One of many beautiful Acacias adapted for pot culture and early Spring flowering 
of $A$. armala or A. Riceana don't even need pruning back; give them a shift, plunge the pots outdoors or bury them all together until Fall, when they can get another shift and be brought in to the coldest house.

\section{AGALYPHA}

Some of the Acalyphas make showy pot plants, but they are best known to the florist as bedders on account of their beautiful foliage. We see them used in the public parks and on large estates where they are treated almost like show Coleus. Cuttings taken from overwintered stock plants need, like those of Coleus, a bottom heat of $65 \mathrm{deg}$. or so in order to root quickly. A. Sanderi, with its long, red, drooping flower-spikes, makes the best sort for pots and can also be used for outdoors. Among the bedding sorts we have $A$. marginata, with green and rose-colored foliage; A. Miltoniana, light green with a white edge, and $A$. bicolor compacta, with yellow blotches on the leaves.

\section{ACER JAPONICUM (JAPANESE MAPLE)}

With their beautifully colored leaves in different shades of yellow, light red and deep red, these Maples make most showy pot plants during early Spring. They are, therefore, desirable decorative material for the retailer.

You can obtain either potgrown stock or such as is in a dormant state with naked roots, from your nurseryman. After being heeled in in a deep frame up to the middle of January, they should be brought indoors, potted up in a good, stiff soil and allowed to come along slowly in a cool house. Increase the temperature a little when they are once under way, but don't subject them to a hot, dry house at any time. Lefitover plants can be planted out in the field and used again.

\section{ACHILLEA}

When you once get a row of Achillea established, and get into the habit of cutting the flowers during the Summer months, you will never want to get along without it. I am speaking of Achillea Ptarmica "The Pearl," or, what is still better, Boule de Neige, a more double sort.

The flowers of these Achilleas come ten or more on a graceful stem and resemble those of Feverfew although only about onefourth their size; they are fine for bouquets or design work, lasting for days. No other perennial can get along in poorer soil, or with less care, or is hardier. You can easily increase your stock by division, which is best done by the early part of September; or, if you 


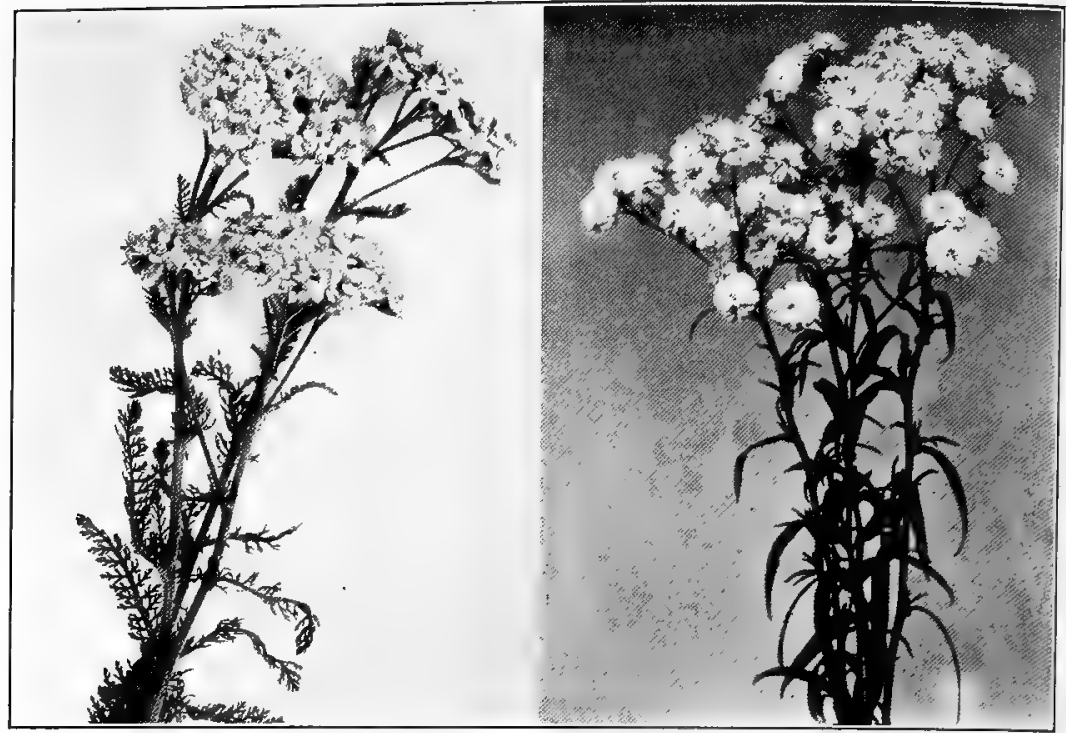

Fig. 86.-Achillea millefolium roseum (left) and A. Ptarmica flore pleno "The Pearl." The former, with its soft, feathery foliage and large heads of pink flowers is most showy in June and July and should be in every hardy border. The latter, easily grown, is hard to beat as a source of white cut blooms for Summer bouquets, alone and with other flowers

like, sow seed under glass in January. The plants will, if planted out in May, flower by July, and there are bound to be some which come single, or are not as double as others. Pull these up.

Achillea millefolium is a desirable perennial, flowering by the end of June. The flowers are quite different from those of "The Pearl," resembling more those of Spiræa Anthony Waterer (with smaller heads, of course) against a setting of beautiful green, feathery foliage. You can grow it from seed or divisions of the old clumps.

\section{AGHYRANTHES}

No matter how many irregular borders of shrubs and perennials you may lay out and plant, there always will be more or less formal bedding done, not only in the public parks, but in the home grounds, too. It is for this that you want border plants with colored foliage, to which class the Achyranthes belong. They come in various shadings. A. Lindenii, perhaps the most popular dark red, with small leaves, can be sheared into almost any shape. $A$. Emersonii has a dark crimson-colored, round leaf, and $A$. Gibsonii has a pointed greenish leaf with yellow markings. All make fine borders, can be used in connection with Alternantheras, or come in handy for window boxes to go with other plants. You can propagate from cuttings the same as with Coleus, but it takes longer to grow a fair- 
sized plant. They do not require as warm a house over Winter as Coleus.

\section{AGONITUM (MONKSHOOD)}

When your customer wants a perennial that will do in the shade, where Anchusas and Larkspurs won't, it is time for you to recommend Aconitum. With a few well-established clumps on your own grounds you will always have stock to draw and propagate from by division. The plants grow about $2 \mathrm{ft}$. and a little over in height and flower during June. Sparks' variety, with rich blue flowers, is considered one of the best.

\section{ACROCLINIUM ROSEUM}

Acrocliniums are graceful everlasting flowers of a most pleasing delicate pink color. Any florist will have plenty of occasions during Winter, especially around the holidays, to use them to good advantage. By combining them with Statice and soft greens a beautiful, low centerpiece can be arranged or a basket can be filled which will appeal to many who perhaps cannot afford expensive fresh cut flowers. As with other everlastings, don't wait to cut the flowers until they are wide open; gather them just as they are opening, put them up in bunches of twenty-five, and hang them, heads down, in an airy shed where they can remain until late Fall. It is well to sow the seed right outdoors in early May.

\section{ADAM'S NEEDLE See Yucca}

\section{ADIANTUM (MAIDENHAIR FERN)}

Adiantum cuneatum has been grown by florists since long before our time, and not so many years ago it was practically alone in the field of greens for indoor use, whether for the bride's bouquet, the funeral design, or the corsage. Since then a long row of new Adiantums, of which Adiantum Farleyense gloriosa (the Glory Fern) is one of the most beautiful, and all kinds of other greens have been introduced to take the place of the old form.

We are using today a greater variety of greens than ever before; some are shipped thousands of miles, others are grown under glass by specialists to supply the demand. Whereas, years ago, one could hardly find a florist who didn't have at least a few pots or a part of a bench devoted to the growing on of Adiantum cunealum to meet his requirements, most men now find it cheaper to purchase the cut fronds (which, if properly handled, will keep in good condition for many days) and devote their time to other things.

Those who want to grow Adiantum should have a house which can be kept at not less than $60 \mathrm{deg}$. The plant's are grown from spores, the same as almost all of the so-called table ferns. This is 


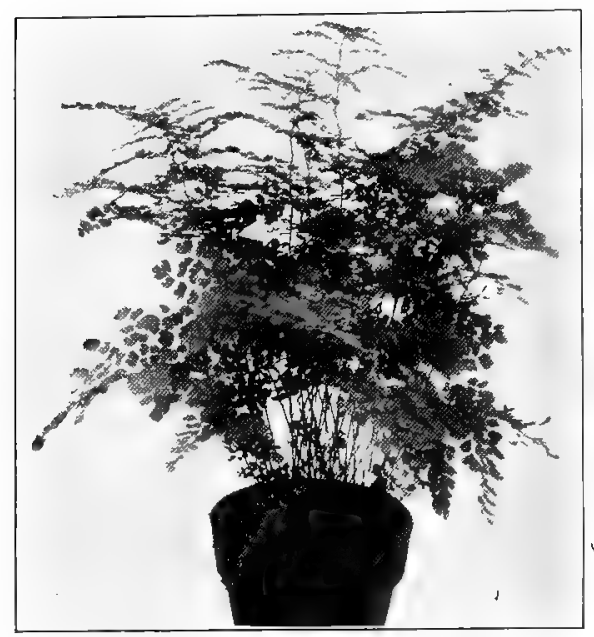

Fig. 87.-Maidenhair Fern (Adiantum CUNEATUM). Although there are several newer varieties of Adiantum, the old Maidenhair Fern is still popular and hard to beat as a light, airy green for the florist shop. If you have a warm house, a few plants always come in handy in Winter best done during the Winter months. Expose the little soil you need for a few pans or bulb-dishes underneath the grate or a clean bed of hot coals in your boiler for fifteen minutes or so to kill all weeds. Thoroughly soak the filled pans before sowing them, gently press the spores into the surface, and cover the pans with a pane of glass. After that, rather than water with the can, place the pan in a dish of water until the soil is well soaked again. The object is not to disturb the seeds. At all times keep the surface moist and maintain as near $65 \mathrm{deg}$. as possible in the house or frame you have the pans in. The young plants can later on be transplanted into a fine on be transplanted into a fine
d when large enough should be mixture of mellow loam and sand, and when large enough should be potted up. For later potting a sandy loam with one-fourth cow manure will suit them nicely. If you want to grow plants on benches, don't allow hot water or steam pipes to be directly under or near the bottom of the benches. These ferns prefer a cool footing and a welldrained, moist soil, but plenty of heat on top, and shade for bench culture. Early Spring is the best time to get busy, and well-established plants in $31 / 2$-in. pots should be used.

For pot culture the treatment is the same, and whenever you get specimens in 5- or 6-in. pots they may be divided; this is best done with plants which have been cut down and after they have been kept in a cool house for awhile to rest. Toward early Spring, when they again show signs of life, you can cut them into four or five pieces, pot them up and bring them into warmer quarters.

\section{AGATH EA (BLUE DAISY)}

The Blue Daisy, as the name indicates, is not a show flower, nor one on which a fortune can be made, but belongs to the same class as double Sweet Alyssum, Forget-me-not and Pansy. Every retail grower always has among his customers a good number who want these flowers during the Winter and early Spring months whenever they can be had, and the Blue Daisy, for the space it occupies and the care it requires, brings in as much as, if not more than, anything else grown on the place. You don't want a house 
nor a bench full of it; but if you retail the flowers you grow at home you should at least have a few plants along the edge of the Carnation bench to cut from. It flowers from Fall until Spring, and since you can use it with almost any other flower, it is excellent for design work.

You can grow Agathæas from seed. Out of the plants you get that way select one or two of the very best and after that propagate from cuttings, which root easily during the early Spring months. Grow the young stock on in pots, and by August plant out either along the edge of a Carnation bench, or on a bench by itself. If you grow a few plants there is bound to come a time during the Winter months when the flowers will come in very handy.

\section{AGERATUM}

Owing to their beautiful shades of blue, their free flowering qualities, and their easy culture, the Ageratums are not only becoming more popular every year, but also, from the florist's standpoint; are becoming more important as bedders to be sold to his customers, and for cut flowers.

We have named varieties ranging from dwarf to tall sorts. If you want a bed or border of just one color, by all means plant named sorts grown from cuttings, but if you need Ageratums for cut flowers or plants in $3 \frac{1}{2^{-}}$or 4 -in. pots in bloom by the middle of May, sow seed of Blue Perfection, or some other tall sort, by the middle of February and grow on in a 50-deg. house.

If you need blue in a window box, Ageratum is the thing to use. If you want to grow stock from cuttings, lift a few field plants in Fall, pot them into $6 \mathrm{~s}$, cut back a little and keep in a 50-deg. house. By the end of January, and from then on, you can take cuttings every week. But almost as cheap a way, and an even better one, is to purchase your rooted cuttings from the wholesale grower. Such cuttings in 21/2-in. pots by the first of April will make bushy plants in full bloom by the end of May.

Ageratum Fraseri is one of the latest introductions, and one of the best bedders of all, growing about 8 in. in height and flowering continuously all Summer.

\section{AKEBIA QUINATA}

If you handle hardy climbing plants, which many of your customers prefer to the annual ones, you will have calls for Akebias. Their clean, Cloverleaf-like foliage stays green away into Fall, and the small, sweet-scented blossoms appear in July. The vines will cling to woodwork or brick, and are really adapted for porches only where you can support them on wire.

When you order your other climbers from the nurseryman, include just a few Akebias and pot them up so they can be planted 
any time during Summer and Fall, or kept over until the following Spring.

\section{ALOYSIA CITRIODORA (LEMON VERBENA)}

Your bedding stock, no matter how large the assortment, is never complete without Lemon Verbenas. Don't be obliged to say to your customer: "We can fill your entire list of stock wanted with the exception of the Lemon Verbenas." It isn't what you make on the few plants sold during May and June that counts; you should carry them to oblige your customers.

When you plant them out you can grow six-foot specimens which, with their delightful odor, belong in every flower garden; but for stock to propagate from, it is as well to grow them on in 5- or 6-in. pots. Keep the plants in a cool house all Winter and start them into growth about February. The new wood will give you the cuttings, which root easily with a little bottom heat; pot up later on and keep shifted.

The man in need of only one hundred or so plants, instead of bothering with raising his own stock, will find it cheaper, I think, to buy 2-in. stock about April first, shift it into 31/2-in. pots, and be done with it.

\section{ALTERNANTHERA}

There are many florists who go through life without ever handling or growing Alternantheras, for these plants are really only useful for carpet bedding or grave planting.

You cannot help but admire a well laid out and properly kept carpet bed or border. You praise not only the plants in it, but also the man who was able to lay out the design, and the one who carried out the planting. Such beds in the public parks or large grounds always attract well-deserved attention. To the average florist, however, Alternantheras don't mean much; in fact, I often think the men located in the smaller towns could to their. own advantage push carpet bedding a little more. There are occasions when such a formal bed will act as a splendid advertisement. The first thing people will do when looking at one is to wonder who did the laying out, and who furnished the plants.

Alternantheras also make fine border plants where something low is wanted. In full sunlight, if not planted too close, their beautiful, ornamental leaves are always greatly admired.

Give Alternantheras heat, sun and moisture and they will grow in almost any soil. They stand still during the Winter months even in a house where Roses do their best. Take cuttings during early August and place them closely in flats filled with half soil and half sand; they will root in a few days in a frame where they can remain until September. Bring indoors to a light bench, and a house of not less than $55 \mathrm{deg}$., and let them remain there until the end of 


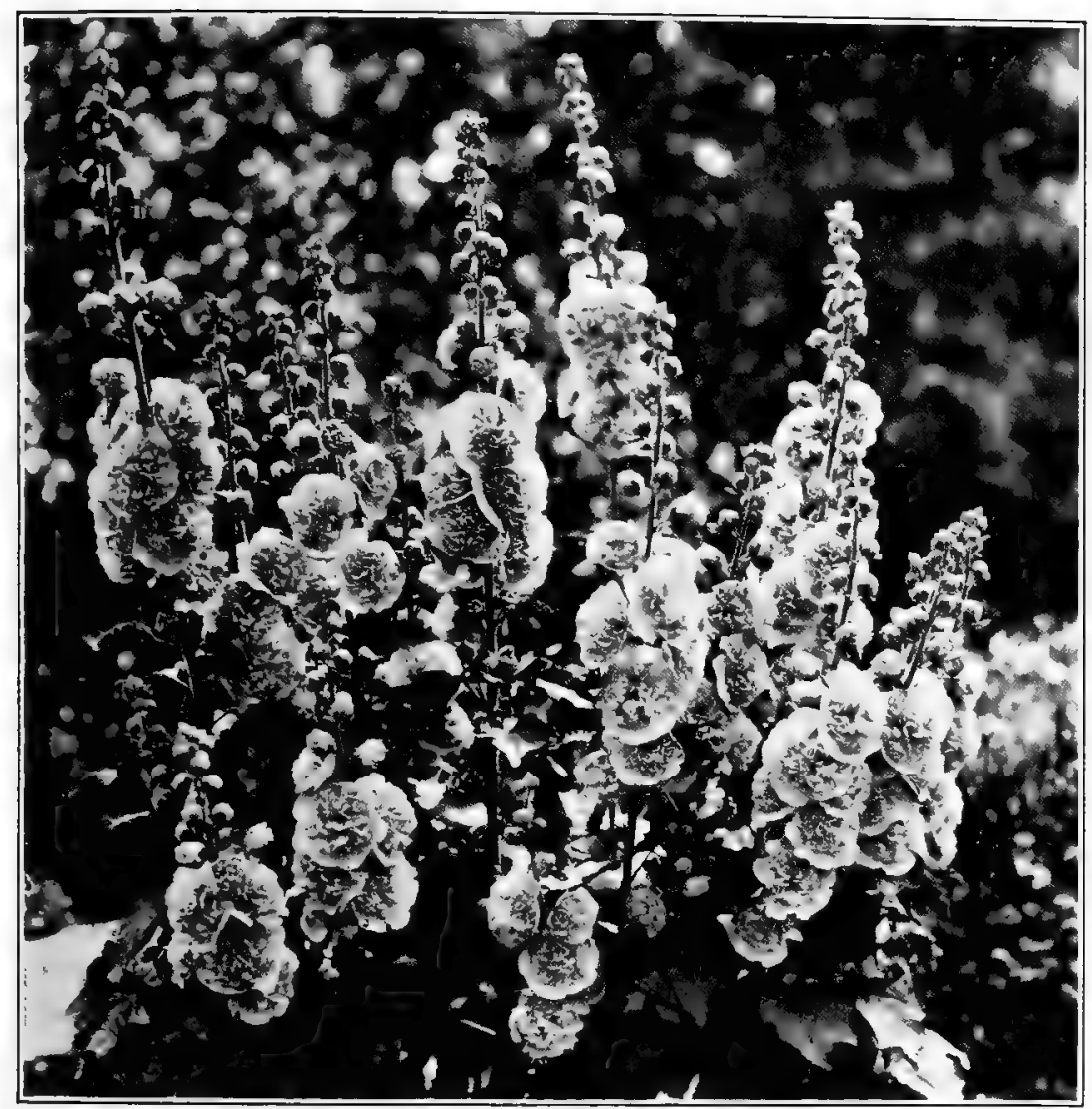

Fig. 88.-Dourle Holdyнocks. Few plants are more showy or more stately than the double Hollyhock and every retail grower should have a display of them on his home grounds

March, when the first hotbed is ready. Pot up the cuttings separately in 2-in. pots, and plunge in the hotbed, where they can remain until wanted for bedding. Among the sorts usually carried are $A$. brilliantissima, the best red shade; $A$. Swybolde, a good yellow and a heavy grower; $A$. Carroll, a dark bedder, dwarf red; and $A$. aurea nana, dwarf yellow.

\section{ALTHFA (HOLLYHOCKS)}

One cannot very well imagine a so-called "old-fashioned" garden without Hollyhocks. While their stay is but a short one compared with that of other flowers, yet when they are in full bloom hardly anything else can get itself noticed.

The day is past when we grew Hollyhocks, picked the individual flowers off the stems and sold them by the hundred (for as little as thirty or forty cents) to be used on toothpicks for design work; the 
floral pillow or the wreath in those days was covered solid with the flowers before anything else went on it. We no longer call this artistic, nor have we the time to give to such work; yet Hollyhocks are greater favorites among herbaceous plants than ever.

The florist has call during both Spring and Fall for field grown plants, or such as have been grown on in pots; he should use them whenever planting a hardy border, or when asked to furnish an assortment of hardy stock. With their colors of white, yellow, red, and beautiful shades of pink they can be used in almost any color arrangement, and but very few people object to them in their gardens. Those who don't like them double can have handsome single sorts.

To grow a strong, healthy Hollyhock, sow in the open about July fifteenth. Don't make use of a heavily manured, finely sifted soil and a shaded frame; maybe you have seen them grown by the roadside or near the fence on a farm, without the least sign of rust or other disease, while plants grown with the greatest care elsewhere have proved a failure. Transplant the seedlings later on and keep them cultivated; that is more important than keeping them soaked with the hose. By the end of September you will have heavy stock ready to sell, or to plant where it is to flower the next Summer. If you cut most of the leaves off when transplanting, the plants soon become reestablished and make a few large leaves by the time they are cut down by frost. In the case of the man who retails a few hundred plants each Spring it is as well to take up every other one, letting the rest remain to flower.

Usually, it is best to cover the plants lightly over Winter, although plants need but little protection when well established. Always carry a few over in frames; they might be sold in the Spring if not needed to replace winterkilled specimens. Or they can be planted out to flower. However, the best plants will be those that were transplanted about August, and given a foot or so of space at that time. You can also sow seed about September and pot the seedlings up; keep them in a cool house and shift so as to have heavy plants in 4s by April ready for planting out. But you won't get the same results as from those sown in July.

Hollyhocks can hardly be considered good cut flowers, yet there are sometimes occasions that call for the cut stalks. In that case a good way is to cut them a day or so before they are wanted, and place them deep in water in a dark, cool place. Freshly cut and exposed in a hot room they, won't last three hours.

\section{ALYSSUM}

The double Sweet Alyssum is a very useful little plant for the retail grower. A few plants along the edge of the Carnation bench will not interfere in the least with the Carnations, but will furnish you with flowers from Fall until Spring, just what you want when 
having to make up a wreath or other floral design. Cuttings rooted during Winter will make 21/2-in. or larger plants which you need to put with other stock when filling window boxes, hanging baskets or vases; or you can plant them as a border around a Geranium, Petunia or Ageratum bed, where they will flower up to November.

The dwarf single flowering Alyssums are also much used for the edging of beds and borders, and the florist sowing seed about the parly part of March can have little plants in full bloom by early May. Little Gem is the sort mostly grown on for that purpose.

\section{AMARYLLIS (HIPPEASTRUM)}

We are apt to give the name Amaryllis to quite a number of plants with bulbs and large Lily-shaped flowers which really do not belong to that species. As a matter of fact, the so-called Amaryllis which interests the florist belongs to the Hippeastrums. These two may be alike in appearance, but the Amaryllis, like the Bella Donna Lily, doesn't flower until August, while the Hippeastrums come in bloom in February and on through March. Some of the hybrids have gorgeous large flowers, and while they are not of great value to the florist, and while flowering bulbs come rather high, a display of plants in flower in the show house is bound to be a good advertisement and a drawing card. If you never sell a single plant, you should carry a few just the same. If you start out with flowering-sized bulbs, pot them up according to size in 5-, 6-, or 8-in. pots, and carry them in a 55-deg. house.

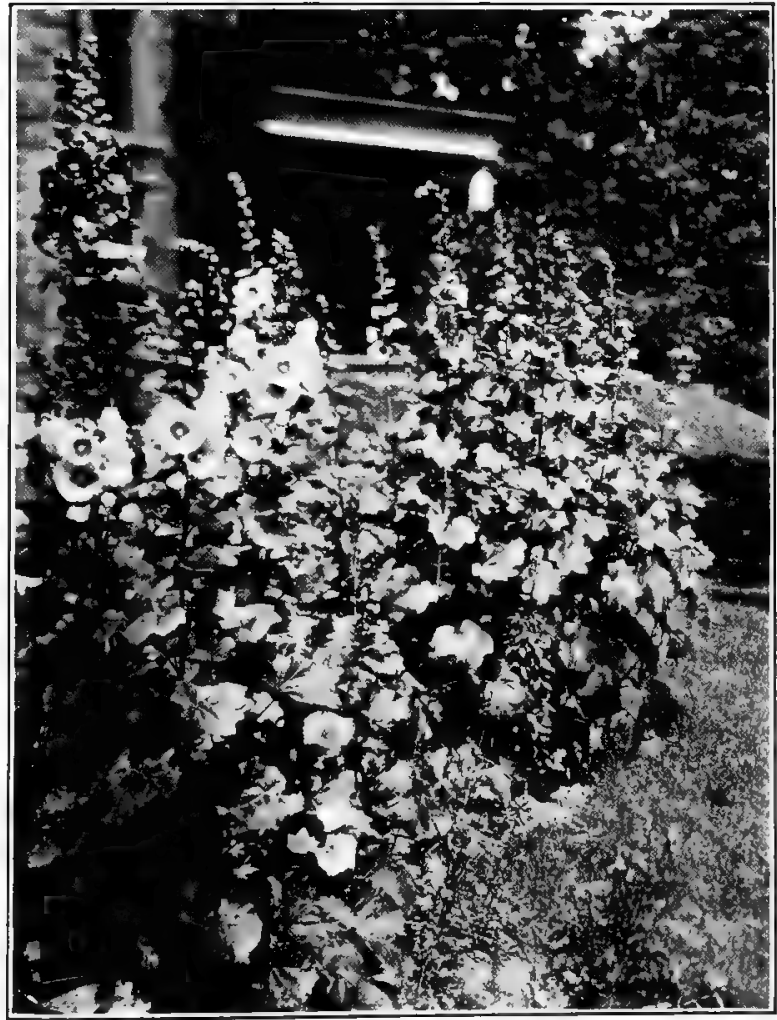

Fig. S9.-Single Hollyhocks. These, when displayed in masses are fully as desirable as the double sorts and, indeed, are frequently preferred by some of your patrons 
After they are through flowering they make their growth, so keep them dormant during Summer and then start them up again. In late Fall the plants in the large pots don't need repotting; give them a top dressing of well-rotted manure and soil thoroughly mixed.

\section{AMMOBIUM}

Ammobiums, like most of the other everlastings, are grown in great quantities by the European florists, and made use of during the Winter months, usually in design work. Here we have enough other flowers for such purposes; however, they should be classed among the desirable varieties to grow on for those who have use for everlastings. Their white flowers are produced in great masses and the culture of the plants, which are annuals, doesn't differ from that of Acroclinium. (See page 245.)

\section{AMPELOPSIS}

The Boston Ivy (Ampelopsis Veitchii) is a plant which the florist should carry not only during the Spring months in a dormant state, but all through the year in pots, so that a customer wishing to plant some, around a newly-finished residence perhaps, can do so at any time. Wherever there are stone, concrete or brick foundations the Ampelopsis can be planted and is being used more and more each year. It doesn't pay the florist to grow the plants on from cuttings rooted during August from half-ripened wood or from seed which takes two years to grow into a salable plant. Let your nurseryman supply you with nice dormant, 18- to 24-in. stock, about March; pot it into 5s after cutting it back just a little-removing the tips is enough. Then give each plant a neat green stake.

Carry the plants in a cool house and by the end of April they are just as well off outdoors in a frame, where they can remain all Summer, or until sold. Whether you or your customer plant them out be sure they are cut back to within 6 in. of the ground, for it is the new shoots that will cling to the wall, and the closer they start from the ground the better. If you cut the plants when they are potted up, you won't get as good looking plants, and you will have to cut them back again at planting time. If you want a still smaller and more graceful leaf than the ordinary Boston Ivy, plant Ampelopsis Lowii, or if you desire something heavier and of ranker growth than the Boston Ivy use Ampelopsis Engelmannii. Something still heavier but not quite as good for wall covering is the Virginia Creeper (Ampelopsis quinquefolia). Pot some up of all four; they won't take up much space and they sometimes come in very handy. 


\section{ANGHUSA}

Anchusa italica, var. Dropmore, with its brilliant, dazzling blue flowers on 5- to 6-ft.-tall stems during June, is one of the desirable plants for the hardy border.

We find that it pays us best to treat this plant like a biennial, sowing seed during early Spring under glass and later on planting the small stock in the field. By the following year the plants will be at their best.

\section{ANEMONE JAPONICA}

This is without doubt the most beautiful of all late flowering hardy plants. Not only is it in bloom when almost everything else has gone, but the flowers when cut with 2-ft. stems will last in water for days. Varieties rosea superba and Queen Charlotte are both semi-double pink sorts-most unusual colors among our late flowering perennials which mostly come in shades of white, light blue, yellow and brown. In many localities these Anemones are hardy only when planted on well-drained soil, and when they receive, after being cut down by frost, a 10-in. layer of dry leaves and a covering of manure; but they are well worth all the trouble one goes to. Whirlwind is a fine white sort, also semi-double.

Spring is the best time to plant these Anemones; plants out of $3 \frac{1}{2}$-in. pots will flower nicely the first season. If you wish to increase your stock, and have some field plants on hand, lift them, cut the roots in 1-in. pieces and lay in flats between layers of sand; keep them in a cool house, and by March place over a little bottom heat. Every piece will grow into a plant, which should be potted up and planted out later.

\section{Anemone apennina}

While the Japan Anemones flower in late Summer and Fall the tuberous-rooted ones, to which Anemone apennina belongs, bloom in early Spring. To the florist they are interesting only because, if tubers can be secured, by planting them in Fall in bulb pans and gently forcing well-rooted stock, he can get them to flower around Easter the same as Ranunculus.

\section{ANTHERICUM}

The florist shouldn't get along without Anthericum-it is too useful a plant. To begin with, we haven't a great many variegated plants, and among those we have, few are inexpensive or very hardy. Anthericum possesses both of these qualities. You can use it in a small state as a center plant in a fern dish, and when larger it will go well in a plant arrangement in an indoor window box, or a Christmas basket. You can plant it and have it do well in the shade 
where nothing else will grow, or you can give it full sunlight. That's quite enough reason for us to consider it a useful plant.

A. Mandalanum is a great improvement over the old variety; while not quite as large, it has more of a white border to its leaf. When you once have a stock in large pots, you will have no trouble in obtaining all the small plants you want by division during early Spring, or in fact, at any time during the year. Place the pieces having no roots in the sand with a little bottom heat.

\section{ANTIRRHINUM (SNAPDRAGON)}

Snapdragons are important cut flowers and money-makers for many florists. They can be successfully handled even on a small scale; besides, they form one of the crops to follow Chrysanthemums.

While it is possible to have Snapdragons in flower around Christmas, it is during the early Spring months that we have them at their best. When we display them at Easter time it is hard to have a customer take anything else. Rust has in a way caused quite a few florists to slacken somewhat in the growing of Snapdragons. There was a time, about twenty-five years ago, when this was considered a disease that made the growing of Carnations almost impossible, yet it disappeared to a great extent. So let us hope it will let up on the Snapdragons. As far as is known, the best remedy, or rather preventive, is not to keep the plants too cool and not to wet the foliage any more than necessary, which sounds reasonable. Snapdragons are cool house plants and should never be exposed to a high temperature during Midwinter; as the days get longer and everything under glass takes a jump, it doesn't matter whether the temperature in the house stays up over night around $55 \mathrm{deg}$. and over, but this would never do during December or January. Keep at $50 \mathrm{deg}$. or a little under, but avoid excessive moisture in the house.

\section{For Midwinter Flowering}

For early flowering the plants should be grown from cuttings rooted during May and June, the plants grown on in pots, shifted and kept pinched so 4 -in. pot stock can be benched by the middle or end of August. If you use dwarf or medium tall sorts, which are best for early use, allow $12 \mathrm{in}$. between the plants and don't let them make flower stems until October. They will produce a good crop during November and December, and send up more shoots after that, and such as have been benched later may not start into flower until December; a great deal depends on weather conditions. Keep the flowering wood clear of lateral shoots, which, by the way, usually furnish ideal material for cuttings.

\section{To Follow Ghrysanthemums}

The average florist is not so much interested in Snapdragons for Midwinter flowering, (which means having his benches occupied dur- 
ing the Fall months when he needs them) but rather as stock to plant after the Chrysanthemums leave the benches. For that you should root cuttings about the end of August, or sow seed about July fifteenth. This will give you plants in $31 / 2$-in. pots by the end of October or early November, and in most cases the soil in the 'Mum benches is good enough, but if you want to, add a layer of fresh soil before you spade it over. Stock planted around the middle of November in benches and kept in a 48-deg. house will not flower much before March. Another way is to plant on solid beds following Chrysanthemums and if you should have a house you want to keep just from freezing, the Snapdragons can stand anything over $32 \mathrm{deg}$. They won't do anything in such a house, but if you lift a plant about February you will find that there are all kinds of new roots; and if you start about March to keep the house near 50 deg. you will find that in a short time the plants catch up with the others, and by the middle of April are a mass of buds, and you will have a great crop of flowers during May. However, I don't think there is

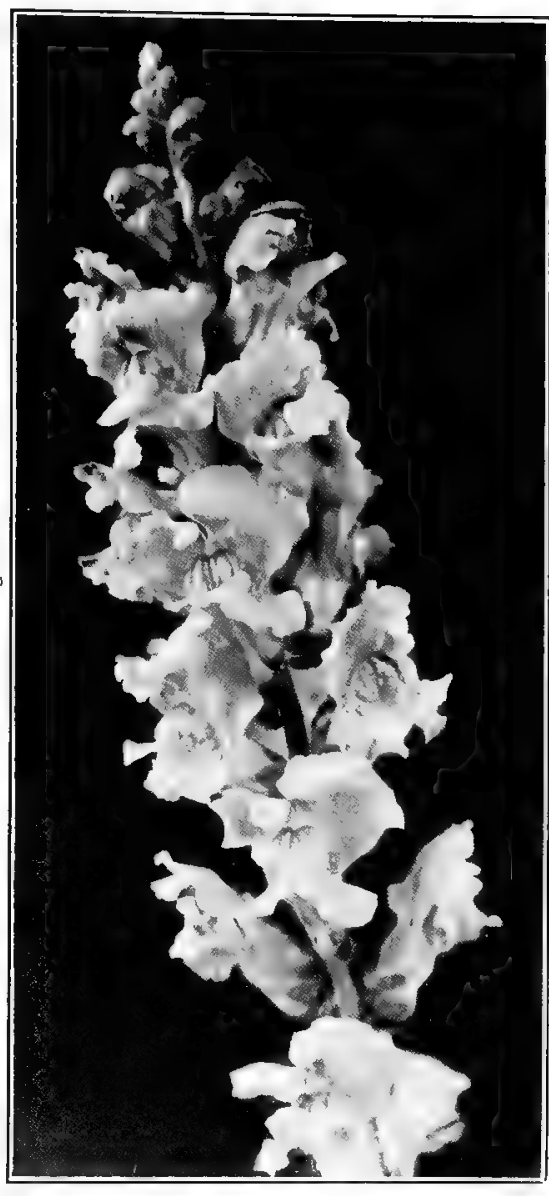

Fig. 90.-Snapdragon (AnttrRhinum). This is a favorite with everybody. Of late years it has been largely grown by florists under glass, for which purpose some excellent varieties have been brought out a great deal gained by it, not, at least, for the man with limited space; by planting on benches following early Chrysanthemums and keeping the house near $50 \mathrm{deg}$. you can have your main crop cut by early May or the first of that month, and have the bench ready for bedding stock, which appeals to the man who gives his Geraniums and other bedding stock the final shift around that time.

If you want a crop of Snapdragons for Memorial Day, it is time enough to root cuttings during early February or to sow seed in January and bench or plant out $2 \frac{1}{2}$-in. stock about March twentieth. It doesn't take nearly as long in Spring to get the plants 
to flower as during Midwinter. Snapdragons, like Sweet Peas, can be planted any time during the Winter months; it is just a matter for those who want every available foot of bench space for bedding stock to figure out how to squeeze in a crop of them, between the Ghrysanthemums and the time in Spring when he needs the benches for his pot stock.

\section{FloRist's SORTS}

Nelrose, Enchantress, Silver Pink and Ramsburg's Light Pink are all desirable sorts; in fact, if you have only space for a few hundred plants, you will do every bit as well to plant just pink shades alone. Nelrose not only makes a fine cut flower, but from rooted cuttings in February you can grow by the end of May 5-in. pot plants in full bloom which are bound to sell; for bedding, also, this sort is to be recommended. If you desire the long 4 -ft. stem ones for early Spring flowering, the tall growing sorts should be used, for they are, after all, the showiest and can also be grown for outdoors. With the exception of the very dwarf sorts, all Snapdragons should have support of some kind to keep the stems straight.

There is offered today an excellent strain of seed of some of the popular varieties, and quite a number of growers prefer growing

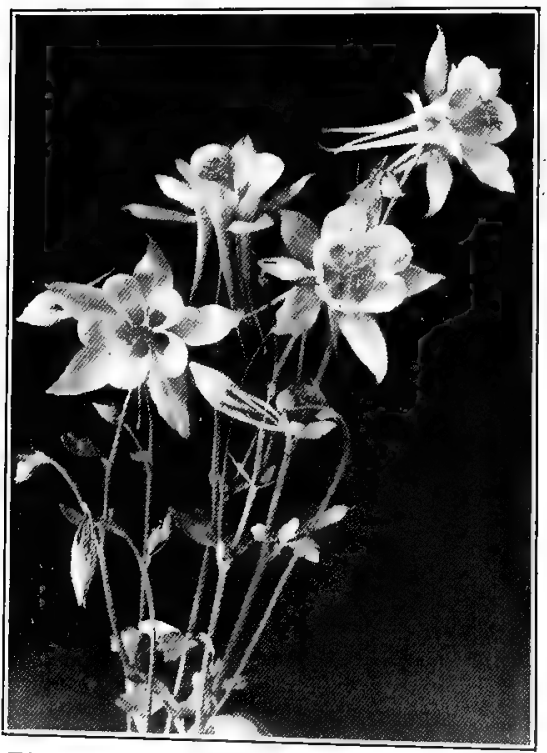

Fig. 91.-Aquilegras grown under glass. Field-grown clumps lifted in Fall, overwintered in frames and planted in a solid bed in February in a Violet house temperature will start to flower in April. The cut flowers are fine keepers and with their Maidenhair Fern-like foliage are much in demand. They should be more used from seed entirely, claiming the plants are more vigorous and more rust-resisting; the sorts come almost true from seed.

To grow from cuttings when you once have stock on hand and the plants are in good shape is easiest and quickest.

\section{SNAPdragons For OUtdoor Planting}

The average florist has not a great deal of use for Snapdragons during the Summer months, but for all of that he should plant out a nice lot of $21 / 2$-in. stock for cutting; they will be especially fine during September, with its cooler nights. Such plants will also furnish the very best kind of cuttings for such stock as you want to grow on for Winter.

Besides what you want for your own requirements, a good 
stock of plants in 21/2-in. pots should be grown on for the Spring trade. Everybody planting annuals for cut flowers is sure to include Snapdragons. You can sell a great many if you happen to have a few plants of a good strain in flower at the time of planting out, and it is as well to grow on a few 31/2-in. or even 4 -in. pot plants, such as are ready to flower. Many people are willing to pay a little more to obtain plants which will flower shortly after being planted out.

\section{AQUILEGIA (COLUMBINE)}

Get better acquainted with the Columbines, for they rank with the leaders in perennials. They are among the very first to send up in Spring their beautiful Adiantum-like foliage and well above it stems covered with graceful, spurred flowers in a great variety of colors. Whether you use Aquilegia cærulea (the blue Rocky Mountain Columbine), Aquilegia vulgaris (the European Columbine), the common American form, $A$. canadensis, the white $A$. californica, the golden $A$. chrysantha, or the endless varieties coming out of a package of seeds of the long-spurred hybrids, all of them are good. The more you see of Columbines, the better you will like them.

In Spring and Fall you can always dispose of field stock to your customers for their hardy borders. You can have a few plants in pots for planting out during the Summer months; you can use the flowers to cut from, and nothing goes better with them than their own foliage. Always place them in water for a few hours in a cool place before you send them out; they will last better. You can also use the plants for forcing under glass and have them in flower by the middle of April. They won't stand strong heat. Pot up some field clumps, which have been overwintered in a frame, about February tenth, and place them in a 45 -deg. house; in a week they will get busy and start into growth.

Old clumps can be divided into small pieces and replanted any time after August, but an easier and better way is to sow seed about February under glass, using a little bottom heat, and grow the little plants on in a 50-deg. house in pots, to be planted out in May. They will not flower the first year, but you will get nice, heavy plants ready for sale by Fall; the following Spring your stock will be a mass of bloom during May and June, and when planted in the hardy border the foliage will usually stay green all Summer. Aquilegias usually survive the most severe Winter, while a lot of our socalled perfectly hardy plants disappear by Spring. No matter in what soil or how misused, they are right there to greet you as soon as the Lilac buds begin to swell.

\section{ARAUGARIA (NORFOLK ISLAND PINE)}

What a lot of fine Araucarias were sold before the World War, when we imported them from Europe by the carload! Since then 
the smaller florist has hardly had a chance to obtain any of the few plants that are at present grown from cuttings in America.

I have seen an attempt made in Eureka, California, to grow them on in lathhouses, and while apparently not very successful, I am sure we will yet succeed. Every florist will welcome their reappearance and a chance to sell them at a reasonable price, for there is nothing more appropriate for Christmas in the way of a foliage or decorative plant, and they are equally good house plants.

\section{ARBORVIT $\nRightarrow$ See Thuya}

\section{ARDISIA GRENULATA}

In spite of all the fine Solanums which have been introduced in recent years the Ardisia is still the most stately of all the berried plants we have for Christmas, and no other plant with berries is likely to replace it for awhile.

It will not pay anyone but the man who specializes in Ardisias to grow them; not that it is such a hard job, but you might say that two years are required to do it. The plants must have proper attention and be kept not only clean but growing in order to get something out of them.

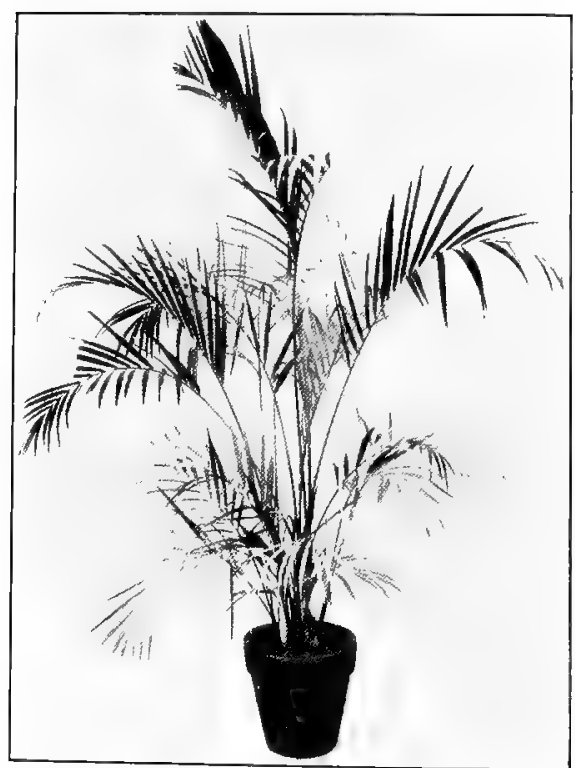

Fig. 29.-Aneca Lutescens. These Arecas make usable plants much more quickly than the Kentias. While not as lasting or as hardy, nevertheless they are most useful, especially when three plants are grown in a pot
You can buy Ardisias for Christmas some weeks ahead and keep them in fine condition by giving them a cool house. You no doubt have customers who are willing to pay a little extra for a berried plant which won't drop its foliage as quickly as the Cherries or Peppers; that's the time to mention Ardisias. Even after Christmas there are occasions when you can sell these beautiful plants. Don't grow them on yourself, but sell all you can.

\section{AREGA LUTESGENS}

This is one of the many useful Palms the florist carries. For hardiness it is not to be compared with the Kentias, but it has a softer green color, is more graceful in a small state and will grow quicker 
from seed into a salable plant. Being less expensive than a Kentia we often use it when filling indoor window boxes, or even as a single plant in a 4-, 5- or 6-in. pot. As a rule it doesn't last as well, as a house plant, as other palms do; then again we find customers who appear to have better luck with it than with almost anything else. It doesn't pay to grow your own plants from seed; you are better off purchasing the different sizes wanted from the palm grower.

\section{ARTEMISIA LAGTIFLORA}

By the first week in September the perennial border isn't usually overcrowded with flowers, that is, if you depend on perennials entirely. At any rate, it would be well to have there a few plants of Artemisia lactiflora. Here you have a stately plant with from 4to 5 -ft. stalks of Spiræa (Astilbe)-like flowers of a creamy color and sweet odor. No matter what else you may have in the border, these Artemisias will help to make the whole setting more beautiful. Increase from divisions of the old clumps, which can stand a little Winter protection.

\section{ASPARAGUS}

The average retail grower doesn't pay nearly enough attention to Asparagus Sprengeri, which constitutes one of the most valuable and useful of florist's greens. He will insist on trying to grow Carnations or other cut flowers on a bench that is, perhaps, too shady or too warm, and instead of devoting it to this Asparagus will keep on buying the cut green at a high price, and at the same time get no returns from what he does grow on that bench.

I don't want to imply that you should pick out a dark corner to grow Asparagus in, or a spot where nothing else will thrive, but, especially in older houses, there are usually places where a few plants could be grown either in benches, boxes, pots or hanging baskets, the cut greens of which will bring greater returns than anything else.

Green of some sort you need every day in the year, whether you think best to charge for it or not when putting it along with a dozen Carnations, Roses or Freesias. A box of flowers is hardly ever complete without Asparagus, and there are times during the Winter months when the green you purchase comes as high as the flowers themselves; or being cut in California or Florida it is anything but satisfactory by the time it reaches you. There are a good many florists who save themselves quite a shock by not keeping a record just for one year of what money is paid out in the purchase of cut Asparagus. True, you may not be able to grow as good stock as the man who devotes houses to its culture, and it may be cheaper to buy what cut strings of Asparagus plumosus you need. But with Asparagus Sprengeri, even in a small way and with not the best of success, you can make it pay and pay well. 


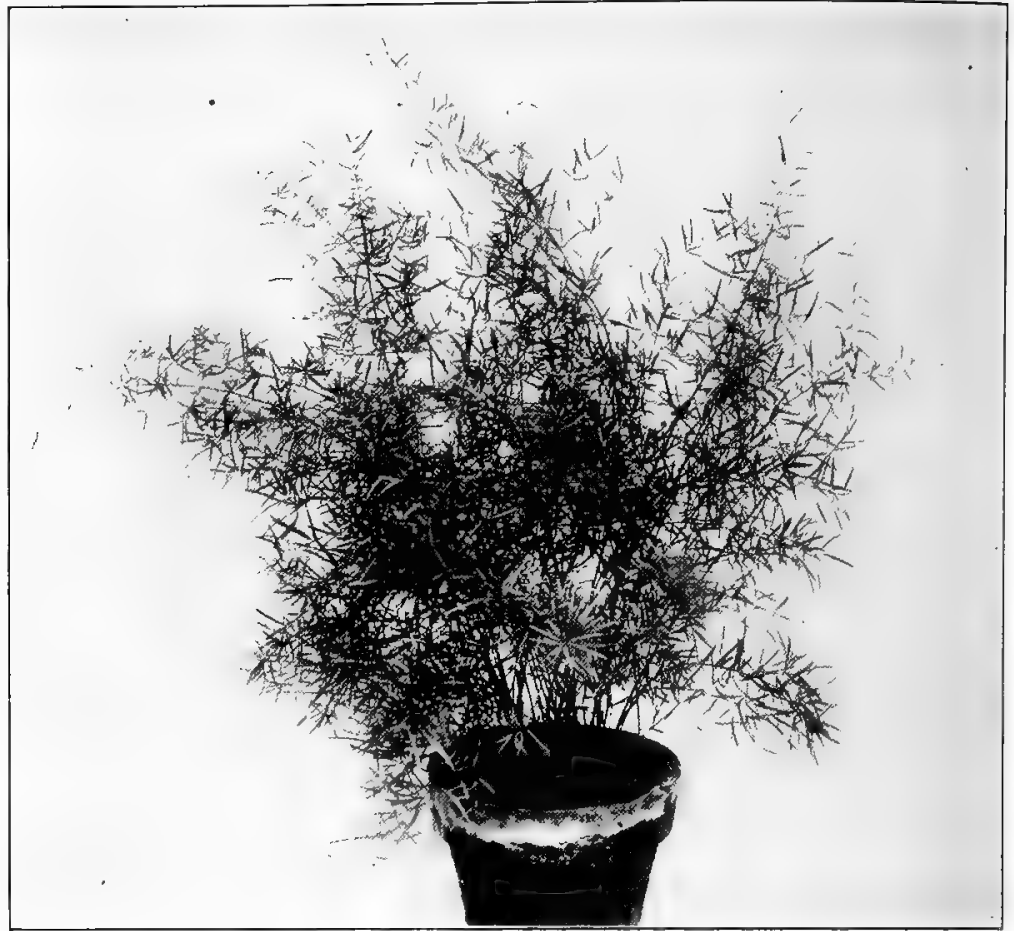

Fig. 93.-Asparagus Sprengeri. This is the most popular and most useful of florist's greens today. It is of easy culture and can be made to pay in houses that are not ideal for growing cut flowers

\section{Culture of Asparagus Sprengeri}

We will not consider how the big fellow does, but rather how the florist with limited space can bring this about.

Start out by purchasing good $3 \frac{1 / 2}{2}$ or 4 -in. pot plants when your bedding plant season closes; if you can, plant them out on a bench or solid bed, allowing not less than 12 in. of space each way. You can grow them in 6 in. of soil, but 8 in. or 10 in. is better, for the roots will soon go through the soil, and in a shallow bench often suffer. When a bench cannot be had, boxes, 8 by 10 in. inside measure, or not quite so large, can be made and planted. Fit them in at the sides or end of some house where there is perhaps a little space going to waste. Plant three plants in a 10-in. bulb pan; or as good a way as any is to plant three in a 14-in. wire hanging basket. These baskets need not be hung up right away; place them in a frame if no other place can be had, and leave there until September, after which fasten the hangers and hang on a purlin or below some gutter-anywhere you can find a place, without interfering, of course, with a crop below. 
It is for each man to find out the best method and the best place to use. I never believed in carrying the plants over the second year. It can be done and is done with good results, but a yearly clean-up means more. From strong stock costing in the neighborhood of ten dollars per hundred you can cut greens from September on.

In early Spring clean out the benches and use the space for something else, and then replant with new stock. These Asparagus plants are great feeders and should have liquid manure and a mulch during Fall and Winter. Don't strip every plant in early Fall. There are times when it is cheaper to buy what green you;want, for your own won't spoil. Go slow about it, as it means twice as much to you with zero weather outdoors, when, usually, it is at a premium. Go over the hanging baskets once in awhile and see to it that there is enough moss around the edges, so that when you apply water the plants will get the benefit of it. This Asparagus doesn't differ from the garden variety in regard to always wanting moisture around its roots; you cannot grow either in a dry soil nor where drainage is lacking.

Asparagus Sprengeri is easily grown from seed, but if you only use a few hundred plants it hardly pays, since it is possible to purchase small stock at a reasonable price. Frequently you have call for Asparagus baskets in May and June for porch decoration. You may be able to use some of those you cut from during Winter, if you didn't cut them too close, but a better way is to make up the baskets fresh about April. A heavy lining of good sheet moss looks best, and about five 4 -in. pot plants will in six weeks cover the sides, and with proper care look fine all Summer.

You can also by June use the plants out of 4-in. pots for filling vases or window boxes for shady positions; they will do there when some other so-called hanging plants or vines will not. You should have a supply of small plants on hand during the Fall and Winter; for indoor window boxes to go with Boston Ferns they are just the thing.

\section{Asparagus plumosus nanus}

Aside from the fact that this variety is excellent for cutting when planted out and that it often can be used where a Sprengeri won't do, it is of still greater value to the florist as a pot plant in the smaller sizes. So much so that every retail grower should always have a stock consisting of $2-, 31 / 2^{-}, 4-$ and 5 -in. plants on hand. Good plants in 5- or 6-in. pots will do for cutting and the others come in handy when calls are made for plants to be used in filling baskets, pans and dishes. 


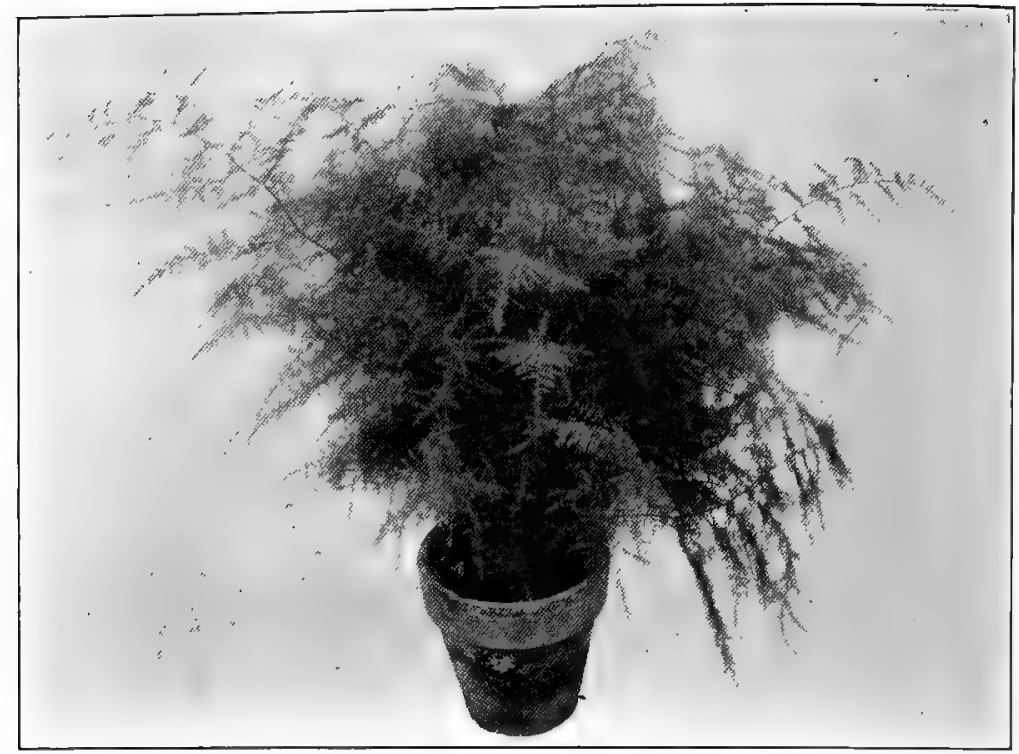

Fig. 94.-Asparagus plumosus. While primarily a decorative green, this should be carried by every florist, particularly the smaller sizes (in from 2- to 5 -in. pots) to be used in fern dishes, indoor window boxes and made-up plant baskets

After September you start filling fern dishes and can use 2-in. A. plumosus. Some people even prefer their dishes filled entirely with it. . In the less expensive ones you often use a bushy plant for the center instead of the higher priced Cocos. During Christmas week you want the plants again for plant baskets. Small Cincinnati Begonias, say three plants to an 8 -in. bulb pan, and about four Asparagus plumosus will do nicely. You need them with other flowering plants, and especially with "bare-legged" Poinsettias, and all through the Winter you want them, with an extra heavy supply again for Easter week. What is left after that keep shifted and grow on into larger pots for cutting.

It will pay to grow the plants on from seed, or, in order to save time, to purchase the small seedlings from the fern specialist at prices in the neighborhood of ten dollars per thousand. $A$. plumosus needs a little more than a Carnation house temperature, yet if you have well-established plants by Fall they can get along there; they won't make much growth, but they will stand it.

Don't try to grow the long strings on a small scale, it doesn't pay; they are only used for special occasions. If you grow enough of the pot plants to supply your wants you can afford to let the man who is properly equipped make a little money by supplying what you want in long strings. 


\section{ASPIDISTRA LURIDA}

The one decorative plant which neither neglect nor kindness is very likely to kill, and the one which can be used for fifty different decorations during the Winter months and come out on top the following Spring.

A shapely 6-in. Aspidistra, particularly one of the variegated forms, with clean, shiny leaves, is not only the very best of house plants, but an attractive one, too. Whether it is in the bright sun of the bay window or at the foot of the front stairway with never a ray of light, but where icy air strikes its leaves every time the door opens during the Winter months, seems to make but little difference. Not only has every florist customers who want the hardiest palm or foliage plant he can recommend, but he himself has plenty of use for such. To gradually work up a good number of Aspidistras means putting money in the bank.

I had occasion while a young man to work with a firm by which these Aspidistras were grown on by the thousands, and to those who are anxious not only to keep in good condition the plants they have, but to see them increase and grow, these notes may be of assistance.

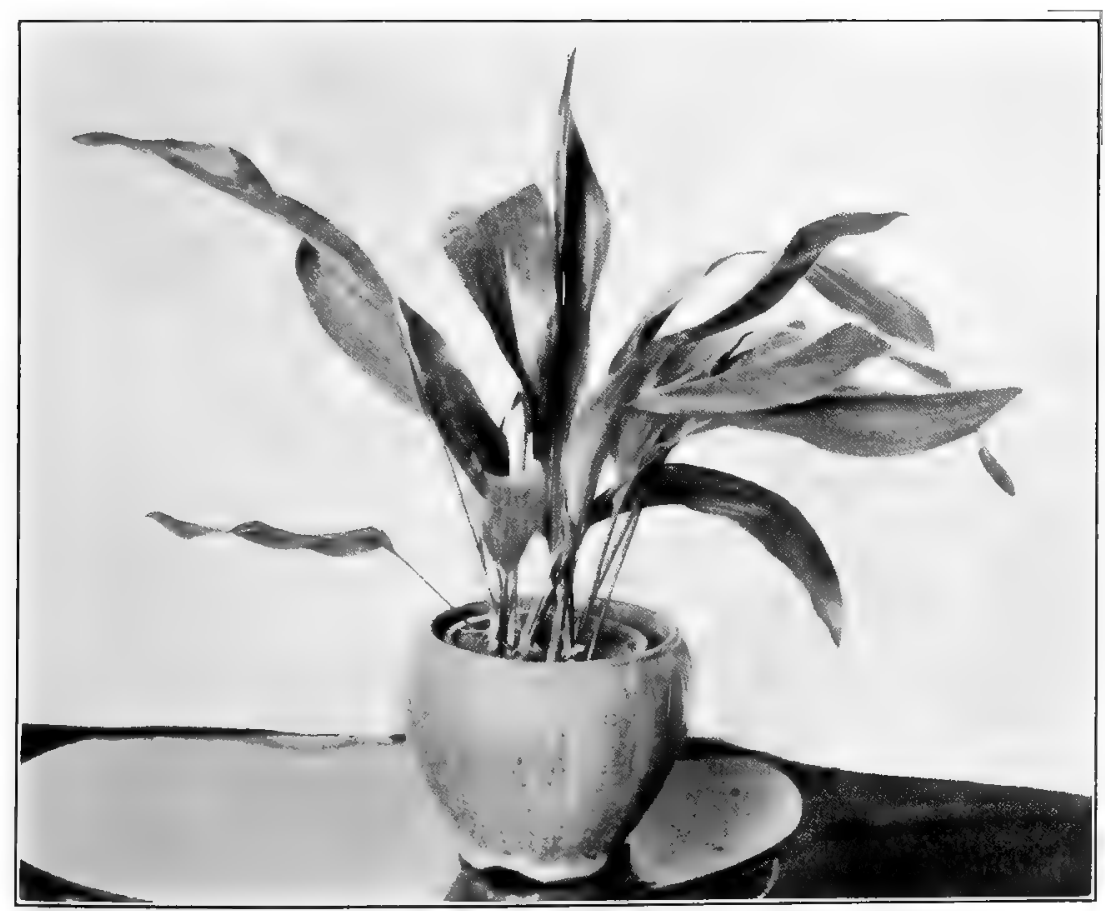

Fig. 95.-Aspidistra lurida. This is the hardiest of all the decorative plants the florist carries and it will outlast anything else as a house plant. You run some risk of becoming overstocked with good Aspidistras 
The old plants in 5-, 6-, and 8-in. pots were never disturbed during the Winter months, but kept in a rather cool house. By the first part of May, however, every plant of over 5-in. stock was taken out of the pots, divided into pieces and put in 2-and 3-in. pots, and these were plunged up to the rims in a hotbed with a high enough frame so the tips of the leaves wouldn't touch the glass. The glass was shaded to prevent sunburn, and very little air was given. The plants were watered but little, but were sprayed with warm water three times and more each day. In about eight weeks, while there wasn't any apparent increase in the number of leaves per plant, the pots were full of heavy white roots and the rhizomes began to form eyes. The plants then received a shift into $4 \mathrm{~s}$ and the pots were again plunged up to the rims in a fresh hotbed. By September the last shift was given into $5 \mathrm{~s}$ and another hotbed, after which the plants were kept in a close atmosphere. By the end of October, when the stock was brought in, some plants would have up to fifteen leaves, and others, of course, less; the plants in 4- and 5 -in. pots in May got to be 6- and some even 8-in. specimens under the same treatment. You may think this altogether too much trouble, but it is nevertheless one way to make Aspidistras grow into money. You cannot do it by keeping them under a bench in a coldhouse.

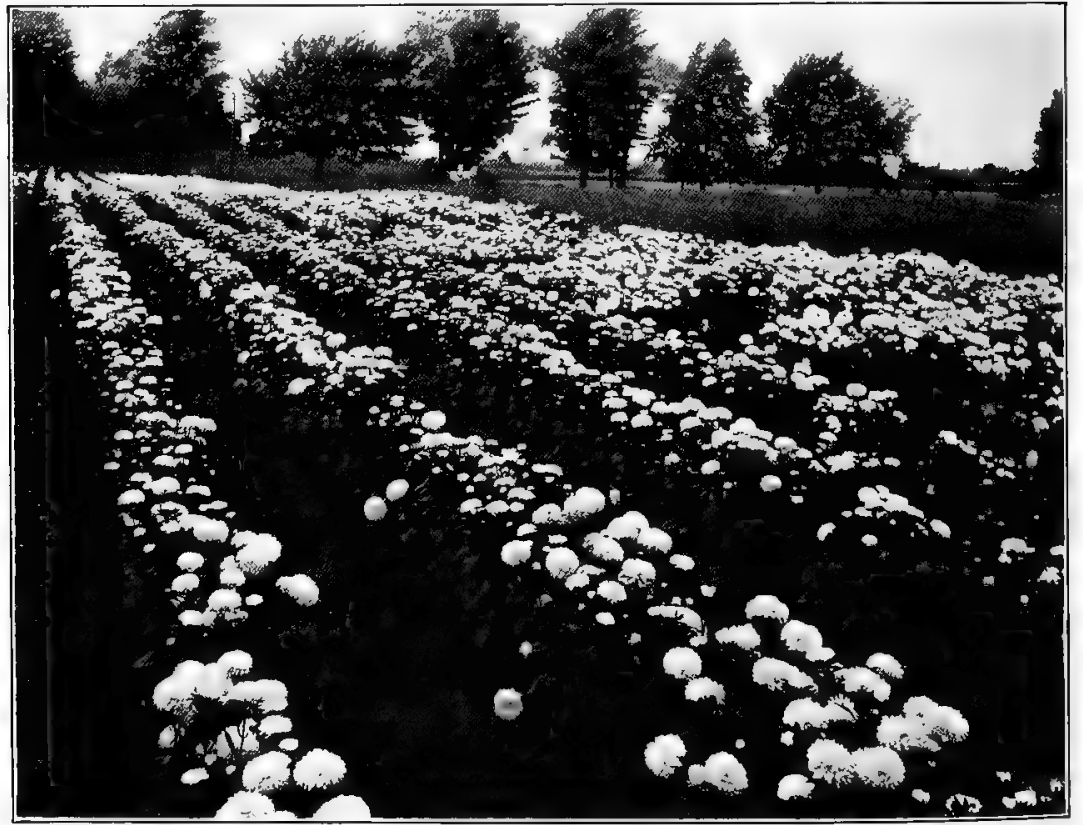

Fig. 96.-A Fiedd of Asters. Well-built double flowers of large size and good color borne on long stems are needed if Asters are to prove valuable property for the florist 


\section{ASTERS}

To make money out of Asters you must grow the latest and best sorts. Grow them well, and if possible, avoid the annual Aster glut.

Asters are among those flowers which are today better grown than ever. New sorts, most of them originated in this country, are producing flowers of a size and length of stem never known in former times. But any and all of them, old and new, rank among the most important of Summer flowers.

The retail grower doesn't have to worry about whether or not it pays in August and part of September to ship cut Asters to the wholesale market, but he should try to have a supply of flowers from early to late Summer. The man in the retail business never knows at what moment a call may come in for an order in which cut Asters can be used to good advantage, and even if you don't use all of the flowers you grow in the field not much harm is done.

By using the different sorts and giving them good handling, you may have flowers from the latter part of June up to November. We have sections where it seems almost out of the question to grow good Asters, no matter what one does nor how good the seed; or we may have off years when the flowers are not as good. But wherever Asters can be grown, every florist should have a good showing of them, and ever strive to produce better stock than the ordinary, for it is that kind that sells and brings a fair price when ordinary stock cannot be given away. Take, for instance, a vase of extra well grown branching Asters and display it in your st ore alongside of a short-stemmed, small sort; it will be the big fellow that sells. Try to grow Asters that your customers will buy because they are so much better than any they have in their own gardens. That's the kind that will pay you.

\section{Cultural Notes}

Almost anyone can sow a package of Aster seed in the garden. If the weather conditions are at all favorable they will grow and later on make a fine show. But you, as a florist, should man-

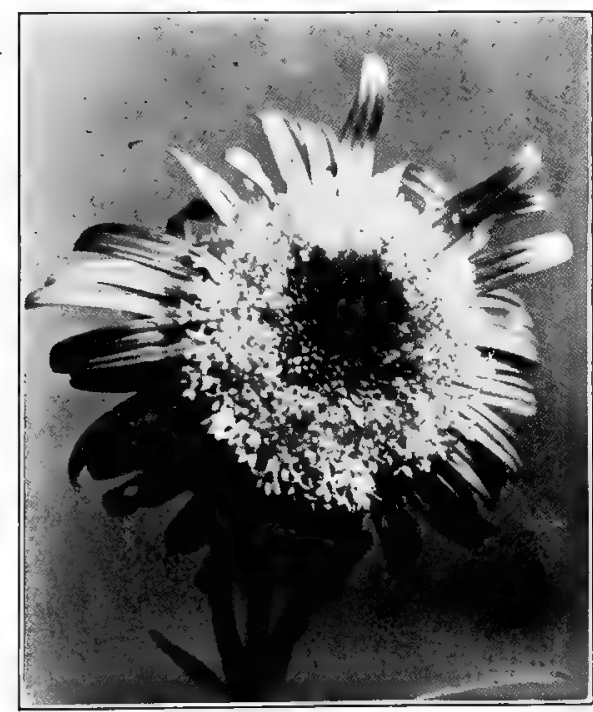

Fig. 97.-Dostalek's Aster (grown by. Anton Dostalek, Glencoe, III.) This beautiful Aster, white overlaid with pink and nearly six inches across, is the result of crossing the large single Japanese Aster with double sorts 


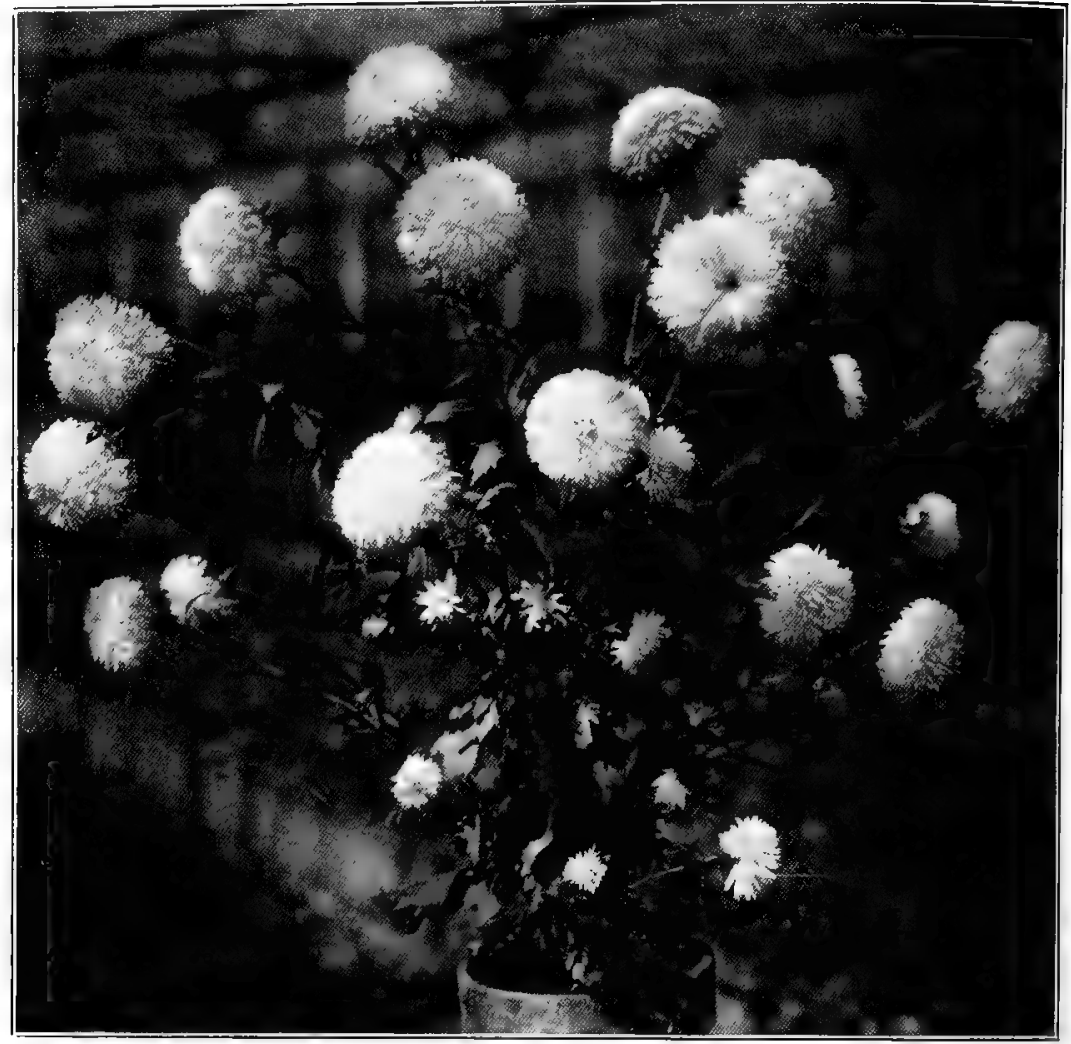

Fig. 98.-Ball's Improved Aster. A handsome plant is this remarkable Aster which resembles, more than anything else, a well-grown Chrysanthemum. Being of the late branching variety, it is especially valuable as a cut flower, its long stems supporting the large double flowers perfectly. It is indeed an American Aster of great mexit

age to have your flowers coming along either long before or long after, so it will pay you to make the first sowing early in March under glass. Queen of the Market is still considered one of the best of the early ones, the same as it was in 1889 when I got my first package of seed of the variety from the introducers, Vilmorin and Andreux of Paris, France.

There is this to be said about these early ones: Stunt the plants once and you might as well throw.them out. If you want large flowers on fair-sized stems, keep the plants going at all times. You can sow Queen of the Market in a flat; if allowed to remain in a flat after being transplanted once the plants will flower right there. However, keep them shifted and in a 48-deg. house, then plant in a frame. with glass protection until danger from frost is over, and you most likely will have plants in flower by the middle or end of June. Early Wonder is another good sort, and as a second early the Improved or 
Crego Aster is excellent for cut flowers. Both or all three of these Asters may be grown under glass in benches; the only trouble is that the average retail grower has anything but space to spare for them around April and May.

It is the late branching sorts, howeever, which give you long stems and flowers almost as large as you find among the Chrysanthemums. Su ch, if wanted late, can just as well be sown outdoors and transplanted later on into the field. Now and again somebody will advise us to avoid much manure in our Aster bed; then, later on, some private gardener brings us a bunch of Asters twice the size of our own, and on examination we find that he grew them right alongside some Melons in

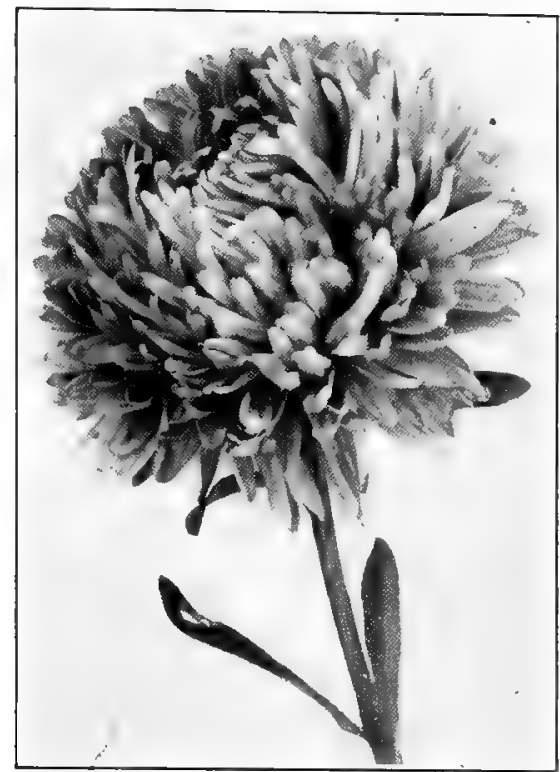

Fig. 99.-The Late Branching. Aster. This type, of American origin, closely resembles the Chrysanthemum, not only in size of flower but also in length of stem

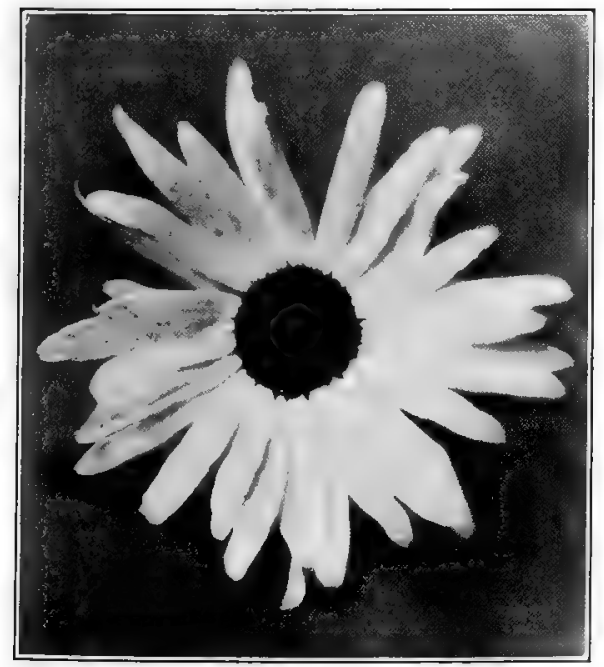

Fig. 100.-The Sngere Aster reminds one of a Shasta Daisy, but this bloom actually measured five inches across. I predict a great future for these Asters which, before long, we will have coming true from seed in all colors the garden where the soil is just full of manuire. Asters, in order to bear the big flowers, need a rich soil and not too much water, but all the cultivation you can give them. Among the florist's sorts, Balls' White has proved a splendid late kind.

\section{Asters Under Grass}

The florist who has the space can plant such sorts as Crego, Astermum, Beauty Aster and Sensation under glass on a solid bed, and in a well ventilated house can make them a paying crop. Plant about 10 in. apart, and as the plants begin to touch each other remove the smaller side branches and allow 


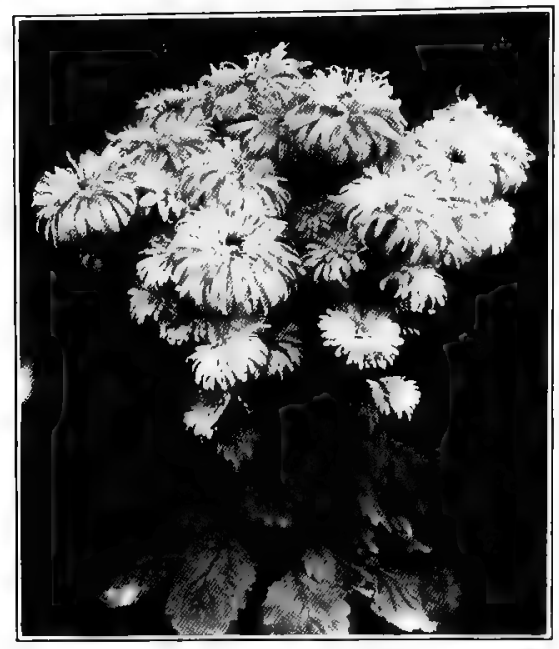

Fig. 101.-ThE IMproved Comet Aster. This is one of the most desirable sorts for early and midseason use

five or six of the strongest stems to remain. If the weather isn't too hot, Asters of the later sorts can be grown to perfection; on those of the branching type stems 30 in. and over, with large flowers can be had.

\section{Single Sorts}

Of late years a fine strain of single Asters has been worked up, of which the white, light pink, rose and light blue are the most desirable colors. Many people prefer them to the double, and they are particularly well adapted for use in cut flower baskets or centerpieces.

\section{Asters for Spring Sales}

Every retail florist has call for Aster plants during the Spring bedding-plant season. It is always well not to carry just one sort, but to have both the best there is and a less expensive strain. One way is to sow out, about the first of March, midseason and late sorts and pot the seedlings up in 21/2-in. pots. For ordinary stock, sow in rows in a frame; either transplant once, or sell right out of the rows they are sown in. The man who pushes the sale of Aster plants out of a frame in Spring, is likely to realize fifty or seventy-five cents per dozen for the stock and to sell enough plants, so that he really needn't care if he gets left with a few hundred flowers in the field in September; he will have made his money in May and June.

\section{Hardy Asters}

If you handle perennials at all, you should work up a good stock of hardy Asters. Whether used as single plants in the hardy border or for mass effect, few plants are more effective during September and October. Besides that, they are good cut flowers, lasting for days. Such sorts as Novi-Belgii Climax, with its light blue flowers 1-in. in diameter and over, and the White Climax, are especially to be recommended. When you cut the flowers treat them as you would the Chrysanthemums, placing them deep in water for about twelve hours in a dark, cool place; after that they will last in good condition for a week or more. Among the hardy Asters, or Michælmas Daisies, there are sorts such as Novi-Belgii Cleopatra (heliotrope) and Chapmanni (blue). They will grow 4 to $5 \mathrm{ft}$. in height. 
Among the dwarfer Alpine sorts we find excellent June-flowering forms for planting along the edge of a perennial bed, but they are not as suitable for cut flowers. Of the taller Fall-flowering varieties it w ll pay well to have a long row planted out, if for no other purpose than to supply cut flowers. If your customers have a chance to see them, you are bound to sell plants as well.

\section{ASTILBE (SPIRAA JAPONICA)}

Spiræa japonica, of which there are today some beautiful hybrids, is usually brought into flower by the florist for Easter. They make showy pot plants, and he is enabled to sell them at reasonable rates compared with other stock but they are most useful for decorative purposes, and such beautiful sorts as Gladstone, Queen Alexandra, and others can also be used as cut flowers.

The clumps are potted up in November in pots just about large enough to hold them, after which they are placed underneath a bench in a cool house. Never permit the soil to become dry, and if for any reason the dormant clumps reach you in a dry state, instead of trying to water them after they are potted, throw them into a half-barrel of water and let them soak for an hour before you pot them. Astilbes love moisture and soon show the effects of drought.

By the end of January or thereabouts you will notice growth appearing, and that means that you must bring the plants up onto a sunny bench. If you grow only a hundred or two, it will pay you to provide saucers for the pots, and keep them filled with water. With Easter coming around the early part of April you can get the plants in flower by that time in a $5 \dot{5}$-deg. house. If, by the first week in March you don't notice signs of buds pushing their way above the foliage, let them have a few degrees more heat; or if they are too far advanced, move them to a 50-deg. house.

They cannot stand heavy fumigating, but regular light doses to keep green fly down will not harm the foliage.

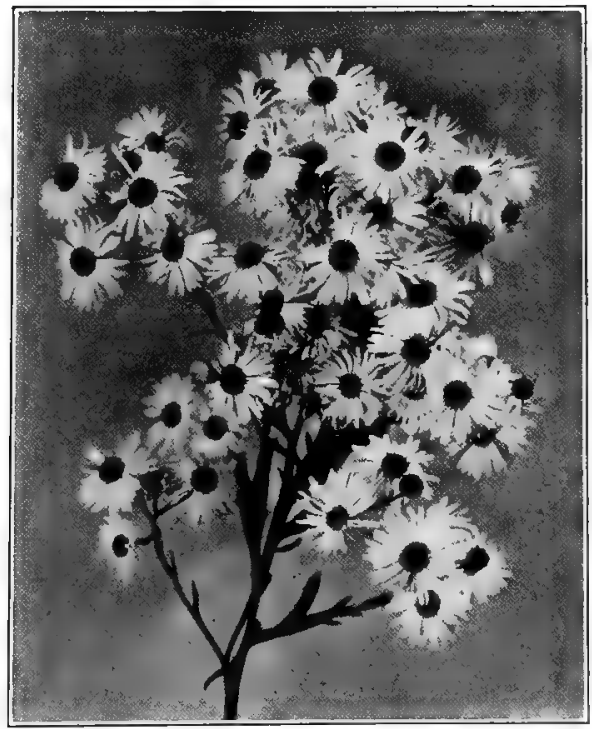

Fig. 102.-Hardy Aster "Novi-Belgir" Gimax. Hardy Asters are most valuable for late Summer and early Fall cut flowers, but as yet are not nearly enough appreciated. The cut blooms keep in perfect condition for ten days 


\section{Astilbe DavidiI}

While we have often tried to use forced clumps of Astilbe japonica for planting out, and also clumps which had not been forced, we never had much success with either. They would do for a year or two, and then go back: On the other hand, Astilbe Davidii makes a fine plant, with spikes of pinkish flowers, for late June flowering, and there are several hybrids, among them $A$. Morheimii, which grow $6 \mathrm{ft}$. in height.

These Astilbes can stand quite a little shade, but must have well-drained soil and plenty of water. Astilbe Arendsii has three or four beautiful pink varieties, all of which are splendid for the hardy border. You should recommend them to your customers.

\section{AUBRIETIA DELTOIDEA GR EGA (ROGK GRESS)}

To meet the demand for plants suitable for rockeries and for planting in the crevices of stone walls you should recommend the Rock Cress (Aubrietia deltoidea), the græca variety of which has rather large blue flowers in early Spring. These Aubrietias form a dense, moss-like growth and cover things up in a short time, and for ordinary purposes answer better than almost anything else. With an ever-increasing demand for rock gardens and the use of stones and boulders in the construction of dry laid walls or to form the sides of terraces or the background of a pool or water garden, the florist will be called upon to supply some of the plants used in connection with them to partly cover or soften things up. It won't hurt his prospects at all to become acquainted with at least a few of the many sorts suitable for that purpose.

When you once have a stock of Aubrietias, you can easily propagate them by division of the old plants. Pot them up into 3-in. pots in a sandy soil and place them in a coldframe around the early part of August. They can remain there all Winter or until you want to use them.

\section{AUGUBA JAPONIGA AUREA}

These splendid plants are of such value for decorating, for the filling of window boxes, and as single specimens that they deserve more attention from the florist.

Frequently an order calls for window boxes, especially for locations on public buildings, banks or hotels, to be filled with foliage plants and English Ivies, and it is here that Aucubas can be used, no matter what the exposure. The same applies when they are used for decorative purposes; they go well in connection with palms and can stand abuse better than almost any other plant you carry in the greenhouse. Even freezing weather which would kill an Aspidistra won't affect them. Therefore, they are subjects the retail grower needs and should carry a stock of, especially now, when there is anything but an oversupply of decorative stock from Europe. 
Aucuba can be grown to perfection here. It would almost seem that some men located in parts of our great land where climatic conditions are less severe than in the East and Middle West should go into the growing on of Aucubas more extensively and advertise their many good points. We can get along without them, and the majority of florists do so today, but we would be better off if we all had a good stock on hand.

Cuttings taken from the plants after the young growth made during June and July has hardened off a little will root freely during the Fall months in the propagating bench. Keep the little plants in pots during Winter and plant out the following Spring in a coldframe with good soil; either pot up in Fall or lift the plants with a good ball of soil and plant out on a solid bed in a coldhouse. Plant out again the following Spring and by the middle of September root-prune the plants; this is done by taking a tiling spade and cutting the roots say 4 in. or so from the plants all around them. This will cause the remaining roots to make a lot of small, fibrous rootlets, and when you lift them by the end of October you will have plants which will be large enough to go into 8in. pots that won't notice the transplanting at all. Keep them in a cool house over Winter and the following year plunge the pots outdoors and let them have a couple of good doses of liquid manure.

Of course it is best for the average retail grower, to purchase plants 2 to $3 \mathrm{ft}$. in height in 6- or 7-in. pots; or even smaller stock suitable for immediate use.

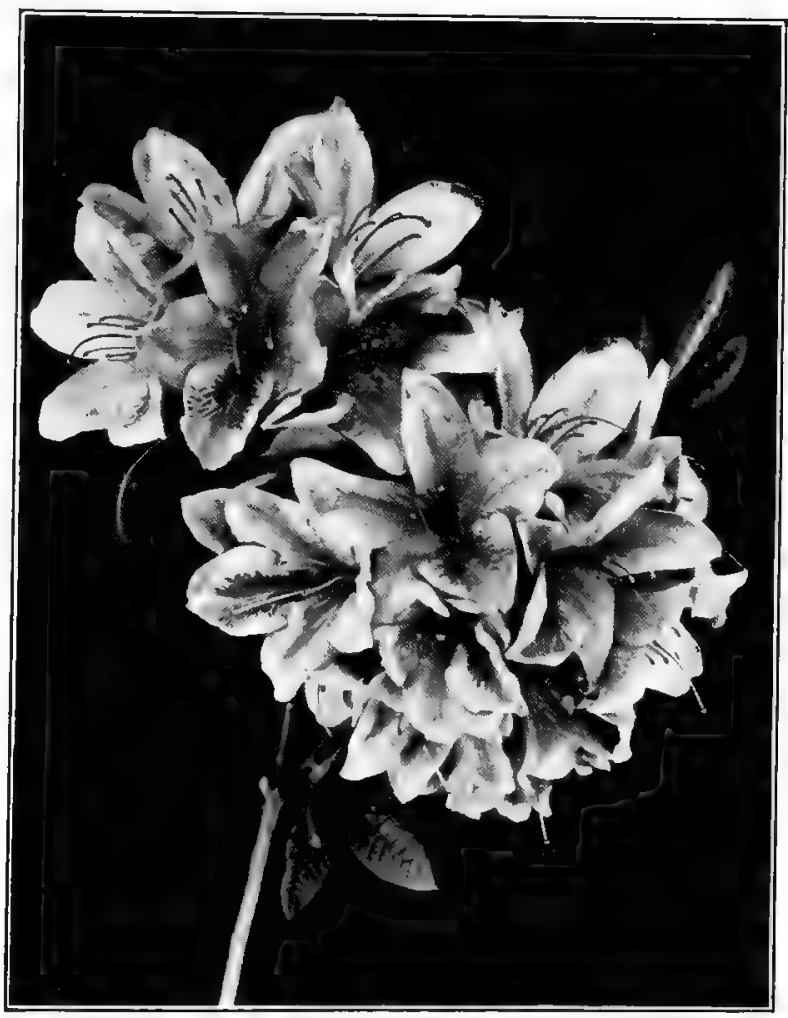

Fig. 103.-Azalea Anthony Koster. This is one of the showy varieties belonging to the hardy class 


\section{AZALEAS}

Azaleas such as we use for Winter flowering are among the most beautiful of all flowering pot plants. In spite of all that has been said to the contrary, I predict that the day will come when they will be successfully grown on in this country, so that the retail grower will again be supplied with them, and bring them into flower for Christmas and all through the Winter and up to Easter.

I claim a great deal of credit is due the late C. W. Ward for having had sufficient faith in the climate and soil prevailing in Humboldt County, California, to induce him to go into Azalea culture to the extent he did at Eureka. I made a special trip there, and beheld the plants by the tens of thousands, planted outdoors in all stages, and as many more of small grafted stock under glass. While the plants did not have the dark green leaves of those coming from Ghent, or grown in parts of Central Europe, they looked mighty promising, and whether or not they will ever be fully a success there, yet they will be grown somewhere in this country.

The best we here at home could ever do with imported Azaleas was to keep the plants alive for a few years; with all possible care and attention they would gradually go back, and finally be discarded. But we, and I know thousands of others, have missed them greatly since their importation has been prohibited. We may do just as much business at Christmas and Easter, but there is more to it than that. Having had Azaleas for so many years the display for the holidays doesn't seem complete without them, no matter how many fine Cyclamens, Poinsettias, Lilies or Rambler Roses we may have. On the other hand, if not being able to get them from Europe will ultimately result in growing them here, the result will be well worth waiting for.

\section{Azalea Hinodigiri}

This Azalea has become quite popular of late, especially as an Easter plant. Of rather dwarf habit, the specimens are literally covered with small, red flowers and so make very attractive pot plants. They are grown on in great quantities in this country, so that while it wouldn't pay the average florist to attempt this on a small scale, he can purchase his requirements in plants from four to six years old and treat them as coldhouse stock. They can either be planted outdoors and lifted in late Fall, potted up and carried in a frame (as they are not much affected by ordinary freezing) or they can be handled in pots altogether. With just a little heat for four or five weeks, you can easily bring them into flower for Easter, and what are left unsold you can carry over for the next year.

\section{Kurume Azaleas}

To many of the visitors to the National Flower Show, held in Indianapolis in the Spring of 1922, the most interesting exhibit was 
the collection of these Japanese Azaleas shown by the Henry A. Dreer Co. of Philadelphia.

Whether we will be always short of Ghent Azaleas, or whether they will again become as plentiful as they were before the World War, there will still be a great future for the Kurume varieties in white, pink, and red, single and semi-double. What should make them still more popular is the fact that a fair-sized plant in a 5-in. pot can be produced from a cutting in about the same time it takes to grow a specimen Cyclamen. This means that the retail grower can sell the plants reasonably and still make a fair margin of profit.

Easter may be Lily time and for those who don't so consider it we have plenty of variety in the way of suitable flowering pot plants. Yet outside of the French Hydrangeas nothing new has been introduced for many years and for the great majority of the smaller florists, Azaleas have been too expensive to handle. I look for these newcomers from Japan to prove a blessing. More than that, they are likely to be grown on, by even small growers, when their culture is once understood.

\section{Native or Hardy Sorts}

In sections of the United States where Azaleas will overwinter outdoors and thrive, they should certainly be used freely in the planting of home grounds. They are all deciduous shrubs and with their bright colored flowers-which appear during May and early June, mostly before the leaves-and especially when planted in groups, they brighten up the landscape as few other plants will.

The nurseryman lists a number of varieties consisting of collected native stock, but while such plants, especially. when in a small state, do nicely' for planting out, there is more or less risk connected with them, especially if they are not watched carefully until they become well established. A better way by far is to obtain stock which has been grown on in the nursery for one or more years. It costs a little more, but with such plants there is hardly ever any loss. 
Most of these Azaleas are natives of the Southern Alleghanies and the Blue Ridge Mountains. Azalea calendulacea (Flame Azalea) brick red, yellow and orange-colored, A. arborescens, a fine, Juneflowering white, $A$. roseum (canescens) a sweet-scented, May-flowering pink, and $A$. Vaseyi, the Blue Ridge Mountain pink variety, are all desirable.

\section{BACHELOR BUTTON \\ See Centaurea}

\section{BAPTISIA (FALSE INDIGO)}

Baptisia australis, while not quite hardy with us and requiring a heavy covering over Winter, is nevertheless a fine perennial and, with its pea-shaped blue flowers, is very attractive. The plants grow about three feet in height: You don't want many in the hardy border, but five or six specimens planted in a group will add to your assortment.

Baptisias can be grown nicely from seed sown in the greenhouse during January, or you can sow fresh-gathered seed outdoors in a frame where the seedlings will appear the following Spring.

\section{BEGONIAS}

The retail grower can greatly increase his assortment of flowering plants by paying more attention to the many beautiful sorts of flowering Begonias, among them some of the old favorites of long ago, which, of late years, we have partly discarded.

When we mention Begonias we usually have in mind either Gloire de Lorraine or the beautiful introductions of J. A. Peterson of Westwood, Cincinnati O., who has given us several that are today among our showiest Christmas plants. These sorts have almost put all other Winter-flowering sorts out of business, for when wellgrown and in full bloom you can't compare any others with them. But it takes a specialist to grow a specimen Cincinnati Begonia, and you want a house full in order to do it right. The average retail grower can make more money by purchasing his requirements for the holidays, ready grown, than by attempting, with all his other work, to grow them on from cuttings. There is bound to be a time during the nine or ten months it requires to grow them when the plants will get a setback. There are other Begonias the smaller florist can grow, and do it nicely, though not altogether for Christmas, for he needs plants in flower all through the year. There are many beautiful ones to select from, not only for their flowers, but for their foliage as well. Among our customers there are still many who remember the sorts of yesterday and the fine house plants they made.

Besides this, we have today splendid sorts for bedding purposes, which the retail grower should push. Some will require a little shade 


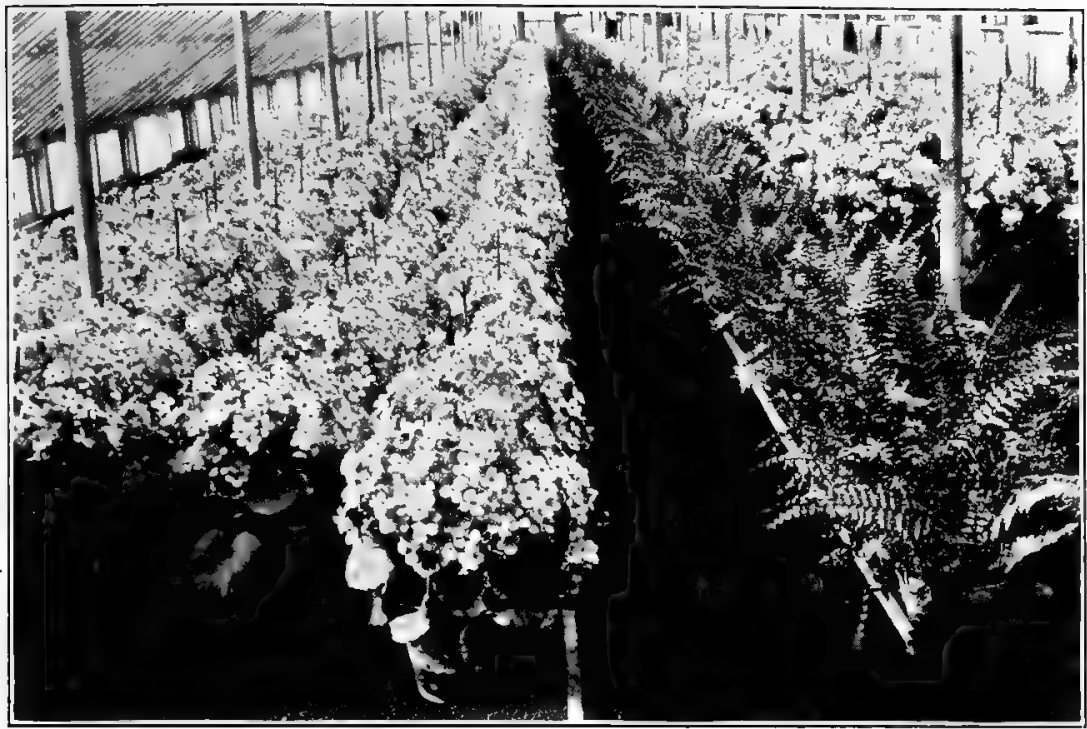

Fig. 105.-A Begonia Factory. A house of Glory of Gincinnati as grown by J. A. Peterson of Westwood, Cincinnati, 0 ., who originated this grand variety which is now a specialty of large firms all over the country. The retail grower should purchase plants ready for the counter, rather than attempt to grow them on a small scale

in order to do their best; others, again, will delight in full sun and often form a pleasant change from Geraniums, Salvias or Verbenas. Let us take up some of the principal florist's sorts, according to their present-day importance.

\section{Glor y of Gincinnati}

This variety, which has almost completely replaced Gloire de Lorraine, is propagated through leaf cuttings. Well-matured leaves are taken the end of December and during January, and after the stems have been shortened a little, they are inserted with the leaves a little above the sand. You need clean sand, a rather moist atmosphere about the cuttings, and bottom heat of $70 \mathrm{deg}$. However, if you like to grow some of your own stock, I wouldn't suggest beginning here; I consider it far better to purchase 2-in. stock and have it shipped to reach you as soon as you are through with the Spring rush and can begin to think about getting ready to stock up for the coming Fall. Shift these plants into 3s, making use of a sandy, mellow loam, with just a little well decomposed cow manure and, of course, plenty of drainage in the bottom of each pot. From the end of June on the plants want an airy, cool house and a little protection against the hot rays of the sun. While they will grow, they won't make the same headway as during September and October. Examine them occasionally, and 


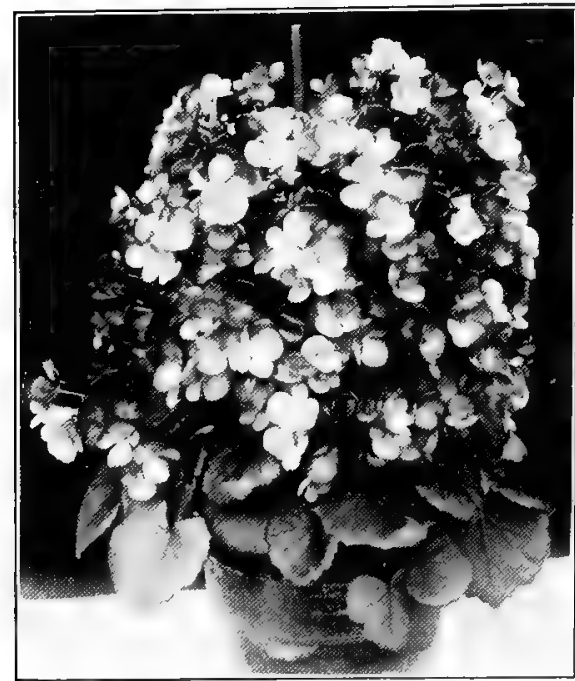

Fig. 106.-Begonia Mrs. J. A. Peterson. This is of the Glory of Cincinnati type with dark-colored bronze or reddish foliage. It is a desirable Christmas sort because of its habit, its bright, pink-colored flowers and the setting provided by its fine foliage. It appeared in 1915

when you notice the fine roots starting to become potbound it's time for a shift. When you begin to fire don't let the house go down below 55 deg.; in fact, keep it nearer the 60 deg. point and give the plants full sunlight. Stake your plants and have the stakes of sufficient length to allow for further growth.

The rest you will have to find out for yourself, no matter how much you may have read of the experiences of successful growers.

You may grow these Begonias at the first attempt without knowing even as much as is stated above, by hitting upon the correct method of treatment and by chance selecting the right house or bench, but it is more likely that you will improve through actual experiments and practice. Even if you don't succeed in producing 6- and 8-in. specimens covered with so many flowers that you can't find a leaf-just masses of pink blossoms-and even though all you can get are 4- or 5-in. pot plants, it will pay you to grow them, for they make good stock for the holidays. Later propagated stock and plants in 21/2- and 3-in. pots, if well in flower, come in handy for made-up pans and basket work. Take three such plants, plant them in an 8-in. bulb pan with Adiantum or Asparagus plumosus around them and you have an arrangement hard to beat. Two sorts similar to Cincinnati which we grow today are Melior, which holds its flowers better than Lorraine, and Mrs. J. A. Peterson, a dark pink with bronze foliage.

\section{Gloire de Chatelaine}

As we call the Schizanthus "The Poor Man's Orchid," so among Begonias we may well call Gloire de Ghatelaine "The Poor Man's Cincinnati." To me it seems almost useless to handle any of the socalled semperflorens type of Begonias when you can have Gloire de Chatelaine, especially now that we have its deep pink sport, Mrs. M. A. Patten, and Pride of Newcastle, a fine red.

This Begonia you can have in bloom all the year around and even in Carnation-house temperature you can flower it for Christ- 
mas. While not to be compared with Cincinnati in appearance, and growing only about 10 in. in height, it makes a pleasing pot plant and, of course, as a house plant, it outlasts the Cincinnati. It is in flower when you put the cuttings in the sand, and keeps it up until you throw some of the old plants out. As a bedder it has no equal, whether kept in the hot sun all day or in shade where a Geranium or Petunia would refuse to flower.

You can root cuttings at any time of the year and please the customers with 4 - or 5 -in. pot plants during the Winter months, particularly those who can't afford to spend two, three or five dollars. Whoever gave it its nickname made a good job of it. I consider it a plant every retail grower should handle, and as a Begonia of importance for the smaller grower I would want to place it at the head of all others.

For plants for Easter, at which time it usually is just full of flowers, propagate in December and if convenient carry in a 55-deg. house; shift the small stock and give full sunlight. If your plants are rather small by Easter, take three or more and make them up in 8-in. bulb pans. For bedding purposes root cuttings from January on; if you want extra good plants give them the final shift about April 15 and plunge the pots up to their rims in a hotbed, allowing just a little space between them. For bushy 5-in. pot plants for Christmas, grow on some of your late propagated bedding stock and keep it shifted during the Summer months; such as you have left over after Christmas can be divided if you wish.

\section{Tuberous-rooted Begonias}

These are the handsomest of all the many Summer-flowering Begonias, whether wanted for indoor or outdoor culture, but as yet they are entirely overlooked by many florists whose retail trade would appreciate them.

The man who doesn't grow at least a few plants of tuberousrooted Begonias misses a whole lot. Not to grow them because they don't do well outdoors as bedders is a mighty poor excuse, for they are first among the plants to keep your show house or store attractive all Summer, and no other plant is of easier culture or gives you less trouble. Anyone can grow them when he has flowering bulbs to start with.

For early flowering you plant the bulbs, or rather tubers, about January, in flats of sandy soil, barely covering the tops. Place on a propagating bench with a good bottom heat, or on the return pipes, and keep fairly moist-not soaking wet. As. soon as growth appears, pot them up in 31/2-in. pots and place in a 55-deg. house on a sunny bench. Such early started ones may flower for Easter, even if that day does come in April, and beautiful, attractive pans can be made up by using three or five plants to an 8-in. pan. For 


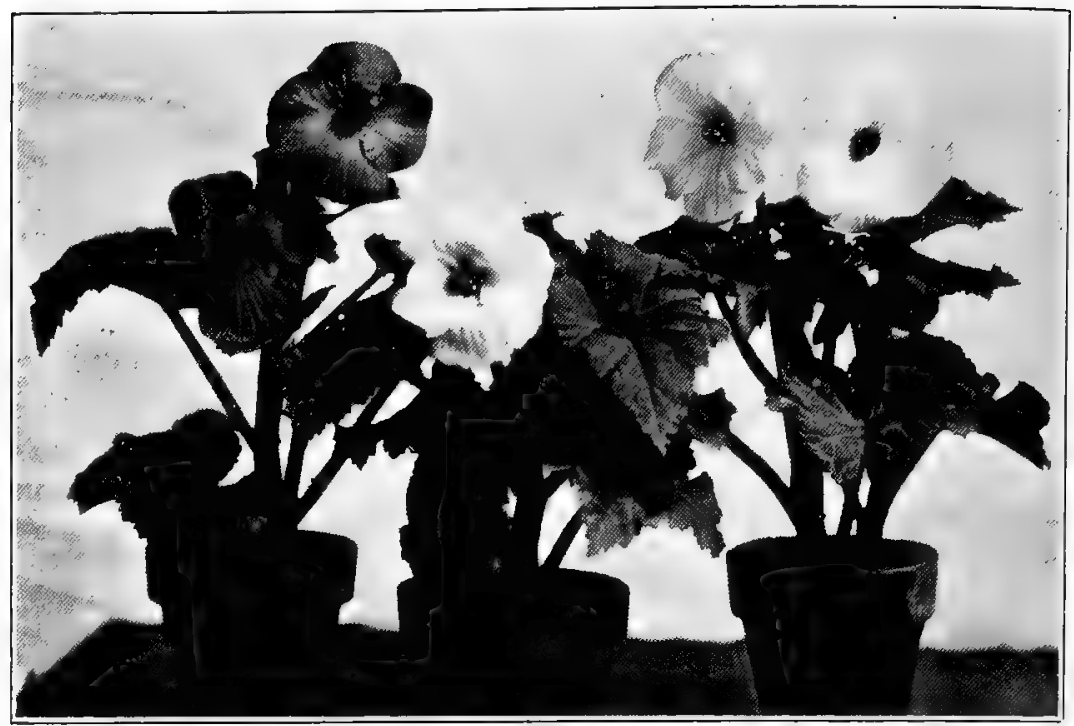

Fig. 107.-Tuberous-Rooted Begonias. Four-inch pot plants ready for bedding out the end of May. For this purpose you want short, stocky plants which, grown in a 50-deg. house, have room to develop and harden off. You can also use these beautiful Begonias in made-up pans for porch decorations or for the show house in Summer

bedding purposes start about the early part of March and treat the same way., but during April and May carry the plants in an airy and rather cool house, to avoid a soft growth. Another batch can be started about April first, and the plants, after being potted up, brought to a hotbed where later on the sashes can be removed and the plants hardened off.

The best place for the plants outdoors is a spot where they can get a little shade during the hot noon hours. They don't need any in the early morning or late afternoon, and often one can select a place where a certain tree will provide shade for three hours or so during the middle of the day. This shade or protection means more to them than the soil they are planted in. They will never do their best in a very shady position, but if you have to fill a window box for a spot too shady for other flowering plants you can use them and get results.

For Summer flowering indoors keep the plants inside and shift the fours about June first into 5- or 6-in. bulb pans. Carry in an airy, light house, with just a little shade, and they will be a mass of blossoms until Fall.

In colors we have white, light and deep yellow, daybreak, rose and deep pink, orange, red and crimson, and in types, single and double, crested and frilled-no end of beautiful variations. The tubers, of either the ones in pots or those grown outdoors, if dried 
off slowly and kept in a warm dry place over Winter in sand, can be used again. You can also grow them from seed (though, on a small scale, it is cheaper to buy flowering stock.) When large enough, pot the seedlings and later on plant in a bench in a cool house or in a frame outdoors with shade of some sort. Some of the plants will flower the first season, but they are better the second.

\section{Small-flowering Bedding Sorts}

There is still a place for the small ever-blooming bedding sorts of Begoniás, all of which are usually grown on from seed sown in pans about the first part of January. The seed should never be covered, but gently pressed into the surface of finely sifted soil and sand. Cover the seed pans with a pane of whitewashed glass and apply water with a Scollay sprinkler. A strong bottom heat will help germination. Gloire de Chatelaine grows from seed and is by far the best rosepink; Luminosa is excellent for a fiery red; Prima Donna is a good soft pink; Erfordii, carmine pink, and Vernon, with its dark leaves and orange-carmine flowers are always effective when planted in masses. -

There are other Begonias which, while not as showy nor as valuable for Christmas plants, are, as a rule, good house plants and deserving of more appreciation. When well grown in a 55-deg. house, with their showy flower clusters, they always find admirers.

B. incarnata Sanderii, with its soft pink flowers and fine foliage, is one of the most attractive of the whole family. Metallica, with its beautiful metallic or lustrous bronze leaves, is a fine foliage plant and still more attractive when loaded with small clusters of creamy white flowers. Thurstonii is a fine house Begonia with large, glossy green

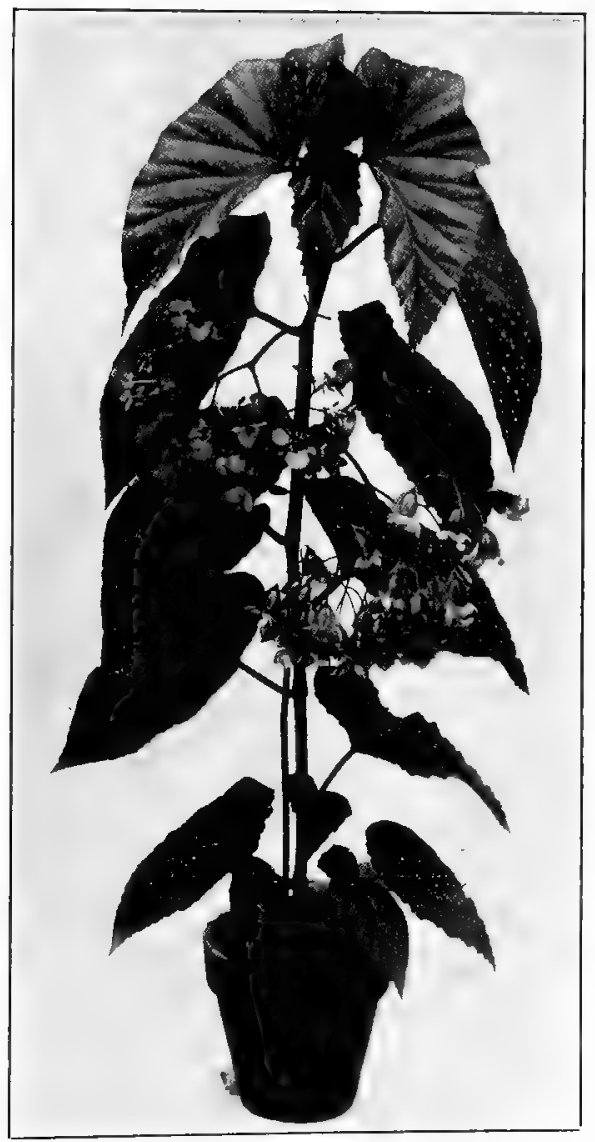

Fig. 108-Begonia Coraruina de LuCERNE. Showing into what a fine specimen this beautiful Begonia can be developed 
leaves, reddish underneath, and large clusters of flowers of a pinkish coloring; on long stems it will live for years in a window. Otto Hacker is another fine house plant with great clusters of coral-red flowers and fine, shiny green foliage. Corallina de Lucerne has spotted leaves and light red flowers; Saundersoni, deep green leaves and drooping clusters of reddish flowers. Haageana is a fine old sort with rosy pink flowers; President Carnot has brownish leaves and bright carmine flowers; rubra has red flowers and is a strong grower; nitata has light pink flowers and is very good; ricinæfolia has beautifully cut foliage and pink flowers; and argentea guttata, bronze foliage and silver spotted and creamy white flowers. We could keep right on mentioning others of the many good sorts. They will root easily with a little bottom heat, are not particular as to soil, and, especially with the out-of-town florist, should prove a paying crop to grow. These Begonias don't need to be sold in a week or month; they stay good all through the year. At one time they were among the most desirable of flowering pot plants and they will come back, not so much perhaps in the large cities where the average customer doesn't care much how long a plant lasts, or where people don't take the time to care for them, but in the country. Here things are different, and there are plenty who take the greatest pleasure in seeing a plant keep on doing well after they get it to their homes. It is here that these Begonias belong.

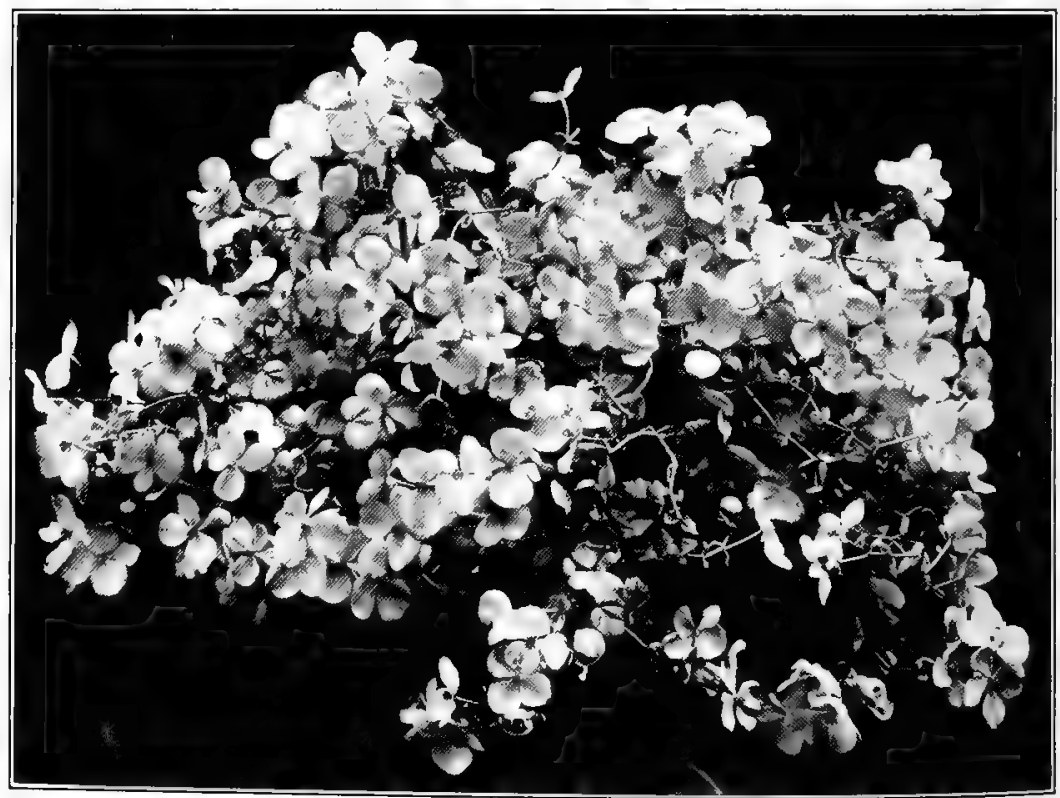

Fig. 109--Begonta GLotre DE Lorraine. Although smaller flowering, less showy and more delicate than Cincinnati, this is, nevertheless, an excellent variety. Note the graceful habit of this particular plant which was grown without staking 


\section{Rex Begonias}

We no longer see those fine Begonias in the florist's window as we used to, and I doubt whether they will ever be as popular as in years gone by. They are hardly suitable for present-day demands, but nevertheless they are really beautiful and will always find a place in the conservatory and the private greenhouse. They are propagated by laying one of the matured leaves flat on the propagating bench, making insertions an inch long at the junction of the ribs or veins, and holding the leaf in position down on the sand with small pieces of broken pot, or small pebbles. Even the small plants of Rex Begonia are beautiful and the larger they grow the more so they become. Yet to an extent and in spite of all their fine coloring there is something too formal about them.

\section{BELL FLOWER, JAPANESE \\ See Platycodon}

\section{BELLIS PERENNIS (ENGLISH DAISY)}

There are three plants - the Pansy, the Forget-me-not, and the English Daisy-that are favorites with almost every lover of flowers. When just coming into flower in Spring and properly displayed they always find a ready sale.

You should always include a few Bellis when making up your list of seeds to be ordered for August sowing. There isn't much to growing on a few hundred plants. Transplant the seedlings when large enough to handle, about 3 in. apart in a coldframe where they will start to flower the following March. The main thing is to obtain a good strain of seed. We used to have, many years ago, an excellent deep red sort which we grew on by dividing the old plants, but somehow it got away from us and we have never been able to obtain another like it. During Spring these Daisies sell best when displayed twelve in a small basket; this method will save you a lot of time.

\section{BERBERIS THUNBERGII (JAPANESE BARBERRY)}

The Japanese Barberry is without doubt one of the most useful of all shrubs, especially when you have an order for the planting of grounds with limited space. Whether you consider small plants or specimens $5 \mathrm{ft}$. in height and covering as much space, they present their gracefulness, dense foliage, beautiful coloring in Fall and loads of berries practically all Winter.

There is no end of the uses to which you can put Berberis Thunbergii. A group of five or more makes an ideal finish for a shrubbery border. At the entrance of the walk leading from the street to the residence a few plants are always in place. You can use them in a foundation planting, and as a hedge they are hard to equal, whether 
kept down to $2 \mathrm{ft}$. or where a heavy screen, 5 to $6 \mathrm{ft}$. in height, is wanted. The florist who does landscape work at all, and has a little nursery or land to spare, cannot do better than have his nurseryman supply him each year with a few hundred plants, say 12 to $15 \mathrm{in}$. in height, and plant them in rows. In this way he will have each year a nice lot of stock to draw from and can let some of the plants grow into specimens, which should always be lifted with balls of earth.

If you use them in a hedge and have the room, plant a double row. If along a public sidewalk keep at least $4 \mathrm{ft}$. from the lot line with the outside row. It is always poor policy to plant without figuring so as to allow the plants to spread and develop. If you do, you will find a few years later, just when the plants are at their best, that they are overhanging a walk or driveway to such an extent as

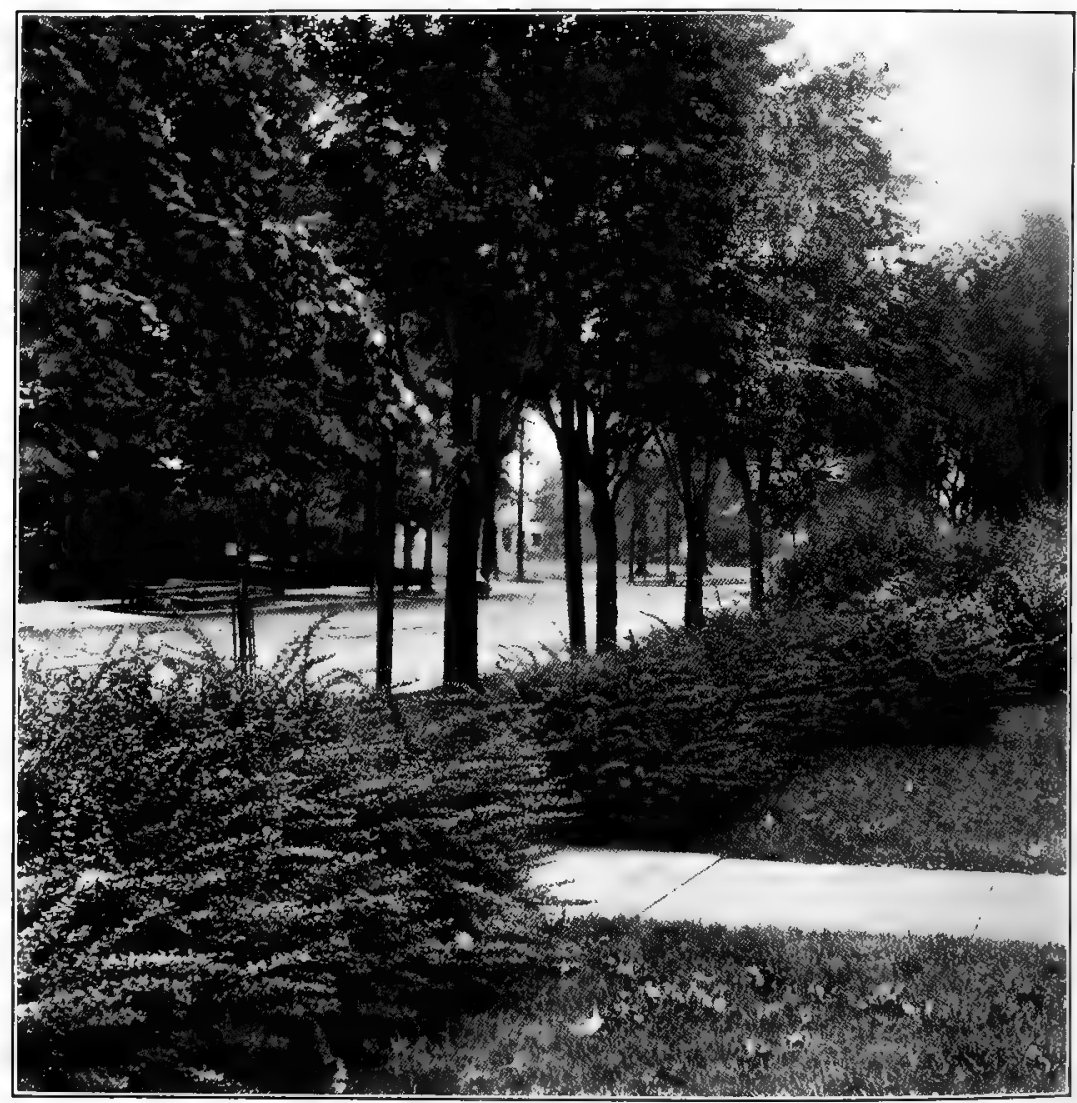

Fig. 110.-Berberis Thundergir. Few shrubs are superior to the Japanese Barberry for hedge planting and a still smaller number excel it in hardiness. When you consider its beautiful, dense foliage, its graceful habit, the showy coloring of the leaves in the Fall, and the many bright berries that last all Winter, you cannot help but like it 
to be in the way, and will have to be removed. Having most likely been crowded in, they are usually worthless for further use.

You can cut down a Barberry hedge almost to the ground and in one season obtain again a beautiful effect; or if desired, and in a section where Boxwood cannot be grown, you can trim a Barberry hedge into almost any shape you wish. However, the plants are at their best only when allowed to grow their natural way. Unfortunately, we have no longer with us the tall-growing purple Barberry (Berberis vulgaris atropurpurea), another grand sort whether in leaf or during Winter, when its graceful branches are full of berries. It is claimed that it is a spreader of the dreaded Wheat rust, but they have rust where there isn't a Barberry within a thousand miles. While I don't want to say that Barberry has nothing to do with spreading of rust, let us hope that someone will discover a different remedy for the disease than the extermination of the Barberries.

For those desiring a substitute for Boxwood hedging, the new Box Barberry, a dwarf sport of Berberis Thunbergii, is the thing to use. It can be clipped to make a perfect border edging only a few inches high.

\title{
BIGNONIA RADICANS (TRUMPET FLOWER)
}

Maybe you have seen a five- or six-year-old Trumpet Flower in full bloom, covering the trunk of a dead tree. It's quite a sight, but by the time such a climber gets to the top, the dead tree is usually ready to fall over. Yet we have call for this plant, and it is to be recommended where it can be given a place to grow to a great height undisturbed. As a small plant, it doesn't make much of a display.

\author{
BITTERSWEET \\ See Celastrus \\ BLACK-EYED SUSAN \\ See Thunbergia \\ BLEEDING HEART \\ See Dicentra \\ BLUE BELLS \\ See Mertensia
}

\section{BOGGONIA (PLUME POPPY)}

There are times when you want something growing from 6 to $8 \mathrm{ft}$. in height for mass effects to form the background for a perennial border, perhaps to take the place of a group of Hollyhocks that have stopped flowering. Bocconia cordata can be used to good advantage for this. It is showy, even when alone, but most effective when planted in large groups. Its creamy-white flower spikes are often over $3 \mathrm{ft}$. in length and stand well above the foliage.

Like the Gaillardias, Bocconias will thrive in almost any soil 
and they can stand a dry Summer better than most plants in the border. They are also easily raised from seed sown in the greenhouse in January or outdoors during Summer.

\section{BOLTONIA (FALSE CHAMOMILE)}

As single plants the Boltonias are not much for show. You must see them growing in masses in order to appreciate them. In the background of a perennial bed or planted along a fence, with a foreground of smaller plants, they surely liven things up when covered with their Daisy-shaped flowers. You can also use them cut for decorative purposes, but before using them place the stems deep in water for at least twenty-four hours in a cool, dark place; otherwise, they soon wilt. They are propagated by division of the old plants after they are through flowering and either planted where they are to flower the following year or given about 4 in. of space in a frame to be transferred to their permanent quarters the following Spring. There are two colors $B$. asteroides, white, and $B$. latisquama, light lavender.

\section{BORONIA ELATIOR}

Boronias are among the finest of early Spring-flowering pot plants, but as yet they are grown on only in small quantities. The

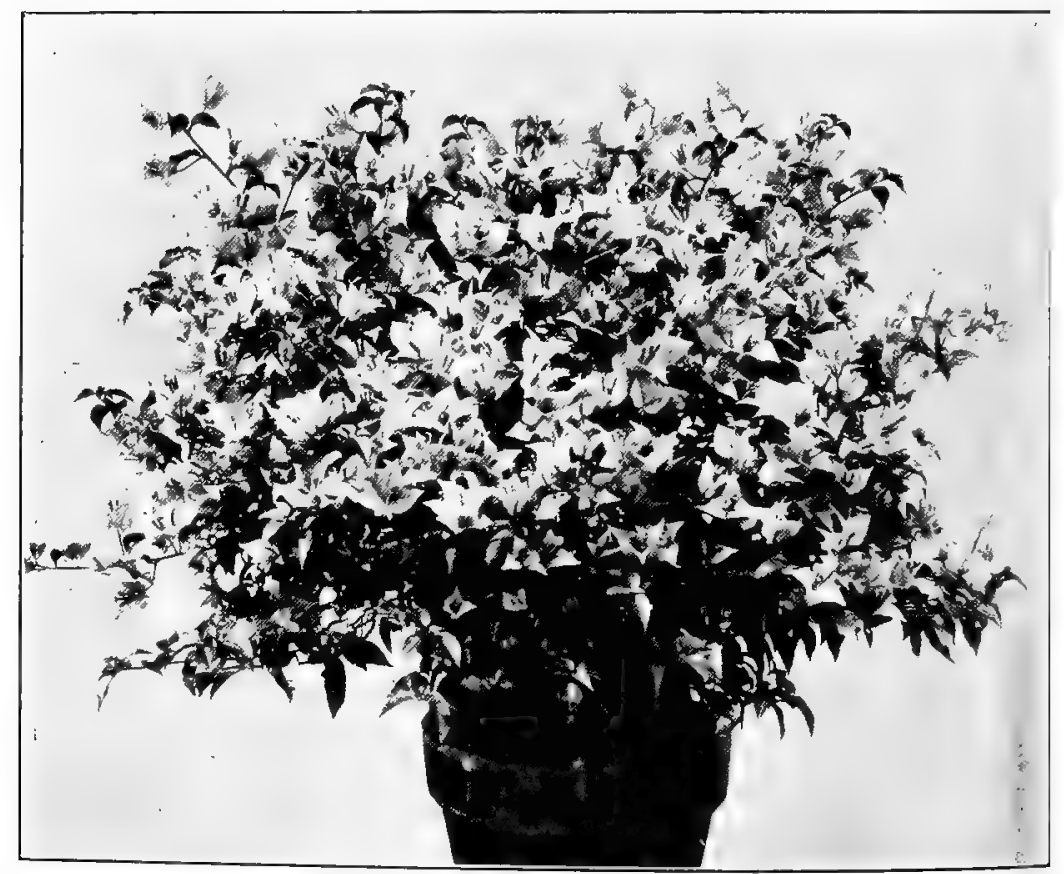

Fig. 111. - A Bougativillea in a seven-inch Pot. A specimen like this doesn't require much trimming in order to become a showy Easter plant 
fragrant little flowers come in great masses along the stems and in quite a variety of shades, ranging from a pinkish to a deep reddish brown on the same plant. Their treatment is similar to that of the Ericas, and like these, they require many months of cultivation before even fair-sized plants result. Therefore the retail grower isn't much interested in their culture. You can obtain a few wellgrown specimens during the Winter months from the specialist, and no trouble need be experienced in getting them into bloom in a cool house. They really belong to the shrubs and come to us from Australia, whence have come quite a number of other interesting florists' plants.

\section{BOSTON IVY}

See Ampelopsis

BOTTLE BRUSH

See Metrosideros

\section{BOUGAINVILLEA}

In order to fully appreciate what can be done with the Bougainvillea, one should go to Central or Southern Florida, where the plants are given a chance to grow outdoors, their natural way, and are not kept pruned and pinched back. But even as pot plants, when covered with hundreds of light purple bracts such as those of

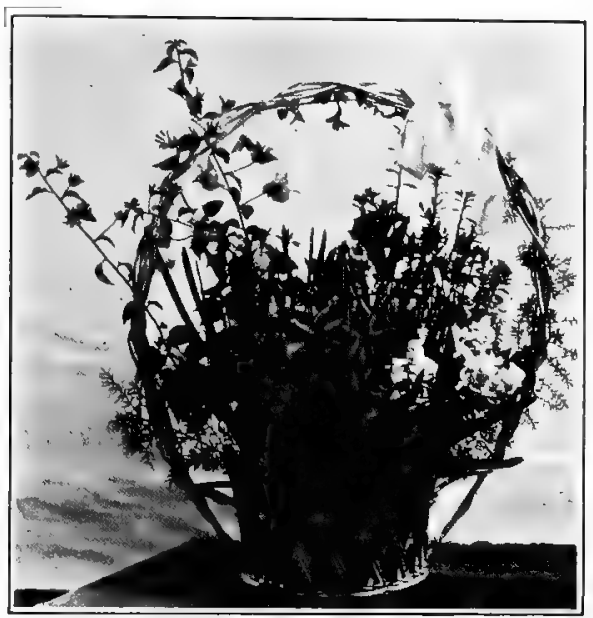

Fig. 112.-Bougainvillea Basket. Bougainvilleas are especially fine for basket work; some of the long shoots can often be trained around the handle. White Hyacinths combine with them nicely

Bougainvillea glabra Sanderiana, they are most desirable around Easter for the florist of the Northern States. B. glabra Sanderiana is about the only one we see in the greenhouse, but among others, and even more attractive, are: Crimson Lake, of a rich glowing crimson color; $B$. rosa catalina, a deep pink; and $B$. spectabilis lateritia, a brick red. There is a place for all of these during the months of February and March, or for a longer period. Even as small plants in 5- and 6-in. pots, they can be had full of bracts, but the growing on, while not a difficult matter, should be left to the specialist.

Purchase ready grown plants in Winter and hold them in a house of a little over $50 \mathrm{deg}$. What you don't sell, shift after Easter and grow on in a cool house until Summer; then plunge the pots outdoors and bring them back into a 50-deg. house by Fall. 


\section{BOUVARDIA}

Every retail grower should have at least a few plants of Bouvardia Humboldtii to flower during November and December. Their beautiful waxy-white, orange-blossom-scented flowers are quite different from anything else to be had at that time, and the plants require but little care in order to do well.

But few men specialize today in Bouvardias; the time of the average grower is taken up with other, perhaps more profitable, things. Those who can produce fine Roses, 'Mums and Carnations during late Fall and early Winter find them better paying crops than a bench or house of Bouvardias, yet we see the flowers used as of old in corsages. A few are still grown in spite of the general run of the usual assortment found in the larger establishments. I don't look forward to seeing Bouvardias ever come back, any more than Camellias, but the retail grower will make no mistake in planting some for his own use.

Bouvardia Humboldtii, the most showy of all, will thrive and do well in a Carnation house temperature, and you can make the plants pay on a small scale. You can use the flowers for the wedding bouquet, the corsage, as cut material and in design work. There is nothing that can equal a spray of Ophelia or Columbia Roses and white Bouvardia, or a centerpiece of the same. A few plants in flower will always be a great attraction to visitors to the greenhouses, and even one plant in bloom will fill a $100-\mathrm{ft}$. house with its sweet fragrance.

If you desire a little more of an assortment than what everybody has to offer, by all means plant a few Bouvardias.

\section{Cultural Notes}

Bouvardia Humboldtii is grown from cuttings of the old plants, which, after having been overwintered underneath a dry bench up to the end of January, are cut back a little and placed in a 52-deg. house. The softwood will easily root, but must have a good bottom heat. After the cuttings are rooted, pot up, keep shifted and plant them out on a bench or solid bed by the end of May; or you can grow them on in pots under glass. Still another way is to plant them outdoors, keep them pinched back up to the end of August, and bench them afterward. The more soil you can bring in clinging to the roots, the better. Shade the plants well for a few days after housing, and provide a stake for each; they will start to flower in September, but the best flowers on the longest stems are not cut until November. Nevertheless, pinch after August or the plants are apt to become too full of small shoots and develop no buds.

You will find that, lifted with a ball of soil and placed under a bench, a cut-down plant will not suffer in the least if water 
is withheld entirely. Shake the plants out by the end of January, cut them back and pot them up into $5 \mathrm{~s}$ or $6 \mathrm{~s}$. These plants will easily be at their best the second year, and will beat any young stock for flowering.

\section{Cultural Notes on Other Sonts}

Among the hybrids and the sorts we found forty years ago in almost every greenhouse we have such favorites as Hogarth, brilliant scarlet; Maiden's Blush, light rose, and Alfred Neuner, double white or creamy pink. All these are smaller flowering than B. Humboldtii and not

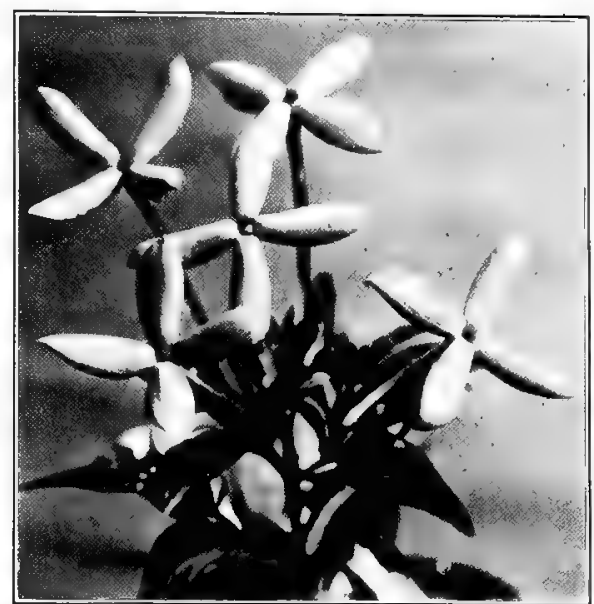

Fig. 113.-Bouvardia Humboldtil. This, grandest of all Bouvardias, is easily grown in a Carnation house temperature where it flowers from early Fall up to the middle of December. There is nothing more suitable for a wedding bouquet, corsage spray or wreath. The flowers are beautiful and have a delightful Orange-blossom fragrance

sweet scented, yet they are valuable cut flowers. The easiest way to propagate them is to cut the roots into 1-in.-long pieces about February, when, usually, they are through flowering and scatter them over a layer of sandy soil, either in flats, bulb pans or on the propagating bench, with a good bottom heat; if you have no better place, put the flats on the return hot water pipes. The cut pieces of roots, of course, have to be covered with a thin layer of sand or sandy soil and kept moist. Pot up the young plants later and treat practically the same as those of $B$. Humboldtii and most other flowers; plant them out and bench them by the end of August. While they can get along in a house of 50 deg., you will get better results in one of $55 \mathrm{deg}$.

For those interested, it might be said that any of these Bouvardias can be grown into attractive flowering pot plants. If grown on in pots they should be carried outdoors during the Summer months, the pots plunged up to their rims and the plants kept pinched back. Don't shift after September, and if you keep them in a 55-deg. house, after the first crop is off, they will flower again during February.

\section{BUDDLEIA ASIATICA}

Buddleia asiatica is a plant every florist should grow. It can get along in a 48- or 50-deg. house; it grows in any soil; and, while not a show flower, in its delightfully sweet fragrance it reminds you of your favorite perfume. "A mixture of Freesia, Lily of the Valley and 


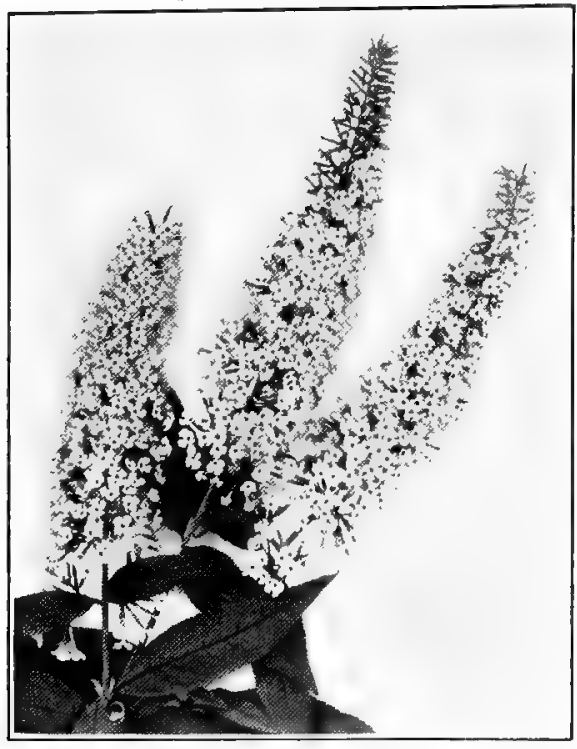

Fig. 114.-Buddleia variabilis. This is also known as Summer Lilac and Butterfly Bush. Even though not hardy everywhere, it should be tried in every garden. A thrifty 3-in. pot plant bedded out in May will bloom all Summer and furnish most useful cut flowers

mens. You can flower them in the pots or by September take the 4-in. pot plants and bench them in a Carnation house. Even with plenty of Stevia on the place there is room for this little flower, particularly as it comes into bloom around New Year's Day.

\section{BUdDLEIA VARIABILIS}

The hardy Buddleias, while not hardy everywhere, should nevertheless be planted far more extensively and be handled not only by the nurseryman, but also by the florist. Best known by the name of Butterfly Bush on account of the sweet-scented, brightcolored flowers, they are also called Summer Lilacs partly owing, again, to the fragrance of the lilac-colored flowers borne on graceful spikes.

If, in your locality they are not hardy, it is an easy matter to overwinter the plants in a frame, or root softwooded cuttings during early Fall and grow them on in pots over Winter. The plants out of 21/2- or 31/2-in. pots bedded out in May will start to bloom in July and keep it up. They make fine cut flowers and are used by the best florists in design work and corsages. The plants are most attractive when three or more are planted in a clump.

\section{BUTTERGUP. See Ranunculus}




\section{BUXUS SEMPERVIRENS (BOXWOOD)}

The day is bound to come when Boxwood, such as we were in the habit of importing from Europe, will be grown in this country. By going far enough South or West this can be done, and the finished plants delivered to the florist in the East, North and Middle West at prices that will allow him a fair margin of profit.

Maybe it was because of the cheapness of imported Boxwood that we didn't appreciate it in years gone by, or take proper care of the plants. While some fine specimens are being grown here in the East and West, the average florist, especially the smaller retail grower in the central part of the United States, sees but little of them. Their high cost makes it difficult for him to handle them, nor is there any possibility of relief in the near future. At present it costs more than ever to produce a 3-ft. or 4-ft. plant in a location where the plants cannot be grown and handled outdoors all the year 'round.

Boxwoods in pyramid or globe shape in tubs at either side of the entrance to a residence, along the top of a terrace, along a walk, in front of public buildings and hotels, and last, but more important than all else, in making your own entrance attractive, are almost indispensable and deserve a better fate than to be abused when stored away over Winter. While many beautiful plants suffer for want of a little water during Summer, there are just as many or more ruined through careless handling during the Winter months while in the hands of the florist.

In order to overwinter Boxwoods, you want some kind of shaded spot where you can

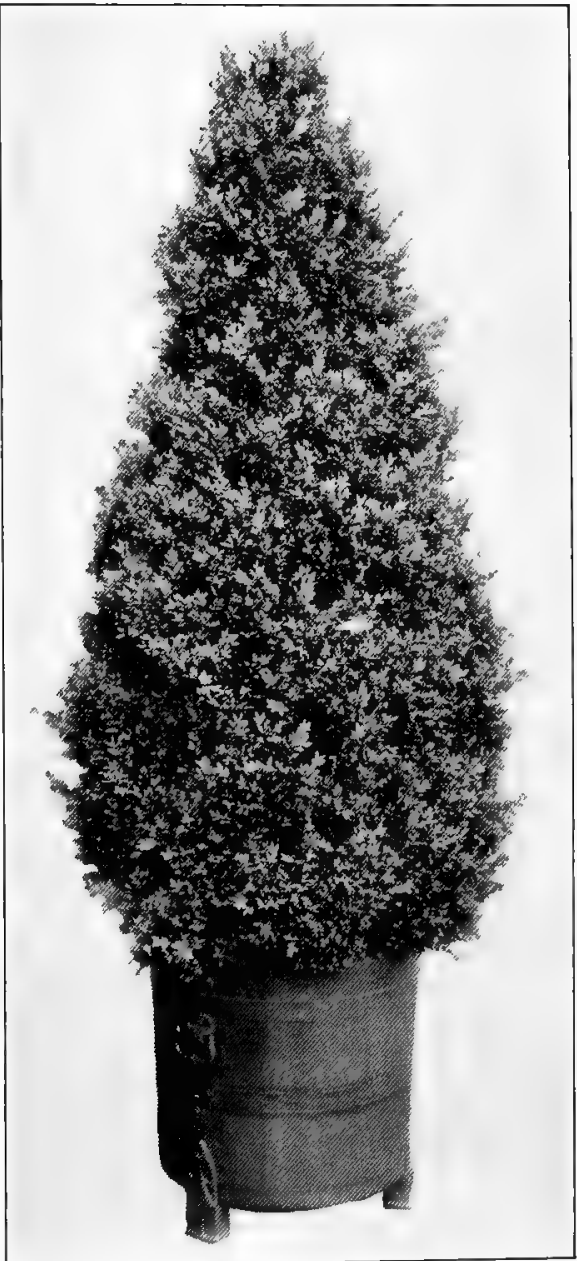

Fig. 115.-Boxwoon IN TuB. The pyramidal Boxwoods are the most popular, but because they are known to stand a lot of abuse, they are often neglected. A specimen that may have taken years to develop can be ruined in one short Summer 
keep the temperature just above freezing and see to it that the soil around the roots is always kept moist. Nothing will finish them quicker than a hot, dry place and dry soil about their roots. In March or early April the plants should either have a shift or get a good top dressing of rotted manure. If, for want of a better place, you have them in a cool greenhouse, they may start to grow about that time. If kept in a crowded condition they will suffer, whereas stock you received from your customer the previous Fall, perhaps not in the very best shape, if given sufficient space when the new growth starts, will be much improved in appearance by the time you return the plants.

\section{Cut Boxwood}

From November on to early Spring the florist uses cut branches of Boxwood as green and there is nothing better for wreaths and other design work. The dark green, glossy leaves and excellent keeping qualities make it so. Every florist with proper facilities should put in a good supply in early Winter and always have some on hand. There is no better place to store it than in a deep coldframe where you can heel the stems into the soil to a depth of from 4 to 6 in.

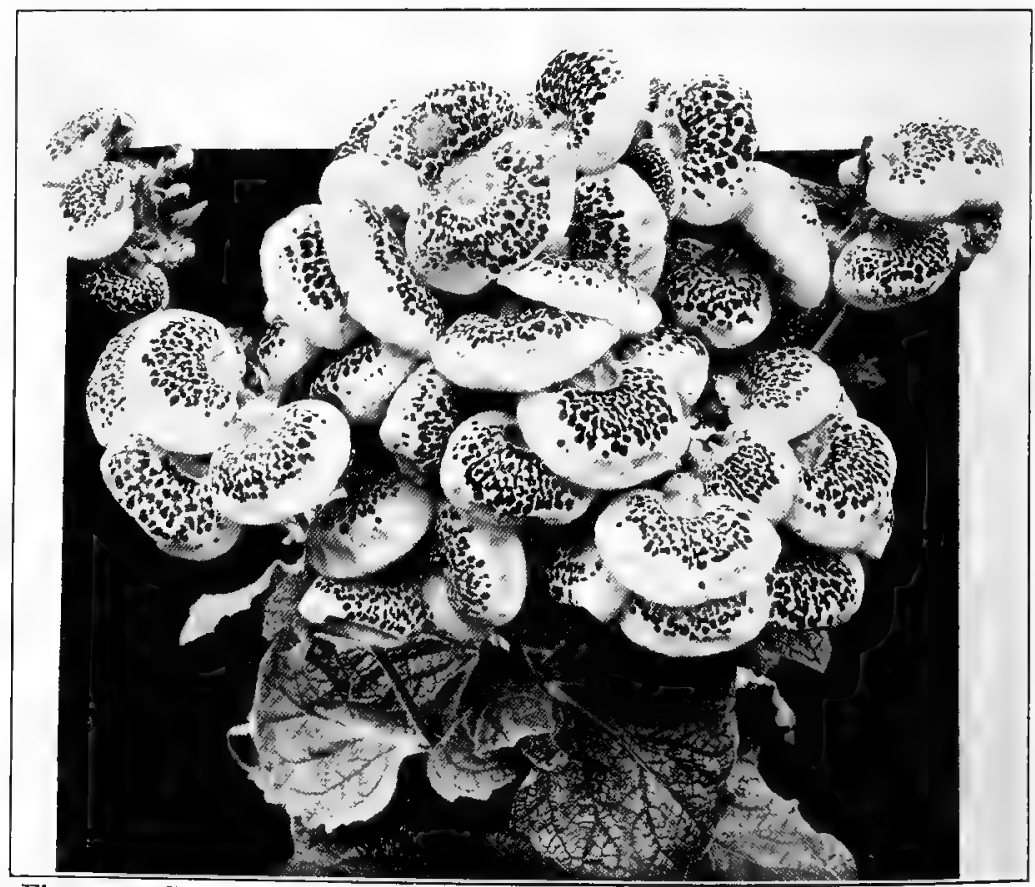

Fig. 116.- Galce OLAria. The man who can grow a good Calceolaria has always been considered a good gardener, for while its culture is no secret, it requires patience, careful handling and constant attention-which three qualities, for that matter, go far toward attaining success with any plant 


\section{CACTUS, GHRISTMAS \\ See Epiphyllum}

\section{CALADIUM ESGULENTUM (ELEPHANT'S EAR)}

Caladiums are mainly used for bedding where a sub-tropical effect is wanted, or as border material for large Canna beds. The richer the soil and the warmer the Summer and the more water you can give them, the larger the leaves will be. Outside of that we have but little call for them.

Start new tubers the same as you would Cannas, about early March. They are too cheap for you to try to keep them over. The fancy-leaved sorts are among the finest decorative foliage plants for the Summer months and should be carried by every florist who realizes the necessity of keeping up an attractive looking store or show house during the Summer. Start the tubers with good bottom heat; as soon as they show growth pot them up into $31 / 2 \mathrm{~s}$ in a mellow, sandy soil, and keep in a 60-deg. house. If you can still give them a little bottom heat, so much the better.

When these plants are well established, you can plant four or five in a 7- or 8-in. bulb pan. These pans, during Summer, make a better showing than single plants would. Or you can use $31 / 2$ - or 4-in. stock for the filling of window boxes in sheltered locations, a little protected from the sun. You can make a pleasing arrangement by planting them with tuberous-rooted Begonias and they can also be used for bedding, doing finely where neither heavy winds nor too much sun can get at them. But in order to see them at their best you want to grow them under glass with just a little shade, where you can obtain the beautifully colored and veined leaves, such as no other plant possesses.

You can dry the plants off toward Fall and keep the tubers in the pots in a dry place to be started into growth again the following February.

\section{GALGEOLARIA}

We keep on talking about new things and keep our eyes open for anything offered as a novelty in order to grow a greater assortment; yet, at the same time, we don't take trouble to look up the old ones, some of which are so old and so little seen that if they were shown the public would consider them novelties. The Calceolarias; when well grown, are among this class, and to get them that way isn't hard. They are as fine flowering pot plants as you can wish for and quite different from anything else; even if you never sell a plant, they will repay you by making your greenhouses look attractive.

If I had to pick out just a few plants that the average retail grower should grow, I would certainly have the Calceolarias among them, and I would want to help make them as popular as possible, for they are among the plants which deserve it. A display of them 


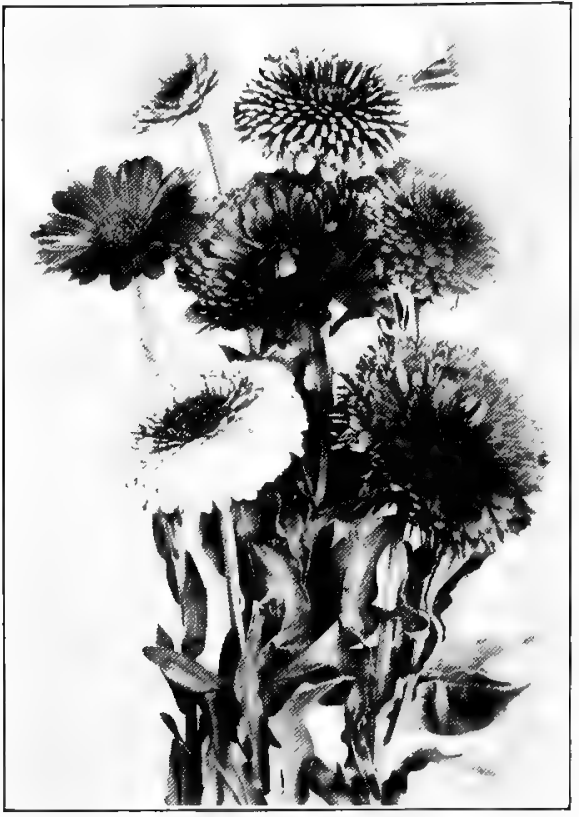

Fig. 117.-Calendulas in Variety. The variety most used by florists for indoor culture is "Orange King" or "Orange Prince." It is an ideal coldhouse crop and a money maker for the retail florist who doesn't have to send his flowers to the wholesale market in competition with others

in bloom with their endless different shadings and their odd flower markings will attract more attention than almost anything else you have in the show house. It is, therefore, bound to help sell other things.

Calceolarias are easily grown from seed, which should be sown during July. The cooler and more airy the house the seedlings are in, the better; let them have a little shade, too. You can grow them nicely on the same bench with your Primulas and Cinerarias while small. During Summer they make but little headway, but with cool nights they soon make up. Let them have a light, porous soil, especially when small, and when you shift them into 4s (which is usually about the end of November) loam with one-fifth well-rotted cow manure makes a good mixture. Keep them in a cool house, say $45 \mathrm{deg}$. over Winter and keep them shifted, for it is after October that they make their main growth.

What causes more failures, perhaps, than anything else, is letting green fly get a foothold among the leaves and at the center of the plants. This pest is so fond of Calceolarias that if there are any plants in the house, they surely will be full of green fly before any other plant shows even a sign of them. This means that you have to be continuously on the lookout; a good practice is to not only spray and fumigate regularly, but also place some tobacco stems between the little pots or around the flats or below them. If you keep them clean, cool and use a little care in watering, you should be able to grow them in almost any kind of house.

\section{GALENDULAS}

These plants well deserve to be called money makers for the florist.

A good many dollars have found their way into the pockets of the florist since he started to grow Calendulas under glass and display them in Midwinter at a time when their bright, orange-colored flowers 
three and four times the size of outdoor stock, contrast happily with the usual white, pink, and few red flowers available. Here, again, we have an ideal coldhouse crop which always appeals to many. Calendulas, from Thanksgiving on-which usually means the beginning of the end of the Chrysanthemum season-find a ready sale with the retailer and keep it up all Winter and Spring. They can even be made to pay as early started plants in a frame which will come into flower during May and June, and up to the time they begin to flower in your customer's own garden. While considerable bench space is today devoted to their culture by specialists or wholesale growers, the man who grows them and retails the flowers makes the most out of them.

\section{For An Extra Early Chop}

Calendulas can be grown equally well on a bench or solid bed, but delight especially in a 45-deg. house, with their roots in a deep, cool soil. When on benches you want to keep heating pipes away from the bottom. For November flowering, seed should be sown not later than the first of August. If you make use of solid beds, sow the seed in rows about $1 \mathrm{ft}$. apart and later on thin the plants to about 6 in. in the rows. If they are to be benched sow outdoors or in flats and transplant the seedlings into $21 / 2$-in. pots to be benched not later than September fifth, about $1 \mathrm{ft}$. apart. They require a rich, well-drained soil, and for best results should never be stunted.

The first buds usually come on short stems and rather than use them (which, in order to obtain a 10-in. stem, would mean to sacrifice two or three more buds), pinch out the first and second buds before they open. Whether you always have use for the flowers or not, they shouldn't be allowed to go to seed. Keep the plants clean, the soil cultivated, and, when you once begin to cut large, long-stemmed flowers, a dose or two of liquid cow manure will do the plants good. Green and white fly often attack, especially the Midwinter flowering plants, but regular spraying will keep them down. There is hardly ever occasion to stake the plants, unless you have an extra fine lot, and grown at 45 deg. the plants hardly ever become too tall. But there are growers who claim they pay better, have longer stems and larger flowers when grown in extra rich, heavy soil, and with a night temperature of $50 \mathrm{deg}$.

\section{To Follow Ghr ysanthemums}

Calendulas to follow Chrysanthemums should be sown about September tenth, which will give you heavy $2 \frac{1}{2}$-in. pot plants ready to be planted out by the middle of November. The soil in the Chrysanthemum benches or beds is just what they want, even if heavily manured. Plants benched about November fifteenth should, if not kept too warm, keep in good shape all Winter. 
You can sow and plant Calendulas all Winter, and a nice batch of $21 / 2$-in. stock on hand often comes in handy when some other crops have failed. After January, and as we approach Spring, a temperature of $50 \mathrm{deg}$. won't hurt in the least. For a good crop during May, sow out about the end of February and plant in solid beds in deeply cultivated, heavily manured soil, and you will cut the largest flowers of the whole season.

\section{For OUtdoor Flowering}

You will hardly find it profitable to have Calendulas in flower during the Midsummer months, but even in localities where the ground of an old Calendula bed is full of small plants by May, it usually pays the florist to have a few rows in his hotbed devoted to plants to be sold along with his other annuals. If a crop of flowers is wanted by the end of September and during October, a time when the plants which have been flowering all Summer are played out, sow seed in rows in the open about July fifteenth, or even a little later.

\section{VARIETIES}

There are many sorts, but usually the florist selects Orange Prince as the most desirable. While culture has everything to do with the size of the flowers and stems one obtains, there are offered today several selected strains of Orange Prince, the seed of which

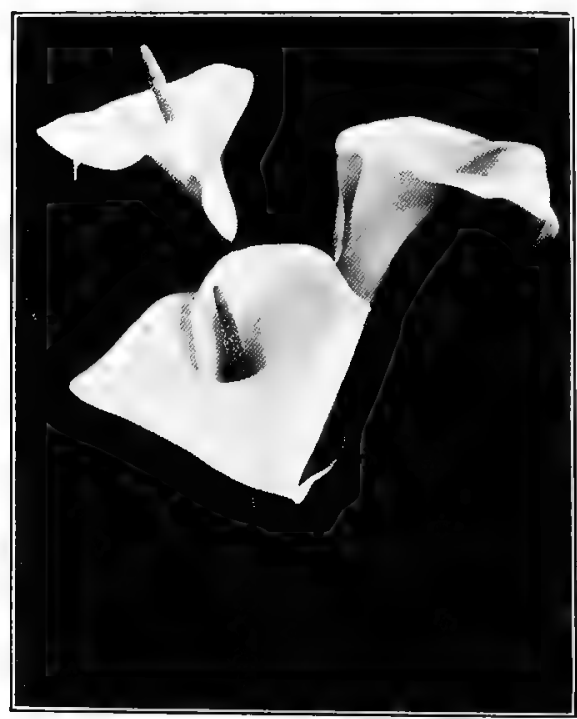

Fig. 118.-Callas. For floral designs and sprays the Calla holds first place with many. During the Winter months blooms cut and placed in a cooler will keep in perfect condition for two weeks or more is saved from the best flowers from selected stock grown under glass, which really should prove superior to ordinary stock, especially for indoor culture.

\section{CALLAS}

It is a mighty fine thing to be able to cut a few Calla blooms each week during the Winter and early Spring months. The retail grower may not always find it profitable to grow the socalled Easter Lilies, but if he has a house of $55 \mathrm{deg}$, Callas can always be made to bring good returns.

Wherever a retail grower is located there is call for cut Callas. For funeral sprays they always have been, and no doubt always will be used. Even if a man grows a hun- 
dred plants and can cut just a handful of flowers each week they form a profitable crop. Few other flowers will last longer than Callas if kept in a cool place, so hardly ever does one go to waste; all are made use of for something.

You can plant the tubers in August in solid beds, in benches, or in pots and get good results. For the retail grower with just a few plants, I should recommend pot culture, for the reason that, as a rule, one can put the pot plants in any convenient place, and, when advisable, move them to some other place; this, of course, is not possible when they are planted out. In pots they bloom as freely, if not more freely than when handled any other way, but of course they are a little more work.

Plant the tubers in August in as small pots as you can conveniently get them in; place them in a frame or on a bench in a cool house, and in October shift the started plants into 6-in., or, if extra large, 7-in. pots, then carry them along in a 55-deg. house. They want sunlight, but will get along even in a partly shaded spot. Have good drainage in the pots and water every day. In December, and from then on, apply a weak dose of liquid cow manure twice a month. The plants will flower up to late Spring, when they should be slowly dried off, and finally laid under a bench to rest. Later clean up the tubers and start them into growth again by August.

Among the best for cut flowers, although not quite as large as some others, is the Godfrey sort. This is mostly grown right through the year, and in many establishments, it has replaced entirely the old variety, Calla AEthiopica.

\section{The Yellow Galda}

Calla Elliottiana, with its deep golden yellow flowers, is a most showy variety and well worthy of a place in the retail grower's establishment. You wouldn't want to grow it in as large numbers as the white varieties, which is not to say that the flowers wouldn't sell, but rather that it is especially valuable as a pot plant during the Spring months. The yellow flowers and the whitish-spotted foliage go well together, making a good Easter plant.

For March and April flowering, you needn't start the plants until the end of October. Grow them on in a rather cool house, allowing plenty of space between them so as to obtain short, stocky growth. To have a few will help add variety to your assortment, if nothing more, and even that is worth something.

\section{GALLIOPSIS}

This is a showy annual-you might call it a miniature Coreopsis - with yellow flowers and, usually, dark centers. Sown outdoors, it quickly grows into bushes $2 \mathrm{ft}$. to $3 \mathrm{ft}$. high, soon covered with hundreds of little single flowers on graceful stems, fine for cutting. 
If you want it for Fall, sow outdoors about the middle of July and it will be in full flower by the end of September, a time when you have use for yellow and brown flowers. It wouldn't pay the retail grower to grow this little plant for flowers for the wholesale market, but he should sow some for his own requirements.

\section{CAMBRIDGE SCARLET See Monarda}

\section{GAMPANULA MEDIUM (GANTERBURY BELLS)}

You can grow and flower Canterbury Bells without a greenhouse, but they can be grown better in one, and made to bring good returns for every retail grower.

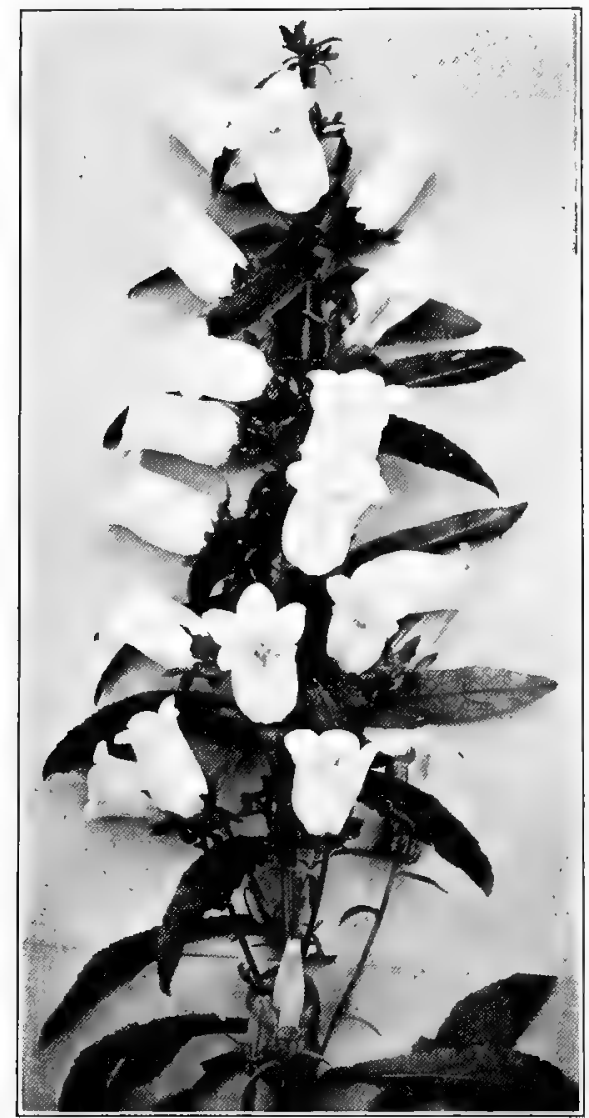

Fig. 119.-Campanuta medium. Although it is as old as the hills, the retail grower doesn't pay enough attention to this desirable biennial. The plants are not only showy for the border, but also real money makers when slowly forced under glass for early Spring flowering

Campanulas, whether the single Canterbury Bells or $C$. medium calycanthema (the Cup-and-Saucer variety) have been favorites for ever so many years. They are among the most showy of biennials for the hardy border during June, and when gently forced under glass make grand pot plants. Or they can be used as cut flowers. They are being grown by quite a few florists, but those who really could make them pay good returns-that is, retail growers everywhere - pay but little attention to them.

\section{Pot Culture for Early Forcing}

Sow seed about March in the greenhouse. Fresh seed will germinate as freely as that of Asters. Transplant the seedlings into flats and later on pot up into 2s. Keep under glass all Summer if you want to, or bring them into a frame in May. Keep them shifted so as to have them in 6- or 7-in. pots by October, and bring these into a cool house until January, after which they can 
be brought into a 50-deg. house. Keep them in the same pots and they will start to flower early in April.

\section{Field Gulture for Later Flowering}

Sow in March, carry in small pots and plant in the field in May. Lift in October and heel the plants into a coldframe until the middle of February, then pot up and let the plants come along slowly in a 45- or 48-deg. house. Don't make any attempt to force them in a high temperature; they will not stand it. They can also be planted out on a bench or solid bed where they will flower by early May.

\section{For Outdoor Flowering}

Sow any time from March to May; give field culture during Summer; lift plants in Fall, overwinter in a frame, and plant out where they are to flower during April. You will always find it advisable to overwinter at least a part of your stock in frames, as during a hard Winter they are liable to freeze if left out in the open, even when covered.

\section{Other Desirable Campanulas}

Among the many Campanulas, $C$. carpatica, in different shades of blue and white, makes a fine, hardy border plant of dwarf habit. It is covered with small, bell-shaped flowers and should be planted near the edge. C. persicifolia is taller growing and makes a good cut flower; so does C. pyramidalis, and all of these are easily grown from seed. If this is sown outdoors and the seedlings are once transplanted the plants will flower the following year.

\section{CANNAS}

The florist who says "We don't do much in Cannas, our trade calls more for other plants for bedding," would be iar more correct if he blamed this condition on the fact that although Cannas are becoming more important as bedders each year, he has but little call for them, because by not handling them and pushing their sale he manages to have his patrons and himself get along without them.

In few other bedding plants have greater improvements been made in the past thirty-five years than in the Cannas. After Mme. Grozy came out Cannas ceased to be just plants to be used for subtropical planting or massing around a Castor Oil Bean plant with Dusty Miller as a fitting border. Each sort is now planted in a bed or border by itself according to the particular color effect wanted, and we obtain a mass of blossoms from July until Fall. While Cannas are most attractive and make the best showing when large beds can be used, even in the small home ground they can and should be used. Such grand varieties as King Humbert, San Diego, Mrs. F. Conard, or The President are showy even when planted singly or 


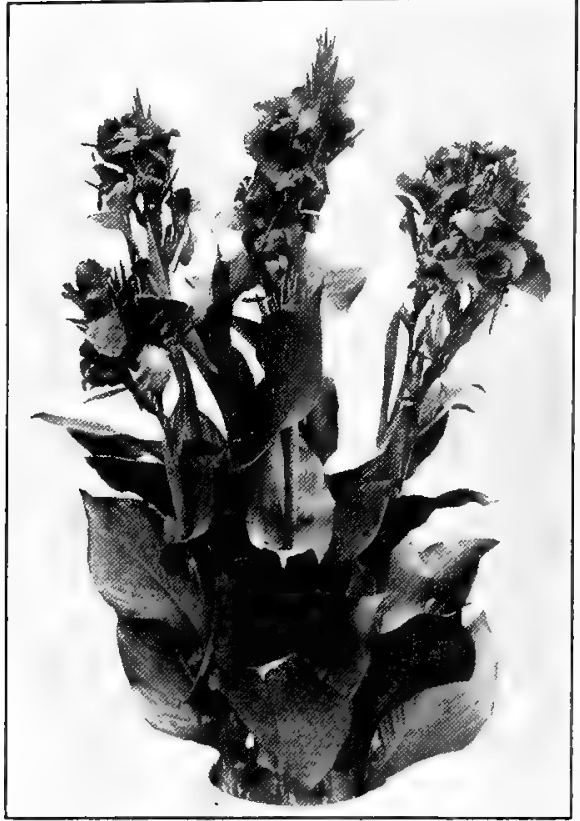

Fig. 120.-Pot Gannas. If you want to sell Cannas for bedding get a few plants of each variety in flower by May 10, by starting eyes in January with three plants in a clump. Nor need they be planted in beds by themselves if lack of space prevents. They can be used to advantage in the perennial border, where if planted in clumps, they take the place of some perennials or biennials that finish blooming by early July; or they can be made to brighten up the shrubbery border if no other place can be found.

We have always found that starting a few plants early, say about the middle of January, so as to have specimens in flower in 5 -in. pots by the middle of May, results in the purchase of Cannas by many of our customers who had no such intention when they entered the place. If you make an effort to have people buy Cannas, you will not only do more business, but also please your customers with the results they obtain; for. while Cannas, in order to do their best, should be encouraged with a well-prepared bed and plenty of water during the Summer months, even where they don't get the best of care they still make a good showing.

Every retail grower with a little space outdoors should arrange for a good display of Cannas in order to advertise them. This is always a good investment, nót only as an advertisement, but because from each single $31 / 2$-in. plant grown in good soil and properly attended to, he will obtain from eight to twelve more for use the following year.

\section{Gultural Notes}

If you sell your customer Cannas during the bedding season it is always well to call attention to the fact that they will do best in a deeply dug-over bed where the soil contains a liberal amount of manure. If one can add to a bed say 6 or $7 \mathrm{ft}$. in diameter about twenty-five pounds of bonemeal, so much the better. Don't have the bed crowned up in the center. A flat bed, as long as there is plenty of drainage below, is better, for the plants will get more benefit from the rains or the water you apply during the Summer months; and water they must have. 
Plants such as you have left over at the end of the bedding season can be planted out in the field. If wanted for the increase you can get out of them in the way of eyes for propagating for another year, keep them cut down; that is to say, as soon as a flowerspike forms, instead of letting it come into bud and bloom, cut it off, say 8 or 10 in. from the ground. This will make the plants keep on sending up new shoots which in turn can be cut. It is well not to practice this after September first, as you don't want too many small shoots, only 5 or 6 in. above the ground, by the time you lift the plants. The first heavy frost will finish the plants, but if they are labeled and a spell of good weather sets in, as usually does afterward, let them remain in the soil for several weeks; they will make better roots, or rather rhizomes, as they are called, which contain the eyes.

\section{Storing Gannas}

The reason your customer usually loses his Cannas stored away over Winter is that the plants are lifted, every bit of soil is shaken from the rhizomes, and these are thrown in a box and most likely placed somewhere near the furnace. The right way is to lift the plants (after they have been cut down to within 6 in. of the ground) with as much soil clinging to the roots as possible, and store them away in a dry, cool place, with just enough moisture in the soil to keep them plump. The florist can store his stock under a Carnation bench, setting them on boards close together. The boards are put

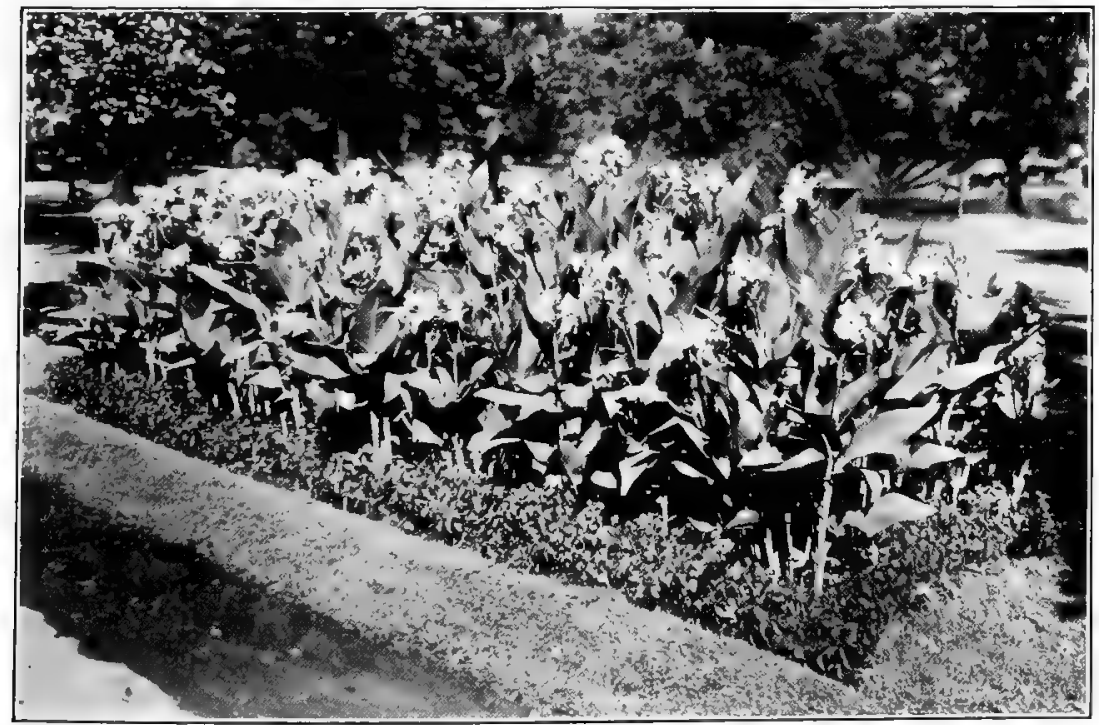

Fig. 121.-Bed of CanNa, variety SurPrise. Cannas never show to best advantage in a three-foot bed; indeed, the larger the bed or border, the more effective the display. Surprise is one of the many good varieties now available 
there to prevent the roots from getting busy in the moist soil below and starting a top growth. Look after your Cannas and once in awhile examine them. They don't want any drip from above nor heating pipes so near as to dry them up.

\section{Starting Cannas into Growth}

The man who propagates many thousands of Cannas makes use of the propagating bench with about $70 \mathrm{deg}$. of bottom heat. $\mathrm{He}$ uses every live eye and but little of the rhizome or stem so as to get as many in the bench as possible. The retail grower, however, finds it best and most convenient to start his eyes in ordinary flats, covering the bottom with about a 1-in.-thick layer of coarse soil and following this with a thin layer of sand on which the eyes are placed, pointing upward, each eye with a 2- or 3-in.-long piece of rhizome. More sand is placed over the eyes-just enough to cover themor even soil will do; the flats then receive a good soaking and are placed on the return hot water pipes. The first batch of eyes, intended for bedding stock, is usually started about the latter part of February, but in order to have every eye make good, you must have at least a little bottom heat. Without this, they are very likely to rot. With the second and later lots bottom heat isn't so important, yet it is best to use it. When the young growth develops and is about 3 in. in length, remove the flats to a light bench and two or three weeks later pot the plants up singly in $3 \frac{1}{2}$-in. pots where they can remain until bedded out. Those started first can be grown on in larger pots, but you never want anything from more than a 4-in. pot for bedding stock. When you take the small plants out of the flats you will always find some just starting into growth, and others hardly large enough to be potted; place the latter back in the flats, or rather use them to make up new flats and put these back on the pipes for awhile.

\section{ARIETIES}

Here, as with other plants, the only way to get good results is to invest a few dollars each year in the new introductions. Some of the finest sorts we grow today are from American breeders, and new ones are coming right along. Mrs. Alfred F. Conard and Hungary are especially in demand on account of their beautiful pink color, and both are ideal bedders. Maybe you have never tried them as cut flowers, yet it can be done. There are times in the Fall, after the Gladiolus season is about over, when you are in want of long. stemmed pink flowers. Cut a Conard with two or three flowers, and you cannot beat it for decorating. King Humbert, which replaced that old standby Egandale, is still the most showy of all for large bedding, but what we could use today would be a large yellow with King Humbert bronze foliage. The President is one of the 
finest green-leaved sorts, with red flowers, and San Diego is an excellent yellow; but you will have to keep on trying the newcomers in order to keep uptodate and in touch with the best. Good sorts come and go and others take their place. It is only once in awhile that a King Humbert happens.

I well remember thirty years ago we bought twelve Canna plants of a recent introduction. It was called Star of '91, a dwarf red, and never was anything more closely watched for the first buds to open. We couldn't imagine anything grander at the time, but its light soon grew dim as other brighter stars appeared, and finally went out. So it has been going ever since that time, and thirty years hence others will recall "has-beens" which today seem to us almost perfection itself.

\section{GANDYTUFT \\ See Iberis}

\section{GARNATIONS}

It is just about forty-five years ago that my grandfather at Frankfort-on-the-Main, Germany, showed me for the first time how to prepare a Carnation cutting to be put into cocoanut fiber mixed with washed sand, and impressed on me the fact that Carnations formed one of the florist's main flowers, even if he himself never could actually make any money out of them.

I have been in touch with Garnations ever since, have watched their development, tried my hand at bringing out new sorts, met with a lot of disappointments, and then forgot all about them when awarded a certificate of merit or able to bring home a few blue ribbons from the shows. I have spent many happy hours in the potting shed with old-timers, going over some of the sorts we could call to mind, that had made their entry to the accompaniment of a lot of noise from the introducer and all kinds of promises. We would recollect all the many remarkable qualities they were to possess, how the new star would in a short time outshine all others and bring us wealth, how they occupied the "footlights" for awhile-and then disappeared into everlasting darkness without leaving even a trace.

Here and there was an exception. It took Enchantress to replace Daybreak, and Enchantress has outlasted any other sort; and those that are considered best of all that are with us today are still on trial. To be sure, we are going forward, making headway. Look at a vase of well grown Laddie, Maine Sunshine, White Delight, Democracy, Denver, or Eureka, and then recall to mind Portia, Garfield, Tidal Wave, Hinze's White, or Grace Wilder. But what Wm. Scott predicted to me in Buffalo, twenty years ago, that the day would come when every Carnation grower would raise and grow his own seedlings, has not come true. As with the Rose and 
the Chrysanthemum, so with the Carnation; the bringing out of new sorts is in the hands of a few specialists and the florist and Carnation grower look to them to do it. All other kinds of predictions came true, especially John Thorpe's as to the size of the flower; but no one, not even the most optimistic dreamer, dared to prophesy that the day would come when it would be possible to realize, around Christmas, $\$ 7.50$ retail for one dozen red Carnations. Yet to the grower this is more important than anything else.

Whether you are among those who actually make money from Carnations, or whether you grow them and yet cannot say that there is much money for you in the returns from your plants, nevertheless, if you are a florist retailing your stock and depending on a local trade, you should by all means keep on growing them. You may use several hundred Carnations daily, but if you can cut some-even only twenty-five - of them from your own plants, the very fact that you have these few plants growing in your own establish-

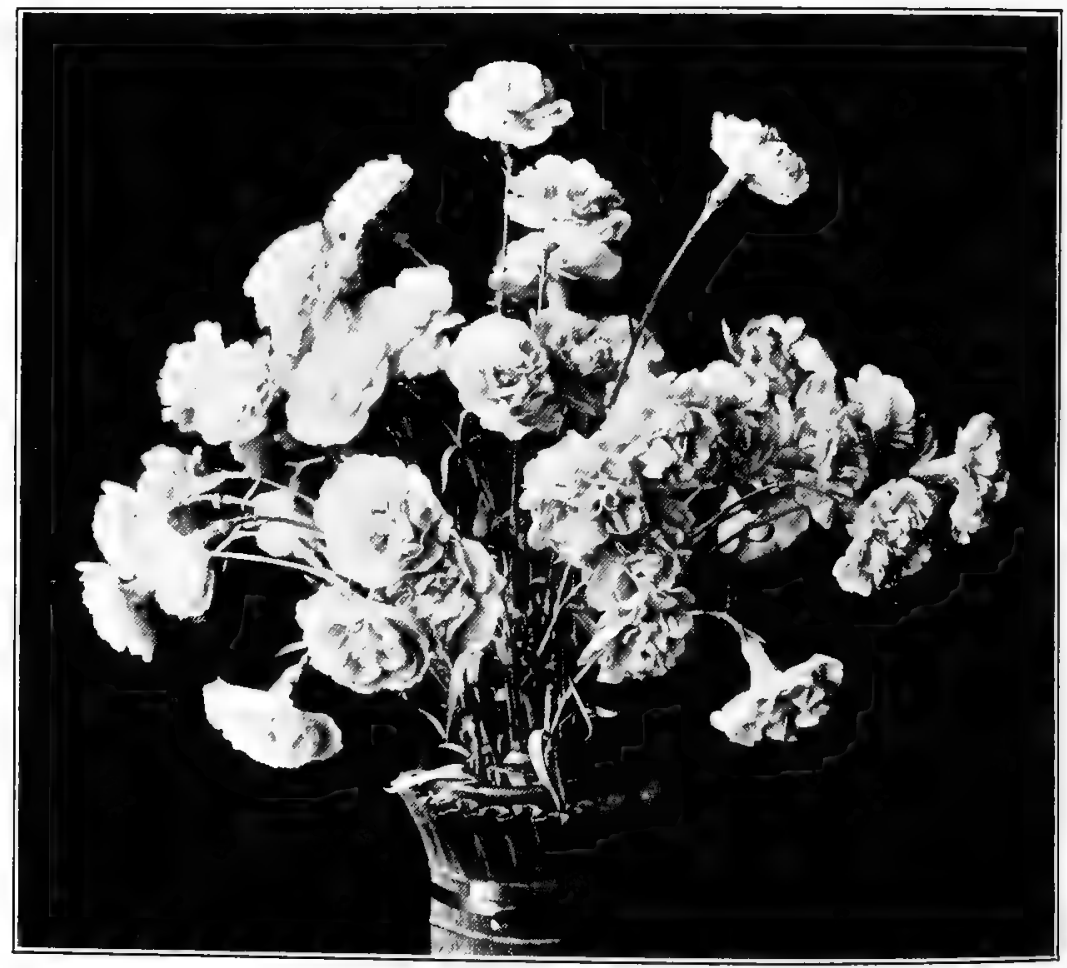

Fig. 122.-A Vase of Carnation Enchantress. Peter Fisher's Enchantress' has proved one of the most remarkable Carnations brought out in our time. For over twenty years - during which more new varieties have been introduced than ever before - it has remained the "bread and butter" sort for thousands of retail growers 
ment, so that your patrons can see them while in your houses, means a whole lot; it is a mighty good ad. Then there are bound to be times when the fact that you can cut a few dozen of your own flowers in an emergency will mean a lot to you.

A Carnation is not like an Ophelia Rose which has to be cut just at the right moment; it can stay a day or two-some varieties even longer if need be-and still be in good condition. The smaller retail grower with just one bench can easily arrange to keep a goodlooking show of flowers on it practically from Fall to Spring. Again, Carnations will thrive and do well in a house of $50 \mathrm{deg}$., which sounds good to those who have to buy coal when the thermometer keeps going down and down. Besides all this, one should take into consideration that Carnations form a crop to follow bedding stock and can be handled so as to make room again when your Geraniums get their final shift in April.

The man who is independent of the wholesale market, and retails his stock and arranges matters so as to cut Carnations from September until April, cannot help but make them pay, even if his flowers are not of the highest quality, or even if he doesn't get the number of blooms per plant that some experts claim they obtain. With funeral and other design work, and orders not calling for any particular flower, if you happen to have an extra heavy crop of flowers on your plants you can always use them to advantage: On the other hand, if you have good success and your flowers are good, you will have no trouble in disposing, at paying prices, of all the surplus blooms you may have at any time.

Carnations have not, in any way whatever, lost their popularity as some try to make us believe, nor have they ever brought higher prices. The thing is to grow good ones if you want to compete with others, and if you grow for your own retail trade make proper use of them and treat the plants half-way decently. Even if for some reason or other you cannot make the plants produce enough flowers to actually pay for the space they take up, I should still suggest growing a few, if for no other purpose than that of having your patrons know that you are growing at least a part of your requirements.

\section{About Varieties}

If you are at all interested in Carnations you should join the American Carnation Society. Attend its conventions whenever possible and thereby keep in touch with whatever advance is being made. Stick to the standard varieties, such as you know will do well with you, but the minute you see or hear of a new sort, try it; the price of the young stock will never be so high that you cannot afford to invest in at least a few plants and give them a fair trial. 
The day is over when a firm of good repute will send out a Carnation knowing it is worthless. Frequently a new sort holds up for three or more years and then gives out, but if you wait until dead sure that it is a really good thing, it is too late to make money on it, for by that time everybody has it.

There is no such thing as the three or six best sorts for the florist to grow. Soil and climatic conditions, the houses they are grown in, and the way they are handled make a certain sort a success in one locality and a failure in another. The man who wants to go into growing Carnations and doesn't know what sorts to plant cannot do better than find out what is being successfully grown by others in his neighborhood, or what growers make use of within a radius of a hundred miles or so if there are none in his immediate vicinity. But never omit to invest each year in at least a few new ones; don't feel sore because the sorts you tried last year turned out badly; forget about them and keep on trying out new ones. It is the only way.

\section{The Necessity of Early Housing}

I have yet to find a live retail grower who isn't crowded for room eight months out of the year. About the only time he sees the bottom of the benches is right after the bedding stock leaves the house, and if that runs into July, somebody has to get busy repairing the benches, cleaning them, and refilling them with soil, for the Carnations from the field are ready for housing by the tenth to the fifteenth of that month. If they are housed early it means that the plants become re-established in a few weeks and during the middle of September start to flower on fair-sized stems.

Early housing is most important for the florist who has to throw his plants out in early April in order to make use of the bench space for Spring stock, for he has to get the most out of his plants up to that time. Such as have been benched during July or in early August will give you fine flowers and stems during November and December, which cannot be said of such as were lifted and housed the end of September or during the month of October.

Stock lifted from the field in July usually consists of plants with six or eight short, stocky shoots which when benched will, in the shortest possible time, become established and go ahead. Plants by the middle of October usually are of enormous size, are hard-wooded and therefore are set back considerably. when housed, hardly ever producing a crop of really good flowers and stems before the middle of January. Even small, late propagated stock, housed about October, will require considerably longer than stock planted in July when everything is in favor of plant growth. 


\section{Gultural Notes}

Plants which have been growing in the benches from July on will usually produce side shoots at the base of or along the flower stems by November, which, when about 3 in. long make ideal cuttings. No knife or trimming is required. Hold the stem with the left hand and with a sideward twist of the right you can easily remove the shoot its entire length, ready for the propagating bench. Insert in the sand a good inch deep and press the sand firmly. Don't shade the cuttings during December; they won't wilt if the sand is kept fairly moist at all times, and if just a little bottom heat can be had. Inside of a month ninety-five per cent of the cuttings are rooted, ready for 2 -in. pots. A house of $50 \mathrm{deg}$. is all right for propagating as well as for the small stock. By February the plants are ready for a shift into $3 \mathrm{~s}$ and the removal of their centers so as to avoid developing a flower stem, and to encourage the plants to grow bushy. By the middle or end of April, the plants can be transferred to a coldframe to be hardened off, the first and second week giving plenty of air on bright days and finally removing the sashes altogether. Get ready to plant in the field by early May, allowing about 10 in. between the plants in the row, and sufficient room between the rows to permit cultivating.

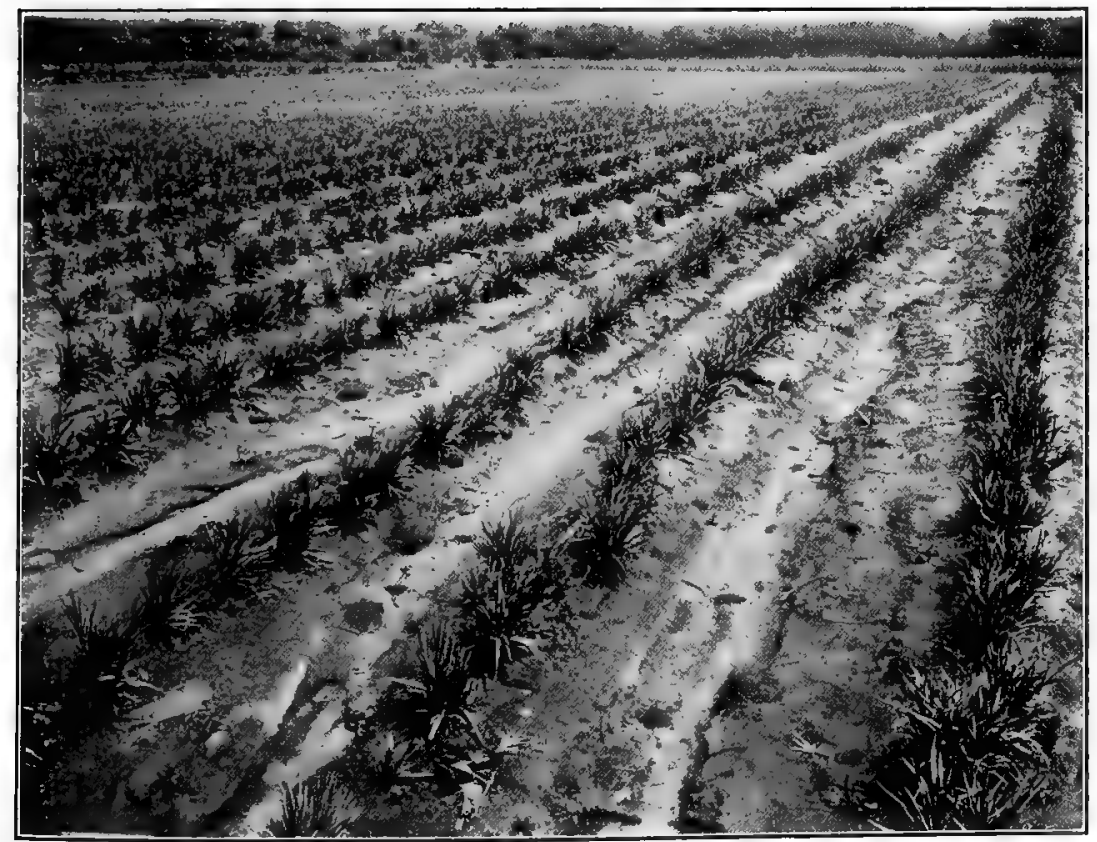

Fig. 123.-Ciarnations IV THE FIELD. Some 65,000 plants grown as a substitute for farm crops near Washington, D. G., for a retailer in that city. Set out in April, the plants were well along when this picture was taken in July. 


\section{Conserving the Essential Moisture}

One good watering after planting is usually sufficient except in an exceptionally dry season; but if you have a deeply worked soil to start with and run between the rows with a hoe or cultivator once a week, watering with the hose is likely to produce soft growth and do more harm than good. Keep the plants pinched, never allowing buds to form. By the middle of July the plants are ready to be lifted with a spading fork. If the soil is too dry let this be done so as to get a good mass of the roots and a little soil clinging to the plants, either wait for a good rain or water the plants thoroughly a day or two before they are to be lifted.

In the meantime the benches should have been made ready; the soil in them should be neither too wet nor too dry. Plant, according to the sorts, approximately 10 to $12 \mathrm{in}$. apart and just a little deeper than they were in the field. During very hot weather put a good mud wash on the roof of the house. Water thoroughly after planting and spray the plants lightly several times during the day so as to prevent wilting. After the third day remove a little of the mud and keep this up so that in about a week after planting the glass is clean again. Examine the soil in the benches from day to day and try to keep it moist, but not soaking wet; also let up on the spraying except on hot days during the noon hour. Cultivating the surface of the soil will keep it moist and cool below.

The first buds will be on short stems and should not be allowed to flower; pinch them out and let the strength go into the next lot of shoots. Apply wires lengthwise and twine crosswise over the benches to form supports long before the plants need them. Fumigate regularly to keep green fly down and cultivate and remove any yellow or decayed foliage. If you have made use, when filling the benches, of rather heavy soil with about one-fourth well-decomposed manure, the plants won't need feeding until Christmas, when, after a light cultivating, a layer of bonemeal and sheep manure just thick enough to cover the surface will be in order. Follow this with a 1or 2-in. layer of good soil. Or a mulch consisting of equal parts well-decomposed cow manure and soil can be used instead of the bonemeal and sheep manure. In the case of healthy plants and such as are producing flowers, more food may be applied by the end of January. Keeping the flowering stems free of side shoots and allowing just one bud per stem will make for large flowers, yet there are times during Midwinter, with flowers scarce and a retail grower having design work on hand, when it might be considered desirable to allow two buds to remain on the white and light pink ones. If there should be no call for long-stemmed flowers by the time the first bud of the pair opens, the flower may be removed and the second bud allowed to bloom. 


\section{Summer Gulture Afield and Indoors}

To the man with limited space during April and May, planting his Carnations in the field will always appeal; for with houses full of bedding stock there is but little room for the Carnations. Planting them out in the field will permit of cleaning out the houses and repairing the benches. The plants themselves are out of the way for ten weeks or so while the busy season is on, which is better for them; the few weeks in the open help to keep them healthy. However, those who have sufficient space and can get a bench ready for planting by early May and have well-established $31 / 2^{-}$or 4 -in. plants, might just as well bench them for it will result in still earlier, longstemmed flowers.

\section{Benches and Solid Bed Gulture}

Carnations can be grown to perfection in benches holding from 5 to 6 in. of soil, and are mostly grown that way today. Yet there are successful growers who plant them on solid beds and even prefer this method. In this case the plants, when through flowering after Memorial Day, are removed and the beds get a dose of lime, a layer of manure, are spaded over and replanted with young stock. There are some growers who have successfully used the soil left in the benches the second year, but it stands to reason that after you have had the plants growing in the benches for about ten months, with almost a daily watering it cannot be as good as fresh soil, which has never been used in benches. For those who can make use of the old soil, but who don't find it too hard to obtain fresh soil, the latter course is advisable.

\section{Late Benching}

There are occasions when another crop occupies a bench that is, later on, to be filled with Carnations. Rather than leave the plants out in the field until October or November, a better way is to pot them up, say about the middle of Angust, carry them along in a frame or house, and plant them out when the space is ready for them. A plant potted in a 5-in. pot, in good soil, with proper drainage and taken care of, will keep on forming new roots, and will, when planted out later on, go right ahead. Good Carnations during February and later pay as well as at any other time; if specially wanted during this period the plants can be benched or planted on a solid bed to follow Chrysanthemums.

\section{For Outdoor Flowering}

There isn't a florist who sells bedding stock during the Spring months who cannot dispose of a good number of Carnations for Summer and Fall flowering. There are seasons when, after the housing is completed, the surplus of Carnations left in the field and al- 


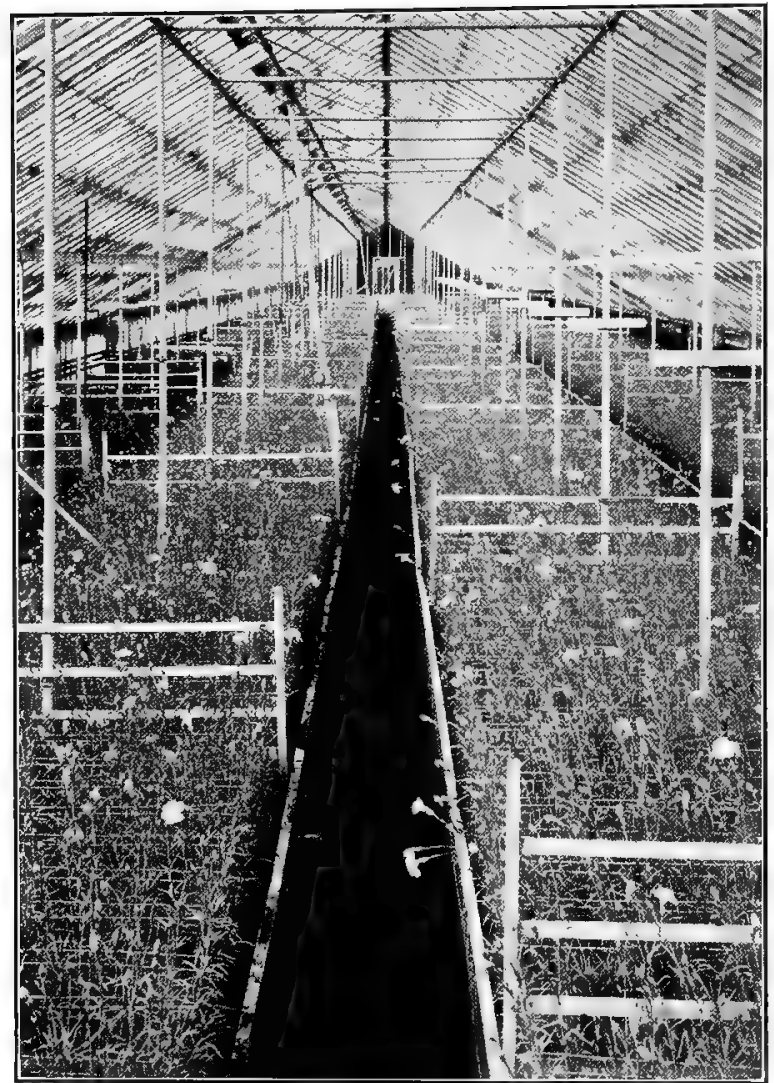

Fig. 124.-A Good-Lookmg Garnatron house. It would look even better if it had not been cut over just before the picture was taken. But the plants are there and healthy enough, too lowed to flower will bring in good returns, for they will bloom until stopped by frost. Still better results can be had by growing on the Novemberrooted cuttings for that purpose. Keep them pinched and shifted during the Winter months so they will develop into bushy plants in 4in. pots by May. If planted out during that month and not pinched any more, they will start to flower in early July and keep it up. Almost every one of the sorts we grow under glass today is suitable for this purpose.

\section{Stem-Rot and Other Diseases}

Stem-rot is one of the dreaded diseases to which Carnations are subject. It usually starts soon after the plants have been benched. It is caused by a fungus, and anything in the fungus line thrives best when there is excessive moisture, stuffy air or lack of ventilation, either in the house or the soil. While I like to plant just a little deeper in the benches than the plants were in the field-the object being to allow for the settling of the soil around the plants after several waterings have been given-this doesn't mean to plant a bit deeper than necessary, or so that a part of the foliage is covered with soil. The best preventives of stem-rot are: The avoidance of too much moisture; the removal of every affected plant the minute it shows signs of getting yellow or starting to wilt (lift the plant 
with a little soil if possible and throw it out); the keeping of a good circulation of air; and the light cultivation of the surface of the soil so it can breathe.

A hot, dry atmosphere and heating pipes too close to the benches will bring red spider; light salt-water solutions are best for this enemy, or even clear water applied under high pressure. A too damp, cold atmosphere will produce rust. Crippled buds and foliage are caused more by insect pests than by anything else, and here, as with Chrysanthemums, regular spraying with nicotine solutions, or fưmigating will be found most effective in keeping the plants healthy and clear of insects and diseases. Information about the different troubles and the best known remedies may be found in the several State Experiment Station bulletins, which are easily obtained. But plants which, due to neglect of some sort, really become so sick as to show marked effects, are hardly worth doctoring up and saving; too much valuable time and space are lost in getting them back into shape. Better, and to my mind more sensible, it is to throw all such plants out and give some other crop their place.

A Carnation plant can stand more cold than heat. While 50 deg. at night will suit most varieties best, you can keep them healthier in a 40-deg. house all Winter than in one of $55 \mathrm{deg}$. or over. They may not flower profitably enough in a 45 -deg. house during Midwinter, but they usually make up for it later on. But give them a too warm house and you soon will notice a weak growth, which is the time when they are subject to diseases of all sorts. The critical time for Carnations is from November until February. During that period avoid keeping the foliage wet over night or the soil too moist, which is as bad (though no worse), than to allow it to become dust-dry before water is given. To keep it evenly moist with a rather dry atmosphere prevailing in the house, with good ventilation, is the thing, and if you have healthy stock by the first of November there is really no good reason why it should not be kept so by using ordinary precautions; yet even the best of growers fall down sometimes, and a lot of plants on one bench will go wrong while another variety in the same house, subjected to the very same treatment flourishes. Such cases are hard to account for. There is a lot we know about Carnations, but far more that we don't know.

\section{CASTOR BEAN}

See Ricinus

\section{GELASTRUS SGANDENS (BITTERSWEET)}

You always have use for branches of Bittersweet during Midwinter when they are covered with their berries or fruit of orange- 
yellow color. Many people prefer them to flowers and they can be used by the florist in several ways. You can grow this climber in almost any location and soil as long as you provide supports for it to cling to. Your customer may want a vine to cover a fence in a somewhat shady place; Bittersweet will do it, and when you mention the fact that it bears berries during Fall and Winter, it is no trouble at all to secure the order.

Always include a few small plants when you make up your

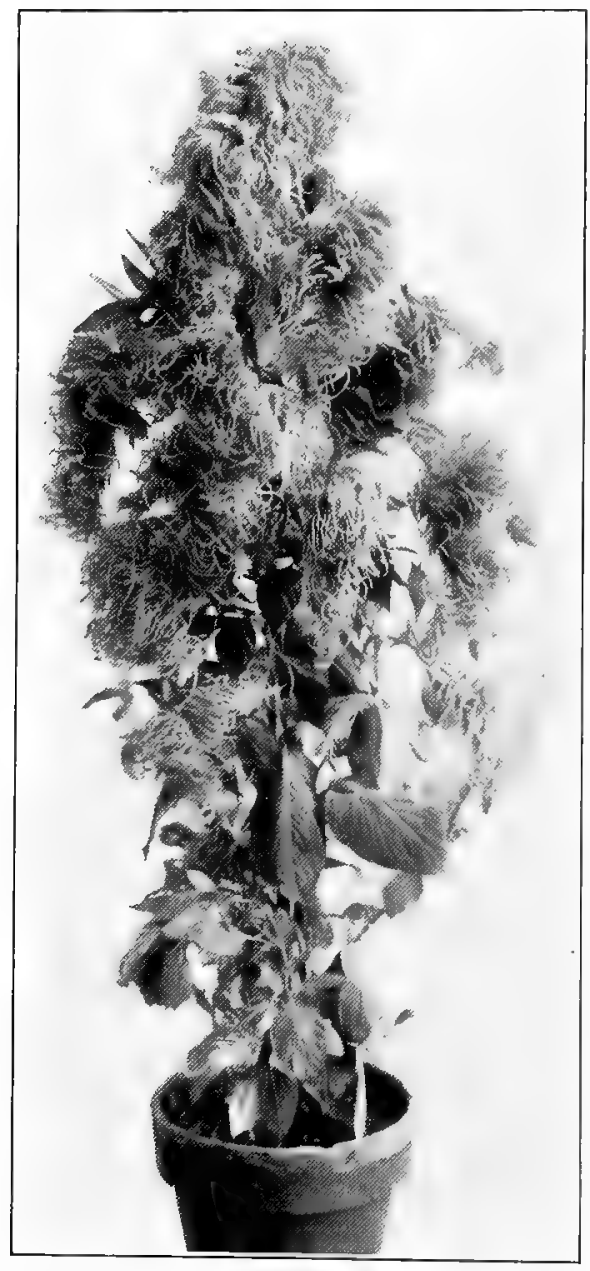

Fig. 125.-Celosia "Pride of Castle Gould." By sowing seed of this Celosia in Summer and keeping the plants shifted and under glass later on, you can provide in Fall showy plants that are well adapted for decorative purposes order for nursery stock.

\section{CELOSIAS (COCKSCOMB)}

The florist hasn't much use for Celosia cristata, the crested Cockscomb, but it is nevertheless a fine bedder, easily grown from seed sown about March first. The little plants delight in a hotbed where, with the heat, moisture and a situation close to the glass they do far better than in a greenhouse.

Among other Celosias we have the Chinese Woolflower (C. Childsii) a most attractive annual growing to almost $3 \mathrm{ft}$. in height and producing large, scarlet flower heads resembling balls of wool. Also the Plume Celosia (C. Thompsonii magnifica) which produces large plumes of yellow and red. Pride of Castle Gould, a strain of this type, is attractive with its compact, erect habit and large flower heads.

There is perhaps nothing more showy in the way of a formal bed than a long border filled with Empress Cockscomb. That is where these plants do best. Climatic conditions also have a great deal to do with their success. On the other hand, 
the average florist, will hardly ever get a call for a bed or border of these dwarf, large comb-producing sorts which are really only good for bedding, although a well-grown 5-in. pot plânt is certainly attractive.

If you wish to grow on plants of Celosia cristata for Spring sales, sow seed about the middle of March in gentle heat; pot up the seedlings into $2 \mathrm{~s}$, and carry in a 55 -deg. house; shift by the end: of April and get them into a hotbed. No plant enjoys bottom heat, a close atmosphere and being close up to the sashes more than these Celosias. An uninterrupted growth is absolutely necessary if you want to obtain a large comb of flowers.

\section{Celosia plumosa, or Feathered Cockscomb}

The feathered Celosia should be considered one of the most attractive annuals for the garden, and there are occasions when you can use it to good advantage as a cut flower. When cut with 2-ft. stems the blooms are very decorative and will last nicely. While red and yellow, cannot, perhaps, always be used to advantage during Summer, there are times when they are just what you want. Treat these Celosias the same as other annuals. As good a way as any is to sow them right out in the open and thin them a little later on.

The Thompson's hybrids of Celosia plumosa are the showiest of all and are particularly fine for pot culture. Sow seed in early August and keep the plants shifted. In good soil they will grow over $3 \mathrm{ft}$. in height and bear enormous plumes of feathery flowers, excellent for the showhouse or store.

\section{CENTAUREA CYANUS (BAGHELOR BUTTON)}

Since we now have the double forms of Centaurea cyanus, there is hardly any use considering the single one any longer.

For cut flowers outdoors the earlier you sow seed the better, for the plants don't do much in the heat of July and August. A good way to do is to sow a little seed about March, grow the plants on in pots and plant them out in a coldframe in April. This will give you some excellent long-stemmed flowers by the end of May, and they will keep right on and still be good by July 4 th-a day when you will most likely need blue flowers.

\section{For Foraing Under Glass}

If you want 15-in. stems and large flowers during April, sow seed in January, transplant the seedlings into $2 \mathrm{~s}$, and by the end of February plant on a bench about $12 \mathrm{in}$. apart in a house of $50 \mathrm{deg}$. Later on supply stakes for them. If you plant in a solid bed you will have still better results, but the plants won't flower quite as early as those on the benches. 


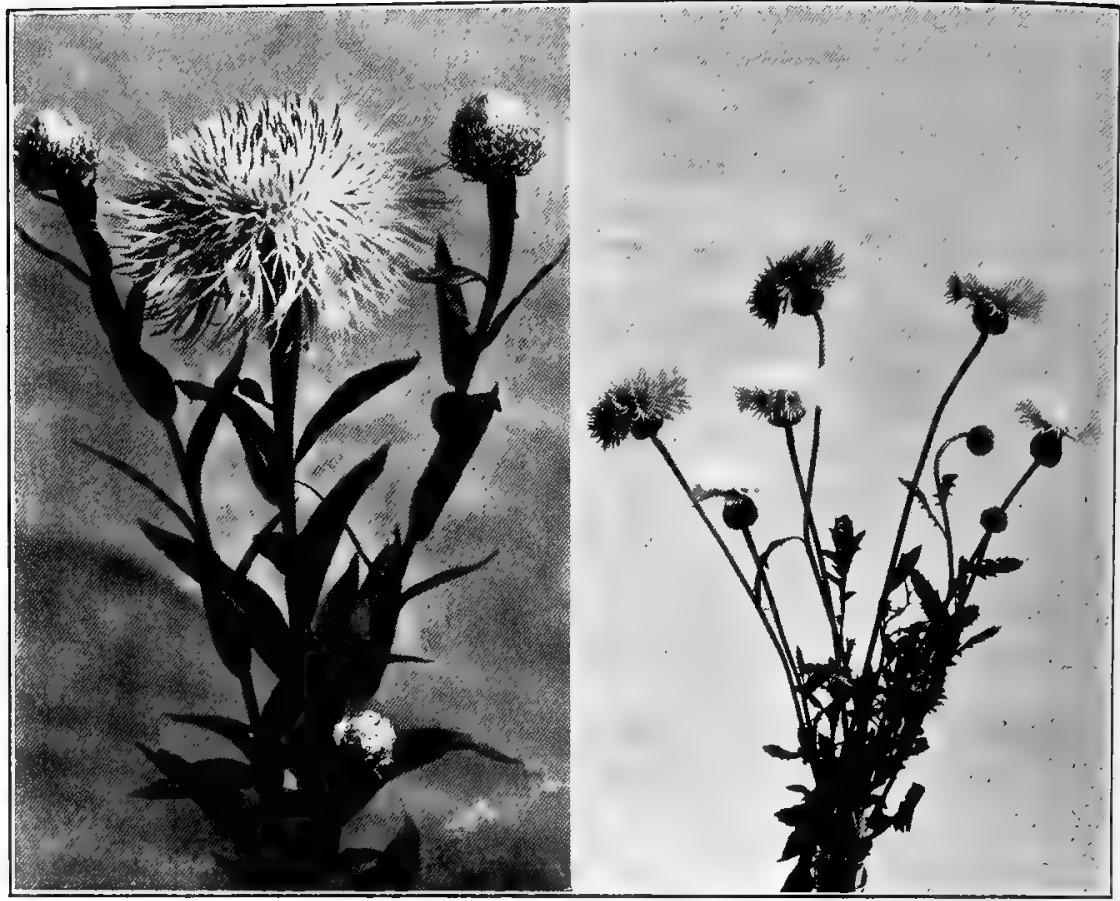

Fig. 126.-Two Useful Centaureas.-C. americana, on left, is only suitable for outdoors, $C$. imperialis is a strain of hybrids from $C$. moschata and C. Margaritz. Best known as Royal Sweet Sultans, they range through white, lavender, mauve, pink and yellow shades. Glorious for cutting indoors or outdoors. Must have abundance of lime in the soil

Every florist can make good use of these Centaureas during the Spring months, and even a small space devoted to them will pay well for the little trouble they are to raise.

Another good Centaurea for growing under glass in gentle heat for early flowering is $C$. imperialis or Royal Sweet Sultan. It is best to either sow the seed or transplant the seedlings on a solid bed. You can obtain pure white, light lavender, and light pink-all good for cut flowers. These will also be fine for outdoor flowering, but you must sow early. Centaurea suaveolens is the yellow Sweet Sultan, which can also be grown under glass. However, we find that this variety does best when given a rather poor soil; in one that is heavily manured it is liable to damp off while in a small state.

Still another beautiful sort, but adapted only for outdoor flowering, is Centaurea americana, far too little seen and used by the florist. It is also called Basket Flower. The large, Thistlelike flowers often are $4 \mathrm{in}$. and more across and of a beautiful rosy lavender color. Sow the seed in rows outdoors in May and the 
plants will start to flower by the middle of July and keep it up until frost. They seem to delight in hot weather, being in this quite different from the others. For best results, cut the buds just as they begin to open; the flowers will then last in good shape for four to five days, and with their long stems they come in very handy. The plants will grow fully $3 \mathrm{ft}$. tall and in rich soil should be staked.

\section{GENTAUREA GYMNOCARPA (DUSTY MILLER)}

While Centaurea candidissima is also known as Dusty Miller, and is a better colored border plant than $C$. 'gymnocarpa, it is the latter which the average florist raises from seed and uses most extensively for that purpose. It is much easier to handle and grows in a shorter time.

For plants in $21 / 2$-in. pots of the right size for borders, sow seed by the end of February and grow on cool. If you want extra sized plants in $31 / 2^{-i n}$. pots to help fill vases and window boxes, sow in early February and grow on in a house just under $50 \mathrm{deg}$. The plants when well grown and about 10 in. in height, with their fernlike foliage and silver-gray young leaves, are just the thing to go with Geraniums.

\section{GERASTIUM TOMENTOSUM (SNOW-IN-SUMmER)}

This is another desirable, hardy little foliage plant, as well as a flowering plant, for the rockery. When in flower it presents a sheet of white blossoms, but with its silvery leaves, it is every bit as good when out of bloom. If you set out just a few plants in the open, you will always have a stock to draw from when a customer wants a clump or a dozen planted on his or her grounds.

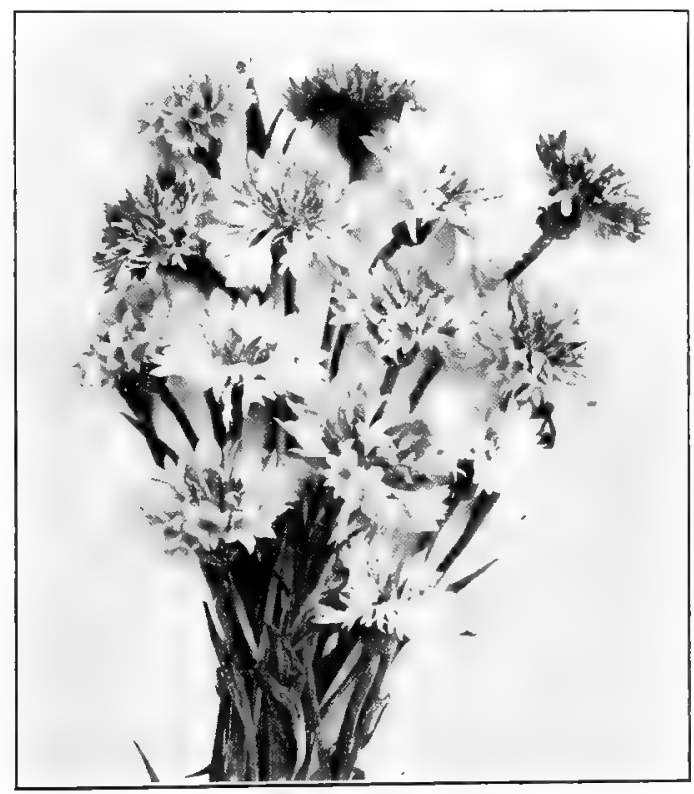

Fig. 127.-Centaurea cyanus which, sown outdoors in April, will produce great numbers of splendid cut flowers in many attractive soft shades on 12-in. stems, all Summer long 


\section{CERASUS (FLOWERING GHERRY)}

Both the double- and single-flowering forms of Cerasus make desirable shrubs to plant. You can get the weeping double-flowering sorts in the shape of small trees which will give you a little change from the usual Weeping Mulberry found on almost every place.

\section{CERGIS GANADENSIS (RED BUD OR JUDAS TREE)}

I don't believe in having one small home ground laid out and planted just like another. You should do all you can to avoid it; certainly there are enough ways and enough kind of shrubs and trees to make it unnecessary. But I don't think there would be the least harm in having one good specimen of Red Bud or Judas Tree in every yard. Maybe you have seen it in full bloom, the branches covered with the lilac-pinkish blossoms ahead of almost everything else among the flowering shrubs and trees.

The plants are usually small when you buy them, but it is well to select an open spot for them, as they will grow in time into little trees. Of course they are usually not at their best when small.

\section{CHAMOMILE, FALSE See Boltonia}

\section{CHEIRANTHUS GHEIRI (WALLFLOWER)}

Why not more Wallflowers? There isn't a retail grower anywhere who, during early Spring, couldn't sell Wallflowers in pots or as cut stock if he had them. We call them English Wallflowers, but they are as popular and fully as much used in other parts of Europe as in England. Many thousands are sold in each of the larger city markets.

It seems that everybody loves Wallflowers and this, to a great extent, is due to their delightful fragrance. While they are fine for outdoor blooming, you can have them at their best under glass. Can you possibly imagine a more charming combination for a basket in March or April, than Wallflowers, Forget-me-nots, Mignonette, Jonquils and a few Pansies? The best part of it is that even the florist with not the best of houses or heating facilities can have a supply of each of these flowers on his benches. It is these simple flowers that people want today. Their simplicity and sweetness is what makes them so desirable. Don't worry about not having Roses to cut or orchids; grow some of the above-mentioned old favorites and grow them well, and you needn't worry. You will make profit enough to enable you to buy Roses and orchids.

\section{Gultural Notes}

There are quite a number of single and double sorts of Wallflowers. The most desirable, however, has large, single flowers, 
of a brownish-red shade, the plants being of medium height and adaptable to both pot culture and to the production of cut blooms. Sow the first lot of seed about the middle of April and transplant the seedlings when large enough to the open field. Lift in October and pot into $5 \mathrm{~s}$ or $6 \mathrm{~s}$ according to their size. The plants, up to February, are just as well off in a coldframe.

About the middle of February the first lot can be brought into a Carnation house temperature where they will start to flower in March. A heavy plant in a 6-in. pot will have from fifteen to twenty flower spikes and can either be sold as a pot plant or the flowers can be used for cutting. Other batches of plants may be brought in from time to time; also a later sowing can be made, say, about the middle of May. If you have plenty of field plants they can be carried along in frames and planted on solid beds in a coldhouse or in benches and grown on for cut flowers. Or plants carried in a frame can be planted outdoors in early Spring where they will make a showy bed. Of course, it all depends on what variety you plant. You cannot make a cheap strain of mixed seed pay, but there are excellent named sorts such as Goliath, dark brown; Ruppert, brownish-red; and Goliath Triumph, purplishcrimson.

CHERRY, FLOWERING See Cerasus

GHERRY, JERUSALEM See Solanum

CHINESE LANTERN PLANT. See Physalis

CHORIZEMA

ILLIGIFOLIUM

(TANGO PLANT)

You may never want to grow on a stock of Chorizemas yourself, for it takes several years to grow a fair-sized specimen from a cutting; and even then, although the plants, covered with their light green, Holly-like, glossy leaves and pink flowers, are attractive, it isn't likely you will sell many. Leave the growing on of the plants, then, to the specialist. He who knows how

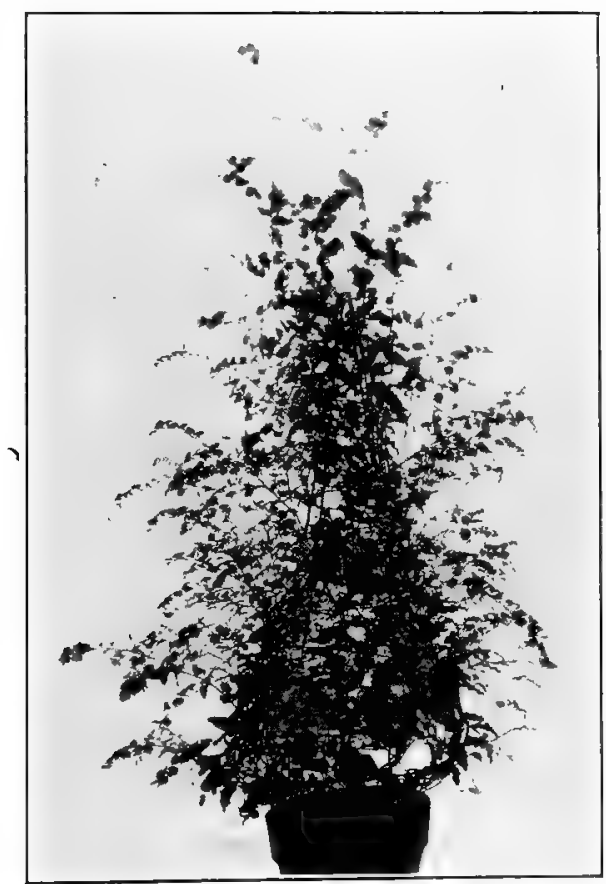

Fig. 128.-ChORIZEMA MACROPHYLLUM IN Flower. When well grown a number of the Chorizemas make beautiful flowering pot plants, but even though they are coldhouse plants it hardly pays the smaller florist to grow them on from cuttings 

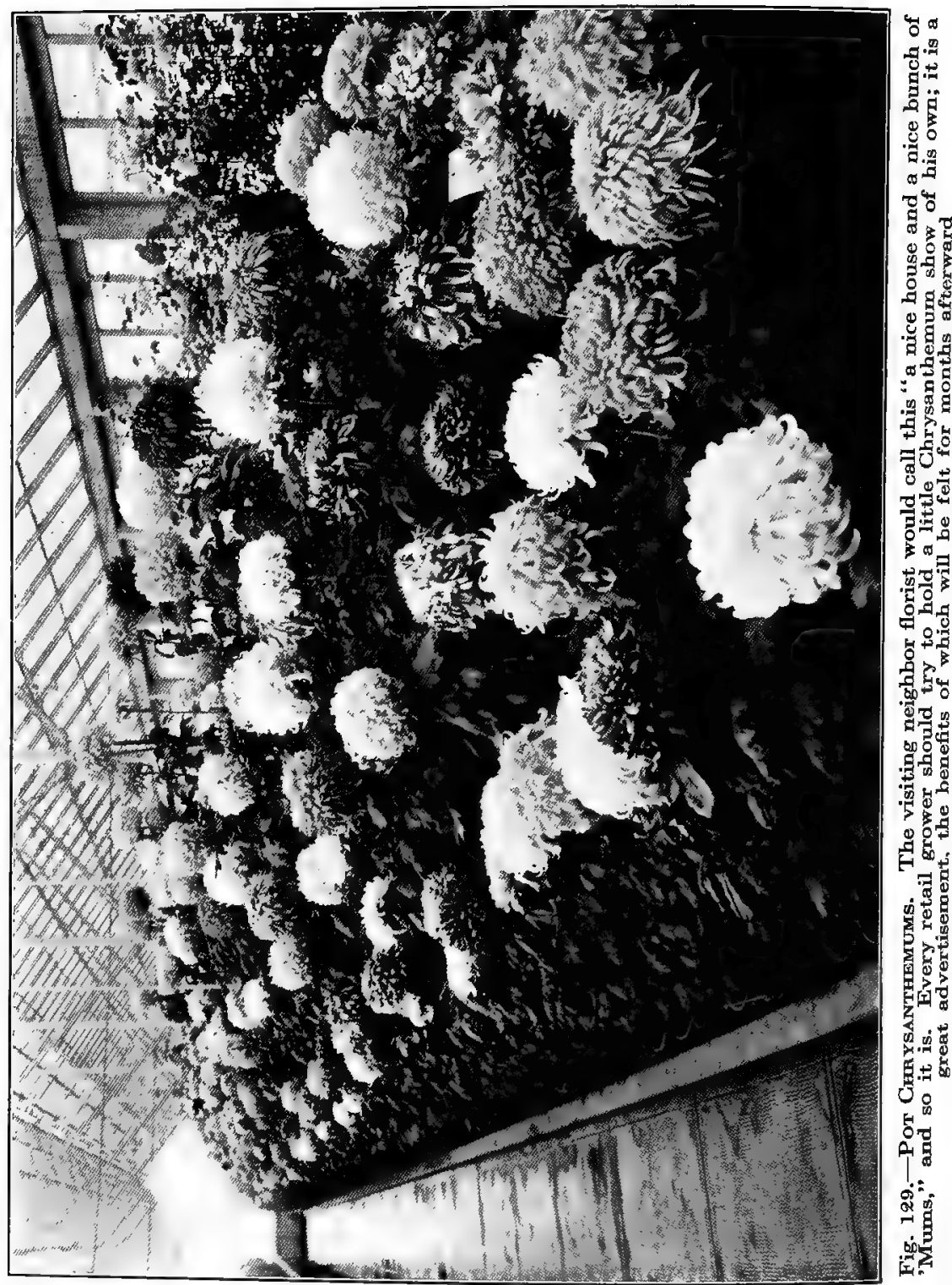
to handle Ericas most likely will also handle Acacias and Chorizemas. If you have any leftover plants, cut them back a little, shift them into larger pots in May and plunge them outdoors in a frame over Summer. You will have no trouble in overwintering them nicely in a cool house, so as to have them in flower again during March.

\section{GHRISTMAS CAGTUS \\ See Epiphyllum \\ GHRYSANTHEMUM FRUTESGENS \\ See Marguerites}

\section{GHRYSANTHEMUMS}

Roses and Carnations are with us all through the year, while the season of the Chrysanthemums is over in just about ten weeks; yet the latter make up for it by occupying the entire stage when they do appear. Everything else in flowers has to take a back seat during their stay; they crowd all competitors into the corners of the display cooler. They decorate the show window and the store as nothing else is able to, and with their endless variety of sizes, forms and colorings make possible exhibitions all their own in the largest show halls of the country.

JUST about when the Hickory sheds its weather-beaten brownish $J$ leaves, the Bur Oak and Maple put on tints of Fall, the Dahlia and the Cosmos hang their heads newly touched by frost and Nature outdoors makes ready to go to sleep, the Ghrysanthemums in gorgeous color array usher in a new, busy Winter season for the florist. They liven and brighten up dark November days and help us to celebrate Thanksgiving; and then, one by one, they make way again for the Rose, the Violet, the Carnation, the red Cyclamen, the Poinsettia, and the Christmas rush, having tarried with us but for a little while. We are pleased enough when we behold the first flower ready to be cut, and equally glad when the last one leaves us.

\section{Their Value to the Florist}

Chrysanthemums will thrive in a greater variety of soils and climates than perhaps any other plant the florist handles. They respond freely to good care, and while the wholesale grower doesn't always find them profitable, mostly on account of market conditions, they are one of the most important crops the retail grower has. Not only can they be successfully grown in the most uptodate greenhouse structure, but good results may be had if one has only a sashhouse. They fill the benches when emptied of bedding stock and, in turn, make room for a Winter crop, for small stock to be grown on for another year, or for Easter plants.

The florist out in the country couldn't have a better advertisement for the opening of the Fall and Winter seasons than a little 
Chrysanthemum show all his own, which is bound to boost things and have a beneficial effect all Winter. There isn't a better business stimulant, not to say anything about the advantage of turning your crop into dollars.

The retail grower who doesn't make Chrysanthemums pay often has only himself to blame. By not paying sufficient attention to the sorts he handles and how he treats them, he is apt to keep on growing outofdate sorts for which there is but little demand; or he fails to recognize the necessity of carrying early, midseason and late sorts in the right proportions, which, to my mind,.is of as great importance as anything else.

\section{How to Grow Ghrysanthemums}

For the man who retails the Chrysanthemums he grows the main thing to bear in mind is to plan so as to have flowers to cut from the middle of October up to near Christmas. This may be easy enough for those who can devote several houses to them, but even when the plants are handled on a small scale it can be done. Avoid the mistake made by so many who grow in the neighborhood of 2500 plants consisting of say, 1000 Major Bonnaffon, 500 Eaton, 500 Ivory, and 500 mixed Pompons. One may make money out of such an assortment, but one is more apt to have to dump a large

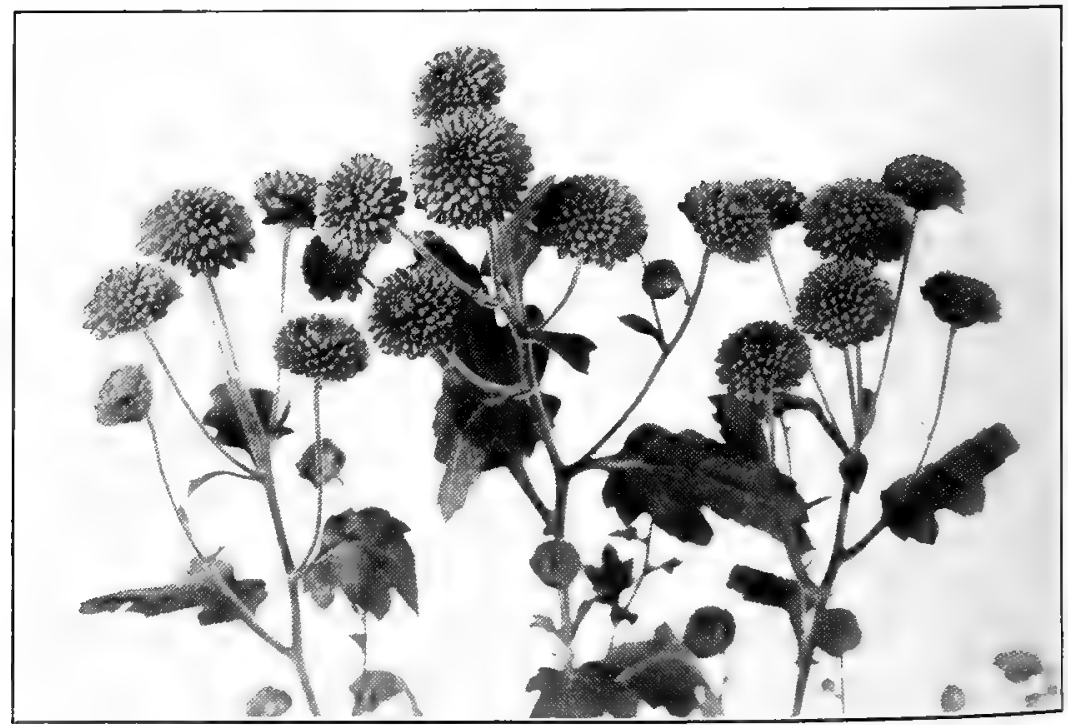

Fig. 130.-The Pompon Chrysanthemum. But little disbudding is required by the Pompon, yet there are times when, with certain varieties, you can help things along by proper pinching back. This produces graceful sprays with the flowers evenly distributed-a feature that makes the plants much more attractive 
surplus on the market at a time when the large grower ships in his main crop, and when the returns cannot possibly equal what it has cost to grow the plants. While single-stem sorts are classed as show flowers, and while every retail grower should have a bench or more devoted to them so that his patrons can admire them, he will find that it is the Pompons, singles and small flowering sorts, such as are suitable for table and house decoration that bring in the money from a retail trade, even though he may not sell them all. Let us take, for example, a florist who benches 2500 plants. For money-making purposes they should consist of not over 700 singlestem sorts as follows: About fifty each of early white, pink, bronze, and yellow; fifty each of midseason pink, and white, and 100 midseason yellow; 100 each of either pink or white, and yellow; and about 100 more varieties of other colors and exhibition or show flowers. The remaining 1800 should consist of small flowering sorts, extra early, early, midseason, late and very late. The retail grower who has to ship surplus flowers to the wholesale market usually loses money on them, but you can safely figure that he who grows only enough to supply his wants and often has to buy as many or twice as many more flowers besides, is making money. Cut your flowers as you want them, yet not so close as to prevent your house or houses from looking well until the end of the season. Don't plant a batch of Niza alongside of Diana, or Golden Climax by the side of Godfrey. Plant the sorts in rotation and when one is through, clean up the space and do not let the sight of cut-down stalks or Bamboo canes detract from the effect of plants coming into flower nearby. Ghrysanthemum time is show time. Always have that in mind.

\section{What Varieties to Grow}

To my mind, there is no better way nor easier way to find out exactly what varieties to grow than to go by what the larger growers select for their own use. While there are still with us a dozen or so old-timers that we have had for the past twenty years whereas new ones come and go, still it pays any man growing. Chrysanthemums to invest a few dollars each year in novelties. It is the only way to keep to the front. Discard what you don't want and forget about it, and the following Spring, when the specialist sends out his latest list, select some more and send your check for them. If you are a lover of flowers you will keep on looking forward to seeing these plants grow and flower just as you have done in previous years.

\section{Cultural Hints}

For detailed cultural notes get Elmer Smith's "Chrysanthemum Manual," a little book full of valuable information. But 
to the beginner I would like to say that the Chrysanthemum is anything but a hothouse plant. In starting out, and even in the case of the man already established but with only a limited amount of space in which to carry his stock plants properly over Winter and not under a bench, the best way to grow commercial sorts is either to purchase, during March and April, rooted cuttings of the desired varieties and pot them up into $21 / 2$-in. pots, or to buy healthy $21 / 2$-in. stock ready for planting out by the end of April and during May.

Just as soon as you can get the benches ready for planting after they have been emptied of bedding stock and thoroughly cleaned, provide proper drainage by spreading on the bottom a thin layer of partly rotted sod or strawy manure. While a mellow, sandy loam mixed with one-fourth well-decomposed manure makes; perhaps, the best material for filling of the benches, almost any good garden soil with a liberal amount of manure will grow good Chrysananthemums. Allow 8 to 10 in. for the single stems and 12 in. for the Pompons. For single stems remove all side shoots and growth from the base of the plants; for the early ones select your buds around the first part of August; the end of August and early September is time enough to disbud the midseason and late sorts.

Bear in mind that in order to obtain good stems and large flowers the sooner after the middle of April you can bench the plants the better. Not that you cannot obtain good results from such as are planted out by the end of May, but in this case, you should have heavy stock to start out with. Midseason and late sorts can be planted all through the month of June, and also the Pompons, which should be kept pinched up to August so as to obtain from six to eight branches. All the buds on these branches are usually left to flower unless you have sorts on which you prefer to have, say, three or four flowers to the stem instead of six or eight, which means that you must select the largest buds, properly spaced, and remove the balance.

\section{The Art of Disbudding}

In the single-stem sorts we have crown and terminal buds. The crown buds appear first and alone. In the case of early sorts consisting of plants which have been benched in early May so that by the time this bud appears the stems are $21 / 2 \mathrm{ft}$. and over in height, heavy, and with good foliage, these buds are allowed to remain and, flower. This of course necessitates the removal of the lateral growth surrounding them and any and all of the growths which may appear along the stems afterward, as you want to direct all the energy of the plant toward developing this bud. On the other hand, if this bud is removed and a lateral shoot is allowed to continue the growth of the plant, while some sorts make a second 


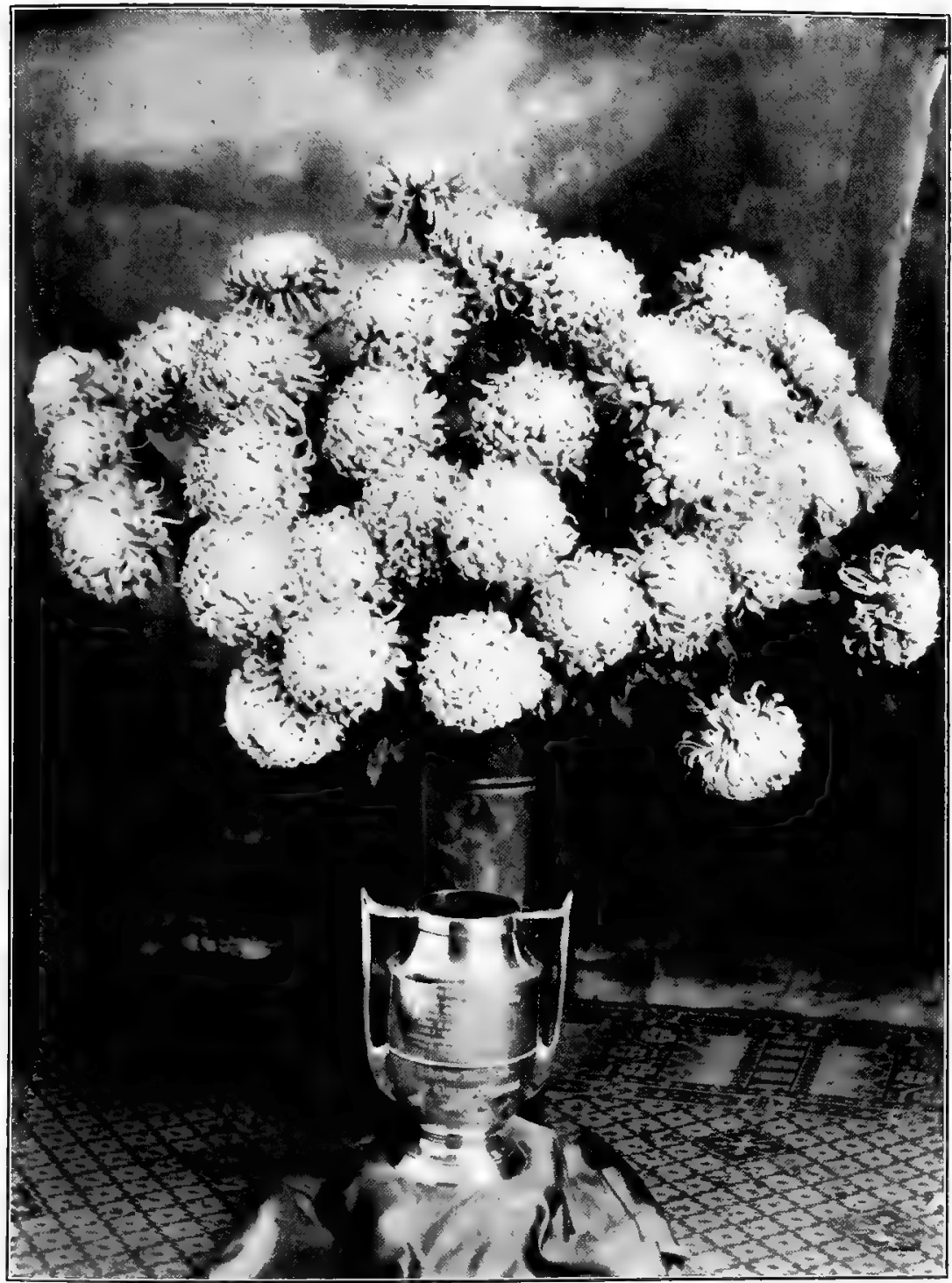

Fig. 131.-The Vase of "Chadwick" Chrysanthemum (grown by Fritz Bahr) that won the silver cup offered by the Chicago Greenhouse Manufacturers at the first National Flower Show at Chicagu, 1908.

crown bud, usually a cluster of buds will appear in the course of a few weeks, the center one of which is called the terminal bud, and is finally selected to produce the flower. Remove all of the surrounding buds unless the center or largest of these cluster buds , is deformed in some way, in which case it is well to take it off and select one of the others. 
Some sorts will produce better flowers from crown, others from terminal buds. If you purchase new sorts from a specialist he will tell you which to select. Climatic conditions also make a great difference. Although when growing single flowers on a small scale you may not be much out of the way whichever one you select, experience- will soon show the best method to apply with each of the sorts you handle.

\section{Feeding}

There is far more harm done by overfeeding than by starving the plants. To the beginner, I would say, if you have a good soil to start out with and if the plants are doing nicely, let them alone until the buds are well formed. Usually by that time a mulch consisting of two parts well-decomposed cow manure and two parts good soil spread over the surface of the benches 1 or 2 in. in thickness will be helpful; or this can be applied later-say, the latter part of July. By early September give light doses of liquid cow manure every two weeks. Never use chemicals unless you obtain them from reliable sources and then use them carefully according to directions.

\section{Insect Pests and Diseases}

There are about twenty different insects and diseases ready to ruin your plants, but 'whether the pest is midge, aphis or thrips (which are among the most troublesome) nicotine in one form or another will control it best. Büt you must keep at it, and examine the plants daily in order to keep them clean. Never propagate from diseased stock.

\section{Bench, Solid Bed, or Pot Gulture}

For single-stem flowers I prefer raised benches with about 5 in. of soil in which you can control things better. For Pompons either benches or solid beds will do. Frequently growers have houses which are closed during the Winter months; these can be used for bedding stock during Spring, and then for Pompons up to the end of November, thus requiring but little heat and yet paying well.

Almost any sort of Chrysanthemum is adapted for pot culture, but there are some, of a dwarf habit, such as the Cap family, which for commercial purposes are better. For the busy man and the one who only wants 5-, 6- and 7 -in. pot plants, a good way is to start out with 2- to $21 / 2$-in. stock during May or June and keep the plants pinched and shifted during the Summer months. Plunging the pots up to their rims in a frame outdoors and allowing plenty of space between them saves work. Another way is to plant them 
out, keep them pinched back up to the middle of August or the first week in September, pot them and carry them along in a cool, airy house. "There is always a demand for pot Chrysanthemums during October and Novembernot so much for specimens, but rather for plants that can be retailed at from $\$ 1.50$ up to $\$ 4$ or $\$ 5$ each. These almost every retail grower can handle himself, but if he wishes a few extra large specimens such as require a lot of care and attention during the Summer months, he is bet-

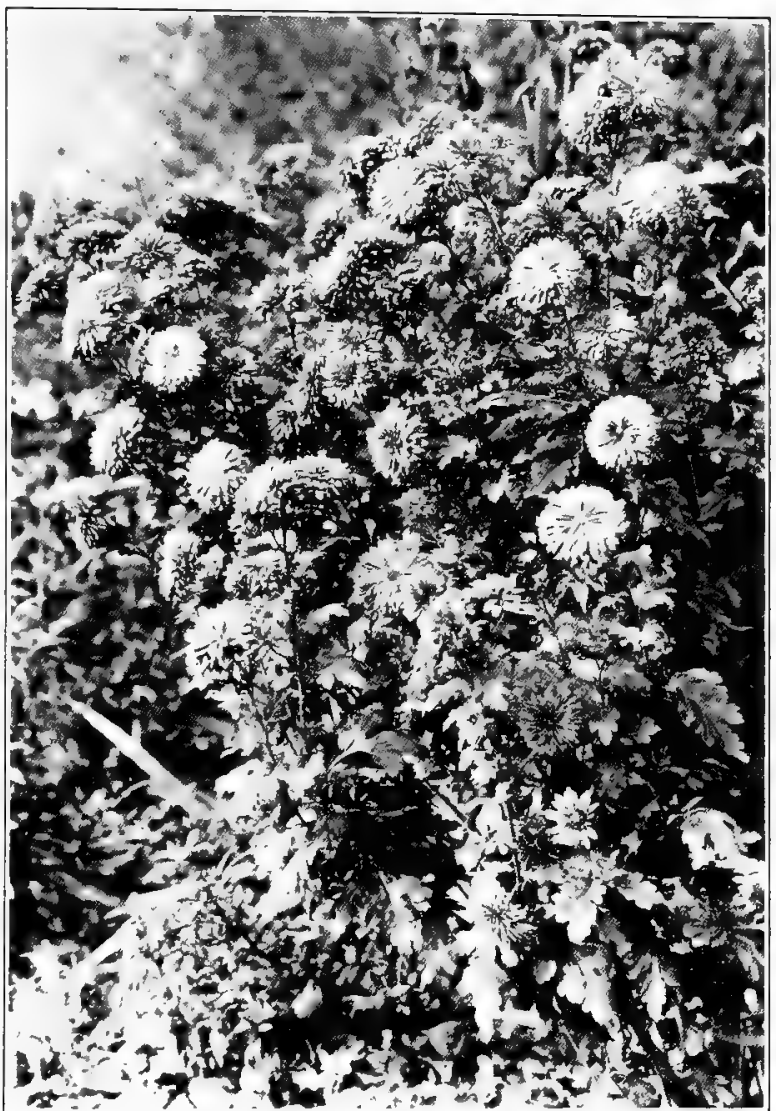

Fig. 132.-Early Flowering Hardy ChirysantheMUMS. In this class of Chrysanthemum the fact that the plants flower early enough to escape frost injury is of far greater importance than their hardiness ter off if he has the specialist supply them when he is ready to finish them off in readiness for early sale.

\section{Early Sorts in Frames}

Almost any sort that comes into flower from the middle of October until the early part of November can be grown in a temporary framehouse or frame, and so doesn't need to take up valuable greenhouse space which can be occupied by sorts coming into flower later. To those not having a great deal of bench space this means a great deal.

For frame culture, prepare beds about $4 \frac{1}{2} \mathrm{ft}$. in width, holding four rows of plants, allowing not over 10 in. of space between the plants in the rows. By the end of September they will have set 
buds and a temporary frame can be built over the beds to support 3 by $6 \mathrm{ft}$. sash. Even if there be no danger of frost the sash should be placed over the plants for rain and damp nights don't do the opening flowers much good. Close planting will give you longer stems and softer growth, so sufficient headroom should be provided when you build the frame.

\section{OUTDOOR SoRts}

There may be sorts which flower early and overwinter almost anywhere with little or no protection. But after many years of experience we find our climate in the Middle West too severe even for the most highly recommended ones. There is not, however, much to regret about it, for if your customer pays you twenty-five cents in May for an early outdoor flowering Chrysanthemum, and such a plant in the garden is loaded down with flowers by October when everything else has practically gone, that quarter was well spent. Every retail grower should not only be on the lookout for early sorts for outdoor flowering, but sbould grow on a good-sized stock and push its sale. For they are a requisite in every garden, and it isn't going to interfere in the least with the sale of flowers you have under glass to handle them. Flowers from plants grown in the open usually have such hard-wooded stems that they make poor keepers when cut, but you cannot beat them-with all their different shades and colorings-when planted in masses. While there are seasons when early severe frosts may affect them, ordinarily when a customer once plants them it means repeat orders every succeeding Spring.

\section{Carrying Stock Plants Over Winter}

If you want 200 plants of a certain sort for another year's planting, lift about twenty cut-down plants and plant them in a flat not less than 3 in. deep. Label and place in your coolest house until the end of February, when they should be brought into a Carnation-house temperature and planted on a sunny bench. Or you can carry the stock plants in a frame. Quite a few growers plant out in the field each Spring small $2 \frac{1}{2}$-in. plants to be lifted in Fall and carried on as stock to propagate from. To my mind there is nothing better than this method for obtaining healthy cuttings full of life.

Those anxious to make the greatest number of cuttings from a small number of plants, can, by setting out their stock plants during early February on a bench and later on taking the first batch of rooted cuttings and planting them out again, keep on taking cuttings all through the Spring. With proper care the plants will continue to furnish breaks and a cutting with three or four joints will root as easily in sand as a Geranium. It needs no shade up to 
April, after which just enough shade should be applied to keep it from wilting.

\section{GIBOTIUM SCHIEDEI}

There are several beautiful, stately so-called Tree Ferns, but only a few of them are of interest to the florist, the most useful being Cibotium Schiedei, a native of Mexico.

For store, conservatory or show house, this makes an excellent decorative plant. Furthermore, being able to stand a dry atmosphere, to which many of our other ferns object, we find it frequently giving satisfaction as a house plant.

While the plants are easily grown from spores, because of the space they take up and the time required to obtain specimens with long fronds, the retail grower finds it best to purchase fully developed plants from the specialist. You will want only a few at a time. In fact, for the average show window, one plant with a spread of from 4 to $6 \mathrm{ft}$. is quite enough.

\section{GINERARIAS}

If you want to brighten up the show house during the Midwinter months, there are no better plants to do it with than Cinerarias. Your customers may object to them on account of their coarse foliage or because they don't make ideal house plants, but they cannothelp but admire a properly staged benchful, with its lively colors. It is just another way to advertise and make people think of flowers.

Every retail grower can manage to have good Cinerarias during the Winter months - in fact the plants seem to much prefer the old sash house and a rather close atmosphere to anything else. They want to grow where it is moist, yet not too warm; they like good soil and plenty of water; and, as with the Galceolarias, they want to be kept free from green fly. Almost any plant house with a temperature ranging from 45 to $50 \mathrm{deg}$. but closer to the $45 \mathrm{deg}$. point during Winter, and plenty of sun will suit them. Put them in a hot house and on a bench where they will dry out quickly-and you can do nothing with them.

\section{For Christmas Flowering}

Many thousands of Cinerarias could be disposed of by retail growers around Christmas and it is an easy matter to have a batch in flower during December. You can always sell plants in flower at holiday time for from a dollar and a half to two dollars each. At present we don't cater enough to those who cannot afford to spend more. We have no trouble in getting stock which we have to retail at five or ten dollars in order to make anything, but during and right after the World War, we didn't pay enough attention to those who couldn't pay that price. 
To have Cinerarias in flower by Christmas, sow seed in late June, keep the little plants alongside your Primulas in a cool, airy house, and shade them a little. Don't let them suffer for want of water or moisture in the house and keep shifting them so you will have them in 6-in. pots by October. Give them full sunlight after that and place them in the Carnation house on a bench, allowing plenty of space between the plants. Plants not shifted after the latter part of September will, as soon as they are potbound, set buds, while those you keep shifted into larger pots will most likely keep on growing until the end of January, after which date it is hard to stop any from flowering.

\section{Plants for Later Flowering}

Seeds of Cinerarias may be sown up to October and plants had in flower up to Easter, but the later you sow the more careful you have to be not to let the plants become stunted, as this usually

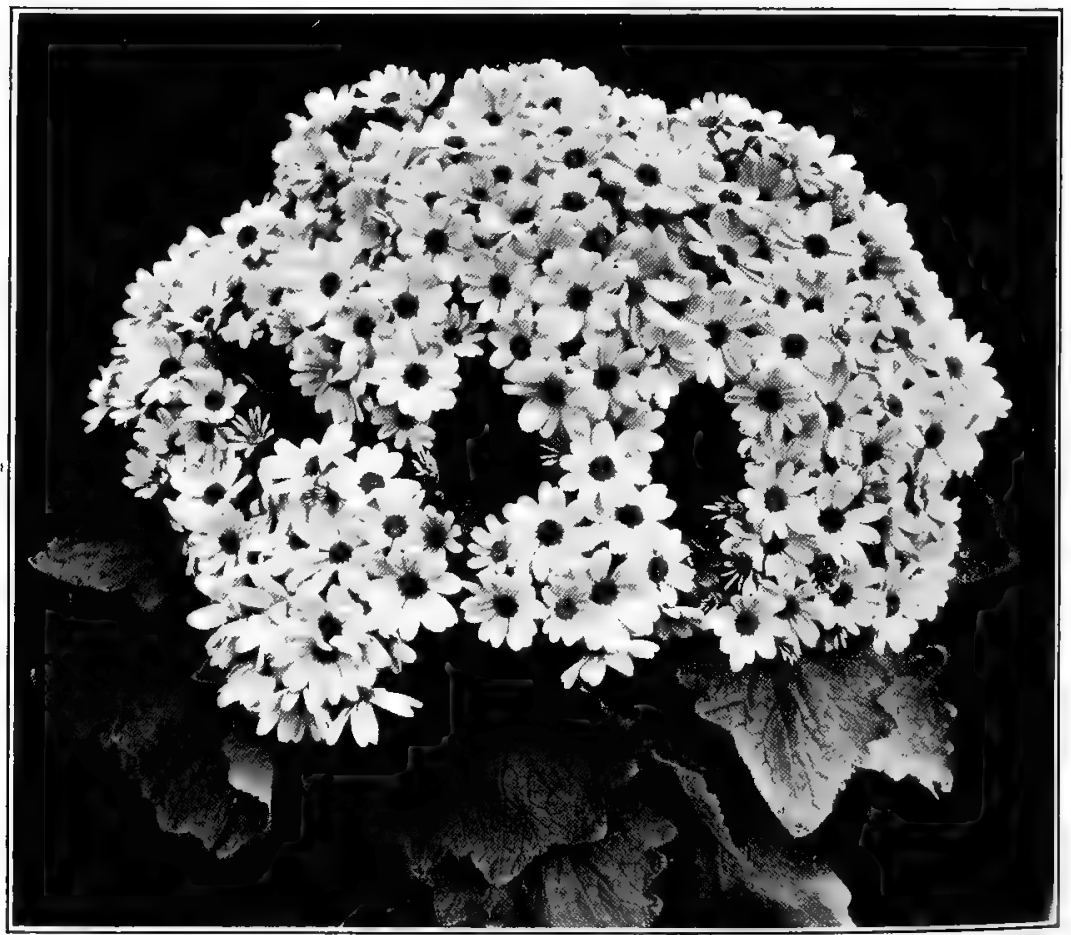

Fig. 133.-A Specimen Cingraria showing what can be done with a good plant. A few like this about the middle of January will make things lively in the show house. Pot into rather heavy soil and give plenty of room and a cool but sunny house 
results in their setting buds and flowers. If you can keep them going they can be grown up to 5 - and 6-in. specimens, even for late flowering. Your largest plants, however, will be those sown in Midsummer and kept shifted during late Fall. With proper management, specimens in 8-in. pots, thirty inches across and over can be had, but I don't know whether such pay any better than good stock in 6 s.

You can also grow the plants in frames outdoors during the Summer and Fall months as long as there is some one to take care of them.

There are some excellent strains of Cinerarias to be had and seed of light and salmon pinks can be bought separately by those who are not in favor of the deeper shades of red and purple. $G$. stellata is a fine variety, growing into enormous plants producing 30-in. stems, loaded with hundreds of small star-shaped flowers, some of them of exquisite coloring and fine for cutting. Even if you never sell a plant, it will pay you to always have a nice lot of Cinerarias on hand during the Winter and the first three months of the year. They will help you in keeping up the show, which is more cheaply done with Cinerarias than almost any other stock, especially if you don't have to buy them.

\section{GLARKIA}

The improved sorts of Clarkia, such as Salmon Queen and Queen Mary, are well worth growing among your annuals for cut flowers. They grow fully three feet tall, bloom all Summer and their double flowers are borne on long stems. Treat them the same as other annuals.

You can also use them for flowering under glass, sowing. the seed about December, growing the little seedlings on in pots and planting in a cool house in February. They don't stand a hot house, but if given plenty of time, like the Lupines, they make good cut flowers which, if cut when only partly open, will last for days.

\section{GLEMATIS}

Every florist should plant out at least two dozen Clematis paniculata somewhere on his own grounds, just to cut from when in flower

Clematis paniculata doesn't stay in flower much more than about three weeks, but during that time you will have good use for the beautiful little, sweet-scented, white flowers on graceful branches covered with their small foliage.

You cannot get a better effect for a floral wreath, about the end of August and early in September, than a combination of Lilium speciosum rubrum and this Glematis; and there is nothing finer for a spray than a few 'sprigs of Clematis with some larger flower. 
Even if you haven't any use for the flowers themselves, if you have the plants in a place where they can be seen, you will have a good ad that will lead to your taking orders for plants for the following Spring's delivery.

This Glematis is one of the best hardy climbers you can recommend. C. Jackmanii and C. Henryi often cause disappointment by dying after having made five or six feet of growth, but $C$. paniculata hardly ever causes trouble or fails to do well even when planted in soil not of the best.

This Clematis is easily grown from seed but it won't pay the florist using only a few plants each year to raise it. Rather let your nurseryman furnish what plants you need. Among the shrubby forms of Clematis are several good ones; C. erecta is especially good, about three feet in height and covered with white flowers in June.

\section{COB EA SGANDENS}

Easily the best of all Summer climbers; a fast grower, almost free from disease or insect pests, and good for sun or shade. Starting out with heavy plants, the purchaser doesn't have to wait until October before the vines cover the front porch trellis.

If you have among your customers some who are willing to pay the price, you can afford to sow seeds of Cobæa about the first of February, pot the seedlings into 21/2-in. pots, then pinch them several times, shift them into $4 \mathrm{~s}$ and later on into $6 \mathrm{~s}$ and put a 6 -ft. Bamboo stake in each pot. Keep on tying up the six or eight shoots as they grow and by May the plants will be as high as the stakes. If planted out, they will, by the end of July, have made another six or eight feet of growth.

For smaller plants, sow a month later-and you may well have another batch coming on from seed sown the end of March. The seeds should always be put in edgewise; have the flat filled with soil and press each seed into the surface no matter what else you do. Usually the two seed leaves will have a 2 - or 3-in. stem; when you pot the seedlings up, try to get them well down into the pots, so the two leaves touch the surface of the soil. Then, when you shift the next time, set the plants as deep as you can and never neglect to tie the plants in good time. It is an awful job to tackle a batch of plants which have been allowed to grow into each other for several weeks or a month.

GOGKSCOMB

See Celosia

\section{GOCOS WEDDELLIANA}

Always carry a small stock of this dainty palm, whether you purchase plants in 2-in. pots for the center of fern dishes or specimens 


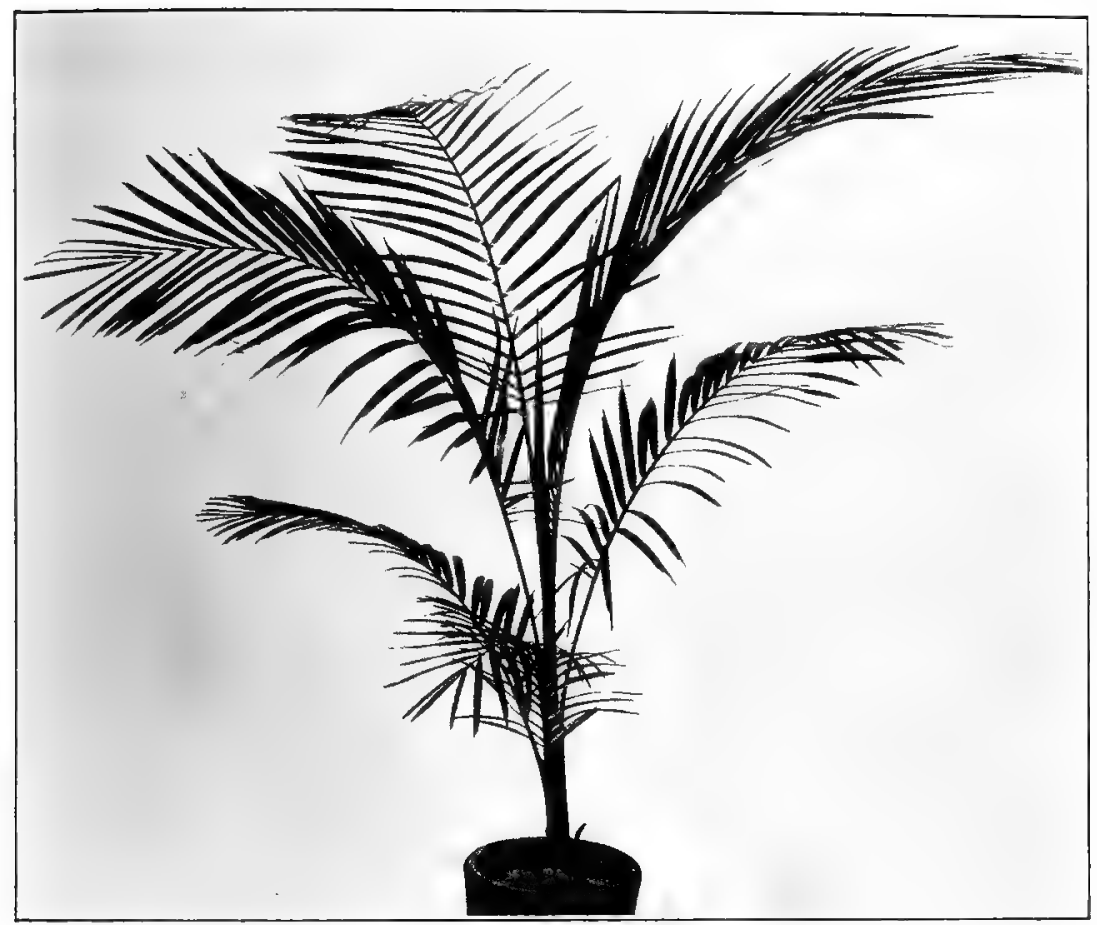

Fig. 134.-Cogos Weddeldiana is the ideal center plant for a fern dish in a $21 / 4$ or $2 \frac{1}{2}$-in. size. When grown on into a $6-, 7-$, or 8 -in. specimen, no other palm can compare with it in gracefulness; besides, it makes an excellent house plant

in 5- to 6-in. pots. One is as soft and graceful as the other, and all are among best house plants. Often a customer will call you up and have you send for her fern dish to refill it; everything in it has died, but the little Cocos in the center is still there in good shape. Let the palm specialist grow the Cocos you need and you do the selling. It will pay you best.

\section{GOLEUS}

Coleus are part of your bedding stock in Spring. The day is over for making use of them as decorative pot plants during Winter, which is not to say that they are not beautiful, but, as in the case of the Rex Begonias, something more graceful is wanted as a border for flower beds or for use by itself in beds and borders. Very showy effects may be had with Coleus and many are used for cemetery planting; they may also be used to advantage in filling window boxes and for that purpose you want bushy stock out of 3 - or 31/2-in. pots. A good way is to root cuttings during January, use the little plants for cuttings again and, from April on, let them grow the way they want to without any more pinching. 
"Of all the stock we grow under glass, nothing will grow quicker into a salable plant during Spring than Coleus." That remark was made about thirty years ago by the late Peter Henderson and is true today. Only, at that period Coleus ranked almost second to Geraniums in importance as bedders, and three to four weeks from the time the cutting was put into the sand the plant was ready in a 2-in. pot for bedding out. You can still practice this method today, if you have enough stock plants to take good sized cuttings from and use enough bottom heat and a 55- to 60-deg. house to grow them in.

For propagating purposes, root cuttings in August, grow the plants on in pots and shift into $4 \mathrm{~s}$ by October; overwinter them in a 55-deg. house, pinch them back several times and by February those stock plants will furnish you and keep on furnishing you with great quantities of cuttings from which, later on, you can again start propagating.

\section{Varieties of Goleus Used Today}

For hanging baskets and window boxes the pink and yellow Trailing Queen are used quite extensively; if in a sunny position and not starved they are very effective. Golden Queen and Verschaffeltii are the best when you want yellow and red effects for bedding. Christmas Gem, Queen Victoria and American Beauty when well grown in 5- or 6-in. pots can be used to advantage for Ghristmas, for which purpose cuttings should be rooted in early August and the plants kept shifted and pinched up to the end of October. The good sorts for both bedding and pot culture are: Butterfly, Lord Palmerton, Beckwith's Gem, Salvator, Firebrand, Pink Verschaffeltii, Defiance, and May Laver, but these are only a few of many others.

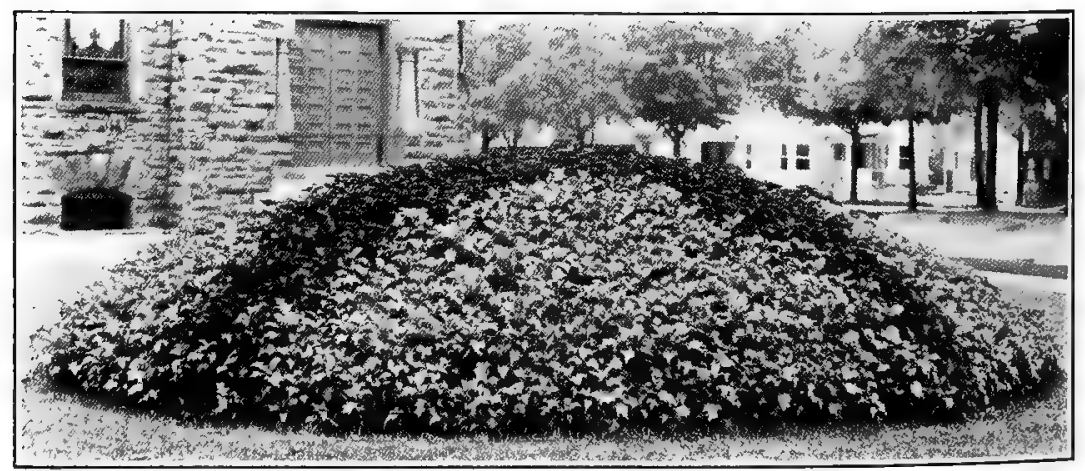

Fig. 135.-An EFfective Goleus Bed. As long as bedding plants are used, there will always be a place for Coleus. No other class of plant furnishes a greater variety of gorgeous foliage colors or is better adapted for beddin 
GOLUMBINE

See Aquilegia

\section{COREOPSIS LANGEOLATA}

A fine plant for the hardy border and as good a cut flower for the florist. The large, deep yellow, Cosmos-like flowers are borne on long stems and are fine keepers. Though at their best in early Summer, the plants will produce a few flowers even up until Fall. Sow seed outdoors in July and transplant seedlings to six inches apart where they are to flower; or, if you expect to sell part of your plants during Fall or Spring, set them in beds in rows about four inches apart and leave every other row when thinning and selling.

Under glass Coreopsis can be brought into flower by the middle of April nicely. Sow in June outdoors and transplant the seedlings into good soil allowing eight inches between them. With at all favorable growing conditions, they will form heavy plants by October. After the frost has cut down the foliage-not beforelift the plants and heel them in a coldframe where they can remain until the end of January; then bring in and plant them in a solid bed in a 45-deg. house. If, in March, the temperature goes to 50 deg. and over, it won't hurt; but the plants will not stand for hard forcing.

\section{GORNFLOWER ASTER \\ See Stokesia}

\section{CORNUS (DOGWOOD)}

Not everywhere does Cornus florida, the large white-flowering Dogwood do well, and in colder sections we have to be satisfied with some of the others, which are used mainly for the sake of the wonderful coloring of their bark while they are dormant.

Cornus sanguinea and $C$. sibirica are among the showiest of all dormant shrubs during Winter, with their red twigs sticking out of the snow. You want to plant them in masses in order to see them at their best, and each year cut out a little of the old wood in order to encourage new growth which will be the best colored. There is also a Golden Dogwood (C. lutea) which is well worth planting. While it is good in Winter and can be planted as a foreground for the red twigged sorts, it is most highly colored in early Spring, just as the sap gets into the branches and before the leaves appear.

These Dogwoods grow in any soil, but of course do best with plenty of moisture. If you ever figure on a planting for a good Winter effect, try to plant conifers as a background. In front of them, place Red Dogwood, not in regular rows but rather in irregular groups or large clumps; and still more in the foreground plant the Golden Dogwood. Then, if you wish, finish off with dwarf Barberry (Berberis Thunbergii.) 


\section{GOSMOS}

There isn't a great deal of money to be made out of Cosmos, but the florist should include it among his annuals for Summer and Fall flowering. In Spring you need the plants your customers will want for the old-fashioned border or the cut flower beds; and in Fall they are among the most graceful of cut flowers if frost doesn't come too soon. Some grow Cosmos in pots and place them under glass in the early Fall to cut from when the outdoor ones are past.

We now have an early sort, also a semi-double, and we can not only grow the small plants in a frame, but also have some in $21 / 2$-in. pots for those who want to pay a little more, rather than plant out from the frame seedlings ten inches long, which usually wilt badly for a few days after they are set out.

\section{GRAB APPLE See Pyrus \\ GRANBERRY, HIGH BUSH See Viburnum}

\section{CRAT FGUS (HAWTHORN)}

Hawthorns make beautiful large shrubs and small trees, but don't make the mistake of planting them in the small shrubbery border of a $50-\mathrm{ft}$. lot, for these plants want room to develop and can never be seen at their best until after they have been planted five or six years.

There are double white-, pink-, and red-flowering Hawthorns and among the native sorts we have those which flower in Spring but are most admired for their bright red fruits, which cover the branches long after the frost has cleaned them of all their leaves.

\section{GROCUS}

There isn't much to an idividual Crocus flower, but when you see a mass of them in the lawn right after the sun has melted the snow away-often so early that there are still traces of it on the north side of the residence-they surely look attractive.

Every retail florist can sell Crocus bulbs in the Fall and should recommend them. He can also fill a few fern dishes with the bulbs, let them root in a coldhouse or frame and bring them into flower during Winter.

The Fall Crocuses, which we can see covering the meadows of Europe in Autumn, are interesting. The bulbs will flower without being put into soil, sand or water and it doesn't hurt to have a few on display on your bulb counter. While some of these belong to the Crocus genus, others are really Colchicums. 


\section{CROTONS}

With the varied forms and colorings of their leaves, there is absolutely nothing to equal the Crotons as decorative foliage plants. When you look at fifty different sorts side by side, not one resembling the other and each more gorgeously colored than the next, you wonder how it is possible. One does not have to behold large specimens four or five feet tall in order to see them at their best; even the 21/2-in. pot plants-particularly those of the small or narrow leaf varieties - are just masses of color and therefore most useful for the florist.

Grotons are used today by the thousands, but more by the retail florist in the large city than by the retail grower out in the country. The latter isn't nearly as well acquainted with them as he should be. He will try to get along without them and, as a reason, claim that they are poor keepers. I grant that they are as house plants but that doesn't cut much figure. After all, the demand today around Christmas and, in fact, all through the Winter months and at Easter, is for basket arrangements rather than single specimen plants, and there is nothing to compare with Crotons for that purpose. They usually last as long as the other contents of a basket and longer than a Cincinnati Begonia or a Poinsettia.

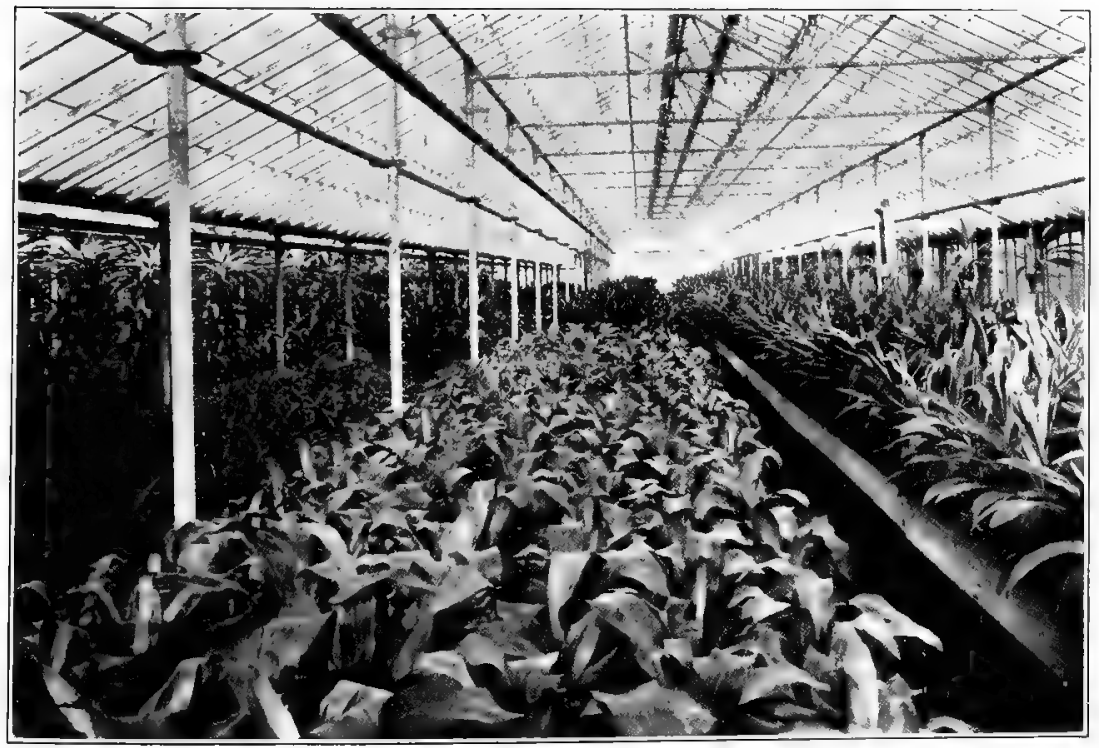

Fig. 136.-A House of Dragenas. The popular D. Massangeana with its broad white and green foliage occupies the center. $D$. terminalis or Cordyline terminalis and other types are seen on the side benches. These plants are best left to the specialist; the small grower can better purchase strong stock as wanted. See text on page 355 


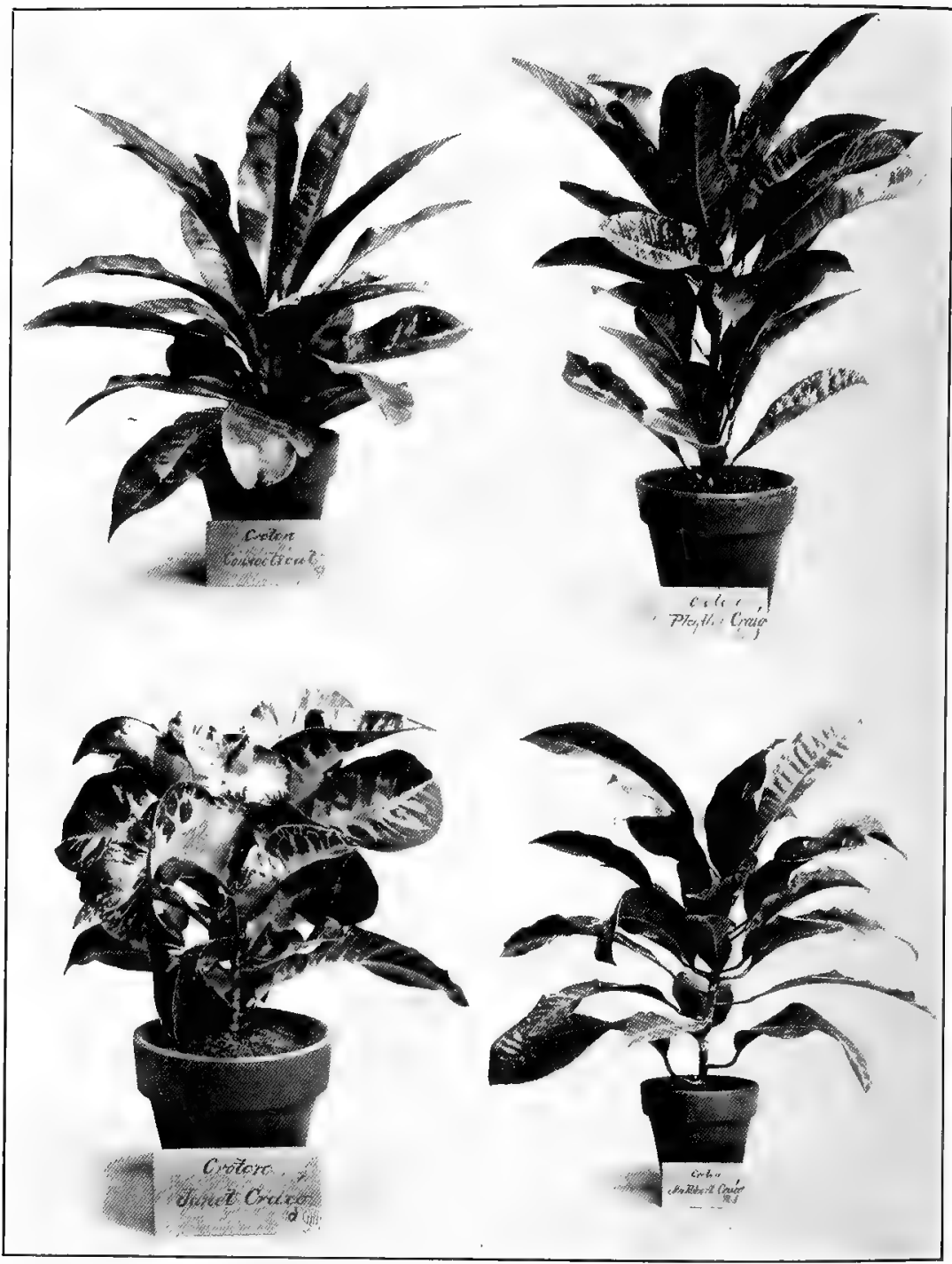

Fig. 137.-Trpes of Crotons (By courtesy of the Robert Craig Co., Philadelphia). There is almost no end to the different varieties of Crotons, with their leaves of all shapes and a most varied array of colors. They are among the nost showy of all foliage plants and around the holidays frequently take the place of high-priced cut flowers in basket arrangements. We are just beginning to appreciate their value and usefulness. Those shown are, above, Connecticut and Phyllis Craig; below, Janet Craig and Irs. Robert Craig 


\section{Grotons for Ghristmas}

What you want is that the basket shall look well, shall look its best, on Christmas Day; that is what counts most. Pandanus Veitchii, Dracænas and these Crotons are the plants to use in connection with others, especially during times when flowers and flowering plants are scarce or at their highest price level. Yet, even with flowers galore, these Crotons are just as desirable, for they are every bit as beautiful. While there is such a thing as trying to get along without them, you will, by using them, do more business, make more money and (as important as anything, perhaps) show your patrons who have seen them used one way or another elsewhere, that you are uptodate.

During the Summer months Crotons should be used more freely for decorative purposes in the store and show house. They go well with your display of tuberous-rooted Begonias, fancy leaf Galadiums and Gloxinias. You can also use Crotons to advantage in filling outdoor window boxes. In places a little too shady for flowers, what better material could you have to take their place than Crotons? Or you can bed them out. Plants can be safely set outdoors by the first of June, giving them a little protection from the sun. If you wish, they can be left in the pots, but in this case bury the pots, getting the rims a couple of inches below the surface. If you can lift the plants again during September, give them a shift and place them in a 55- or 60-deg. house, where they will come along all right.

The leaves of Crotons are excellent for use in wreaths the same as Magnolia leaves. They provide a welcome change.

\section{Gultural Notes}

Heat and then some more heat is what Crotons require. Let them have a steady temperature of 65 or even 70 deg., plenty of sunlight, enough moisture and they will flourish. With the same temperature but a dry atmosphere, such as prevails in our homes, they soon drop their leaves.

When you are once established and get a shipment of plants in November, if they haven't suffered in transit, they will show no bad effects if given a 60-deg. temperature or even less for a month or so, but they cannot stand it long.

It would be folly for the retail grower to attempt to grow Crotons from cuttings and make them pay, when a bottom heat of $80 \mathrm{deg}$. and a house of $70 \mathrm{deg}$. is required to do it. We have today specialists who grow them by the houseful. I suggest that those who like to handle them purchase in May or June what they want for Summer trade; then another lot in late Fall for their Christmas demands; and perhaps still another lot later on. 


\section{GUP FLOWER See Nierembergia}

\section{CUPHEA IGNEA (FIREGRACKER PLANT)}

As long as a porch box or vase isn't to be filled with just one variety of plant you can always use Cupheas to advantage along the edges. No matter what the color scheme, the little reddish firecracker-like flowers aren't showy enough to interfere with others in the arrangement.

Cupheas are always in bloom. Each new leaf means another flower, and the graceful habit of the plants makes them just the thing to hang over the sides of a box, vase or hanging basket. Lift a few plants in the Fall, pot them up and carry them over Winter in a Carnation house; you can begin to propagate in February. They root as freely as German Ivy. Pot them up into 21/2-in. pots. and later into $3 \mathrm{~s}$, and if you can set them along the edge of a bench where they can hang over, so much the better.

\section{GURRANT, MOUNTAIN \\ See Ribes}

\section{GYGAS REVOLUTA (SAGO PALM)}

It used to be a common thing for the smaller florist, during early Summer, to start a few dozen Cycas stems in pots just about large enough to hold them, and therefrom produce a crop of fine leaves after awhile. We used to sell these plants, the same as palms or Rubber Plants, but we got away from it. If you go far

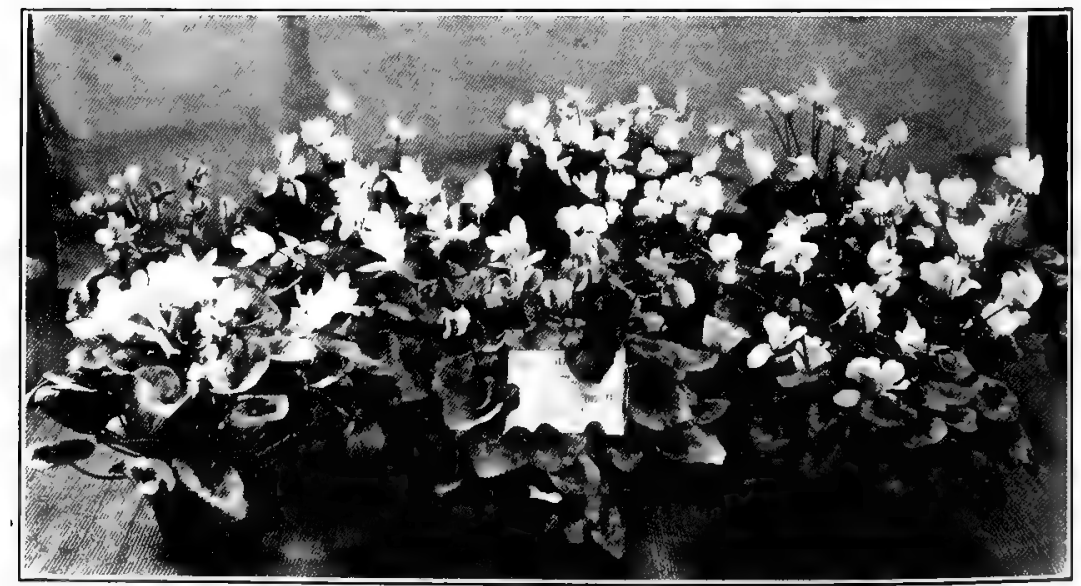

Fig. 138.-Ten Good Gralamen-Prize winners grown by the author. You can grow fine Cyclamen plants inside of twelve months, but if you want them in full bloom by early December, allow from sixteen to eighteen months from sowing. One plant with perfect foliage and six to twelve flowers in December is worth four in January or February 
enough South or Southwest, you will find this Cycas planted out on the front lawn, all the way from small plants on up to specimens with stems six feet tall and over. Today the florist in parts of the country where they don't grow outdoors is most interested in them because of their leaves, which are used in a small state for wreaths or other floral designs and, when two feet long and over, in sprays. However these consist mainly of the prepared article.

Once in awhile we have a customer come in and demand the real freshly cut article. If you happen to have a large plant on hand in the palm house it comes in handy at such a time. The fact is that these Cycas are most dignified plants for the palm house and it isn't a bad idea at all to have just a few on hand.

When starting the stems you will get better results and obtain finer leaves if you can provide a little bottom heat for the pots they are in. Of course you will want a warm house and a little shade to protect the leaves which come out all at one time.

\section{CYCLAMEN}

Cyclamens are better grown today than ever before. They have always been great pot plants, but it is only during the past twenty years that American florists have made up their minds to grow them better. Since the World War their popularity around Christmas has put them at the head of almost everything else, partly, perhaps, because of a lack of Azaleas and other stock from Europe, but to a far greater extent because of the wonderful specimens grown, loaded down with greatly improved flowers.

IT IS strange that twenty-five years ago although there were some 1 mighty fine greenhouse establishments and all kinds of good growers in this country, and while Cyclamens were grown in enormous quantities all over Europe, with us their culture was in the hands of a very few men. Those who could do Cyclamens well were considered past masters in the art of gardening, but even then we had but few plants in flower for Christmas; a plant with six blossoms open in December was a good one.

Today we find the plants being successfully grown from coast to coast. Everywhere we find successful growers and those who cannot grow the plants have no trouble in obtaining all they want of plants in full flower from November on. And, what is just as remarkable, we see good plants grown in all kinds of soil, from a finely sifted and carefully prepared mixture of leafmold, sand and a little manure, to a heavy loam.

We are no longer so particular in regard to having the corm half way above the soil, as the writer was taught to plant it. For the past four years the biggest plants I have seen have had their corms buried fully one inch below the surface of the soil; this would 
have been considered absolutely wrong in former years. I learned the business where Cyclamens were made a specialty, have grown them by the thousands here and have shown blue ribbon stock, but of late years we have found it advantageous to buy our requirements. Such plants as we have seen in the past six or eight yearsthat is, specimens-were way ahead of anything I have ever seen here or abroad.

\section{Growing Plants from Seed}

It takes from sixteen to eighteen months to grow a Cyclamen. You want it at its best for Christmas, and you should have that date in mind if you grow them. No matter how you plan and figure and how fine your plants may be, you will always have some which won't be in flower by that time. Let them come in later, but remember that one plant in full bloom in December is worth two in January.

If you grow only a few hundred plants sow the seeds in rows in flats in any mellow, sandy soil. The seedlings come up rather irregularly, but in a month after sowing you may be able to carefully lift the first one; the sharp end of a wooden label is as good as anything to do this with. Have another flat ready, and transplant into it, in rows, allowing an inch or so between the plants. You will keep on removing seedlings from the seed flats for two months to come, but those first ready for transplanting will always be the strongest. The young plants in the flats can get along nicely in a house where your Primulas and Cinerarias do well, for they want a bench shaded just a little, a lot of moisture and plenty of fresh air and ventilation.

You cannot ever grow Cyclamens in a dry house, and if there is a secret about growing them at all, it is not to stunt the plants at any time when they are once under way; that is the whole thing in a nutshell. You must find out for yourself what suits them best, so as to keep them growing uninterruptedly. Once stunted, the best grower will never be able to make anything out of them. On hot days wet the walk and below the benches. The plants will delight in that sort of atmosphere but it doesn't do to have it musty or sour under the benches. Keep things clean and sweet, but always moist during the first as well as the second Summer and Fall.

\section{Favorable Conditions for Cyclamen}

I claim that the atmospheric conditions surrounding a Cyclamen have far more to do with success or failure than the soil it happens to be in. Make use of the finest kind of leafmold and give proper drainage, an even temperature and careful watering. But if you don't provide the necessary moisture you will have trouble. A house 


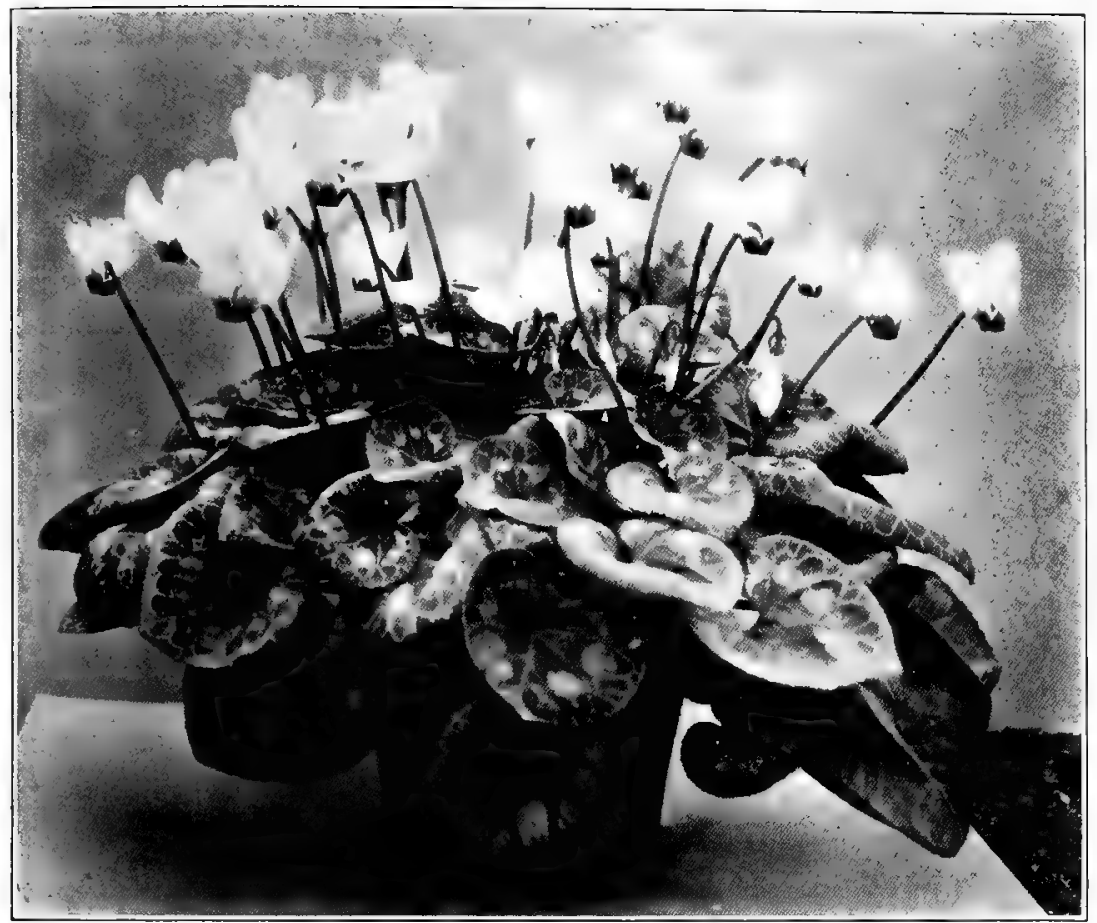

Fig. 139.-A Well-grown Cyclamen. This plant would easily hide the top of a bushel basket. We thought we knew how to grow Gyclamen forty years agobut we know better now

where there is so much ventilation as to dry out everything on top and below the benches is no place for Cyclamens.

Those who, in spite of using good soil and everything else, don't seem to make a success can usually trace their trouble to the lack of sufficient moisture during the plant's growing period. Don't take that to mean "Keep everything soaked," for that would be just as wrong as in giving a little protection against the hot sun during Summer to make the house pitch dark. All the shade Cyclamens want is just enough to prevent the leaves from wilting; spraying several times a day and a very little shade will do that.

The little plants should be potted up in late Fall or early Winter. As they won't do much during Winter they can remain in 21/2-in. pots until late Spring. A good way is to stir up the surface of the soil in the pots several times during the Winter. When you notice the white roots getting busy around the inside of the pots it usually is time for a shift, even if there isn't much top growth to speak of. While Cyclamens grow steadily, it is during July, August and September that they actually go ahead so that you can notice it; and that is the time they need the most encouragement. 


\section{Garr ying Plants Over the Second Summer}

Plants which have been in $21 / 2$-in. pots up to March or so, and are shifted during April into $31 / 2$-in. pots should have not less than a 50-deg. house; a couple of degrees over that won't hurt. On sunny days always spray them about noon. See to it that not only the soil in the pots but also that between the pots and the surface of the bench is always moist. From April on, and during Spring, the house where you grow good Geraniums, Fuchsias and Petunias makes a good Cyclamen house. With daily waterings in such a house, sunny days to warm things up to $70 \mathrm{deg}$., or even a little over, and just enough fire at night to prevent a damp, cold, stuffy atmosphere, you have the ideal growing conditions for Cyclamens. Then, with a porous soil in the pots and good drainage, it is just a matter of keeping up these same conditions right along. It will get warmer, of course, as you go on and no fire will be needed after awhile, but there is a difference between having a couple of hundred Cyclamens standing on a bench by themselves in a house with the other benches empty, and having them with other stock, all growing and being watered every day.

I would just as soon have a 10 -ft. sash house without concrete walks to carry the plants in during Summer, for that is the ideal place for growing things in hot weather, much as we appreciate, during the dark Winter months, the $50-\mathrm{ft}$. wide house and all that goes with it. A Cyclamen plant that, three weeks or so

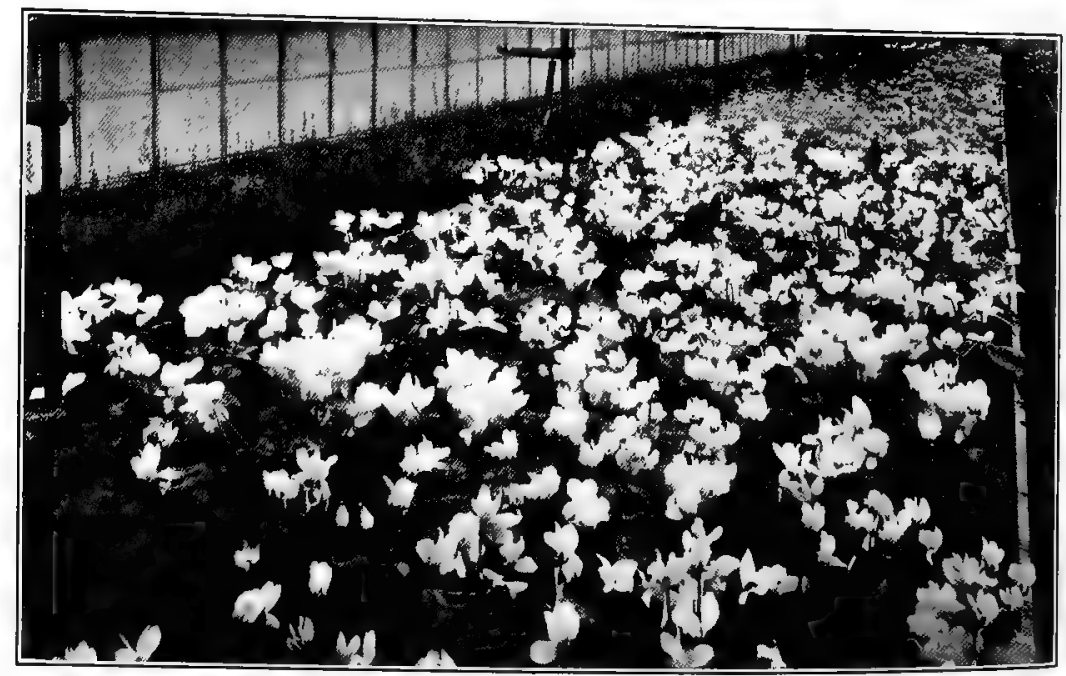

Fig. 140.-A Bench of Cyclamen. This is the way Cyclamen look when well treated, but it means constant care and watchfulness for from sixteen to eighteen months. Yet we find more florists than ever succeeding with them 
after having had a shift, doesn't need water every day during bright weather throughout July and August, is likely to be a sick plant or to lack proper drainage.

\section{Frame Culture}

You can also grow the plants successfully in frames outdoors during Summer. This means bringing them, after they have had a shift in June, into a frame. The pots may be set on ashes, cinders or torpedo sand; instead of placing sashes over the plants, you may place on top the usual $4-$ by $6-\mathrm{ft}$. lath shade frames. Some mighty fine plants are grown by this method. Here, again, it is proved that the plants standing on the moist ground, even if on a layer of cinders or sand, just delight in the moisture from below. It is that which makes for the good leaves that are so essential to a good Cyclamen. I think a well-grown Cyclamen with perfect leaves, one overlapping the other just a little, all beautifully marked, as is the case especially with the many white sorts, makes a most attractive plant even without flowers. The leaves are what make the plant and to get them is what you should strive for.

To begin with, a little too much shade will cause a weak growth; and the same thing results when you crowd the plants during their period of growth. Spray the plants every day while in the frame and wet things down around the frames as well. A light spraying just at sundown to refresh the leaves after a hot July day is a good thing.

Don't ever try frame culture unless you are sure the plants will get attention; with just a few on hand they are much more apt to be taken care of under glass. This is not to say that they are not every bit as well off outdoors, but you cannot put them there and let it go at that.

\section{Hotbeds for Gyclamen}

If you have the facilities and want to be "real good" to your" young stock, prepare a mild hotbed in April and, after you have given the plants a shift, plunge them in it and don't give too much air for awhile. Such treatment gives a real boost to plants that are a little backward and you can repeat it after the next shift, say the end of May. At this time use not a real hotbed, but just a mild one. I have had excellent success with this treatment and others have had the same. After May, however, a hotbed would be out of place, so when giving the next shift place the plants in a frame without heat below. 


\section{Care of the Plants in Fall}

For the plants you want in flower for Christmas, the middle of September is as late as they should be shifted; a potbound plant will always flower earlier than one that isn't potbound. That is also a good time to have your plants get ready to set buds, and not be so much concerned about more growth. While the plants often do a lot of growing even up to November, you are more interested in seeing the buds push their way up toward and through the foliage. To encourage that, give full sunlight and provide no more moisture than is absolutely necessary to keep red spider away. Set the plants on pots, if you wish, in a 50- or 52-deg. house to let the air get around every plant and the sun get into it; this will in a way arrest the growth and at the same time promote the development of the buds. On hot days a light spraying won't hurt. Toward December you can even give the plants a $55-\mathrm{deg}$. temperature to hustle things up a little, but don't make the mistake of forcing a lot of plants when there is no chance to ever get them into flower; keep those which are too late for Christmas in a 50-deg. house and let them take their time.

\section{Possible Troubles}

There is more crippled Cyclamen foliage due to green fly than to anything else. The pests settle near the base of the plants and you no sooner get rid of them and think all trouble is over, than you notice that the young leaves as they develop are all crippled-

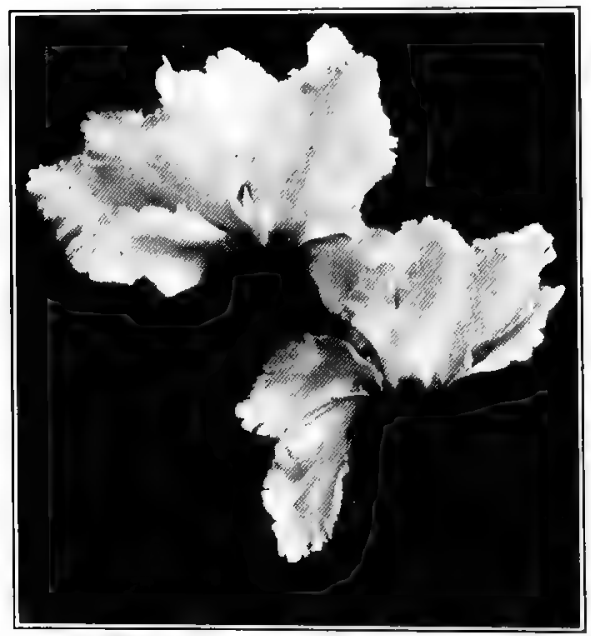

Fig. 141.-Improved Gyclamen Blooms. Some of the modern forms remind one of orchids more than anything else the result of a former dose of green fly; and so it keeps on. Either spray or fumigate regularly, as long as you have the plants on hand, from the seedling stage to the time they are in flower.

Red spider, as we all know, comes from a too-dry atmosphere and will never occur if you pay attention up to the flowering stage and maintain enough moisture. Thrips is another nasty thing, but spraying with nicotine will keep it in check. We all have heard of "the mite" attacking plants just when full of buds. Just what it 
is I don't know; it has caused many a large grower to have a headache. The plants simply won't bloom; the buds get brown or dry up before they open. It was the same with Chrysanthemums years ago; we hardly knew what it was to have trouble aside from aphis or green fly, but the longer we are in the growing business, the longer becomes the list of insect pests and diseases we have to fight.

\section{Garr ying Plants Over}

It isn't so very long ago that the dormant corms were imported from the other side, many florists starting them in the Fall and blooming them during the early Spring months. But we got away from that and the large grower no longer thinks of carrying over either plants or corms for another year. However, the retail grower may do so, especially in the case of plants of a superior strain, which he would like to grow another year for seed; or in the case of a lot of small plants left over at the end of the season. It is not at all necessary to even dry off the plants before starting them again.

Let us suppose that by the end of February you have a nice batch of $31 / 2$ - or 4 -in. pot plants, either through flowering or without buds; remove a few of the older, outside leaves, lift the plants out of the pots, carefully remove most of the soil, cut back some of the heavy roots and destroy the dead ones, and then repot. Plants that were in $5 \mathrm{~s}$ can go into $4 \mathrm{~s}$, and those from $4 \mathrm{~s}$ into $3 \mathrm{~s}$. Use a rather sandy soil to encourage root growth and keep the plants in a 52-deg. house. Some of the remaining leaves may get yellow and can be removed.

In about four to five weeks, sometimes even before, you will notice new growth. During Spring and the following Summer treat the plants the same as the seedlings. Your large left-over plants can be handled the same way, only if they are full of leaves remove most of the old ones. You can also take 5-in. plants and shift them into $6 \mathrm{~s}$ and let all the leaves stay on; some of them may come off during the Summer, but mighty fine specimens can be developed for another year from such stock.

\section{GYDONIA JAPONICA (JAPANESE QUINCE)}

Among the extra early flowering shrubs you should include the Japanese Quince. It is almost the very first to flower in Spring, and the larger a specimen becomes, the more showy it is, because of its bright scarlet (or, less commonly, pink) flowers.

If you get from your nurseryman a few 2 - to 3 -ft. plants they will grow into money. You can either let them develop into large specimens which are easily transplanted no matter how large they may become, or you can divide the plants from time to time, as it is the nature of these flowering Quinces to send up suckers from below like Lilacs. 


\section{GYPERUS ALTERNIFOLIUS (UMBRELLA PLANT)}

For a time we almost gave up growing Umbrella plants. Years ago they were found in every greenhouse and often were used for indoor window boxes, as single plants for house decoration and, in a small state, for the center feature of fern dishes; then other things took their place. Of late, however, we have been using them quite a good deal during Summer. Our customers want them planted alongside of bird baths, or use them planted in bulb pans in the Lily pond, the natural pool, or the fountain. That is, after all, where these plants really belong. They are easily grown on in the greenhouse from cuttings; root these in December and January so as to have heavy 5 - and 6-in. pot plants by June. Take an 8-in. fern dish, close the hole in the bottom with a cork, fill the dish with sand, then pour into it as much water as it will hold; remove the old leaves from the plants, leaving a 1-in. piece of stem to each leaf; trim the leaves themselves back to one inch in length and insert them into the sand so they are partly covered. They want a little bottom heat. You can also root such cuttings in the propagating bench, but you should keep them well soaked at all times; otherwise they dry up before making root.

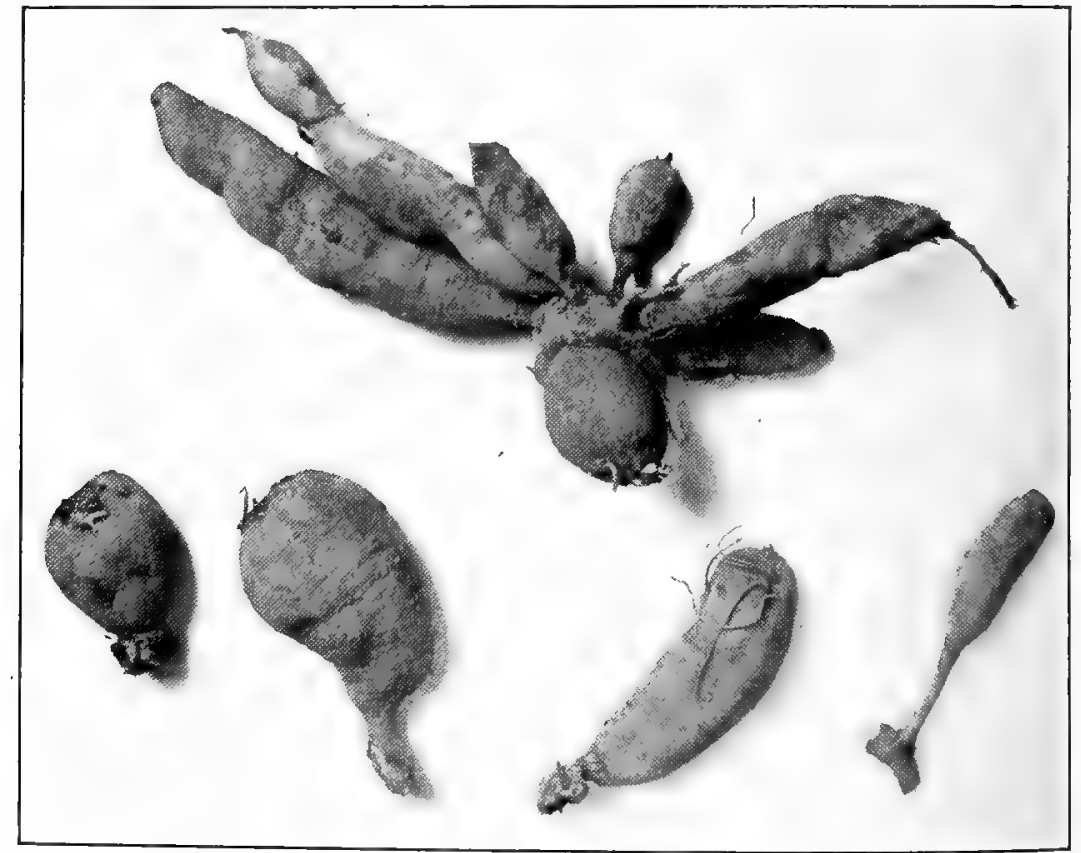

Fig. 142.-How to Divide a Forced Glump of Dahlia Tubers in early Spring for planting in the open is shown here. If many plants are wanted, the tubers should be started in the propagating bench and cuttings from the young growth rooted with a little bottom heat 


\section{GYTISUS (GENISTA RAGEMOSA)}

The Genistas when covered with golden-yellow pea-shaped flowers with a delicate odor, are hard to beat as show plants. But this is only in the cool greenhouse; in a hot, dry room their beauty is soon gone and the floor is covered with wilted blossoms inside of two or three days.

Genistas are best when allowed to come along and flower in the coldhouse where the temperature is about $45 \mathrm{deg}$. During the Winter months they can stand this or even $40 \mathrm{deg}$. When in flower, they often are at Easter what the Cincinnati Begonias are around Christmas-just a solid sheet of beautiful blossoms. But those who buy them really buy cut flowers, for there is no lasting to them.

You can carry on the plants left over from Easter for another year. Repot them, shear them back a little, carry them along outdoors during Summer with their pots sunk into the ground up to the rim, bring them in again about October, keep them in a coldhouse and you will have some fine large specimens loaded anew with flowers.

Root cuttings in February with a little bottom heat, grow them on in pots, keep them shifted and, if desired, shear or pinch them up to December, when they should be left alone so as to develop graceful flowering wood. (For illustration see page 37\%.)

\section{DAHLIAS}

Where Dahlias do well one doesn't need much in the way of cultural directions; and where they don't do well all the cultural notes in the country won't help you much.

My experience with Dahlias has proved to me that while I have seen wonderful flowers and plants covered with them, both East and West, grown successfully by both trained gardeners and those who didn't know the first thing about growing them, plants grown from dormant tubers set out in the field and others grown from cuttings won't amount to anything five seasons out of six around Chicago. Whether we planted them in light soil or heavy, early or late, kept them wet or dry, all we were able to tell about even the best novelties was what the labels alongside the plants said.

This much is sure: that you must have a suitable climate if you want them to bloom. The finest Dahlias I have ever seen were in Oregon, Washington, Victoria, B. C. and San Mateo, Galifornia. Out of those collections of hundreds of varieties it seemed as if every one was good. Throughout the East and even in parts of the Middle West as well as the North, Dahlias are among the most showy of Summer and Fall flowers. Certain sorts do better in one place than another. Those who can grow them 


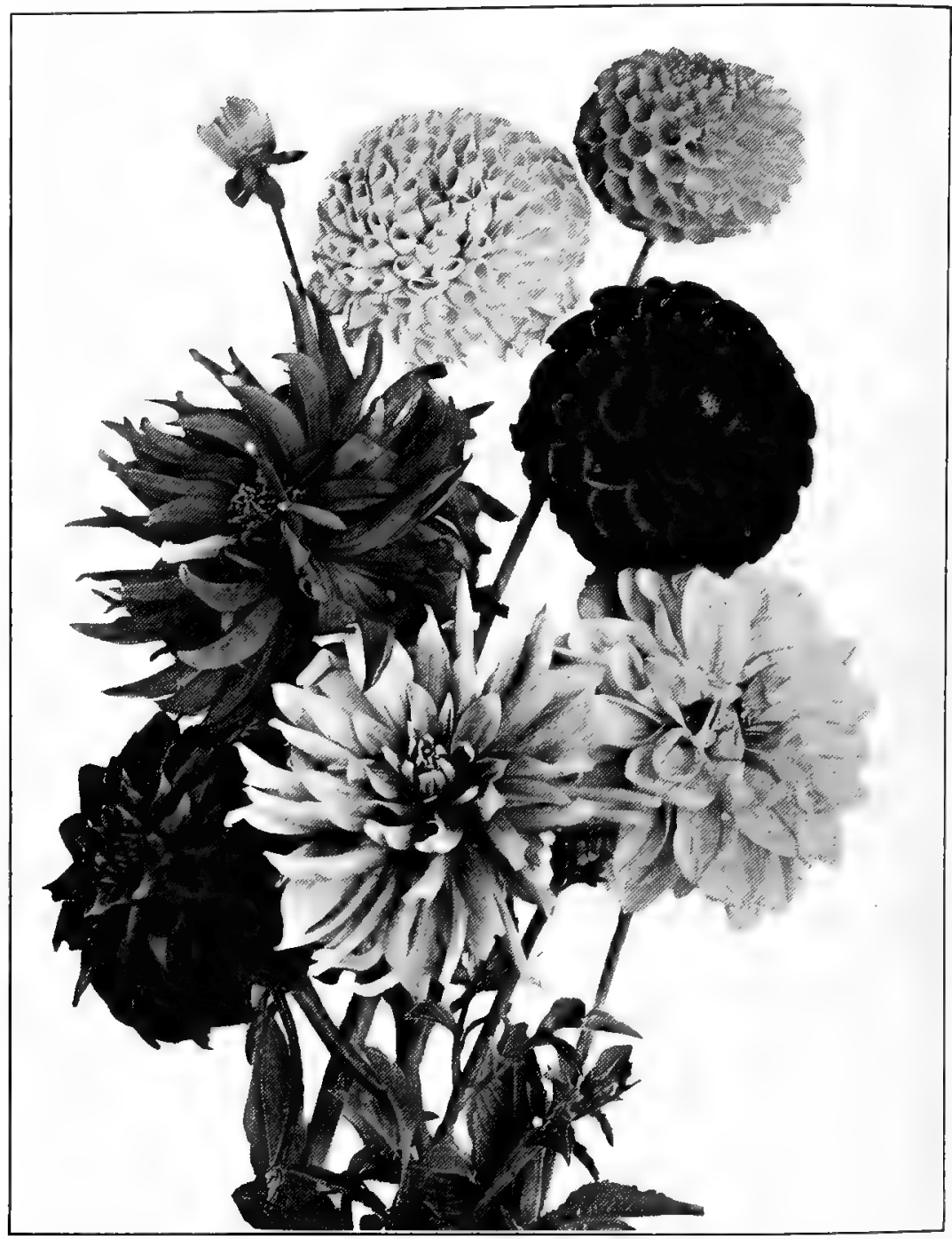

Fig. 143.-Some of the Many Types of Dahila. There is no end to the many fine varieties of Dahlias available. Wherever they do well there are few other, Summer-flowering plants that can equal them for showiness

should always have a good show for their patrons to look at, should use them as cut flowers, and should push the sale of small plants or tubers during the Spring months.

We have, today, many specialists growing old and new sorts for the trade; new and more gorgeous varieties are coming out each year. Keep on giving them a trial and grow the best sorts; those your customers haven't as yet secured. 
Even those who are not very successful with Dahlias should keep on investing a little each year in "new ones." In time we may come across the kinds which do well under conditions not favorable to older sorts.

\section{From Tubers and Seed}

Dahlias can be grown from the tubers or from seed. The tubers will overwinter nicely in the Potato cellar and if you want to get a lot of plants out of a few tubers place them in a 50-deg. house on a sunny bench with just a little bottom heat and you will soon have all kinds of cuttings which will root easily. Pot them up afterward and, if you want to, you can again use the tops of the young plants for cuttings.

Always try to keep your sorts properly labeled and don't carry along such as have proved worthless with you, no matter how well they may do elsewhere. It just means waste of time. Even if you only want the plants to sell during Spring, it would be wrong to sell customers in your locality sorts which don't do well with you.

Sometimes we can grow the single sorts where the double ones won't thrive. In that case plant them, for to have plants full of blossoms is after all far more important than to have a great big bush of some excellent variety with nothing on it but leaves and a few buds with inch long stems, opening the day before we usually get the first heavy frost.

Seed sown in February or March will usually give you flowering plants the first season. With us, in a rather cool Summer with a nice rainfall, we get a fair number of flowers, but during a hot, dry Summer they usually don't do much. For all of that we realize that Dahlias are an important class of plants, and where they do well they should be grown.

DAISY, AFRIGAN ORANGE
See Dimorphotheca
DAISY, BLUE
See Agathæa
DAISY, ENGLISH
See Bellis
DATE PALM
See Phonix

\section{DELPHINIUM (HARDY LARKSPUR)}

It is only of late that the florist has begun to notice these grand perennials and appreciate their value as cut flowers. They are without doubt, among the very best of all hardy plants and on account of their long flowering period, easy culture and splendid keeping qualities as cut flowers, they are not far from being considered ahead even of Peonies and Phlox. 


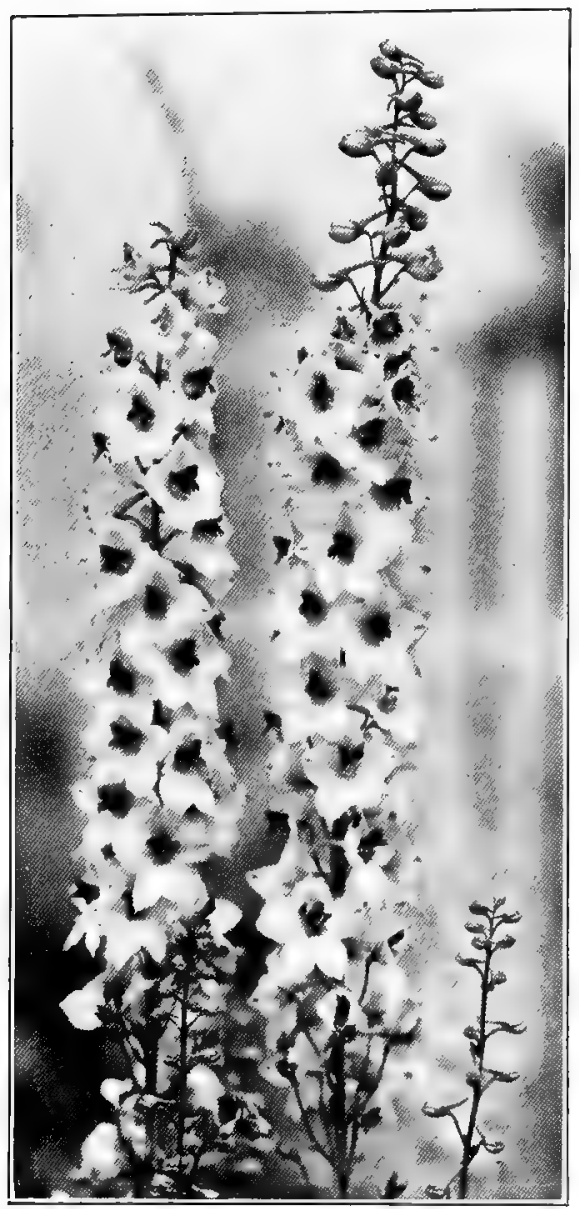

Fig. 144.-Delphinium. This may well be considered the most valuable of all perennials-for the florist, at least. For cut flowers the Belladonna hybrids are the most useful
The hybrid Delphiniums that we grow from seed, with their blue flowers of many shades, are among the most stately subjects for the perennial border. Growing up to five feet in height, they are not particular as to soil so long as it is not too heavily manured. As cut flowers they are hard to beat and, as with Belladonna, while the main crop will come in June or early July, if not allowed to go to seed the plants will flower until late in the Fall. The flower spikes of the young plants are usually only about eighteen inches long; used with Shasta Daisies they make a most pleasing arrangement. Those with greenhouses can also use the field-grown plants for forcing under glass. Besides all this, every retail grower should be able to dispose of great numbers of plants among his customers in Fall and Spring.

Everybody likes Larkspur, especially the lighter shades and the turquoise blue, as found in the Belladonnas. D. formosum while a fine sort, is almost too deep a shade of blue; under artificial light it is rather dull.

\section{Growing ON Stock}

For the forist, the best way to grow on a good stock of Delphinium plants is from seed. Purchase either Belladonna or a good strain of mixed hybrids, or both. You will have good use for all the different shades and if there are any you especially like, there is nothing easier than to save your own seed.

The best time to sow is in January, in flats. With fresh seed ninety per cent will germinate and make good plants. Grow in a 50-deg. house and carry the plants along in the flats into which you 


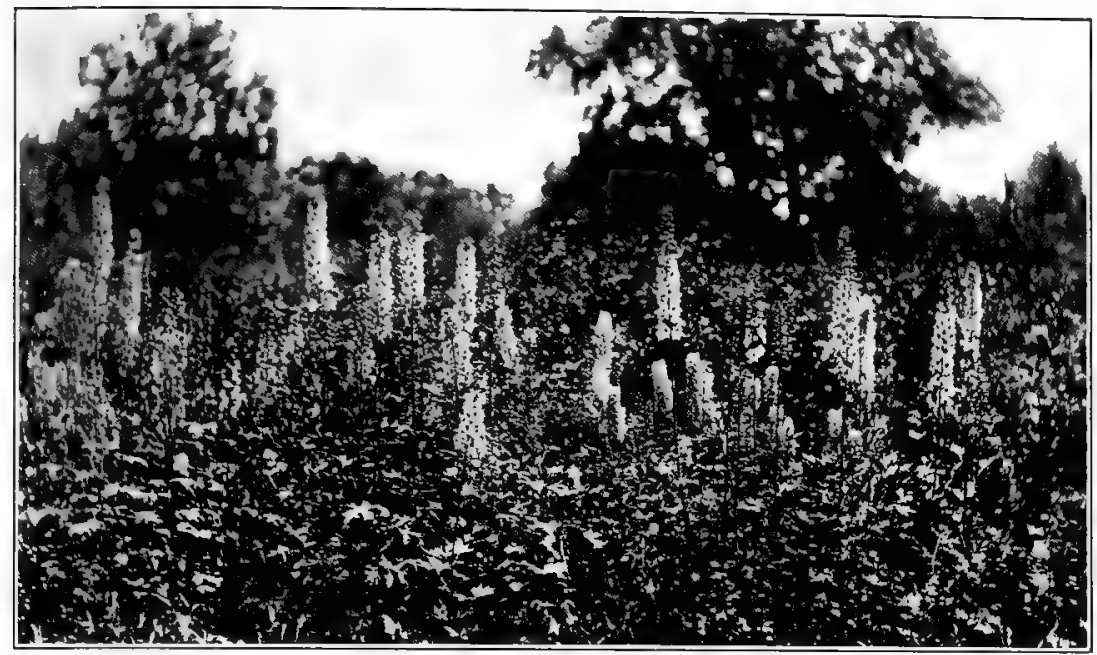

Fig. 145.-Delphintums IN THE GaRden where their stateliness is steadily winning them increased popularity. In a few more years the florist will give them the attention they deserve for forcing under glass

have transplanted the seedlings, or pot them up into $21 / 2$-in. pots; they are well worth the trouble. By the middle of May plant out into the field, allowing about ten inches between the plants and several feet between the rows. These early sown plants will nearly all flower the first Summer and you should have a good crop in Fall. They need but little protection over Winter and will be at their best the second Summer, coming into flower by the end of June or early July. It is always well to provide stakes for the plants as the flower spikes get too heavy and with a heavy rain or windstorm are likely to break off or fall over. Delphiniums are good for years, yet it is always best to sow a few each year and keep on pushing and selling the plants each Fall and Spring.

\section{Forcing Under Glass}

Lift some 2- or 3-year-old field plants in October, heel in in a coldframe and bring into a 45 - deg. house about the early part of February. They are best off planted on a solid bed and you can do nothing with them in a hot house. The more slowly you allow them to come along, the better the results; and you can cut some grand spikes during May. For a large cut flower basket, take these Delphiniums, some long-stemmed America Gladioli and some Clara Butt Tulips (all of which you can grow easily under glass and should have by that time), and the largest city florist cannot show anything finer. 
Of course you can sow Delphiniums out in the open during Summer without a greenhouse, but you can obtain quicker results by starting them under glass as stated above.

\section{DEUTZIA}

Of most value to the florist among the fine flowering shrubs is Deutzia gracilis, for as a pot plant in bloom it is most desirable for Easter or early Spring flowering when its branches are loaded down with the small, white, bell-shaped flowers.

For best results let your nurseryman supply you in Spring with small, field-grown stock which should be potted up into $5 \mathrm{~s}$ or $6 \mathrm{~s}$ and

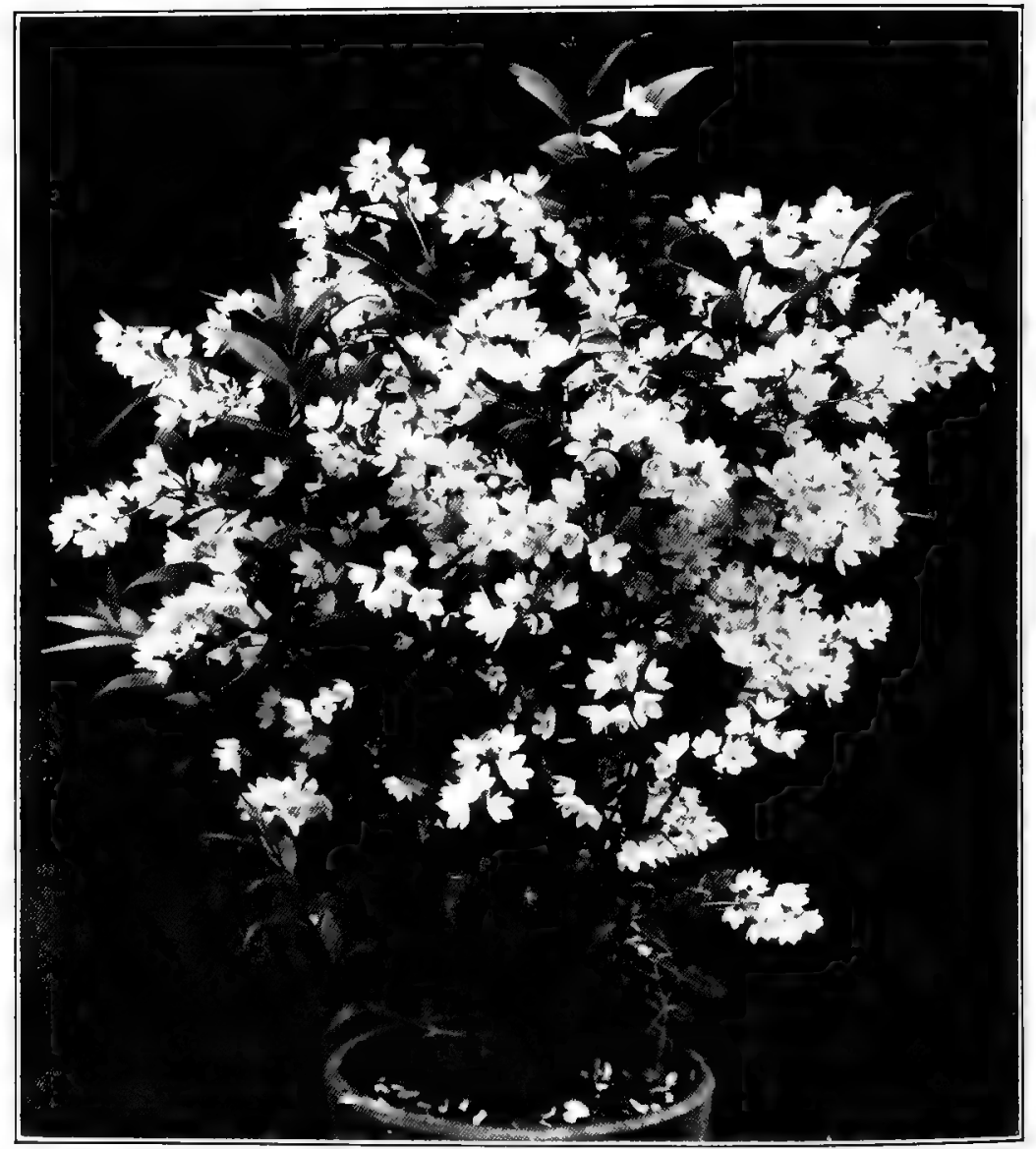

Fig. 146.-Deutzia GRACILIS. Deutzias grown on in pots during Summer force easily for Easter and when loaded with flowers and good foliage are most desirable. Failure is often the result of too severe forcing or of making use of field-grown stock potted up during Winter-which is useful only for May flowering 
grown in these pots during the Summer months. This will assure the best flowering wood. Let the plants get touched with frost in Fall, then bring them into a deep coldframe to stay there until the end of January. After that keep them in a 45-deg. house, moving them to warmer quarters by the end of February. They can, if necessary, stand a real hot house after that, but they are better off if not forced too hard. If wanted for Easter and found a little ahead of time, they can be placed in cooler quarters again.

Wherever this Deutzia is hardy it should be included in the list of desirable flowering shrubs as should the other sorts such as Pride of Rochester, magnificata, venosa, Lemoinei, candidissima, crenata and Watereri. These are among the most showy of early flowering shrubs, but unfortunately, they are not all hardy enough everywhere. They don't always winterkill, but may freeze down far enough to spoil the flowering wood.

\section{DIANTHUS (PINKS)}

Of the hardy varieties of Dianthus, a number are of value to the florist, and I might say that of these Sweet William (Dianthus barbatus) is the most valuable. For not only is it a showy plant in the hardy border, but also it can be used to good advantage as a cut flower. This is true especially of Newport Pink, since of this color there isn't an oversupply in May and June. The easiest way to propagate Dianthus is from seed sown in July or August; later on transplant the seedlings six inches apart where they are to flower the following Spring, or you can transplant stock in Fall or Spring. They don't all come true and if you should wish to improve your strain, select a few of the best plants when they are in flower and save them for seed.

Of the border Pinks there are some fine double sorts which make showy, low border plants even when not in bloom. You will find that the best way to propagate them is by means of cuttings, rooted in early Fall inside, or in a frame and carried in a cool house.

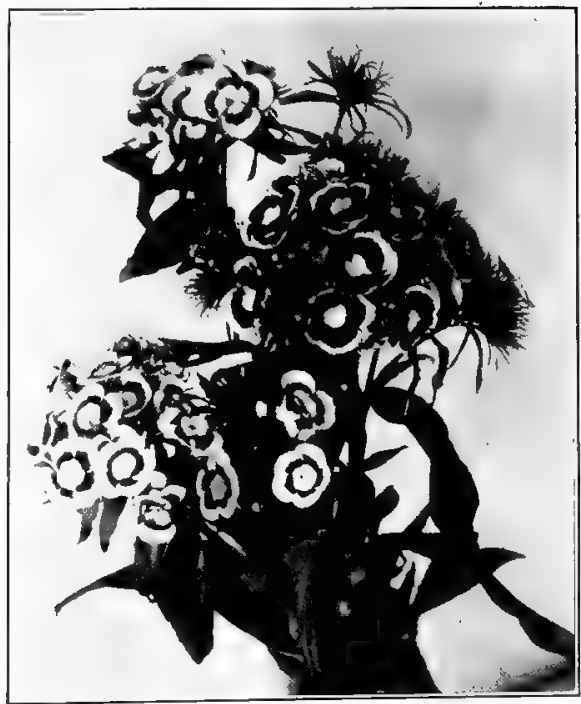

Fig. 147-Dinanthus barbatus. Oldfashioned Sweet William belongs in the perennial border, but the retail grower can also grow it for cut flowers and then sell the plants 


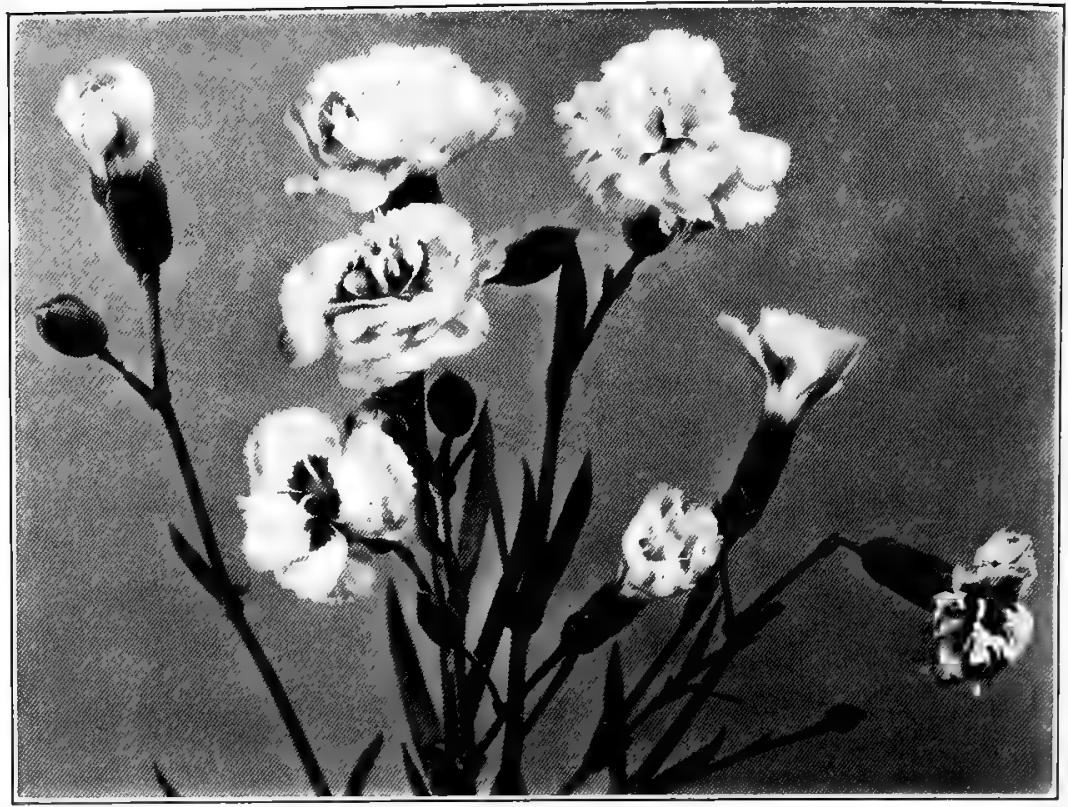

Fig. 148.-Hardy Pinks, Variety Aluwoodir, which will give you all Summer large, double, fragrant flowers on 10- to 12-in. stems. A few good stock plants will furnish quantities of cuttings which root freely in Winter

Among other so-called hardy Pinks we have the double and single clove-scented ones and the Pheasants' Eye type. They can be propagated by cuttings taken about September, or you can grow them from seed.

You might try the new strain Alwoodii, which is a freer bloomer than any, flowering all Summer, more or less, like a Carnation.

Among the annual sorts the so-called China and Indian Pinks are showy, but they are hardly of a great deal of importance to the florist. Still, a little seed may be sown with the rest of the annuals under glass in early Spring and the little plants grown on, in pots, for the bedding season.

\section{DIGENTRA SPEGTABILIS (BLEEDING HEART)}

With Maidenhair-like foliage similar to that of the Columbines and with graceful stems hanging full of little heart-shaped flowers, the Dicentras during early Summer are just as pretty in the herbaceous border as can be. You should carry a stock of them along with all the other plants meant for the hardy border. You may have call for only a very few each year, but it means just that much more business and when you once have a few plants and let them have 
a spot where you can take care of them, you can every other year, divide the old stock and so steadily increase your supply. .

\section{Plants for Forcing}

Two-year-old clumps of Bleeding Heart lifted in Fall can be gently forced and had in flower around Easter time without much trouble. When well done the retail grower will find good use for them. Heel them in in a frame and keep them there up to the end of January: Then bring them in, pot them up, and let them have a 45-deg. house. With Easter coming around the first of April, they should be brought into a 55-deg. house by the latter part of February. They need a lot of water while in the pots. You can plant the leftovers outdoors again.

\section{DIGTAMNUS FRAXINELLA (GAS PLANT)}

The Gas Plant-meaning the red form as well as the whiteprovides showy, hardy, flowering plants that can be used either in groups or borders. When planted in masses they are as showy as any flowering plant you have. When planted in a double row they make an ideal border for a walk, growing very uniform in height. But you will want to plant something else alongside of them as they do not flower all Summer. Sow seed in May or early June in order to have good-sized plants to flower the following year.

\section{DIDISCUS CARULEA (BLUE LAGE FLOWER)}

If you wish to add to your assortment of flowers during the Spring months and please those patrons who are always wanting something different, you can do it by growing on a few plants of the so-called Blue Lace Flower (Didiscus cærulea). While not a showy flower nor of large size, it is nevertheless very attractive and when used in connection with Sweet Peas, Freesias or Valley with Adiantum, it makes a beautiful centerpiece or corsage. If you want it to flower during April and May, sow seeds about the end of December or January in a house of 50 deg., transplant the seedlings later on into small pots, and in four or five weeks plant out on a bench, allowing about four inches between the plants in the rows and one foot between the rows. They will thrive in almost any soil and in a Carnation house temperature.

\section{DIERVILLA (WEIGELA)}

The Weigelas are among the dozen or so best flowering shrubs for the home grounds and you have to consider them. They are not only loaded with flowers during early Summer, but their foliage is always fresh and clean and some of the sorts (among them $D$. 
rosea, perhaps the best known one) have large leaves which turn to a beautiful bronze brown when touched by the first frost in Fall.

Cut your plants back well each Spring and when they are through flowering you will admire their beautiful foliage. The deeply veined leaves in Fall take on a bronze shade and hang on as long as anything in the border.

Some of the sorts sometimes winterkill a little with us, but we keep on recommending and planting them. Their many bellshaped flowers range from white $(D$. candida) to dark carmine $(D$. Eva Rathke) and appear from the end of May through June, in fact, there are scattered ones all Summer long.

D. Abel Carriere is one of the newer hybrid sorts with large deep rose-colored flowers and Chameleon is another good early rosepink sort. D. rosea nana compacta has pink flowers and beautifully variegated foliage and is of dwarf habit, but not as hardy as we would like to have it.

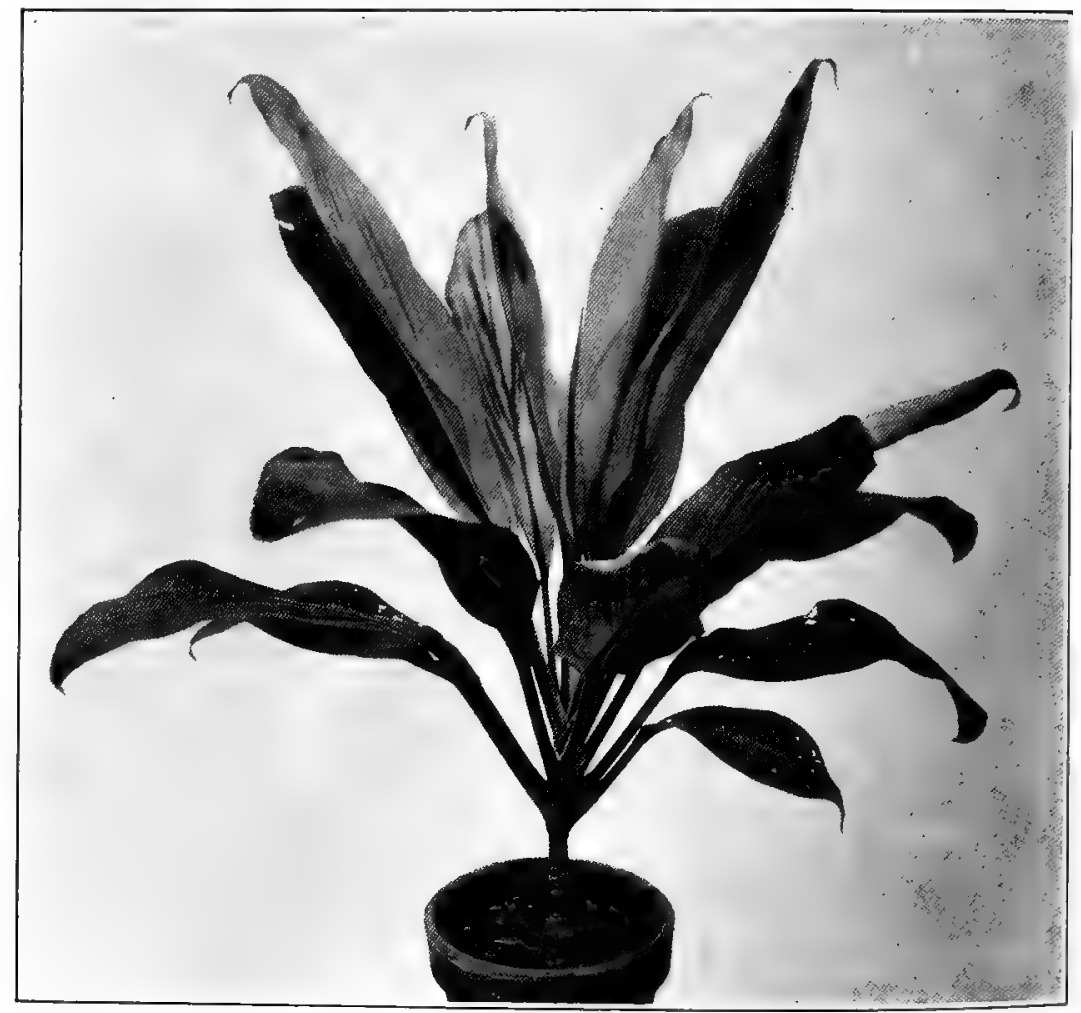

Fig. 149.-Dracana amabilis. We are blessed with many beauliful Dracænas in a great variety of colorings. Practically all of them are useful as decorative plants during the Winter season, especially around Christmas time 


\section{DIGITALIS (FOXGLOVE)}

Foxgloves are biennials and as handsome as can be, especially when planted in large groups. If you sell perennials and plants for the hardy border you are bound to have call for Foxgloves and should grow on a good batch each year.

Sow the seed about March. The seed is almost as small as that of Lobelia, and the seedlings remain almost at a standstill for the first month. Transplant later on into flats, allowing about $1 \frac{1}{2}$ in. between them, and plant outdoors in May.

They thrive in any soil, and make heavy plants by Fall. The best way to overwinter them, is to lift the plants and carry them into a coldframe, planting them out again as early as possible. They will come into flower by the end of June. You can also sow outdoors in April and get good results.

\section{DIMORPHOTHEGA (AFRIGAN ORANGE DAISY)}

These little annuals are mostly grown for outdoor flowering and for that purpose are sown usually where they are to flower. D. aurantiaca hybrida produces flowers on fair-sized stems, ranging in colors from creamy white to deep orange, but the florist hardly ever grows them to any extent during Summer. However, they will give you something a little different and attract attention if sown during the latter part of February in rows on a solid bed in a 45-deg. house, where they will begin to flower by early May. They last well when cut and with stems 10 in. long can be used to good advantage for table decorations. Your customers are always ready to buy something out of the ordinary.

\section{DOGWOOD \\ See Cornus}

\section{DRAGÆENA}

Perhaps the best known to the florist of all the many fine varieties of Dracænas, is $D$. indivisa. While by no means to be compared with some of the others for beauty, it is used in great quantities each year, especially for the center of vases. Frequently we see smaller ones also used in window boxes in connection with other foliage plants.

There seems to be no other plant quite as graceful or which, as a foliage plant, can take the place of this Dracæna for the center of a vase during the Summer months; nor any which can be grown as cheaply. A lawn vase, whether a rustic affair or of iron or concrete, no matter how well you fill it, is never complete without the Dracæna in the center of the arrangement.

These Dracænas are easily grown from seed, yet I doubt if it pays the retail grower who uses three to four dozen of 5- or 6-in. 
pot plants each Spring to take up his time with it. I believe he is ahead if he purchases some 3-in. or 31/2-in. stock by the first of June, plants it in the field, lifts the plants by the middle of September and pots them up into $5 \mathrm{~s}$, places them in a house of $50 \mathrm{deg}$. over Winter, maybe gives them another shift in February, and has them ready for his Spring trade. Those who are in need of smaller plants for boxes or hanging baskets and who want to grow their own stock, can sow seed at almost any time during the year.

Next, perhaps, to $D$. indivisa comes $D$. terminalis, the popular, oldtime, red leaf sort we use so extensively for Christmas, either as single plants or in plant arrangements for baskets. This sort, like many others, is usually propagated from canes. These are cut up into $1 \frac{1}{2}$-in. pieces and laid in sand in the propagating bench with about 70 deg. of bottom heat, where they make root and break. The retail grower with old plants on his place of varieties such as $D$. terminalis, D. fragrans and others, can cut the plants down, use the canes in this way and root the tops-and, most likely, new breaks will appear from the base of the cut down plant.

\section{Some Fine New Sorts}

Some very fine Dracænas have been introduced of late years; these make ideal house plants, and to a great extent they have made up for the shortage of palms. Among many we might mention the following: $D$. Massangeana, with a large green leaf with creamy stripe along the center; D. Lord Wolseley, with a broader leaf than $D$. terminalis, but a fine shade of red; $D$. Lindenii, green with yellow border; and $D$. Warneckii, with a green and silver-white leaf. These are just a few of many, and the retail grower, around the holidays in particular, should always stock up well with a good number of them. If he is short on blooming plants, such stock will come in very handy and what isn't sold is a good asset later on; for Dracænas kept in a 55-deg. house will not spoil, but will keep on growing in value. Most any of them in the smaller sizes are fine for madeup baskets.

\section{DUSTY MILLER}

\section{See Centaurea}

\section{ECHEVERIA SEGUNDA GLAUCA (HEN AND GHIGKENS)}

Echeverias really belong to the Cotyledons, of which there are a great many sorts, but most of them are of but little interest to the florist. We know $C$. secunda glauca best for we see it used most extensively in carpet beds in connection with Alternantheras, Santolinas and others; or in the cemetery in the same company. I don't know but what quite a few retail growers could use a few of all these plants to good advantage by making a little display of their own on their show grounds. In most cases a small border 
or bed would attract a great deal of attention and that always means effective advertising. Echeveria-by which name we know these plants best-forms perfect little rosettes, and if you don't want too many, they need but little heat over Winter and can be carried in almost any house, but must be kept on the dry side.

\section{ELEPHANT EAR \\ See Caladium \\ ENGLISH IVY \\ See Hedera}

\section{EPIPHYLLUM TRUNGATUM (GHRISTMAS GACTUS)}

In Europe and even in this country forty years ago, these Epiphyllums were among the most highly thought of Christmas flowering plants. Poinsettias weren't as popular then as they are today; Begonias of the Cincinnati type were unknown; little effort was made to have Azaleas that early in the season and the same with Cyclamen, of which but very few were grown in this country particularly. Chinese Primulas were among the Midwinter flowering stock, but no other plant could more safely be depended upon to be in full bloom Christmas week with a temperature around $50 \mathrm{deg}$. than the Epiphyllums.

I don't suppose they will ever have another chance to become popular, yet I believe well-grown plants in bud and bloom around Christmas would sell. The flat leaves, 1 -in. long, will readily root in sand, and if you grow them in an airy house, in two years you will have heavy plants. Even the smallest of them will flower the first Winter. They make ideal house plants.

\section{EUPHORBIA JACQUINIAELORA}

Of the favorites of long ago, this Euphorbia has come to the front again and forms a valuable cut flower during the Winter months. It can be grown entirely in pots, or cuttings rooted during April from young wood, may, after a turn in small pots, be benched during Summer. Like the Poinsettia, it needs a house of 60 deg. from Fall on, plenty of sun and good drainage. Long sprays of this Euphorbia with the stems covered with small, red flowers are especially useful in basket arrangements.

\section{ERICA (HEATHER)}

The time will come when every retail grower will have Ericas for sale from December on up to and after Easter and offer a good assortment of all the many remarkable varieties there are. The American public will then be as well acquainted with them and think as highly of them as they do and have done for ever so long in Europe.

Whether or not the florist in the Middle West will ever be really successful with Ericas, matters little. There will be enough grown in the East and in the extreme West to go around; nor will we always have exorbitant express rates to make the shipping of the plants too 


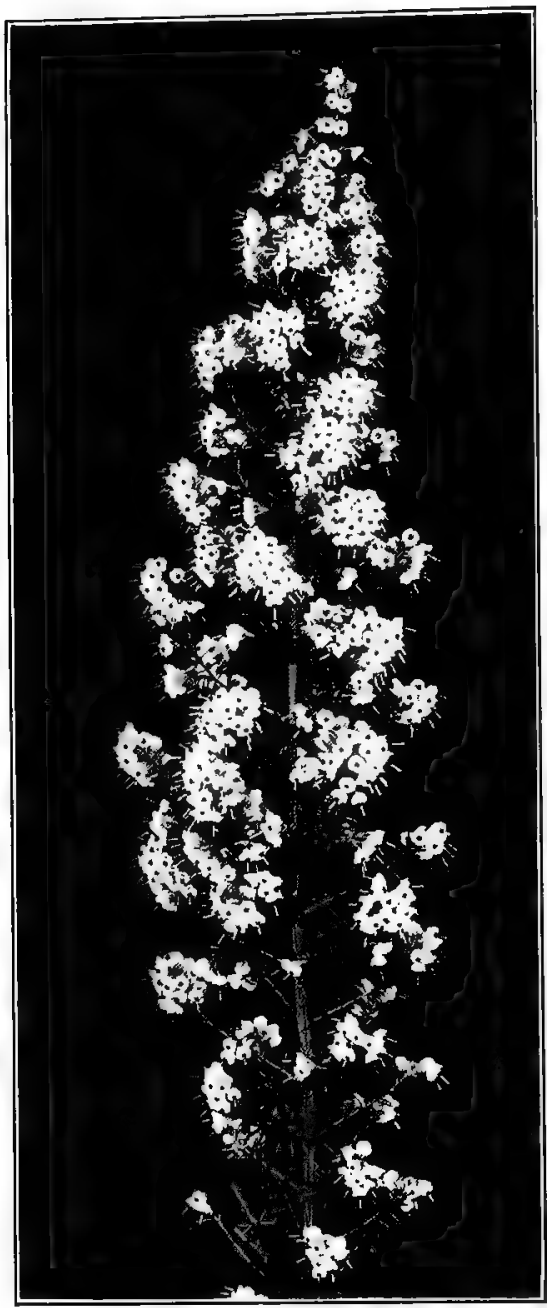

Fig. 150.-Erica Melanthera. A single, well-flowered branch of this bestknown Ghristmas-blooming Heather. Three-inch pot plants for baskets are as valuable as 8 - or 10 -in. specimens expensive. The very fact that today a number of firms in the country are interested in the growing on of Ericas and that tens of thousands of them are sold (some of them in sections where years ago it was considered impossible to grow Ericas) is proof enough that we are making great headway.

I don't expect the smaller retail grower to go into growing his own requirements; we have passed that stage. But he will become interested in them the minute they are obtainable and can be handled at a profit.

Flowering pot plants are the ones to be pushed for the Winter season. Long-stemmed Beauty Roses or extra fancy Laddie Garnations are the flowers to use for the elaborate dinner or the wedding, but for the lover of flowers, who wants to see them last awhile and cheer up the home, "flowers" will always mean pot plants, and here is where the Ericas come in. They are among the very best of keepers, and are liked by everybody, rich and poor. Almost every florist, no matter how small

his greenhouses, can overwinter and flower Ericas. If he has a chance' to purchase his requirements during November, he can keep the plants in good shape in a coolhouse until they are in flower; that again should be an inducement for him to carry them.

There is no use in the retail grower attempting to grow on plants from cuttings. With the length of time it takes to grow on a fair-sized plant, and the care it must have, he cannot afford to. As stated above, purchase your requirements in late Fall already 
grown. Erica melanthera is the ideal Christmas variety and you should always have a nice, well-balanced stock of it on hand, from small-sized ones for baskets to a few large specimens. All they need is a cool house and to be kept well watered. The plants may not show right away when suffering for want of sufficient moisture around the roots, but the first thing you know the little buds turn brown and dry up-and it is too late then to keep them wet.

\section{How to Propagate Ericas}

The specialist propagates during Winter and early Spring, using the tops of the young growth. You want washed sand and a rather close atmosphere, but no bottom heat is necessary. It takes a couple of months to root the cuttings. Some growers practice pot culture during Summer, and others plant out in beds, making use of a mixture of leafmold, good mellow loam and sand. A little shade is necessary. If you grow from cuttings, it takes two and three years time to obtain

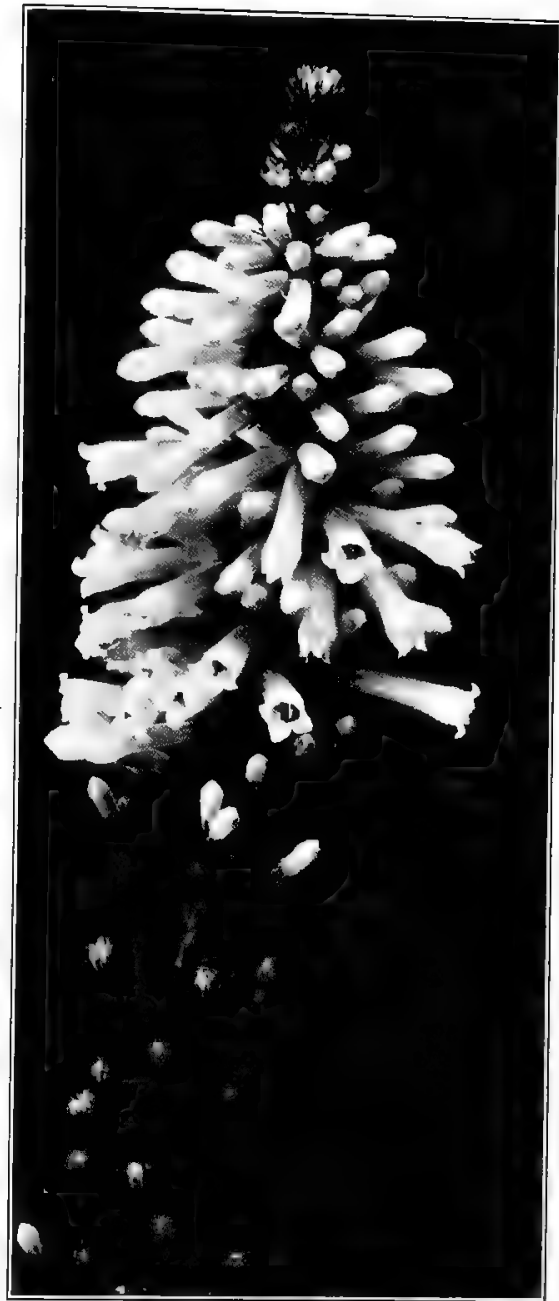

Fig. 151.-Erica Wrllmoreana. One of the several beautiful species of which more are being grown each year. At this rate they will soon be as popular as they have long been in Europe good specimens. During Winter, give them a house of about 40 deg., increasing the temperature, of course, for the plants that are wanted to flower. Old plants left over should be cut back well and if you can plant them outdoors during Summer, so much the better; then lift in October and pot up.

What is of more interest to the lover of Ericas if he is a retail grower, however, is the fact that more plants than ever are being grown today in the United States and in many beautiful varieties besides $E$. melanthera. We actually note advertisements of firms quoting 


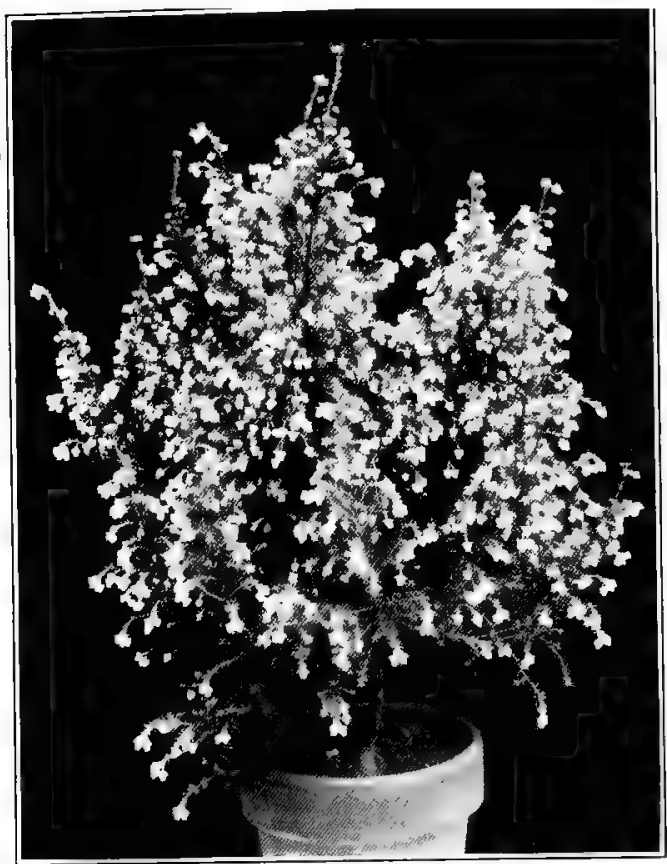

Fig. 152.-Eríca cupressina. You couldn't ask for a more showy flowering pot plant than this Heather, yet it is only one of a long list of grand varieties that you can select from

such as President Carnot, King Edward, Codonodes Veitchii, Willmoreana, Felix Faure, regerminans ovata, persoluta and others; more men are getting interested in them right along and that looks mighty promising.

\section{ESCHSGHOLTZIA (CALIFORNIA POPPY) \\ While for the florist the Eschscholtzias are} anything but moneymakers, they are nevertheless most showy annuals, especially when planted in masses, just as we see them at their best in California in Spring when the hills and roadsides present a glorious sight. I have seen them to good advantage sown among Oriental Poppies to take their place after the foliage had died down, and they can also be used for cut flowers, although for that purpose Hunnemannia, the Giant Tulip Poppy, is really better; or even the Iceland Poppies which come almost in the same shades and colors and also hold their foliage all Summer.

\section{EUONYMUS}

Euonymus japonica is one of the sadly neglected plants. Every florist ought to have a good stock of both the green and the varigated forms. Like Aspidistra and Aucuba, Euonymus provides ideal plants for decorative purposes; it can stand all kinds of rough usage, and when a few years old and grown into pyramids in tubs, it gives desirable subjects that can be used like Boxwood or Bay Trees.

The florists of the United States have never really endeavored to make money out of Euonymus, as those of Europe have. We found it easier to import the Boxwoods and Bay Trees than to bother about anything else. It was simpler up to a short time ago to let the other fellow do the growing; but as we go along we gradually take more notice and are beginning to look around for plants 
which can not only be used as substitutes for imported stock, but which can also be grown on here.

\section{Growing on Specimen Stock :}

The florist who wants to grow on a stock of Euonymus, cannot start out any better than by purchasing a batch of well established plants out of 4-in. or 5-in. pots. If he wishes to grow these on for specimens and gets the plants in Spring, I would suggest taking the tops off and rooting them indoors in a well-prepared, deeply cultivated soil. Maybe you have an empty, cooled-off hotbed that will be just the thing, if there is enough soil on top of the manure. If not, put on a 6-in. or 8-in. layer and dig the whole bed over. Give the plants plenty of water during the Summer and they will make a nice growth; pinch off the long shoots to keep the tops in shape. You can lift the plants by the end of October and if you have a cold house, I wouldn't pot them, but would plant them close together on a solid bed. The following Spring give them a good root pruning (it won't hurt them a bit) and plant them out again. With three seasons of such handling, you will have the third Fall 5-ft. to 6-ft. specimens that will require butter tubs. If you kept them pinched nicely, they will be bushy, shapely plants for which you will have all kinds of good use. In the meantime the cuttings you rooted during early Spring and some more of halfripened wood taken in Fall, have grown into nice, bushy plants, some in 6-in. pots.

The florist who has window boxes to fill (such as we often see displayed during the Summer months on buildings in the business section of a town) and who therefore needs foliage plants, couldn't possibly have anything more appropriate than variegated Euonymus. They also make fine house plants if not kept too hot; or they can

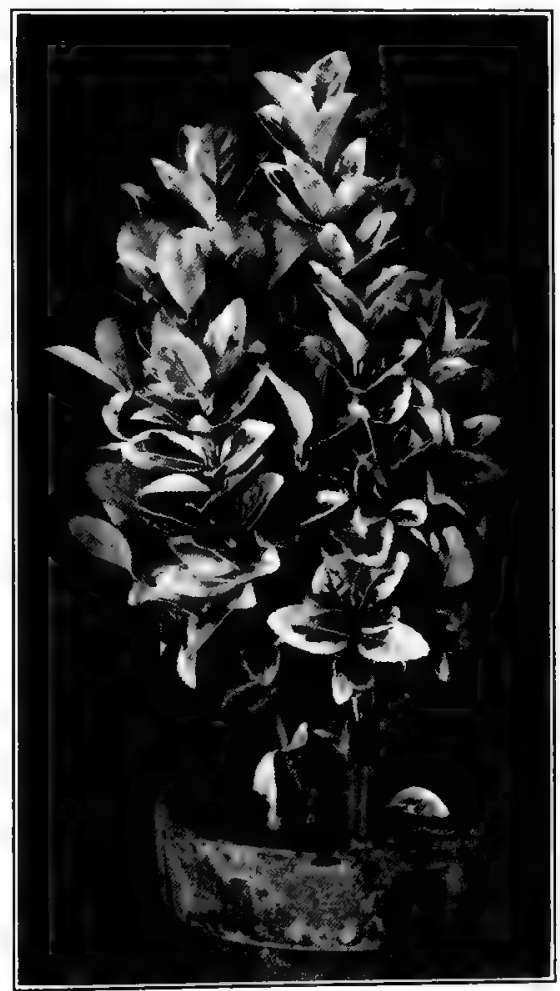

Fig. 153.--EUONYMUS JAPONICA LATIFOLIA AUREA. This and other related forms deserve more attention. They can be used for decorating like Boxwoods and Laurels and can stand a great deal of abuse 
be used for the filling of indoor boxes. For use in made-up baskets for Christmas, you can take the smaller sizes; or, if you have boxes to fill with conifers and evergreens, Euonymus will answer. Besides it will take the place of valuable palms or ferns for church or wedding decorations during the Winter months. E. japonica latifolia aurea, and $E$. $j$. aurea marginata, are fine variegated forms, but don't grow as rapidly as the other two.

The Silver-leaved Euonymus $(E . j$. argentea), with light green leaves, each with a white margin, makes a most desirable plant to be used in a Christmas arrangement. Small plants in $21 / 2$-in. pots are also most attractive and will come in handy for filling fern dishes. Half-ripened cuttings root easily with a little bottom heat during Winter, and nice little 2 - or $21 / 2$-in. plants can be grown on for the following Fall.

\section{Hardy Sorts for OUtdoor USE}

Euonymus japonica, being evergreen in the South, is sometimes used there as a hedge plant. $E$. radicans, another evergreen, is fairly hardy even in northern sections; being a trailing or climbing shrub it is a good substitute for Ivy where the latter is not successful.

The Strawberry Bush is a small tree or shrub much sought after for the smaller home grounds. We find specimens in the border or planted singly on the lawn. What makes these shrubs so attractive, is the scarlet pods that surround the pink fruits against the background of bright green foliage.

Euonymus alata is also an interesting shrub due to its branches being "winged" or covered with corky ridges. Euonymus europæa makes a fine, tall-growing shrub for the border and in Fall bears many seeds contained in deep pink-colored capsules. E. atropurpurea, the Burning Bush, is another strong-growing, hardy shrub, with brilliant scarlet fruit capsules.

\section{EUPATORIUM RIPARIUM}

The Eupatoriums, while making up a class of plants with nearly 400 species, are not of great interest to the average florist. Still there are three or four of them worthy of culture. Eupatorium riparium grown from cuttings rooted in early Spring can be planted out and potted up again in Fall; if grown on in a cool house it will furnish useful cut flowers similar to those of Stevia. While the flowers are not as graceful, they come in handy and the retail grower can handle them to advantage in combination with other flowers. E. Fraseri and E. ageratoides are both good perennials for the border or to cut from, the little whitish flowers coming in dense heads. E. coelestinum, with blue flowers, is also hardy and flowers in late Summer.

Some seedsmen and nurserymen list.-certain Eupatori- 
ums as Conocliniums, Hebecliniums, and even as Ageratums. Most of the hardy species are natives of North America, but the tender species hail from South America, Mexico and the West Indies.

If you once get established on your grounds a good number of Eupatoriums, you can divide a few clumps in early Fall and replant what you need both for cutting and to be sold as plants during Spring and Fall. Stock can also be grown on from seed, which when sown under glass in February will give you flowering plants the first Summer. Plants from seed sown outdoors during June, while they will grow into salable stock by Fall, will not bloom until the second season.

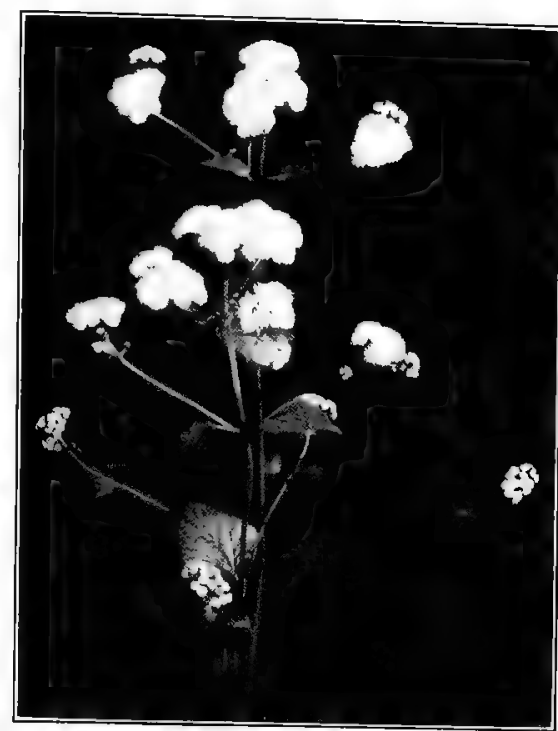

Fig. 154.-Eupatorium RIParium will flower by the end of February in a Carnation house temparature, the plants having been grown outdoors the previous Summer. $\boldsymbol{E}$. Fraseri and $\boldsymbol{E}$. ageratoides are perennials flowering outdoors in August

\section{EVERLASTING FLOWERS}

Everlastings, so-called because the flowers when in a dried state remain in an attractive condition for a long time, have of late years become very popular, and many acres are devoted to their culture along the Pacific coast where climatic conditions are almost ideal for their development. Yet most of them can be grown elsewhereEast, South and North-perhaps not with as great success, but well enough to make them pay.

Quite a number of florists still hesitate to have anything to do with their culture, or even to handle the flowers. They don't consider them of enough value or think them not quite the proper thing to carry in connection with fresh flowers. Nevertheless, great quantities are used each year and as the demand for many varieties is on a steady increase it seems that every florist with a retail trade should pay attention to their culture.

The following list of ten varieties of plants suitable for cutting is only a short one, and there are many others that produce flowers that may be used in a dry state during the Winter months. However, these ten will give any one a good assortment, and all are of easiest culture. They all are annuals with the exception of Statice latifolia and Gypsophila paniculata, which are perennials, but, to my mind, just as important as any as stock for the florist to cut from. 
Acroclinium noseum (page 245) a

AMmoBium alatum (page 252).

GompHrena gLobosa (Globe Amaranth) (page 388).

GyPsophILA Paniculata (Baby's Breath) (page 390),
Heltahr ysum BRACteatum (page 394), Rhodanthe atrosangutnea (page 492). Statice latifolia (page 525).

Statice sinuata (page 525).

STatice Suworowil (page 525).

Xeranthemum anNuUm (page 553).

\title{
FALSE DRAGON HEAD \\ See Physostegia
}

\section{FAN PALM}

\author{
See Latania
}

\section{FERNS}

Next to flowering pot plants, ferns in pots are of most importance to the florist. He has use for them every day in the year, and especially around the holidays, when, no matter how grand his display of flowering plants may be, some will want a Fern. With all the fine new sorts which have evolved from the old Sword Fern (Nephrolepis exaltata), it usually isn't hard to please all tastes, yet the "Bostons" are as popular as ever, largely on account of their famous keeping qualities.

If there is any one sort of more value than all the rest, it is that which we know as the Boston Fern. We use the plants in one

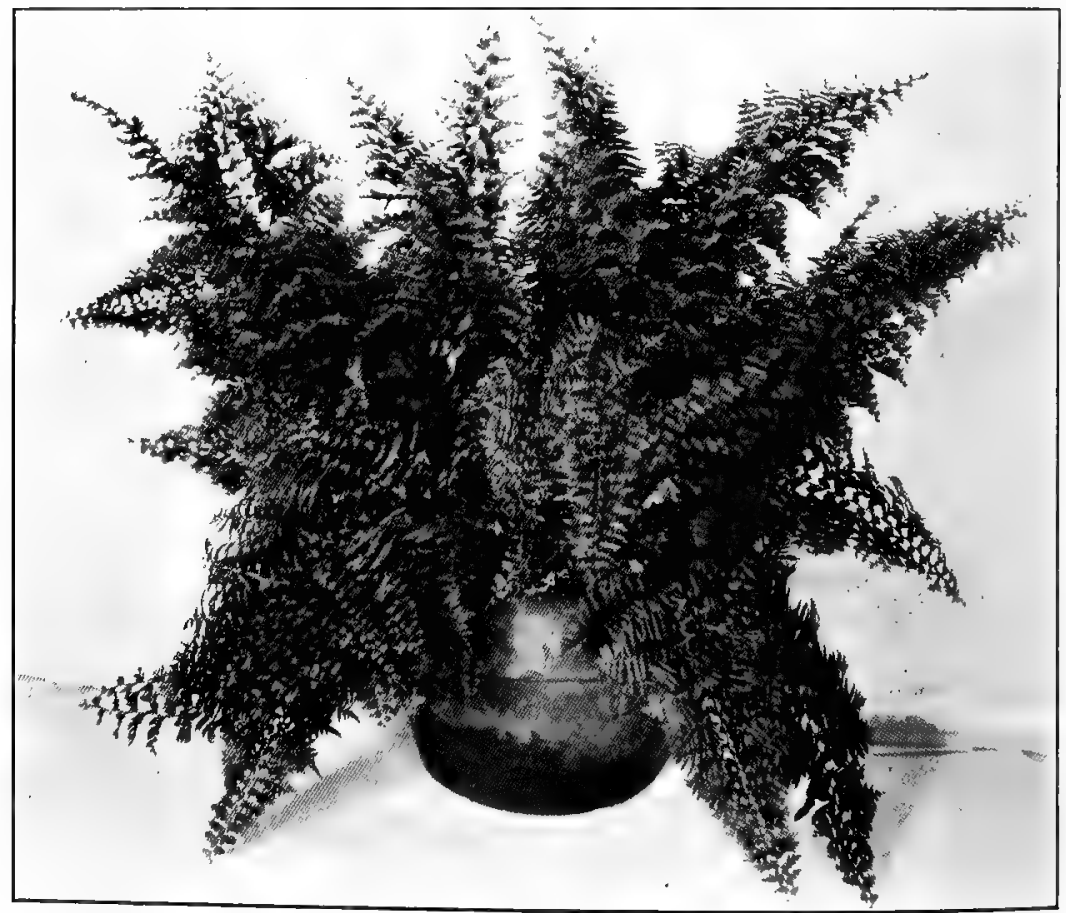

Fig. 155.-Nephrolepis elegantissima. One of a long list of Nephrolepis sports that we grow today - and to which new names are being added every day 
way or another from $21 / 2^{-}$or 3-in. stock on up to specimens in 8- and 10-in. containers, in basket arrangements for the holidays, in outdoor and indoor window boxes, and in hanging baskets.

For those with limited space, it is every bit as well to obtain what they need from the wholesale grower or to make use of empty benches during the Summer months, purchasing small stock in Spring and planting it out. Three-inch stock benched after the bedding stock is gone will grow by Fall into nice, bushy, 5- and 6-in. plants, which can be potted up separately; or the smaller plants can be used for made-up pans.

You can grow such ferns in almost any soil so long as it is well drained. They want a lot of water and should have a little shade. They can also be grown in a frame outdoors with good results; in fact, they will do better there than in a dry house. All ferns love more or less moisture and while they can stand almost any amount of heat on top, they object to warm feet. The Bostons are no exception; give them a little shade, and they will make great headway.

During the Winter months they should have a house not under 55 deg. (a little over that point won't hurt), well drained pots and a porous soil. They can stand watering almost every day, but in a sour soil they soon go to pieces.

The man who has only one hundred or so of these ferns on hand at a time and has to have them in a house with a lot of other mixed plants, should not expect to get the same results

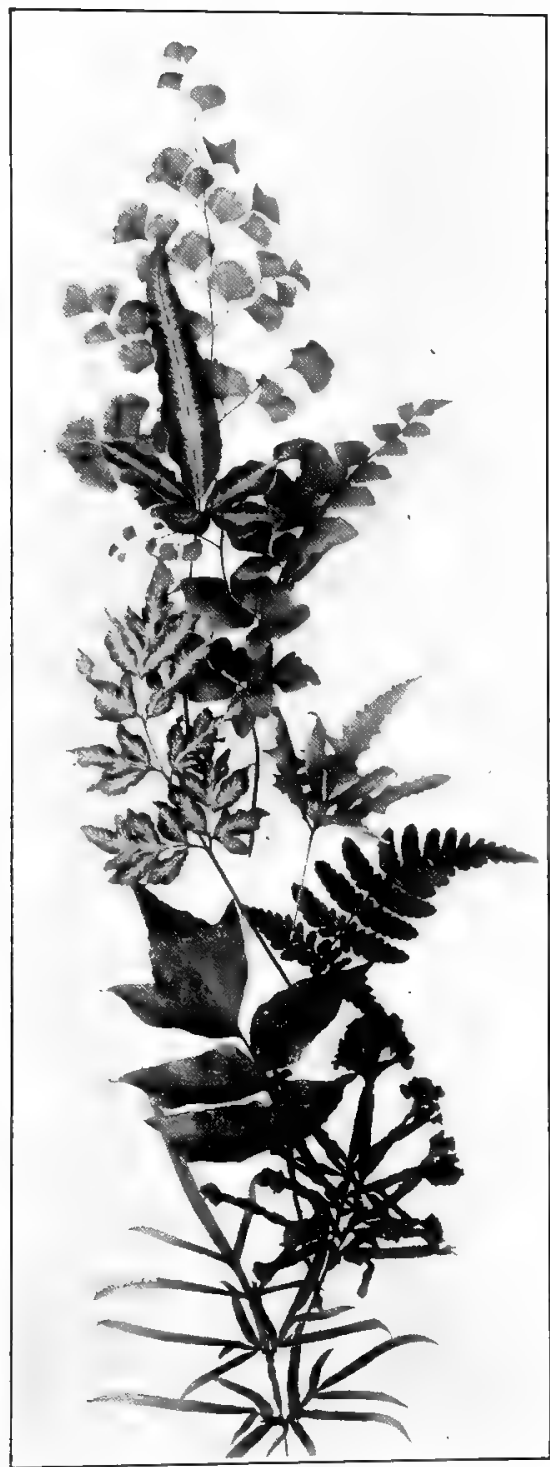

Fig. 156.-Table or Dish Feris is the name given to 2 or $2 \frac{1}{2}$-in. stock of Pteris, Asplenium, Aspidium, etc., mostly used for filling fern dishes 


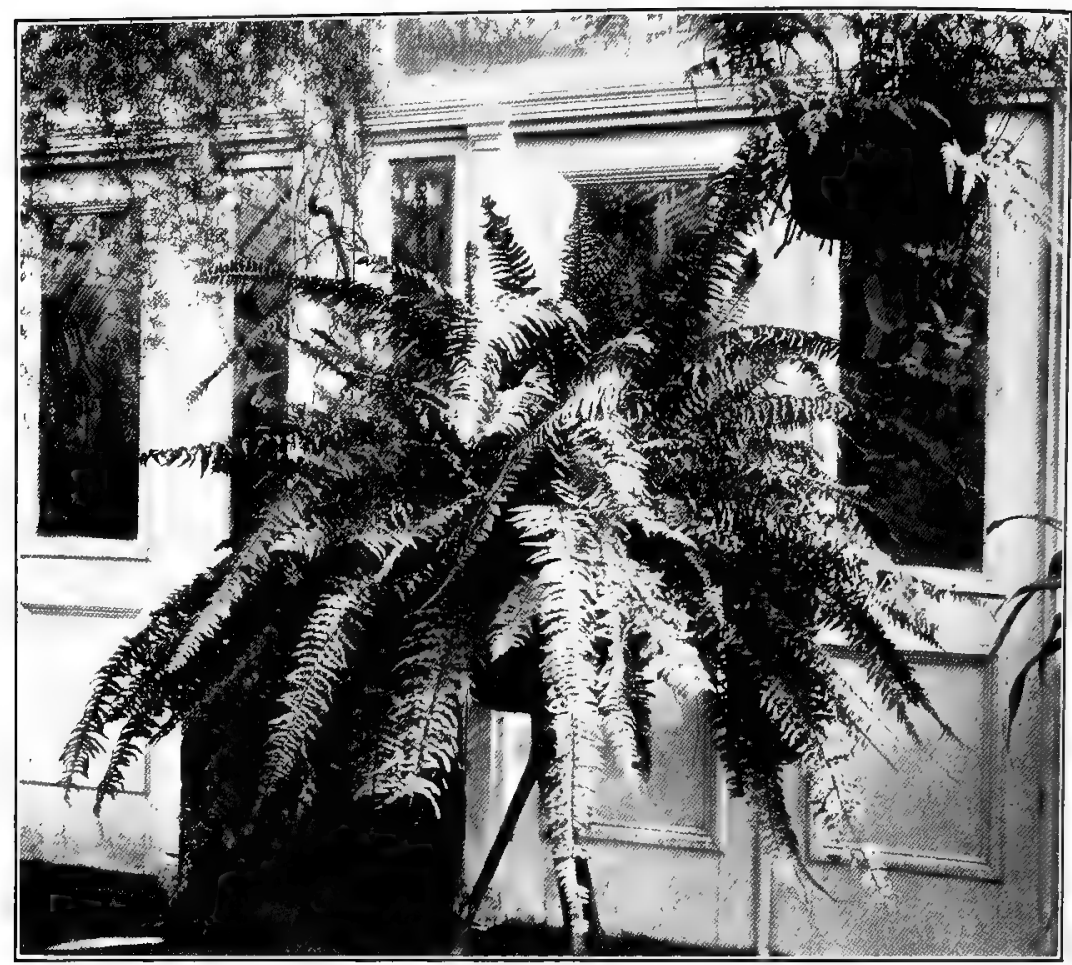

Fig. 157.-A Boston FerN. The "Boston" which replaced the Sword Fern (Nephrolepis exaltata) over twenty years ago has held first place ever since. New sports come and go, but the Boston stays and hundreds of thousands are grown in all sections of the country. Yet there are times each year when certain sizes are hard to get

as those who can devote whole houses to them. He will make more money purchasing what he needs and pushing the selling end.

Bostons once infected with scale or white fly even though cured of their troubles, plants subjected to a house too dry, too shady or not warm enough, or those in pots with poor drainage, soon take on a sickly look. This holds good with all varieties, not only the Bostons, but the many beautiful sports, such as Nephrolepis elegantissima, N. Smithii, N. Harrisii, N. Roosevelt, N. Teddy Jr., N. Whitmanii, N. Verona, N. Wanamaker, N. Macawii, N. Scottii (or the crested form of Teddy Jr.) and N. Victoria.

\section{Table Ferns}

Under table ferns the florist classes such varieties as are mostly used in the filling of fern dishes. As with Asparagus plumosus and $A$. nanus, so with these table ferns-every retail grower should always carry a good stock of them from early Fall until late Spring. 
As soon as the first good frost has finished the flowers in the garden, the first empty dishes to be filled with small ferns - start to come in, and they will keep on coming all Winter long until away after Easter. For a fern dish always makes an attractive decoration for the center of the dining room table. While some of our good patrons will make such a dish last all Winter, these are the exception; usually from six to eight weeks finishes the best of them, and that means an order to refill with new plants.

These ferns, to be most useful, should by October be in 2- or 21/2-in. pots. As such they are also most useful during the Christmas rush for the filling of small baskets in connection with Roman Hyacinths, Primroses and other flowering stock. If kept shifted, practically all the varieties we use will grow into fine large specimens in 5- and 6-in. pots thy the following Fall. Cyrtomium Rochfordianum, known as the Holly Fern, is a good example of this sort of stock.

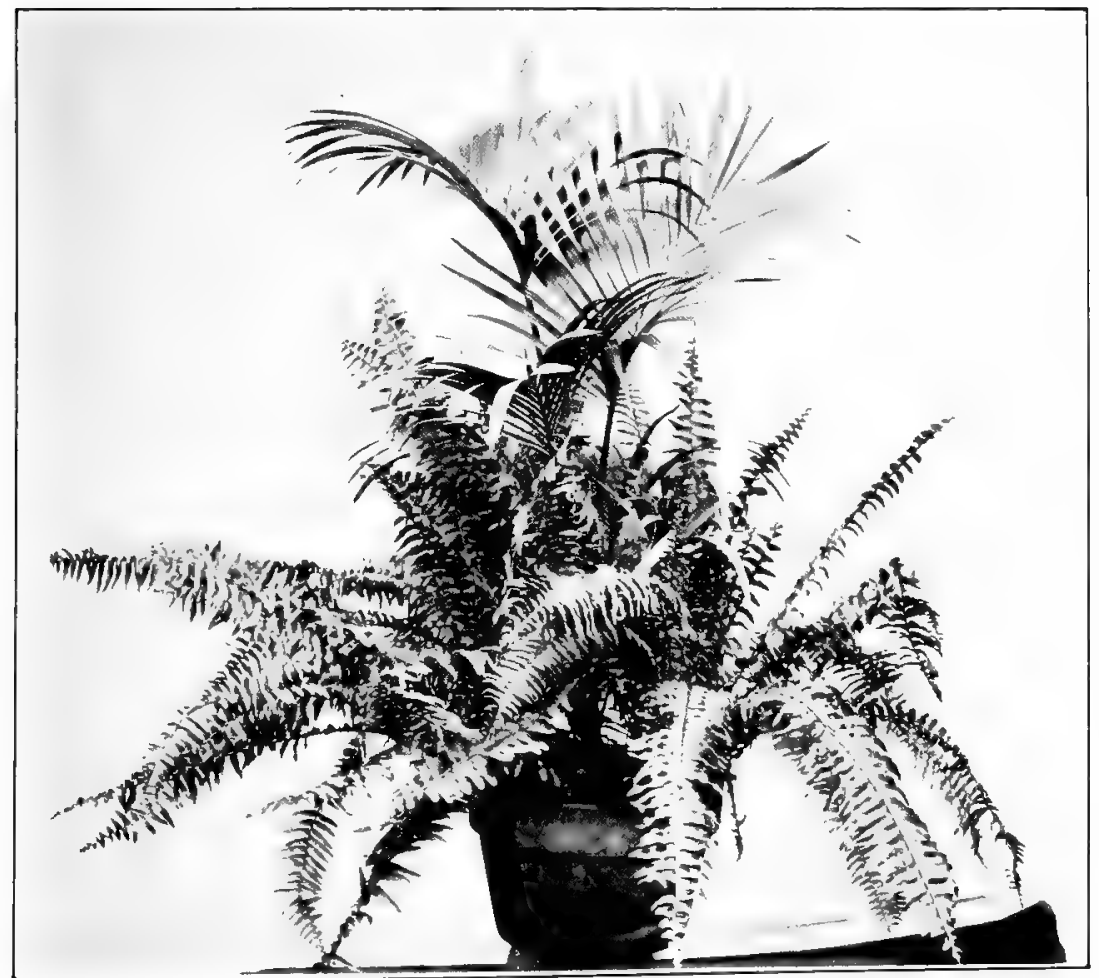

Fig. 158.-A Palm and Fern Arrangement. Around Christmas especially, made-up plant arrangements are much in demand. A 5-in. Kentia or Areca surrounded by Boston Ferns may be preferred by many to a tender Begonia or shortlived Poinsettia pan 


\section{Gultural Notes on Table Ferns}

If you want to grow these ferns from seed or spores, treat them the same as Adiantum cuneatum. But why care for the seed flats or pans and the little seedlings for about six months when you can buy from the fern specialist heavy transplanted stock ready for 2 or $2 \frac{1}{2}$-in. pots for something like $\$ 10$ per 1000 ? If you order such stock to arrive about the first part of July and, after potting it, place the plants on a shaded bench, they all will grow into fine plants by the time you are ready to fill the first dish. During Summere there isn't a florist who cannot provide facilities to grow these ferns. If your houses cannot be kept at $60 \mathrm{deg}$., instead of making later plantings of stock to follow the first batch, you may find it cheaper to buy ready grown plants such as you will want after Christmas.

As to varieties suitable for fern dishes, if you leave the choice to the firm you buy from, you will usually get from six to ten sorts best suited for the purpose. Of course, the selection must take into account the nature of your trade. While it is desirable to have

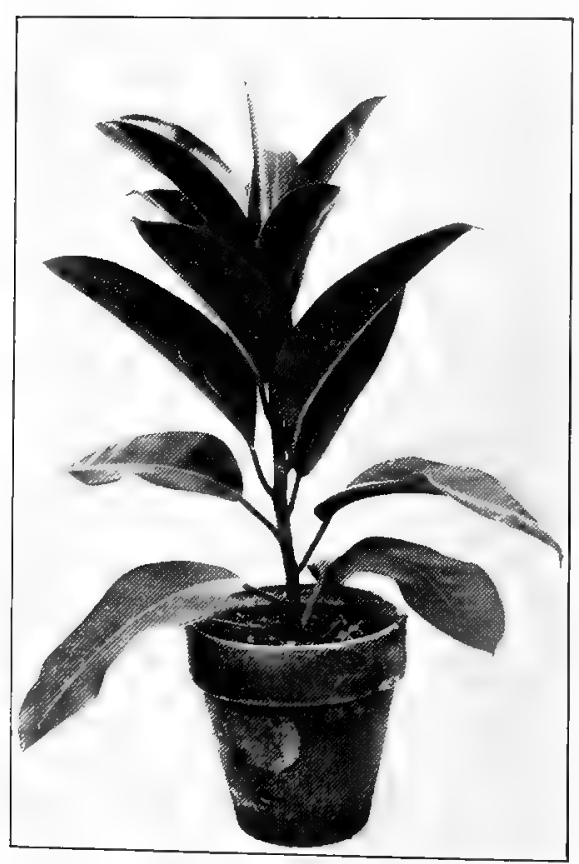

Fig. 159.-Ficus elastica. The Rubber Plant is and long has been a universal favorite wherever decorative foliage plants are used. 'There are few florists' establishments where we don't find it--even though sometimes it may be much neglected as varied an assortment as possible, you should avoid varieties that are too delicate to give satisfaction under average house conditions.

\section{Hardy Ferns \\ (See also page 206)}

During Spring there is always call for hardy ferns for outdoor planting in locations that may be a little too shady for flowers. Or they may be wanted for the rockery or some shady spot near the water pool. Almost any of these ferns will thrive in the shade; in fact, they require shade in order to do well. Among the better known ones are the Aspleniums or Spleenworts; Aspidium acrostichoides, the Christmas Fern; Adiantum pedatum, the Maidenhair Fern; Onoclea Struthiopteris, the Ostrich Fern; and Aspidium Goldieanum, Goldie's Wood Fern. 
You can purchase your requirements in early Spring from the specialist and what you have left over plant out on your own grounds. They will be good for another year.

\section{FEVERFEW \\ See Matricaria}

\section{FICUS ELASTIGA (RUBBER PLANT)}

The Rubber Plant has always been considered one of the best of the decorative house plants, mainly on account of its excellent keeping qualities. Some of your customers may keep them for years in the bay window until they finally outgrow their quarters and you are asked whether you would not like to buy them back.

The retail grower doesn't sell as many as in former years, but during the past few years, with the shortage of palms, they have again come to the front. Plants 2 to $3 \mathrm{ft}$. in height in 5- and 6-in. pots, with stem or stems covered with large, shiny, dark green leaves, can often be sold when a palm is too expensive. We also have noticed them of late years in among the foliage plants in city window boxes where they stand sun, heat and dust about as well as English Ivy.

The time to root cuttings of this variety is during the Winter months. Do it where you can have bottom heat of 80 deg. with a temporary frame over the bench to create a close atmosphere. Make cuttings with one leaf, cut the stem below the joint and pot up into $21 / 2$-in. pots filled with very sandy soil. Place a stake 10 in. long in each pot, loosely roll the leaf around the stake and tie it with raffia. After that it is a matter of keeping the pots moist at all times. A good way is to fill in around them up to the rim with sand and moss, keep a steady bottom heat, and spray the leaves each day with warm water, placing a sash or piece of glass over the frame and leaving just a crack for air. Another way is to root the tops with

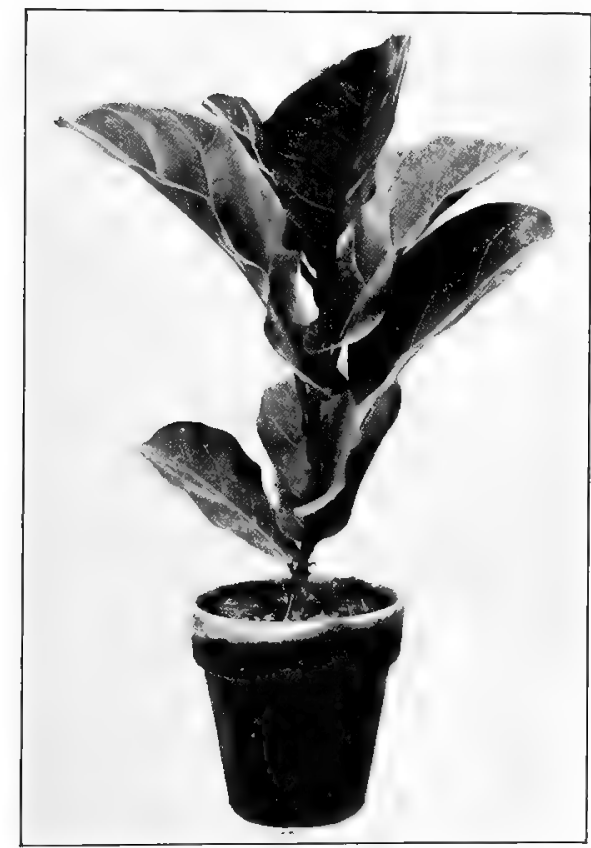

Fig. 160.-Ficus pandurata. 'This species, while a grand decorative plant for the home and differing but slightly from $F$. elastica in cultural requirements, finds it harder to win recognition by the smaller florist 
three or four leaves, tying these up also. But don't attempt to root leaf cuttings from hardwood.

Still another way, often advisable on large plants with a number of branches, is to root 2-ft.-long tips right on the plant. Make a cut just below a joint, half way through the stem and then upward for about 2 in. Where you stop with the knife, place a toothpick crosswise to keep the cut open, then fill in and around the cut with Sphagnum moss so as to form a ball the size of your fist when tied with thin wire. In a temperature of $70 \mathrm{deg}$., if you keep the moss wet at all times, you will soon notice roots pushing their way through. Wait a few more days, then remove the top, carefully unwind or cut off the wire, and pot the top up. Keep it shaded in a warm house and you will soon see the leaves straightening out and red tops appearing-always a sign of new growth.

Ficus repens is a fine climber under glass on walls, even those of wood, but it is not of much use to the florist.

Ficus pandurata is a beautiful foliage plant with large leaves, used extensively by the florist. It is a good plant to carry in the show house, but its propagation and growing on are best left to the specialist.

\title{
FIR, GOLORADO WHITE \\ See Abies \\ FIREGRAGKER PLANT See Cuphea
}

\author{
FORGET-ME-NOT \\ See Myosotis
}

\section{FORSYTHIA (GOLDEN BELL)}

With the lawns full of Dandelions in bloom, you may have some of your customers object to Forsythias which, in early Spring, have their stems loaded with golden-yellow, bell-shaped flowers before their leaves appear. Usually, however, these fine shrubs are wanted in every collection. We haven't many yellow-flowering sorts, and surely none as effective as the Forsythia.

The one we usually plant and the leader as far as flowering is concerned is $F$. viridissima, of upright habit; but for gracefulness and places where you can give the plants all the room they want $F$. suspensa is the more beautiful. It is a small plant and not as free flowering, perhaps, as the other; but with its drooping habit and fine leaves it makes an ideal foliage shrub and is especially desirable when the first light frost turns the long pointed leaves a beautiful brown. 


\section{FOXGLOVE \\ See Digitalis}

\section{FREESIAS}

THERE is hardly any other flower that the florist, particularly the retail grower, handles during the Winter and early Spring months as useful as the Freesia. Whether you have to fill an order for a bride's shower bouquet, a corsage, a funeral design, a spray, a basket for the table or a box to go to the sick room, Freesias are most appropriate; nor can you mention any flower that they won't go with. They can be had in flower from Christmas to Easter, and among the crops it pays even the small grower to handle, they hold first place.

Your patrons may object to Paperwhite Narcissi, but I have to find one yet who didn't like Freesias. Their beautiful, sweetscented flowers will last for days in water, especially if cut when only partly open.

Most retail growers who force Paperwhites and Roman Hyacinths are usually pretty well through with them by Christmas and there is a shortage of bulb stock from that time until perhaps the end of January. It is during this period that Freesias pay best. Their culture is as simple as can be, nor do they want a house over 50 deg. at any time. This fact alone should cause them to be far more appreciated than they are at present. While there are men who have made their culture a specialty for many years and grow them on a large scale, the average florist, who caters to a retail trade and who could use them to best advantage for practically five months in the year, usually plants just a few bulbs, say about September or October, and lets it go at that.

With Freesias, as with so many other of the florist's flowers, great improvements have been made. While we had practically only one sort in all the years we depended on the other side for our supply of bulbs, as soon as California took up Freesia growing we gradually broke away from the old yellow-throated sort. Fischer and others have since given us some wonderful hybrids, which no doubt, more than anything else, will help to make the florist recognize and appreciate the flowers to the extent they deserve.

\section{For December and Early January Flowering}

Experience has taught us that for the extra early flowering of Freesias nothing but the largest bulbs should be used. No matter how early you plant small bulbs nor how you treat them, they are apt to run into leaves, and while a few may bloom, nine-tenths won't. However, these same bulbs used for late forcing will most likely all flower. 


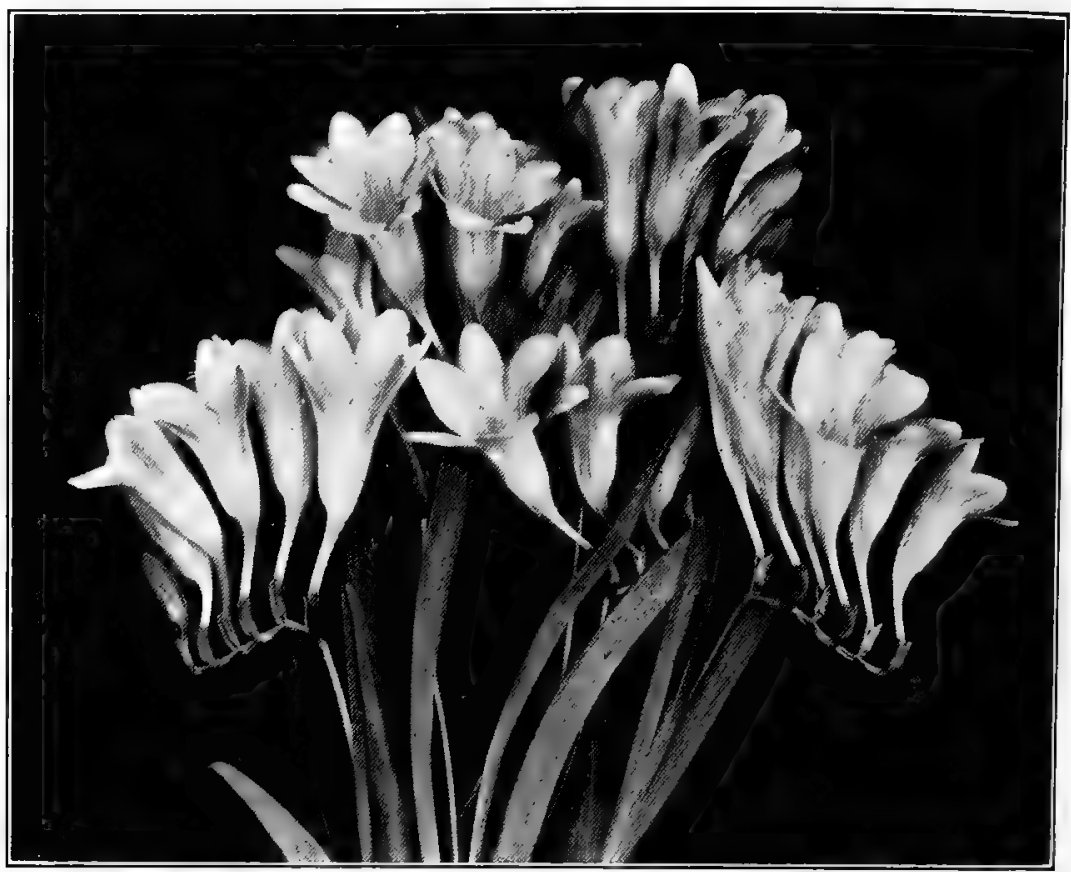

Fig. 161--Freesias. American-grown Freesias and also improved nlew hybrids of American origin are now proving a blessing to thousands of florists

By the average retail grower Freesias are usually considered one of the many crops to follow Chrysanthemums, and he plants themsay five three-fourths size bulbs in a 4-in. pot-by the middle or end of August. The plants will be about 4 in. in height by the time the early Chrysanthemums are through, and if planted by the end of October they will start to flower by Christmas.

Use good soil and plant deep enough to just cover the bulbs, allowing as much space between them as possible. Put the pots in a coldframe, over which place shade frames, not so much to keep them dark as to prevent the sun from heating up the soil in the pots and drying the bulbs out. Keep evenly moist but not wet. By the middle of September their grass-like foliage will appear and then they are better off without shade. If you don't want to bring them under glass by early October, watch out for frost, and if necessary, cover the frames with sashes. Plant in the benches in rows $1 \mathrm{ft}$. apart; by making a trench you can place the plants close together in the row and $1 \mathrm{in}$. or so lower than they were in the pots. Later on support the plants the same as you would Carnations, with wire lengthwise and twine crosswise. Freesias, when once in a growing state, need plenty of water. To allow them to dry out means yellow 
or brown tips and perhaps blind buds later on. Provide good drainage, as otherwise they are likely to suffer from over-watering.

For those who only wish to grow a few early ones, bulb pans may be used instead of a bench. Six-inch pans are the handiest, allowing about 2 in. of space between the bulbs. The bulbs can also be planted at once in the bench, but for the early ones this really means a waste of bench space, as they will do just as well in the pots and you may as well harvest your crops of early 'Mums first.

\section{The Midseason Freesia Cirops}

Bulbs scheduled to flower from the end of January to early April may be planted from October on until the end of November, and can also be started into growth in pots and later planted out; or you can use bulb pans or plant in 3-in. flats in which they are to flower. For this purpose five-eighths to three-fourths size bulbs are perhaps the best. Select the larger-sized bulbs for January and February, and the smaller ones for March and April flowering.

\section{For Easter and Late Flowering}

With Easter coming early in April, bulbs of Freesias should be planted about the middle of December. In using $1 / 2$-in. bulbs a good way is to plant them in 6-in. pans, allowing not more than 1 in. of space between them and placing the pans underneath a Violet or coldhouse bench. By the middle of February bring into a Carnation house, place on a sunny bench and they will start to flower by the end of March or early April. This will give you short, stocky plants, hardly in need of supports, that every florist around Easter can dispose of to good advantage. Another way, if you happen to have a lot of bulbs on hand by the middle of December, is to plant them in a solid bed in rows where even bulbs a little below the $1 / 2$-in. size will flower if you let them come along slowly.

\section{Saving Bulbs}

There are always, especially from the smaller-sized bulbs, plants which fail to flower but which, if properly handled, will bloom the following year, and there are growers who save their bulbs from year to year, or at least a part of them, and purchase the rest. In the case of plants which have been grown in pots or pans, after they are through flowering, it is just a matter of giving them less and less water and so gradually ripening them. Later on take the bulbs out of the soil, select the large ones and throw away the small ones. With plants which were grown in a bench, however, a little more care has to be taken. Lift the plants, soil and all, and carefully place below the bench. The less you disturb the roots and the more soil you leave around the bulbs the better, for you want the tops 


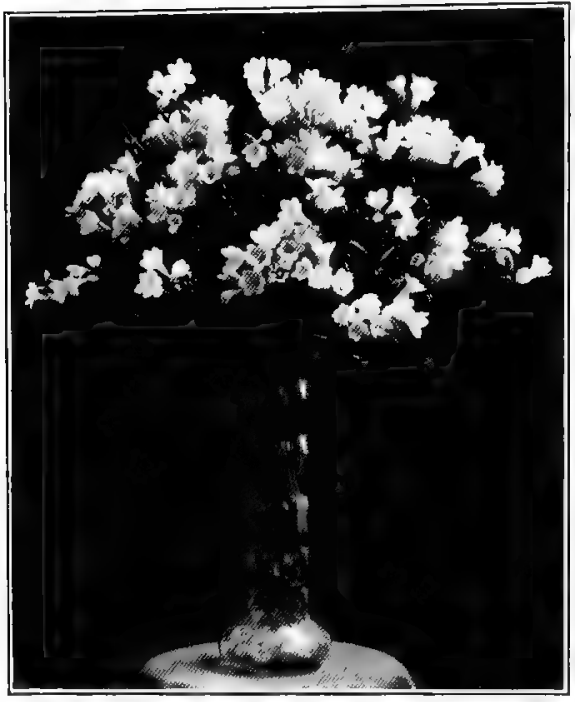

Fig. 162.-Fifty Well-grown Freesias on long, strong stems, the result of giving the plants plenty of space in a house a little below 50 deg. The bulbs were planted Aug. 1 and the flowers cut Feb. 13. Mignonette was grown between the rows for Christmas to dry off slowly. This may necessitate a little watering once in awhile, just to keep the soil moist. After two months or so, remove the bulbs and store them away in a cool, dry place until they are again wanted for planting. Never dig up plants in Midwinter and shake them out the same as you would Gladioli or Onions, but dry the plants off gradually with the soil around them.

\section{FUCHSIA}

You can't ask for a more showy plant than a Fuchsia when loaded down with its bell-shaped flowers and numberless buds. There are so many beautiful varieties to select from and yet, coming into flower mostly during early Spring and Summer, they are not such fine money makers for the florist, after all.

I am sure Fuchsias are among the plants which are grown by quite a few florists not for what they bring in in the form of dollars, but just because it doesn't seem right not to have a few of them around coming into flower in Spring. Only once in awhile do we sell a plant separately, but rather we make use of them in filling window boxes for shady locations or use them to plant a bed or border not quite sunny enough for Geraniums. Those who can get plants in full bloom by Easter are bound to find a sale for them, especially when from three to five plants are used in a made-up pan.

The trailing Fuchsias are excellent for hanging baskets; in fact, I don't know of anything showier; but it does require careful attention to keep the plants in good shape.

\section{Gultural Notes}

You can propagate Fuchsias almost any time, but we usually take cuttings from stock plants carried in pots, about January. They root freely with a little bottom heat and for best results the young plants should be kept moving right along. Keep them shifted, use good soil and provide drainage; they enjoy a rather moist atmosphere and most varieties don't need pinching, unless you want to secure more cuttings. 
You may also propagate in April, grow the plants all Summer in pots, let them dry off by October, store them away under a bench in a dormant state until the end of December and then start them into growth again. Fuchsias can be grown into large plants. If you ever go to San Francisco, be sure to visit the little beauty spot back of the superintendent's office at Golden Gate Park where there are planted out some Fuchsias 10 to $12 \mathrm{ft}$. in height. Once in awhile on private places we see $F$. speciosa planted out in a solid bed and grown into a standard well worth a long trip to see when in full bloom.

\section{Frame Gulture}

No plant more than the Fuchsia enjoys a hotbed. Here it can be grown to perfection. Provide one with plenty of headroom, and when you give the plants their final shift into $4 \mathrm{~s}$ or $5 \mathrm{~s}$ have the bed ready. Plunge the pots in it up to their rims and maintain a close atmosphere. Allow enough room between them for development, and, with the bottom heat and the moisture, you will obtain some wonderful plants better than anything you can ever hope to grow in a house.

\section{VARIETIES OF Fuchsias}

Trailing Queen is what you want for your hanging baskets, and for this purpose grow the plants on in pots up to the middle of April and then plant from five to seven in a 12-in. wire basket. They don't need to be hung up until the branches begin to droop over the sides.

Black Prince is a single variety, used by the florist more extensively, perhaps, than any other on account of its fine, upright habit, good foliage, and early flowering. Its color is carmine. F. speciosa has white sepals and an orange corolla, making it one of the most attractive of the single varieties and a particularly fine specimen plant. Among the double ones, the best known are Storm King, with scarlet sepals and white corolla; President Carnot, crimson and mauve; and Phenomenal, which, as the name indicates, is of enormous size. There are many other fine sorts, both single and double. Rose of Castile and Little Beauty are two of them.

\section{FUNKIA (PLANTAIN LILY)}

This is an old garden favorite and it is well to have a small stock on hand to take divisions from in case a customer wants a few plants; but it is the variegated form which interests the florist most. Field grown plants may be lifted, carried in a coldframe and potted up about February. They will in a few weeks make most attractive pot plants, and be just the thing for the show house. If you have enough of them, in say, 5-in. pots, you can create a 
fine effect by bordering your bench of Easter stock with them. While the foliage of the variegated Funkias is beautiful even outdoors when used as a border, it is more so on the plants you force in pots under glass where they are in an even temperature and not exposed to wind and weather. If you plant out a batch of plants you will be able in a couple of years to divide the plants the same as you would Iris or Peonies and have all the stock you want.

\section{GAILLARDIA GRANDIFLORA}

The perennial Gaillardias are among the best dozen for cut flowers. They grow about $2 \mathrm{ft}$. in height, have, when at their best, 15-in. stems tipped with large, golden-yellow flowers with brown centers, and, when cut, are excellent keepers. While they do their best in a rich soil, they will, when well taken care of, give you good results even in poor soil and during a hot, dry Summer when almost everything else is showing its bad effects. Grow on the same as Coreopsis, but in the greenhouse seed may be sown in early February and plants can be had in flower from July on up to November. For a beautiful basket arrangement, combine Delphinium, Shasta Daisies and Gaillardias.

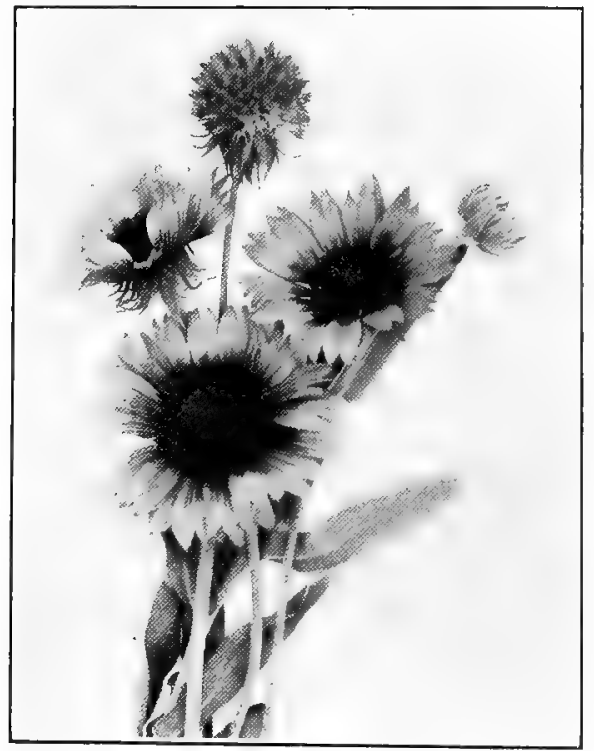

Fig. 163.-Gaillardia grandiflora, a perennial that will thrive in almost any soil, stand the hottest, driest Summer and keep right on blooming. It provides splendid cut flowers and is a good plant for the hardy border

Few perennials are more hardy or need less protection, but you will find it pays to sow a little seed each year; don't depend on the old plants after the second season.

There is also a good strain of annual Gaillardias, fine for cutting. Treat the same as Galliopsis, by sowing outdoors in rows, making several sowings for early and late flowers.

\section{GARDENIA JASMINOIDES}

This beautiful, sweet-scented, waxy flower belongs to the Southland, whence we receive many - sometimes, in fact, too many at once. However, the specialist in the colder sections of the country who grows them in benches and is able to bring his flowers in during the 


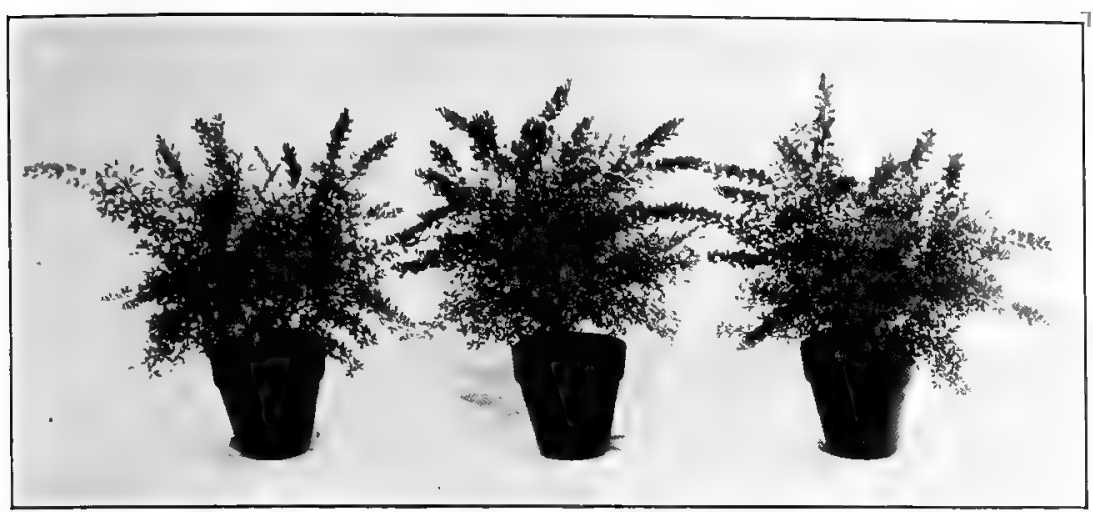

Fig. 164.-Genistas in 41/2-nN. Pots. Close shearing does not always improve Genistas, as many patrons prefer plants with a graceful habit like that shown here. (See Cytisus, page 345.)

Midwinter months, finds ready sale for them, for they are much in demand for use in corsage bouquets.

For the retail grower, Gardenias are hardly to be considered of great importance. To grow them successfully, you must give them a house by themselves. Young stock propagated during Winter is planted in benches with strong bottom heat, and kept pushed along with a night temperature of $60 \mathrm{deg}$. Whenever you see yellow leaves, they are always due to poor root action, mostly caused by poor drainage or by keeping the plants too cool.

If the smaller grower wants to have just a few flowers and is willing to wait for them to flower in February or a little later, he can carry a few plants in pots.

\section{GAS PLANT \\ See Dictamnus}

\section{GENISTA RAGEMOSA}

See Cytisus and Fig. 164, above.

\section{GERANIUMS}

The reason Geraniums have always been considered the most popular of all bedding plants is because people are successful with them almost everywhere. North, South, East or West, they are in flower from Spring until Fall, and keep on all Winter in sections where they don't get killed by frost. They can stand the driest Summer if they have just a little cultivation, and they will do well in light or heavy soil. Why shouldn't they be popular?

Geraniums are the backbone of your bedding stock. You may have a customer change from Geraniums to something elsebut usually he or she comes back to Geraniums again, especially if 
the best of attention is not given to the beds in Summer. At present the pink shades, particularly Mrs. E. G. Hill and Poitevine, have the call, but you want others-among them S. A. Nutt, considered by "Uncle John"' Thorpe the best red more than forty years ago. This variety is still at the head. You will also want a good white. Suppose you grow 5000 plants; I would suggest 3000 pink of two or three sorts, 1000 red of two sorts, 500 white of one sort, and 500 mixed to please those who come in to purchase a dozen plants of as many different varieties. Of course the man near the cemetery wouldn't be satisfied with such an assortment; no doubt he would include many more white ones.

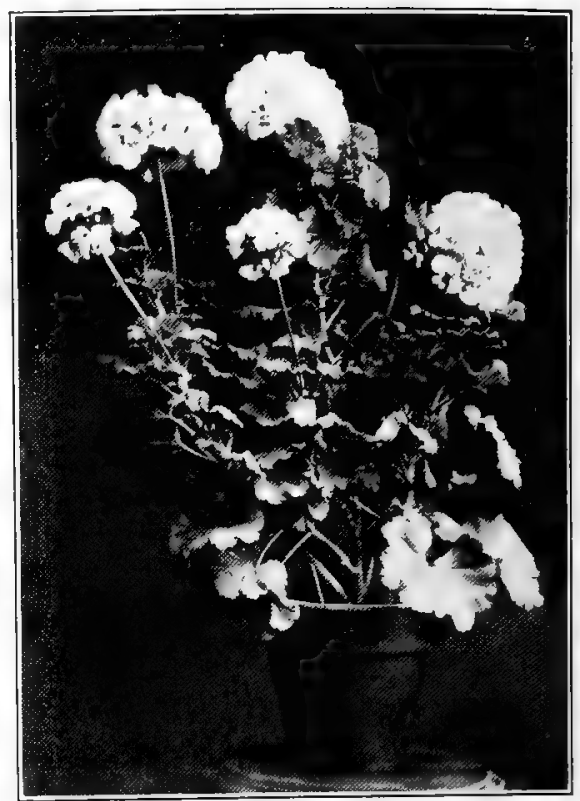

Fig. 165.-The Geranium Mas. Geo. E. Buxton. A bushy 5-in. Geranium during the early Spring, especially around Easter, when carrying half a dozen large trusses of flowers, will always find admirers. The color is of nearly as great importance as compact habit, good foliage and plenty of buds and flowers

To grow Geraniums successfully you want a house of $50 \mathrm{deg}$. over Winter, a rather stiff loam, good drainage and plenty of sun. You can take cuttings in September from plants grown outdoors, but there is then always more or less loss, especially if we have a wet season which causes soft growth. A better way is to grow on a few plants planted out on a bench and keep on taking cuttings from them all Winter. Such cuttings if removed with three or four eyes can be potted up at once into $2 \mathrm{~s}$ or $21 / 2 \mathrm{~s}$ in a sandy soil and will soon root; or, if desired, they can be placed in the propagating bench. Here, especially during Winter, a little bottom heat will help matters. Hardly ever do such cuttings require shade.

\section{Growing Good Four-Inch Stock}

To grow good 4-in. Geraniums, you should root the cuttings from September on up to January and carry them in $21 / 2 \mathrm{~s}$. The earlier propagated ones should have a shift into $31 / 2 \mathrm{~s}$ by the first of February and if in good growing condition, may have their tops removed to be used as new cuttings. But don't do this unless you have three or four eyes left on the plant for new breaks. Those 
propagated in Midwinter can go into $4 \mathrm{~s}$ from their $21 / 2$-in. pots by the time you give all of your plants their final shift.

April first, or thereabouts, is usually the time to do this final shifting, and it is always well to mix an 8-in. potful of horn shavings with every wheelbarrowful of soil. If you haven't got the shavings, use a 7- or 8-in. potful of bonemeal. A heavy soil and firm potting will give you stocky plants and large flower trusses. Place your plants, pot on pot, and as they grow space them to allow more room between them.

If short on bench space, a mild hotbed can be used by the middle of April, or a coldframe by the first of May. You can grow Geraniums for Winter flowering, but it doesn't pay. Your customers who have had Geraniums all through the Summer, get tired of them and there are so many other flowering plants to select from.

Plants which have been used for stock, can be planted out the following Summer and will be fine for flowering or to take cuttings from in Fall. Another way is to root cuttings from outdoor plants in flats filled with a sandy soil about September, and keep them in frames until the first Ghrysanthemums are out of the way, after which they can be potted up into $3 \mathrm{~s}$. The most satisfactory way of all is to bench in Summer the plants you wish to propagate from.

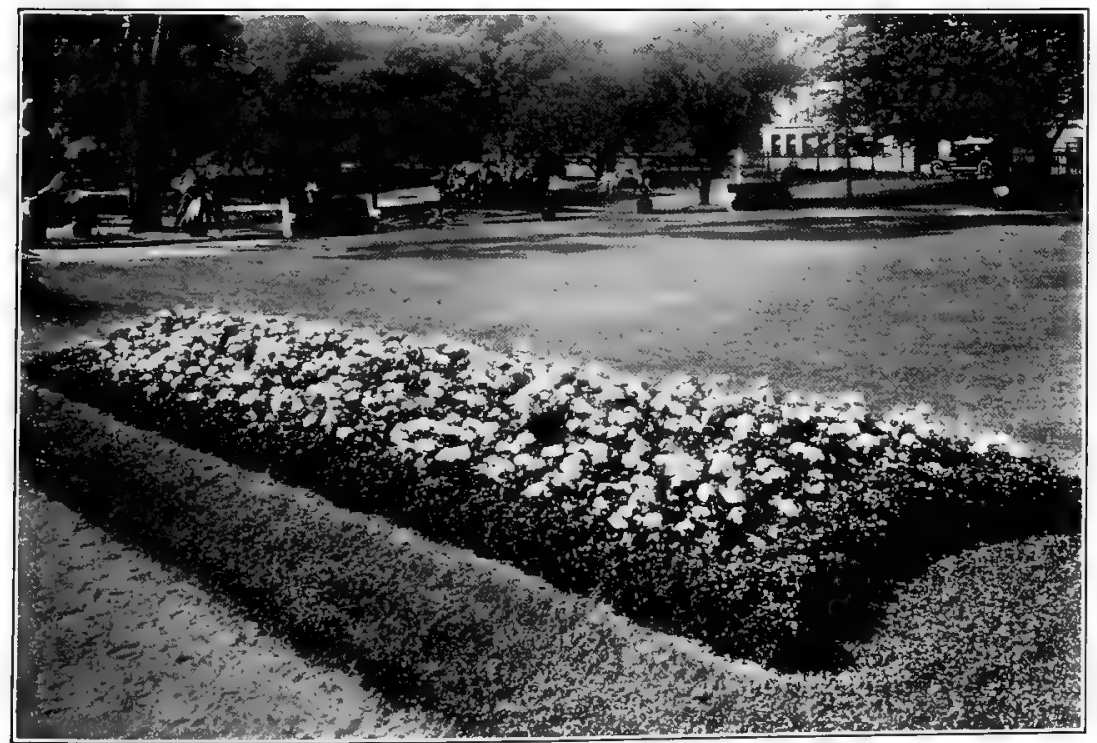

Fig. 166.-Geranium Mrs. Lawrence. Because of its freedom of bloom, ideal habit and charming soft salmon-pink color, Mrs. Lawrence makes one of the finest of bedding sorts. You can sell other Geraniums besides Nutt, Poitevine and Hill if you give your patrons a chance to see them displayed as shown here 


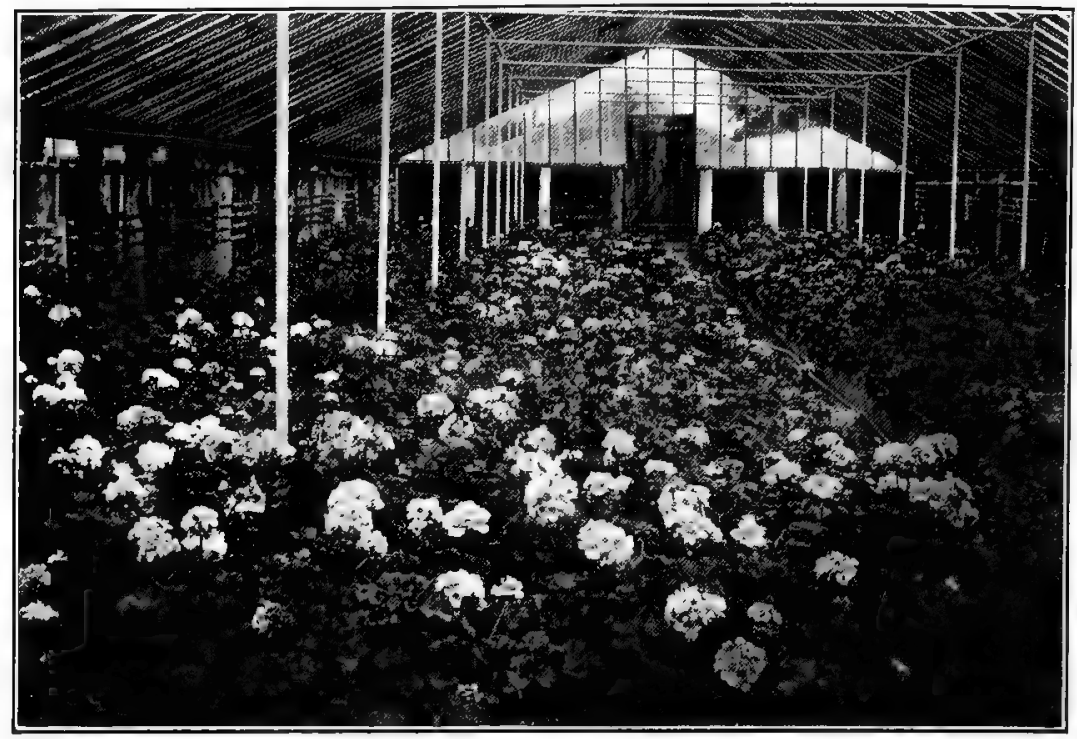

Fig. 167.-A House of Geraniums. One good Geranium blooming the week before Memorial Day is worth two in bloom the week after. Early propagation, a cool house, rather heavy soil, a shift at the right time, plenty of room and a sunny bench all help to secure large plants and early flowers

\section{Ivy-Leaved Geraniume}

Years ago a window or porch box was never complete without a few Ivy-leaved Geraniums. They were planted along the edge of the box and usually kept on flowering up to August. When they are in bloom with their graceful, hanging branches they are indeed showy, but of late years they have not been used much. I am sure, however, that the day for them will come again, as it has with other old favorites.

They are as easily grown as the bedding Geraniums, but for extra heavy stock in $4 \mathrm{~s}$ by the middle of May, you should root cuttings not later than February and grow them on in a cool house.

Another way to grow them is to propagate in August and keep on shifting the plants until they are in $6 \mathrm{~s}$ by February. Train the plants up on fan-shaped wire frames. Around Easter they most likely will be solid masses of bloom, and you will have no trouble in selling them. During the Winter they require a cool house and the same treatment as the show Pelargoniums. There are a number of named varieties from snow white to dark pink, both single and double, but it matters little which one or ones you grow. They are all beautiful: 


\section{SweEt-scented Geraniums}

As with the Lemon Verbenas, we always have to have a good stock of these Geraniums, especially the rose-scented ones. Not only is this variety on account of its fragrant and fern-like leaves, desirable for the flower border during Summer, but many retail growers are using it for greens during the Winter months. Planted out in a Carnation house on a sunny bench, with about $1 \mathrm{ft}$. of space allowed between the plants each way, the plants will furnish fine sprays of green up to June. Where is there a florist who cannot make good use of-it? It often takes the place of more expensive Asparagus, and many people will much prefer it.

The quickest results will be had if you have 4-in. pot plants (maybe left over from your Spring stock) and bench them at the same time the Carnations are housed. Keep the young growth pinched back a- little up to the end of September; after that keep on cutting it, whenever it is about 12 in. or so long. Always leave a couple of eyes to break again. If you give this a trial you will soon have your customers ask for the green, and the part of the bench the plants are on will pay you as much as any other section of the house, if not more.

Other varieties of sweet-scented Geraniums are the Oak-leaved, Lady Marie and capitatum (quercifolium), but the Rose is the most popular and the best for indoor planting.

\section{GERMAN IVY}

See Senecio

\section{GEUM}

There is quite a number of Geums, some of which can be used in the rockery on account of their dwarf habit, but are of no great value to the florist. Among the others, which make showy border plants, is Geum flore pleno, the double scarlet; also an improved form of this, Mrs. Bradshaw, which not only has good color, but produces flowers throughout almost the whole Summer and provides a most effective border plant. Generally speaking, while you have no trouble with the white, pink, blue or yellow shades in border plants, it is hard to sell anything red; that is why so many object to red Geraniums or Salvia splendens. Geums like a rather moist place and a light soil, and if you can give them partial shade, so much the better. Grow them on from seed or divisions of the roots. 


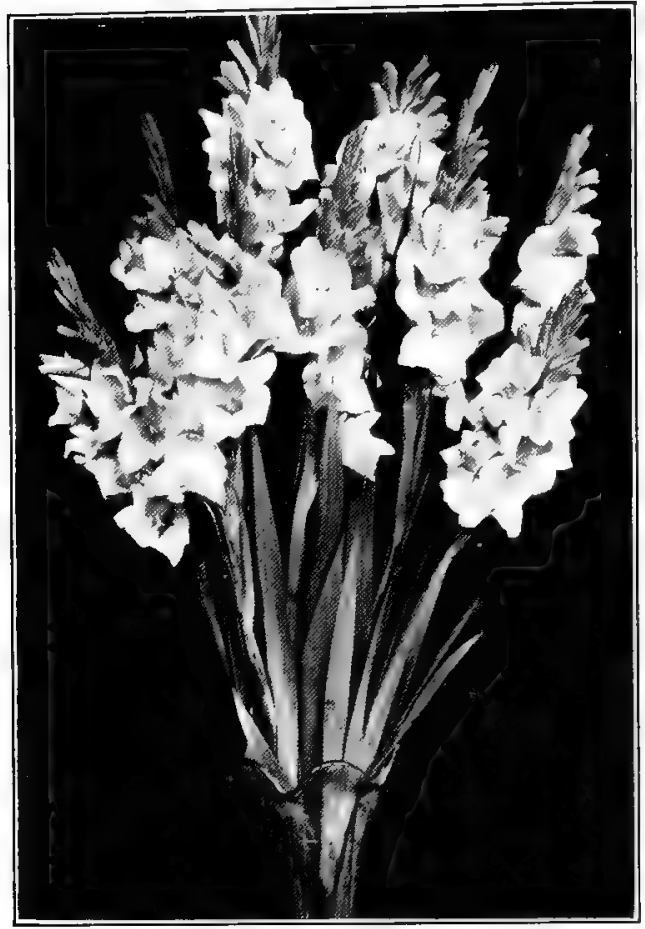

Fig. 168.-Gladiolus "Schwaben." One of the many good recent introductions. A yellow sort and one of the showiest for outdoors, it often carries from eight to ten perfect flowers open all at once

GIANT FALL DAISY

See Pyrethrum

\author{
GIANT REED \\ See Ornamental Grasses
}

\title{
GLADIOLUS
}

The Gladiolus is popular but of ten not profitable; in the following paragraphs is pointed out the reason why.

Wonderful progress has been made in the development of the Gladiolus, and in the enormous spikes, giant flowers and endless sorts of exquisite shades of today we hardly recognize the varieties of twenty-five and thirty years ago. Still better kinds are coming right along and a Gladiolus society composed of enthusiasts is helping to make this very popular flower still more so. Specialists have appeared in almost every section of this country who devote their entire time to the growing of bulbs, of which many millions are produced annually. And so, while in nearly every State the Gladiolus has become one of the most desirable Summer flowers in the public eye, the fact remains that every year, almost without exception, there is a Gladiolus glut on the market, during either the latter part of August or the beginning of September. It almost seems that the higher the price you pay for bulbs of the choicest sorts, the greater the loss if you happen to strike the market at this particular time.

From the present outlook there is absolutely no chance of a change in conditions; in fact, the more popular Gladioli become the more of a glut we will have to look forward to during the period when the flowers are in bloom in every bed, border, and backyard. Yet florists in general will keep on planting their bulbs, as they have always done during Spring, in the open ground. They may make several plantings so as to obtain early, midseason and late crops, but as they cannot control weather conditions their main 
crop will usually come in at the very time when the whole country is full of Gladioli. One might say that carloads of flowers are dumped on the market by men who grow the plants for the bulbs, and while such plants really shouldn't be used for cutting, they are, nevertheless. Such flowers may not be as good nor as longstemmed as others, yet they are being made use of for occasions where cheapness in price counts for more than quality of stock. It is beyond the florist to change these conditions, but it isn't beyond him to not only arrange matters so as to avoid competing during the time of a glut, but actually to make the growing of Gladioli a paying proposition.

\section{How to Make Gladioli Pay}

During the months of April, May, June and July the florist has the market in Gladioli practically to himself. If he takes advantage of this fact be needn't care whether hundreds of thousands of flowers go to waste on the market the next two months. Almost any greenhouse with three feet of headroom above the benches can be used for Gladioli. Their culture is very simple and, at the same time, the demand on the part of the public so brisk that one cannot help but wonder why the average retail grower does not pay more attention to it. There is no trouble in realizing from $\$ 2$ to $\$ 4$ per dozen for well-grown stock during April and May. No other flower we have to offer at that time compares with the Gladiolus in stateliness, beauty and attractiveness; there is nothing finer for decorative work, nothing more lasting. Besides, the blooms form a pleasant change from what your patrons have been getting

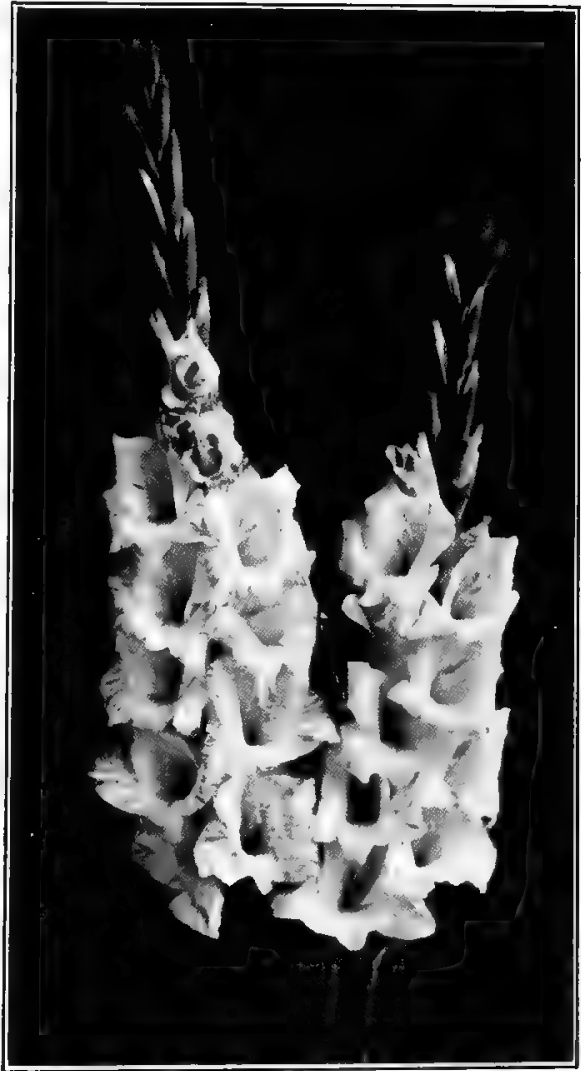

Fig. 169.-Gladiolus "June." It is the number of open, perfect flowers that counts. A variety in which the first flower wilts before the fourth opens is of little use, no matter how large and well-colored.

(Courtesy of the J. L. Childs Co.) 
in the way of flowers. A Gladiolus spike can be cut as the first flower opens and will, with just a little care, keep on opening for a week or more; or it can be left on the plant for a number of days after it is first ready to cut. By proper management the grower can even arrange so as to have a constant supply of flowers coming along from the beginning of April until the first flowers are being cut outdoors from bulbs planted in the open during April. While he has to have flowers all Summer he should plant only lightly for such as will come in during late August and September and try to follow up with a crop ready for cutting during October or until the snow flies. Gladioli are bound to turn out a money-making crop when handled in this manner, especially when only good varieties are made use of.

\section{Forcing Gladioli Under Glass}

Fór early forcing one should have early ripened bulbs, such as have been grown in rather sandy soil. Growers of bulbs intended for early forcing are-beginning to pay special attention to such stock. These plants have their buds pinched out as soon as they appear and when the foliage dies down the bulbs are lifted and properly cared for; such treatment makes better bulbs for forcing. The first planting should be made in early December and while there isn't a great deal of difference in the time of flowering between these and such as are planted during early January, even five or six days often means a whole lot in getting your flowers ready for market. For the man who wishes to force only a few hundred bulbs at a time, it hardly pays to take up valuable bench space for the first or second planting. It is every bit as well to pot up into $4 \mathrm{~s}$ and let them remain below a bench in the Carnation house until the plants are from four to six inches in height; but whether they have made that growth or not, examine the pots once in awhile and plant out before they become too potbound.

Plant out on a sunny bench in double rows allowing about four inches between the plants and twelve inches between the rows. Almost any soil will do, and if you happen to have a run-down Carnation bench or another where a crop has either failed or is through, the soil in the benches will not have to be changed. But don't make the mistake of planting Gladiolus bulbs in between your Carnations, where a plant has died out or an opening appears. Not only will the Carnations shade the Gladioli, but usually by the time the Carnations are ready to be thrown out, the Gladioli will be scattered all over the bench, not half filling it but making it impossible for you to use the space for anything else. 


\section{Timing the Flowering Period}

The retail grower who has use for a hundred flowers a week from the twentieth of April on up to August first should plant, in order to cut that quantity, approximately 300 bulbs for the first batch in late November. These will produce about seventy-five per cent of flowering plants and start to come into bloom the latter part of April and continue to the middle of May. The second 300 should be planted about December fifteenth. These will come into flower from April thirtieth up to May thirtieth. Bulbs planted January tenth will come into bloom about the early part of June, and so on. The later you plant, the shorter the time required to get them into flower. While the first batch may require from seventeen to twenty weeks, those planted under glass in February can be brought through in about fourteen weeks. It is always safe to plant thirty per cent more bulbs than you figure getting flowers. You may obtain a much higher yield, and frequently out of a lot of one hundred bulbs planted at the same time there will be quite a number coming into flower fully four weeks later than the rest. If you grow your first plants on in pots, as soon as they are cut the rows may be replanted with stock coming into flower about the early part of June (from bulbs potted up about the end of February). You can also make a planting of potted plants in. a mild hotbed by the middle of April and remove the sashes in early May when the plants begin to touch the glass. Another lot can be planted out of pots in a coldframe by the end of April, and still another lot out of pots into the open field.

The proper way is to mark down the dates as you plant the bulbs, preserve a correct record, and keep on changing the dates of planting and the number of bulbs made use of

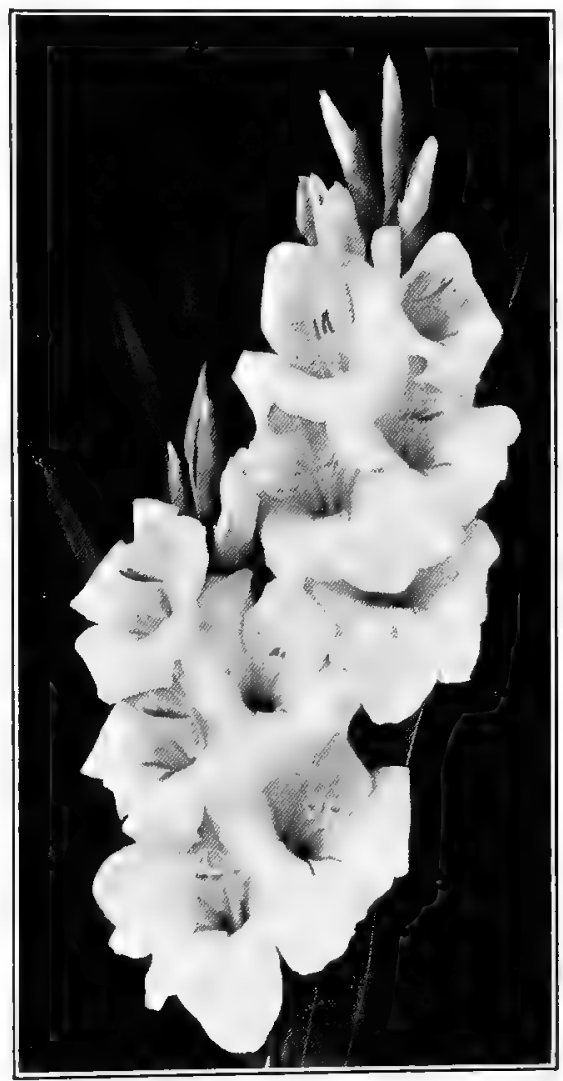

Fig. 170.-GLadiolus "Amertga." We have today grander varieties than this good old standby, but the florist still thinks well of it as a paying proposition for both outdoors and indoors 
at each planting to suit your own requirements. This much, how. ever, is certain: Gladioli can be made to bring good returns if grown under glass and the florist who doesn't do this is not taking advantage of what has been accomplished in their development.

\section{Flowering Gladioli in Pots}

Gladioli cannot only be started and grown on in pots to be planted out on benches later, but they can also be successfully flowered in pots. A $11 / 2^{-i n}$. bulb is too large for a 4 -in. pot. On the other hand, putting one into a 5 -in. pot means taking up a lot of space. A better way is to plant three bulbs in a 6-in. pot. This is better than starting them in 4 - or $31 / 2$-in. pots and repotting later as it avoids disturbing the roots. To the smaller grower in particular, pot culture will appeal as he usually is crowded for space and can place the plants in pots whenever there happens to

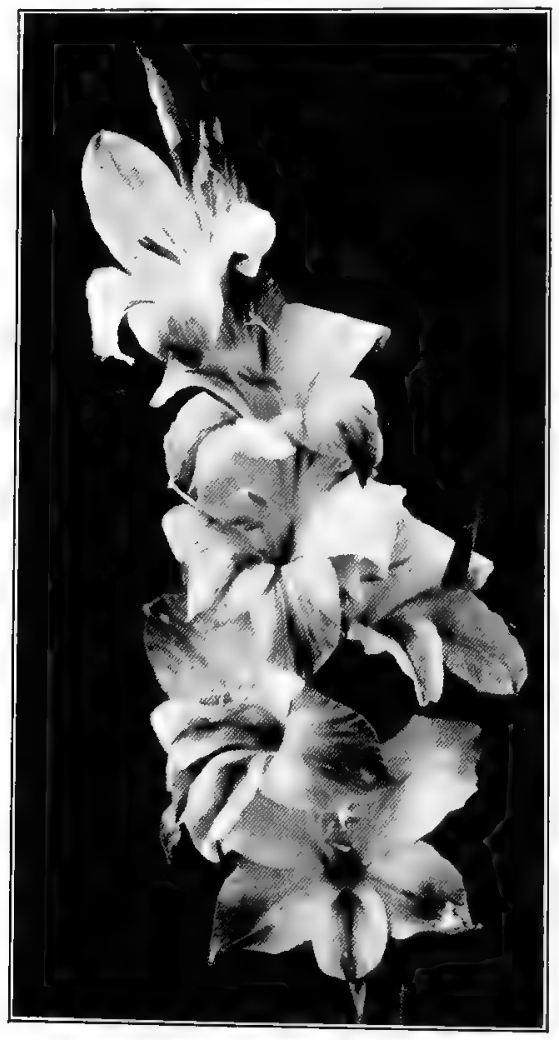

Fig. 171.-Gladiolus “Mrs. Francis KnvG." Coming into flower a little later than America, this is one of the best of the standard garden varieties be room. Or, if by early Spring he finds that a bench or part of one can be had, he can still plant the stock out even from the large pots, for it requires less care and labor to attend to them when planted out. If you prefer pot culture, get the bulbs down at least an inch or so below the rims of the pots so as to afford space for watering.

\section{Varieties and Cultural Notes}

To try and name six or twelve of the best florist varieties of Gladioli is, to my mind, impossible. There are far too many "best" ones to recommend just a few or to mention all of them. Of the sorts of today perhaps none is more extensively used for forcing than America, yet for extra-early April flowering I would prefer the Primulinus hybrids; while somewhat smaller in size they are among the easiest forcers. For_an earlier pink than 
America, but somewhat darker in color, Halley can be used, and Wilbrink is another extra-early, flesh-colored pink. Mrs. Francis King is still a great favorite for forcing, of light scarlet color. Chicago White is a good forcer, and so are Mrs. Frank Pendleton and Prince of Wales. For second early and later flowering, almost any of the newer sorts can be used; among them Schwaben is a fine yellow, variety. Myrtle is light rose, and l'Immaculee is a grand white.

In regard to cultural directions a house at $50 \mathrm{deg}$. is most suitable up to April. Benches are better for early stock and solid beds for the later plants. Many failures with bench culture result from allowing the soil to become too dry; this is likely to result in the plants coming blind in shallow benches. Feeding with manure in the shape of a mulch as soon as the first buds show is in order, and the plants should be staked long before they actually need it.

\section{GLOBE AMARANTH}

See Gomphrena

\section{GLOXINIA}

The only drawback to Gloxinias is that they don't flower during the Winter months. But even in Summer they are of value, if for no other purpose than to decorate your show house. They are fit companions for the tuberous-rooted Begonias and the fancy-leaved Caladiums, and while they are a little more particular as to how you treat them, when you can obtain tubers during early Spring it isn't hard to have them in good shape and full of their beautiful, richly colored flowers.

Start the tubers in 4-in. pots in a mixture of leafmold, sand and a little well-rotted cow manure with good bottom heat. Keep shaded and as the leaves appear be careful with the watering. You cannot do it with the hose so make use of the old-fashioned waythe watering can-and go over each plant carefully. Examine every one and don't apply water unless it is needed. On the other hand, they suffer every bit as much if they don't get water when ready for it, for they want a moist soil.

Keep the leaves dry; to get them moist on a hot day early in the morning doesn't hurt, but they soon go if you wet them every time you water the plants. They want most of all a little shade, but if you overdo it you may obtain fine foliage, but no flowers. Gloxinias are easily grown from seed but the retail grower has other things to do and is better off buying a few tubers each year. 


\author{
GOLDEN BELL \\ See Forsythia \\ GOLDEN FEATHER \\ See Pyrethrum \\ GOLDEN GLOW \\ See Rudbeckia
}

\title{
GOMPHRENA (GLOBE AMARANTH)
}

This is a pretty annual that can be used the same as the Helichrysums and other Everlastings. Its blossoms, similar in shape to Clover heads, come from pure white to a dee'p red and the plants are covered all Summer with a mass of bloom. You should recommend them for the old-fashioned flower border and grow on a nice lot of plants for your Spring trade. Sow seed and treat the same as you would Asters, Zinnias, or Marigolds.

\section{GRAPE HYACINTH \\ See Muscari}

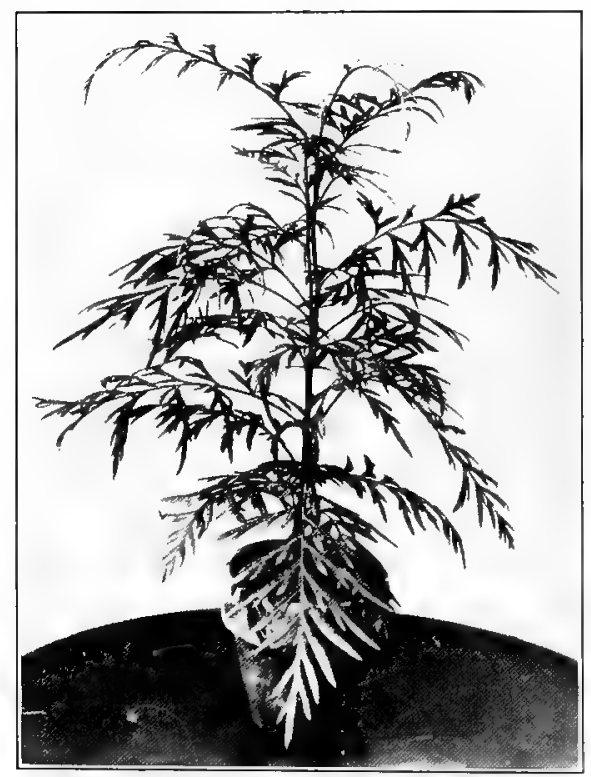

Fig. 172.-Grevillea robusta, or Silk OAK. Sow seed in July or August grow on in a 50-deg. house and you can by May have 12-in. plants in $31 / 2$-in. pots. They can take the place of Bostons and will stand anything a Geranium or Vinca will

\section{GREVILLEA ROBUSTA}

Grevillea robusta, or Silk Oak, is a plant which, though as old as the hills, is not as yet nearly enough appreciated by the retail grower, despite its great usefulness and easy culture. Besides that, it can be grown in a temperature of 45 to $48 \mathrm{deg}$. over Winter; that is, it can get along under such conditions without showing bad effects.

When you fill window boxes and vases during the months of May and June and have the Vincas or Ivies along the edge with perhaps Geraniums, Heliotropes and Coleus as the central feature, you are in need of something light, feathery and graceful to overcome the formal appearance. That is the time you will appreciate 
having on hand a nice lot of Grevilleas about twelve inches in height and in 4-in. pots. It means a saving in Boston Ferns of which, in the smaller sizes, there has been a shortage during May and June every year as far back as I can remember.

The Grevilleas can stand full sunlight during Summer, but they do as well in window boxes filled with an assortment designed for shady positions. Again, you can use the plants during the Fall and Winter months, especially around Christmas, for made-up baskets; and small stock out of $21 / 2$-in. pots will make fine center plants for the filling of fern dishes. Seed of Grevilleas can be sown any time between April and June in flats. In about six weeks the seedlings will be large enough for $21 / 2$-in. pots. By October shift them into $31 / 2$-in. pots, in which they can remain all Winter, going into $4 \mathrm{~s}$ by March. Give them a cool house or a frame during Summer and make later sowings if you desire $21 / 2$-in. stock during Midwinter to be used in fern dishes. It doesn't pay the florist to carry the plants over into the second year.

\section{GROUND IVY-See Nepeta}

\section{GYPSOPHILA ELEGANS}

This is only a little annual, but one of great usefulness to the florist. You have the annual and perennial Gypsophila during the Summer months and Stevia from November to the end of February, but you are very apt to be short on a small white flower on graceful stems during March, April, and May (when really you have as much use for it as at any time of the year) unless you sow some seed of Gypsophila elegans the last week in December. Transplant the seedlings later about two inches apart in 3-inchdeep flats, where they can remain until they flower. If you have no bench space, the flats are just as well off on a shelf. By making several

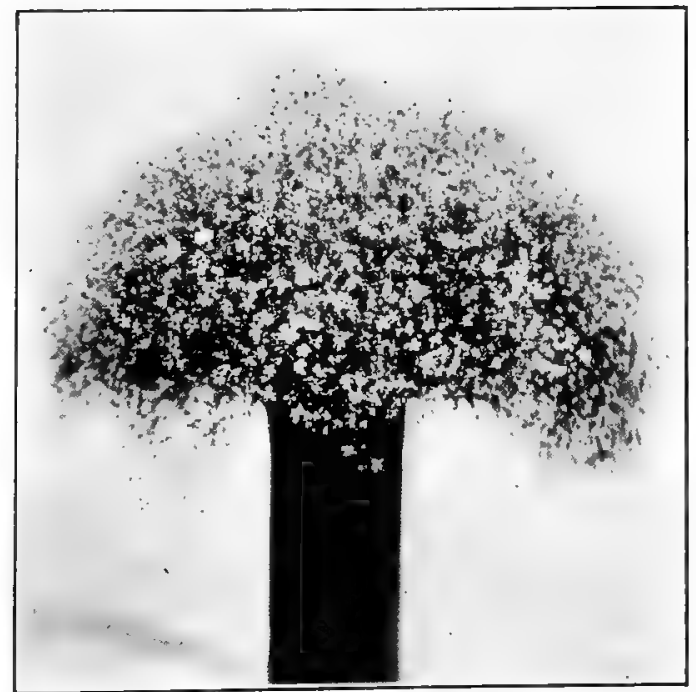

Fig. 173.- Indoor Grown Grpsophila elLegans. Buy seed by the pound and sow it every few days from January on, first in benches, later in frames and outdoors. With it you can improve almost any floral arrangement and save on other flowers and expensive greens 
sowings you can have flowers to cut indoors almost up to the time the ones first sown in a hotbed (about April first) are in flower outdoors, which would be about the end of May. If you keep on sowing seed every two weeks outdoors during Summer you can cut flowers up to November. There is no one more in need of small white flowers all through the year than the retail grower, and, of course, for design work such material is of special value. This annual Gypsophila will furnish you with such flowers, and under glass as well as outdoors needs less attention than almost any plant I know of. There is now a light pink variety of this Gypsophila which gives flowers of a better color when grown under glass than when grown outdoors. For frame or outdoor culture sow in rows about ten inches apart and not too thickly, and cover the seeds very lightly.

\section{GyPSOPHILA PANIGULATA}

Like the annual sort, the perennial Gypsophila paniculata, or Baby's Breath, is of most value as a cut flower during the Summer months, though even in Winter in a dry state it is useful.

If seed is sown in January and the small plants are kept moving, they will flower a little the first year; but they won't be at their best until the second Summer. We now have also a double form, very attractive and more showy than the old one. The plants will not stand for a heavy soil or poor drainage, and while, with many, they grow as easily as weeds, there are other people who find it hard to get them established.

HARDY SWEET PEAS
See Lathyrus
HAWTHORN
See Cratægus
HEATHER
See Erica

HEDERA HELIX (ENGLISH IVY)

We won't discuss the hardiness of the English Ivy or how well it does in Europe or along the Western Coast. The florist is mostly interested in good 4- or.5-in plants, bushy and from three to five feet in height or length. If one could produce such plants and do it reasonably, there would be practically no limit to the number he could sell; but at present there is, and for some time there has been far greater demand than supply. No matter how hardy the English Ivy may be or what abuse it can stand, the hot, dry atmosphere of the average residence is too much for it. Yet this doesn't seem to bother the public in the least and more Ivies than ever are sold. No florist can make a mistake in stocking up well with Ivies of all sizes 
In a cool greenhouse it is no trouble to keep the plants growing and doing well. The heavier and bigger the plants the more money they will bring, and those who have room should keep on taking cuttings of half-ripened wood and increasing their stock. Small Ivies may be planted outdoors during Summer and lifted in Fall, and often, by making use of several plants in a 4-in. pot, salable stock may be had the following Spring. Some growers root the cuttings and at once plant them in 2 or $21 / 2-$ in. pots, set out that way and pot up again in Fall. If you want to plant out again the

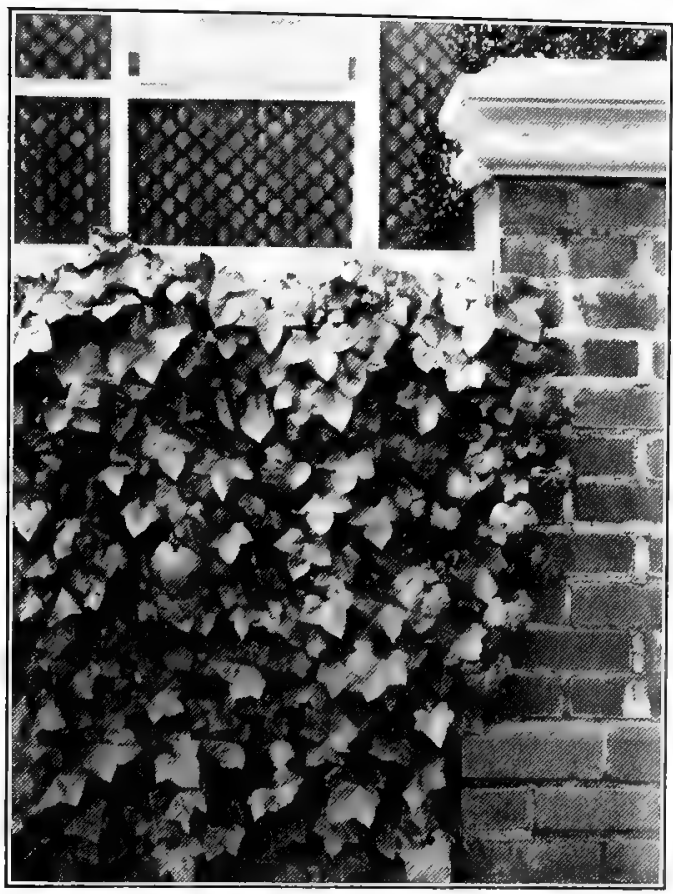

Fig. 174.-Enguiser Ivy. There are many sections in the United States where this is not hardy, but grown in pots under glass it is a great favorite everywhere second year, the plants should be staked while outdoors, as otherwise they will take root along the ground. The retail grower who is always in need of Ivies may find it best to purchase his requirements; and yet it won't hurt him to grow on a few hundred plants each year himself. It takes from three to four years to grow bushy 5- and 6-ft. specimens. However, as they do not require a hothouse and can stand neglect and still thrive, they are money makers even when handled on a small scale.

\section{HELENIUM}

This is a fine perennial when planted in clumps for Fall effects. Of upright growth and about three feet tall, the plants are covered with hundreds of single, brown and yellow, Daisy-shaped flowers and are very effective. For those who want flowers in September and October you should recommend Heleniums.

There are five or six fine sorts: $H$. grandicephalum strictum, with deep orange-crimson striped flowers; H. Riverton Gem, a deep glowing yellow and terra cotta; H Riverton Beauty, clear 
yellow and brown; $H$. Hoopesii, which starts to produce its large yellow blossoms in July; and $H$. autumnale superbum rubrum, of a deep blood red color.

Heleniums are best propagated by root division as soon as the flowers have gone and it is always well to plant a few in a frame where you can protect them in case something happens to those out in the open.

\section{HELIANTHEMUM (ROGK ROSE)}

The Helianthemums, of which there are a number of named varieties, are not of much value to the florist as cut flower plants, but they do come in handy as hardy border plants. They can be used to advantage in rock gardening as they thrive in the hottest, driest spots and hardly ever grow over ten to twelve inches. They come in a great assortment of shades from pure white to a red and their flowering period extends over several months. During July most of them are completely covered with blossoms. Also the plants are evergreen and grow easily from seed, or can be divided. Sudberry Gem is a fine buff-colored sort; Rosy Gem is pink, and $H$. aureum, yellow; a good double red is Mrs. Earle.

\section{HELIANTHUS (SUNFLOWER)}

What interests us most among the different forms of Helianthus are the hardy varieties of which there are a half-dozen or

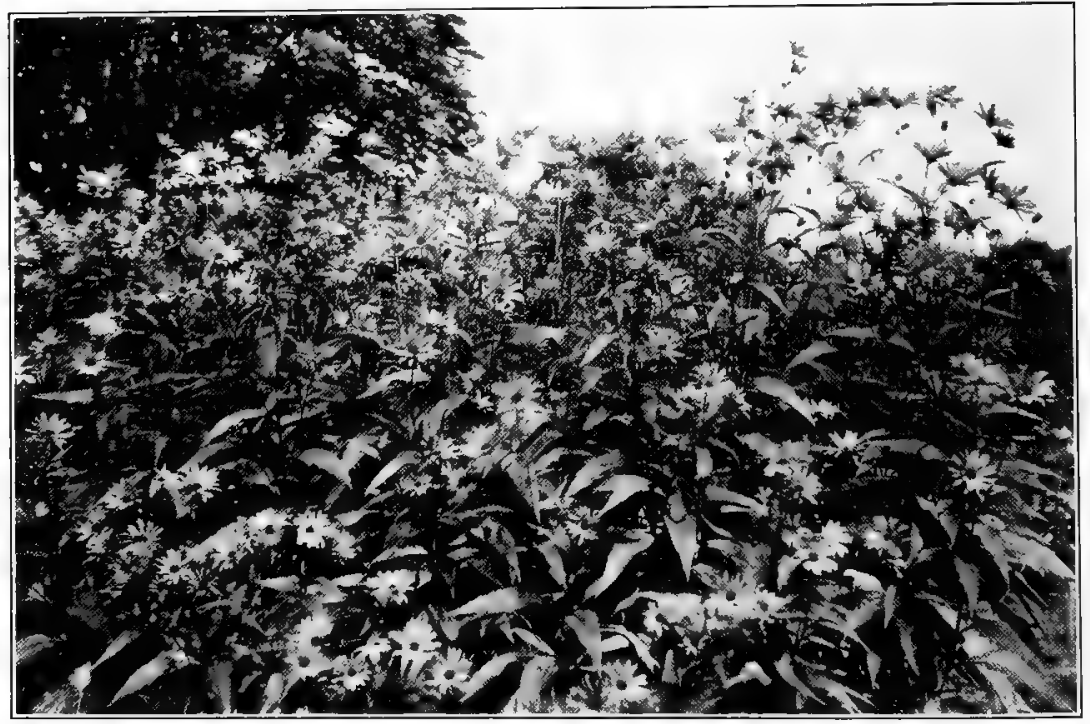

Fig. 175. - Helianthus. In September and October when the hardy border begins to thin out, this hardy single Sunflower is at its best. One plant once established will soon grow into a huge, attractive mass 
more, all desirable and well worth planting. Some of them, especially single ones such as $H$. orgyralis, $H$. mollis and H. Woolley Dod, when once planted are likely to overrun everything in time and even establish themselves in a macadam driveway. But they are easily kept in place and during the late Summer months will become masses of yellow blossoms.

If you plant them along a fence and they once become established you will always have stock to sell from in Spring and Fall, and flowers to cut. Should any of your customers want something for mass planting or naturalizing, you couldn't recommend anything better.

H. multiflorus flore pleno is the hardy double Sunflower and while not as rank a

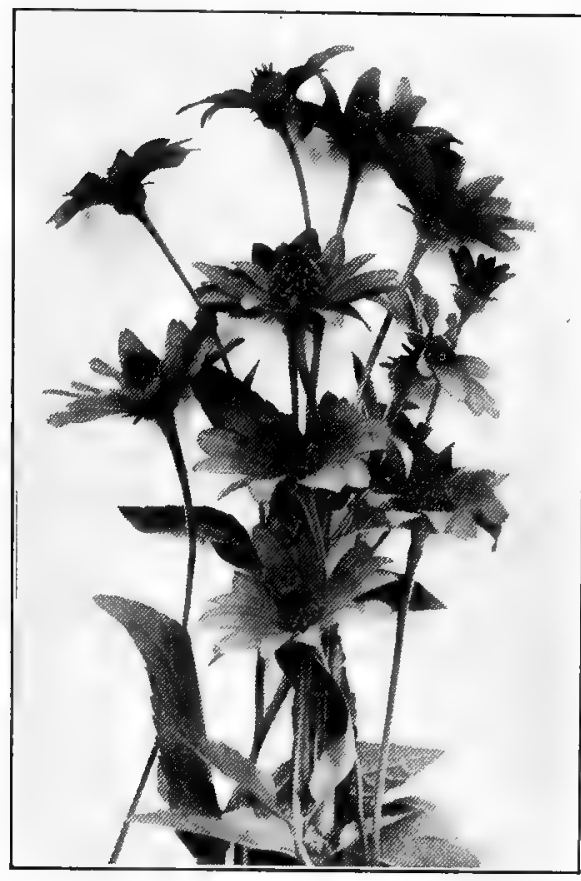

Fig. 176.-Helianthus multiflorus. Fiveand six-ft. stems of this hardy Sunflower, loaded with their golden-yellow flowers, are fine for decorative work grower nor, in a cut state, as graceful as the single sorts, it is well to carry a stock for those who handle perennials.

Among the annual varieties there are some small, single-flowering sorts which, when sown outdoors in May, will provide masses of desirable cut flowers, fine for decorative work, during July.

\section{HELIOPSIS (ORANGE SUNFLOWER)}

Heliopsis Pitcheriana always attracts attention when in bloom in the hardy border. Its large, Daisy- or Sunflower-shaped blossoms of deep orange color make it so, and the fact that it flowers in August is another good feature; besides it lasts for days when cut.' If you handle hardy plants include it in your list. It is easily grown from seed which, if sown during the Summer, will give you flowering plants the following year. Moreover, the plants don't need protection over Winter. H. scabra excelsa is a fine, pure yellow, semidouble border plant, especially when used in groups or masses. It grows fully three feet tall and blooms in August. 


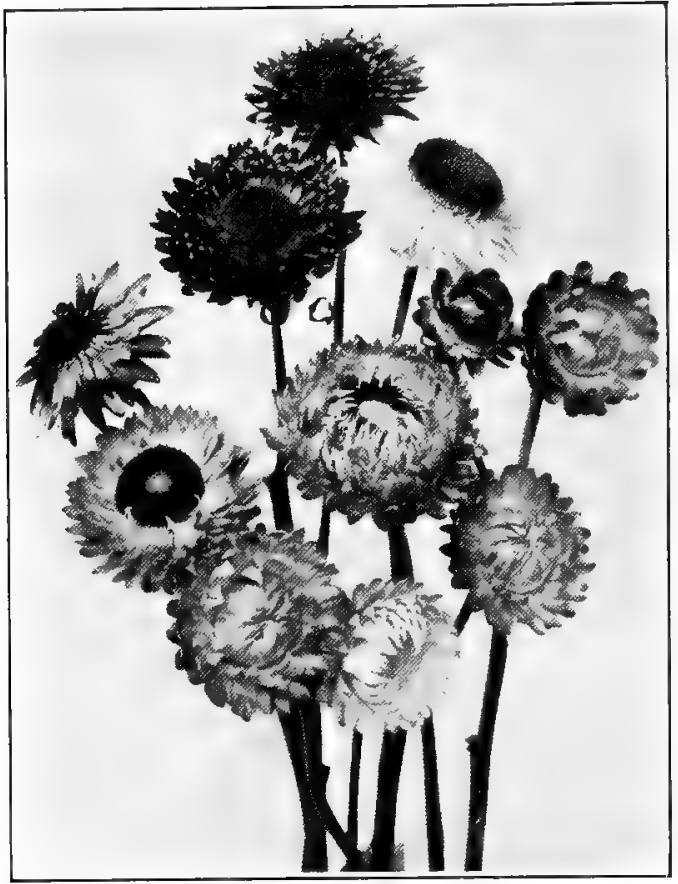

Fig. 177.-Helrahrysum. This, the most popular of the Everlastings, is easily grown from seed sown outdoors. The flowers are useful in many ways during Winter

\section{HELICHR YSUM}

If you retail flowers you will have to carry the so-called Everlastings. No matter whether you personally care for them or not, there are always some among your patrons who will want them and it is an easy matter to sow a long row or two outdoors about the end of April. They will start to flower by July and keep it up until November Always cut the flowers just before they are fully open, and what you don't sell, hang up in an airy shed, tied in bunches of twelve or twenty-five.

You will also find it well to sow a few indoors and have a good supply of seedlings on hand for your Spring trade.

\section{HELIOTROPE \\ See Valeriana}

\section{HELIOTROPIUM}

The Heliotropes, with their sweet vanilla-scented flowers and flower heads ranging from almost white to deep blue, are today mostly used for bedding. There was a time when we trained them into standards, sold large specimens in pots, or had specimens planted out to cut from; but at present it is only in the gardens that we find them popular, except for a few in the greenhouse of the private estate. They make splendid bedders and if you place the cut flowers up to their necks in water, and let them remain in a cool dark place for about ten hours they won't wilt the minute they get into a warm room.

For stock, either grow on a few plants in pots or lift some in Fall to be potted and carried in a 55-deg. house. Gut back a little by January first and the plants will soon break and give you any number of cuttings which should have a bottom heat of 70 
deg. in order to root quickly. Rooted cuttings potted up by April first will grow into 4-in. pot plants and be in full bloom by the end of May. If you have trouble with your plants making enormous growth but not flowering enough during the Summer, try this: Enlarge the hole in the bottom of the 4-in. pot the plant is in to about the size of a quarter, and instead of setting out the plants, leave them in the pots, or rather, plant pot and all.

\section{HEMEROGALLIS (YELLOW DAY LILY)}

It isn't everybody who cares for this plant, yet wherever hardy plants are made use of, we usually find a few specimens. Sometimes, when given a chance, they have spread over a great area. They are really very showy planted in a mass when in full bloom.

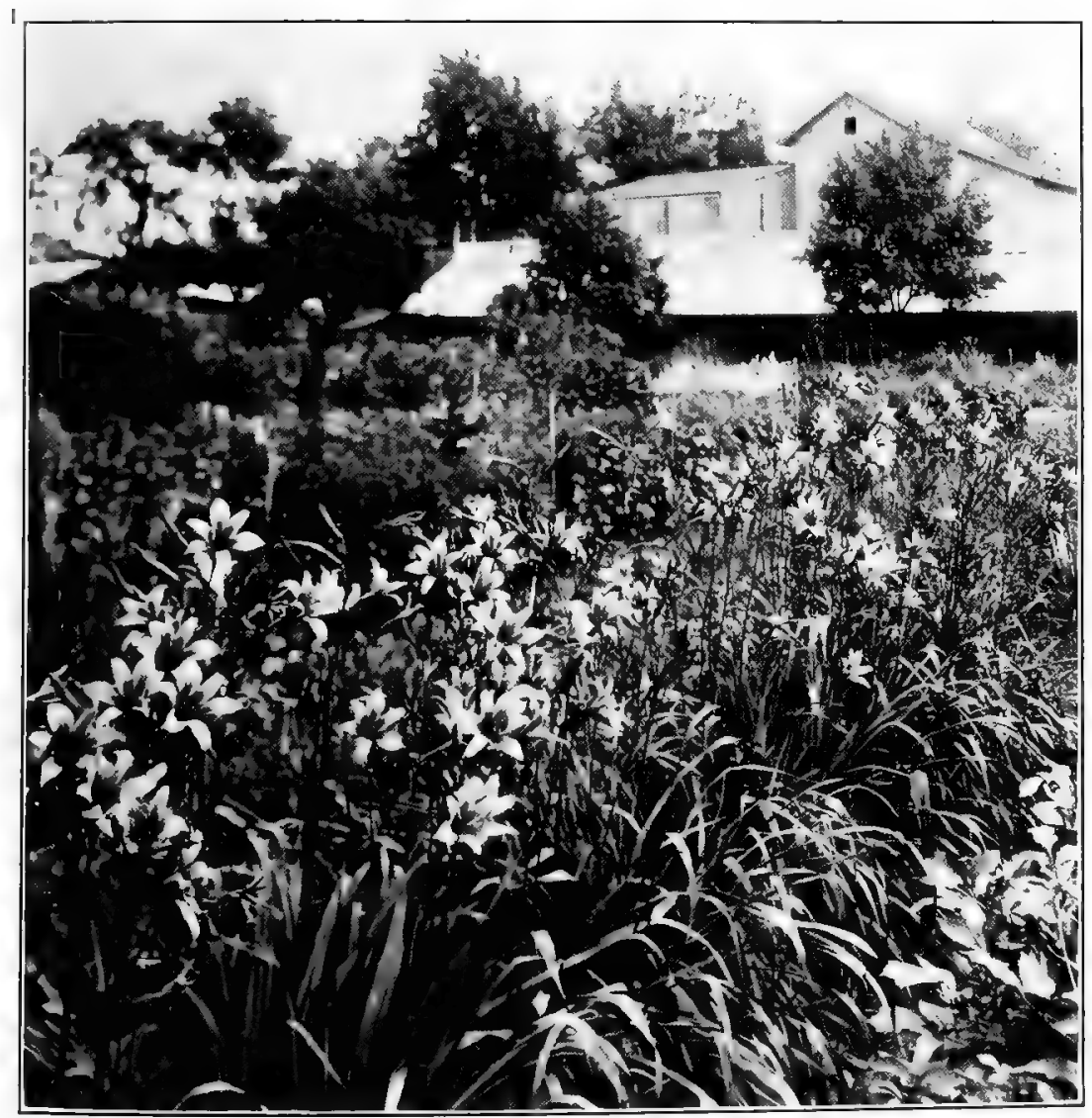

Fig. 178.--HemerocaluIs FLAva. While not much of a florist's flower, this has always been a favorite hardy border plant. Masses are needed to create a real effect 


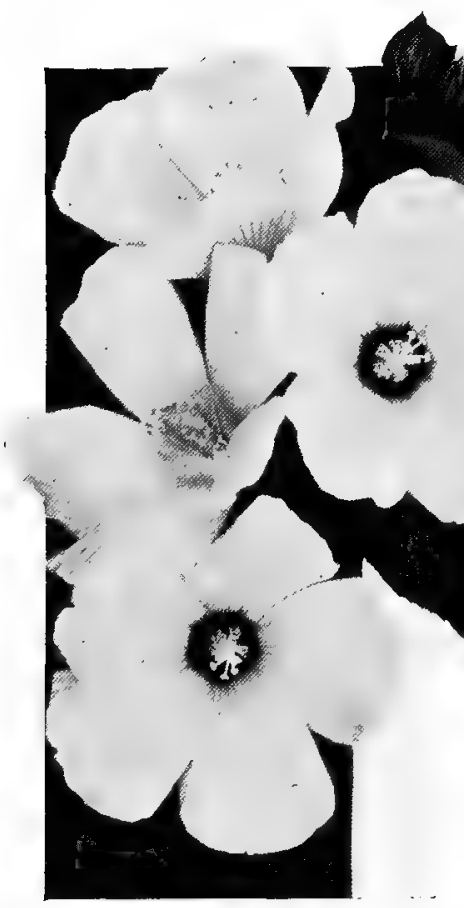

Fig. 179.-Hibiscus may be used in the hardy border or given a place by itself. Its large, showy flowers always attract attention borne on slender stems. While you may have the Shasta Daisies, Gaillardias, Coreopsis, Delphiniums, Sweet Williams and many others at their best, your assortment is hardly complete without Heuchera. A few sprays cut with stems 18 in. long will go nicely with almost any basket arrangement of cut flowers and will surely be appreciated by your patrons.

It was away back in 1893 that I sowed a little package of seed sent to me by the introducers, Haage and Schmidt of Erfurt, Germany, and I have managed to grow a few plants each year ever since, propagating them partly from seed and partly by division of the field clumps in early September.

Of late years quite a number of other beautiful Heucheras have been introduced, among them "Walker's variety," with larger and better colored flowers than $H$. sanguinea. $H$. splendens has bright scarlet flowers and Nebulance has creamy white flowers. 


\section{HIBISGUS (ROSE OF SHARON, OR SHRUBBY ALTHÆA)}

This Hibiscus is best known as Rose of Sharon and in localities where the Winters are not too severe the plants will grow into large specimens. These are covered with large single and double, beautifully colored flowers during September when but few other shrubs are in bloom. Even in severe climates where there is danger of the tops of the plants being winterkilled, the florist who handles nursery stock should recommend it. Often plants of such showy double sorts as Jeanne d'Arc and Leopoldii or H. rubra pleno will flower freely the first season, but of course they will be much better if pruned back severely the following Spring and allowed to make a graceful growth of slender stems covered with dark green, shiny leaves.

While Hibiscus Rosasinensis, with its large trumpet-shaped flowers and dark green leaves, makes a showy greenhouse or conservatory plant, it is of but little value commercially. But what we know under the name of Giant-Flowering Mallow

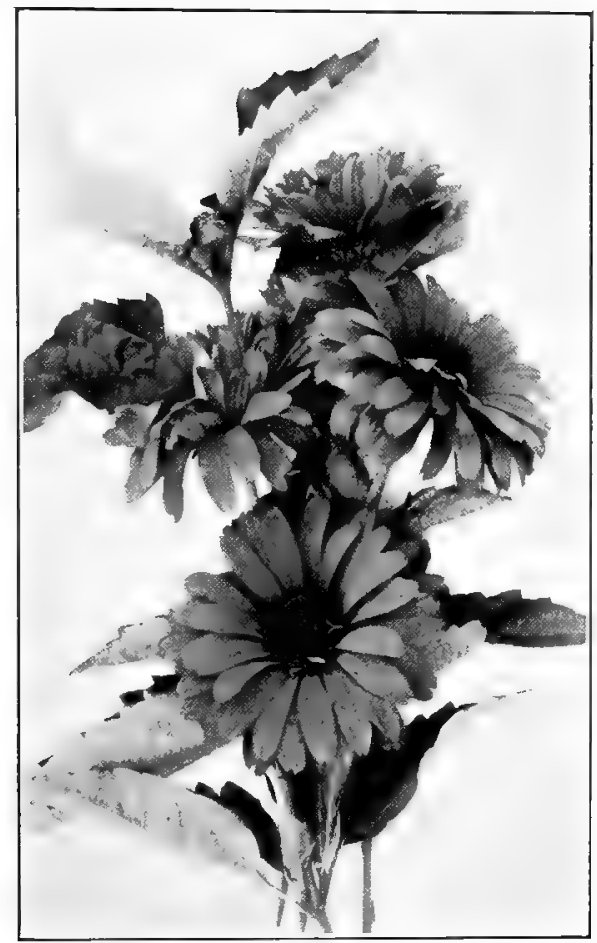

Fig. 180.-Heliopsis Pitcheriana. This perennial flowers from July on and is fine for cutting. The color is rich golden yellow. H. scabra excelsa is a superb double form. Both seed freely, but are best propagated by division

Marvel, flowering all through the Summer season, makes a showy subject for the hardy border or shrub bed and needs but little attention when once established. To have a few plants on your own grounds, means that you will take orders from those of your patrons who want more of a variety in their hardy borders.

HIPPEASTRUM

See Amaryllis

HOLLYHOCKS

See Althæa

HONEYSUCKLE

See Lonicera 


\section{HUNNEMANNIA (GIANT YELLOW TULIP POPPY)}

The average florist isn't well enough acquainted with this beautiful Poppy with its golden yellow flowers which, when cut just as the buds open, will remain in good condition for three or four days. With its graceful foliage there is nothing finer for the centerpiece of a dining table.

Hunnemannias can be sown outdoors in April and will flower from June on; another sowing can be made about July and these plants will give you the finest flowers in late Fall; even light frosts won't affect them.

Another way is to sow in March indoors and as soon as the seedlings are large enough to be handled, pot them up separately into $2 \mathrm{~s}$ to be planted out later on in a coldframe, allowing about ten inches of space between them.

Hunnemannias are also fine for indoor flowering. Sow the seed about Christmas, transplant later into small pots and bench in a cool house in February.

\section{HYACINTHS}

The Hyacinths the florist uses belong to the Dutch bulb stock with the exception of the Romans which we import from France. They are all most showy plants when in flower and have been favorites longer than any of us today can remember.

Even the small florist can easily, with the help of the Romans, manage to have attractive pots, pans, dishes or made-up baskets in flower from the middle of December on, closing the season with the heaviest supply during Easter week.

\section{Roman Hyacinths for Forcing}

You cannot imagine anything more simple to handle or more useful around Christmas than Roman Hyacinths. On many occasions during my time can I recall a patron selecting a low basket filled with Roman Hyacinths, a few table ferns and an Adiantum, Winterberries and a bow of red ribbon at from $\$ 5$ to $\$ 6$ in preference to a Cyclamen, Begonia or Poinsettia. While in actual value the Hyacinth basket wasn't to be compared with the other plants, the way they were arranged and presented sold them, and so it is with a good supply of Romans in flower at Christmas time-you are enabled to make up little pots for those with limited means as well as more expensive arrangements. Or, if the flats the plants are in are placed in a coldhouse, the flowers will last for many days and you can use them cut; there is nothing finer for design work and they are as good in a corsage.

The bulbs usually arrive in September and for those who want to use the plants both for pans and dishes as well as to cut 
from, the best way is to plant in flats 3-in. deep, barely covering the top of the bulbs with soil. Place the flats in a coldframe, but instead of covering them with soil as you would for the Dutch stock, place shade frames over them and keep them rather dark, never allowing them to suffer for water. By the middle of October (or before there is any danger of frost) bring the flats inside and place them below a Violet bench; they may even go into a Carnation house by early November. Active growth will soon appear and most likely, if placed for a few days in a Rose house temperature around the first of December, the plants will all be in full bloom by December twenty-fifth. If, by early in December, the plants haven't made several inches of growth a good way to hustle things along is to place the flats on the hot water returns. Then as soon as the buds are visible, remove them to the light.

Romans, if lifted out of the flats, and even if deprived of all their roots, will not show bad effects as long as you keep the soil moist in the dishes or pans in which you use them. Let those you want to have for January come along in a 50-deg. house; in fact, the cooler it is the better.

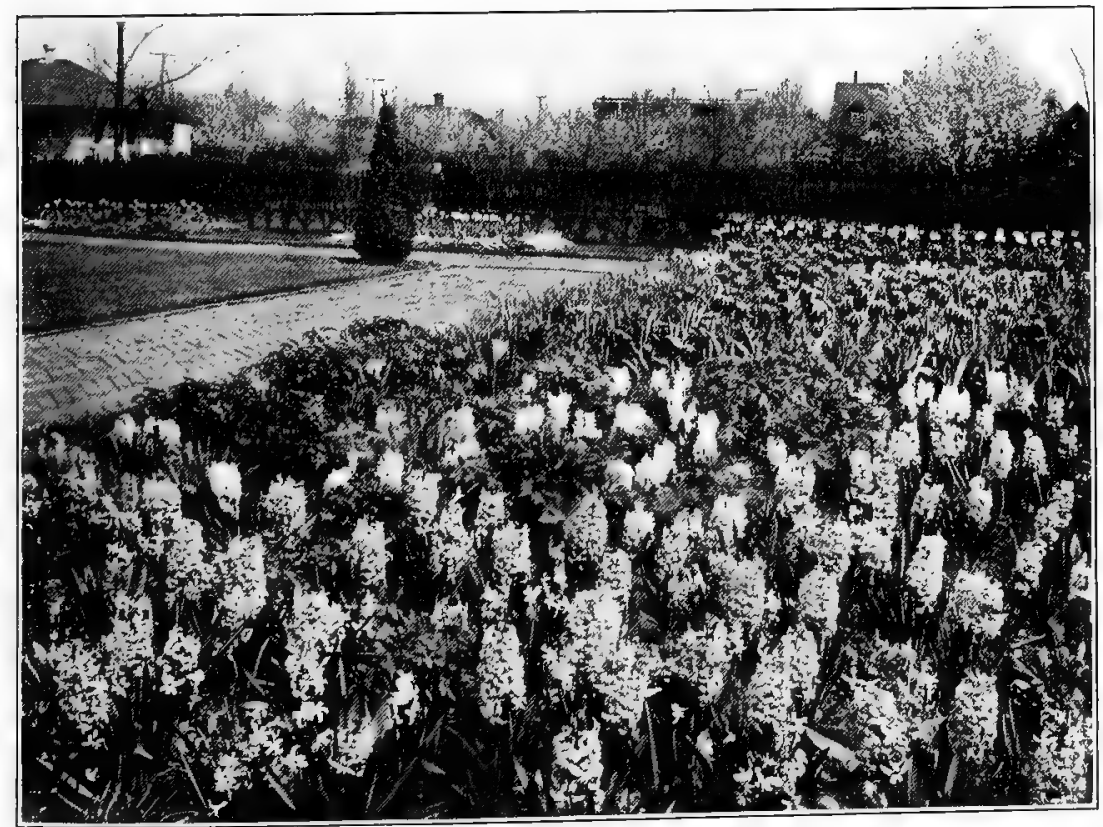

Fig. 181.-HyacrnTHs AND Tulips. Hyacinths, though less satisfactory than Tulips for mass planting, their heavy flower spikes needing support, are so showy that they deserve a place wherever a Spring display is wanted. Back of those in the picture are some Keizerkroon Tulips 


\section{Dutch Hyacinths}

While these Hyacinths are used for bedding, to have them at their best they should be grown or forced under glass and every retail grower should have a few coming along into flower from the middle of January on. There are grand named sorts which, if exhibition or first-size bulbs are made use of, should always be planted separately in pots-either $4 \mathrm{~s}$, or in the case of some of the largest ones, 5s. The smaller size bulbs frequently offered as miniature Hyacinths are best for pans and there are two ways of handling them. One is to plant the bulbs in flats three inches deep, allowing a little space between them; and the other is to plant them directly into the pans. The latter saves work, yet there are times when the plants in these pans don't all come even or flower at the same time which doesn't make a very attractive pan for the counter. A good idea, therefore, is to make use of both ways and if you get some uneven pans you can take the plants out carefully and replant to suit you. There are some varieties-and among them Gertrude, a fine pink-which are apt to show the effects of being lift:d when in bloom; other sorts don't mind it at all.

\section{Foncing Dutch Hyacinths}

As with most other Dutch bulbs that we import, the sooner you plant them in late Fall the better; the sooner they will make

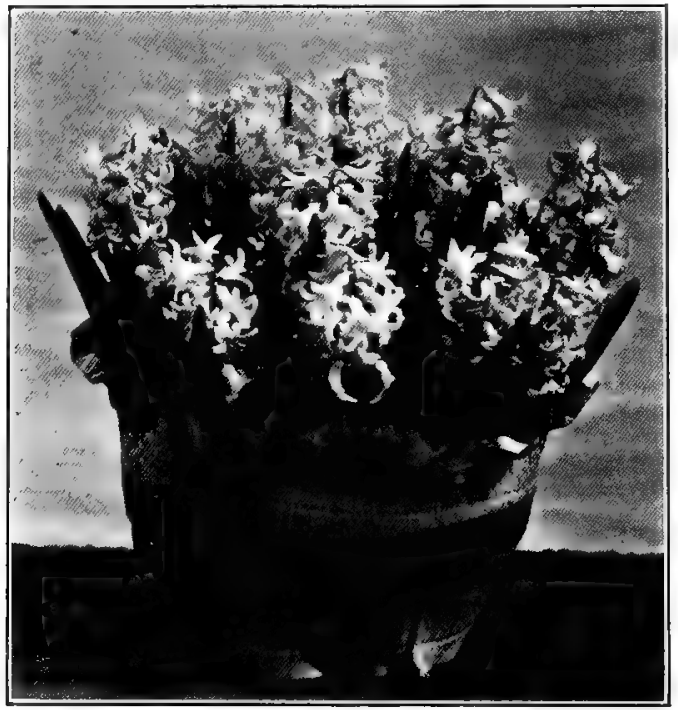

Fig. 182.-Miniature Hyacinths. You don't need stakes for pans of miniature Hyacinths grown cool and given plenty of time. Easily handled, they are for the retail grower most important Winter- and early Spring-flowering stock root growth and become potbound-and there is absolutely no use in bringing into heat a Hyacinth which isn't potbound. Plants poorly rooted will never amount to anything. They may make a fine growth of foliage but usually they will bloom without a flower spike or stem and prove worthless.

Plant early, and if you have no bulb cellar put the pots outdoors in a coldframe, water throughly and cover them with about twelve inches of soil and later on with a layer of strawy manure. During Fall examine the pots every 
so often and never allow them to dry out; the soil in the pots must be kept moist at all times. The first batch can be brought indoors around Christmas and placed under a bench; a warm, dark place will in a few days cause the tops to get busy, and when these are about six inches long they should be removed to more light. Always avoid a strong bottom heat and go over the plants twice a day to prevent their drying out. The less forcing you do after the plants have made six or eight inches of growth, the better. Whenever you notice that the buds are apparently stuck at the bottom and that the leaves make a good growth but not the flower stem, there is absolutely no use in bringing in any more of the same batch of plants for the present. Let them remain outdoors for another month, when the plants will have'had a chance to become more potbound and when less forcing ; will be required.

Here it is in a nutshell: Plant early; keep the soil moist; prevent severe freezing while outdoors; don't bring in until pot, pan or flat is filled with roots. After that it is a matter of keeping the plant in a dark, warm place with plenty of moisture in order to obtain foliage and a fair-sized flower stem; and, finally, light is needed to develop the flowers.

As soon as the buds show color, a well-shaded, cool place should be given to finish and harden the flowers. In such a place during February you can keep them in good shape for days, whereas a sunny bench in a warm house two or three days finish them. During January, February and March it takes a full month of forcing to bring Hyacinths into flower, whereas less than three weeks is required in April. The larger and heavier the spikes, the more they are in need of being properly staked. There is nothing better than the regular green Hyacinth stakes for that purpose; you can stick them right into the bulbs, close up to the stems, and use green twine for tying.

Many retail growers make use of miniature Hyacinths during the Winter, both for the making up of pans and for cut.flowers. For these purposes we need only a few of each color at a time. A good way to do is to plant in flats divided into equal parțs, setting the three most called for colors - white, light pink and light blueseparately. In this way you won't need to force a whole flatful of a single color, while you can bring in as many flats as you like.

There is hardly any use describing the different sorts, there are so marry beautiful ones. However, the following are just a few of the best known: In white, l'Innocence, Grandeur a Merveille and La Grandesse; in yellow, Princess Perfection; in light blue, Queen of the Blues, Perle Brillante and Enchantress; in dark blue, Grand Maitre, King of the Blues and Marie; in rose-pink, 


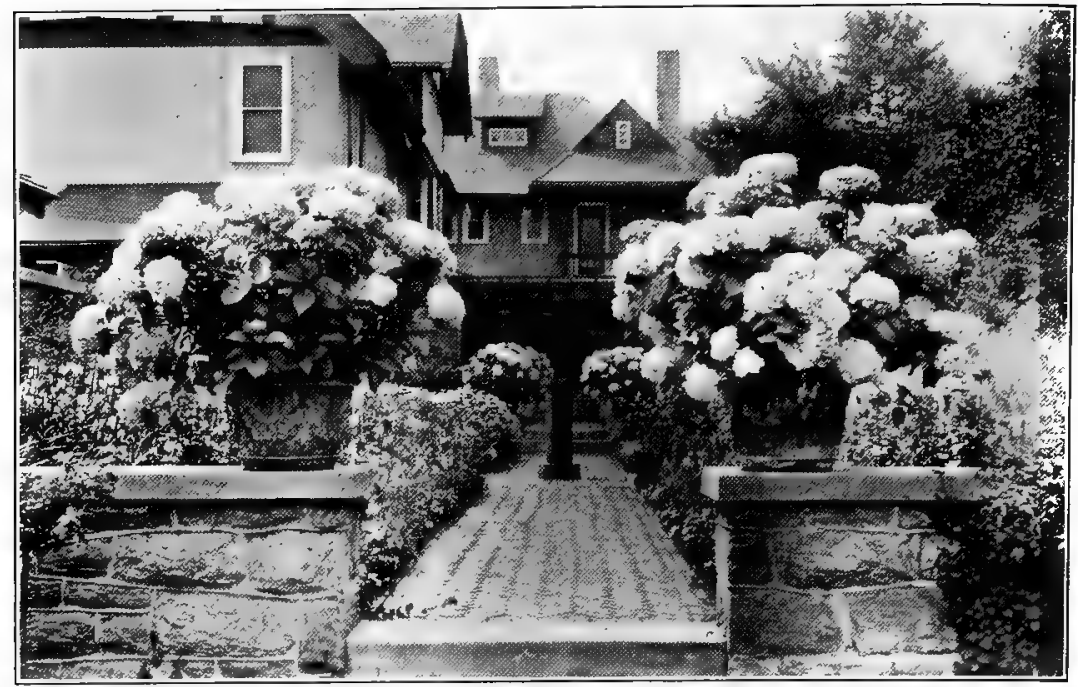

Fig. 183.-Hydrangea "OTAKsa." The many beautiful French types have failed to crowd out the old Otaksa. Here the plant to the right is particularly fine. You don't need a greenhouse to overwinter plants that will flower in Summer; any place just a little above $32 \mathrm{deg}$. will do. Country florists should make more use of Hydrangeas around their places

Gertrude and Queen of the Pinks; in deep pink, La Victoire and General De Wet. Gigantea is a beautiful pale pink and so is Lady Derby.

\section{Prepared Hyacinths}

The Roman Hyacinths will always be the main ones to use for Christmas forcing, but of late years the Hollanders have put on the market what are known as "prepared Hyacinths." "These consist of certain varieties which have been dug early and cured so as to make them suitable for extra early forcing.

Every florist has call right after Christmas for bulb stock, when a few Hyacinths of the Dutch sorts are desirable. With just a little care you can get these prepared bulbs to bloom, but of course the earlier you can get them under way in Fall the better. Get them well rooted before placing them in heat.

\section{HYDRANGEAS}

All Hydrangeas are beautiful and all are valuable to the florist whether you consider the old standby, H. Otaksa, the many fine French sorts which have been introduced of late years and helped us out so much in overcoming the shortage of imported stock for Easter, the so-called hardy sorts, $H$. paniculata grandiflora or $H$. arborescens grandiflora.

There are nurserymen today and large growers, too, all over the country, who make the growing on of Hydrangeas, such as 
Otaksa and the French sorts a specialty, and I doubt whether it pays the florist who uses a couple of hundred plants during the year to attempt to propagate and grow. on his own requirements. I know we all feel like taking cuttings and rooting them when we have a plant with a lot of fine, shoots, and it isn't a great deal of trouble to carry the young plants along with the other stock, but isn't it cheaper to buy in Fall either field- or pot-grown plants?

\section{For Easter Flowering}

Whether Easter comes early or late, the best plants to flower for that date are those which have been grown on in pots during the Summer months. If kept shifted during the Summer, say up to August and the pots plunged up to their rims out in the open, with perhaps just a little shade above, the wood of the plants is ripened or hardened off by gradually withholding water from the end of September on. A light frost will usually help to get the plants into a dormant condition. They are then placed either in a frame with proper protection or in a cool house.

As you want them to rest for awhile they need only enough water to keep the buds on the end of the stems in good shape. Care must also be taken not to have them freeze, for those end buds will later on produce the flowers. Destroy them and you destroy the bloom. The plants are brought to a 45-deg. house around Christmas and will soon get busy. Often the mistake is made of waiting too long in getting the plants under way, which means either getting the plants in bloom too late for Easter or subjecting them to a too high temperature. If they are allowed to come along slowly, much bet-

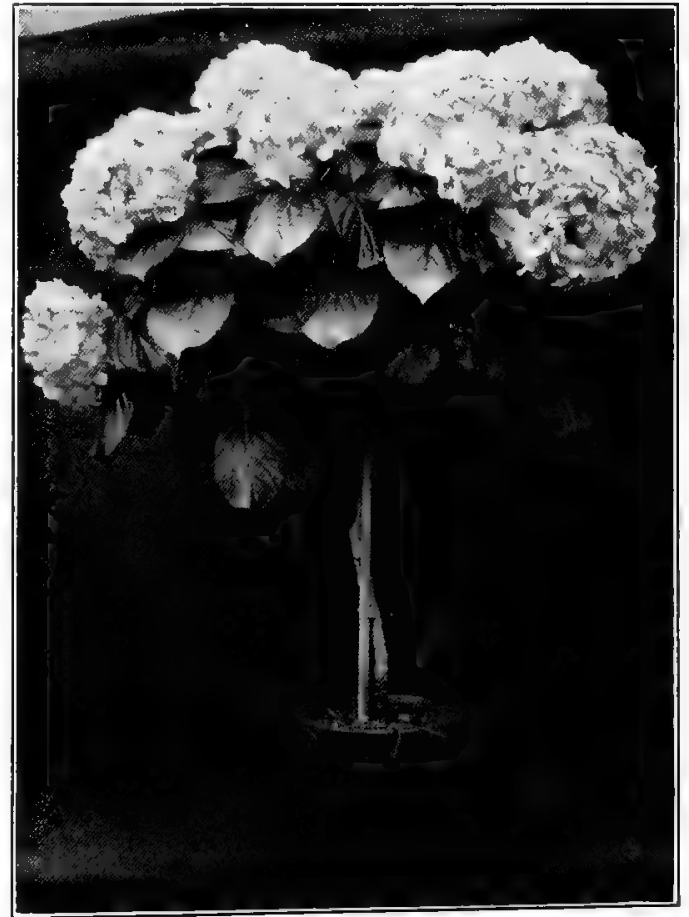

Fig. 184.-A Standard Hydrangea. For variety's sake and as something a little out of the ordinary around Eastertime, a few standards like this will be useful 
ter results can be obtained. Keep on increasing the temperature so as to have the buds show six weeks or so before Easter. Potbound plants properly treated in Fall and started slowly can, toward the end, stand almost any temperature as long as you water and spray them. If they show color weeks before Easter, gradually lower the temperature so as to harden them off before they are sold.

\section{Forcing Field-Grown Plants}

Some growers are quite successful in handling field-grown plants and getting them into flower by Easter, but weather conditions have a lot to do with it. To begin with, you want a good soil, wellmanured and deeply cultivated to plant in, with plenty of drainage so you can water during a dry season without causing yellow foliage as a result of sour soil. All Hydrangeas like moisture, but good drainage, too. During a season of favorable conditions, the plants will make good growth and if lifted and potted up by the middle of September, brought into a frame, shaded a little and carefully watered, with a light spraying during the noon hours on hot days, they will keep on growing and become re-established in the pots by the middle of October. That's just what you want. Start in to keep them on the dry side and during November and most of

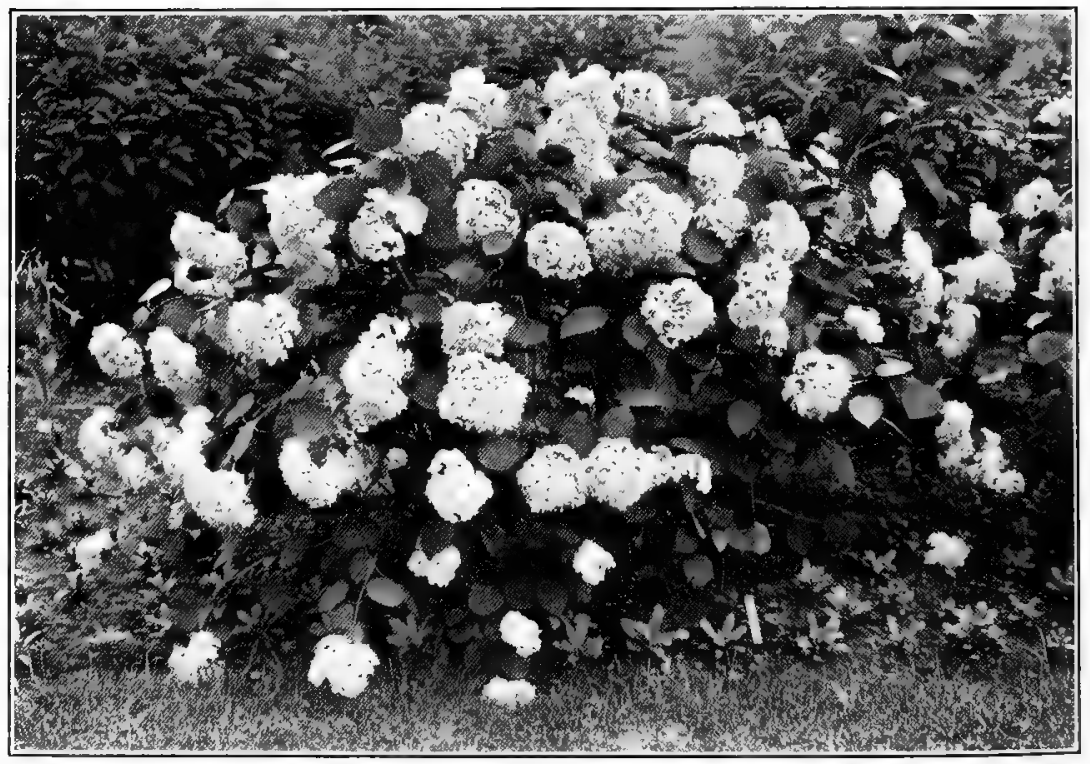

Fig. 185.-Hydrangea arborescens is not only a desirable outdoor flowering shrub but a valuable florists' cut flower as well. Plants cut back in early Spring will bloom fully a month ahead of $H$. paniculata grandiflora. Place stems in water in a cool place for twelve hours after picking. For best results divide fleld plants every second or third year 
December rest them; after that treat the same as the pot-grown ones. If you want to make money, instead of insisting on getting the plants in for Easter, when you know it is very doubtful, don't rush them, but let them come along in a 55deg. house and buy what you want for Easter. You will want your plants for later on, up to Memorial Day and even later.

You might put down page after page of cultural directions, yet you haven't conditions under control with field plants as with those grown indoors. Here we have at times gone through wet Summers when the plants made a soft, rank growth only to be cut down by an extra heavy early frost that killed every top bud and

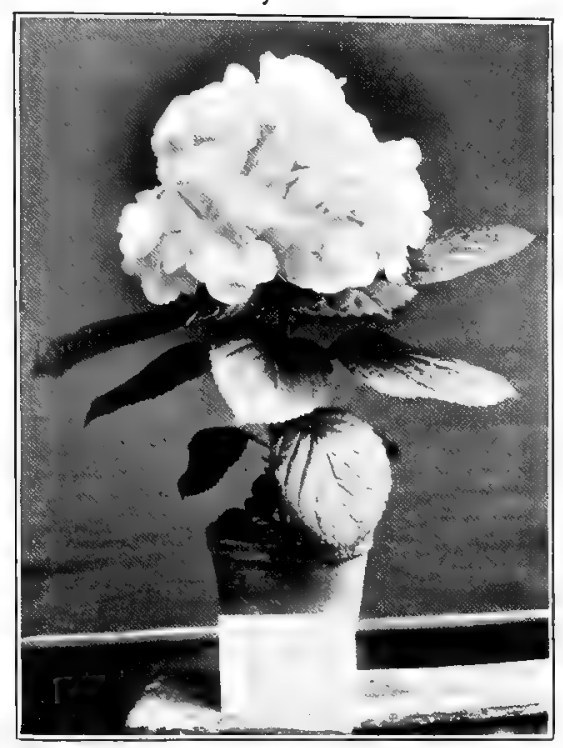

Fig. 186.-Hydrangea "Mme. MouLLIËRE," one of the many beautiful French sorts-a splendid white Easter plant. You can grow it much branched or to a single stem from Spring cuttings kept in pots over Summer part of each stem. Again, we have passed through hot, dry Summers when, despite all the watering they received, the plants stood practically still. This was followed by an unusually wet Fall and the plants kept on growing away into December; there was. no way of ripening the wood and we didn't get hardly any flower buds. This is not to say, however, that such conditions don't affect even the plants in pots; in fact, you run chances either way.

\section{Plants for Summer Flowering}

I believe that the retail grower is better off buying either stock ready for forcing in Fall, or the plants in flower for Easter. I also claim that he should pay more attention to making use of Hydrangeas in pots and tubs for Summer flowering. We see beautiful specimens displayed on lawns, terraces and in front of the main entrance of a residence, but we don't see enough of them, particularly at present when there is a shortage of Boxwood. Specimen plants of $\mathrm{Hy}$ drangea should be pushed, and plants which come into flower during July and August are the most valuable. To grow such specimen plants on, or to get them ready, is an easy matter. Field grown stock can be carried in a coldframe or house all Winter and three plants which ordinarily would be large enough for 6-in. pots can be planted in a butter tub about April, but still kept in a frame or 


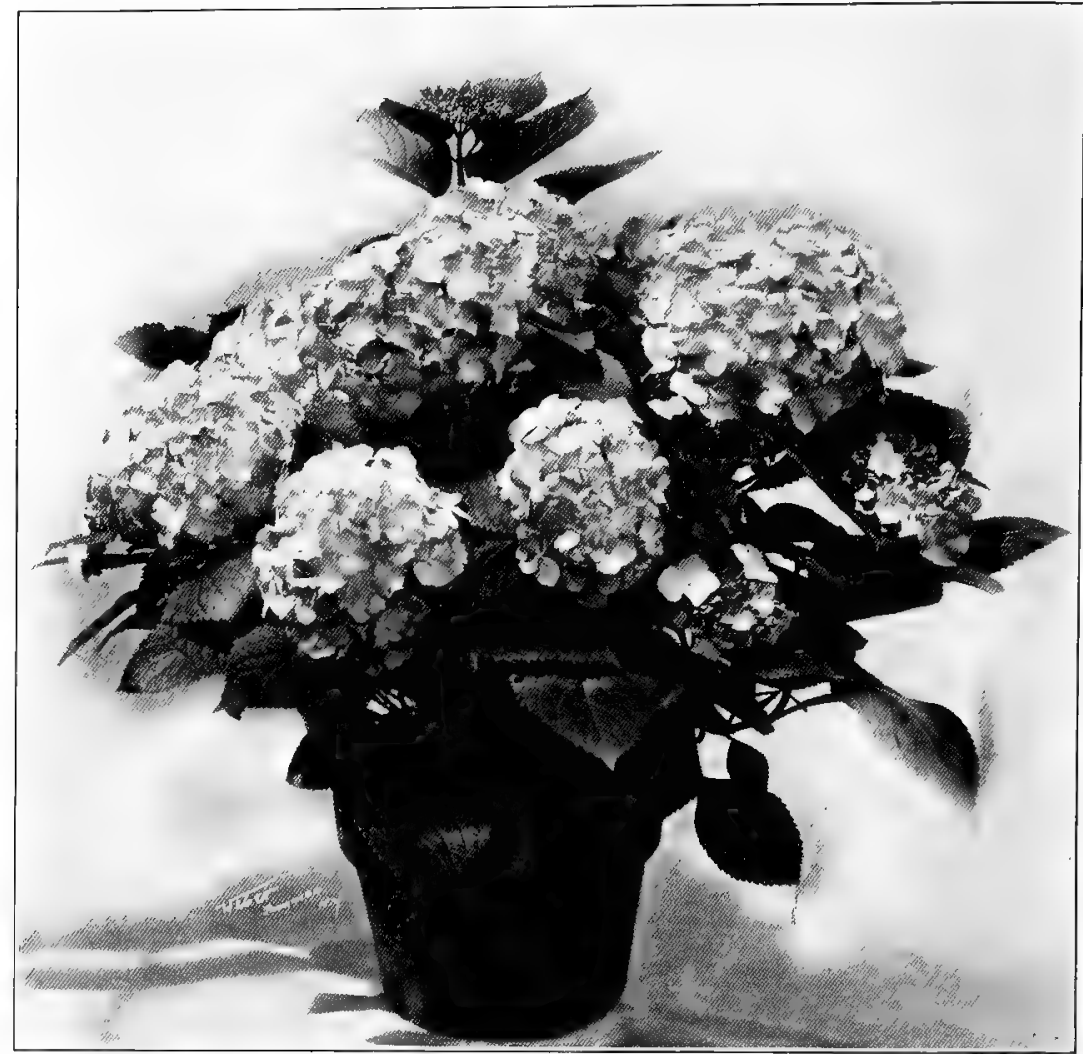

Fig. 187.-A Specimen French Hydrangea. A well-grown Hydrangea not only has large heads of perfect flowers, but also bears good foliage right down to the rim of the pot

cool house. The idea is not to force them in any way. Of course, if you want plants in flower by June, bring them into a 50-deg. house in April. Leftover plants from Easter needn't be thrown away, but can be cut back and planted out, and will make fine stock for Summer blooming the second year.

Hydrangeas are easily grown from cuttings rooted during early Spring when there are usually all kinds of new shoots appearing from the base of the plants you are forcing. Place them. in sharp sand with bottom heat.

\section{Desirable Varieties}

H. Otaksa is still grown very extensively, especially for Summer flowering. Among the many beautiful French sorts let me mention just six which for variety of color are among the best: Avalanche is a large white and a close second to the popular Mme. E. Mouillère; 
E. G. Hill and Souvenir de Mme. de Chautard are good pink sorts; General de Vibraye and Eclaireur are deep rose; and Trophee, one of the latest, is almost red in color. There is no doubt but what still finer sorts will be introduced and among them some which will be especially adapted for outdoors. Before long I look for some real double ones, of which we have already a forerunner in "Domotoi."

\section{Hydrangea paniculata grandiflora}

When these hardy Hydrangeas are in bloom, there isn't much chance for anything else. In fact all the other favorites, such as the Lilac, the Spiræa and the Philadelphus have gone long ago. Nature is far too lavish with her display of flowers among the shrubs in early Summer when everything seems to be in bloom at the same time. These Hydrangeas form one of the few exceptions. We have them with us from July on, and they remain and are still showy with their dry, brownish flower heads, even in November.

Every retail grower should devote a fair-sized patch of ground to them, not only because they are so showy, but also because they are decorative as cut flowers and because you can use them in design work. The smaller blooms on long stems are fine for sprays.

When you plant them in the field let them have good soil and drainage and a liberal amount of manure. Next in importance is to cut the plants back severely each Spring. That is, if you want large flower heads prune back last year's growth to one or two eyes. In that way you will obtain 3- to 4-ft. straight stems with from 8- to 10-in. flower heads, six inches across at the base. By merely trimming the plants a little you will develop only a lot of small wood bearing small flowers on short stems.

If you sell plants to your customers, don't prune them before they are delivered. A better way is to deliver and plant them and prune afterward, for there isn't much left after a 2- or 3-year old plant is cut back. Your nurseyman will supply you with what you want and it won't hurt to order a few plants trained into standard form; the little trees are very effective.

\section{Hydrangea arborescens grandiflora}

This is better known as the Snowball Hydrangea and is also of value to the florist. It flowers in June and the last blossoms are usually cut as the first ones begin to appear on $H$. paniculata. The snow-white flowers come on long stems, are good keepers and can also be used in design work. The plants like a rather moist soil and will do well even if partly shaded. They should be well pruned each year since the new shoots which break from the bottom produce the showiest and largest flowers. Old plants can be taken up and 
divided, in fact they are better off for such treatment. You can also recommend them for planting as a background in the hardy border or with perennials.

\section{IBERIS UMBELLATA (GANDYTUFT)}

Candytuft is of most value to the florist when grown under glass, so as to be in flower during May: When well done and grown cool in a rather rich soil on a solid bed, such sorts as Improved Empress make splendid cut flowers. Sow seed from January on in flats; the seedlings are best potted up and later on transplanted where the plants are to flower, allowing four inches between the plants and fully a foot between the rows. Another way is to sow right in the bed or bench they are to flower in and thin out when the seedlings are about two or three inches in height. If you care more for quantity than quality, this is the cheapest way.

For outdoor flowering, sow in rows where the plants are to bloom. This can be done in early May, or you can make several sowings during the Summer months. However, the ones which

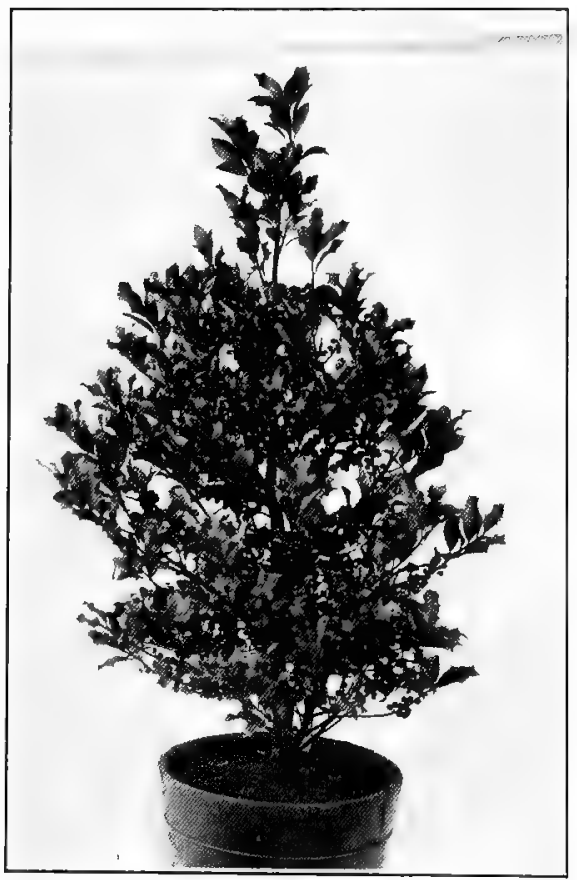

Fig. 188.-ILEX AQUIFOLIUM. The Holly genus contains a number of fine sorts with glossy leaves and ornamental Berries. I. aquifolium makes a showy plant for Christmas, but, like all the species, it is of slow growth and not profitable to grow on a small scale had a chance to make growth during cool weather will be the best. Indoors, never subject the plants to a temperature above $50 \mathrm{deg}$; a little less is even better up to April.

\section{Hardy Candytuft}

(Iberis sempervirens)

Along stepping stones, the margin of the pool or the edge of the rock garden is the proper place to plant this showy hardy Candytuft which, like the annual sort, is just one mass of white when in bloom. While this happens but once a year and lasts for only a few days, the foliage is evergreen and the plants hardly ever suffer even in severe Winters. It is easily increased by division in August, and the young plants are best carried over the first Winter in a frame. 


\section{ILEX}

A great majority of florists become acquainted with Ilex only around the Midwinter holidays when the cut Holly sprays are used as Christmas decorations. Ilex opaca is one of the hardy American Hollies. Its beautiful glossy green leaves and red berries are known to us all, and we find it in its native state all the way from the Louisiana coast along through to the Eastern States. We find Hollies of different species in Florida and along the western coast, and some, more on account of their showy berries than the quality of their foliage, find their way to the middle western and northern markets where they find a ready sale, because local climatic conditions are not favorable for the growing on of any of the Hollies.

Ilex aquifolia, or the European Holly, is a beautiful evergreen shrub and so is Ilex crenata. When we behold either of them as specimens on lawns or growing in tubs, we feel badly because we cannot get the same results at home. But as in the case of palms, Dracænas and other plants, I have seen in the West Indies enormous specimens growing in soil we would have considered worthless in the potting shed. Climatic conditions have to suit the plants if they are to thrive, and so it is with the Ilexes. I look forward to the time when more of these beautiful plants will be handled by the florist at a reasonable price. It is as plants full of berries in pots and tubs (which every florist can use to advantage during Winter) that these Hollies mean the most to us.

\section{IMPATIENS}

If you sell bedding stock you will have to carry Impatiens, for there are always some of your patrons who have shady places around their homes where Geraniums, Salvias or Petunias fail on account of the shade. In such cases you can't recommend anything better than Impatiens, and if there are objections to the red colored ones, you have sorts with beautiful shades of light and dark pink as well as white ones. All do equally well and, except in the pitch dark, will be masses of bloom until frost stops them.

It takes just about three good sized 5 -in. pot plants in the Fall to work up a stock of one thousand or more of $21 / 2^{-}$and 4 -in. pot plants in full bloom by the following May. Once in awhile you have call for plants in bloom during the Winter months but there are other plants than Impatiens to choose from. This is not to say that Impatiens doesn't make a good house plant, but I am sure that every florist can dispose of a good number during the Spring months. It might even pay you to grow on a few extra heavy 4- and 5-in. pot plants to be used for the filling of window boxes in shady places. 
Seed of Impatiens is now offered and in three months after sowing you can have bushy plants in full bloom. But of course they come in all colors and shades, and a better way, if you have a good sort on hand, is to propagate through cuttings.

\section{IPOMEA GRANDIFLORA (MOONVINE)}

The only trouble with these grand climbers in our northern climates is that while they grow finely and cover a lot of space, they never flower, or do so so late that it hardly pays. This is due to planting out too small plants or such as have been grown from late-sown seed. Moonvines, with their large flowers often measuring over six inches in diameter, are among the showiest of all climbers, but should be heavy 4- or 5 -in. pot plants by the time you plant them out in May. Such stock will start to flower in July and keep it up, the plants becoming each evening a mass of color. The flowers, like those of most Ipomoas, remain open a good part of the forenoon. In order to get large plants by Spring, root cuttings of the outdoor plants in early Fall and keep them going all Winter inside. In early Spring they will start to move rapidly and should have several shifts.

If your patrons ask for Moonvines you will only disappoint them by selling small stock, that is, in any section of the country where the real Summer season is a short one.

\section{INDIGO, FALSE \\ See Baptisia}

\section{IRIS}

Among the desirable perennials, those best known and able to get along with the least attention, the German and Japanese Iris almost head the list. Not that they can take the place of Peonies, Delphiniums or Phloxes, but they can stand more abuse. Among the German Iris, in particular, some grand new sorts have been brought out of late years. They are money makers for every florist who handles hardy stock because, once established, they can be increased in great numbers and they will thrive in almost any soilnot only in a deep, rich mixture and where the roots are moist at all times, but on high ground too poor for other plants.

\section{Iris Germanica, or German Iris}

As stated above, some grand sorts have been of late years brought out in this group. Of these Iris pallida dalmatica is one of the very finest, growing fully four feet in height with a mass of large lavender flowers. These flowers have only to be seen by any of your patrons who are fond of the hardy border to bring you an order. Other good sorts are Sherwin Wright, a pure golden yellow 
of good size, the plants growing about thirty inches in height; Lohengrin, with extra large flowers of a deep mauve; and atropurpurea, a beautiful rich purple of large size. Of course these are only a very few of many good ones, but you cannot make a mistake in working up a stock of all the above named sorts and pushing them.

The best time to divide the field clumps is in early August; by doing it then you will have well established plants to sell the following Spring. Always see to it that the sorts are kept separate; there is no call now for mixed lots and no reason for them with so many

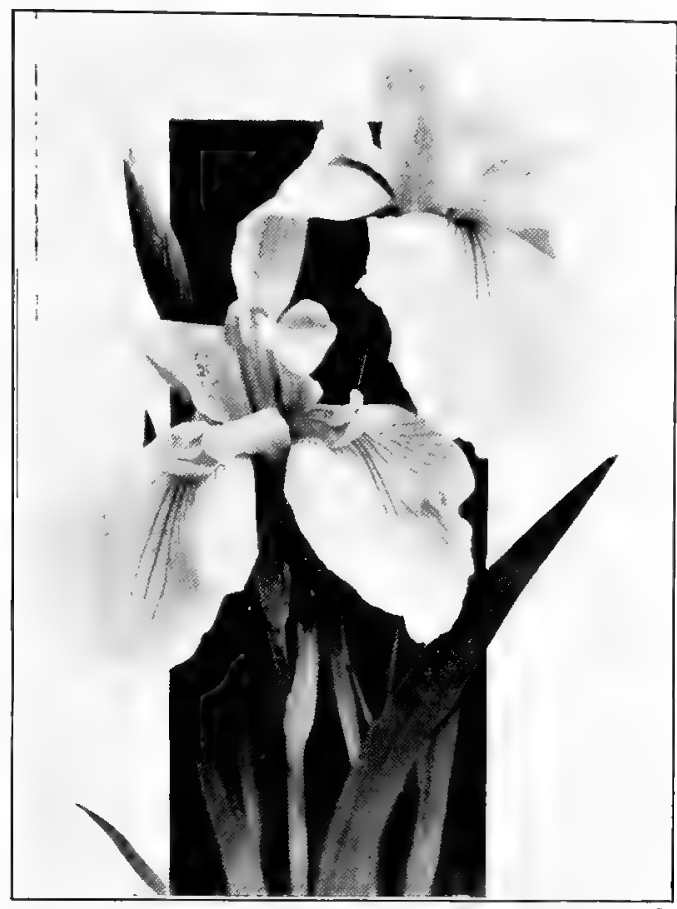

Fig. 189.-JaPANESE IRIS. There is an almost endless variety of Japanese Irises, many of them, with their beautiful, soft shadings, resembling orchids. Even more than the German Irises they are fond of moisture

beautiful ones to select from. The man who only has a limited call for Iris should not carry over six or eight sorts, including the different distinct shades. Keep on trying out new sorts and discard the old ones.

\section{JAPANESE IrIS (Iris Kaempferi)}

These require about the same treatment as the German type and come in an endless variety of shades. They require a moist position in order to do well. It is almost impossible to carry just a few hundred plants and keep them separate so if you have a good mixture on hand it usually answers. In case a patron insists on having only certain shades or colors, you can have your nurseryman supply you with them.

\section{Other Irises for Outdoor Planting}

Iris sibirica orientalis comes in a rich blue and a white sort (Snow Queen). It grows fully three feet in height and produces masses of fine flower stalks. Iris interregna is one of the earliest of all Irises to flower, coming in bloom usually about the middle of 


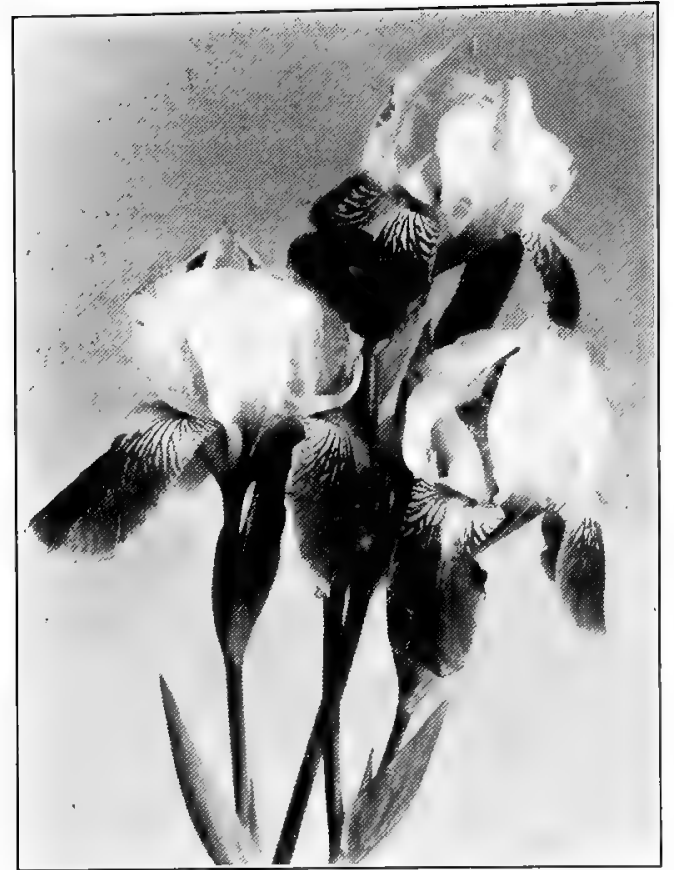

Fig. 190.-German Iris. We cannot consider these Irises - not even the many showy new varietiesof any great value to the florist as cut flowers. As hardy border plants, however, they are becoming more and more popular

May, with stems from fifteen to twenty inches in length. The flowers, like those of most Irises, are fine to cut, but you mustn't wait until they are fully open; rather gather them just as the buds begin to open. They will never do for shipping, but you have good use for them at home.

Iris pumila hybrida is another early flowering sort and splendid for borders as it only grows about ten inches in height. It comes in white, yellow and deep purple.

\section{Bulbous Irises}

Among the Bulbous Irises we have the English and the Spanish forms, and of the latter, those called Dutch Iris are said to be an improvement on the original Spanish, coming in bloom several weeks earlier. Iris tingitana is a still earlier type.

Both English and Spanish Irises can be planted outdoors. but what makes them of particular value to the florist is that they adapt themselves so well to growing and flowering under glass during the early Spring months.

Up to a few years ago the supply of bulbs came almost entirely from Europe, but they are now grown by the acre in California, the same as the Freesias, and are offered cheap enough for every retail grower to plant a few thousand and force them. So used they usually find a ready market, for they make ideal cut flowers. The bulbs can be planted in bulb pans allowing a little space between them, or flats can be used the same as for other bulb stock. Carry in a coldframe up to the middle of February when the first batch can be brought in and placed in a cool house. Later on increase the temperature, but never subject them to too much heat. 
IVY, GERMAN

See Senecio

IVY, GROUND

See Nepeta

JAPANESE

BELL FLOWER

See Platycodon 諒

JAPANESE

KUDZU VINE

See Pueraria

JERSUSALEM

GHERRY

See Solanum

JONQUILS

See Narcissus jonquilla

JUDAS TREE

See Cercis

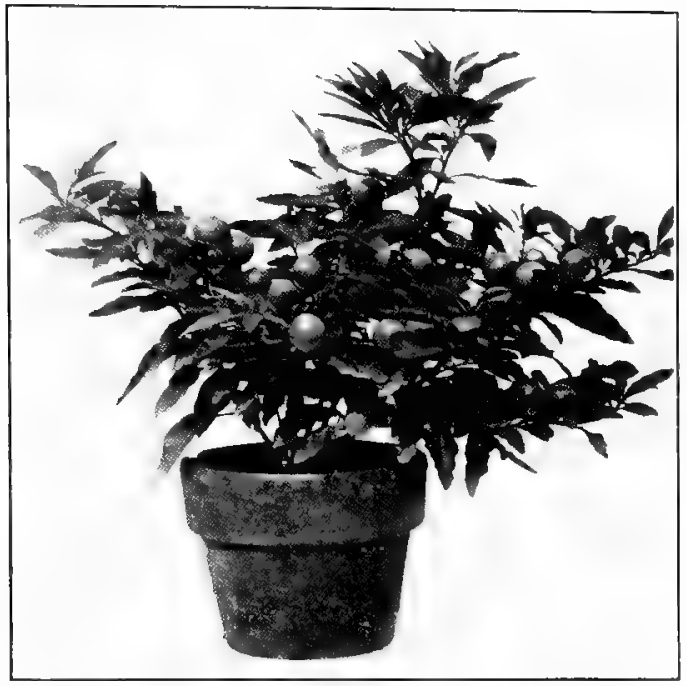

Fig. 191.-Cleveland Cherry. This is a great improvement over the Jerusalem Cherry (Solanum Capsicastrum), and a most desirable inexpensive Christmas plant. (See page 522.)

\section{JUNIPERUS (JUNIPER)}

The Junipers are among the most desirable of conifers. Every florist who does landscape gardening ought to know some of the varieties such as $J$. virginiana (Red Cedar), $J$. Sabina and the Irish Juniper, and, if at all possible he should carry a few plants of each on his home grounds.

The Irish Juniper ( $J$. communis var. hibernica), while not hardy everywhere, makes ideal stock to be used in connection with a formal garden or to be planted on terraces, in sunken gardens or anywhere a dense, evergreen column is wanted. While it grows to a height of twenty feet and over, specimens three to five feet are the ones mostly wanted.

Juniperus Sabina (which we call here the Savin Juniper) is one of the most graceful of all conifers and many are its uses, for there is always demand for a low-growing, spreading evergreen: This variety is absolutely hardy and the florist who can obtain from his nurseryman a few small plants each Spring and plant them out to grow and develop on his own grounds, is bound to reap good returns for the money expended. The same holds good with the Red Cedar (J. virginiana, called Savin Juniper by some). It happens every Spring that some one wants a couple of upright evergreens to be planted near the gate or the steps at the entrance of the residence. Spruce or Arborvitæ are not to be considered, but Red Cedars will fill the bill every time. 


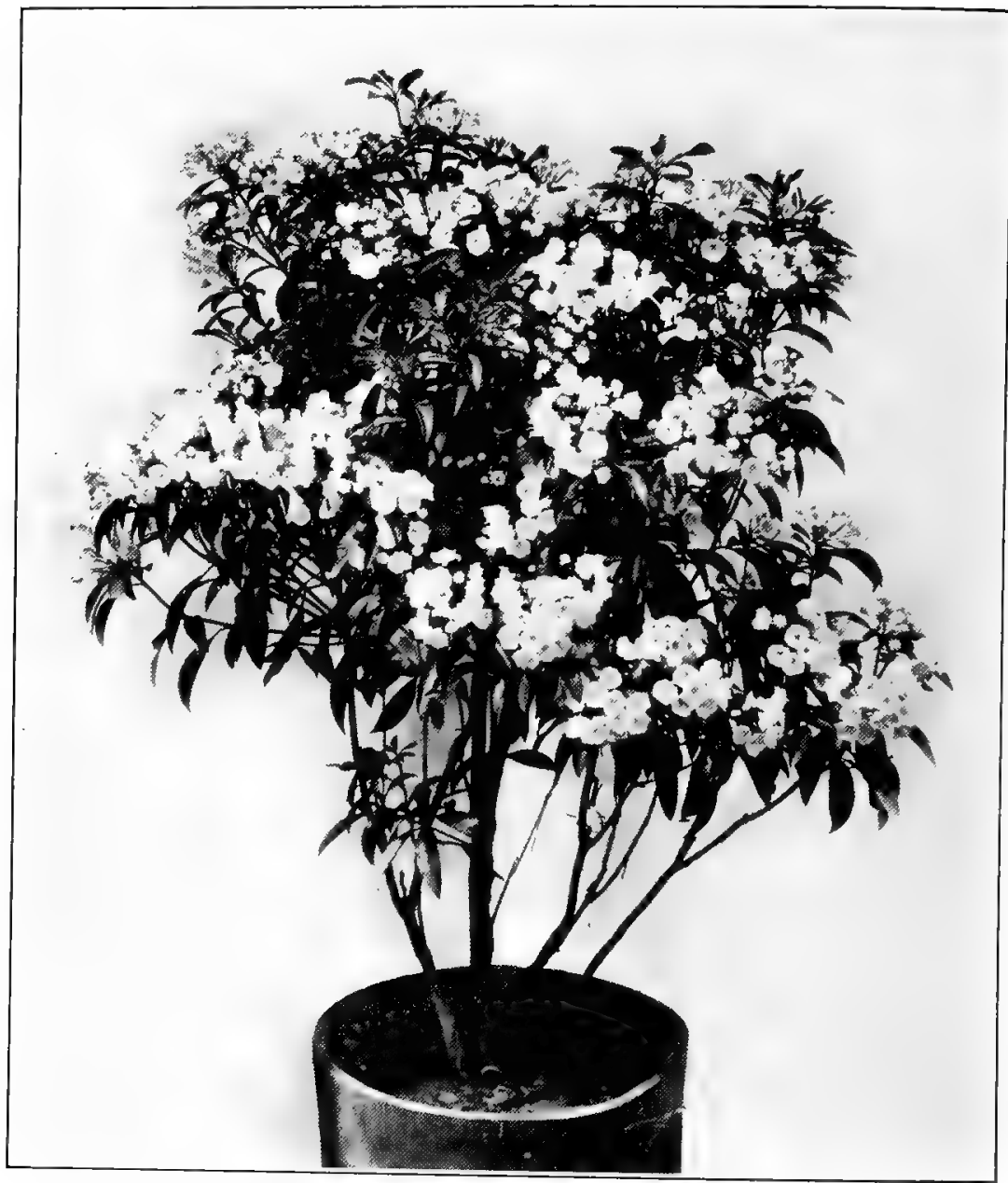

Fig. 192.-Kalmta Latifolia in Flower. Here is a fine Easter plant just a little different from the usual run of stock.

\section{KALMIAS}

Kalmias are native hardy flowering evergreens valuable for garden use like Rhododendrons, and for Easter forcing in pots and tubs. The oddly beautiful white and pinkish flower of $K$. latifolia, the Mountain Laurel or Calico Bush (and the most widely cultivated species) is the choice of many for a national flower. To propagate, sow seeds in early Spring in sand in a frame or cool house; prick off as soon as possible and when seedlings are established, grow on outdoors. Retailers had best buy stock already grown. Kalmias can be transplanted fairly easily but should be well mulched the first season. They dislike clay and limestone soils. 


\section{KENTIA}

The Kentias are the most useful of all the palms for the florist. In the case of the retail grower, a good stock of them will always yield a handsome dividend and no matter what you have to pay for well grown specimens, they are bound to prove a good investment. Give them a warm house with sufficient shade on the roof to prevent burning the leaves, and keep the soil in the pots as well as the atmosphere in the house moist at all times, and the plants will keep on growing into money.

There is one good thing about the shortage of these plants and their higher price: it leads us to take better care of them. When it was possible to import them at comparatively low cost, they were slaughtered here just for the reason that they were able to stand a lot of abuse.

Every florist can make use of Kentias (whether Belmoreana or Forsteriana) all the way from those in 2-in. pots for the center of fern dishes, on up to extra-large specimens for decorative purposes. Plants in 5-in. and 6-in. pots are the best for counter trade.

You should always have some nice plants to offer around the holidays, for many people will prefer them to flowering stock, looking upon them as more lasting. I have always claimed that as long as you have a stock of good palms and ferns on hand, you are never sold out around the holidays. And what is left over of such plants forms a mighty fine asset later on.

When you purchase Kentias, you are not purchasing perishable

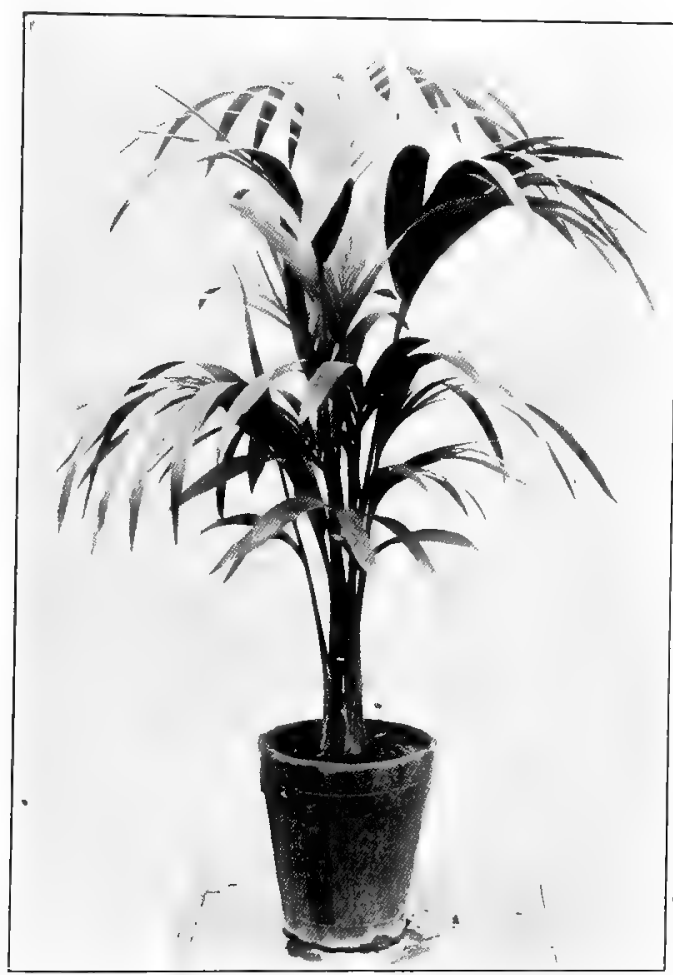

Fig. 193.-Kentia Belmoneava. The larger Kentias become, the more stately and graceful their leaves and general appearance. However, if you want a palm for an indoor or outdoor window box, a 3 -in. or 4 -in. $K$. Belmoreana will help the effect and prove as hardy as the ferns, Ficus or Pandanus used with it-if not hardier 
stock. A well filled palm house, no matter how small, always creates a good impression on the visitor and is a thing for the owner to be proud of. The little florist and the beginner don't always realize nor appreciate this fact, yet, after all, it isn't the grand structure you possess in the way of a greenhouse, but what you have in it that counts. You can make a plain looking interior of a palm or show house look good with a stock of Kentias, but without them, no matter what else you have in the house, things are not complete.

I suggest to every florist who retails stock that he invest liberally in a nice lot of small and large Kentias and that when he gets them, he take care of the plants. Not only that, but let him make the best use of them in the decorating of his establishment. It pays.

\section{KERRIA JAPONIGA}

You should carry a few Kerrias in your assortment of shrubs. The double form is the best, flowering practically all Summer and

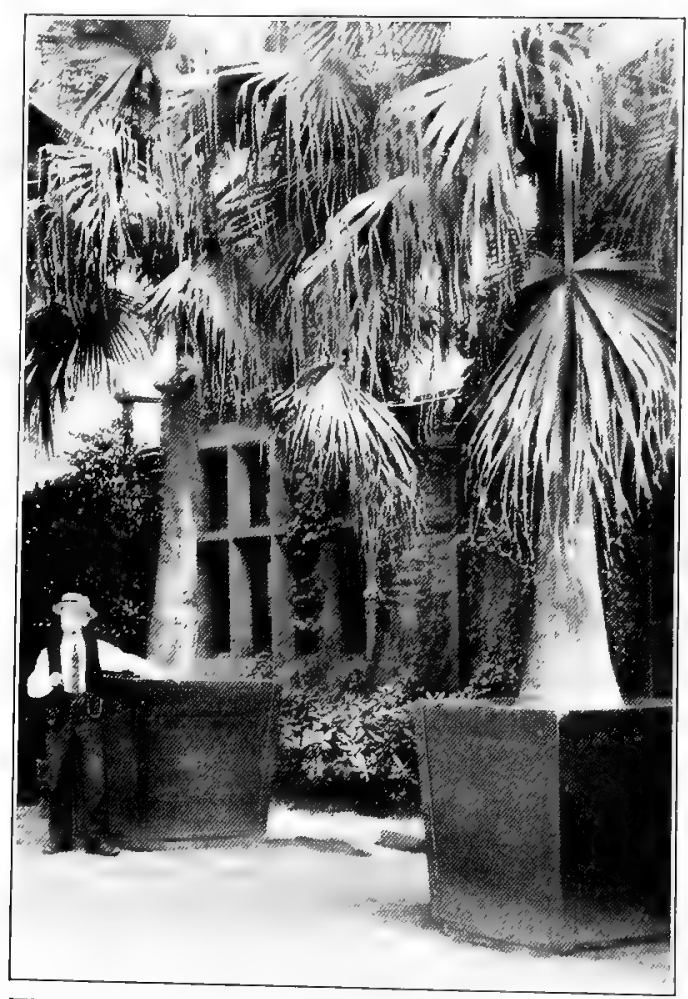

Fig. 194.-Some Palms in the East. To what size Kentias will grow outside of Florida and California is well shown here. Compare the size of the tubs with our friend G. Thommen of Boston, standing by them it is good not only for single specimen plants but also in hedges.

For Winter effects also the Kerrias are desirable on account of the bright green color of their branches. You should consider them whenever a customer wants anything of that kind - and there are plenty "who do. Take the red and yellow twigged Dogwood, the brown barked Philadelphus, the gray colored branches of the upright Honeysuckle, and the Kerrias to furnish the green, and you have quite a combination in these few alone.

For a hedge, you can clip or prune the Kerrias as formally as Boxwood or Privet and in time, obtain a dense growth. 
KUDZU VINE

See Pueraria

\section{LAGE FLOWER, BLUE \\ See Didiscus}

\section{LANTANA}

There isn't any longer the demand for Lantana that there was in former years when it was largely used for bedding. But for all that, the retail grower should always have a few well-grown $31 / 2$ - and 4-in. pot plants on hand during the Spring months. They not only make good bedders, but do finely in porch boxes. The trailing sort is best adapted for the latter purpose and makes a showy hanging basket for the porch and a good companion for the trailing Fuchsia.

Carry along in pots a few plants left over from Spring; they are best kept in a frame with the pots plunged in soil. Bring to a Carnation house in October and keep a little on the dry side. By the middle of December cut back a little and shift into larger pots; the new breaks will be ready for the cutting bench in a few weeks and will want a little bottom heat.

\section{LARKSPUR, ANNUAL}

(For the perennial sorts, see Delphinium)

The annual Larkspurs are among the desirable Summer flowers and are equally well adapted for indoor flowering during the early Spring months. They come in many shades of white, pink, and blue, and nothing is more graceful in a basket of garden flowersor more lasting.

For outdoors sow seed in flats about March first; carry the little plants in $2 \mathrm{~s}$ or $21 / 2 \mathrm{~s}$ and plant in a mild hotbed or coldframe in April. They will flower by early May. Another lot can be sown in rows in a frame in early April, and by the end of that month you can transplant indoor started plants to the field. Still another batch of seed

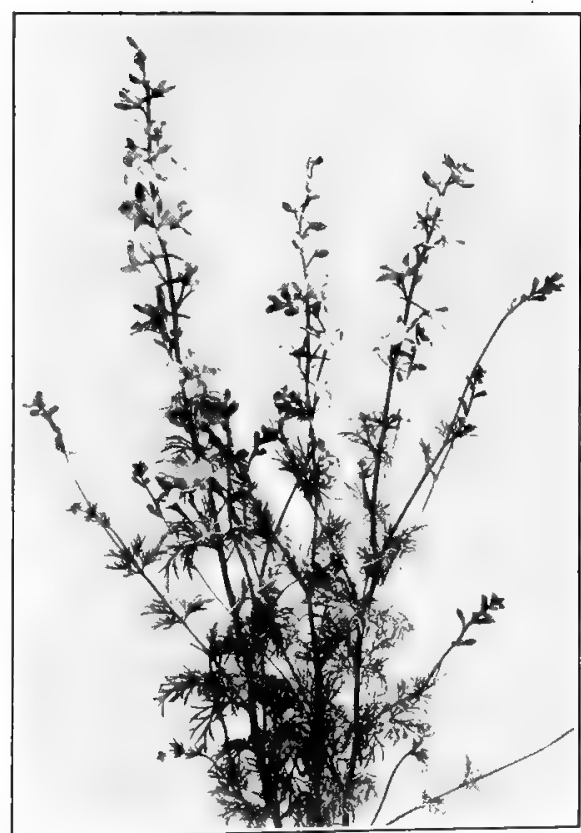

Fig. 195.-Summer LaRKSPUR. Its graceful habit, long stems, finely cut foliage and soft-toned flowers of blue, pink and white, make it desirable for cutting and equally as good for growing under glass for early Spring blooming can be sown in the open about June fifteenth, which will give you fine spikes toward Fall when the others are pretty well played out. 


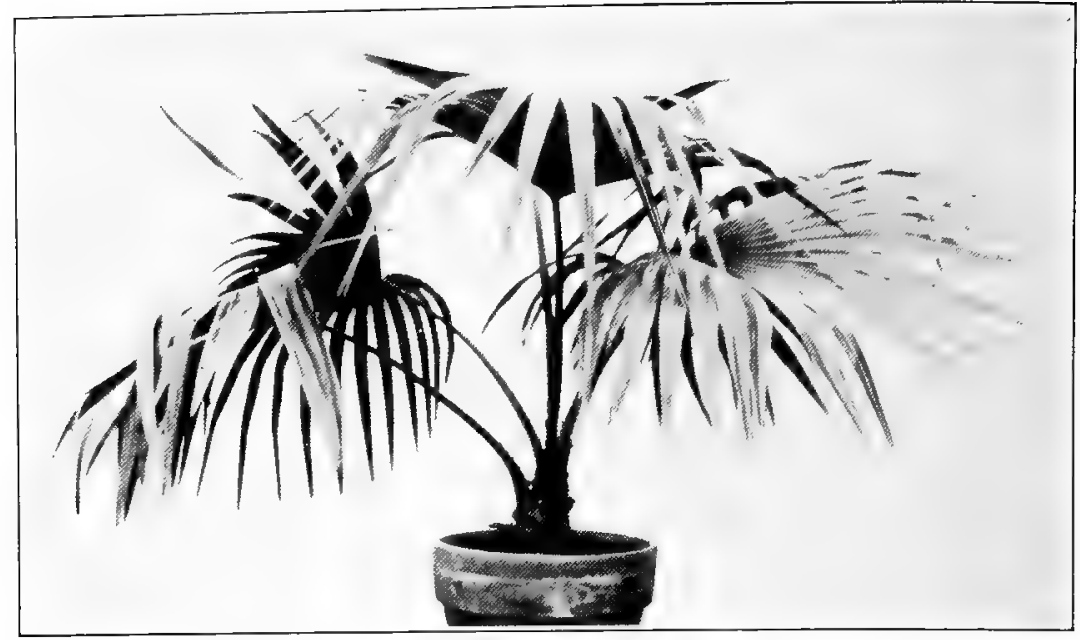

Fig. 196.-Latania borbonica. This is, perhaps, not as popular as in years gone by, but it is still a desirable palm, growing into a salable plant more quickly than most varieties

For indoors sow seed in December, and later plant the seedlings in a bench or a solid bed, allowing about four inches between them in rows eighteen inches apart. A later sowing can be made by the end of January. These will be at their best around Easter and I doubt whether you could have a more desirable crop in bloom at that time. In fact, every florist retailing his stock will find these Larkspurs desirable whenever he has any to cut, no matter what the time of the year.

\section{LATANIA BORBONICA (FAN PALM)}

As house plants the Latanias are not to be compared with Kentias, Arecas or Phonix Roebelenii, for they lack the gracefulness that the others possess even as small plants. Yet as decorative plants able to stand rough usage, they are of value. The florist who uses palms for decorating can easily purchase 4- or 5-in. pot plants of Latania and let them develop into larger specimens. Of late years the smaller sized Latanias have been used freely in the filling of window and porch boxes in connection with ferns, Ficus and English Ivies; here they can stand as much as the other plants, whereas the use of other palms would prove too expensive.

\section{LATHYRUS LATIFOLIUS (HARDY SWEET PEAS)}

While not of great value to the florist, these Sweet Peas seem to be gaining in favor every year. We have call for them to be 
planted at the gate entrance of a garden, along low wire fences and to cover stumps or rockeries.

The plant is perfectly hardy and there are both white and pink colored sorts. The best way is to get your plants from the nurseryman or sow seeds indoors, carry the plants in a cool house over Winter, and have them ready for planting out the following Spring.

\section{LAVENDER, SEA See Statice}

\section{LAVENDULA VERA (LAVENDER)}

Since hardy plants have come to the front, a call for a couple of Lavender plants is a common one. When filling an order for perennials including one or two each of Rose Geraniums and Lemon Verbenas to complete a list of bedding stock your customer wants, you will find Lavender desirable on accounts of its delightful fragrance, its little blue flowers during July, and its hardiness. You will want just a few clumps in your collection.

\section{LEMON VERBENA \\ See Aloysia \\ LIGUSTRUM \\ See Privet \\ LILAG \\ See Syringa}

\section{LILIES-GREENHOUSE SORTS}

What we know as Easter Lilies have become important florist flowers for not only Easter but the rest of the year as well. They are used for all purposes from weddings to funerals, are adapted for all occasions where flowers are used in pots or in a cut state, and with the help of cold storage bulbs, they are with us almost every day of the year. The display in the florist's cooler can hardly be called complete without a vase of cut blooms and buds in the center, whether the time be Winter, Summer, Spring or Fall

THERE are several varieties of Lilium longiflorum, that used almost entirely by the Lily specialist for Easter being giganteum. This is the easiest to handle on a big scale, that is, if proper heating facilities can be had so as to maintain a 60-deg. temperature at all times. Without this, you cannot force the Lily successfully, and you are far better off purchasing your requirements ready for the counter from the large grower.

\section{Forcing Lilium giganteum}

The bulbs from Japan usually reach us in November, but whether late or early, you should have pots and soil ready so you 


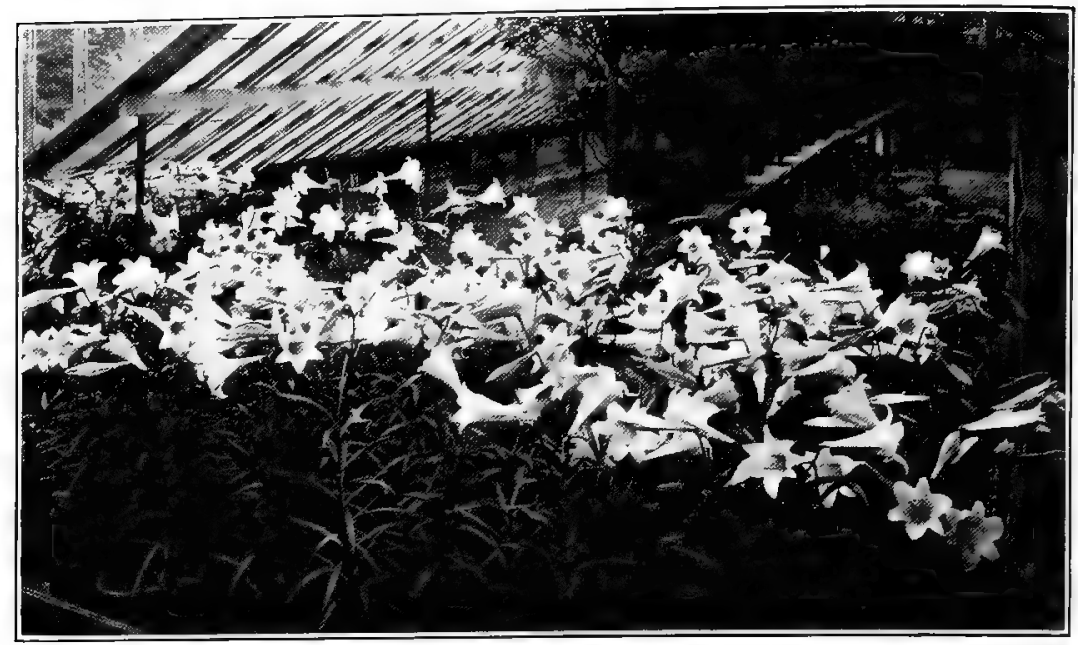

Fig. 197.-FASTER LILIES. If a few hundred bulbs of Lilium longiflorum develop into flowering plants just in time for Easter week they will pay well. But most smaller florists find it more profitable to let the specialists grow their Lilies for them

can get at the bulbs as soon as they reach you. There are growers who prefer planting the bulbs in the smallest size pot possible and shifting them in about six weeks or so; then there are some who use 5 - and 6-in. pots and let them remain in these pots; others who plant the bulbs one inch or so below the surface; some who have the tops just even with the surface; and still others who have them stick above the soil an inch or so. Some place the pots under a bench on top of each other, some put them in a frame and some place them at once on top of the bench.

Well, all these ways are all right, but to my mind, they have absolutely nothing to do with success or failure. Use common sense, make use of a fair, porous soil and drainage in each pot; start the bulb slowly in a 50-deg. house, and when once rooted and growth has begun gradually increase your temperature to $60 \mathrm{deg}$. and keep it there. If you have sound, well-matured bulbs to start with, such as haven't suffered in transit (which is often beyond the power of the importer or cannot be noticed in looking at the bulbs) you are reasonably sure of success if you keep up the temperature, keep the plants clean of insects and water them properly.

Read the experience of the most successful Lily growers, and this will be the sum and substance of their story. The fewer Lilies you force in the same house with a lot of other stock, the more certain you are of success. When a whole house is devoted to their culture with proper heating facilities and one man in charge to attend 
to their wants, condition are most favorable. But in either case, one has to start out with the right kind of bulbs.

A giganteum Lily can stand a temperature of $90 \mathrm{deg}$. toward the last two months if well rooted and in good health, but not quite far enough advanced in regard to showing buds. It is always safe to have this happen about six weeks before Easter; this is not to say that they can't be brought in in a shorter time, but it is better to increase the temperature above 65 or $70 \mathrm{deg}$. after the buds show, rather than before. Always bear in mind that the harder you force, the more particular you must be with watering, and the chill should always be taken off the water. Spraying freely is also neceessary. What makes for success is an even temperature, having the plants grow on during January and February, increasing the heat to $70 \mathrm{deg}$. if necessary, and slowly lowering it again later on to harden the plants off. A sudden drop with the buds partly advanced is likely to result in splits. On the other hand, to maintain a night temperature of $60 \mathrm{deg}$. and then, during a severe cold spell, to let it go down to $50 \mathrm{deg}$. for a week or more, will start trouble for certain. A Lily once stuck or stunted is usually beyond the reach of the best skill. It might flower, but it would be minus the stem which a Lily should have to be worth anything.

\section{LILIUM FORMOSUM}

This, to my mind, is the ideal retail grower's Lily, for the reason that you can successfully grow it if necessary in a 50-deg. house. This does not mean that you will have the plants in for Easter should this great Lily day fall on an early date. To insure this, the house should be kept a little above $50 \mathrm{deg}$. From bulbs planted in October, you will start to cut flowers from early March on and some of the plants will come in about May. But what of that? With sound bulbs and just a little attention, almost ninety per cent will develop into good flowering plants that you can use as they come along. If you are willing to subject some of the late ones to enough heat and hold those a little too far advanced back in a cool house, you can manage to get a good percentage in for Easter Week. Those who experience trouble with the giganteums should try the formosums.

\section{LiLium Harrisi}

Years ago we used Lilium Harrisii altogether for Easter and for years didn't know what it was to have a failure. But gradually this changed and since the introduction of $L$. giganteum, Harrisii is only made use of for extra-early forcing. With quite a few it is still a favorite, and the same is true of $L$. multiflorum, but giganteum and formosum are not likely to be replaced by them. 


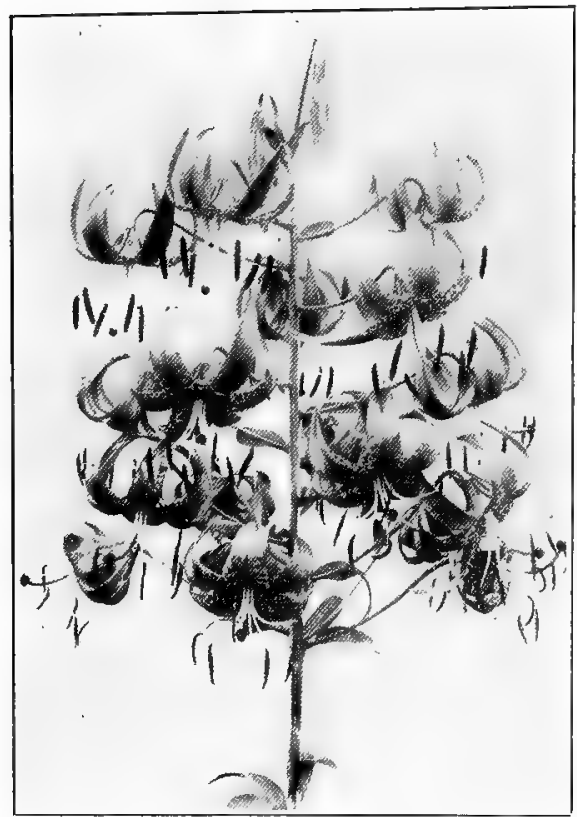

Fig. 198.-Lnium TIGRINUM, one of our many beautiful native Lilies, hardy over a great part of the United States

\section{Cold Storage Lilies}

Cold storage giganteums are being made a paying crop, not only by the specialist, but also by the florist, who has use for only a single case of bulbs at one time. To bring them into flowering condition is a comparatively easy matter and should be practiced more during the Summer and Fall months when there is no trouble about temperature; when, in fact, if anything, there is too much heat. Start the bulbs in a cool, dark place and later on let the plants have a sunny bench. As they start to open, use a shaded house and with a little care you can prolong the flowering period quite materially. You certainly will experience no such trouble as is often encountered in the case of plants intended for Easter blooming.

\section{LILIES-HARDY SORTS}

Under hardy Lilies the florist classes those varieties which, during the Summer and Fall months, flower outdoors. Of these, Lilium candidum, L. speciosum rubrum and $L$. $s$. album, and $L$. auratum are the most valuable to him; and of these four L. speciosum rubrum really should head the list as the most important, particularly from the retail grower's standpoint. Plants of this variety in flower can be had from late June on up to after New Year's - that is, with the help of cold storage bulbs. There is use for the flowers every day whether they are to be used with long stems for decorative purposes or as single flowers to take the place of an orchid in a corsage bouquet or in a floral design arrangement. If you want a beautiful wreath make it out of rubrum Lilies, Gypsophila elegans and Asparagus plumosus. You cannot beat this combination during the Summer and Fall months and the best of it is that even the smallest of florists can and should have all three items growing in his own establishment. 


\section{LILIUM SPEGIOSUM RUBRUM}

These bulbs usually reach us from Japan in November. If wanted for permanent planting in the hardy border and if the ground has been prepared and covered with manure to keep the frost out, the bulbs can be planted at once. For the best effect from seven to twelve bulbs should be planted in a clump allowing about ten inches of space between them and planting them about six inches deep. As long as the Winter isn't too severe they will come out nicely in the Spring; however, it is always best to apply a heavy covering for newly planted bulbs.

The florist will most likely want his plants to flower

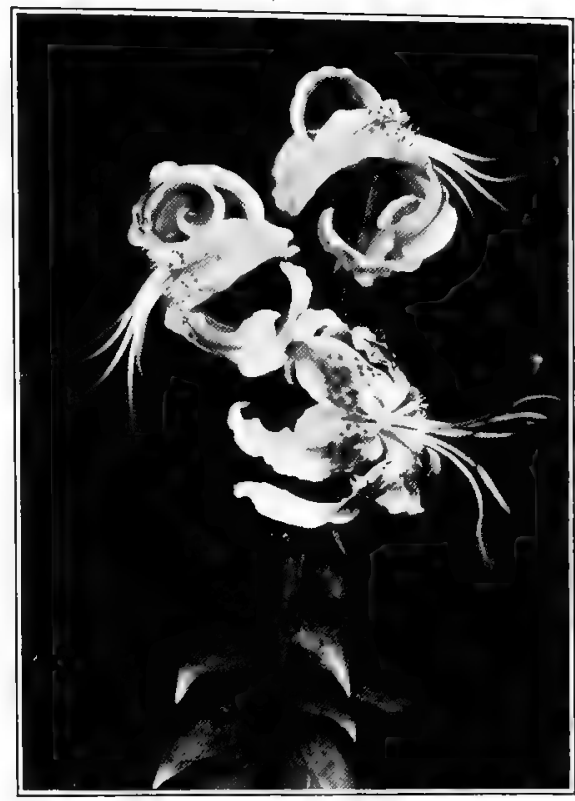

Fig. 199.-LIIIUM SPECIOSUM RUBRUM. This is a money making Lily. With the aid of cold storage bulbs the florist is able to cut flowers over a long period

in pots This makes their handling easier, if he doesn't want them to flower all at the same time. Even so some plants are in bloom for almost a month from the time the first flower is ready to cut until the last one opens.

Pot up the bulbs in the pots they are to flower in, getting the top of the bulb just below the surface, water throughly and either place in a cold house or, what is as good, in a deep coldframe with a layer of soil or straw on top of the pots, for while freezing doesn't hurt them, if you can prevent it, so much the better. By the first of March a batch of plants might be brought into a 45 -deg. house where active growth will start in a couple of weeks. The plants brought into a Carnation house later on will start to flower toward the middle of June; another lot can be brought in by the end of March and treated the same way. By early April all covering over the pots should be removed as otherwise the plants will grow through it. You can then either bring all of the plants in or only a part, leaving the balance in the frame where they will come into flower by August.

Cold storage bulbs can be planted from February up to July and these will flower from August on until January. We have had 


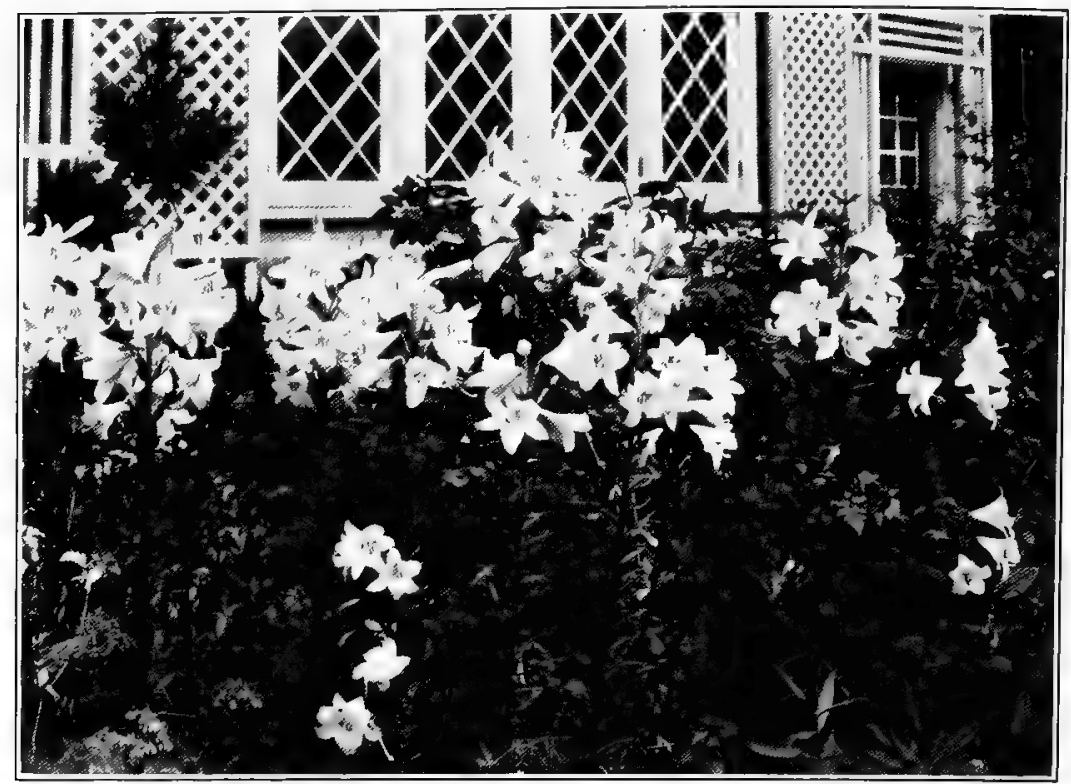

Fig. 200.-Lilium CANDIDUM. This is a splendid hardy Lily which can also be flowered under glass-although it will not stand hard forcing

these Lilies in 6-in. pots and after flowering have allowed the plants to dry off slowly. Then the bulbs, soil and all, were carefully planted in late Fall in a frame and almost every one of them produced a fine plant the following Summer and flowered. Lilium speciosum. album, the white form, while beautiful is not as hardy nor do we use anywhere near as many plants of it as we do of rubrums.

\section{LILIUM CANDIDUM}

With Lilium giganteum and others which can be had' in flower almost the entire year available, $L$. candidum isn't much used by the florist. Yet it is of value, especially when grown outdoors in 5 -ft. beds with temporary frames placed over them. Here one can get the flowers several weeks ahead of time. The retailer can always make use of the graceful flowers on long stems. Bulbs may also be potted in August or September, carried along in frames and later in a cool house. Placed in a temperature of 50 deg. by March, they will flower for Memorial Day or thereabouts. But they will not stand hard forcing like $L$. giganteum or $L$. Harrisii. To behold $L$. candidum at its best it should be planted in large clumps in the hardy border.

The bulbs are usually offered in August and the less they lie about the better, for they are quite different from other Lilies. 
They apparently don't have a period of dormancy and therefore suffer when out of the soil.

\section{LILIUM AURATUM}

This is, perhaps, the most showy of all hardy Lilies. Its large, dark-spotted flowers borne on heavy, tall stalks always attract attention. The bulbs reach us from Japan the same time those of L. speciosum do, and can be treated the same way. They will flower well in pots, yet the flowers are not as useful to the florist as those of $\mathbf{L}$. speciosum.

\section{Other Hardy LiLies}

For permanent planting both Lilium tigrinum splendens and its double form (flore pleno) are excellent and good even for cutting. Both are of an orange color.

Lilium superbum, of reddish orange color, is also fine. Lilium Henryi has a dark yellow flower with brown spots; it is also called the yellow speciosum. L. Hansonii is a fine orange-colored sort with dark spots, excellent for outdoor planting. While some of our showiest hardy Lilies hail from Japan, L. regale (myriophyllum) came to us from Ghina. With its large flowers, white overlaid with pink and with a yellow throat, it is one of the most stately

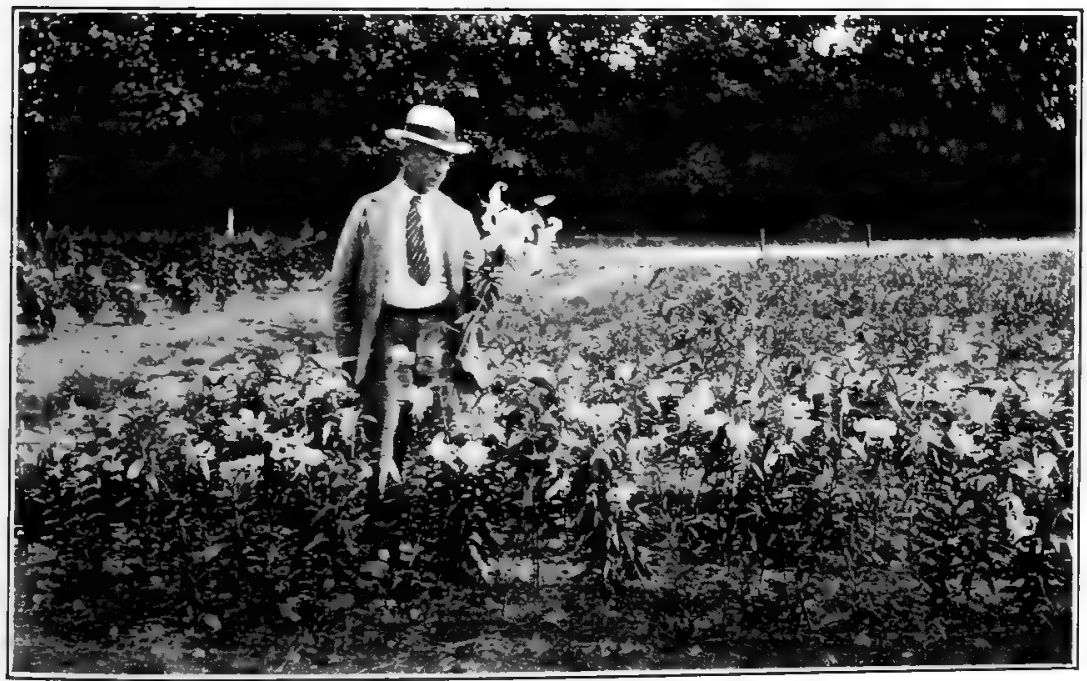

Fig. 201.-Growing Hardy Limies IN Ameruac. A block of hardy Lilies grown hy P. M. Koster in New Jersey and called by experts superior to many raised from imported Japanese bulbs. The plant in Mr. Koster's hand is a seedling L. auratum; it flowered in eighteen months from seed 


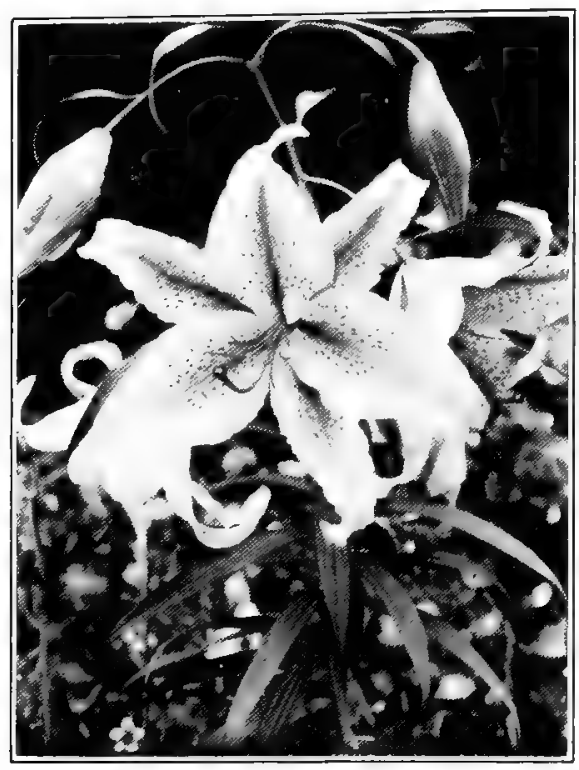

Fig. 202.-Lilium auratum. While not as valuable for the florist as some others, this is one of the showiest of all hardy varieties and a fine companion for Lilium speciosum of all. Treated like $L$. speciosum rubrum or $L$. auratum, it appears to be as hardy as either and a most welcome addition to what we already have. It can also be grown and flowered in pots.

\section{LILY OF THE VALLEY}

The flowers of the Lily of the Valley are used the whole year around by the florist. With the help of cold storage facilities, the pips are available for forcing at any time and the great demand for the flowers has produced specialists near the large flower markets in every section of the United States who force many thousands of pips and put a steady, daily supply of flowers on the market. Here,

as in so many other lines, it no longer pays the retail grower to think about doing the forcing himself and making it pay, with the exception, perhaps, of doing it for special occasions like Christmas, St. Valentine's Day and Easter. Whether or not he uses cold storage pips, as is necessary for Christmas forcing, it is always well to allow about twenty-four days from the time the pips are put into sand until the flowers, or the majority of them, are ready to be cut.

The specialists and large seed houses can supply you with any amount of cold storage pips just when they are wanted, which makes it unnecessary for anyone to try and do the storing.

For Christmas, pips should be planted in sand in the forcing frame or they may be potted up into 5 - or 6 -in. pots, using as many pips as a pot will hold and cutting the roots back if too long for the pots. Place the pots in the forcing frame. This can be of any size, made out of 12-in.-wide lumber and fitted over a bench with sufficient bottom heat so as to create an $85-\mathrm{deg}$. temperature around the pips. The frame can be covered with a shutter or sash and should be covered so as to keep all light out for the first twelve days. It is a matter of heat, darkness and moisture. In order to produce three or four inches of growth supply these requirements and don't 
chill the young growth with cold water, but rather have it of the same temperature as the air in the frame. After ten or twelve days, let up a little on the heat and allow just a little light. By the twentieth day the first buds will be open; then more air and less heat should be given to properly finish them.

Just what you use to plant the pips in matters little; proper heat, moisture and shading have to do the work and that holds good with any you force. The later you force the easier it is and the less heat is required. For Easter almost any place will do for forcing. Six- and 7-in. pots or half pots filled full of pips and placed on the hot water returns twenty-four days before Easter will without much trouble develop into well-foliaged and well-flowered plants which will find ready sale.

Here, as with everything else, we have failures as well as successes, and actual experience is necessary in order to become efficient, but you have only to force a few thousand in order to find out that except for the above-named special flower days, on which there is always an increased demand for Valley, it is cheaper to purchase the cut flowers and that, no matter what they cost you, they are cheaper than you can yourself produce them on a small scale.

\section{LOBELIA}

Lobelias-the dwarf as well as the trailing sorts -belong in your bedding stock assortment. The dwarf sorts are used for borders around beds, and the trailing ones are just the thing to hang over the edges of a porch box or lawn vase. Seed should be sown in January in order to obtain stock. The seedlings are so small and slow growing for the first weeks that it is hard to imagine them ever amounting to anything and many make the mistake of taking four or five of them in a bunch when transplanting them into flats or later in potting them up. This will result in obtaining larger

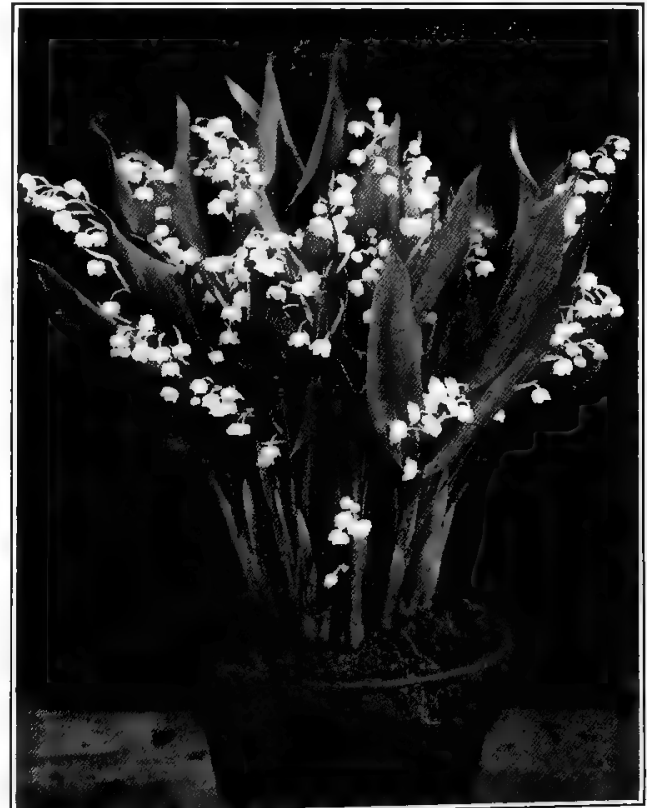

Fig. 203.-LILY OF THE VALLEY. It takes a specialist to force Valley profitably during Midwinter. Toward Spring, however, even those with not the best of facilities can have nice pans in bloom and sell them eithe
flowers 
plants in a shorter time, but there is no lasting quality to such stock. A far better way is to transplant or pot them up singly; they will then have a chance to branch out and deyelop into bushy specimens by the time you want them in May.

Lobelias can also be propagated from cuttings. Lift a few plants from the field in the Fall; pot them up and carry them over in a cool house. A few plants will give you many hundreds of cutgings. Kathryne Mallard, the double sort, does not grow from seed, but is a fine variety well worth having.

Lobelia cardinalis is a handsome herbaceous plant for the hardy border, most effective when massed. It sends up slender stalks two to three feet tall covered with cardinal red blossoms. It is native to many sections of the United States and when you consider that more or less difficulty is often experienced in growing the plants on from seed with all possible care, one wonders how they become established in low places often under water during Winter and Spring. Yet there they are by the thousand, a mass of fire, more glowing than Salvias at their best.

For flowering plants, sow in late Summer and, if possible, transplant early so as to obtain well established plarts by Fall. They will bloom the following year. There is no use planting Lobelias in dry locations; they want a lot of moisture and a light soil.

\section{LONICERA (HONEYSUCKLE)}

If you handle nursery stock and have a piece of land where you grow on a part of it, by all means carry enough Honeysuckles. For they always sell and there is hardly another flowering shrub that will get along with less care. It doesn't mind in what soil it is grown, where it is planted, or how you treat it; it seems to be ever ready to show its appreciation in a wealth of blossoms, most of them delightfully fragrant; or by covering itself with red berries all Summer, as is the case with $L$. bella albida or $L$. Morrowii.

The best known of the Bush Honeysuckles is Lonicera tatarica, of which we have both a pink and a white sort. There are but few people who don't know a Tartarian Honeysuckle. You may see it as a specimen plant fifteen feet high, loaded down with flowers in June, but even when only two feet tall it is equally as well adapted for use as a hedge plant. Where you want to obtain a quick growth to screen a building or a backyard, there is nothing much better than the Tartarian Honeysuckle.

$L$. bella albida can best be appreciated when given all the room it needs to grow into a large specimen. To my mind it should never be planted in masses or groups, but should be given from ten to twelve feet to grow in. You never see it at its best except when alone. 
Lonicera Halliana or Hall's Climbing Honeysuckle is one of the best of hardy climbers, a clean, rank grower covered with fragrant white flowers changing to yellow, and holding its foliage long after the frost has stripped most other climbers.

L. sempervirens we know best as Scarlet Trumpet Honeysuckle. It is an excellent hardy sort, flowering all Summer and, when once well established, a free grower. The Golden sort is also most attractive, but a slower grower.

\section{LOVE-IN-A-MIST See Nigella}

\section{LUPINUS}

Both the annual as well as the perennial Lupines are of value to the florist. Both, when well grown and with good spikes covered with their Pea-shaped flowers in white, rose, light and deep blue, make excellent cut flowers. Some growers specialize on Lupines under glass and produce enormous spikes which retail at a high price.

\section{Perennial Sorts}

These are not always a success with every one and the plants often are injured during a severe Winter. They must be sown early, say in June, and planted in well drained yet moist soil. They bloom in late June and when massed, if they have not suffered, they make a grand showing. Whenever possible, if you have plants of your own, it is better to fill your orders for them in early Spring, than to take chances with transplanting them in late Fall.

\section{Lupines Under Glass}

The annual sorts are fine for forcing or flowering under glass. For an early crop, sow seed in September or October; pot up later on and perhaps shift, so as to have well established $31 / 2^{-}$or 4 -in. plants by January. They can be planted in a solid bed,

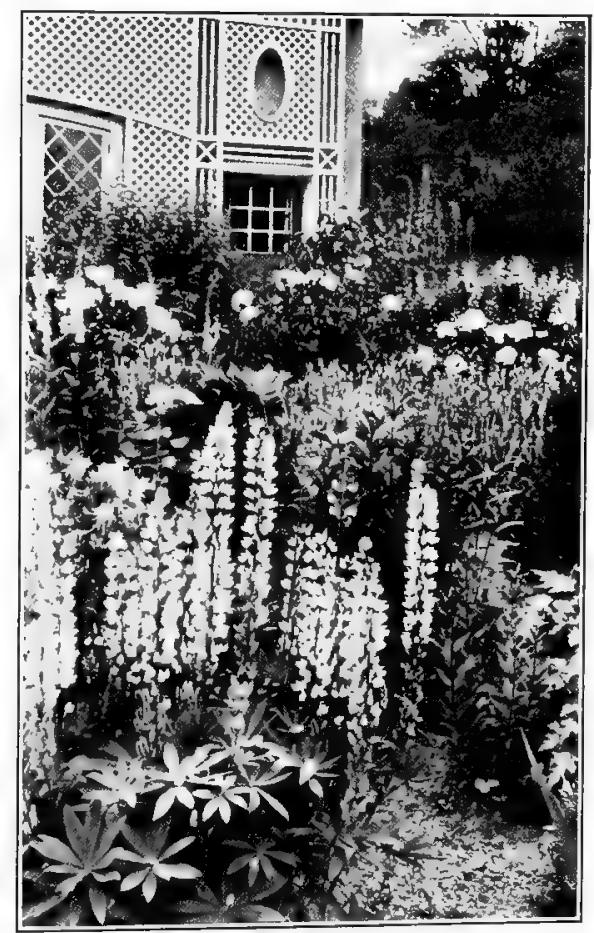

Fig. 204.-Lupines IN A Border. How can people help but fall in love with herbaceous plants when it is possible to create such a pleasing setting as this? Of course, the Lupines will not last all Summer, but what could take their place for the time they are with us? 


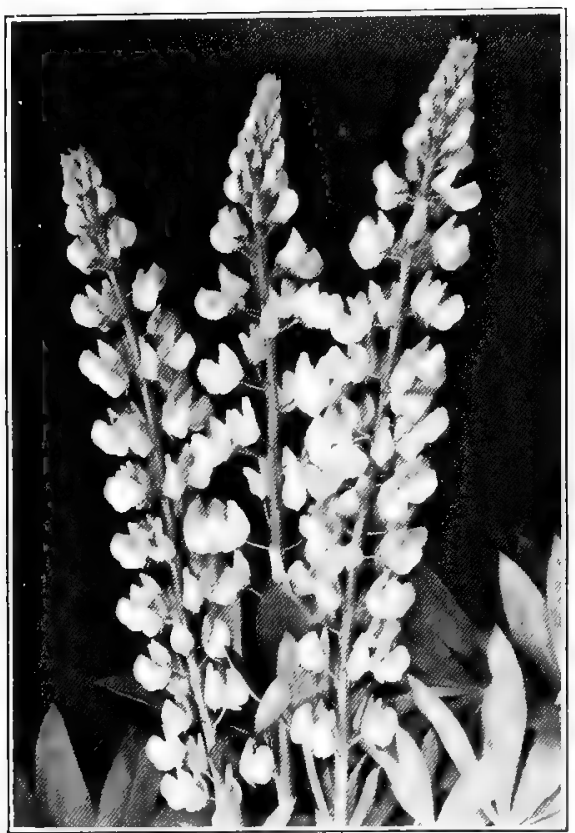

Fig. 205.-Lupines Grown Under Glass. Sown in late Fall and grown in a solid bed in a cool house they give desirable cut flowers from early March on in fact, this is better than making use of a bench. Allow from twelve to fourteen inches of space between them. A house of 45 to 48 deg. is sufficient. The first spikes ready to cut in March will, perhaps, be the largest, but the side shoots coming up from the base of the plants will form the second crop and will be fully as valuable if not more valuable to you. If you desire a good lot of spikes during May, sow seed in January and plant out about March.

\section{For Summer Flowering}

Plants from seed sown in March carried along in 21/2-in. pots and planted in a frame by the end of April will produce flowers in June. Every florist selling bedding stock can dispose of Lupines during the Spring months and should prepare a good number of plants for that purpose.

You can get Lupines to flower from seed sown early outdoors, but when they don't start to flower until the middle of July it is too hot to obtain good sized spikes.

\section{LYGHNIS}

There are a number of showy forms of Lychnis adapted for the hardy border, but one of the easiest to grow is Lychnis Haageana hybrida. If sown in February, under glass; and planted out by the end of April, the plants with their orange, red, and deep scarlet flowers will be in full bloom by June. They can be cut, but are of no great value to the florist except as material to sell, as field plants, along with other hardy stock in Spring and Fall.

\section{LYGIUM BARBARUM (MATRIMONY VINE)}

If you have a call for a vine or climber that will grow anywhere and in any soil and faster than others, that is the time to recommend the Matrimony Vine, good for trellis, arbor, tree stumps and edges of ravines or hard clay banks. 
Your nurseryman will supply plants and when you set them, cut them back severely; the young growth produces little purplish flowers followed by berries that turn red in Fall and remain a long time on the plants.

\author{
MAIDENHAIR FERN \\ See Adiantum \\ MAPLE, JAPANESE \\ See Acer \\ MARIGOLD \\ See Tagetes
}

\title{
MARGUERITES (CHRYSANTHEMUM FRUTESGENS)
}

The old favorite called Paris Daisy has been almost entirely replaced by larger and better sorts, of which Mrs. Sanders is perhaps the best known. Still we continue to make use of the old sort which, grown into a large specimen with a mass of bloom, makes a desirable

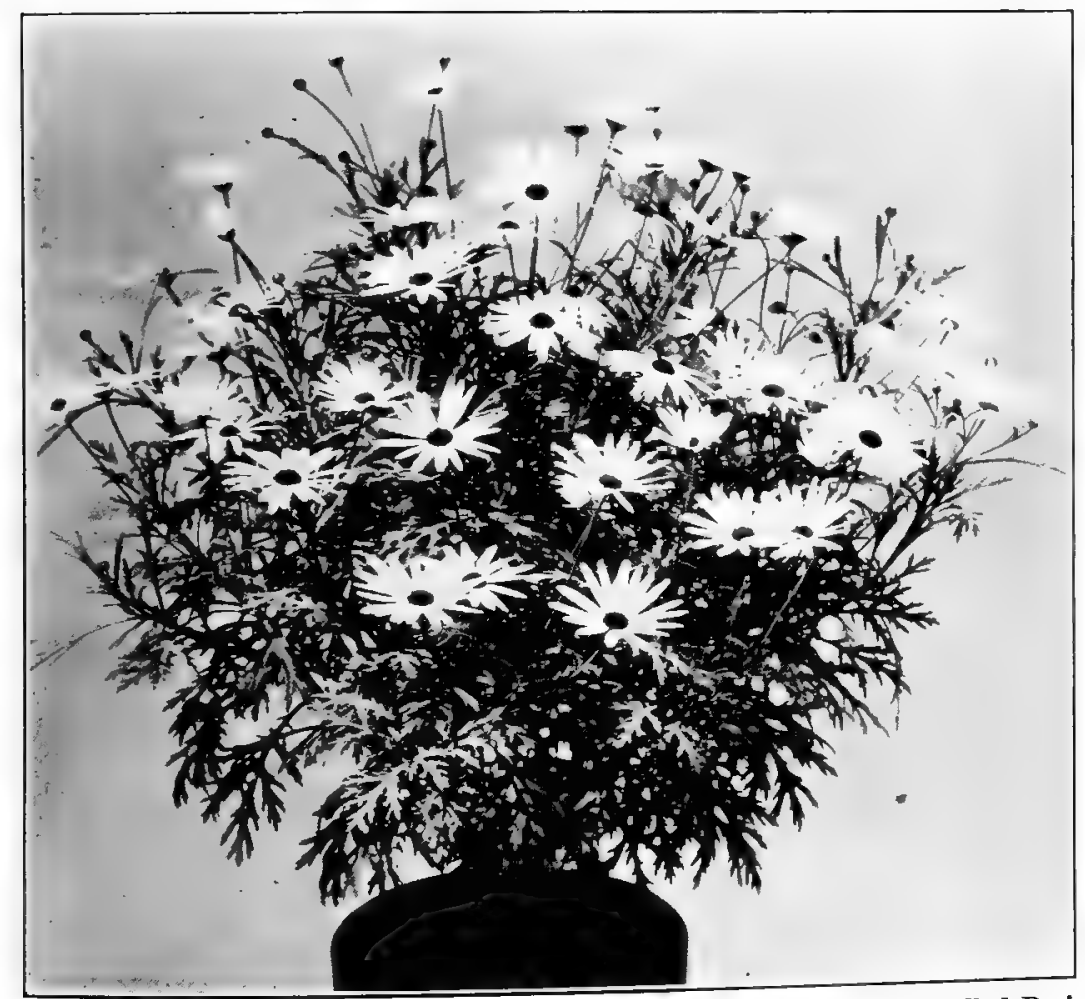

Fig. 206.-A Specrmen Marguerrte. There is little chance for the so-called Paris Daisy when the newer Marguerites can easily be grown into plants like this of Nicholson's White; Boston Yellow is also popular for indoor flowering 
Easter plant. Boston Yellow, which is a good strain of that color, makes a profitable indoor crop to grow for Winter and Spring and there are growers who do it successfully either planted out on benches, in solid beds, or in large pots. With pots, however, there is apt to be a lack of stem. On the other hand, you can cut earlier flowers from such plants than from those planted out where they haven't a chance to become potbound. Another way to make them flower is to grow them in pots, enlarging the hole in the bottom a little, and plunging the pots up to the rim in soil.

For Winter flowering, a Carnation house temperature is about right and it is well to start in Fall with established pot plants. For Spring, use plants such as you want for window or porch boxes. Guttings should be rooted during late Fall and Winter and the plants kept shifted up to April. For Easter flowering in pots, you can take $21 / 2$-in. stock in flower and make up showy pans; or cuttings rooted in late Summer may be grown on in a cool house, keeping the plants shifted until they get into 5-, 6-, and 7-in. pots.

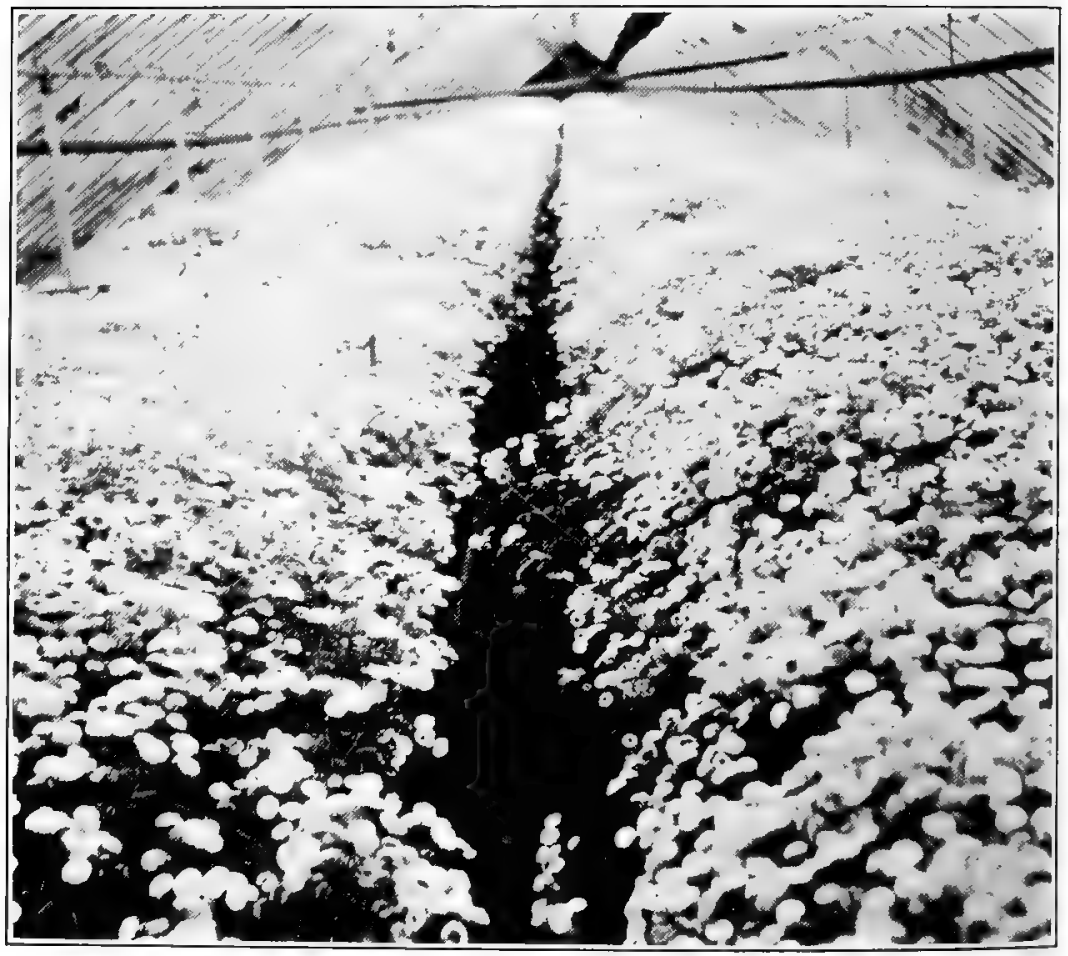

Fig. 207-A House of Feverfew. This is the way Nelson of Framingham, Mass., grows Feverfew for early Spring. To get a crop like this in time for Mother's Day is well worth trying 
After that, instead of giving another shift, feed them every three weeks or so with liquid cow manure.

The variety Mrs. F. Sanders also makes a fine Summer bloomer when planted outdoors. You can recommend it as such and even plant a few yourself.

\section{MATRICARIA GAPENSIS ALBA PLENE (DOUBLE FEVERFEW)}

The double Feverfew in years past could be found in every retail grower's establishment; every window contained a few plants and they were considered indispensable as sources of cut flowers during Summer. It is still grown, but not so extensively.

It pays best as a catch crop for April and May flowering, for which purpose carry a few stock plants in a cool house, and take cuttings during January. Plant out on a bench twelve inches apart and pinch back the center shoots. A few can also be grown on in pots, and sold during the bedding season or planted outdoors. The trouble with them in window boxes is that they don't remain in condition long enough; but as a cut flower they are useful at any time. They also can be grown from seed, but usually there are too many singles among such plants

\section{MATRIMONY VINE}

See Lycium

\section{MAURANDIA BARGLAIANA}

The Maurandias are graceful little climbers of special value for wire hanging baskets. Seed sown in late February will give heavy $21 / 2$-in. pot plants by the end of April when they should be planted in the baskets and the latter hung up. By fastening the vines with hairpins on the sides of the baskets, you can have perfect balls of green by Memorial Day and also have the handles covered. Later on the little blue flowers will appear and help to make the baskets still more attractive. A half shady position will suit them best when grown in baskets during Summer.

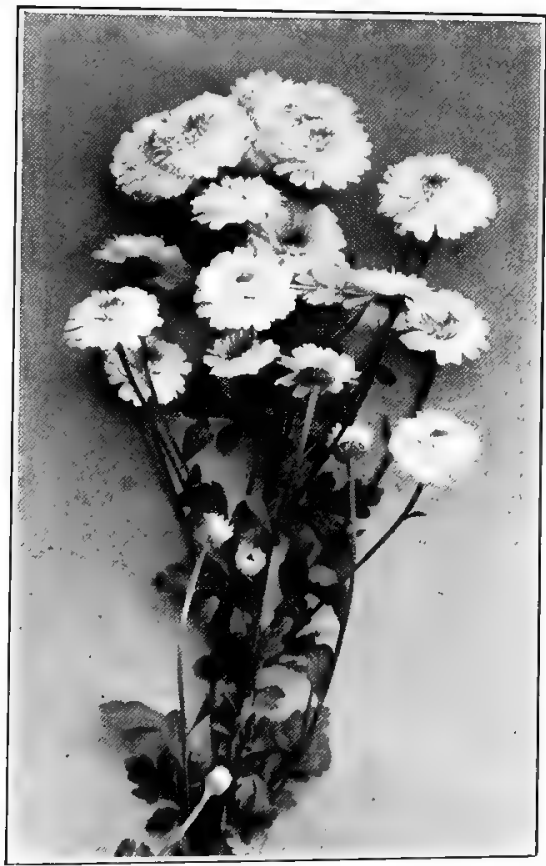

Fig. 208.-Feverwew. A "close-up" of indoor-grown Matricaria which can be made a paying crop during the Spring months 


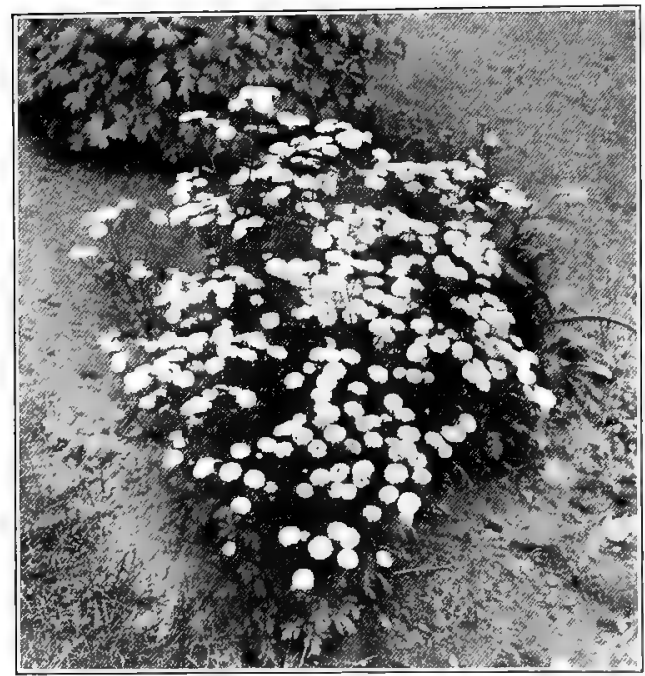

Fig. 209. - FeverFew Outdoors. Showing how bright and attractive a clump can be, either alone or with flowers of contrasting colors

\section{MEADOW RUE See Thalictrum}

\section{MERTENSIA VIRGINIGA (BLUE BELLS)}

The Virginia Blue Bells are fine for planting along the margin of a ravine, for edging a shady shrubbery border, or for naturalizing. Their foliage dies down during Summer, and in cultivated beds or borders this should be provided for.

They have flower spikes about a foot in height, which usually are full of clusters of blue flowers toward the end of

April. That is the reason your patrons will want them. Get a good sized batch started and it will furnish you with plenty of stock, as the plants are increased by division of the roots in Fall.

\section{MESEMBRYANTHEMUM CORDIFOLIUM ROSEUM}

That seems an awfully long name for such a little plant even though it is most useful during the bedding season. It has dark green, fleshy leaves with star-shaped, glistening pink flowers, reminding one of a miniature Cactus blossom. Almost everyone who comes to your establishment will admire it and well-filled hanging baskets with the plants drooping over the sides will always find purchasers. The plants can also be used in the rockery to good effect. Carry a few stock plants in pots over Winter in a cool house; these will furnish you with quantities of cuttings which root easily.

\section{METROSIDEROS ROBUSTA (BOTTLE BRUSH)}

The Metrosideros are among the showiest of Easter plants. With their fine foliage and spikes of small, reddish flowers they always attract attention among other stock in the show house. We used to import them from Europe, but I doubt whether there was ever any real dollars and cents profit for the smaller florist in handling them. However, with them as with a number of other plants, they pay us well in the show they make, thereby helping to sell other stock. It would take too long to raise plants from cuttings, but if you can get hold of some bushy 6- or 7-in. pot specimens 
consider carrying a few in a cool house and bringing them into a 52-deg. house five weeks or so before Easter if you want them in bloom at that time. As to leftover plants, cut them back and handle them almost like Azaleas.

\section{MICHAELMAS DAISY \\ See Aster \\ MIGNONETTE \\ See Reseda}

\section{MIMOSA PUDICA (SENSITIVE PLANT)}

Of the plants which always attract attention, the Sensitive Plant is one. Almost every patron visiting your establishment is usually interested when requested to touch the leaves and see them close up and droop. A good way to advertise is to give a few of these plants away to children who happen to come in. No matter where these plants land, they are bound to make people talk about you and that is what you want.

Sow seed in a warm house about March and you will have nice plants in $21 / 2 \mathrm{~s}$ during the bedding season. A few can be shifted and carried all Summer in the show house.

\section{MIMULUS MOSGHATUS (MUSK PLANT)}

This makes a fine companion for Mimosa pudica (see above), and a few plants should be carried during the Spring and Summer months by the retail grower, if for no other reason than the delightful odor or fragrance of their leaves. Aside from that, a plant in a 5-in. pot will, if given a chance, cover the sides of the pot completely, producing at the same time a lot of little single yellow blossoms. If you are looking for something to attract attention, sow a package of seed about February and grow the plants on in a 55-deg. house.

\section{MIMULUS TIGRINUS (MONKEY FLOWER)}

This is a funny name for this flower and I don't see where the resemblance comes in. The beautifully colored and spotted flowers resemble far more closely miniature Gloxinias or Gesnerias than monkeys. However, they are easily grown from seed sown in February, the plants being carried in a 50-deg. house. I am sure if you have a batch of them in full bloom in $4 \mathrm{~s}$ by the end of May, you will sell them all. They can also be planted out in shaded positions to flower all Summer, but they cannot be called ideal bedders.

\section{MOGK ORANGE \\ See Philadelphus}

\section{MONARDA DIDYMA (MINT)}

Monarda didyma, or Cambridge Scarlet, has very showy, brilliant, deep scarlet flower heads during Midsummer, against a 


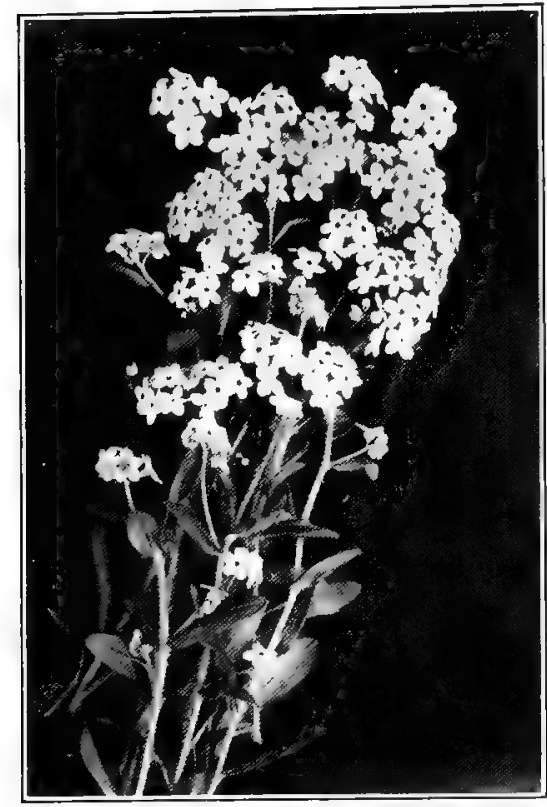

Fig. 210.-Myosotis, to which the florist who retails his crops should always devote part of a bench in a cool house. There is hardly a flower combination sent out in a box that could not include a few sprays

setting of dark green foliage with the real Mint fragrance. As with the common Horse Mint, if you have a few clumps established and have call for the plants, you can take up small divisions to fill your orders with. The thing is to have some on hand if you handle hardy stock at all. For mass effect in a perennial border they are especially to be recommended.

MONKEY FLOWER See Mimulus

MONKSHOOD

See Aconitum

\section{MONTBRETIA}

Montbretias, while not of much value to the florist, are showy plants when grouped in masses among the perennials. The bulbs can be planted in Fall, or, what is safer, in Spring. There are some very showy sorts, mostly coming in yellow and orange shades and a few in orange-scarlet. The most satisfactory way is to start the bulbs in the greenhouse in gentle heat and have plants well advanced, ready for bedding, in May the same as one would do with Cannas or Caladiums. America is a fine deep orange red, California is a pure yellow, and Ernest Davison a light orange, and all will flower during Midsummer and grow about three feet high. While the spikes can be used for decorating, they are not much used as cut flowers. If bulbs are left in the open they will overwinter but they need a good covering.

\section{MOONVINE \\ See Ipomoa grandiflora \\ MOUNTAIN GURRANT \\ See Ribes}

\section{MUSGARI BOTRYOIDES (GRAPE HYAGINTHS)}

The little blue and white Grape Hyacinths are fine for naturalizing and form good companions for the Virginia Blue Bells in that respect. They come in blue, rose, yellow, and white and grow from 
bulbs which we used to get from Holland in Fall along with our other stock. Hyacinthus monstrosus is the blue-feathered Hyacinth, growing less than six inches in height and fine for the edge of shrub beds. Another desirable variety belonging to the hardy border is H. moschatus major, the musk-scented Hyacinth.

\section{MÜSK PLANT \\ See Mimulus}

\section{MYOSOTIS (FORGET-ME-NOT)}

There are a number of kinds of Myosotis-blue-, white-, and pink-flowering, all of which are among the early Spring-flowering plants that the florist carries for bedding. $M$. alpestris Royal Blue is the best real blue. Sow seed of it at the same time the Pansies and English Daisies go out, that is, during late July or early August. Transplant the seedlings about four inches apart in frames where they will flower the following Spring.

M. dissitiflora grows only about six inches in height and if overwintered in frames where you can get at them, the plants can be lifted about four weeks or so before Easter and potted up to provide a mass of beautiful large blue flowers.

\section{For Indoor Flowering}

Good strains of indoor-flowering Myosotis have been worked up and these are propagated through cuttings which root at any time of the year as quickly and as easily as German Ivy. A good way is to root a batch during Summer and carry the young stock in $21 / 2 \mathrm{~s}$ until ready for benching. The average retail grower doesn't want a whole bench full; a few feet will give him all the flowers he wants during the Winter months. Another way is to plant a few along the edge of a Garnation bench.

\section{MYRTLE \\ See Vinca}

\section{NARGISSUS}

$A$ MONG the most important bulb stock the florist makes use $A$ of the Narcissi come next to the Tulips. Almost every variety listed - and there are many - can be used either in a cut state or for pot plants and in most cases for both. No retail grower can do business without Narcissi. Indeed, in spite of the fact that they are so well known all over this country and Europe and have been grown for so many years, they deserve more attention as money makers when grown under glass. At present there are far too many who still cling to the old way of making use of two or three varieties, planting 1000 of each, having them come in practi- 


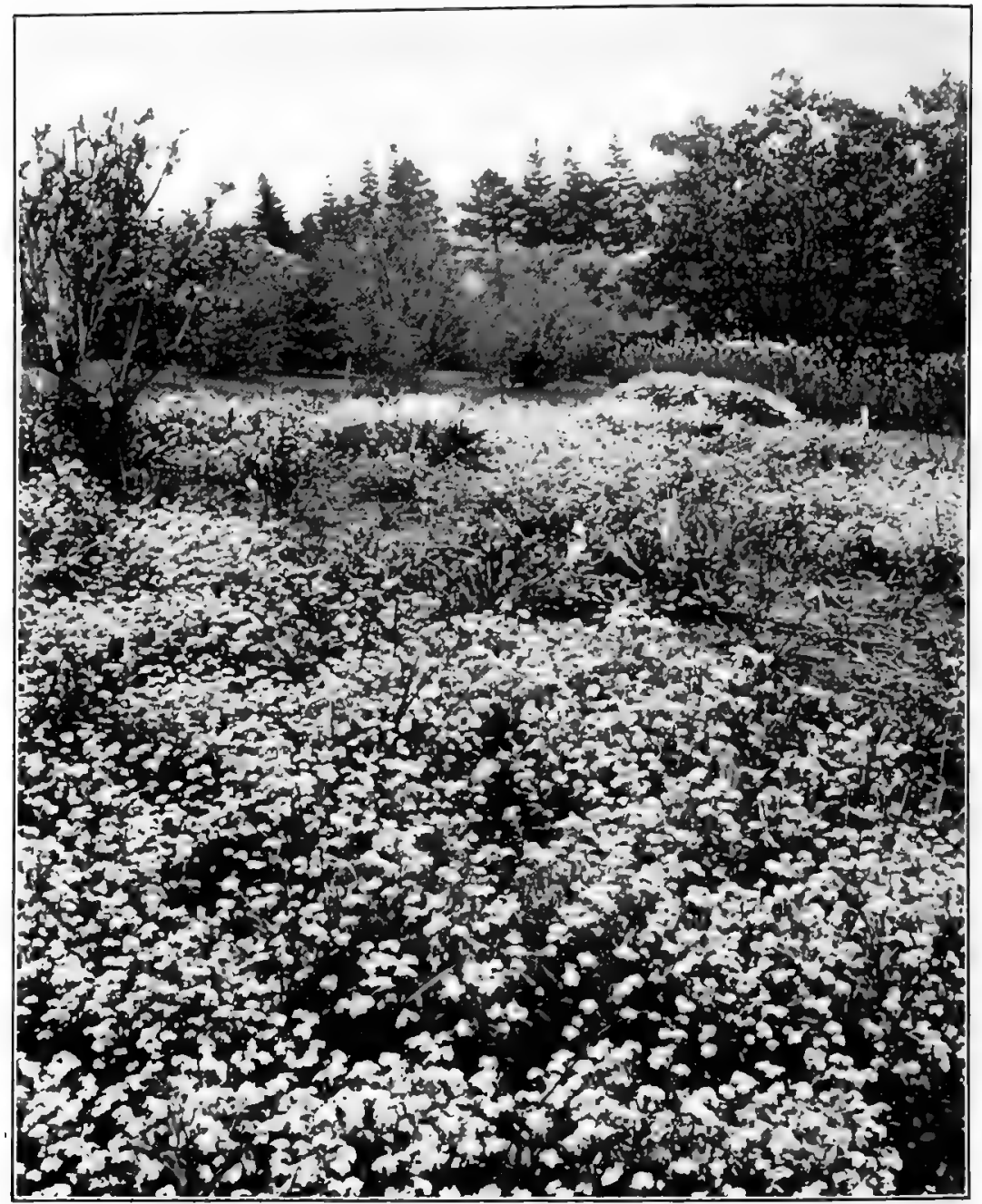

Fig. 211.-A Mass Plantivg of Fonget-Me-Nots hard to beát for effectiveness. Several fine Spring-flowering varieties sown in early August and treated like Pansies are fine for bedding; later they can be replaced with Geraniums or other bedding plants

cally all at the same time and letting it go at that. That is a hit or miss way, makes but a poor effect on the public, and often does not return the original price of the bulbs.

I am sure that a good profit is assured almost every florist forcing Narcissi who arranges things so as to have a small but steady supply of flowers coming in from November on, up to, and after Easter indoors, and from that time on again in frames and outdoors until the last poeticus flowers are cut-usually some time in May. 
After all, it is a simple matter, yet with many it would mean growing ten times as many bulbs and making ten times as much money from them. You may not be able to make Roses and Carnations pay, but I have yet to see the establishment so small or old that it isn't possible to do Narcissi there on a small scale better than the biggest bulb forcer can do them in the most uptodate range and with all kinds of facilities.

\section{Forcing Narcissi for Profit}

To make the most out of the Narcissi you grow under glass, make out a list of the Polyanthus sorts, such as Paperwhites, Grand Soleil d'Or, Double Romans and others you may want, then figure about how many you can use each week from the end of November or thereabouts up to February first. Add twenty-five per cent more to that amount and place your order. When the bulbs are planted and brought into a house, make it a rule not to subject them to any greater degree of heat than you started out to do, so as to be sure to follow your original schedule. There is no harm in having to purchase flowers should occasions demand this; in fact, it is a far better thing than to be caught with flats full of stock ready to be cut but for which you have no use.

While we haven't always control over weather conditions and temperature, a whole lot can be done to avoid having too many flowers come in at one time and then having no flowers at all for the several weeks following.

What holds good with the Polyanthus varieties holds good with the others in regard to figuring out the amount of stock you can use. All other sorts, outside of the Polyanthus, can freeze when once well rooted and kept outdoors; yet freezing is not necèssary in order to have them force well. In fact, too much freezing will, or at least may, hurt them, so see to it that the flats or pans the bulbs are in are not only moist, but are well protected with a layer of earth over them as well as manure or straw on top of the earth. If you are located in a section where several feet of snow in January is nothing uncommon, I should place boards over the straw to make shoveling easier.

\section{Narcissi in Frames}

It doesn't pay the retail grower to plant 1000 or more of one variety of Narcissus (with the exception perhaps of $N$. poeticus) outdoors and place frames and glass over them for early Spring flowering. The flowers don't last long enough to permit you to grow on so many of one variety and dispose of them. What is, however, a good way is to plant just a few--say eight or ten sortsboth single and double; they will not all bloom at the same time and no doubt will come in handy. 


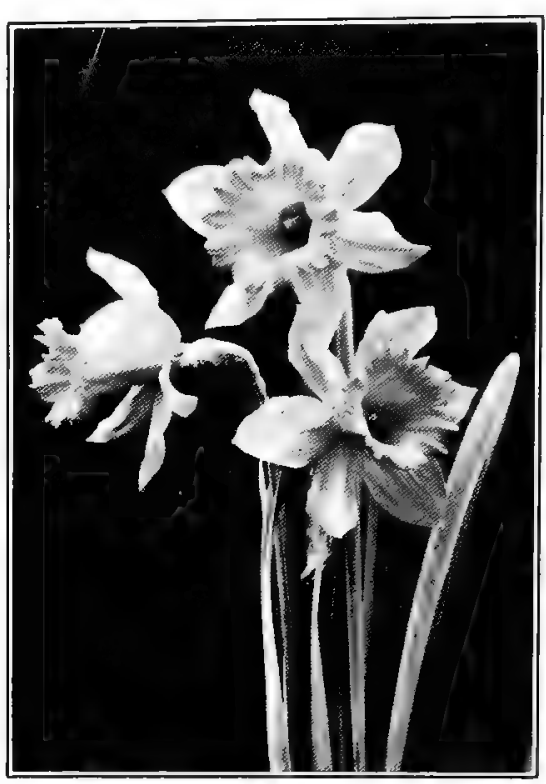

Fig. 212.-Narcissus "Henry Irving." This is one of our many fine Narcissi for either forcing under glass or planting outdoors

but all are good for early forcing.

If you plant $N$. poeticus in a 5 -ft.-wide bed, a part of the bed may be covered with a frame and the flowers be had ten days or so earlier, which also pays.

\section{Paperwhites for Early Forcing}

The Narcissi are divided according to their flowers into three classes: short, medium, and long trumpet varieties. Among the shorts, Paperwhite is the best known and most used, and it is especially adapted for early forcing.

Paperwhites, Grand Soleil d'Or, Double Romans, Grand Monarque, Her Majesty and more than a dozen others belong to this same class which we know as the Polyanthus Narcissi. None of them is hardy

Paperwhites are best planted in 3-in.-deep flats. When forcing on a small scale, allow a little space between the bulbs; the first batch is just as well off in a frame with a little shade as indoors. If planted in September, bring in the first lot by the middle of October.

If allowed to come along in a Carnation house, they will start to flower by the middle of November, and it will be well in December before they are all cut. For Christmas, plant about the same time, but keep the plants cool until the end of November; the cooler they are kept and the less forcing you do, the better the flowers. It is up to about the end of January that Paperwhites pay best; after that Freesias, white Tulips and other flowers are preferred by your customers who are then ready for the change. This is not to say that for funeral design work you cannot use the Paperwhites to best advantage, but their strong odor is often offensive. Yet most people overlook that during December, for the flowers are new to them and a change from Chrysanthemums, Roses, or Carnations is welcome. If you grow them in bulb pans and have them well done, you will find a sale for them around Christmas.

With a scarcity of other flowers you can lift plants just coming into flower out of the flats and use them in made-up arrangements 
in baskets. Not everyone would want such a combination, but some individuals think it just right.

Make three or four plantings of bulbs, having the main crop come on during December; if for any reason you have to make use of strong heat in flowering them, by all means bring them in to a cool place as soon as possible. The same holds good with flats partly cut over for Christmas; you can keep them in fine shape for many days in a cool, shaded place, while in a hot house they will soon give out.

\section{Narcissus Grand Soleil d'Or}

This is the earliest of the yellow Polyanthus Narcissi, and therefore is highly desirable around Christmas. While red

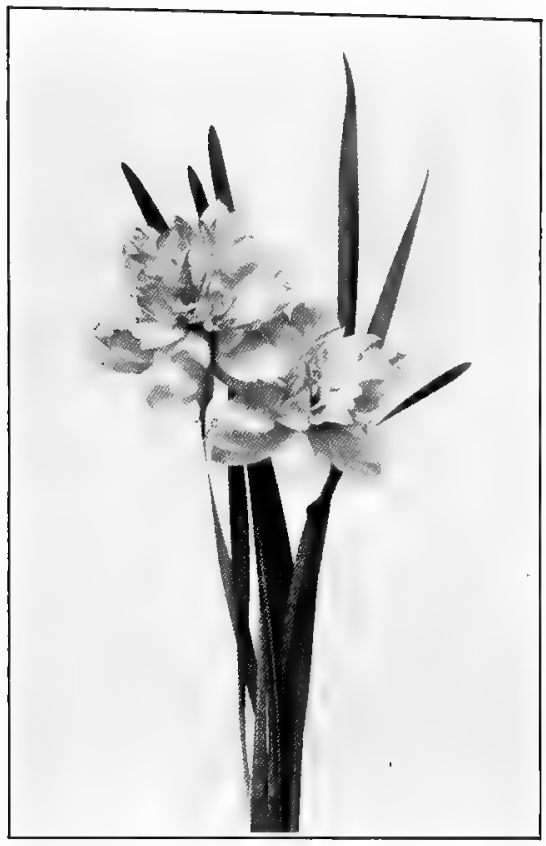

Fig. 213.--Narcissus "Yellow PhoeNIx," a fine sort for late forcing, and also good for cutting or to grow in pans for Easter is the color, many of your customers will look upon these yellow Narcissi with favor and consider them in a way Spring-like; they require about the same treatment as the Paperwhites, only some years we have to give them a little more heat in order to get them in; other years we have no trouble at all. It is a matter of keeping your eyes open. The plants should show color by the tenth of December if you want them in by Christmas; and if by the first of December they appear slow and are in a 50-deg. house, let them have a higher temperature.

This sort also will come in handy for baskets around Christmas, its odor being sweet and quite the opposite of that of the Paperwhites. Its easy culture, desirable color, and the fact that it is among the first to flower, make it an important variety, especially for the smaller florist who doesn't wish to tackle some of the largerflowering sorts.

\section{Double Roman Naraissi}

I mention this variety because it is a white with double orange center and can be had in flower by Christmas. It is as sweet-scented as Grand Soleil d'Or and fine for cutting. Those who grow Paper- 


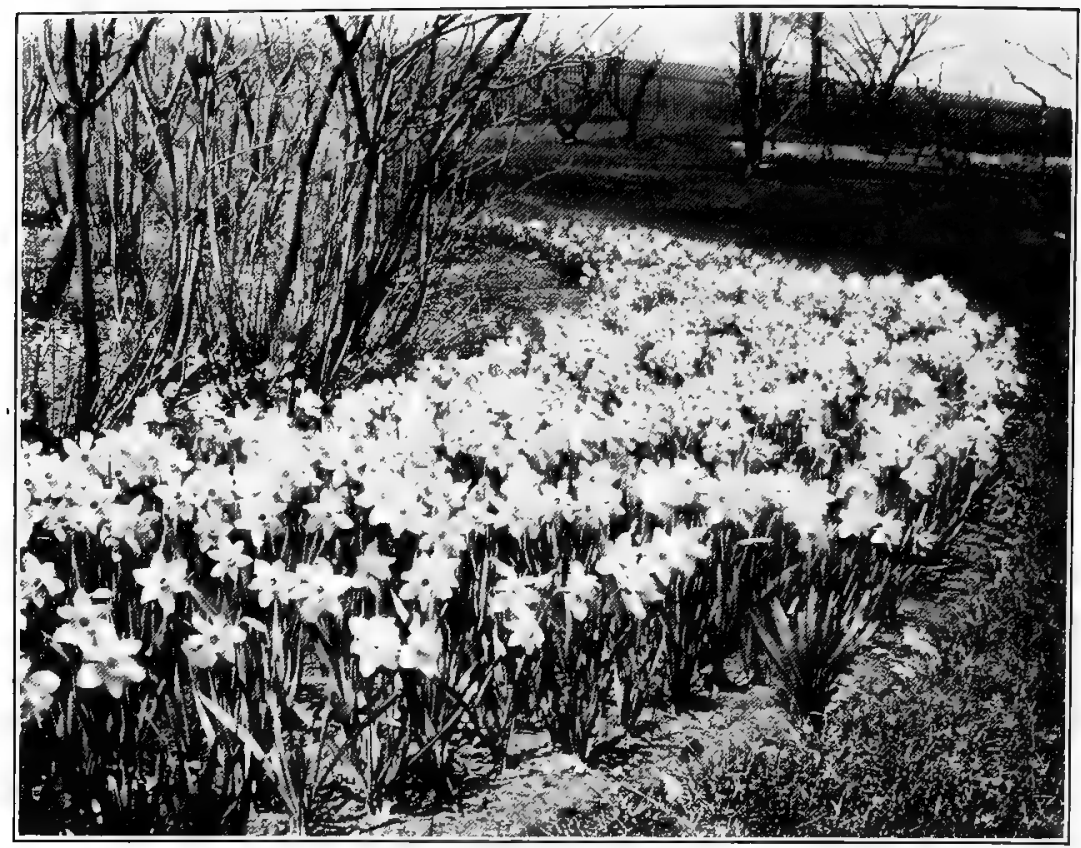

Fig. 214.-A Narcissus Border. Encourage the Fall planting of bulb stock outdoors; the blooms appear long before the trees and shrubs show much sign of life.

To be most effective, bulbs should be planted in masses, as here

whites should always force at least a few double Romans as cut flowers around Christmas when, ordinarily, they are not too plentiful.

\section{Trumpet Major and Golden Spur for Second Early Forcing}

The French-grown Trumpet Major Narcissus is the most widely used for forcing for Christmas and the weeks following. While by no means one of the largest, it belongs to the large trumpet sorts and is of yellow color throughout. If you plan to subject it to heat, to obtain flowers on fair stems you must have well-rooted stock to start with. Otherwise the forcing will prove a failure. Even with heavily rooted stock, a dark, hot place for forcing and the very best of care, the results are not always satisfactory. Of the first or earliest batches frequently only a very small percentage of good flowers is cut.

To my mind it doesn't pay the retail grower to force these Narcissi too early. Let. the specialist do it. And when you pay him a high price for the flowers, you are not paying one bit too much. For even if he is successful with one batch, he runs big chances and is bound to have bad luck with another batch. It is due to this uncertainty that I suggest that the man who just uses 
a few extra early yellow Narcissi and these mostly for their color, use Grand Soleil d'Or instead.

Whether for extra early or later forcing, plant the bulbs as soon as you can in flats and carry them along outdoors, covered over with a few inches of soil and always kept moist. The ones intended for extra early should go inside by the end of November and if well rooted can be brought into heat and a dark place at once. For gentle forcing, a temporary enclosure may be built below a bench of boards and burlap so as to keep the light out and the heat in. The specialist makes use of a regular forcing frame, with sufficient heating pipes to maintain almost any desired temperature. The inside of the frame is pitch dark when it is shut up.

In Golden Spur we have what is the most popular of all single large-flowering Narcissi. Its fine, deep yellow color, good stem and easy forcing qualities make it so. Not only is the variety good for January flowering, but many growers also use it up to Easter.

To those who are not overanxious to obtain extra early flowers but are satisfied to get in the first batch about January fifteenth and cut the greatest number of perfect flowers from a flat, I would suggest planting early and putting the first lot of flats indoors, below a Carnation house bench, about the middle of December. If you can arrange it so as to place the flats on the ground, having the heating pipes a foot or so above them, so much the better. Darken the place and always see to it that the soil in the flats is kept moist. I might say "wet," for in this case it is better to have it wet than not moist enough. You can maintain a temperature of $80 \mathrm{deg}$. or more as long as neither the roots nor the tops come in contact with the heating pipes. Starting out with sound bulbs, planting them early, using nothing but thoroughly rooted stock and never allowing the soil to dry out, will usually mean ninetyfive per cent or more of perfect flowers.

Plant a few bulbs in bulb pans. You can always sell them when in flower. While you can lift the plants out of the flats, the flowers will last twice as long if the bulbs haven't been disturbed.

\section{Other Large Trumpet Nargissi}

Some of the grandest of all Narcissi are among the large single trumpet varieties, but mainly on account of the price of the bulbs the florist cannot always make them pay. However, there are a few which should be forced and can be handled profitably. Among them are Bicolor Victoria, Emperor, Empress, Glory of Leiden (which is a giant yellow throughout), Glory of Nordwyk, Willie Barr, Giant Princeps (a fine forcer), Mme. De Graff and Mme. Plemp. 


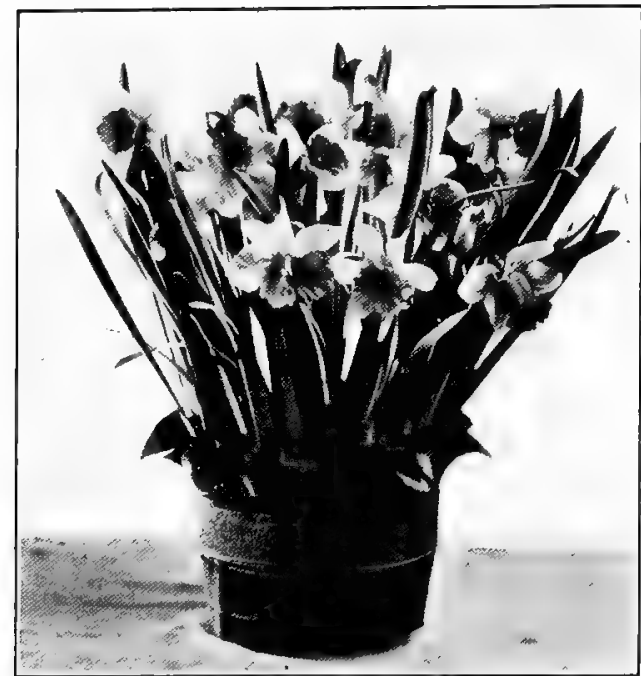

Fig. 215.-Emperor Narcissus. Emperor and Empress Narcissi make stunning pans for Easter, but they must be planted early and grown in a cool house or they will:grow too tall and demand support

Double Naraissus Von Sion

Next in importance to the florist, and also adapted for January flowering is the double Von Sion, better known as the double Daffodil. This variety, like the Golden Spur, responds freely to heat and we can have it coming in toward the end of January; but a wellgrown pan of Daffodils is never more appreciated than around Easter and it is for that time that a good batch of stock should be put aside.

No florist with a retail trade can make a mistake by having one or more flats of Daffodils to cut from each week from the end of January on. When the buds begin to turn yellow, move the flats to cool, shaded spots and let them develop slowly. There is a great difference between those so treated and those kept in a hot house.

I don't know but what, for the smaller grower, it isn't just as well to make use of bulb pans entirely for what Daffodils he plants. There is always a chance of his disposing of such pans when in flower and if he does not sell them that way, he can cut the blooms.

\section{Sulphur Phoenix and other Double Sorts}

Sulphur Phonix is a splendid variety and both it and Orange Phoenix are fine for cutting; they also stand moderate forcing. $N$. alba plena odorata, the double Poeticus, can only be grown in the open ground where it requires a moist situation.

\section{Short and Medium Trumpet Narcissi}

Among these are several which make fine pans and are equally desirable for cutting. Leedsii White Lady, with pure white petals and a yellow cup, makes a fine cut flower; Leedsii Mrs. Langtry is just as good; so are Barrii Lady Godiva (white petals and yellow cup edged with orange), incomparabilis Autocrat (yellow perianth 
and deeper yellow cup) and incomparabilis Sir Watkin, the largest of the medium class, with yellow petals and a deeper yellow colored cup.

\section{Poet's and Poetaz Narcissi}

For outdoor planting in particular do we use the Poet's Narcissi "and it will pay every florist to get a long row or bed of them established. They will flower each Spring, providing a mass of bloom and furnishing excellent material, especially for design work. Poeticus ornatus is good for forcing and the bulbs are cheap enough so that you can make money out of them. Poeticus King Edward is an improvement on ornatus, has a larger flower, and is also a good forcer. Poetaz Elvira is a cross between ornatus and polyanthus,

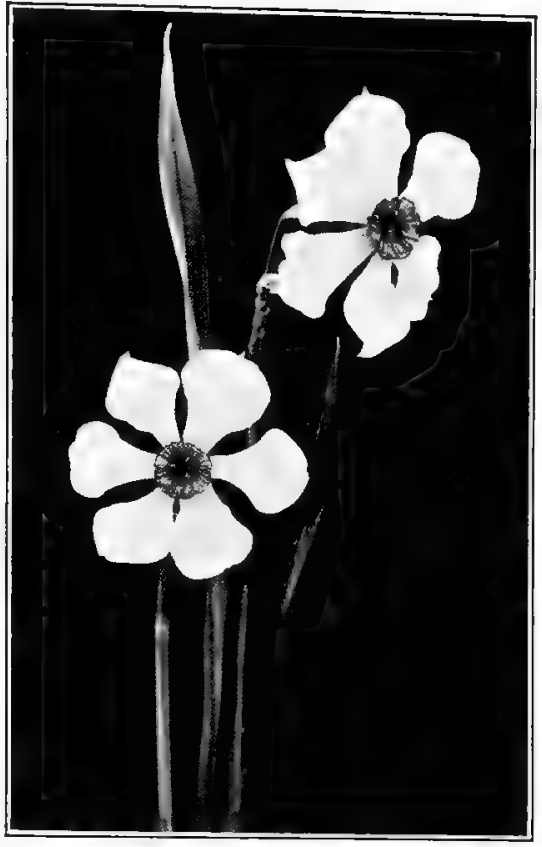

Fig. 216.-Nancissus Poetraus. It will pay almost any retail florist to plant a few rows of the Poet's Narcissus. Once established these bulbs will flower each Spring for years

but perfectly hardy and as effective for mass planting as any of the poeticus group.

\section{Nargissus Jonquilla (JonQuils)}

The Jonquils make a more slender growth than the other Narcissi and their sweet-scented double and single flowers come in clusters. Practically all of them are hardy and can also be flowered nicely under glass. $N$. rugulosus, especially, is good, while $N$. rugulosus pleno is a good double.

\section{NEMESIA}

As a Summer-blooming annual this isn't of great value to the florist, but when grown under glass, flowering in early Spring, he has good use for it. Sow the seed about the middle of January, either on a bench or in a flat and transplant later on. It will produce its little blue, orange, and pink orchid-shaped flowers during April. For outside effects sow early in rows and thin out later on. 


\section{NEPETA GLEGHOMA VARIEGATA (VARIEGATED GROUND IVY)}

This is one of the handsomest of the small-leaved climbers.

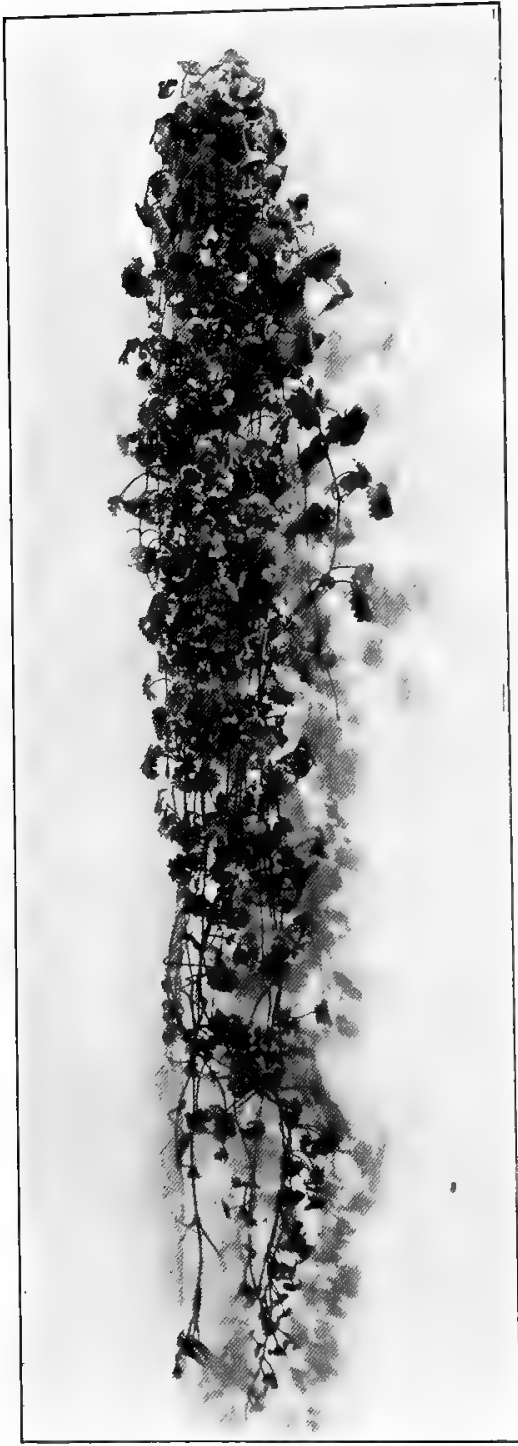

Fig. 217.-Nepeta gleghoma. The variegated Glechoma or Ground Ivy makes an excellent trailing plant for hanging baskets, vases, etc. This is a plant in a 4-in. pot three months after the cuttings were rooted, four of them to a $2 \frac{1}{2}$-in. pot
With its beautifully variegated Ivy-like leaves it is especially well adapted for the rockery, for filling hanging baskets or to go along the edge of vases and porch boxes. While rank growers during Spring and Summer, the plants are absolutely at a standstill during Winter. If you grow a few on for stock in pots, they will by Fall have formed a regular mat, covering any sized pot. Place them in a coldframe or Violet house; by early March divide them into small pieces and pot them up into $2 \frac{1}{2} \mathrm{~s}$. Every one, if shifted later on, will make a bushy plant for which you will find good use.

\section{NIEREMBERGIA (GUP FLOWER)}

Nierembergias make fine trailing, flowering plants for vases, baskets and porch boxes. They come with blue and with white flowers on wiry stems. There was a time when almost every vase or rustic tub filled with plants had a few of them in the assortment, but today we have most call for either red or pink effects, and vases and boxes are usually filled with just one thing which may be Geraniums or Petunias. Here and there, however, we find a customer who prefers a good assortment and that is the time you can use Nierembergias. Sow seed about November and carry the plants along in a cool house, shifting them several times. $N$. frutescens is the blue, 
and $N$. gracilis the white form. $N$. rivularis, with white flowers, is a good creeping perennial for the rockery.

\section{NIGELLA (LOVE-IN-A-MIST)}

The Nigellas belong to the Summer-flowering annuals and when planted in masses, with their finely cut, dense foliage and light blue flowers such as the variety Miss Jekyll has, they are very attractive. They can also be used as cut flowers and a wellfilled bowl in your cooler will surely be commented on by your customers. Nigellas can also be grown under glass for Spring flowering, requiring the same treatment as Nemesias.

\section{NORFOLK ISLAND PINE See Araucaria}

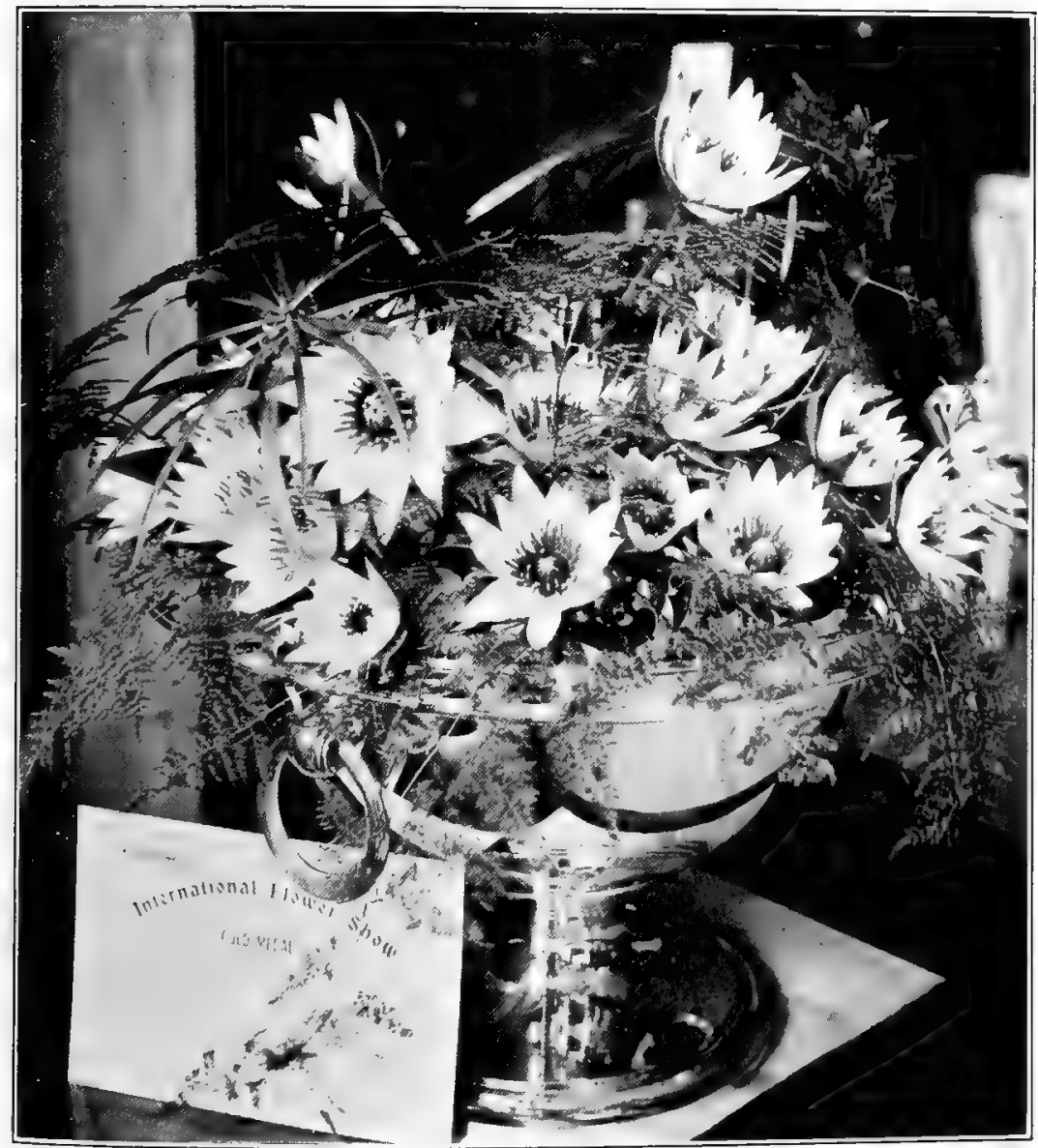

Fig. 218. NYMPHALAS. These are the most popular of all aquatics; and the hardy varieties are of the easiest culture 


\section{NYMPHÆAS AND NELUMBIUMS}

To grow on Nymphæas and Nelumbiums is a business by itself. We have good firms in the country that specialize in these as well as all other so-called aquatics, supplying anything from Wild Rice and Lizzard's Tail up to Victorias. More than that, they not only publish lists of all the desirable varieties, but also give full descriptions of each of them. The florist who does landscape work is bound to have calls for such stock and to be asked for information about it. Getting acquainted with the principal varieties of the hardy, tender, and night-blooming Nymphæas, the Lotus and its requirements, the Water Hyacinths, the Water Poppies and the showy, variegated Flág is, therefore, absolutely necessary. The knowledge comes in mighty handy, but to write about it here would mean merely copying what others have told before. However, as stated in Chapter VII on Aquatics; any one interested in this line will find good, helpful reading in "Plant Culture," by Geo. W. Oliver.

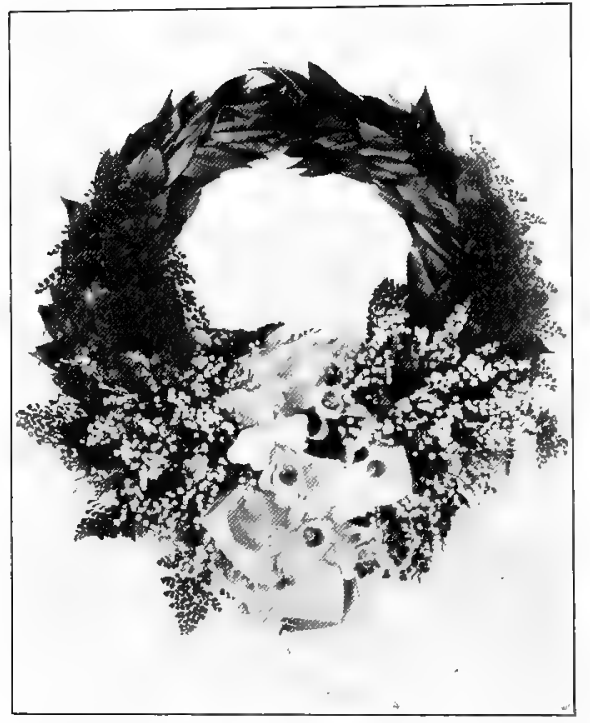

Fig. 219.-The Ever-USEFul OrChid IN A Wreath. Of all floral designs this style wreath is in greatest demand. The orchids add a desirable sumptuous touch

if on the road a long time, they will for many days.

But what I do believe will pay any florist is to carry a few orchids, whether they consist of Cypripedium insigne, which is easily handled in a 50-deg. house and is perhaps the best known, or Cattleya Trianx, which also can be carried in a 50- to 55-deg.

See Otaheite Orange

\section{ORCHARD GRASS}

\section{See Ornamental Grasses}

\section{ORCHIDS}

There are good books on the culture of orchids and neither could I write anything about them which hasn't been told before, nor do I consider this subject of value to the average retail grower. With him orchid culture doesn't mean anything, for he would not find it profitable to take it up. His time is occupied with other things and he can always, even when located far away from the flower markets of the country, have the cut blooms shipped to him. Even usually last in good condition

\section{ORANGE, OTAHEITE}




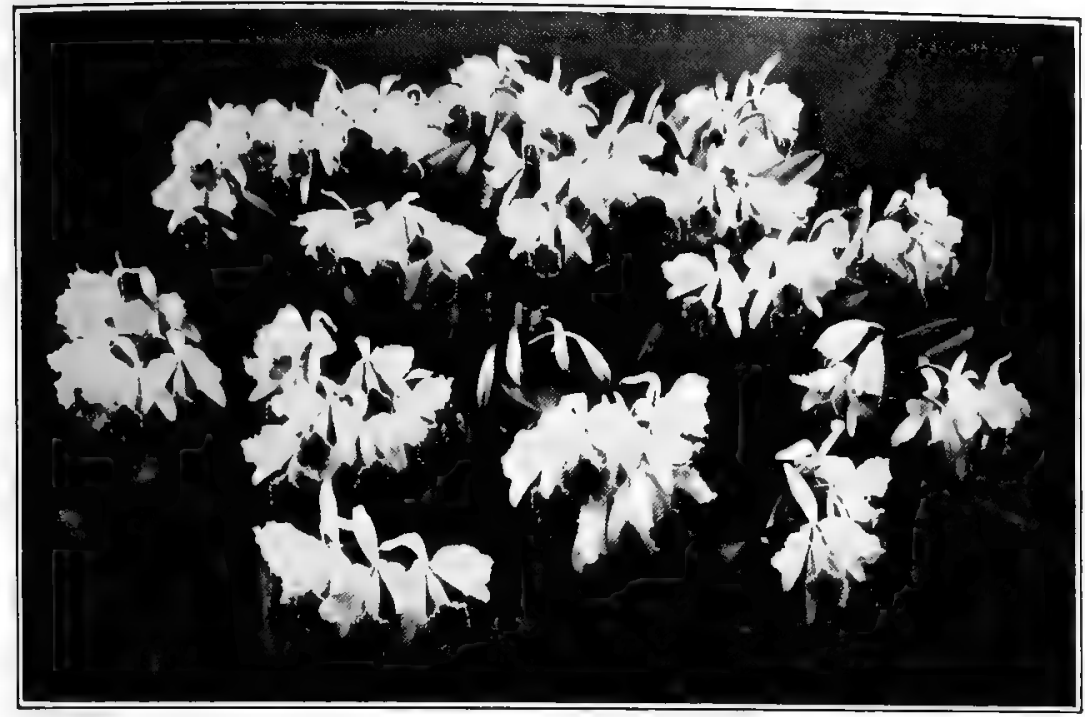

Fig. 220.-Cattueya Trianfe. This is one of the most popular of all the Cattleyas the florist uses. A plant in bloom in your show house, even if not perfect, will always attract attention. But this is the only way you can make orchids pay on a small scale

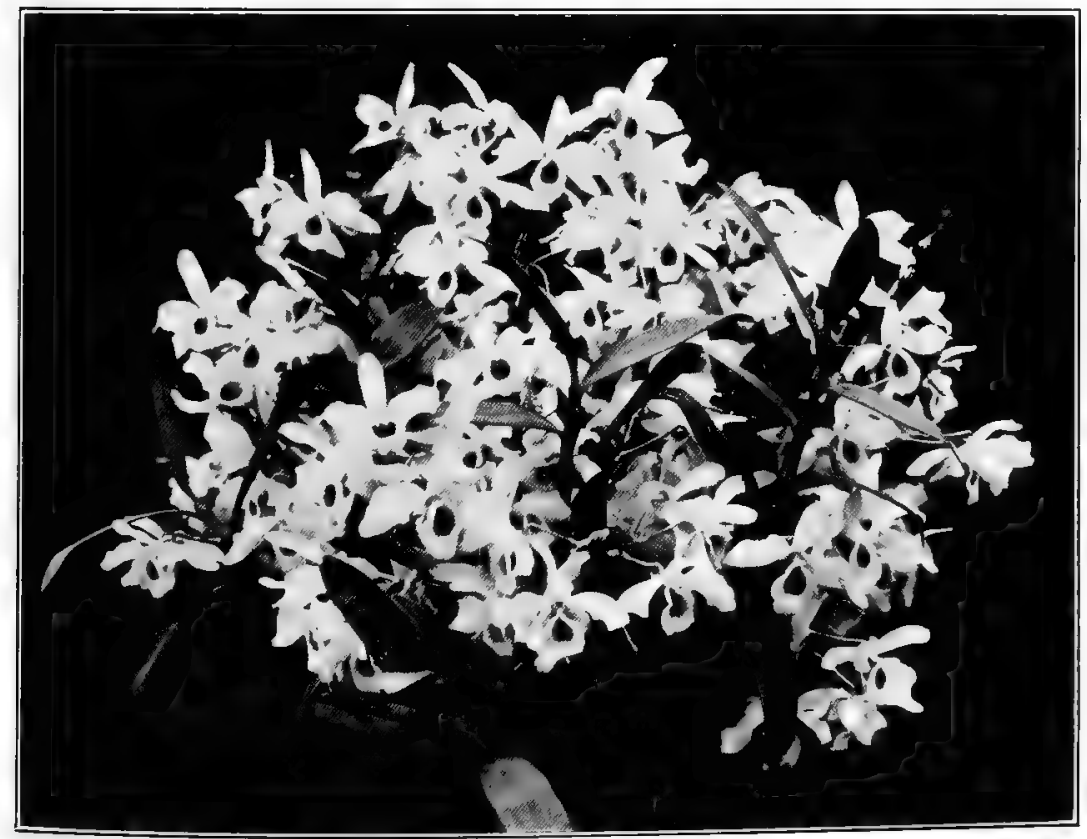

Fig. 221.-Dendrobium NoBILE. The Dendrobiums are among the showiest of orchids and should make up a good proportion of and have a prominent place in every collection 


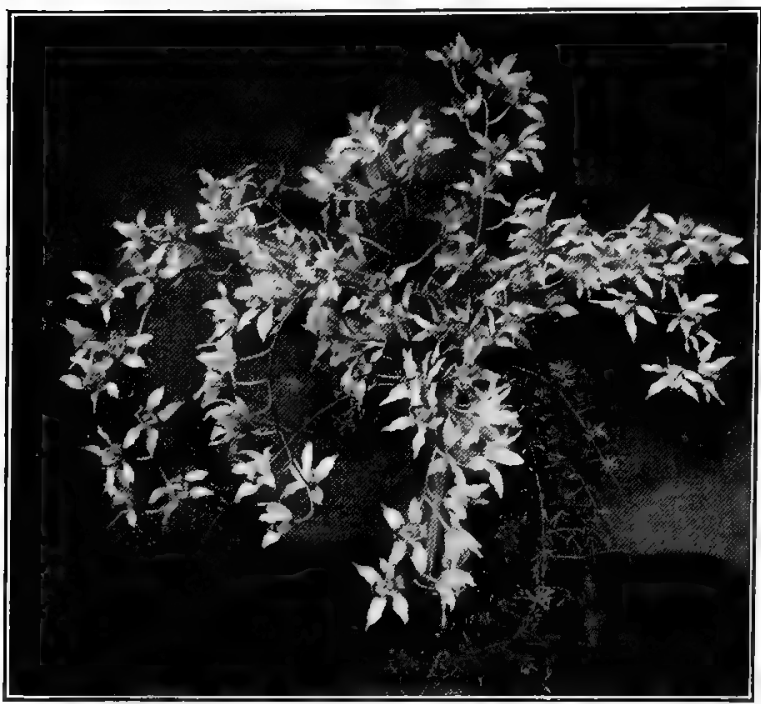

Fig. 222.-Grmbidium Pauwelsil. The keeping qualities of this species are indicated by these flowers which, grown in Belgium, were shown at the 1921 New York Show in March and again at Boston in April, still in prime condition house, or Dendrobium nobile, which, while requiring a little warmer house, can also stand a lot of abuse and still live and flower.

I have seen all of the above carried for years, remaining alive and even flowering with absolutely no care other than regular watering, the. Cattleyas and Dendrobiums getting a little fresh Sphagnum moss now and then, and the Cypripediums an occasional shift.

What I want to get at is this: The average patron, visiting the establishment of the local florist, expects to find everything there that grows. The mere fact that you can say you have orchids and point your finger to a pan of Cattleyas suspended from a purline, or have a specimen, with or without foliage, in bloom during the Winter or Spring months, is bound to have great weight with a visitor.

You should be able to show what an orchid plant looks like; it is expected of you if you retail flowers. I don't care how poor or how good the plants are that you carry, so long as you have some even if only a half-dozen. If they die, get more and charge it up to the advertising expense account.

To make money with orchids you must not only be equipped for it and have the proper facilities to handle the plants, but you must also have a full stock and it will take all of your time to attend to them. In other words, you can't make a side line out of them.

\section{ORNAMENTAL GRASSES}

The florist should be acquainted with at least a few varieties of hardy grasses for they belong in the home grounds whether planted in groups or singly as specimens; whether along the edge of the pool or water garden, in the rockery, or as a clump in the shrubbery border. While perhaps not used extensively on small grounds, 


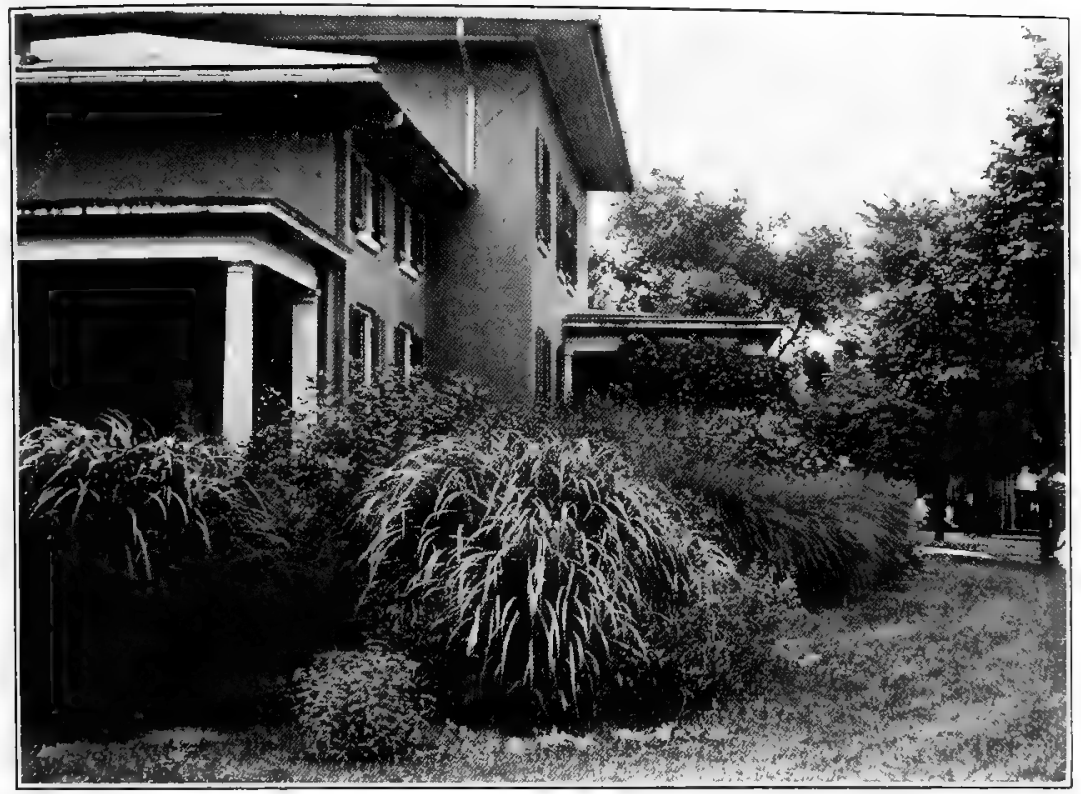

Fig. 223.-Ornamental Grasses, The Eulalias and other hardy grasses are fine in large groups on extensive lawns, but they are really more at home planted near the Lily pond or in the water garden

yet we have calls for such stock and if you have the space for a few plants, when once they are established you will always have a supply to draw from, as most of these plants are easily increased through division which is best done in early Spring.

\section{Arundo Donax (Giant Reed)}

This grass is only used for mass planting. It will grow fifteen feet and over if given good soil and plenty of moisture; it flowers in early Fall.

\section{Dactylis glomerata Variegata (Variegated Orchard Grass)}

This is, perhaps, the most common of all ornamental hardy grasses, yet because of its beautiful variegated blades or leaves, and its ability to grow and thrive where nothing else will, it is highly desirable. You have seen it in the farmyard, in the old rock pile, along the fence and in the old-fashioned hardy border. After everything else has passed away through neglect, this grass will keep on coming up each Spring and as much variegated as ever. A goodsized clump somewhere will give you a chance to sell plants each year and there is always someone who will want a few. 


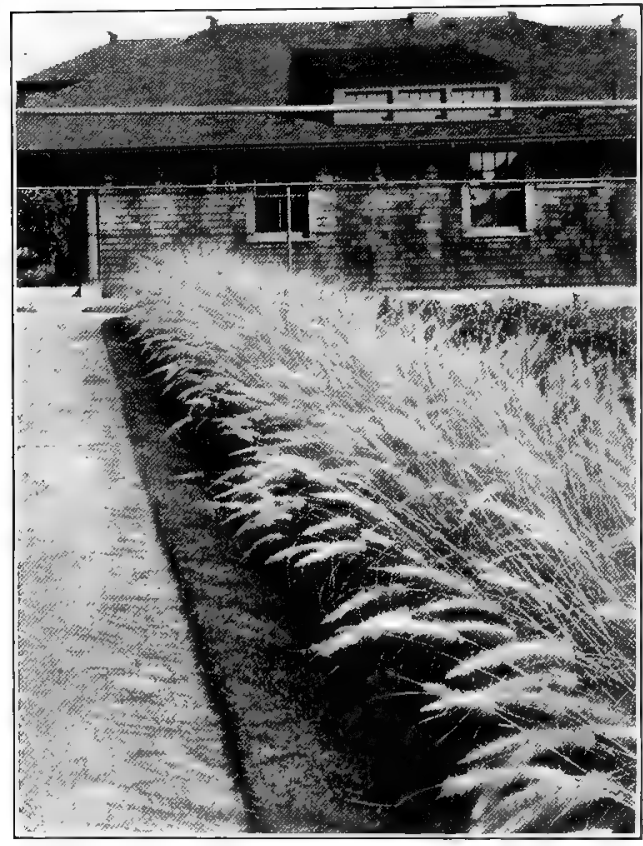

Fig. 224.-Pennisetum Longistylum. It is difficult to find the foliage on these plants. They make a decidedly different hedge, and for a border around the Canna bed you could hardly find anything more fitting

Erianthus Ravenna

(Pampas Grass)

There is nothing finer in hardy grasses than this, especially if one wants plants for single specimens. It will, in a short time, grow into fine clumps with graceful narrow leaves, producing great flower heads or plumes. It can stand a little protection over Winter.

\section{Eulalia}

The Eulalias are among the most popular of hardy grasses and make fine beds all by themselves. E. gracillima with its 5 -ft. narrow green leaves, each with a white rib along the center, is very effective. E. japonica is of somewhat stronger habit than the others and with leaves striped crosswise; this will go well with either of the others if planted in the center of the bed.

\section{Pennisetum (Fountain Grass)}

Pennisetum japonicum is a fine hardy grass and just the thing for the edges of the pool or for planting in groups along the edge of a shrubbery border. $P$. longistylum is the best known of the annual sorts and is used extensively for bordering Canna beds. Allow at least eighteen inches of space between the plants when used for this purpose, so as to avoid a soft, weak growth that will not be able to resist heavy rains. $P$. ruppelianum is even better than $P$. longistylum, as it has purplish colored plumes while the other two have white ones.

All three are easily grown from seed, but don't be tempted, when transplanting the seedlings in March from seed sown in February, to take four or five at a time and later on pot them up in that way in order to obtain quicker results. They look like ordinary grass plants but use them separately. They will all make bushy plants by May. 


\section{OTAHEITE ORANGE}

Around Christmas one finds these showy miniature Orange trees displayed in fancy baskets and hampers, or used in made-up baskets in connection with Ericas, Dracænas and Crotons, in almost every flower shop in the larger cities. Yet but few country florists make any effort to have even a few fruited plants in their display. What is there that could possibly be more noticed or more admired, or what will stay in good condition longer? The fruit of these Oranges begins to cólor toward the end of October and remains in perfect shape on

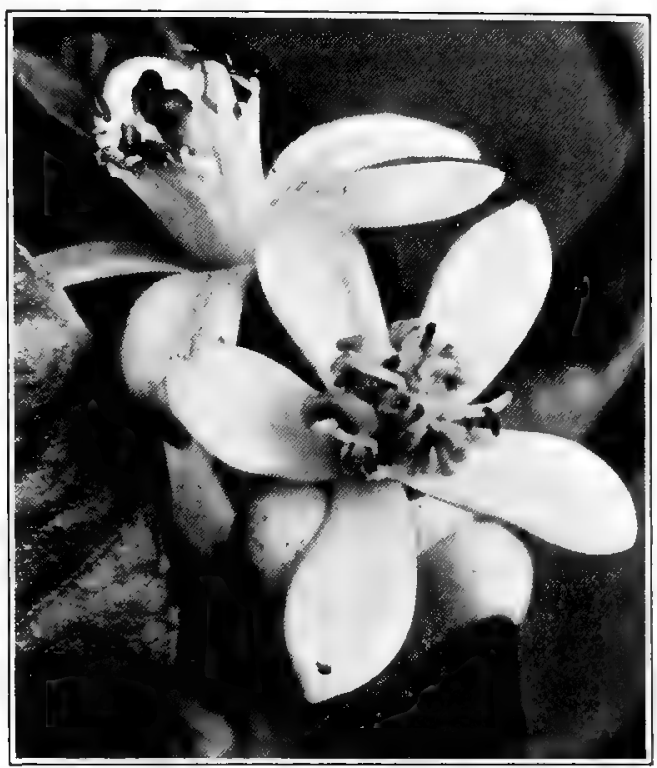

Fig. 225.-The Double Flowering Orange is something quite out of the ordinary. With its delightful fragrance it does not have to produce fruit in order to be a useful asset in the flower shop

the plants practically all Winter. Then, if you cut the plants back just a little in March, remove a little of the top soil in the pots and replace it with fresh soil, the new growth will soon start and the plants will flower in May or June and later bear more fruit. Carry them out in the open then, plunging the pots up to the rim into the ground; if you can give the least bit of shade so much the better, it will help develop a darker colored foliage.

You can purchase the plants set with green fruit from the specialists in the Fall; all they require thereafter is a night temperature of $50 \mathrm{deg}$.

\section{PAINTED TONGUE}

See Salpiglossis

\section{PALMS}

The principal Palms the florist uses rank in importance as follows: Kentias, both Belmoreana and Forsteriana; Phœnix canariensis and P. Roebelenii, Areca lutescens and Latania borbonica. All these are treated under their respective headings, as are also Areca, Cocos and Cycas. There are a lot more fine varieties, but the above are, and, with the exception of Phœnix Roebelenii, always have been the main ones found in the average palm house. 


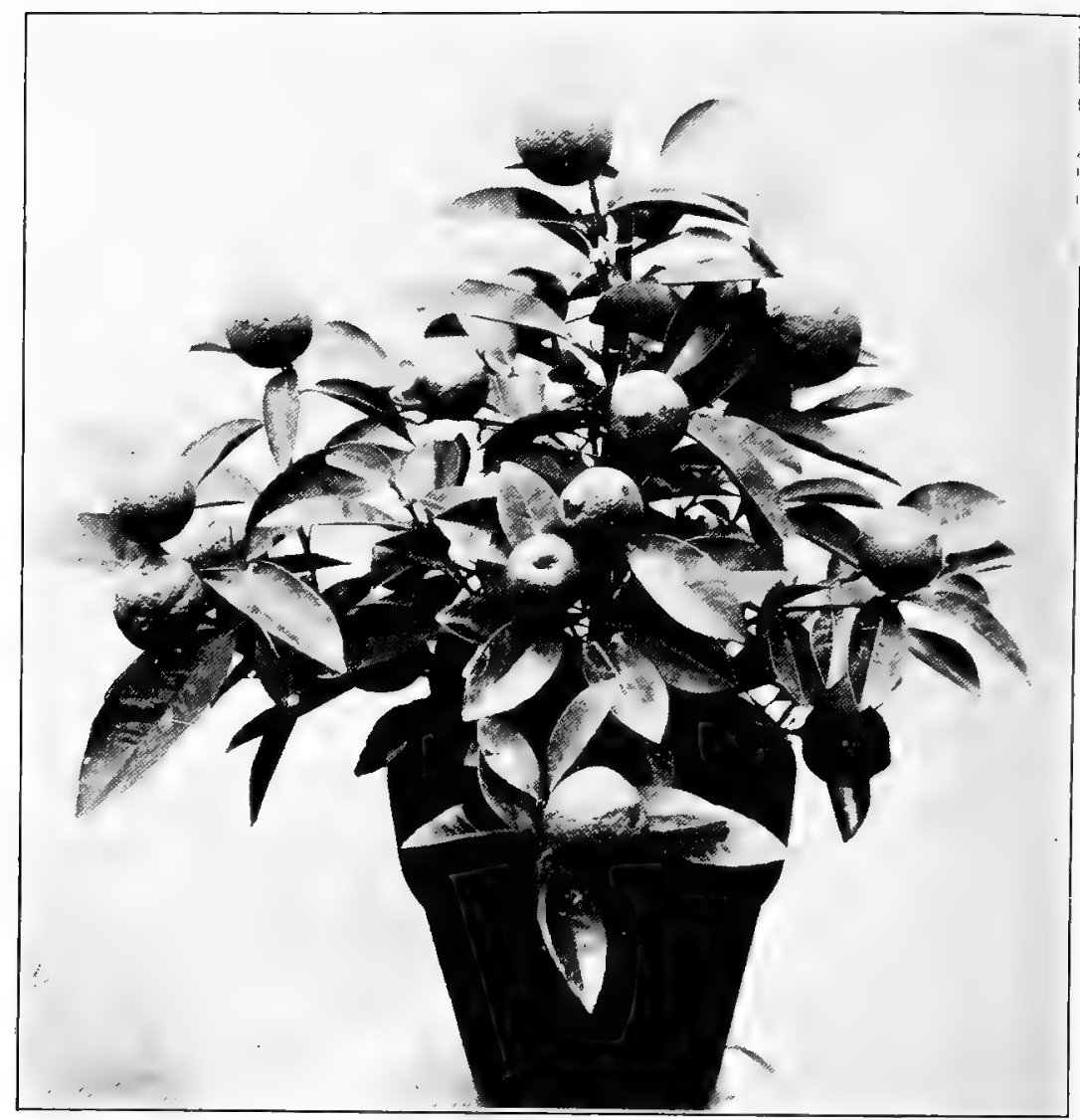

Fig. 226. - An Otaheite Orange in Fruit. Even the red-berried Ardisia finds it hard to compete with an Otaheite Orange loaded with well-colored fruit. Your Christmas display should always contain a few of these miniature trees

No other plants the florist carries are of greater value than good thrifty palms and this is more so today than ever before. A houseful of good palms is one of the best assets any retail grower can possess. For decorating the show house and the store, they beat the most expensive fixtures you could buy. There is nothing you could do to create a better impression on those entering your establishment than to use palms generously. The plants, when at all taken care of, will stay in good condition and, in fact, grow into money. Such as are accidentally injured in any. way are just as valuable for decorating and when used a few times for such purposes will pay for themselves. There are seasons for Peonies, Lilacs, Cyclamen, Lilies and Poinsettias, but the season for selling palms lasts throughout the twelve months of every year. 


\section{The Palm House}

In building a new place the first things I would consider are the palm house and its location. It should be as near to the main entrance of the place as possible. Every one of the other houses has periods when it is not looking at its best, but the palm house always looks good. If you lack an imposing front entrance or an elaborate store, there is, I am sure, a way to manage with a house, a half-house or even a quarter of a house filled with palms displayed to best advantage. If four or even three plain white walls constitute the inside of the room you do business in, a half-hour's work with palms and ferns can transform it into an attractive florist shop.

That is my opinion as to the value of palms. No matter how much or how little a retail grower actually grows on his place, there is no reason for him not to have a good supply on hand. Ours is a show business if ever there was one, and all depends on the show we make. If you retail flowers and want to do it successfully, palms are a vital necessity.

A palm house should have a minimum temperature of $60 \mathrm{deg}$. in Winter and no harm is done if it gets to $100 \mathrm{deg}$. or over during Summer as Iong as you supply sufficient water and shade to prevent the burning of the foliage. The palm house, with the smaller florist in particular, isn't meant for palms alone, but for other decorative foliage plants and ferns. Always see that it is kept in shape and clean, with everything arranged for the best effect. A palm house is always a show house, and should be a house to be proud of.

\section{PAMPAS GRASS \\ See Ornamental Grasses}

\section{PANDANUS VEITCHII}

This is considered one of the most beautiful variegated plants of all the florist carries and every store, show house or palm house needs a few specimens to make things attractive.

As a house plant this Pandanus has no equal. It will grow in time into great specimens, yet even small stock out of 2-in. pots makes most suitable center plants for fern dishes. Or around Christmas and Easter, plants out of $31 / 2^{-}$and up to 5 -in. pots can be used to great advantage with other plants in a basket arrangement.

It doesn't pay the average florist to grow on the plants he needs during the year. He can do better to purchase from time to time the different sizes he runs short of. It is cheaper than to carry a lot of large plants for stock. However, if you have good-sized plants on hand the lateral shoots which appear at the base of the plants are easily removed; and if given a sand bench with strong bottom heat they will soon send out their thick, white roots. The sooner after that you pot them up in a sandy soil mixture, the better. 


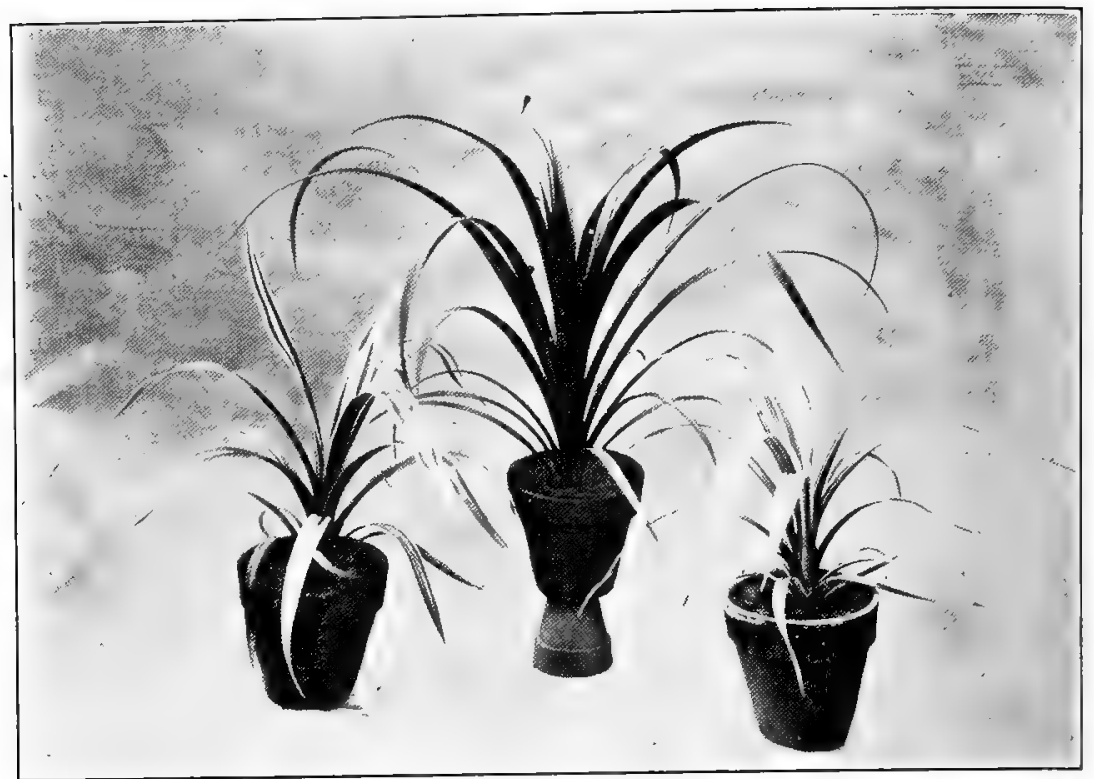

Fig. 227.-Specimens of Pandanus. Pandanus utilis (center), while a most attractive decorative plant, stands but little show alongside the variegated-leaved $P$. Veitchii, which easily heads the list of all the florist's variegated foliage plants

\section{PANSIES}

DO you make money out of your Pansies or are you not sure whether you do or not? They, like everything else, need to be handled right in order to pay. You cannot buy a package of seed, accepting anything so long as it is Pansy seed, sow it, later on transplant the seedlings, and let it go at that.

Wonderful improvements have been made in Pansies as to size of flowers and stems and habit, and we no longer have to depend on Europe to obtain the seed. That is not to say that in England, France and Germany good Pansies are not to be found. On the contrary, they have always been known for their fine Pansies, but of late years, both in eastern and western United States, good men have gone into the specializing of Pansies and with the help of the best foreign varieties have worked up strains that are hard to equal. Such seed can be purchased but it costs money, and on that account alone has to be used right. When the proper attention is given to the growing of the plants they can be and are made a paying crop by many.

I am sure that if the florist has good Pansies in Spring they will sell for a high price. People will buy them when they wouldn't consider ordinary stock no matter how cheaply it is offered. That much for outdoor ones. 
What will, however, mean far more to the average retail grower, is having Pansies to cut from under glass during the Winter and Spring months. Properly handled they will flower as freely as the single Violets (to which they belong), and where is anyone to be found who doesn't like Pansies, especially if they are good Pansies?

Of as great importance are Pansies during Easter Week. There is no other small flowering plant that will give more attractive made-up pans than Pansies. A customer can't resist a well-filled pan of solid giant Pansies, either yellow, blue or white; it makes a stunning Easter favor and needs but little trimming.

Consider for a moment what it takes to grow on a Lily, a Genista, a Rambler Rose, an Hydrangea or an Azalea and then figure out the cost to you of a $\$ 3$ pan of Pansies.

\section{For Early Outdoor Bedding}

To begin with, Pansies like a rather heavy loam in order to do best, and a liberal dose of well decomposed manure and sand will help to obtain good results. Good Pansies will make fair flowers even in poor soil but cheap Pansies, no matter how well you treat them, will produce cheap flowers.

All Violas like a deeply cultivated soil, moisture and a cool temperature in order to produce a healthy growth and the largest flowers. If you want plants to start to flower by the middle of April sow seed in early August outdoors. The seed will come up almost anywhere. If you buy expensive seed you want every possible one to germinate and produce a plant. For that reason, prepare a nice bed for them, making use of a coldframe. Have the surface of the bed level and mellow; sow thinly in rows about four inches apart, barely covering the seeds after they have been pressed down gently into the soil; give a good watering and place shade frames over the bed. Except in very dry, hot weather, no watering is needed until the seedlings are up; if you have but a small amount of space sown it will pay to remove the shade frames (except for three hours or so during the middle of the day) and in about ten days remove them for good. By that time, every good seed is up and the plants when once established don't want any shade. The only reason you place it over the seeds is that you want to do what you can to give every seed a chance.

By the end of September or thereabouts transplant to Winter quarters, or where they are to remain until sold, allowing about three and one-half to four inches between them. The latter is not too much for good-sized plants, and if you intend using some for Winter, Spring or Easter flowering indoors, select the strongest plants and place them apart from the rest where you can get at them any time during the Winter months. 


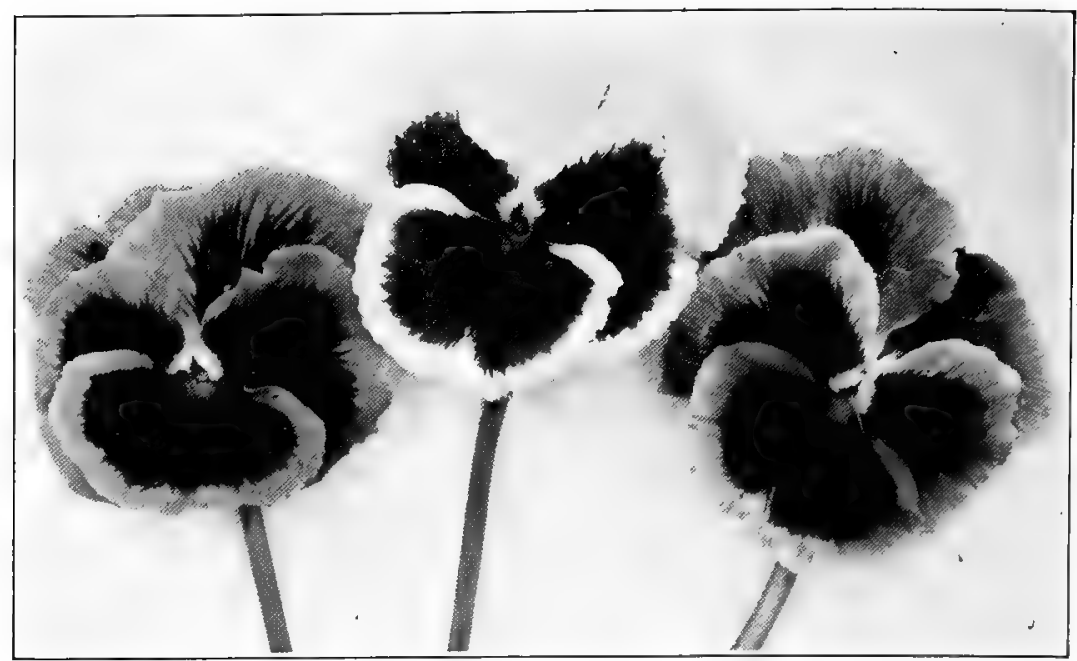

Fig. 228--PANSES-THAT IS, GOOD ONES-GAN B E MADE A PAYING CROP by the retail grower if raised under glass. Like Violets, they delight in a cool house, but they require a sunny bench

Pansies can stand a lot of cold weather, even zero, when planted outdoors. But a good way to do is to protect them a little which is easily done with sashes if you have them in a coldframe. But this doesn't mean to place sashes on in October, and produce a soft growth. Wait until Winter conditions have set in for good and things are frozen. Again, in early Spring, don't let the frames heat up, but remove the sashes early. It will produce stronger, better plants and better flowers.

\section{For late Outdoor Flowering}

While the August-sown Pansies will make the best flowering stock for early Spring and Summer, they usually are not so desirable for later flowering. For this purpose, seed can be sown indoors during January and the plants transplanted into flats and placed on a shelf to be set out in a frame in March.

Some florists make use of this method entirely and have plants in flower almost as soon as from stock overwintered outdoors, but both the plants and the flowers of this late-sown crop lack substance compared with the others. A good way is to use both methods, sowing outdoors and again inside. If the plants are good, ways will be found to use them.

\section{For Indoor Flowering}

For indoor flowering seed can be sown during July; that is, if you want Midwinter flowers. Plant, sow and handle the same 
as the ones wanted for Spring. The object is to obtain a heavy, well-branched plant by the middle of October. It usually takes twelve weeks to obtain such a plant but much depends on weather conditions. I have known hot, dry Summers when it was very difficult to grow on half decent plants; the heat was too much for them and early ones just made a spindly stem and a few leaves and flowers. Those years, seed sown in September produced by December far better plants than the first batch. As stated above, have the plants wanted for indoor flowering in frames and protected so you can get at them.

\section{As a Gatch Grop}

I know of a small grower who had planted a bench of Carnations, variety white Enchantress which someone had recommended to him as a great money-maker. The Carnations started out all right but around Christmas something got into them, and they kept getting worse until the man made up his mind to throw them out. He happened to have a frame of Pansies-plants which, due partly to a favorable growing season, were in excellent condition. He had to use a grub-hoe to lift them, but he did it and, after being thawed out, they were planted twelve inches apart in the former Carnation bench after another dose of manure had been added to the soil. In three weeks those plants began to flower. The first blooms were short-stemmed of no great account, but as the plants became established, they started to prove a paying crop. Toward Spring and around Easter he had the best flowers and would cut a little foliage with them which made them still more desirable for the retailer. When, the day after Easter, his Geraniums were ready for the final shift, the bench of Pansies had all been cut so he used the soil in the bench for the Geraniums. After bonemeal had been added at the rate of a 7-in. potful to a barrowful of soil, the bench was refilled with Geraniums.

That tells the story and this man has had a bench of Pansies ever since, only he plants or benches the stock right after the 'Mums are through. You can plant such Pansies any time during the Winter months, just so you always have a supply on hand to draw from. If, for any reason, you should have no use for them, they can be left outdoors and used in Spring. A mild Winter temperature of from 45 to $48 \mathrm{deg}$. suits Pansies best.

\section{In Pans for Easter}

If you have nice bushy plants in a frame with the colors separate and want them to be in full bloom by Easter, lift them as carefully as you can, that is, with plenty of soil around the roots, and plant them on a sunny bench about five weeks before they are wanted. If Easter falls on a late date four weeks is enough. When the 
plants are in flower a few days before Easter Sunday, make up youi pans; they want to be good and full in order to look at their best. After they have been potted, place them in a cool, shaded house.

\section{As to Varieties}

Always make sure you have enough yellows and blues. In fact, for Spring it is well to sow out one-half of your requirements in the three separate colors: yellow, blue, and white and the other half in a mixture. The same almost holds good for indoor growing; if anything, don't grow quite as many white ones and go perhaps a little heavier on the yellows.

\section{PAPAVER (POPPY) \\ Oriental Poppies}

The Oriental Poppy (Papaver orientale) attracts much attention in the hardy border in June. It makes a large plant with fern-like

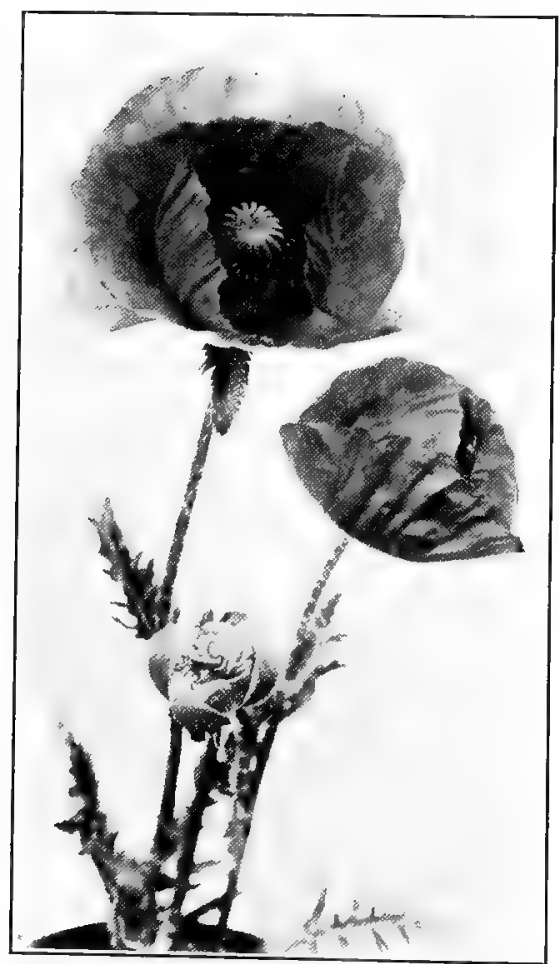

Fig, 229.-Oriental Poppres. These hardy Poppies bloom with the Irises and Columbines and certainly liven up the border. We have them now in white, pink, and scarlet, all the varieties being easily grown from seed foliage, covered for a week or more with long-stemmed, large, single, scarlet flowers. Besides the red there is a splendid pink, Mrs. Perry, and to complete the assortment, you should also plant the white (Perry's White.)

All three grow easily from seed which, with the florist, is best sown out in early Spring. The seedlings, when large enough, should be potted up into $2 \mathrm{~s}$ to be planted later on in the field. None of the Poppies, whether annual or hardy, is fond of having its roots disturbed; that is the reason for potting the seedlings.

The Oriental Poppies die down after they are through flowering and new leaves appear in September; this makes it necessary to plant something between them. When you have them in a hardy border, Gladioli are as good as anything.

\section{IgelaAnd Poppies}

With us the Iceland Poppies are among the first plants 
in the hardy border to flower in Spring and that is enough to make us think well of them. The dainty flowers come in quite an assortment of shades and colors and when cut partly open will remain in good condition for three or four days.

If seed is sown indoors in February and the seedlings are potted up and planted out in April they will all flower freely by the end of May. The plants stay green all Summer and are perfectly hardy. You cannot afford to be without them.

\section{Shtrley Poppies}

The Shirley Poppies are among the best of the many single flowering annual Poppies. While perhaps not to be considered as ideal cut flowers, if cut at the right time or just as the buds open, they will last for several days and make a showy vase.

If you have the space, sow out a bed or long row of the plants. The flowers will last only a day, but there are so many coming right along that you don't miss them as they pass.

\section{Flowering Poppies under Grass}

The single annual Poppies are fine for flowering under glass in early Spring. Seed should be sown either thinly across the bench in rows about one foot apart or in a flat, in February. Pot the seedlings into $2 \mathrm{~s}$ and plant out later on.

If you are anxious to have flowers to cut around Memorial Day this can be accomplished easily by transplanting the seedlings two inches apart into flats as soon as you can handle them and letting the plants flower in these flats. The idea is to stunt the plants and cause them to flower earlier than they would if given all the root room they would like to occupy.

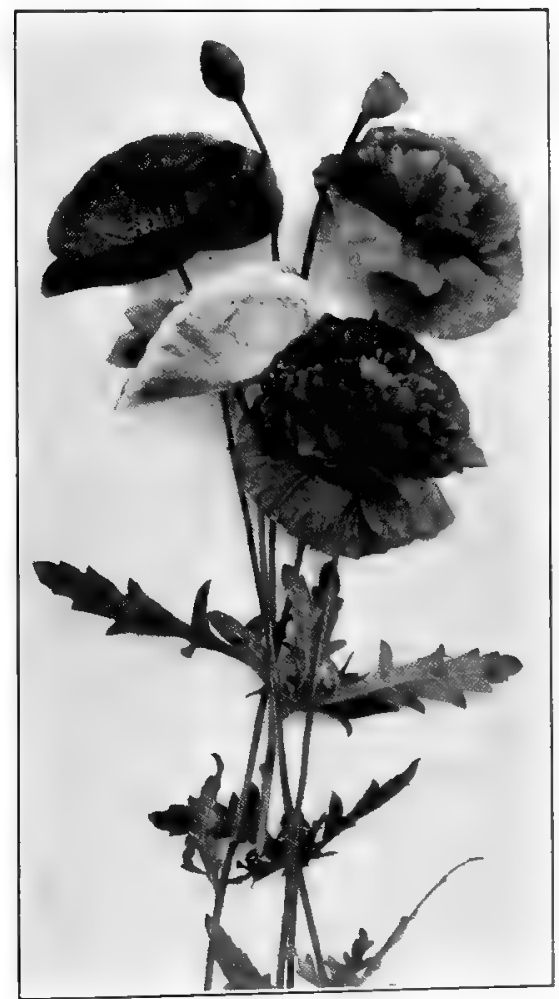

Fig. 230.-Shrrdey Poppies. These annuals, sown under glass in February and grown in flats or shallow benches, will prove a paying crop when in bloom in May 


\section{PELARGONIUM}

Pelargonium is a beautiful name and the name of a beautiful flower. While the bedding Geraniums belong to the Pelargoniums, we hardly know them by that name and it is well that some sort of distinction should be made between them and the beautiful new sorts of show flowers we have today, such as Easter Greeting, Gardener's Joy, Swabian Maid, Wurtembergia, Lucy Becker and Wolfgang Goethe. All these and many others surely deserve to be classed as show Pelargoniums and all make beautiful flowering pot plants for Spring and early Summer flowering. A well-flowered plant is so beautiful that a customer cannot help but buy it.

Usually when you mention Pelargoniums, the first thing you think of is the white fly that comes along with it, either when you first get the plants or after you have them awhile. However, there are plenty of specialists today who will supply you with clean stock.

You should know that a healthy, growing Pelargonium isn't nearly as apt to get infested with white fly or form a desirable breeding place as a stunted one; but if you never had a white fly in your place and happen to have a batch of Pelargoniums at a

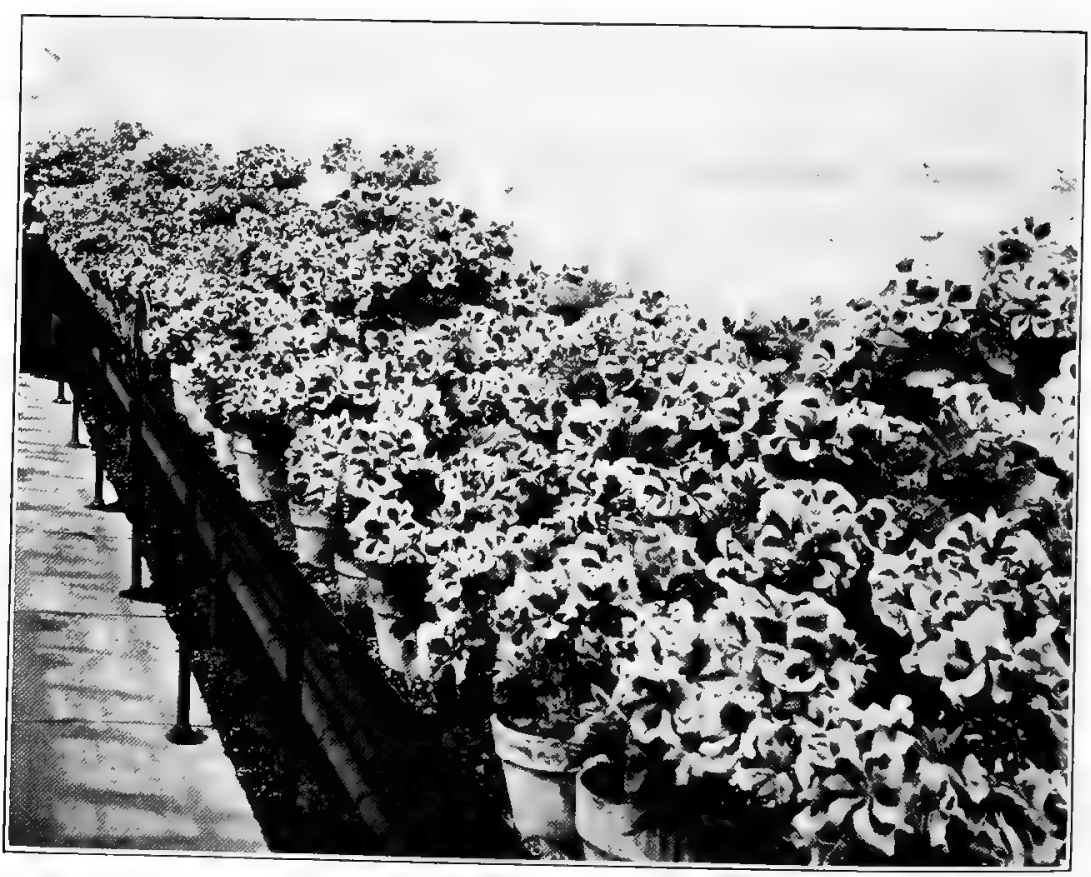

Fig. 231.-Pelargoniums. Whoever named this variety "Easter Greeting" certainly chose well, for it and its companions are among the showiest of Easter plants. They can be grown on, too, at a moderate price which means a good deal to the smaller florist 
standstill somewhere, you are likely to have a visit of the white fly sooner or later.

To kill white fly there is nothing surer than fumigating with cyanide of potassium. However, this is always more or less dangerous for the retail grower with a lot of different kinds of stock in one house, and I am convinced that if you obtain a lot of rooted cuttings, or, what is still better, 2- or $21 / 2$-in. stock, clean in every way, and if you will make it a practice to spray these every week with a nicotine solution and also make it a rule to reach every part of the underside of the leaves as well as the center when you spray-then you won't have white fly, unless your house is full of the pest when you bring the Pelargoniums in.

\section{How to Grow Good Pelargoniums}

No matter whether you have old plants which had a period of rest during Summer, or rooted cuttings taken in late Fall from such plants after they had been started into growth again, or young stock rooted during Winter or Spring, it is during Winter, in a cool but rather moist house that they will make their best growth. You cannot grow them successfully in a dry house or one where the temperature goes much over 50 deg.; a little below that point is even better.

I would prefer a Fall-rooted cutting for growing into a large specimen for April flowering. Such plants like a sandy loam with a liberal dose of well decomposed mianure and, of course, plenty of drainage. For small stock in $31 / 2 \mathrm{~s}$ or $4 \mathrm{~s}$ by May, you can root cuttings during the Winter months.

\section{PEONIES}

One might say that from time immemorial the Peony has been a universal favorite with all lovers of flowers. Today it is better known and more highly thought of by the public than any other flower we have in the hardy border. What is as remarkable as anything, however, is the fact that in the face of all the new and beautiful varieties coming onto the stage from time to time, some of the old-timers, like festiva maxima, that were novelties more than half a century ago, have retained all their good qualties and are still among the most desirable sorts offered.

I CAN not place Pæonia sinensis ahead of all other desirable hardy flowering florist's plants principally because of its short flowering period. There is also the objection that when it is Peony week or month the plants make no distinction; they are in bloom with us and with every one of our patrons in the neighborhood at the same time. It is true that with the help of cold storage flowers may be had many weeks after your own have passed, 


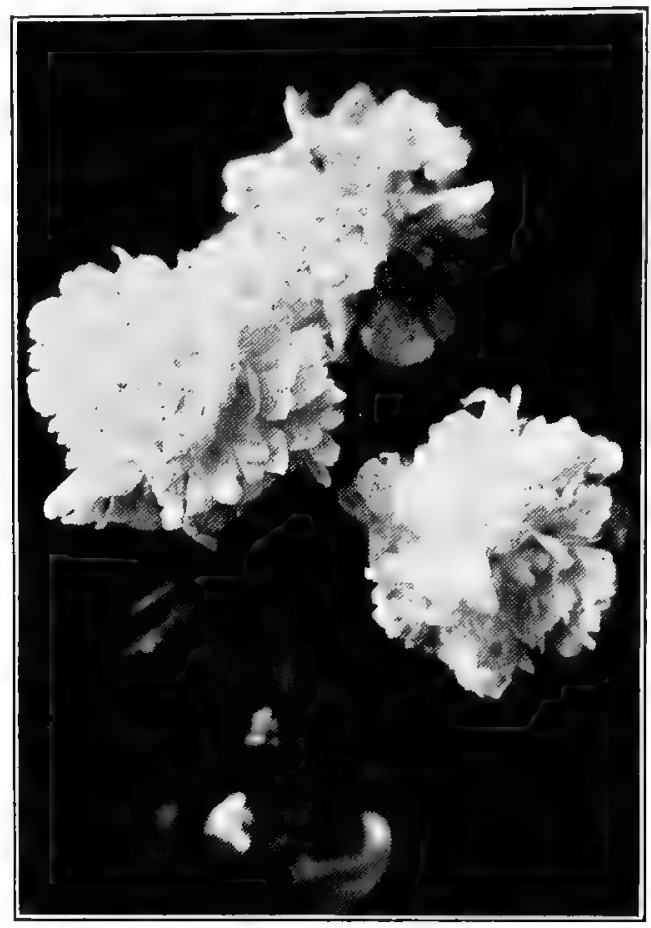

Fig. 232.-PAeONIa Festiva Maxima is one of the oldest yet one of the best of Peonies. Every retail grower should have a good-sized row to cut from and to sell as stock in Fall and Spring but while such flowers are most useful, they often have absolutely no keeping qualities. But, for all that, if you have space outdoors by all means devote some of it to a nice lot of Peonies and be good to them.

Peonies are exactly like Boston Ferns or $\mathrm{Hy}$ drangea paniculata grandiflora. With the tens and hundreds of thousands of plants sold to the public each year one would think that by this time everybody must have all they want. In the case of Peonies in particular, few other plants can get along with less care or stand more abuse; yet each year there seems to be a greater demand for them. This is bound to keep on; in fact, as we go along more will be wanted than ever before.

Among the so-called hardy plants that your patron who is building a new house will first think of planting, are Peonies. Next, most likely will come Iris, then Larkspur or Hollyhocks, and so on. With a good stock of Peonies on your own grounds you can supply that sort of demand. But leave the filling of an order calling for one or two of each of twenty-five varieties to the specialist; or call on him to fill the order. For very few of us who make Peony growing a side line will find it profitable to either carry great numbers of plants or a great number of varieties. The fewer the sorts you have, the more easily they are kept separate. I don't believe in growing your own stock in order to compete with or undersell the nurseryman or specialist, but mainly so that, first, you may have a good supply of flowers yourself during Peony season and second, you may be able to supply field clumps during Spring and Fall whenever there is a call for them.

To my way of thinking, your patrons have a right to expect you, as a local florist, to carry Peonies and other hardy stock to supply 
the ordinary demand in your town or neighborhood. It is far more sensible to do so than to imagine you can grow orchids or Roses as well or as cheaply as the specialist.

The more Peonies you sell in the form of plants, the more Peonies your nurseryman will sell in supplying you and other florists who are doing the same.

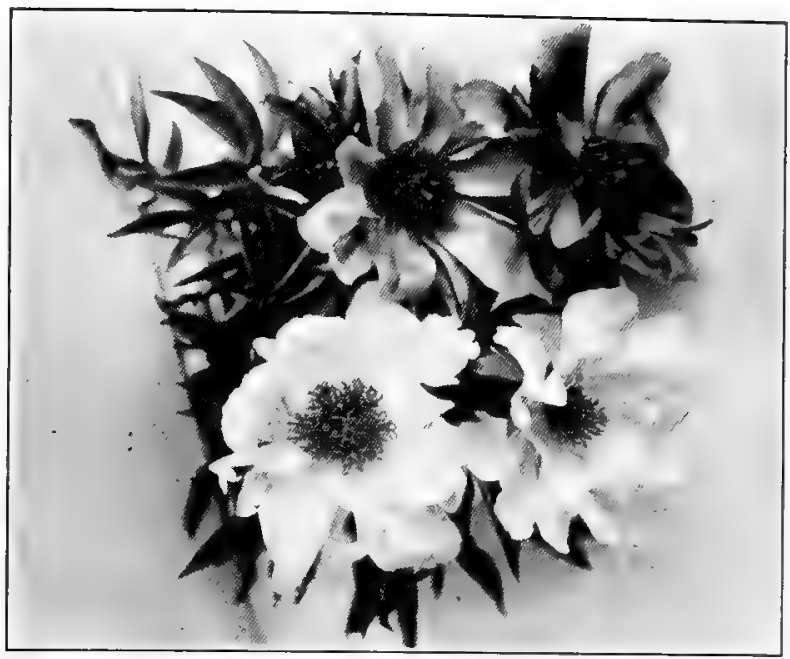

Fig. 233.-Single Peonies. Not all the beautiful Peonies are double varieties. Singles like these should appeal especially to the florist who grows and retails his stock. If cut partly open, the blooms will last for days

If you have a fair soil don't dig trenches as they do in Holland and pile a lot of manure into them in planting Peonies. All they want is a deeply cultivated, well-drained soil. Plant them in rows so you can cultivate between, for the more you cultivate and keep the weeds out the better for the plants. Have the tips of the eyes about four inches or so below the surface and if you plant stock consisting of from three to five eyes, from the third year on you can start taking part of them up each Fall and dividing them, either to be replanted or to be sold. While the best time to do this is in September, you shouldn't miss any chance of selling plants merely because the order comes in Spring.

Your nurseryman will furnish you with a list of the best sorts, some of them even better than any I could suggest, but if you want to start out with six varieties of different colors and shades, I would suggest: Festiva maxima, white; Albert Crousse, delicate pink; Mme. Calot, early pink; Felix Crousse, red; Louis Van Houtte, crimson; and Modeste Guerin, rose pink.

Pæonia officinalis is the first to flower and for that reason is highly desirable. P. rubra, the red sort, is the best known of all of them, but equally as desirable are $P$. rosea superba and $P$. mutabilis, both fine pinks. $P$. tenuifolia flore pleno has finely cut fern-like foliage and is a very attractive sort with its deep red flowers.

The single Japanese Peonies should be better known. They may not be as showy as the double ones, but from the florist's point of view they are every bit as desirable. Of course, they are not flowers you can ship great distances like the double sorts, but when grown on your own grounds where you can cut them just as 
they open and place them in a cooler, they will last for days and you will find many uses for them. I am sure that if you work up a stock of them and if your patrons have a chance to see the flowers, you will have plenty of calls for them. There is a long list of named varieties of these single sorts with Japanese names as easy to spell and pronounce as those of the Japanese Irises. What you are most interested in, however, is a good white, a few good pinks and a red or two.

\section{PENTSTEMON (BEARD'S TONGUE)}

Penststemon, while not hardy everywhere, is nevertheless useful and a most showy border plant. You can obtain a good strain of seed which, if sown about October and if the little plants are carried along with your bedding stock in a 50-deg. house and planted out in early. May, will give you a great display of flowers during Midsummer. The spikes are loaded with miniature Gloxinia-shaped blooms ranging in color from soft rose and lilac to deep crimson. The variety I have reference to is Pentstemon gloxinioides Sensation, but there are other good ones. The plants may be lifted in late Fall and carried over in a frame, or shoots from cut down plants may be rooted in Fall and the young plants carried along in a cool house over Winter. But if you don't want too many and are not particular as to the exact colors, you are, as stated above, just as well off sowing seed.

\section{PERILLA NANKINENSIS}

Those who have use for Coleus, Achyranthes, or other border plants can always use Perillas to good effect. Their bright-colored leaves always form a good contrast with those of other plants and they can stand more rough handling and are less affected by a dry or a wet spell than almost any other foliage plant we have for bedding. A few plants lifted in Fall and carried in a 55-deg. house will give you many cuttings from the end of February on; they can also be grown from seed sown in January.

\section{PERIWINKLE \\ See Vinca}

\section{PETUNIAS}

NLY of late years have Petunias come to the front, but they occupy today a place beside our most desirable bedding plants all over the country, in beds, borders, vases, etc. The progressive retail grower will find that his patrons will prefer, even to Geraniums, plants of the ruffled monsters of American origin in 4-in. pots grown on from seed. Also it is far more profitable for him to handle them. 


\section{Seed and Seeding}

One package of seed will give you at least 300 plants, and by sowing out in January you can have your plants in full bloom in $4 \mathrm{~s}$ by the middle or end of May and retail them at a higher price than Geraniums. Compare that with growing the latter. I am talking from the retail grower's point of view. There is absolutely no more showy bedding plant than one of those giant single Petunias in a 4- or 5-in. pot in .June; many thousands more could be sold if people were given a chance to see them.

For large vases or rustic tubs you couldn't have a better combination than Balcony Queen and Snowball Petunias; nor is there anything better than a

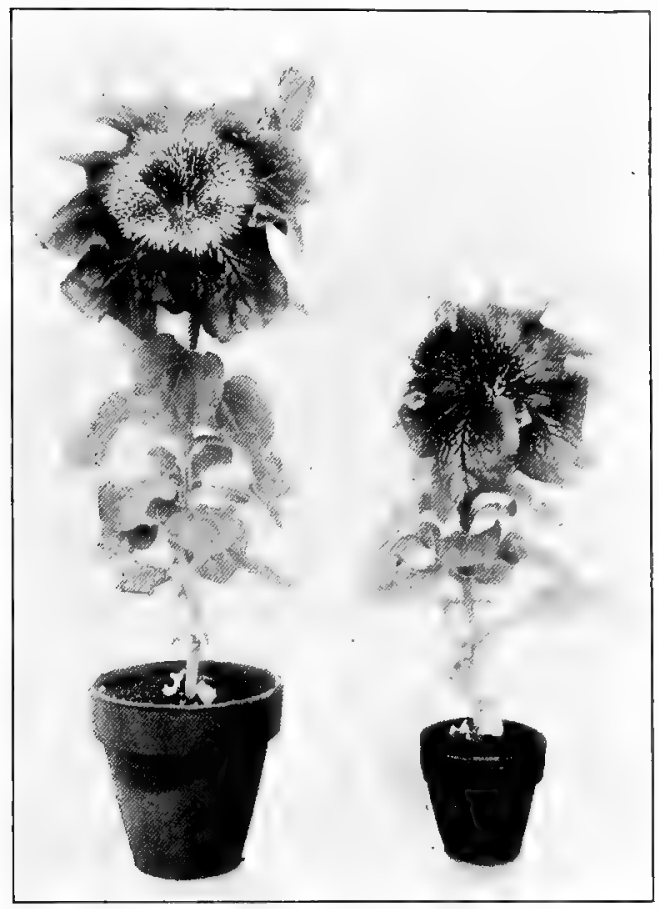

Fig. 234.-Diener's Ruffled Monster PeTUNIAS. A "close-up" of seedlings in 4-in. pots. Some of the flowers are beautifully ruffled, coming in all shades and colors, and some measure easily six inches and more in diameter porch or veranda box filled solid with Rosy Morns.

Petunia seed is very small and should never be covered with soil. Take a 12-in. pan, put over the bottom a 1-in. layer of coarse soil followed by nicely sifted soil well mixed with sand, and fill up to within an inch or so of the top. Press firmly, not only in the center, but also around the edges of the pan. Now put on another thin layer of still finer sifted soil, level it, and give the pan two or three doses of water. When dried off a little, sow the seed thinly and gently press it into the surface; follow this with a light spraying (making use of a Scollay sprayer) and place the pan on the hot water returns-but place a couple of short pieces of lath on the pipes first. Place a whitewashed pane of glass over the pan and each day apply warm water, always making use of the Scollay sprayer. The surface of the soil should never be allowed to dry out if you want to obtain the highest possible percentage of germination and thrifty plants.

As soon as the little plants appear, which only takes a few days, bring the pan to the light, but leave the pane of glass on, placing a piece of stick under one side to allow a free circulation of air. In 
468 FRITZ BAHR'S COMMERCIAL FLORICULTURE

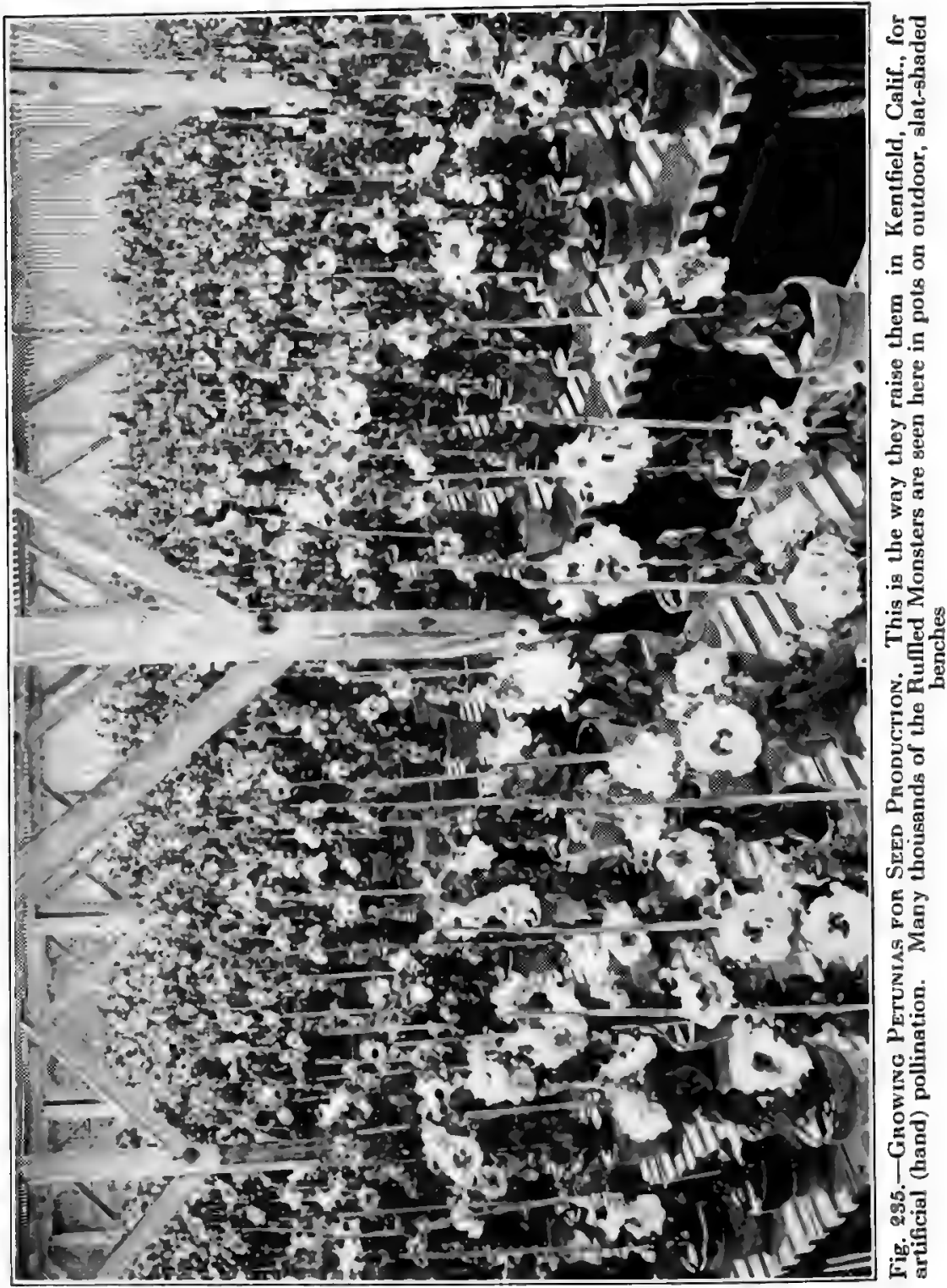


a week or so remove the glass and place the pan on a shelf near the glass, in a 50-deg. house; $53 \mathrm{deg}$. is even better. In about six weeks from the time of sowing those sown in January are ready for transplanting into flats, allowing about one inch of space between the plants. When they touch each other they should go into pots and be kept shifted until in the pots in which they will flower.

Mistakes often made are that the top layer of soil isn't fine enough, or, with careless watering, a lot of seed goes to waste; the seed may be sown too thickly; the seedlings may be left too long in the seed pans or flats; transplanted seedlings are allowed to become spindly and hardwooded before they are potted up; the 2-in. stock is left to become potbound and stunted before it is shifted, or the plants are kept in too warm a temperature. Any of these troubles can be avoided. A stunted plant will flower in the seed pan or in a 2-in. pot if left there long enough; while a healthy plant will make a short, stocky growth and hardly ever need pinching back. It will make side shoots if given room, and not kept too warm.

Petunias are not very particular as to light or heavy soil as long as you have perfect drainage; no plant will show the effects of a too wet soil quicker than a Petunia.

\section{Preparing for Spring Trade}

The retail grower should always bear in mind that the bedding season is liable to start any time in May and apt to extend into July. For that reason, when growing Petunias from seed, it is well always to make at least three sowings ábout four weeks apart, beginning the first week in January. The first batch will be ready in early May, the second toward the end of the month and the last in June. Of course, there are always plants that do not grow as large or as fast as the others, and as with the double sorts grown from seed, we may find some of the choicest among them.

What should be kept in mind, is to try and have different lots of plants come along. For instance, you can dispose of your first batch of plants in flower by May twentieth out of $4 \mathrm{~s}$ and have a nice lot of $21 / 2 \mathrm{~s}$ ready to be shifted into the $4 \mathrm{~s}$, to take the place of those sold, and be ready for the market by the fifteenth of June.

Late shifted Petunias can be had in fine shape and sold when almost everything else in the bedding plant line is sold out.

A nice lot of 4-in. Rosy Morns, if planted a little close, will make a fine looking porch box the day after it is filled, with onethird of the plants hanging over the sides. Often you don't need Vincas or English Ivies at all since the Petunias will take their place. But if you fill boxes or vases early in the season, always allow plenty of room between the plants, for a crowded condition at that preliminary stage of their development will soon ruin them. 


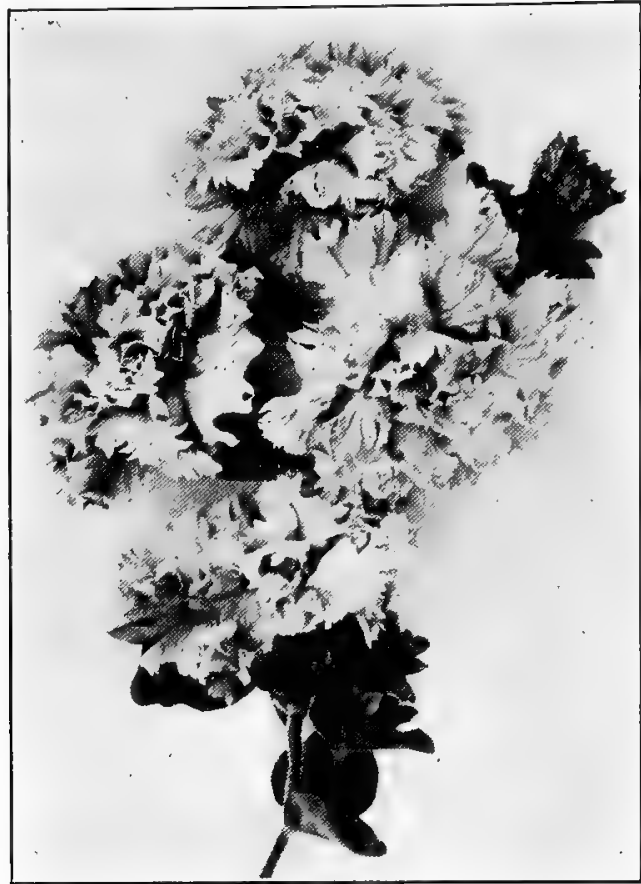

Fig. 236.-Double Petunias. A good double, white and pink Petunia always sells during the bedding season. Plants are best propagated through cuttings. Root these early and grow them on cool to produce sturdy plants

\section{Double Petunias}

There is a place for the double sorts and they make attractive pot plants for Spring, but there is not the demand for them that there is for the single ones. Most florists who use the double ones extensively carry a few plants in pots during Winter and propagate from cuttings. If you have a good plant of white, rose, deep pink or some other color best suited to meet your requirements, that method is the only way to increase your stock so as to have it come true.

Double sorts are even more particular as to perfect drainage than the single ones and whenever you notice a sickly yellow or stunted growth, you usually can trace the trou-

ble to conditions involving improper or insufficient drainage.

Today, September 21st, we filled six window boxes for a new residence with Rosy Morn Petunias. Last July the plants were in $3 \frac{1}{2} \mathrm{~s}$, too straggly to use. So we cut them back to 4 in., shifted them into $4 \mathrm{~s}$, and plunged them in a frame ten inches apart. They came out in fine shape and have more than paid for themselves.

\section{PHILADELPHUS}

The forms of Philadelphus (also called Syringa or Mock Orange) are among the best known and most widely used hardy shrubs; we find them in every assortment on the average home ground.

Philadelphus coronarius is the old favorite and becomes loaded down with its garland-like masses of white, Jasmine-scented flowers in June. P. Gordonianus flowers fully a month later and $P$. aureus is the golden leaf variety, very effective for planting in groups.

The florist who does landscape work or sells hardy stock should have a few specimen plants for his customers to look at on his own grounds, and should carry the usual 2- to 3-ft. stock plants in Spring and Fall. 


\section{PHLOX \\ Hardy Species}

One of the most useful perennials, and the best Phlox for the florist, is Miss Lingard. No other hardy plant I know of is to be compared with it for the florist who has design work to make up, and this applies to about every retail grower. You can have the plants in bloom from the middle of June on and you will cut long-stemmed, pyramid-shaped flower heads, useful for all kinds of purposes, up to time for frost. Then, during Spring and Fall, you can sell the field-grown plants to your customers.

You want white in every perennial border; in fact, I don't think we use enough of it to set off the other colored flowers. It is all well and good to have your lady patron talk about a yellow or blue or pink effect and that she wants nothing else in her border.

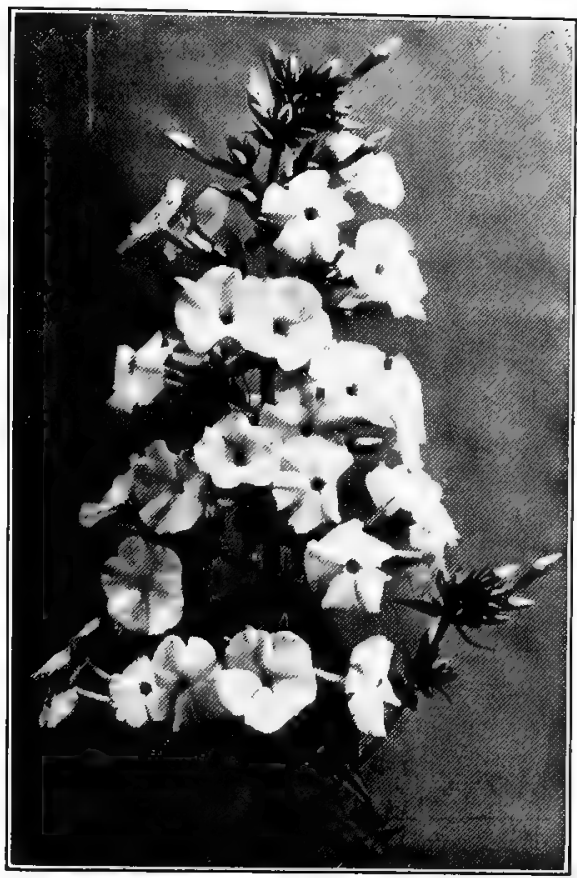

Fig. 237.-Phlox Miss Lingard. If I had to name the one best Phlox for the florist, here it is. Every retail grower should have a few hundred plants to cut from. By rooting several lots of cuttings during the Winter, from plants grown on a Carnation bench, you can cut flowers from the middle of June until snow flies. (See Fig. 81, page 236.) That usually lasts one season, or maybe two; then we go back to a cheery mixture. For after all, the first thing about any border, whether planted with annuals or hardy stock, is that it creates a mass of bloom all Summer, and it takes groups of white flowering plants to bring out the others. Colors never clash if you have enough white among them; white goes well with almost anything.

Not only should every florist have a good batch of Miss Lingard, but he should have some of the other beautiful Phloxes available; among those we have today varieties W. G. Egan and Elizabeth Campbell are two of the finest, being light and rose-pink, respectively, with large flowers. You can always sell a pink Phlox when a red or lavender or cerise one cannot be sold.

When you once have a stock of Phlox, you can with the help of a greenhouse increase it rapidly and easily and there is no trouble in disposing of a good number of plants each year at a good profit. 


\section{Growing Phlox suffruticosa Miss Lingard}

In order to work up a stock of this Phlox, purchase fieldgrown stock clumps, or lift some of your own stock in October, heel it in in a frame and bring it into a Carnation house temperature about January first. Plant on a bench, and when the young growth is about four inches in height take cuttings with three or four eyes, leaving a couple of eyes on the lower part. These will, in a short time, furnish more cuttings; in fact you can keep on taking cuttings up to the end of April. They will root even without bottom heat and should be planted later on in flats two inches apart. From those first planted the tops can in turn be used for cuttings.

Plant the young stock out into the field in April and the early propagated plants will give you heavy spikes of flowers in two months and some a little later. The late ones may not flower the first season, but all of them will produce from five to eight heavy spikes the second Summer. Then, although the plants are good for years, it pays to discard them; by propagating a few each Winter you can always have some strong, vigorous stock to cut from. The foliage and habit of this Phlox differ from those of all others.

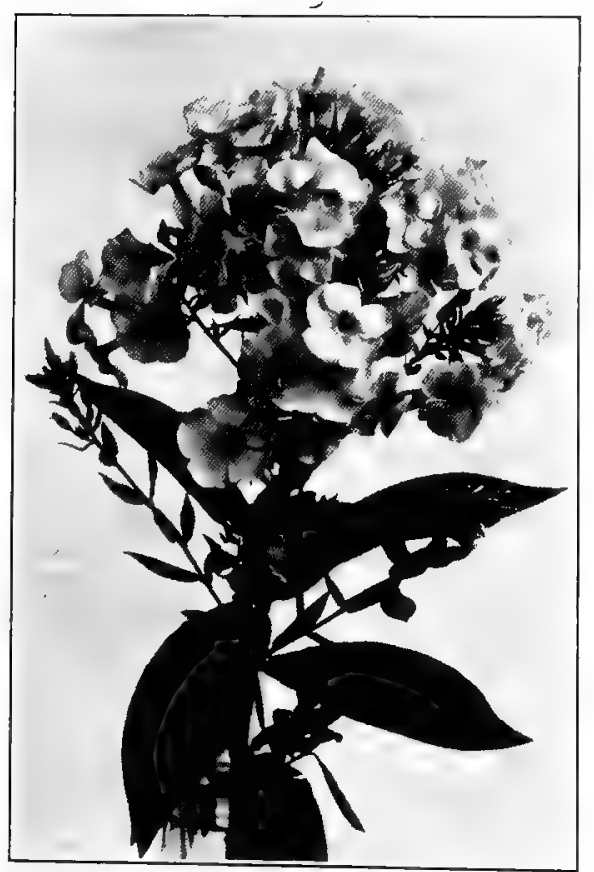

Fig. 238.-Phuox degussata W. C. Egan. If you wish to retain healthy foliage on hardy Phlox don't overfeed the plants with a lot of manure. They prefer a heavy loam and are at their best the second year
The leaves are long, pointed, thick, leathery and glossy green and the time to cut the spikes is when the flowers are only partly open.

I know there is complaint once in awhile of the flowers dropping, but what of that? All flowers droop, wilt or drop sooner or later. However, I don't know of a better flower for rush order design work. You don't have to wire the stems for they are stiff enough to go into the moss without toothpicks. Nor is there a more showy plant for the perennial border, nor a hardier one. It will tbrive in any soil and doesn't need a lot of manure. In fact, it is better off without it. But what you do want to look out for is to have enough plants coming along each year, for it is the oneand two-year-old stock that gives you the heavy spikes. 


\section{Phlox degussata}

The best way to propagate this Phlox, to which belong such fine colored sorts as Miss Jenkins (white), W. G. Egan (soft lilac pink), Elizabeth Campbell (salmon rose), Rynstrom (carmine pink), and Mauve Queen, is through rooted cuttings. Lift two- or three-year-old clumps in Fall; even one-year-old ones will do, and, in fact, usually have the best roots. Remove part of the soil carefully and then with a knife cut off some of the heaviest roots. You can cut to within two inches of the plant, but let all the small roots remain. The plants can then be divided (if they are large enough) and replanted in the field.

The roots you have cut off should be cut into 1-in. pieces. Have flats ready with a layer of soil in the bottom on which is spread a layer-about a half-inch in thickness-of sand; spread the root cuttings thinly over the sand and cover with another layer of sand of the same thickness. Put a strong label with the name of the variety in one end of the flat and place the flats in a coldframe. All the water they need is enough to keep them from drying out. By February bring them in and.place them on a shelf or bench in a 50-deg. house. In a few weeks the young plants will appear and soon are ready to be either potted up or transplanted into other flats to go into the field by the end of April to flower the first season.

These directions are of course meant for the retail grower and not the nurseryman who has no greenhouses. You can by this method quickly grow on a fine stock of plants, and when once under way, you soon will have a lot of fine plants for sale, besides having a grand display of flowering stock on your own grounds.

Plant Phloxes-a lot of them. Use them for cut flowers and push the sale of the plants. It pays every florist to do so.

\section{Phlox subulata and other Hardy Forms}

You will surely have call for this creeping Phlox which is fine for borders or in the rockery with its evergreen; moss-l ke foliage. It comes in a clear lilac pink and a pure white. While it is no good as a cut flower, it surely is most effective when a mass of color in Spring. The pink does not, however, go well with all other colors.

Other hardy Phloxes are: $P$. amcna, which like $P$. subulata, is of dwarf growth forming a dense mass of mossy green and very showy when in full bloom If you want something with mauve or lilac colored flowers for massing in the hardy border, Phlox Arendsii -either Amanda or Louise- - will give it to you. These are early flowering hybrids coming into bloom even before Miss Lingard, and while they are not to be compared with that variety as sources of cut flowers, they are fine, nevertheless, and stay in bloom for five weeks or more. 


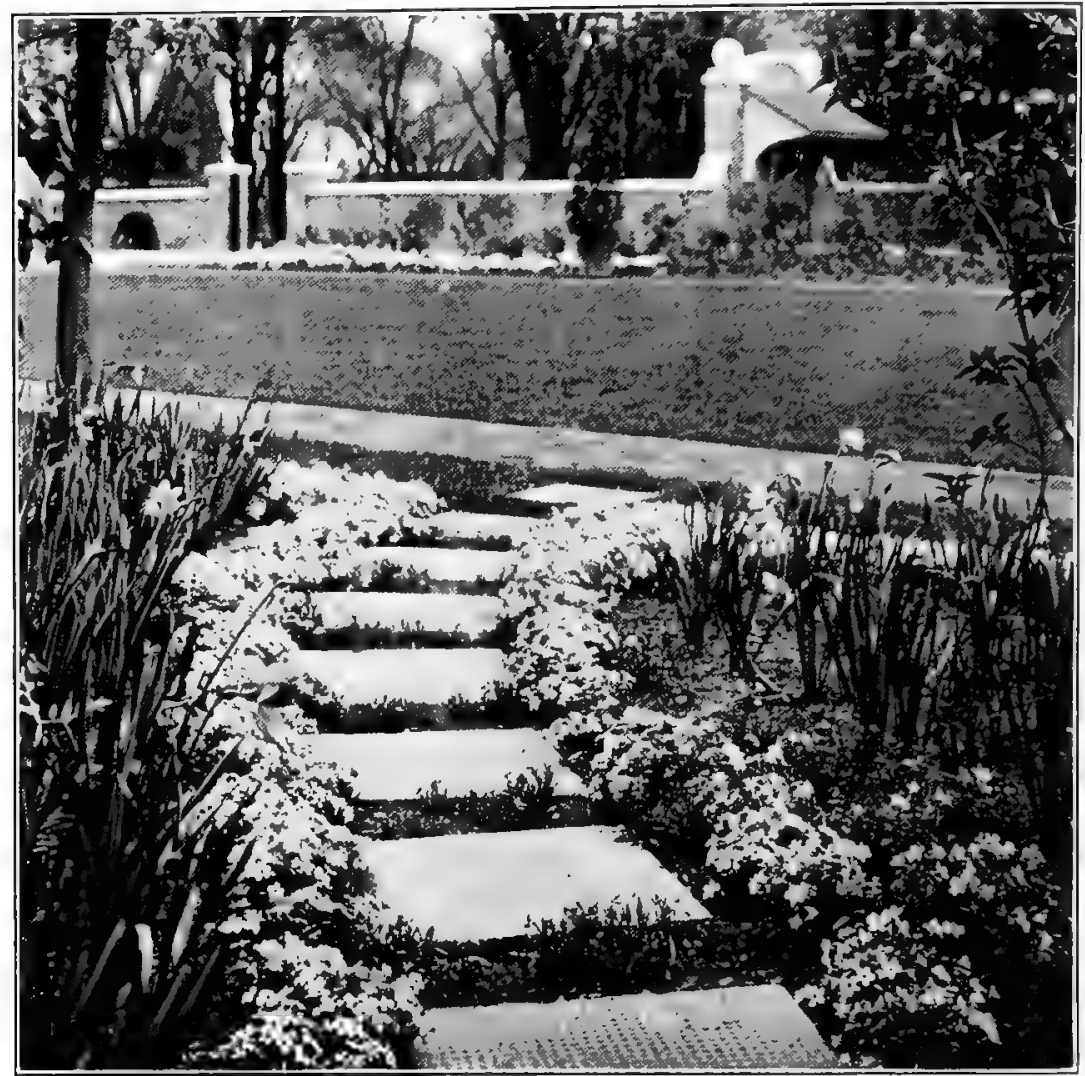

Fig. 239.-Phlox subulata. How to make use of the right plant in the right place is a problem well worth studying. Here we see it solved. Even when out of bloom the moss-like foliage of this creeping Phlox makes ideal border material

\section{Phlox Drummondi (Annual Phlox)}

This annual Phlox, while not of great value to the florist, can be sown across a bench in rows and had in flower with from 10 to 12-in. stems by early May. The flower; will come in handy, especially if you sow a good pink or white strain.

For outdoor flowering sow right in the open. You may also consider sowing seed about March first and transplanting the seedlings, five to a 4 -in. pot. They will make nice bushy plants in that way and bloom by Memorial Day.

\section{PHENIX (DATE PALM)}

Phonix Roebelenii makes one of the most graceful of palms and the larger it gets, the more graceful it becomes; besides it is one of the very best of house plants. You cannot use it for mass 


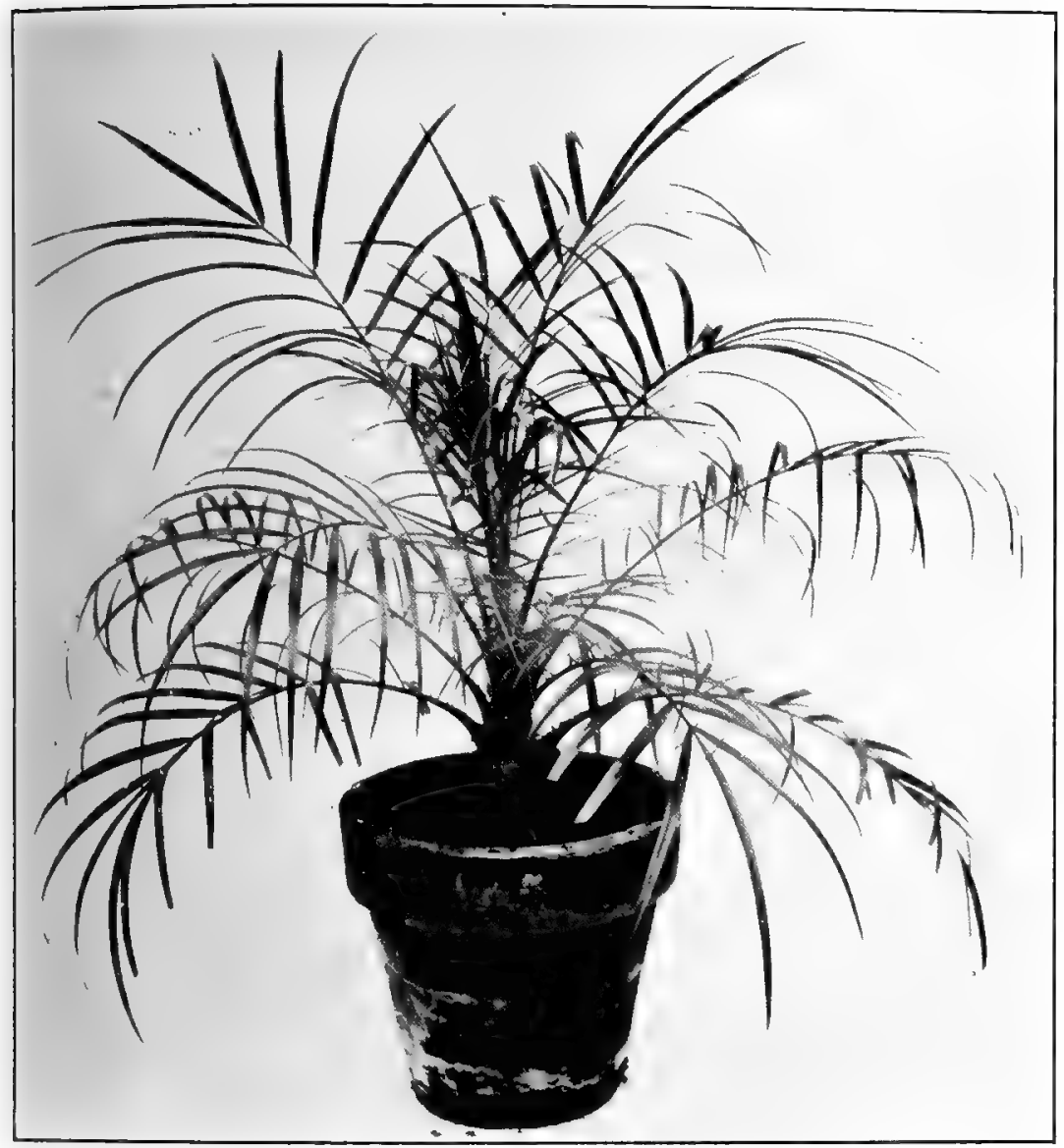

Fig. 240.-The Phomix Paxm makes a good, decorative plant that will stand much rough handling. With this in view $P$. reclinata or $P$. canariensis is mostly used, but $\boldsymbol{P}$. Roebelenii is far more graceful than either

decorative purposes like a Kentia, but there is nothing finer in specimen decorative plants where just one is wanted.

Always include a few in your assortment; you can use the small plants for the center of fern dishes or in indoor window boxes.

Long before we knew of this grand variety we considered Phonix canariensis one of the leading palms for the florist. It belonged to the three leaders, Kentias and Latanias being the other two. This Phœnix grows faster than P. Roebelenii, is coarser and can stand more rough usage and is fine to send out for decorative purposes. Purchase what stock you need of both sorts and do not try, on a small scale, to grow plants on from seed. It doesn't pay. 


\section{PHYSALIS FRANCHETII (GHINESE LANTERN PLANT)}

If you have call for everlasting flowers, plant a few Physalis. This gets its name, Lantern Plant, from the fact that it produces large balloon- or lantern-shaped, red-colored calices in Fall, which remain that way all Winter, even when dry, and are very decorative on that account.

Sow seed in Midsummer as you would that of other perennials, and for a permanent planting select a rather moist situation.

\section{PHYSOSTEGIA VIRGINIANA (FALSE DRAGON HEAD)}

While not two of the showiest of perennials, the Physostegiasboth the lilac pink and the white-are valuable both for the hardy

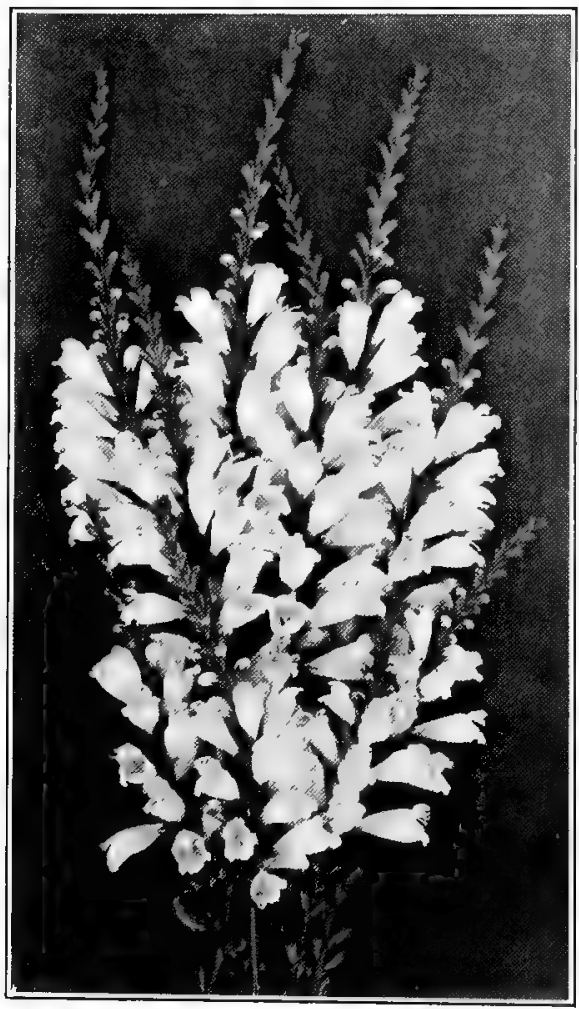

Fig. 241.-Physostegia virginiana is one of the hardiest of perennials and a showy one when planted in masses. Coming into bloom in late Summer it also makes a good cut flower and a welcome change from the stock usually on hand at that time border and as cut flowers. They start to flower in late July and have stems 2- to 3-ft. long covered with tubular flowers which when cut will last in good condition for days.

The plants grow easily from seed or can be increased by division in September. When once established, you will have them always with you and you can recommend them as good perennials needing but little care.

\section{PIGEA (SPRUCE)}

As far as the florist is concerned, there isn't a more useful conifer than Picea, or Spruce, particularly the Norway Spruce. Not that it is as attractive as some of the others, but because of its quick growth (and therefore inexpensiveness) and the fact that even small 8- or 10-in. plants are perfect little specimens and are valuable in window boxes or to be used around Christmas. The plants are money makers for the florist. 
You can purchase from your nurseryman seedlings or transplanted seedlings of Norway Spruce for a few dollars per hundred. These lined out will grow in four or five years into nice stock ranging from two to four feet or thereabouts in height. During these years if you set out enough plants, you will have stock to draw from for the filling of porch and window boxes for Winter effects. You will have calls occasionally for small plants that someone wants for planting out; or in December the most perfect plants can be potted up to answer as miniature Christmas trees, the call for which seems to be on the increase from year to year. Many people prefer a neat, well-developed little tree about eighteen inches high for the center of the dining table, either in a pot or set on a block of wood. (See Fig. 269, page 524.)

I hate to think of sacrificing any kind of conifer and consider it a crime to do so, yet as long as people demand and will pay for them, it would be foolish not to supply them. While some prefer a small size tree to a larger one, there are others again who use both and still others who will select a half-dozen or so of these small Spruces to be sent as gifts to their friends. Sometimes they require a little trimming up; others order them with only a crêpe paper around the pot.

If a florist with room will keep on for about six or eight years planting out each Spring a certain number of such Spruces and will keep on transplanting and giving more space to the larger ones, he will, at the end of the eighth year have a valuable lot of stock on his land which will bring him better returns than almost anything he could plant. To make doubly sure of large returns, along with those Christmas trees he should plant each year a few Colorado Blue Spruce, a few P. Engelmannii and some P. Douglasii. They are all awfully slow while small, but you don't notice this after you have a stock under way and small ones coming on each year.

If you happen to live in a country town you should encourage the use of live Christmas trees. A 6- or 8-ft. Norway Spruce may be lifted with a frozen ball of soil, burlapped and used for three or four days in a cool room or sun porch for. Christmas and planted out later. It isn't claimed that every tree so treated will live or do well, but a majority of them will, and the smaller the tree the more apt it is to grow into a good specimen in years to come. Advise customers who buy these little living trees to prepare places for them in the Fall and mulch them well to keep the ground from freezing. The plants can then be set out when the holidays are over with the least trouble and maximum chances of their living. 


\section{PINUS (PINE)}

The White Pine is one of the finest of native conifers and should be planted far more than it is; so should the Scotch and Austrian Pines, whether for timber or windbreaks or as single specimens. The florist of the smaller town should set an example and make others follow. We need more conifers; almost every city and town does. And when once established as small plants, these Pines will usually take care of themselves.

\section{Pinus Mugho}

This is a dwarf Pine and an excellent one for home ground planting, whether you want it as a single specimen or planted in groups. There are times when three or five of them can be placed to advantage at the end of a shrubbery border or along its edge; or a customer may want an evergreen effect, but object to conifers growing high; or you can use plants for vases or window boxes. They grow slow and at present come rather high in price but, for all that, if you have a show ground, you should plant a few Mughos. They will grow into money for you.

\section{PLANTAIN LILY See Funkia}

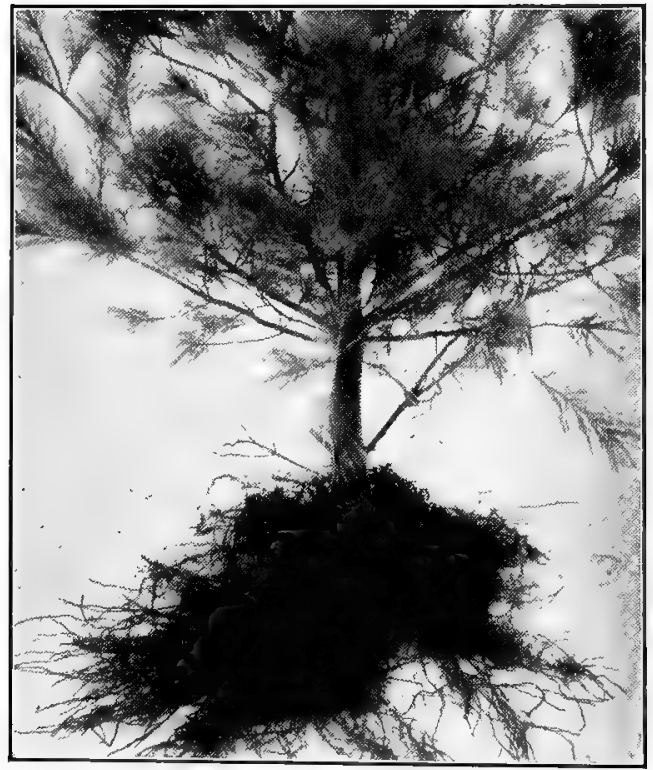

Fig. 242.-A Good Root System on a Pine. Transplant or at least root prune shrubs and trees in your nursery rows so as to produce compact, much-branched balls of fine feeding roots. They are much the easiest to move

\section{PLATYGODON} '(JAPANESE BelL Flower) In itself the individual blossom of Platycodon is about as simple as any flower I can think of; yet when you see a mass of the plants in the hardy border, they are very showyi $\mathrm{Be}$ sides, they can be used to advantage by the florist as cut flowers. He can also make them into sprays for they will last well and go finely with other flowers. They grow about two feet in height on slender stems and come in white and blue. Sown indoors in February and planted outdoors in April, they will flower in July.

PLUME POPPY See Bocconia 


\section{PLUMS See Prunus}

POLIANTHES TUBEROSA See Tuberose

\section{POINSETTIAS}

The Poinsettia is today, as it has been for the past fifty years, the ideal Christmas flower on account of its bright colored red bracts. Perhaps no other plant or flower we handle during Christmas week is shorter lived, wilts quicker or is more disappointing to those who receive it; yet, when the next $\mathrm{Ch}$ ris t m as comes around, there comes again the same demand for Poinsettias and the disappointments of a year ago are all forgotten. Your Christmas display is not complete without Poinsettias in pots and pans as well as cut.

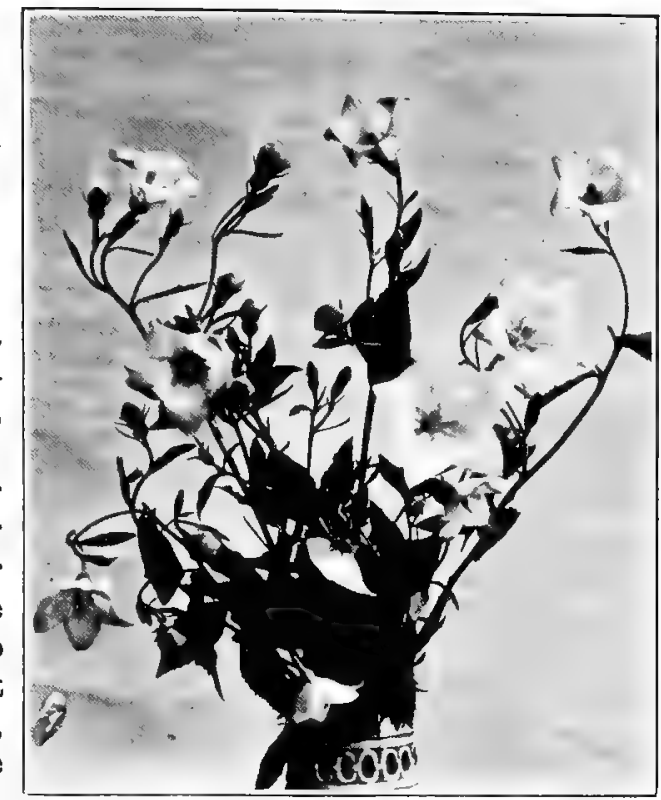

Fig. 273.-Platycodon GRandiflorum. Both white and blue sorts with their simple, bellshaped flowers belong in every collection of hardy border plants; the retail florist will get from them graceful cut flowers with good keeping qualities

To grow Poinsettias successfully, you must have heat; not only that, but it must be a steady heat. Without that you may grow good bracts, but you will have yellow leaves or none at all.

Poinsettias hardly ever have an abundance of real dark green foliage, but you can better obtain such foliage in a greenhouse than find $\%$ in the tropics or out West.

Starting out with 2- or $21 / 2$-in. stock in July, keep the plants, if wanted for pots or pans, on a sunny bench and keep them watered. Those for single stems keep shifted or plant them out on a bench allowing about one foot of space between them; the ones in the bench will give you the largest bracts and are best for cutting. Hardly ever do we sell single plants in pots, but there is always a brisk demand for plants in Azalea pots or pans, ranging from three to five or more to the pan. These usually are wanted short to serve as centerpieces on Christmas Day and for this purpose, later propagated stock is best, such as has been rooted in July and planted from 2-in. pots into the pans in which they are to flower. In early September, or even later, bring in these pans; ten weeks or more of pushing and a good soil should be given.

While it is no trouble to get the plants to do well during the Summer months as long as they are watered properly, there is a 


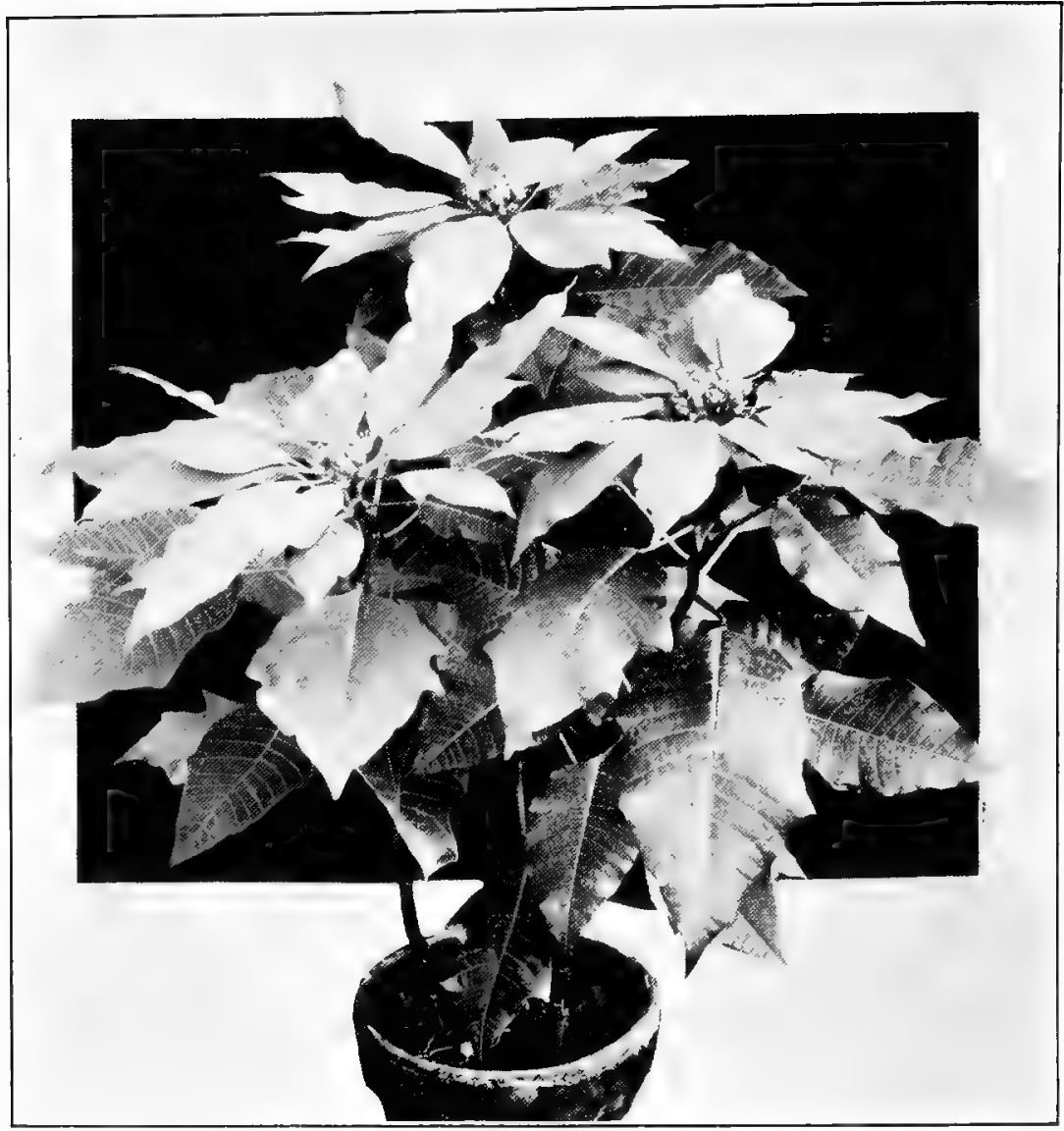

Fig. 244.-A Good Pot of Pornsetrias. Good foliage on a pot-grown Poinsettia is as necessary as large, well-colored bracts. When done well, Poinsettias always find a ready sale at Christmas time

critical time in Fall, when the temperature goes down overnightmaybe not low enough to make you start firing, yet frequently too low to suit the leaves of the Poinsettias. A night temperature with a 60-deg. minimum should be maintained for the plants in pots; those well established in benches can stand a few degrees less. By ear y November, sometimes even before, it is always wel not to apply water as it comes out of the hose, but to take the chill off; apply light doses of iquid cow manure every ten days.

Yellow foliage is usually caused either by a low temperature, by keeping the plants too dry, or by lack of nourishment. Whenever the plants are subjected to all three of these troubles, they may not only get yellow leaves, but the latter may all drop off while the bracts remain in good shape. 
It takes a good grower to produce a pan of Poinsettias with green leaves to the top of the pan, but even with such stock it won't hurt, a couple days or so before Christmas, to set a few good-sized Asparagus plumosus plants along the edge of the pans. For in a hot, dry room the Poinsettia leaves will usually come off inside of a couple of days. I-suggest to the smaller retail grower that if he can manage to purchase his requirements a few days before Christmas and do it at all reasonably, he let the large grower, who makes a specialty of Poinsettias, do the growing for him. With those located long distances out in the country, however, even the shipping doešn't do the plants any good; and it is best for them to create facilities that will in some way enable them to maintain an even temperature in the house where the plants are.

\section{The Gare of Gut Poinsettias}

To prevent the bracts from wilting is easy. Dip the lower end of the cut stem in hot water for a minute or so and wrap each bract nicely in tissue paper. It won't hurt if you fold the leaves close up to the stem and wrap at least the one nearest to the bract along with it. After that, place the flower deep in water and keep it in a cool place until wanted for delivery. If you want to prevent disappointment, let your customer know that if the stems of the Poinsettias are to be cut, in case they are too long, they should, after cutting, be dipped in hot water again.

\section{Delivering Poinsettia Plants}

Those who are anxious to fill orders for Poinsettia plants to be delivered as gifts in good shape on Christmas Day should never let one go out without wrapping it carefully to prevent its becoming chilled on the way. These plants are even more particular in that respect than the most tender Begonia, and you cannot be too careful.

\section{Propagating Poinsettias}

The cut-down plants, whether from the bench or such as are left over in pots or pans, should be stored away under a bench and kept dust dry up to the middle of April. After this the soil should be removed from the roots and the plants potted up, placed on a sunny bench and the soil in the pots kept moist. They soon will begin to break and the cuttings-removed with a heel-will easily root in sand. Cuttings can be taken up to the middle of August, but of course the early rooted ones are best for cut flowers and will give you 5- to 6-ft. stems if planted out early. Those rooted the latter part of August may only grow five or six inches in height, yet when five or six are used in a small pan, they make very at- 


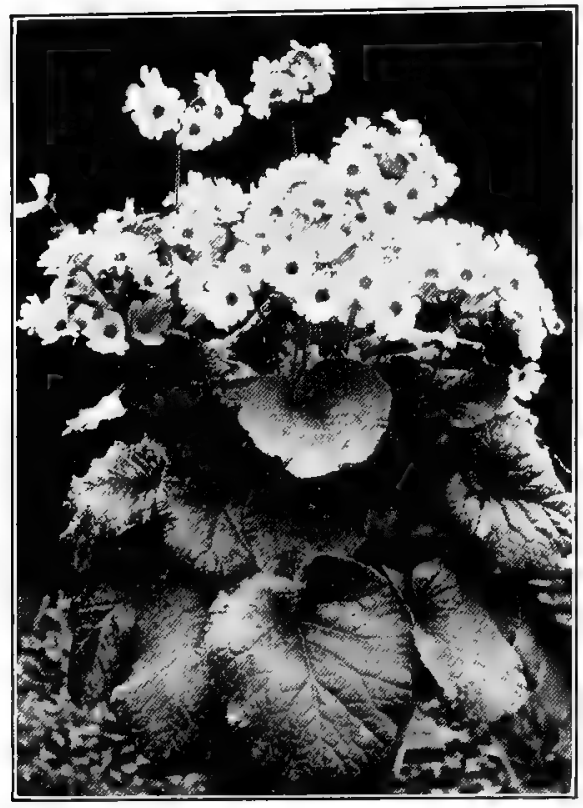

Fig. 245.-Primula obconica gigantea. (Grown by J. L. Schiller, Toledo, 0.) Primula obconica with its greatly improved strains has become of great value to the retail grower, not only as a flowering pot plant, but also because there are times when the flowers can be used to advantage in design work in place of expensive Carnations and Roses tractive Christ mas plants. The less you disturb the roots when planting the 2 -in. stock in the pans, the better.

\section{POOR MAN'S ORCHID See Schizanthus}

$$
\begin{gathered}
\text { POPPY } \\
\text { See Papaver }
\end{gathered}
$$

POPPY, GALIFORNIA See Eschscholtzia

\section{POPPY, GIANT YELLOW TULIP \\ See Hunnemannia}

\section{PRIMULA (PRIMROSE)}

The varieties of Primulas grown for pot plants under glass are of greater importance to the average florist, and especially the retail grower in the smaller cities and towns, than any other stock he carries. Of the main ones for usefulness, Primula obconia heads the list and $P$. sinensis and $P$. malacoides follow. Any of these

can be had in flower all Winter long and obconica and malacoides not only make beautiful, showy pot plants, but are of great value as cut flowers. There are times when Roses and Carnations bring such fancy prices as to make their use almost prohibitive in a funeral design; at such times the flowers of an obconica Primrose will answer every bit as well and last fully as long. Moreover, they can be successfully grown in almost every establishment.

\section{Primula obconica}

Remarkable improvements have been made and are still being made with this Primula and a fine strain of seed is grown right here in the United States. Not only that, but good growers are specializing in it and are growing young stock for the florists at a reasonable price. Those with their houses full of bedding plants can place their orders and have well-established 2-in. stock shipped during July and August which, with ordinary care, will develop into 5-in. plants in full bloom during the Midwinter months. This is simpler than sowing seed and bothering with the seedlings at a time when you have your hands full of other things. 
All greenhouse Primulas require a rather moist atmosphere and so do the obconicas, but they will thrive in almost any good soil with plenty of drainage in the pots. During Summer let them have a shaded house with all the ventilation possible and keep them shifted. Constant spraying with light doses of nicotine will keep them free from green fly and they are hardly ever attacked by anything else. By Fall gradually remove the shade and let them have a house of $50 \mathrm{deg}$. or a little over. They will do nicely in full sunlight, but when coming into flower, they should have some protection; it will result in better flower heads and a richer coloring in the flowers.

For Christmas flowering, seed should be sown about January. Plant another lot about March for a later crop and still another about May first for Easter blooming.

Those wanting the plants mainly for cut flowers should bench a few heavy $4 \mathrm{~s}$ about September first, allowing one foot of space between them. This will result in extra large plants and long flower stems. Such plants can also be lifted and potted up when in full flower. They won't show any bad effects if this is done carefully and if they are kept in the shade for a little while; but they will not have the lasting qualities of those grown in pots.

\section{Primula sinensis}

I consider a well-grown red Chinese Primula in full bloom in a 5-in. pot a most desirable Christmas plant and one which will always find a ready sale as there are always some among your customers not able or willing to purchase other more expensive stock. The large city retailer may not use them nor wish to cater to trade demanding a dollar or a dollar and a half plant, but the country florist wants all such plants he can get. However, the great majority as yet make but little effort to grow on this sort of stock, which, in the case of these Primulas, is a comparatively easy matter.

Well-established 2-in. plants shifted into $3 \mathrm{~s}$ about July fifteenth can be easily grown into heavy $5 \mathrm{~s}$ by the middle of December and

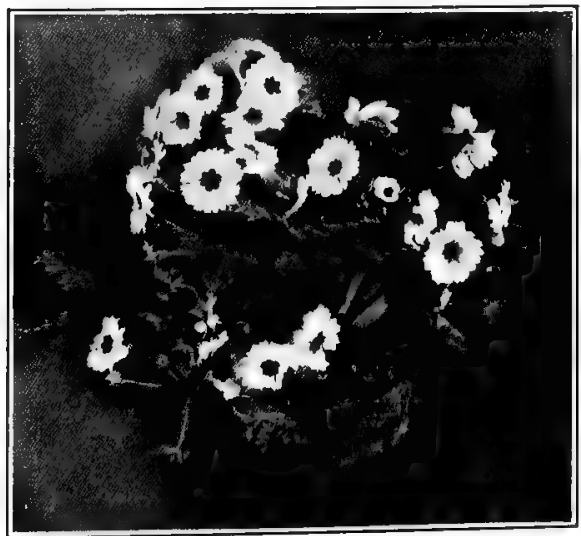

Fig. 246.-Primula sinensis in a FourINCH Pot. With good culture, the Chinese Primulas can be had in 5- and even 6-in. pots for Christmas and every florist can use them to good advantage. However, 4 -in. stock in full bloom comes in very handy for the making up of plant baskets where an assortment of foliage and flowering plants is wanted 


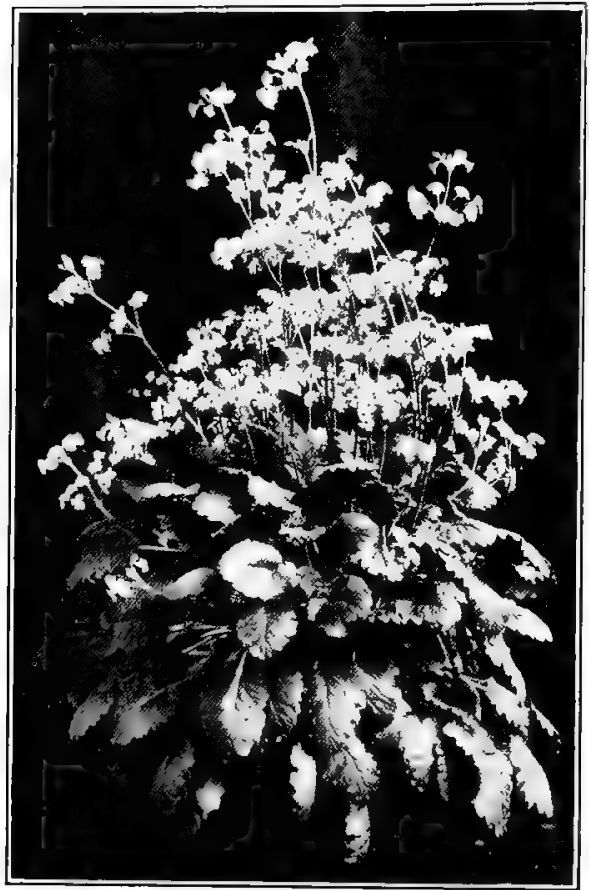

had in full bloom by Christmas. They require a cool, airy house during the Summer months and a little shade; they will need shifting several times and should be given all the room necessary to grow into short, bushy stock. You cannot crowd them and get results; a 50-deg. house, from October on and full sunlight is what they want.

\section{Primula malacoides}

This is called the Baby Primrose and has replaced $P$. Forbesii entirely. New, improved strains are being introduced right along, each more beautiful than the other, and it is hard to imagine how a florist can get along without this species. Even if he never

Fig. 247.-Primula malacondes in a 7 -in. pot. Note the abundant foliage. The Forget-me-not-like flowers on long, graceful stems are excellent for cutting and the plant can be grown nicely in a 45-deg. house

sells a plant he can make them pay and pay well, considering all the graceful, long,stemmed cut flowers a plant will furnish during the Winter and Spring months. The Myosotis-shaped little blossoms of dainty light rose, lavender, and white can be used to advantage in almost any flower arrangement, whether a corsage, a wedding bouquet, a dinner decoration or a funeral design.

Cultural requirements for this species are practically the same as for the Chinese Primulas, only a 2-in. plant by August is plenty large enough

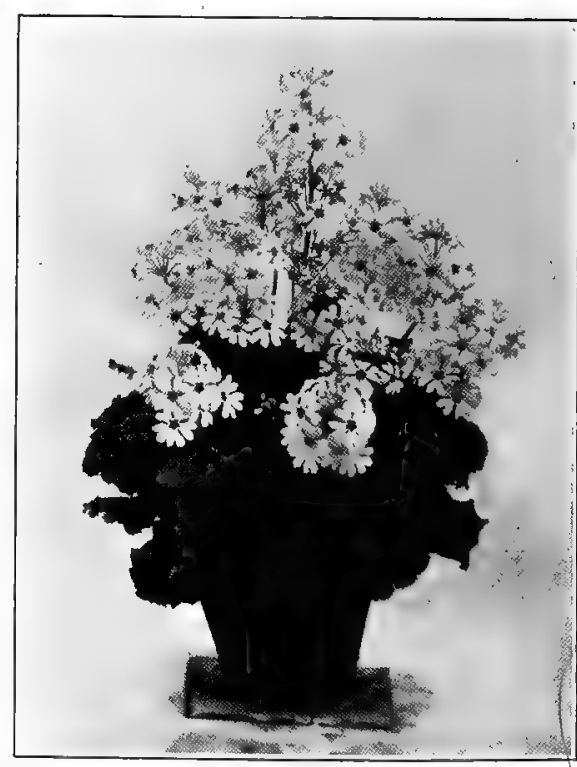

Fig. 248.-Primula Townsendir. This improved malacoides sort makes a most desirable pot plant because of its compact habit and large flowers. Also it starts to bloom very early 


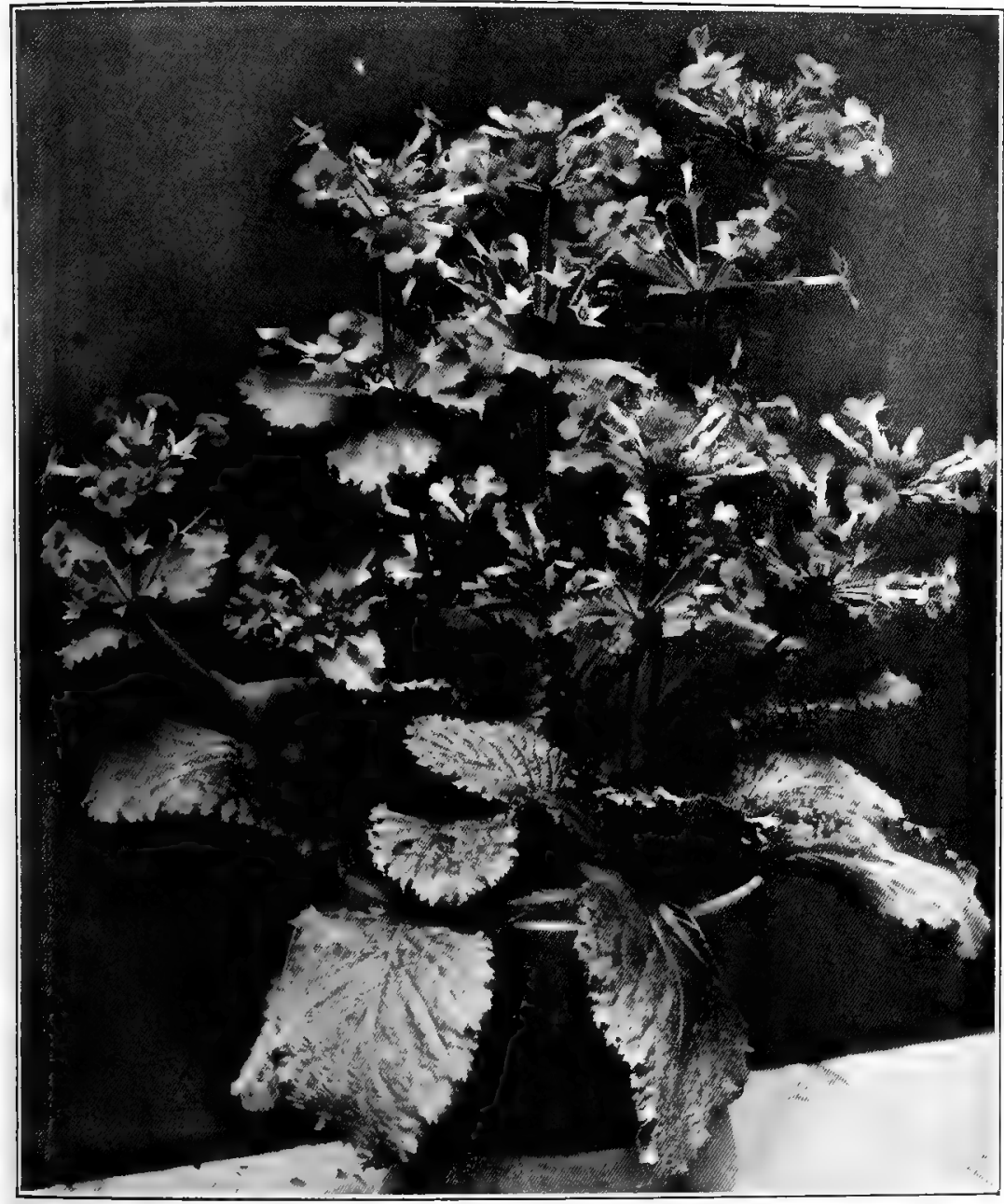

Fig. 249.-Primula kewensis. This species will never become as popular as $P$. sinensis, $P$. obconica or $P$. malacoides, but as it is of a deep yellow color and is in full bloom at Christmas, the florist has plenty of chance to use it

- better even than a bigger one to start with. The stock wants a cool house and can stand and thrive in a 40-deg. temperature if necessary, but, of course, under such conditions, the plants will flower much later.

\section{Polyanthus Primulas}

While there are other so-called greenhouse sorts, such as $P$. floribunda and $P$. kewensis, they are not of great importance. But of the hardy sorts or garden Primroses, what we know as $P$. poly- 
anthus (said to be a cross between Primula vulgaris, the garden Primrose and $P$. veris, the Cowslip) is of importance. When given a sheltered position and a little protection it will overwinter in the East and Middle West and is well adapted for the perennial border, being a mass of bloom early each Spring. It is also used for indoor flowering. Treated like the Violet in a cool house it is a paying crop with many florists. A good way is to carry it in frames up to February and bring it in so as to flower for Easter, but you should never expose it to a high temperature.

An excellent strain of seed is offered which should be sown during Winter, so you can have plants ready for the field by May. Plant them in 5 -ft. beds and shade them a little.

Primula auricula is one of the most beautiful of all the hardy varieties, but, unfortunately, is not hardy enough in most localities to stand our Winters. Likewise, in many places, the Summers are too hot to suit it. But where they can be grown, the plants deserve a place in every collection. The variety of brilliantly shaded flowers is almost endless and the blossoms stand forth well above a setting of leathery leaves.

\section{PRIVET (LIGUSTRUM)}

Ligustrum ovalifolium, or California Privet is perhaps the best known, but it is not hardy everywhere. Even in many sections of the Middle West it frequently happens that a hedge of it, after several years of growth, gets just large enough to be enjoyed by the owner-when a severe Winter kills the wood down to the ground.

Ligustrum Ibota, or the Chinese Privet, is hardier and Ligustrum amurense or the Amoor River Privet is now being used most extensively by those desiring a hedge effect rather than an irregular shrubbery border around their premises. The retail grower with show grounds or a small nursery cannot make a mistake in planting a hedge somewhere on his own property and keeping it neatly sheared. It helps bring orders.

Ligustrum Regelianum, or Regel's Privet can also be used for hedges but it will be more appreciated if grown singly or in groups where it can grow and spread and where the graceful habit of the plant can be admired.

\section{PRUNUS (ORNAMENTAL PLUMS)}

The purple-leaf Plum (Prunus Pissardii) is what you need to relieve the solid green of the other shrubs in a border planting. The foliage is of a pinkish-purple color and the growth is dense. We have the handsome plants winterkilled every once in awhile, but 
what of that? It doesn't happen every year, for here and there one of our patrons will point with pride to a specimen ten or twelve years old still good and unharmed.

These Prunus do not like to be transplanted when large and are best off if placed in the beginning where they are to remain. The smaller the stock you plant the better. Two- to 3-ft. plants are best.

Almost before any of the other shrubs leaf out in Spring you will behold Prunus triloba, the double-flowering Plum, in full bloom, the leafless stems covered with light pink double blossoms. It is these that make it so desirable.

Even when not in flower these Plums are good looking and when you take an order

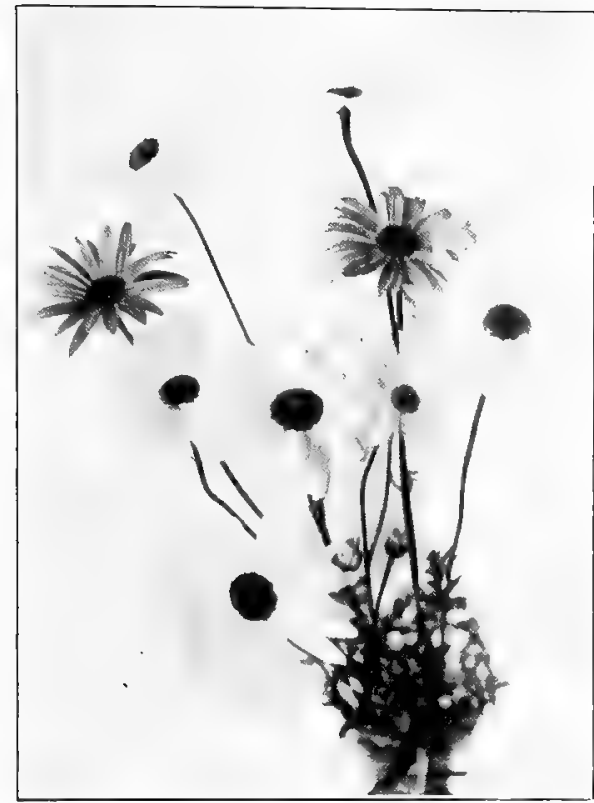

Fig. 250.-Pyrethrum roseum. This perennial, easily grown from seed, is among the first to bloom in Summer. With its endless variety of colors, long graceful stems and Daisy-like flowers, it is fine for cutting for flowering shrubs always mention them, for it will prove a pleasant surprise for those who get them, to have a few of these plants coming into flower after they have been planted a year or two. They may have almost forgotten all about when they were to flower and how they were to look.

\section{PUERARIA THUNBERGIANA (JAPANESE KUDZU VINE)}

This is the vine that grows a foot overnight when once well established; it has large bean-like foliage. This climber you should recommend only when it is simply a question of getting something to cover up a great area and do it quickly. The plant requires but little attention.

Your nurseryman has the plants but they are also easily grown from seed sown inside in March. This will give strong $31 / 2^{-i n}$. pot plants by the middle of May, which if planted out, will make fifteen feet of growth or more the first season.

\section{PYRETHRUM}

Golden Feather, or Pyrethrum aureum is one of the most popular dwarf, yellow border plants the florist makes use of. With 


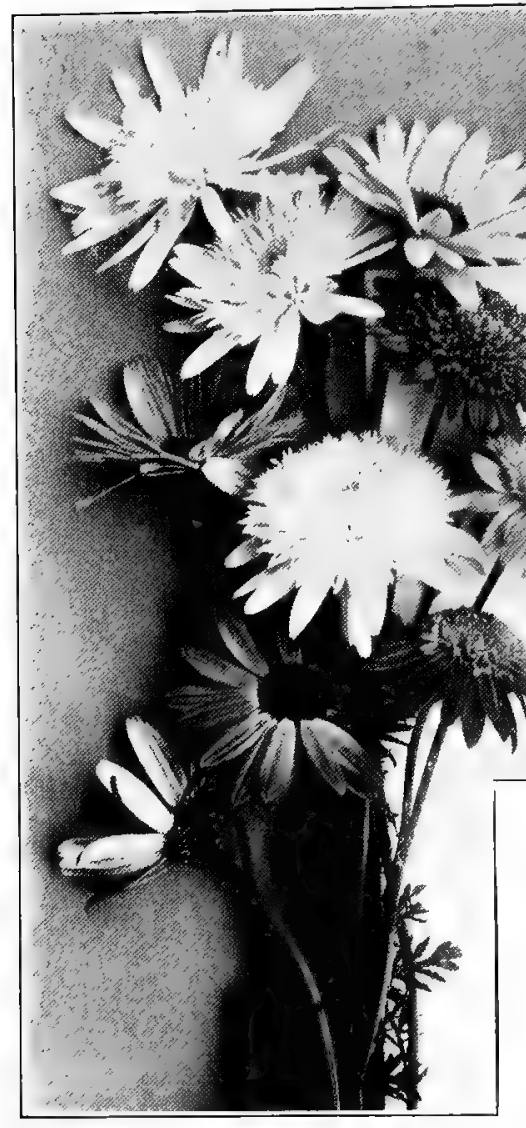

Fig. 251.-Pyrethrum noseum HyBRIDUM. For success with double Pyrethrums you had best propagate by means of cuttings. However, the single ones are easily grown from seed and provide fine early Summer cut flowers its fern-like, wellcolored foliage it makes an ideal finish for a formal border or bed and can be kept in shape by clipping.

Sow seed about February fifteenth and grow on in a cool house; all you want is $2 \frac{1}{2}$-in. stock. If kept too warm or in a crowded condition it is likely to die off.

Pyrethrum hybridium includes fine hardy perennials, best described as colored Daisies. They produce in early June, longstemmed flowers in many shades which make fine material for cutting. You can push the plants, too, for the hardy border. They are perfectly hardy and do well with little attention.

Sow seed in July outdoors for flowering plants. The following year the plants can also be divided in August. There is a good double strain but it is rather difficult to handle. For ordinary purposes and easy culture, the single sorts are best. If you sell hardy stock you want the Pyrethrums; in fact, you want them if for no other reason than to cut from.

Pyrethrum uliginosum is the Giant Fall Daisy. It provides showy plants for the background of a hardy border. By scattering them in groups between other stock that will be out of the way by the middle of September-when these Pyrethrums start to become a mass of large Daisy-like flowers, often growing six feet and over in height-we can have them in bloom almost up to severe freezing. Being white they form a good contrast to the yellow and brown shade; of Helenium, Helianthus, Rudbeckias and other Fallflowering herbaceous plants.

To have them most effective they should always be planted in 


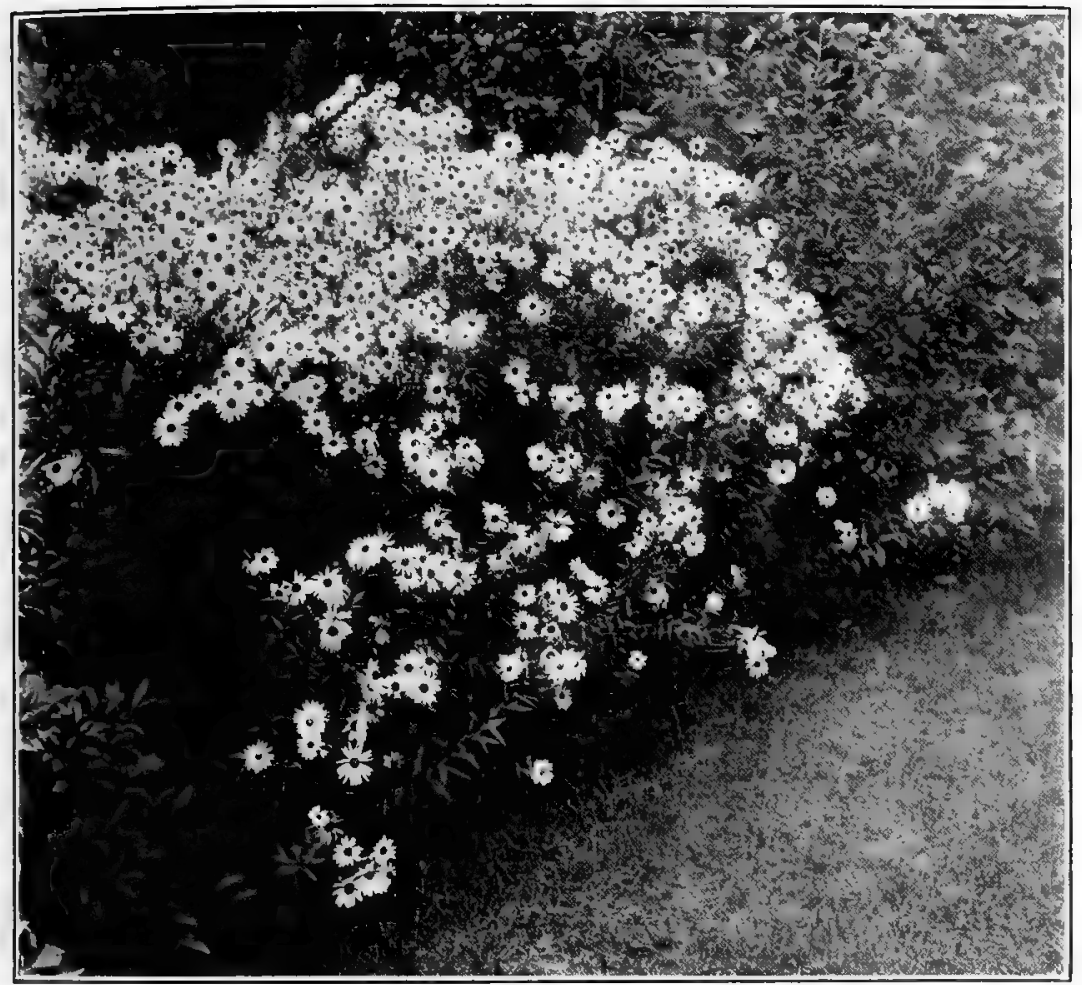

Fig. 252.-Pyrethrum uliginosum. This is hard to beat as a late Septemberflowering perennial for use in the background of the border

groups or masses. They are grown from seed or from divisions of the roots, which are best made in eariy Spring.

\section{PYRUS (GRAB APPLE)}

The single and double flowering Crab Apples should be planted more extensively. They don't amount to a great deal until they become well established but the older they get the more beautiful they are in Spring. Always figure on plenty of space for the single varieties. The best time to move large specimens is during the Winter months when it can be done with a large frozen ball of soil, that serves to keep the roots intact.

The double flowering Crab, Pyrus Parkmanii, is rather slow growing, but when it is loaded with its double pink blossoms during Spring, there is hardly anything to equal it.

\section{QUINGE, JAPAN See Cydonia}




\section{RANUNGULUS (BUTTERGUP)}

\section{Bulbous Varieties}

There are about eighteen or twenty different named varieties of the Persian Ranunculus or Buttercup and almost that many of the Turban sorts, all of which give most desirable cut flowers for Spring if grown under glass. In color they range from pure white to yellow and light and deep orange.

In Fall when you receìve the little tubers the sooner you get them into soil the better. Use 3-in.-deep flats, or eight- to ten-inchdeep bulb pans and allow about two inches of space between the bulbs. The best place to carry them over Winter is in a deep coldframe free from frost. Let them remain there until about the end of February, after which bring them in to a 45 -deg. house and let them come along slowly. They will not stand much forcing, so the longer you give them the smaller the loss and the better the flowers. They will flower in a 50-deg. house by the middle of April and sell well.

\section{Ranunculus acris fi. pl. (Double Hardy Buttergup)}

If you have a clay bank or some other bare spot to cover and have tried everything else, give these Buttercups a fair chance. They will do the trick and, when all is covered, keep right on going. That is, in fact, about the only fault we have to find with them. When using them in a perennial border you must keep on removing their Strawberry-like runners, otherwise they soon will want the whole border to themselves.

The double yellow flowers on stems one foot long come in May and June and make charming cut flowers. You should have a batch of plants somewhere as a stock to draw from. You will need plants each Spring and Fall.

RED BUD

See Cercis

\section{RED-HOT POKER PLANT \\ See Tritoma}

\section{RESEDA (MIGNONETTE)}

The florist doesn't make money on Mignonette during the Summer months. In fact it is only because of its delightful fragrance that anybody will grow it; certainly not for the beauty of the individual flowers. Yet when grown under glass and grown well, the spikes command a good price; besides their odor, they are very effective with other flowers.

To grow good Mignonette you want a good strain of greenhousegrown seed to begin with. You also want a 45- to 48-deg. house, 
either a solid bed or a bench and extra good soil, soil that is porous, rather heavy and that contains plenty of plant food in the way of fertilizer. Well-rotted cow manure fills the bill better than anything else. Finally, you want perfect drainage and a good man in charge. All that may sound like a lot, but really it isn't.

In order to obtain 18- to 20-in.-long spikes, give culture the same as for Chrysanthemums. Everything that is in the plant is directed toward making that one shoot or flower spike a good one. This means constant care and attention and the removal of all lateral growths and I doubt whether any retail grower will find the growing on of fancy spikes a paying proposition.

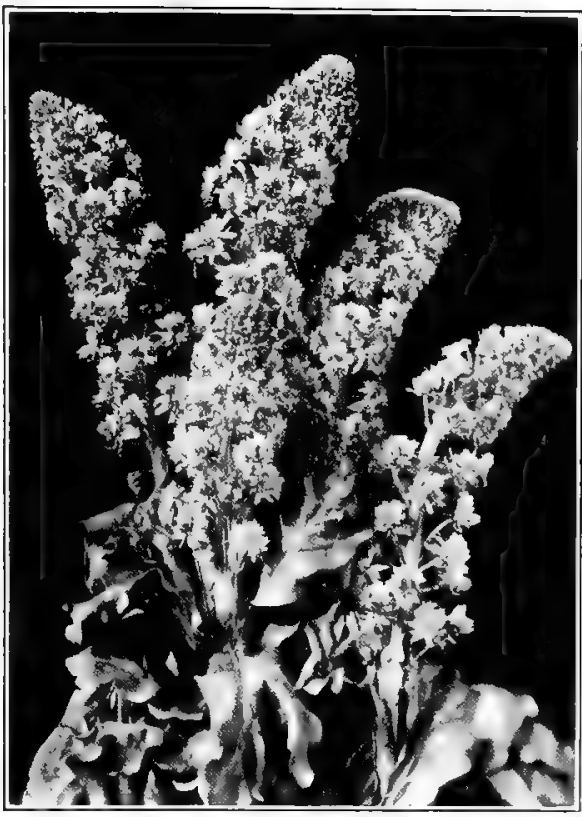

Fig. 253.-Mrgnonetre. This plant requires rich, deep soil, but if you want especially big spikes, provide also a cool house and plenty of sunshine However, I am convinced that it will pay those who retail the flowers they grow to have a bench of Mignonette and allow from five to eight branches to the plant so as to be able to sell them at a reasonable price during the Winter months.

\section{Culture Under Glass}

For December flowering, sow seed in August. Make use of 21/2-in. pots and fill them with soil to within half an inch of the top. After pressing the soil down, sow about five or six seeds to the pot and cover them lightly. They will germinate in a few days. When they are large enough to get hold of, remove all but two of the strongest plants. By the end of September plant out, either on a bench or bed, allowing one foot of space between them. If there are still two plants to the pot, remove one; this is best done by cutting it off just above the soil, rather than by pulling it out and thereby disturbing the remaining one. Mignonette plants don't want to be disturbed; they won't stand for it and you cannot be too careful, even in planting them out of the pots into the benches.

You will find it a good plan to protect the seedlings as soon as they are up with frames covered with cheesecloth. Keep these frames over them up to the time the plants are benched. The common 
white butterfly, usually with us all Summer, seek the Mignonette to deposit its eggs on in preference to almost anything else. I have seen nice batches of seedlings, without a sign of warning, stripped of every leaf in one night. Even when they are planted out, a daily examination is necessary to discover the caterpillars which are hard to detect, being of the same color as the leaves. Your troubles in this respect won't be over until heavy freezing sets in but it is in August, September and October that you are especially bothered by the caterpillars.

In good soil the plants will make a rapid growth and when about four inches in height they should be pinched back. You can allow from three to eight of the new shoots to remain. When they are again three to four inches in height is the proper time to put up wires, the same as you would for Carnations. After you have given the surface soil one more thorough cultivation and as the plants grow, remove all side shoots from the stems. The plants will start to flower in early December and should yield a good crop for Christmas.

Later sowings can be made, or a few plants grown on, as catch crops. You can also grow fine plants in pots, by either having just one plant to the pot and keeping it pinched back, or by allowing three plants per pot, which will give you quicker but not better results. For a Spring crop you can sow across a bench in January and thin out later.

\section{RHODANTHE (EVERLASTING)}

Among the pretty. and desirable smaller-flowering varieties of Everlastings belongs Rhodanthe with its simple pink and white flowers on 10-in.-long wiry stems. It grows from seed sown outdoors, starts to bloom in July and the flowers can be gathered and hung up in an airy shed for drying. You will always have occasions during the Winter months to use them in one way or another.

\section{RHODODENDRONS}

Too many of us are located where these beautiful plants are anything but hardy enough to stand our Winters. We plant such varieties as R. Mrs. G. S. Sargent, $R$. punctatum or $R$. purpureum elegans because they are supposed to stand a little more than others, but even they are not very satisfactory. Here and there in sheltered positions, partly shaded, they live for a little while, but they don't thrive. Where they can be handled, however, they are among the most showy of evergreens and gorgeous when in bloom. At present they are being more extensively grown from year to year in California, and some fine specimens are coming from there which, like Pink Pearl and others, can be had in flower for Easter. 


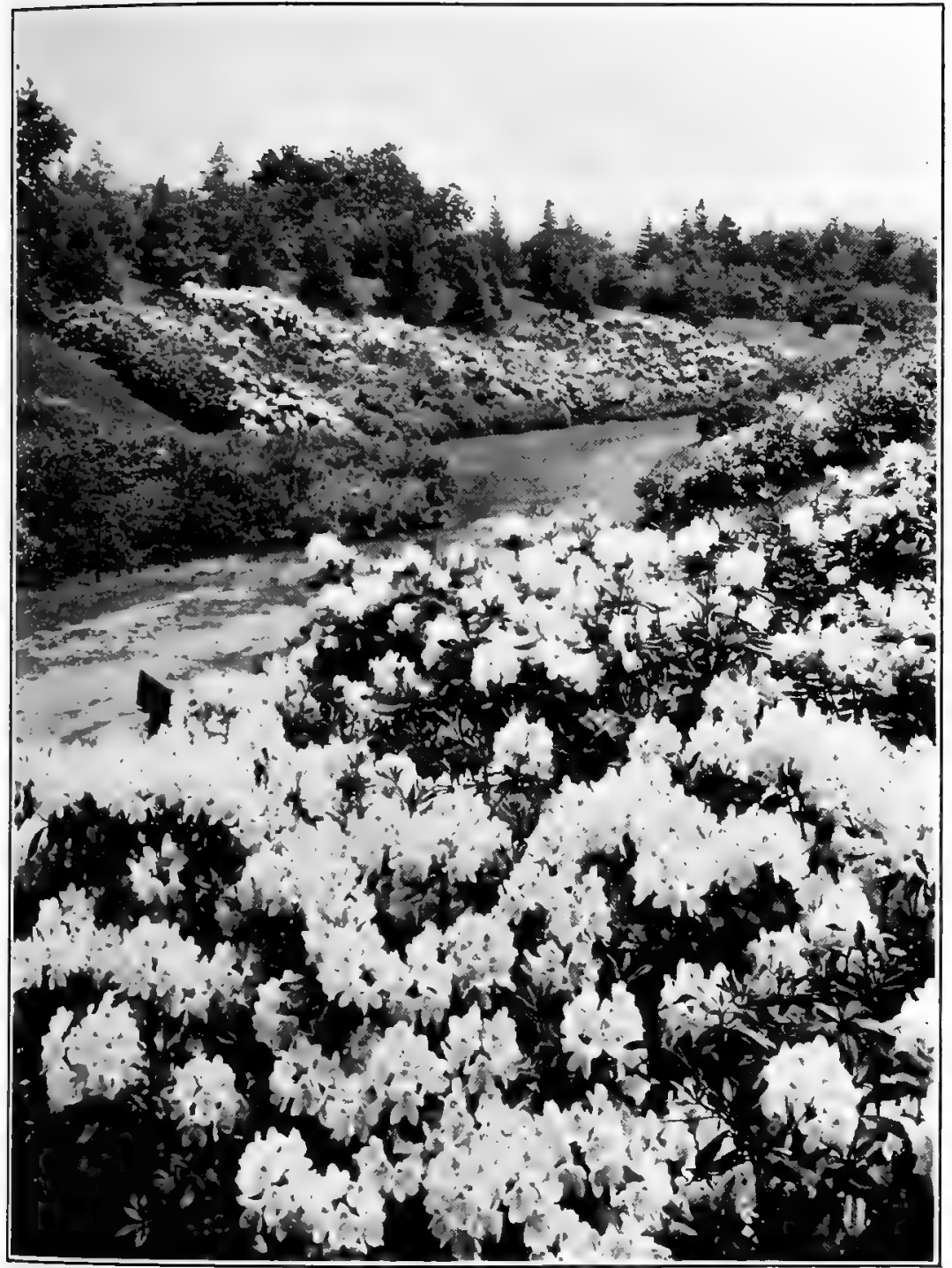

Fig. 254.-RhоDоDENDroNs IN BLOOM. It is hard to imagine anything more showy than a mass planting of Rhododendron like that shown here, in full bloom. This variety is $R$. maximum

Like the Azaleas, they want a cool house from Fall on, but they require a much longer time in which to come into bloom. They can stand a house of $60 \mathrm{deg}$. and over for a month or more even when Easter comes on a late date. An Azalea, even in a 45-deg. house will start to color during February and early March. The heavy buds of the Rhododendrons, however, seem to be at a standstill until well into April. 
Plants which you have left over are best carried along in the pots they are in, plunged outdoors with a little shade over them and given an occasional dose of liquid cow manure. They usually set buds again, that is, the plants that haven't been forced too hard. However, the best way for those who only use a few plants and have no proper facilities for caring for them during Summer, is to purchase each year what they need and to try to dispose of them in some way or other.

\section{The Native Hardy Varieties}

As with the native Azaleas so with the Rhododendrons, of which there are a number of beautiful, showy varieties, mostly natives of the eastern and southern sections of our country. At least, that is the case with those listed below.

The Rhododendrons even more than the Aza'eas deserve recognition, as they are not deciduous but evergreen. For this alone they would be desirable but, in addition, when in bloom and planted in masses, they cannot be equalled for gorgeous effectiveness. It is indeed sad that so many of us located in the Middle West and more northerly sections cannot have them, but there are plenty who can and not only the nurseryman, but the florist depending on a local retail business, should become acquainted with a few of the most desirable sorts and be able to fill orders for them. Here again it is best to locate your stock at a responsible nursery which can supply you with the plants. To collect native plants, you want to be located near the source of supply and make a specialty of it. You cannot make it pay as a little side line or with poor facilities for growing the plants on for several years before selling them.

Rhododendron catawbiense, one of the hardiest of all, a native of the coldest peaks of the southern Alleghanies, flowering in May with reddish purple blossoms, while not, perhaps, as beautiful as some, is recommended by the fact that it can stand more cold than any other. $R$. carolinianum, one of the most profuse bloomers, is pink in color. As to $R$. maximum, I cannot do better than to give La Bar's description of this grand variety: "Noblest of all of America's broad-leaved evergreen shrubs, blooming in July, with large waxy-white or delicately pink flowers. Native in the mountains of Pennsylvania and New York."

\section{RHUS (SUMACH)}

There is a place for the Sumach when masses of it can be planted and enough space given to allow proper development of the plants. They can be kept to a height of five or six feet for years if severely pruned back each season and if the old wood is kept cut out. Their leaves are quite ornamental and their red flower heads, or rather seed heads, are very showy, not to mention the beautiful 
color of their foliage in early Fall. Rhus typhina, the graceful Staghorn Sumach, makes a fine specimen for the shrubbery border.

\section{RIBES ALPINUM (MOUNTAIN CURRANT)}

Not only this Mountain Currant, but also the larger, yellowflowering species, $R$. odoralum and the red one, $R$. sanguineum, are all desirable shrubs, especially for shady positions. To see them at their best and-as in $R$. odoratum--the plants literally covered with sweet-scented flowers in early Spring, you want to plant them in full sun. But there are occasions when you want a shrub in a shady spot where almost everything else has failed to grow. These Currants will help you out and for that reason you want to know more of them. And who hasn't shady positions to be planted?

\section{RICINUS (GASTOR BEAN)}

The Canna bed with the Castor Bean in the center is a thing of the past, and we have only very few calls for the latter plant. Yet it is highly ornamental for the filling of large beds or for subtropical plantings. The variety $R$. zanzibarensis enormis, will grow fifteen feet high during the Summer and bear great leaves, but you must start seed in early February in order to have plants eighteen inches high in 5-in. pots by the end of May. This is about as early as you can risk them outdoors as they will not stand frost.

\section{ROBINIA HISPIDA (ROSE ACAGIA)}

If your customers are in want of something beautiful in the way of a small tree to be planted as a specimen on an open lawn or in a border, recommend the Rose Acacia. You can obtain specimens grown in standard form and worked on Robinia Pseudacacia. The standards come with from 4- to 6 - $\mathrm{ft}$. stems and the tops are loaded each Summer with hanging racemes of deep salmon-pink, pea-shaped flowers. Frequently they will bloom a second time. The plants are perfectly hardy and each Spring should have a good pruning. Care should also be taken not to allow growths from the base to remain; if left they will in time ruin the top. We bave had these standards live and thrive for years, and even when out of bloom the Locust-like foliage makes them attractive trees. The Rose Acacias come also in bush or shrub form, but for the small grounds the standards are best.

ROGK GRESS

See Aubrietia

ROGK ROSE

See Helianthemum
ROSE ACAGIA

See Robinia

ROSE OF SHARON

See Hibiscus 


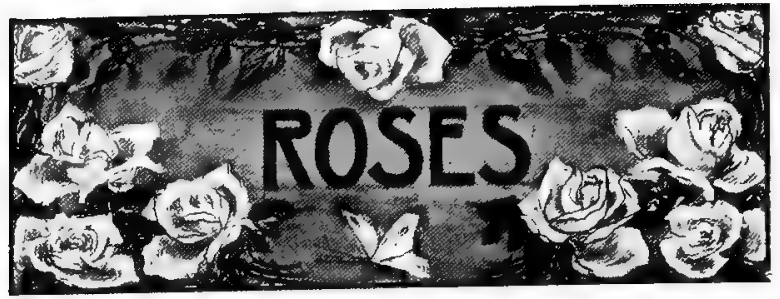

\section{FROM THE RETAIL GROWER'S VIEWPOINT}

WHAT interests the average florist most about Roses is how they can be made to pay. It is with that question in mind that the following has been written.

There are still quite a number of small retail growers who will keep on trying to grow Roses for cut flowers with "fifty-seven varieties" of other stock in the same house, each requiring treatment just a little different from the other in order to do well. Yet a good

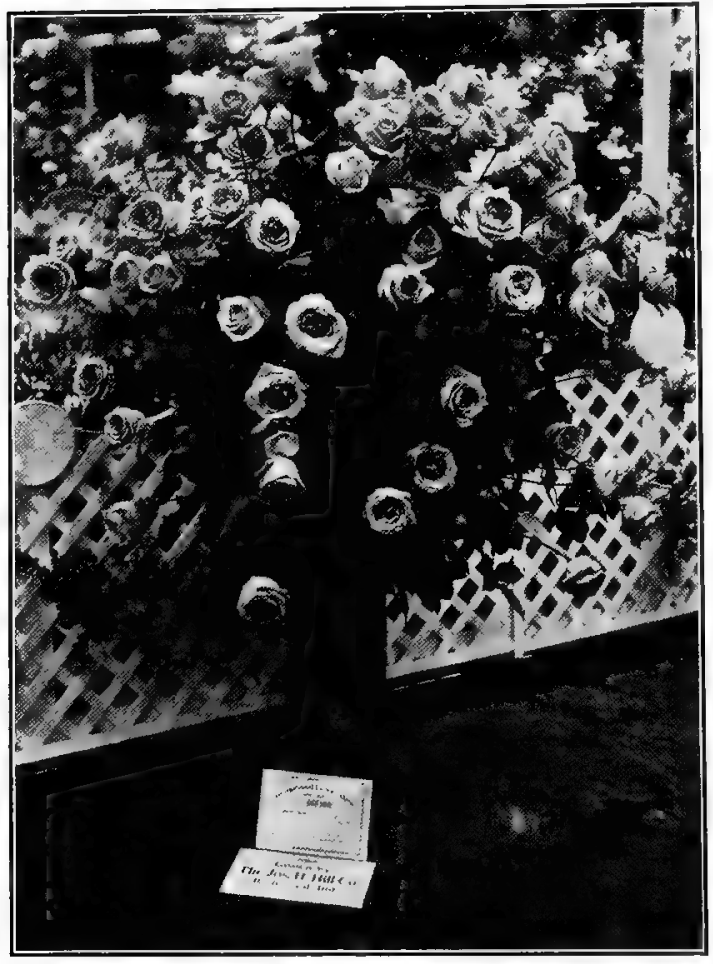

Fig. 255.-The Successful Rose Grower's ReWARD. A vase of 100 Premiers exhibited at the 1921 International (N. Y.) Flower Show by the Joseph H. Hill Co. and awarded first prize percentage of these men will almost totally overlook the great opportunity there is for making Roses pay by pushing them for outdoor planting.

To begin with, there isn't a spot North, South, East or West where wellestablished Teas and Hybrid Teas planted out early enough and in the right way won't do well; nor is there a customer who would object to a bed or border of Roses if you could assure its success. Forget for a minute about such Roses not being hardy in your climate. Which is better, a real hardy Rose that never has a flower on but plenty of worm-eaten leaves all Summer, or a ten- 
der Killarney, Ophelia or Testout, with flowers galore from June until stopped by frost?

Travel from the sunny South along the Atlantic Coast up into Northern Canada, then go West to Winnipeg and several thousand miles farther to Prince Rupert, then go South again to Mexico, and you haven't touched a spot where the retail grower couldn't sell these Roses and have them do well for their purchasers. Yet the number of florists who actually go out of their way to supply the right kind of stock and push its sale is very small indeed.

\section{Don't Grow Gut Roses on a Small Scale}

If there is any one crop which, to my mind, it doesn't pay to grow on a small scale it is Roses. Many years ago the growing of Roses under glass drifted into the hands of specialists and we soon found that it was out of the question to handle them in a small way and grow as good stock, or grow it as cheaply.

You can never hope to grow Roses successfully when mixed in the same house with a lot of other stock. You may cut some good flowers at times, but not enough to make it worth while. In order to make Roses pay you should have nothing else in the houses; watch temperature and ventilation closely; and have one man who knows all about it in charge. When you cannot do this you had better devote the space to something else, for there are millions of square feet of glass devoted to the growing of Roses distributed practically all over the United States, or at least so generally that the cut flowers can be shipped to almost any point and reach those who want them in good cndition. Hardly any other flower ships better than a Rose when cut at the proper time and packed and shipped right.

With the proper facilities and sufficient experience it is no trick to grow Roses under glass. On the other hand, many of us know of cases where a well-experienced and successful Rose grower left his old place for a new position and made a failure of it, not being sufficiently acquainted with new climatic conditions, soil and houses. Or we may find a newcomer who never had any experience in Rose growing before he became tired of growing cucumbers and radishes under glass, going into Roses and right in the midst of Winter bringing in the finest Ophelias on the market, while the Rose specialist a few blocks away is complaining of dark weather and a heavy dose of mildew. But for all that, the retail grower who makes Roses a side line will find before he gets through that he will have one week when he can cut, say, 400 flowers, but has use for only 175 , and when from the wholesale price list he learns that at what they are quoted it would hardly pay him to ship his surplus. A little later he may cut 50 Roses during a week when he needs 300 or more, which he has to buy at a high price. 
This keeps right on and he really never knows where he is at; while his competitor has given up growing his own stock and has placed a standing order for a minimum number of flowers to be shipped to him twice or three times a week direct from the Rose grower or the commission house. This man not only obtains a higher quality of flowers than he could possibly grow himself, but he knows at all times where he is at and what orders he can take and fill, and a telephone call or wire message will get him more. There are exceptions, to be sure, but when one considers the time and labor required to grow Roses, the necessary temperature and, with all that, the inability to produce as high grade stock as the specialist, I am positive that every florist who is within a reasonable distance of a Rose grower is money ahead, and saves himself a lot of trouble and worry by buying the cut Roses he needs for retailing.

\section{ROSE CULTURE UNDER GLASS}

It would be useless to take up space here with detailed cultural notes on Rose growing for cut flowers under glass. Those wishing such information will find Eber Holmes" "Commercial Rose Culture" an excellent guide, and there are many other books on the subject. I would, however, like to mention a few of the requirements for the benefit of those who still want to go into the work on a small scale. Here, as with the growing of all other florist crops, one has to learn the ropes by actual experience. You can tell a man how to do things, but that is all. The successful Rose grower is one who not only reads books, but who also has had years of practical experience in the handling of Roses; and even then he can only do just so much, as crop failures may still happen on account of conditions over which he has no control. But with a thorough knowledge of the cultural requirements a man can often avoid failure, whereas the inexperienced man, if the least thing goes wrong, is at a loss to know what to do.

\section{The Rose House and Equipment}

To start out with, you want a modern house-the larger the better-with perfect ventilation. Steam heat is better than hot water, or if you want to use water have a few steam pipes running through the house. A little steam during Fall before you start steady firing prevents mildew and you can use the steam pipes better for fumigating purposes. Roses, whether for indoors or outdoors, enjoy a heavy loam and prefer cow manure to almost anything else in the way of fertilizer; they can remain for three or more years in the same soil and will thrive if you supply sufficient manure as a mulch and fine bonemeal as a tonic.

Roses are usually planted during early Spring in raised benches of the usual depth, allowing 12 in. of space between the plants in 
the row and about 15 in. the other way for the Hybrid Teas. While the plants are growing during the Summer months keep the soil always fairly moist and spray enough to keep down red spider. Anybody can grow Roses during the Summer months without much trouble, but you are bound to get a dose of mildew during Fall if you carelessly permit a cold, stuffy atmosphere such as you will get by shutting down the ventilators during September or October when apparently there is no real need for firing. A better way is to leave a crack of air above if you can make use of a little steam. Fifty-five degrees is about the minimum temperature for growing Roses so as to make them pay. You can grow them and keep them in good health in less, but you cannot maintain a 53-deg. house one month, run it up to $58 \mathrm{deg}$. or $60 \mathrm{deg}$. the next and then come back" to $53 \mathrm{deg}$. This would soon ruin your stock if kept up. An even temperature around 55 or $56 \mathrm{deg}$. and air during the daytime when it gets above $70 \mathrm{deg}$. is best; few good growers differ much from this. While Roses, when making active growth and when they are in crop, should not be allowed to suffer for want of water, let up a little when the crop is over and the plants are not so active. If you have poor drainage in the benches you will soon see its effect on the plants. The old method of supporting the plants each with a heavy wire stake fastened at the top to a wire running lengthwise

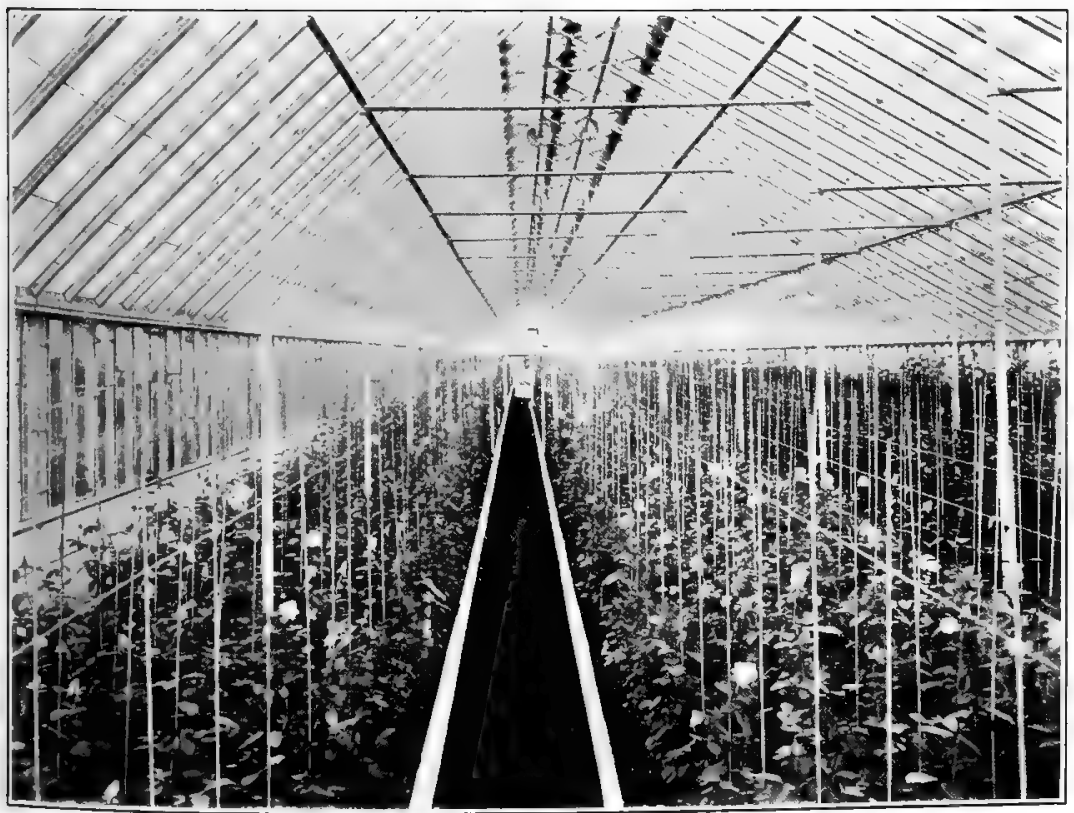

Fig. 256.-A Rose House, showing wire stakes ready in place as supports for the plants as they grow 
is still the best and you cannot grow Roses on straight stems without supporting them.

\section{Getting Started}

For the man starting out, the best way is to purchase well-established $21 / 2^{-}$or 3 -in. pot plants and bench them as early in Spring as possible. One can plant almost any time during the Summer, but there is nothing like getting a good start. The flowers from young stock don't amount to much, especially during the Summer months, and are best removed with a short stem, thereby helping the plant to produce a heavier growth for later flowering. To allow cold draughts to strike the plants always means a dose of mildew, and the softer the growth the worse the dose. Powdered sulphur applied with a blower on the leaves, or a sulphur paste painted on the steam pipes, can be used as a remedy, but an overdose when using the pipe method is as bad as the mildew itself. Ventilation on top without draughts and a healthy growing atmosphere moist enough to prevent red spider yet not sufficient to create mildew, are what the man in charge has to try to attain.

To the beginner I would say: Visit if you can a good Rose grower; he will gladly give you all the information you want. Start out with your mind made up that you are going to grow Roses. Keep your eyes open and think a lot. No matter how well you start out, you are bound to bump into a setback sooner or later, and this is necessary in order to gain knowledge. But if you stick to it you are bound to come out ahead.

\section{HOW TO MAKE ROSES PAY}

Because the retail grower cannot handle Roses for cut flowers under glass on a small scale is no reason why he should not push the sale of the flowers or should not make the most of handling Rose plants for early Spring flowering under glass, as well as plants for outdoor planting.

To begin with, Roses should be found in your assortment of flowers in the display cooler every day of the year. No matter what else you may carry, your assortment is not complete without them. They may not sell quite so well during the Chrysanthemum season, or when it is Poinsettia time, but a good Rose usually will sell when nothing else will.

For Easter, and up to Memorial Day, the retail grower should always carry a nice stock of pot plants in flower. A beautiful Rambler Rose bush is one of the most important Easter plants we have, and even those with no facilities to grow cut Roses can grow on at least a part of their wants successfully.

From Easter on, all through April, May and even June, pot Roses in bud and bloom can be sold. Among them the so-called Baby Ram- 
blers, Hybrid Perpetuals and Teas are the most important, and they, too, can be handled nicely by the retail grower with enough room.

For outdoor planting the Rose holds the position it has occupied from time immemorial, at the head of everything else. There is nothing to be compared with a Rose where you have a climate suitable for it. Even when conditions are less favorable, your customers will keep on planting Roses year after year, no matter how poor their success, and it is for the florist to supply the plants. Whether he grows them on himself or not, there is money in handling them.

For those who use cut flowers during the Summer and Fall months certain sorts of Roses can be planted outdoors and made to pay, as for instance,

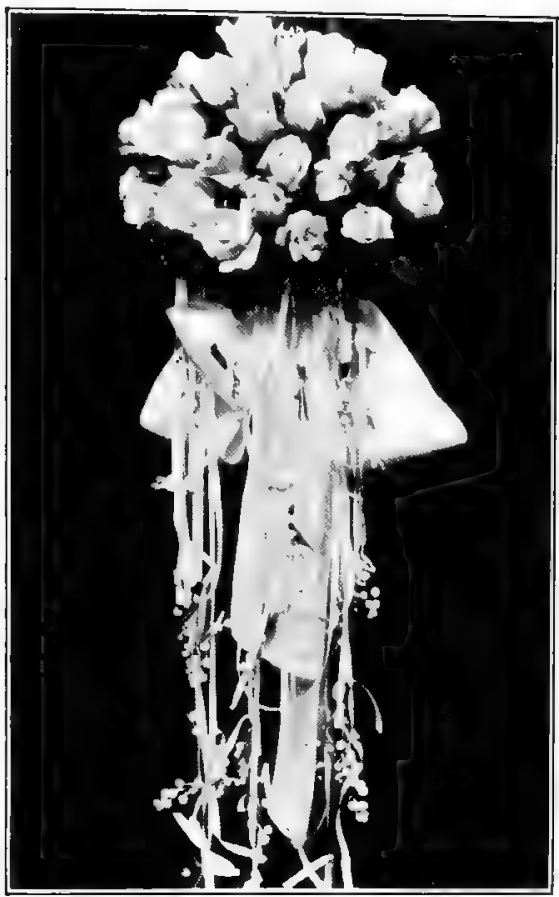

Fig. 257.-AN Always Satisfactohy Use OF Roses. White blossoms, Lily of the Valley, Adiantum and carefully arranged ribbon, etc., make up this handsome and effective bride's bouquet the Ramblers for June and July flowering and the Teas and Hybrids . for late flowering.

\section{TEAS AND HYBRID TEAS FOR OUTDOOR PLANTING (See List, Chapter VII, page 224)}

There is today hardly a Rose growing under glass which will not do equally well outdoors. Any of the Teas and Hybrid Teas make good Summer bloomers - in fact, they are superior in that respect to any other class of Roses, and this is the best possible point in their favor. Your customer, to begin with, wants flowers to look at and to cut; next comes the question of varieties and then hardiness. Tell your customer you can furnish Roses that will start flowering ten days after they are planted and keep it up all through the Summer or Fall, even after the first light frosts, but that will require extra heavy protection over Winter, and you are sure to make a sale. To plant out such Roses from 5-in. pots about the middle of May means action right away. There is no waiting as is the case in planting a dormant Hybrid Perpetual Rose which has been out of the soil since the previous Fall, and of which the roots and wood 
502 FRITZ BAHR'S COMMERCIAL FLORICULTURE

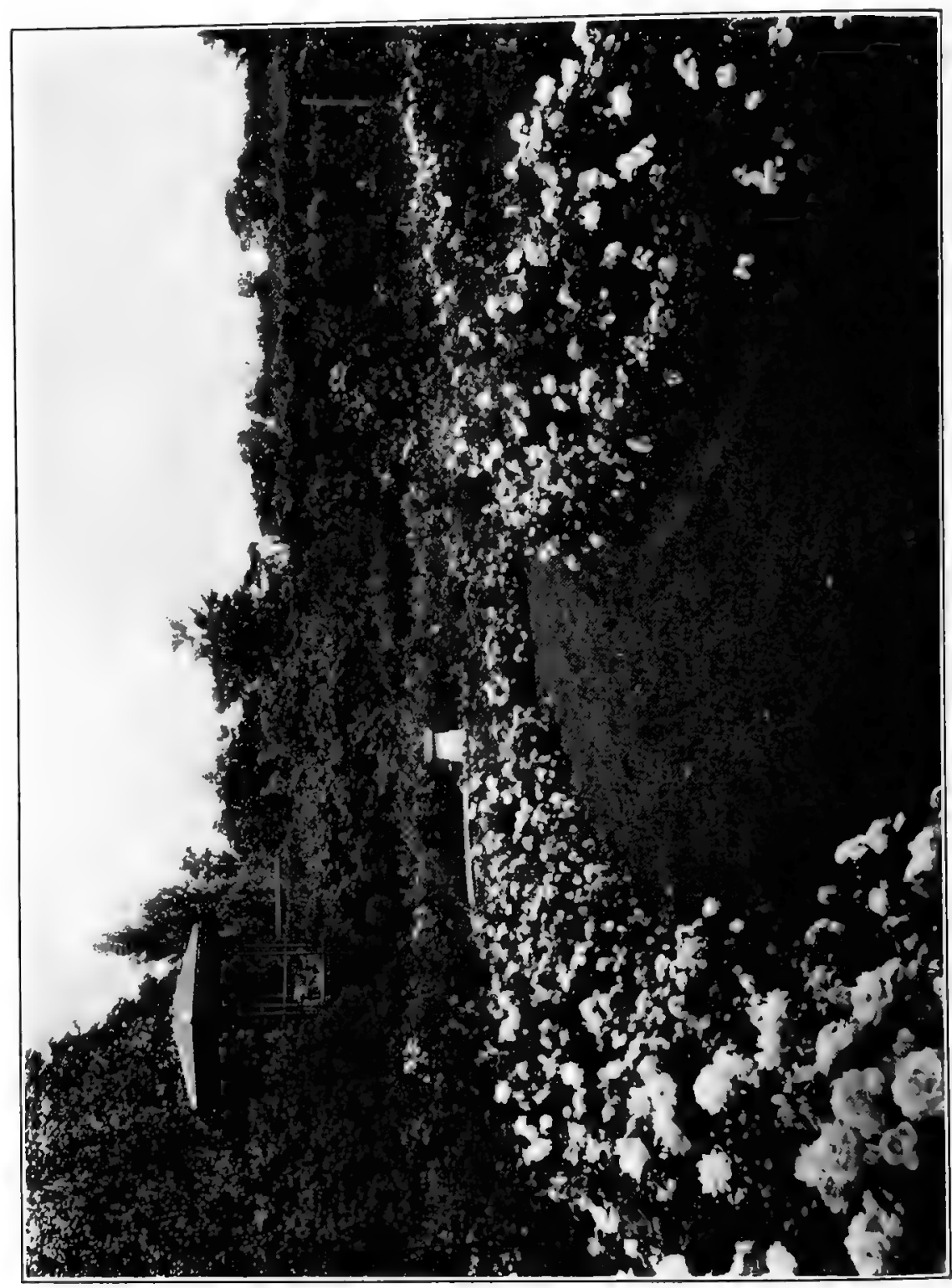

을 을

50

$.5 \frac{5}{0}$

- 8.

ตำ

욜

욘

$8 \%$

శ్

능

동

망

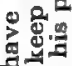

뭉

드음

- 100

룽

0 西

․․ㄴㄷㅗ 궁 9 을 곤 28 뭉 化 吾 둥 등 5 0 홍 年

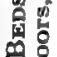
19 $\infty$ \& 8 웅 
are shriveled up. Nothing counts for more today than immediate results and you can get them with these Roses. Everybody loves a garden full of Roses, but most people want them during the first Summer; that is the main thing, and that they can have it should be emphasized in heavy type in any advertising you do.

There are several ways of preparing or getting ready plants wanted for outdoor flowering. Some of your nurserymen make a specialty of field-grown Roses which are usually dug by the end of October. These are best heeled in in a deep coldframe, tops and all, given "a good watering and left there until the latter part of February, when they should be potted into 5-in. pots, cut back a little, stripped of all thin side-growth, and put back into the frame. Provide each plant with a label and be sure they all receive a good soaking of water. The less frost the wood is exposed to the better. Keep the stock in frames until time to bed it. As soon as weather conditions permit, remove the sash, for you don't want forced or soft growth. The more dormant you can keep the plants the better, but potted and kept cool, they will be well rooted by the end of April, ready to go ahead as soon as things warm up.

The list of sorts the average nurseryman in the East, Middle West and South handles is not as a rule a very long one. Of course the nearer home you can get your supply the better, but if you want more of an assortment there are splendid firms in California, Oregon and Washington which have gone heavily into growing Roses outdoors. . These plants are usually dug during the Winter months and will reach you in excellent condition. We have had excellent results from Southern California grown stock. Another source of supply is the Rose growers who have dormant bench-grown stock on hand. Every now and then you will notice heavy stocks of dormant, bench-grown Killarney, Ward, Ophelia, Premier, Columbia and others offered for sale during the early'Spring months. If not too large and old, such plants cut back to five or six eyes, potted up and allowed to come along slowly in a cool house.or frame, will make fine plants for outdoor flowering. Still another way is to grow a few plants on, yourself During Spring small stock is offered in 2- and 21/2-in. pots for benching, which if planted in the field will make fine plants by Fall. Lift them before the ground freezes and bury in a coldframe and treat, later on, the same as the others. Among the good sorts to grow on for outdoor flowering, the following are just a few :

Columbia (rose pink)

All of the Killarneys

Ophelia (creamy pink)

Radiance (deep pink)

Janet (flesh pink)
Mme. Melanie Soupert

Red Radiance

Hoosier Beauty (deep red)

Edward Mawley (dark red)

Kaiserin Augusta Victoria 


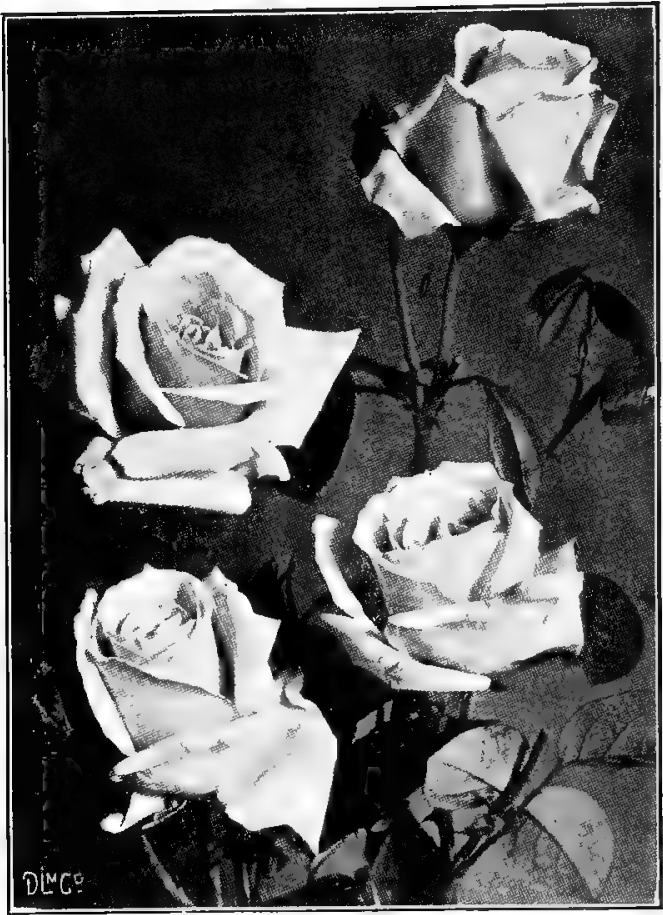

Fig. 259.-The Ever-Popular Killarney. A Rose that is as valuable for the outdoor garden as for the greenhouse, and in which all the colors are equally desirable furnished more than forty Roses apiece. The color is a deep flesh pink, shading much lighter on the under side of the petals. The flowers are borne on good stems and the plants are strong growers.

\section{POLYANTHA ROSES, OR BABY RAMBLERS}

This class is good for both outdoors and indoors. As bedders the plants will flower all Summer and make attractive displays. The flowers, while small, are fine for cutting. Treated like the Hybrid Perpetuals they can be flowered indoors and such varieties as Baby Tausendschoen, Erna Teschendorff, Mrs. Cutbush, Phyllis, white and pink Baby Rambler, Orleans and others make ideal Easter plants. Such as come in too late for that date can be disposed of to advantage for Memorial Day. Field-grown plants treated the same as the Hybrid Teas for outdoor planting need but little pruning, and one of the showiest of all is Mme. Cecile Brunner, the Sweetheart Rose.

\section{HYBRID PERPETUAL ROSES}

Some of the most beautiful of all Roses belong to this class. While used extensively for permanent outdoor planting they are not 
the equal of the Hybrid Teas in regard to free flowering; but almost all of the many sorts listed-each one more beautiful than the other -are adapted for early Spring flowering under glass in pots. For this purpose one should have heavy two-year-old field-grown plants, which when lifted in early November should be potted up immediately, placed in a coldframe and watered enough to keep them moist at all times. To allow the soil to dry out or to permit the sun to shine through the glass and warm up the frame will result in dried-up brown wood by the time you want to start the plants. By the first of February bring the plants into a 45 -deg. house, cut the strong canes back, allowing about four or five eyes of last year's growth to remain, and remove all side growth. The plants should have a daily spraying, for it will encourage growth or breaking. Weather conditions have a great deal to do with the time the plants will flower, but when once under way and placed in a 55-deg. house they can be had in flower by early April, if wanted then. They can be subjected to 60 deg., but you will obtain better results with a lower temperature. For plants wanted in flower before April, stock which has been grown in pots the previous Summer is best; you won't get as heavy growth from it, but not having to disturb the plants in Fall you lose less of them and it is as easy again to force such plants.

For indoor flowering, American Beauty, Paul Neyron, Mrs. John Laing, George Arends, Ulrich Brunner and Baroness Rothschild are just a few of the many desirable ones; for outdoor flowering, all of them, with the exception perhaps of American Beauty, do equally well, and so do Capt. Christy, Prince Camille de Rohan, Magna Charta, Hugh Dickson, Clio, Frau Karl Druschki and Gen. Jacqueminot.

\section{RAMBLER ROSES FOR FORGING}

As pot plants for early Spring use, the Rambler Roses are the most important of them all. No other Rose, no matter how well grown, can be compared with Tausendschoen, Dorothy Perkins or the original Crimson Rambler (which came to us from Japan about twenty-five years ago) when you see a specimen plant in full bloom in an 8-in. or larger pot. Even as small plants in 5-in. pots they are most showy and the florist who has the facilities makes no mistake in growing on plants both for Easter and later flowering. Here as with the other sorts, one-year-old field plants cut back well and potted up in 5- or 6-in. pots during April, the pots plunged up to their rims outdoors in a frame, and the plants grown that way during the Summer months, make the best for early forcing. By the middle of October lift the pots, stand them on top of the ground and gradually withhold water; this will help to harden off the canes. Such plants by November are best handled by tying up the canes 


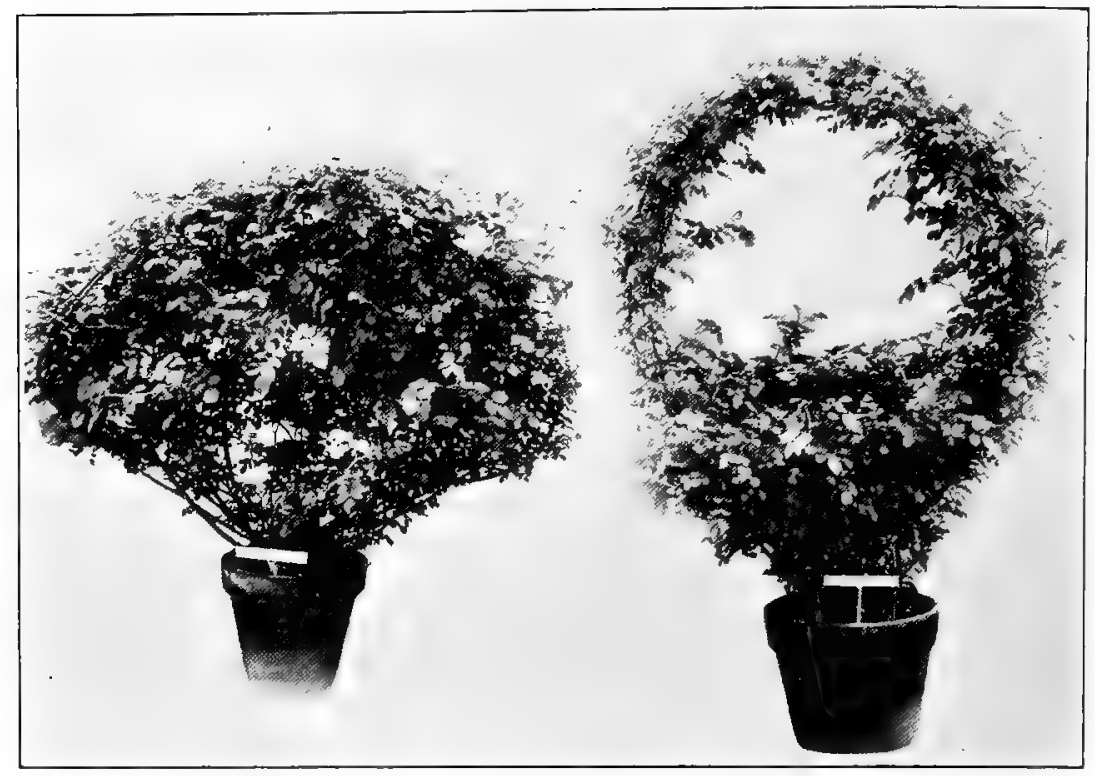

Fig. 260.-Trained Rambler Roses. (Courtesy of the Robert Craig Co.) These illustrations show what can be done with a few long Rambler canes. If tied up straight on stakes, the plants would not be very attractive, but formed into globes, arches or pyramids while in a dormant state they become handsome and much sought after when the wood is covered with beautiful foliage

loosely and then laying the pots on their sides in a frame where they can remain until the first of January. After that place them in a 45-deg. bouse, shortening the long canes a little and cutting out the small lateral growth. Also tie the plants up, which with long canes is usually done by bending them gently over and tying the tips to the base or neck of the plant so as to form a miniature balloonin fact, with a little care they may be tied up in all kinds of shapes to add to the attractiveness of the plants later on when in bloom.

The reason for retaining the canes is that the clusters of flowers will come on the new growth breaking from last year's growth; cut it away and there will be no flowers. Spray the plants well and keep in a 45- to 48-deg. house until growth is well under way, after which the temperature may be increased to $55 \mathrm{deg}$. If you want the plants for Easter and notice that six weeks before that day falls due there is no sign of the formation of flowering buds, increase the temperature to $60 \mathrm{deg}$., or even more. Such plants, however, should get a few days in a cooler house toward the end to finish them off properly. A Rambler Rose is better for having had plenty of time and 55 deg. is better than 58 or 60 . With Easter coming in early April the buds should begin to show color two weeks ahead. 


\section{Handing Field-grown Ramblek Stock}

Field-grown plants are more difficult to force early; they should be lifted about October tenth and immediately potted up and kept sufficiently watered so as to prevent hardening or ripening of the canes from lack of moisture. After two weeks treat the same as the pot-grown stock, though a house of $40 \mathrm{deg}$. will be better than a frame when it gets to $32 \mathrm{deg}$. or lower. With favorable conditions the plants will make root growth and in a temperature of $4.5 \mathrm{deg}$. will start to break by the end of January. Keep them well sprayed to keep the wood moist; it will help them to break easier.

There are men who can successfully force field-grown Ramblers for Easter, even when it occurs on an early date, but it means taking advantage of every minute, so to speak, in preparing the stock. A dry Fall and an early frost will help to ripen the wood. The plants are not allowed to lie around when dug, but are potted up in heavy soil as firmly as the pot will stand. The soil is kept evenly moist after having been thoroughly soaked at planting time and the wood is not exposed to severe freezing afterward; on the other hand, the plants are brought into a dormant state without drying up the canes, which means much in securing new breaks afterward. As already stated, keeping the wood fairly moist by spraying also helps. The plants before and while starting to break are never subjected to a warm house, but when once under way they are kept going.

To force or grow Roses, you should never be handicapped by lack of heating facilities, but should have somebody in charge to maintain an even temperature. You cannot afford to bank your fires at ten o'clock, leaving the house at $55 \mathrm{deg}$. and have the temperature drop to $48 \mathrm{deg}$. by next morning. If you cannot maintain the right conditions, you are better off purchasing your wants for early use and letting your own stock come along for May flowering-a time when every florist can dispose of a good number of plants.

\section{Ramblers and Other Glimbing Roses for Outdoors}

There isn't a home ground where one cannot find room for a few climbing Roses, whether it be on a trellis against the house or porch, over the gate entrance, or along the fence. These Roses do not flower all Summer, as is the case with the more tender climbing Hybrid Teas, such as Kaiserin Augusta Victoria or Testout, but when in flower you can't see anything else in the neighborhood. In order to sell these Roses and make them pay you must not only carry a stock, but also let your customers know about it. These, like the Hybrid Teas for bedding, should be grown on in pots. Save what live canes you can on the plants and tie them up nicely. If you allow them to come along slowly in a frame you will have plants by the end of May with about a 1-in. growth, which will 


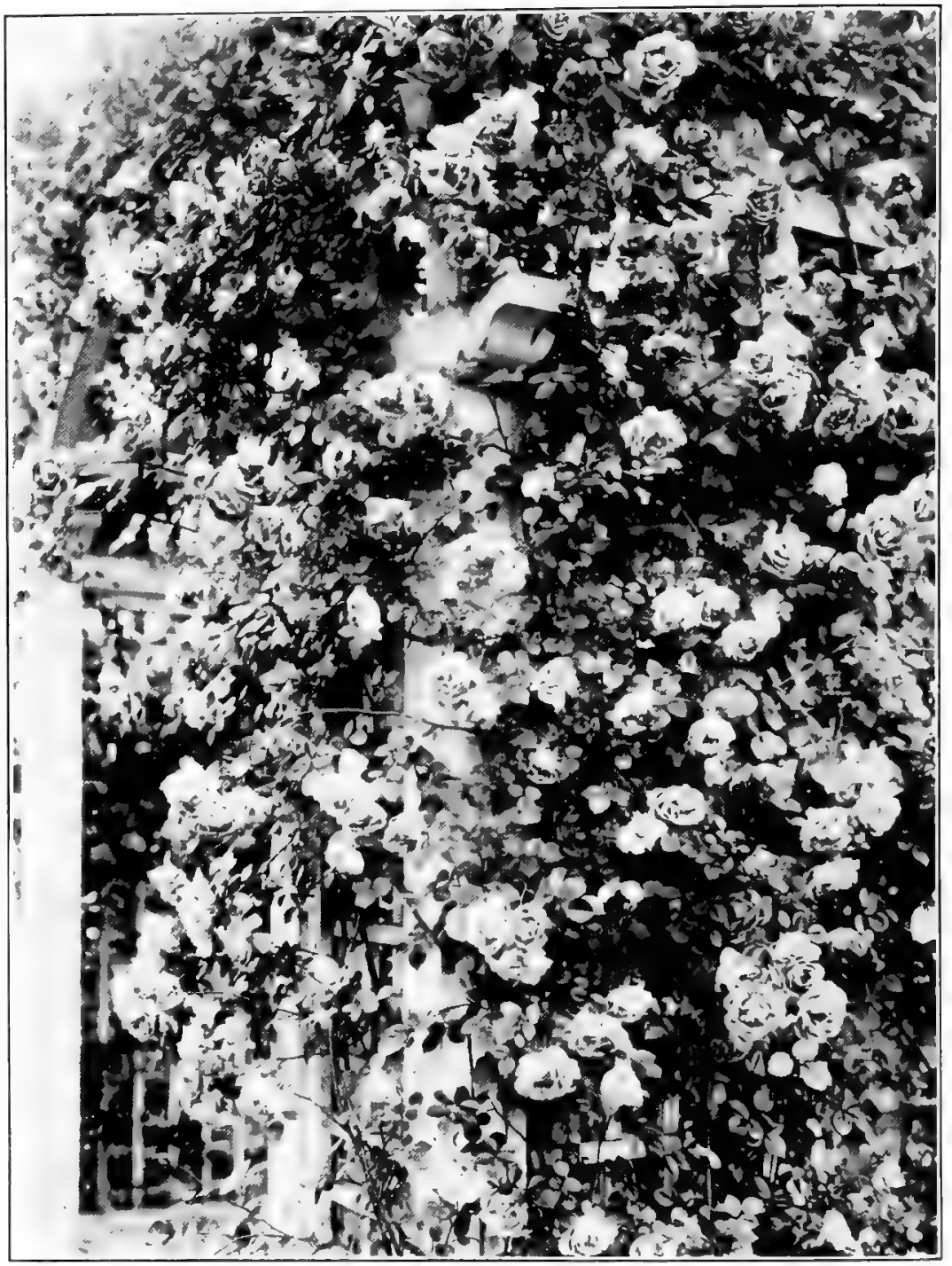

Fig. 261.-The Cumming Rose "American Beauty." This is a fine outdoor Rose for covering trellises and pergolas, but if you happen to be located in a section of severe Winters, always arrange to lay the canes down along the ground and properly protect them as soon as freezing weather arrives

most likely produce a few flowers the first year. Tausendschoen, with its soft pink, graceful flowers, is one of the most attractive. Crimson Rambler, Dorothy and White Perkins, Lady Gay, Silver Moon, American Beauty, American Pillar and Hiawatha are all good. These sorts have to a great extent taken the place of our 
favorities of thirty years ago, such as Baltimore Belle, Seven Sisters and others.

If you are anxious to propagate and grow on young stock, this is easily done even if you only have a house of $50 \mathrm{deg}$. In September take cuttings from your plants in the field; avoid the very soft growth such as is found on the side-shoots of the long canes. It is best to leave three eyes on the cuttings and place them in a sand bench with your Geraniums or such other stock as you usually root at that time. It may take the cuttings several months to root, but they-will root eventually even without bottom heat. Later on pot them up and carry them in a Carnation house until ready to plant them out the following Spring into the field; while not extra heavy, they will be strong enough by Fall to be lifted and potted up to be sold the following Spring.

\section{SoIl For OUtdoon Roses}

You can grow Roses outdoors in almost any soil, but if yours consists of a heavy clay the deeper it is worked over before planting the better. However, it isn't necessary to go to great expense in the preparation of beds or borders. You may have among your customers those who insist on that and if they are willing to pay for it, go ahead and do it; it won't hurt the Roses. But no matter how you prepare a bed, if the stock later on is not taken care of, given proper cultivation, watered in dry weather and kept clean by spraying with a nicotine solution, the plants won't be nearly as good as those planted in ordinary garden soil and taken care of afterward.

If there is any particular soil that Roses in general like it is a good, stiff loam with a 6-in. layer of old cow manure spaded in. If you can't get cow manure use well-decomposed horse manure. In light soil spade in the manure and a month or so after planting, just after the bed has been cultivated, apply a light layer of short manure as a mulch. The appearance of yellow-colored leaves on top is due more frequently to poor drainage than to over-feeding. Good drainage, a fair soil kept moist and cultivated, plenty of sunlight and keeping the insects down go to make up success with outdoor Roses.

\section{WINTER PROTEGTION FOR OUTDOOR ROSES}

All such roses as Hybrid Teas, Hybrid Perpetuals and so-called hardy climbers, if exposed to zero weather, should have proper protection in order to overwinter safely. When a customer tells you that her beautiful Dorothy Perkins Rose makes eight or ten feet of growth each year, but hasn't bloomed since the first year it 
was planted out, you can depend on it that the canes are allowed to freeze down each Winter, the plants sending up a new lot of shoots every Spring that become heavier and longer the older the plant gets. If you happen to be located in a section where from experience you know Roses winterkill, don't stop planting them, but do what you can to protect them. To save the flowering wood of a Rambler is well worth all the trouble it takes, which, after all, isn't much.

To plant such a Rose where for some reason it cannot be protected is wrong to begin with. The best way to protect tender Roses when only a few are grown, is to take the canes, lay them down and cover them with a heavy layer of soil-the heavier the better-followed by a layer of manure and a top dressing of leaves, straw and brush or evergreen boughs.

There is nothing like surrounding the wood of a Rose with moist soil over Winter, with a layer of manure or something else on top of the soil. Even if it all freezes, by Spring the Rose will come out with the wood in perfect condition. A plant left on a trellis, even though well protected with a straw covering won't overwinter nearly as well. It isn't a hard job to train the Roses on wires or wire frames which can easily be taken down in the Fall or when severe weather sets in. In the case of Hybrid Teas or Perpetuals planted in a bed or border, whether you make use of own root or budded stock, always plant deeply and far enough apart to permit, whenever possible, the piling up of the soil around the plants for ten or twelve inches. The soil doesn't have to be taken from the bed the plants are in, but with such soil protection and a layer of manure on top of it you can carry almost any Rose over Winter no matter what the weather. Let the tops freeze, for you will have to cut the plants down anyway by Spring. Of course, the higher you can pile up the soil and the more complete the manure covering the better We have found that a covering of leaves or straw through which the air can reach the wood isn't nearly as effective.

With Hybrid Teas, another way is to lift the plants by the middle of November, lay them on their sides, bury them fifteen or eighteen inches deep, and replant them the following Spring. You cannot do that with the Hybrid Perpetuals, for usually it takes them until the second year to become properly established.

\section{MISGELLANEOUS OUTDOOR ROSE SPEGIES}

\section{Rosa Rugosa}

Whether he favors the single pink and white sorts or the beautiful hybrids, every florist should recommend the planting of Rugosa Roses in the home grounds. There may be only room for one plant, or there may be space. for a hedge of them or a group in the foreground of the shrub border. In any case, their sweet- 
scented flowers appear all Summer, surrounded by dark-green, glossy foliage hardly ever spoiled by insects and, toward Fall, when loaded with large reddish seed pods, they are still more attractive.

Don't be too severe in pruning them when they are once well established; each Spring simply thin out the old wood and small growth and just keep the plants in shape.

Among the hybrids one of the most beautiful is Conrad Ferdin and Meyer, a charming semidouble silver, as hardy as an Oak. Blanc Double de Coubert is a splendid double white.

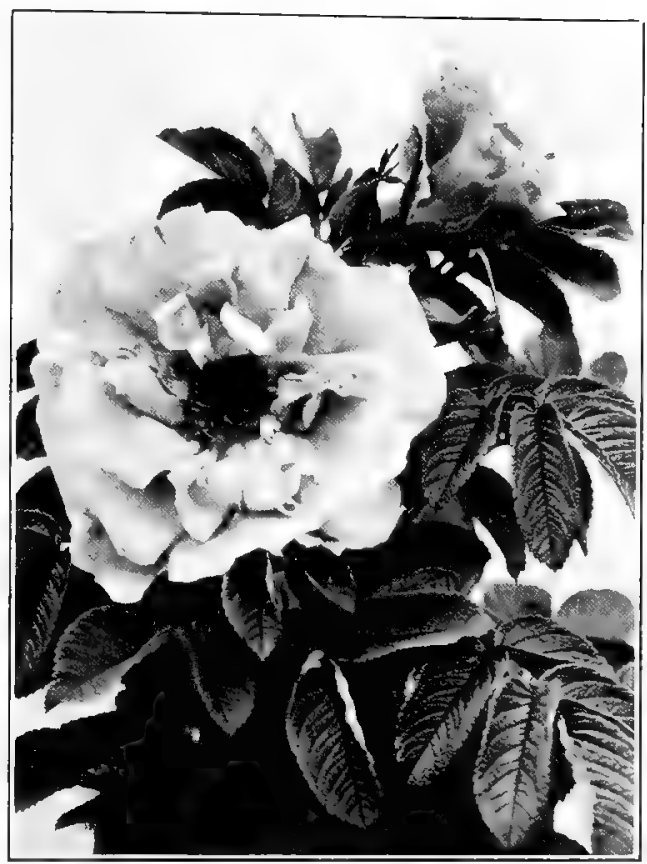

Fig. 262.-Rosa RUgosa. All the rugosas, both single and double, deserve a place in the home grounds. Often they will do nicely where hybrid Perpetuals and Teas fail. They have not only sweet-scented flowers and beautiful foliage, but also, with their red fruit, are attractive long after frost kills the leaves

\section{The Hermosa Rose}

With the introduction of the many hybrid Teas so showy for outdoor planting, this Tea Rose is but little grown today. Years ago it was used by tens of thousands for outdoor planting when, because of its free flowering qualities, it was best known as the "Monthly Rose." We also grew it on in pots or as potted up fieldgrown stock during the Winter months to come in flower in early Spring as well as for Memorial Day.

Even with all the other good Roses, you can still recommend Hermosa as an excellent garden sort, producing without letup its rose-pink flowers and buds on slender stems, 'way into November.

\section{Moss Roses}

There are some who think there is nothing sweeter than these Roses with their buds in a mossy setting, and really they belong in every collection. If you order Roses from your nurseryman to meet your demand in Spring, include a few Moss Roses and you will not only find sale for them but also please some of your cus- 
tomers at the same time. There are four or five sorts available, among them Princess Adelaide, pink, Comtesse de Muranais, white, and Henry Martin, red. Like the Rugosas, they need but little pruning and when once established are good for years.

\section{The Sweet Brieg Rose (Rosa Rubiginosa)}

As in the case of the Moss Rose, every home ground, no matter how small, should contain at least one plant of the Sweet Brier, with its delightfully fragrant leaves. If you want a combination of fragrant leaves and fragrant flowers, plant a few of the several beautiful hybrids or Lord Penzance Briers. Lucy Ashton is a good white with a pink edge; Lord Penzance is yellow, and Anne of Gierstein is red. Don't plant these Roses with your Hybrid Teas or Perpetuals; but put them somewhere near the porch, drive or walk, where they can be loosely tied up to a strong six-foot stake, and where one has a chance to appreciate their flowers and the fragrance of their leaves.

We find another desirable garden Rose in the hybrid Austrian Brier type flowering in June, of which Beaute de Lyon is a showy red. While this sort should be pruned quite heavily, the varieties named above don't need it; simply cut out the old wood and keep the bushes in shape.

\section{Rosa Wichuratana}

Customers calling on you for shrubs, vines and other hardy stock for outdoor planting, will probably get into the habit of asking your advice when not sure as to what to use in planting. If an occasion arises where a steep bluff, a ravine bank, or the side of a slope is to be covered, that is the time when you should suggest Rosa Wichuraiana. Give it sun and just a little chance to become established and it will do the rest.

We have planted it in sandy soil and again in the stiffest of clay and in each case it has made good; the plants not only covered the surface of the ground, but bore a mass of sweet, white, single flowers during early July. You can also use this Rose for fences, arbors or the covering of retaining walls.

Among the hybrids, we have Universal Favorite, a double pink; Evergreen Gem, creamy light pink, and South Orange Perfection, with light pink flowers and dwarfer habit.

\section{The Persian Yellow Rose}

Among the earliest of all outdoor Roses to flower, and as hardy as any, is Persian Yellow, which belongs to the Brier Rose group. Its flowers are not large, but the plants, when once established and not pruned too severely, are loaded down with the fairly double, deep yellow blossoms year after year. 


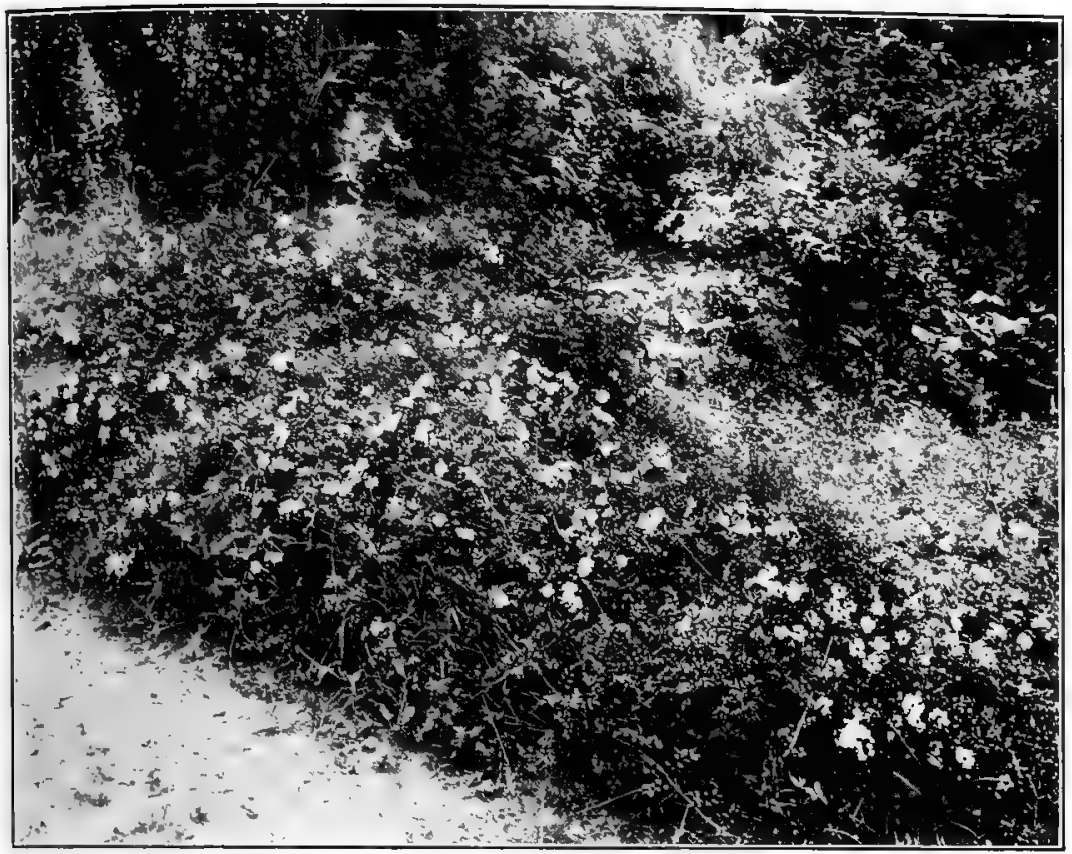

Fig. 263.-Rosa Wichuraiana in a whOLLY APPROPRIATE SETTING. Where there are banks, rocky slopes or steep bluffs to be covered, this Rose will do the trick no matter what the soil nor how little attention is given after planting

Occasionally we have visitors in the store ask the name of this Rose, having seen it in full bloom somewhere. So delighted are they with it that they then and there place an order for a few plants for delivery the following Fall or Spring.

\section{ROSA SETIGERA}

Among other Roses used by the landscape gardener for mass. plantings, for slopes, or on the outskirts of native shrubbery plantings, is the Prairie Rose (Rosa setigera) which, by the way, should be far more extensively used even by florists who do more or less landscape work in and around country towns. There are always occasions when one can advantageously break away from the stiff and formal. Other sorts adapted for heavy plantings, where little or no cultivation is being or can be given after planting, are Rosa blanda, $R$. carolina (the Swamp Rose), $R$. lucida and $R$. humilis. Of course, not every retail grower has use for all of these, yet it doesn't hurt him to know about them; maybe some day this knowledge will come in handy, as it has in the writer's case.

\section{RUBBERTPLANT See Ficus}




\section{RUDBEGKIA (GOLDEN GLOW)}

When Rudbeckia Golden Glow first came out, everybody thought it wonderful for cut flowers and an ideal herbaceous plant for the hardy border. We were able to obtain only small plants then and this very fact was what made it such a success, for nothing runs out quicker than a bed or clump of this Rudbekia if left alone. That is true in most cases today.

If you want to see this plant at its best, divide the clumps about the latter part of September, replant only the outside shoots, singly, and throw the others away. In that way you will have each year real Grolden Glows on long stems with foliage right up to the large flowers, handsome for mass effects and fine as cut flowers for decorative work.

There are other fine varieties of Rudbeckia, which mostly flower in late Summer in masses of yellow and brown Daisy-shaped blossoms. Among the most showy we have $R$. purpurea, which often produces flowers almost five inches in diameter with reddish-purple petals and a large brown center in the shape of a cone (from which it derives its name-Giant Purple Cone Flower). Sow seeds of this Rudbeckia during Summer; it will flower the following year and make a great shôwing in the hardy border, growing about thirty inches in height. Another Rudbeckia, easily grown from seed, is R. New Maine which should be treated the same as $R$. purpurea. It has large, single Daisy-like flowers, deep yellow with a dark cone.

$R$. subtomentosa is the one which will produce in Fall hundreds of small, single, yellow flowers with dark centers, which completely cover the plant. You can lift the plants when in full bloom, pot them up, and keep them for a week on a shaded porch.

\section{SAGE \\ See Salvia}

\section{SALIX (WILLOW)}

The most interesting of the Willow family to the florist is Salix discolor, or the Pussy Willow. Shortly after New Year's we begin to look forward to a few Pussy Willows as a sign of Spring to put into a box of Spring flowers or to make a cut flower basket look more attractive. You may want to purchase your supply of these cut Willows, but it won't hurt to plant a few yourself somewhere along the line of your grounds, if for no other purpose than to cut from. There are other showy Willows, among them the Laurelleaved form which grows into a stately tree and does it quickly. No matter what the season or the weather, the tree all Summer long is a mass of heavy, shiny foliage. The Rosemary Willow, with its narrow, densely covered foliage and dark stems, makes a beautiful shrub, and Salix britzensis is one of the most showy of all shrubs for a Winter effect on account of its bright reddish twigs. 


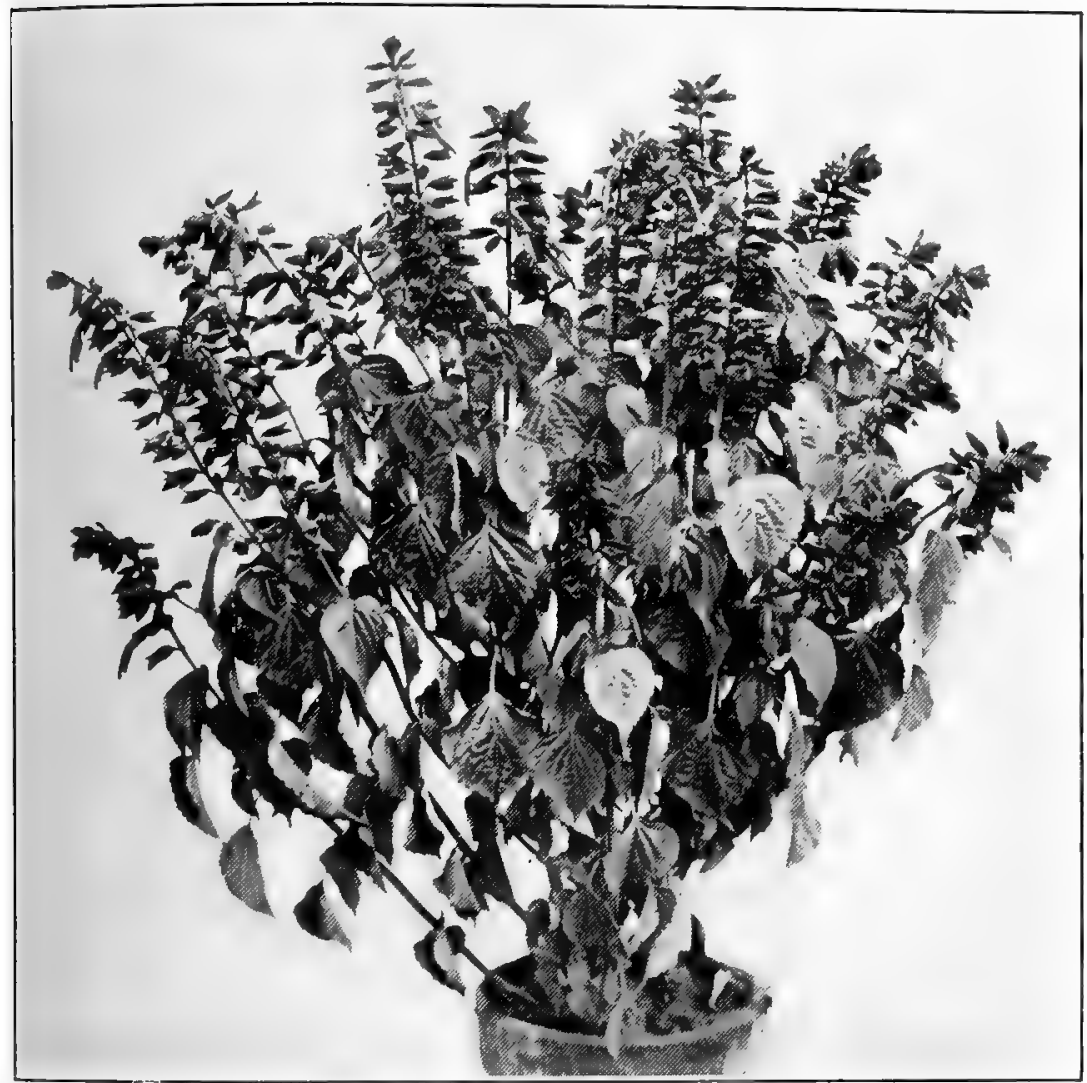

Fig. 264.-Salvia splendens. This, the Scarlet Sage, is the thing to plant when you want a mass of vivid scarlet in the late Fall

\section{SALPIGLOSSIS (PAINTED TONGUE)}

Salpiglossis and Gypsophila elegans (annual Baby's Breath) make as beautiful a combination for the center of a dining table as any one could wish for during the Summer months. It is no wonder that Salpiglossis has become so popular during the past few years. While it is easily grown from seed sown outdoors in Spring, there are plenty of your customers who are willing to pay a fair price if you have well established plants in $21 / 2 \mathrm{~s}$ to offer in May.

Anyone who sells cut flowers has good use for Salpiglossis and you should manage to have a good supply of plants to cut from all Summer long.

\section{SALVIA (SAGE)}

\section{Salvia argentea (Silver-leaved Sage)}

As the name indicates, we plant this Salvia, not for its flowers but for the silvery-gray foliage. There are times when in a planting 
it is just the thing. Those who handle or retail hardy stock should have just a few plants on hand, for when at their best they always attract attention and somebody will want a balf a dozen or so. They are easily grown from seed.

\section{Salvia azurea (Hardy Salvia)}

'This Salvia grows about four feet in height, and has slender stems full of beautiful little light-blue flowers in September. A half dozen or so plants in a group, if given a little support, make a fine showing; and you can also use them for cut flowers. The light blue color of the flowers is quite unusual among the other perennials, and hardy stock in bloom at that time, most of which have yellow blossoms or those of orange or brownish shades

This Salvia is easily grown from seed, which you should sow in January in a 50-deg. house. If care is taken of the young plants, you should have no trouble in getting bushy little specimens by early May. But the plants differ greatly in habit from the Scarlet Sage. A later introduction, considered an improvement on $S$. azurea is $S$. Pitcheri with deeper colored and larger flowers and more of them on the plants.

\section{Scarlet Sage (Bedding Varieties)}

Salvia America heads the list of desirable florist's varieties. It is of dwarf habit, good form and starts to flower early in the season, which, with many of the older sorts, is not the case. There has been a dropping off in the demand for Salvias mostly on account of their bright red color, but every florist can dispose of large numbers during the Spring months. He should have good-sized plants with good-sized flower spikes in 4-in. pots by the middle of May and another lot in smaller pots for later use.

February first is not too early to start with the first batch of seed. Sow it in flats and give bottom heat. The seedlings can be planted in flats allowing an inch and a half or so of space between them. When they have made their third leaf, pot them into $21 / 2 \mathrm{~s}$ and let them come along in a 50-deg. house. They may not make as fast growth in this temperature, but they will grow into better stock. Keep them shifted into good soil and they will have darkgreen foliage and good-sized flowers later on.

Another way, the best with the variety America, is to lift a few of the best-shaped plants in September, pot them up, cut them back a little and place them in a 55-deg. house. By January these plants, if cut back a little more, will begin to break and soon be full of cuttings which root easily in sand with bottom heat. In this way you are sure to obtain a good strain, which is not always the case when you grow on from seed, no matter how fine the plants you gathered the seed from. 
For masses, large beds and wherever it is a matter of obtaining the biggest show during Fall when almost everything else in the garden is through, Salvia splendens is still the most showy of all. It doesn't flower much during the Summer, but when it does it makes up and becomes, indeed, a sheet of fiery scarlet not equalled by any other plant. In sheltered places this Salvia is still good even after the frost has finished all else. S. Zurich is another good dwarf sort. Ball of Fire and Bonfire, two taller growing ones, both come into flower long before $S$. splendens.

\section{SAMBUCUS (ELDER)}

In Sambucus we have the Golden-leaved Elder (S. aurea) and the cut-leaf variety ( $S$. acutiloba) which, with its finely cut, lace-like foliage and its

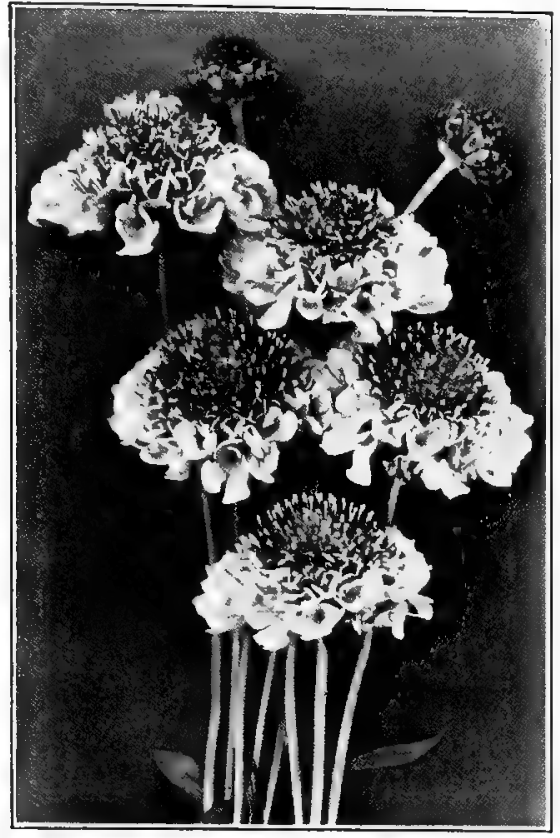

Fig. 265.- Scabiosa Azure Fatry. This is the latest of the many beautiful Scabiosas, a light lavender color with a deeper center. Scabiosas are among the best Summer cut flowers and you can get them in separate colors in almost any shade mass of flowers during early July, is a very desirable shrub.

Elders like a moist situation, especially the Golden-leaved one. In a dry place it makes a poor looking shrub in late Summer. The cut-leaf one does better if placed in a dry position.

There is nothing outside of a Willow cutting easier to root than an Elder. Take three- or four-eyed hardwood cuttings in early Spring, plant them closely in a sandy bed, and keep well watered.

\section{SANTOLINA INCANA}

The florist interested in carpet bedding or border plants of a dwarf, compact habit, will find Santolina a most useful little subject. Its silver-gray dense foliage can be sheared the same as that of Alternantheras and we see it often used in connection with the latter, the two forming an ideal combination.

There are times when you want a border plant which without trouble can be confined to a certain space. That is when the Santolinas come in handy, for you cannot always get the desired result with a Salleroi Geranium or a Dusty Miller. The easiest and quick- 
est way is to grow them from cuttings taken in February from old plants carried in pots over Winter in a cool house. A good-sized plant will give you hundreds of cuttings.

\section{SGABIOSA (PINGUSHION FLOWER)}

The Scabiosas are among the very best of Summer-flowering annuals. Their long-stemmed flowers last in water for four or five days and you can get seed in separate colors, so as to obtain flowers almost any shade you want from snow white to velvety blackpurple, or from soft flesh and rose-pink to a rich crimson, as well as a delicate, light lavender blue. Thus you can use them for the bride's bouquet, the corsage, the funeral spray, the table decoration, the flower basket or the set floral design. They make up into beautiful wreaths and sprays either alone or used with other flowers. They differ from Asters and Gladioli by flowering from June up to time of frost; and they do well in almost any soil.

For extra early blooms, sow seed in early March and pot the seedlings up, planting out about one foot apart in early May. Grow on a good number of plants for your Spring trade and for the main crop sow outdoors in rows about the end of April. Still another batch can be sown by the end of June. This planting will give you somewhat better flowers and longer stems than the plants which have bloomed all Summer.

\section{Hardy Scabiosa}

Scabiosa caucasica is the hardy lavender Scabiosa and $S$. c. alba, the white form. Both furnish desirable but not showy cut flowers. They are easily grown from seed which if sown during June or July, will bloom early the following Summer. These Scabiosas are among the plants a customer will have on her perennial list and if you have them on hand you can sell plants. But you wouldn't want to grow them for the money you can make out of the cut flowers.

\section{SCHIZANTHUS (POOR MAN'S ORCHID)}

You can have Schizanthus in bloom under glass from December on up to Memorial Day and, outdoors, all Summer long. The slender branches are covered with miniature orchid-like blossoms of many shades which when cut will last for days. To flower under glass they require a cool house. As single specimens they can be grown in pots to enormous size for early Spring. Plants in 4- and 5 -in. pots can be had in bloom for late December and January. For outdoor crops the best way is to make two or three sowings. 


\section{Indoor Culture}

The variety used for indoors is $S$. Wisetonensis. This is best adapted for the purpose and produces longstemmed flowers in shades of white, pink and lavender. For December flowering sow seed in late September and transplant the seedlings into pots. Give those in $21 / 2 \mathrm{~s}$ a shift into $4 \mathrm{~s}$ by the middle of November; pinch them back once or twice, but not later than the middle of November. As soon as the plants become potbound, they will set buds and start to bloom, and you can have nice flowering plants for Christmas in a 48-deg. house.

Those intended for later flowering should be kept shifted and pinched. You

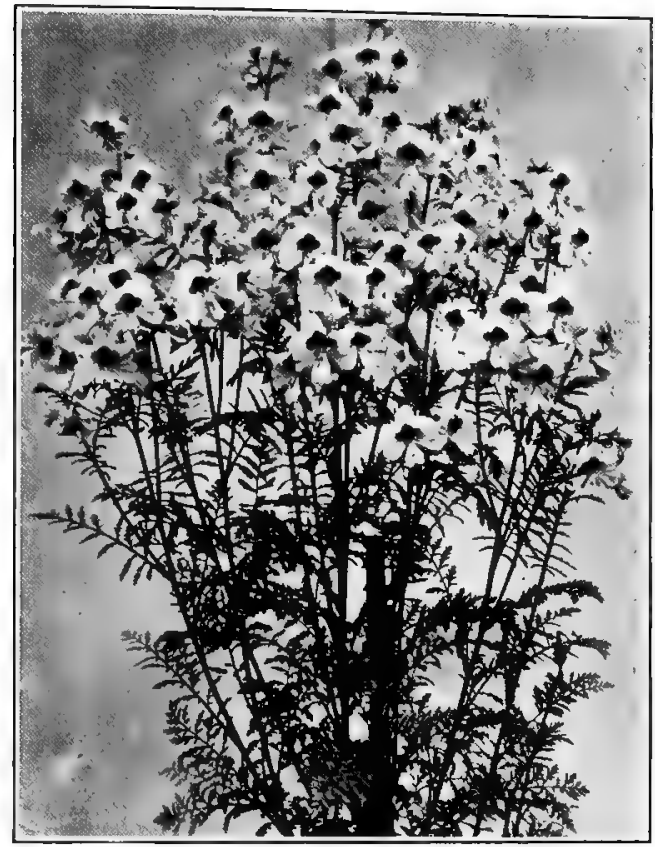

Fig. 266.-Schrzanthus. For both indoor and outdoor growing Schizanthus is a source of desirable cut flowers

can, by giving that treatment systematically, produce specimens three feet in diameter by Spring.

For cut flowers to bloom during the latter part of February and later, plant 21/2-in. stock out on a bench in December. Another way is to sow on a solid bed; this will give you fine flowers during March and April. Always grow in a cool house and if you want plants in pots, shift when necessary, unless you should want the plants to come into flower early, as in the case of the ones wanted for Christmas.

\section{SEDUM (STONECROP)}

There are quite a number of attractive Sedums for the rockery. They are all dwarf sorts and not of much value to the florist. In fact, even among the tall ones, there are hardly any we can call money makers; yet Sedum spectabile "Brilliant," the red-leaf form of $S$. spectabile, is really a most attractive border plant. Its healthy, thick, bronze-red foliage always looks well and the plants are covered in late Summer with a mass of tiny pinkish flowers, borne in large heads, a foot or so above the leaves.

They are perfectly hardy and are easily divided in Spring or Fall. If you handle perennials it won't hurt to carry a few. 
If you desire a couple of the best hardy dwarf sorts, never over five inches in height, for rockery planting, S. stolonifera with pink flowers is a good one and S. acre (Golden Moss) has yellow flowers and is very hardy when once established.

\section{SEA LAVENDER See Statice}

\section{SENEGIO SGANDENS (GERMAN IVY)}

The time when you appreciate this Ivy is when you have window or porch boxes to fill in Spring. These boxes are to go up on the second or third story and vines are wanted along the edges to hang down ten or fifteen feet before the Summer is over. In such cases there is no plant that will take the place of German Ivy. Plant your green or variegated-leaved Vincas, but in between plant every fifteen or eighteen inches a $21 / 2$-in. German Ivy. By the middle of July, if you have not neglected the watering, you will find them away ahead of the Vincas.

Pot up a few plants in the Fall and overwinter them in a cool house to take cuttings from during Winter. There is nothing easier to root, nor anything outside of a Cineraria or Calceolaria of which the green fly is as fond.

\section{SENSITIVE PLANT \\ See Mimosa}

\section{SHASTA DAISY}

A perennial border is never too small nor too large to have a few good-sized clumps of Shasta Daisies in it. Everybody likes Daisies, especially those of the size of Alaska; and even these you can improve upon by selecting the finest flowers for seed and keeping on doing so.

Shasta Daisies are fine plants for the hardy border, flowering until Fall. You can dispose of a good number of plants each Spring and Fall and have a few rows.in the field to cut from during Summer. You can bring plants. into bloom with gentle heat under glass in Spring; so they should be considered valuable stock for the florist.

If seed of Shasta Daisies is sown out in February and the plants are carried in flats and planted out in early May, they will usually start to flower by the end of June and keep it up until Fall. But they will be at their best the following Summer. We consider them perfectly hardy, but every once in awhile we lose them. It doesn't always take a severe Winter to do it, and for this reason it is well to always lift a part of your field stock and carry it over in a frame. Also always sow out a little seed each year so as to have young stock coming along. You can save your own seed without any 
trouble and no matter how good the strain you buy or save, you will always, as in the case of many other things, find some with better flowers than others.

Plants to be forced under glass should be carried in a coldframe up to February and then brought in to a 48-deg. house. Plant them on a bench or, what is better, on a solid bed and let them come along slowly. You can also increase your stock by division, which is best done in late August so you can obtain well-established plants before Winter sets in.

SILK OAK

See Grevillea robusta

SNAPDRAGON

See Antirrhinum
SNOWBALL

See Viburnum

SNOWBERRY

See Symphoricarpos

SNOW-IN-SUMMER See Cerastium

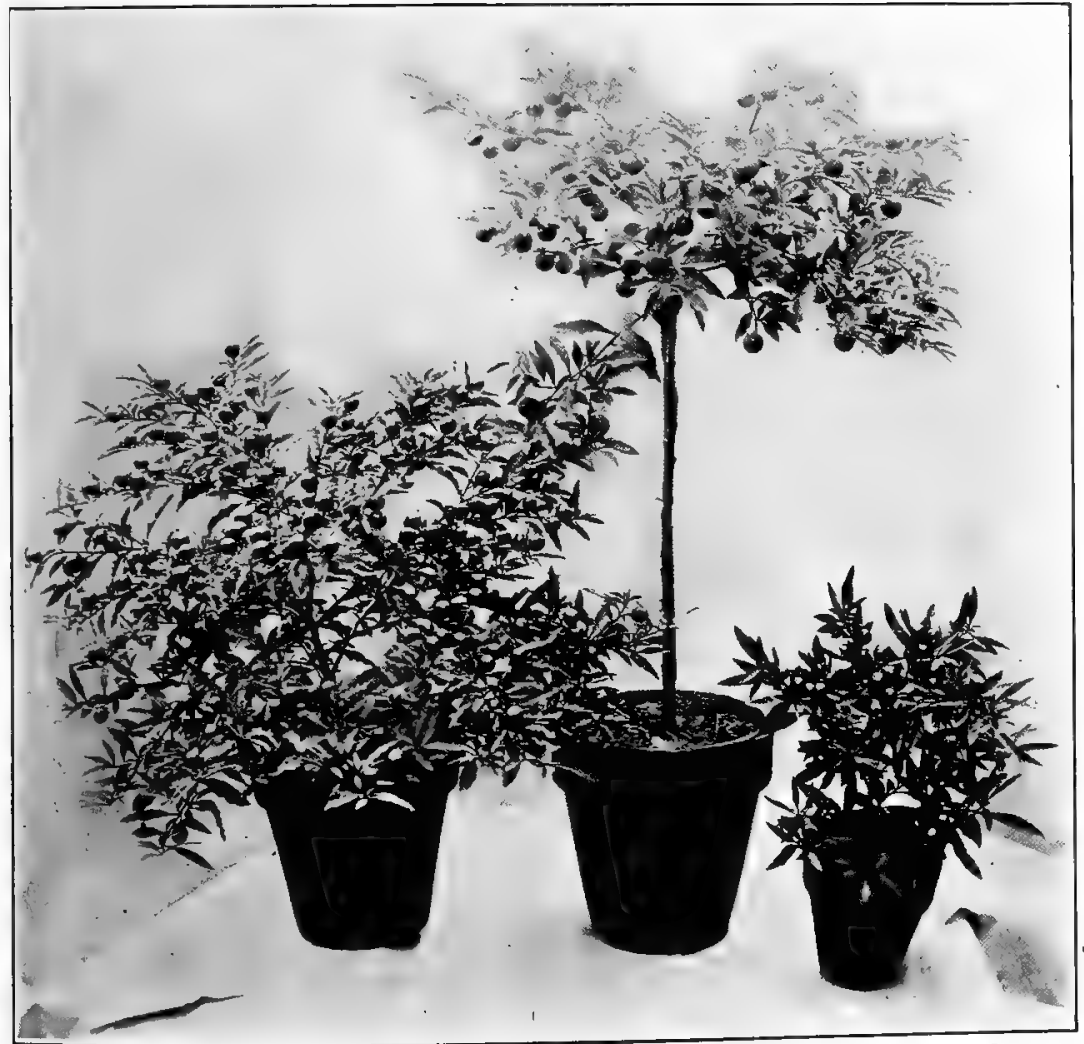

Fig. 267.- Cleveland Cherries. You can carry your Gherries over for the second year (left); or you can train some of the plants into standards (center); but the best seller is a plant in a 5- or 6-in. pot. It requires about ten months from the time you sow the seed until a well berried and highly colored specimen is ready for the counter 


\section{SORBARIA ARBOREA GLABRATA}

I would call this Sorbaria an ideal cut flower shrub for the florist. Several of the genus have Spiræa-like flowers and one, $S$. sorbifolia is known by many nurserymen as Spiræa sorbifolia. The flowers come in terminal many-branched panicles and those of $S$. arborea glabrata are snow white. You will have them at their best during late Summer, even up to October, and they are splendid for decorative purposes. We have kept them in water in perfect conditon for almost five days.

This isn't a shrub that you want to sell as many of as $\mathrm{Hy}$ drangea or Honeysuckle, but there is a place for it and it will pay to have a few on your own grounds, just for cut flowers. The plant when once established will soon be surrounded by suckers, which, easily removed in early Spring, will soon grow on into fine specimens. The foliage of the plant is quite attractive and is similar to that of some of the Spiræas or the Mountain Ash (Sorbus) from which, according to Bailey, the name Sorbaria was derived.

\section{SOLANUM (JERUSALEM GHERRY)}

I doubt whether of late years anything has been introduced of greater use to the average florist than the Cleveland Cherry, which is today such a great seller from November on up to New Year's.

Before its introduction we grew on from year to year the old type Jerusalem Cherry (Solanum Capsicastrum), and once in awhile sold a plant. But where there was one of them sold, hundreds of the Cleveland Cherry are disposed of. There isn't anything more bright and cheerful on a Winter's day than a well-grown plant of this variety full of fruit. Many thousands of them are used for inexpensive Christmas gifts by people who cannot afford anything more expensive. That is not to say that made-up plants or specimens of this Cherry do not often bring five dollars and over, but the fact that makes these Solanums so valuable is that almost every florist can grow on his own stock from seed with but little trouble, and not only satisfy those who want a one dollar Christmas plant, but also make a fair margin of profit on every sale. Moreover, the demand for these plants seems to be increasing yearly.

\section{Cultural Notes}

Whether you want to grow on the red or the yellow Gleveland Gherry, or the Bird's-eye or Celestial Peppers, all these are easily grown from seed sown from the end of January on with good bottom heat. Any of them can be successfully grown in pots, either inside or in frames during the Summer months. On the other hand, there are some very successful growers who practice field culture 
with the Gleveland Cherries and, except in unusually wet seasons, have fine stock each year.

A good way is to grow on a part in pots and plant another lot outdoors. For field culture, plant out in May, allowing plenty of space so the plants can develop properly. Lift in September and place either in a shaded house or in a frame. The end shoots without fruit on are just as well pinched out, as this makes a better looking plant. Small plants may be used to advantage for made-up pans, using from three to five plants to a 6 in. or 8-in. pan according to the size of the plants. Spray them regularly and

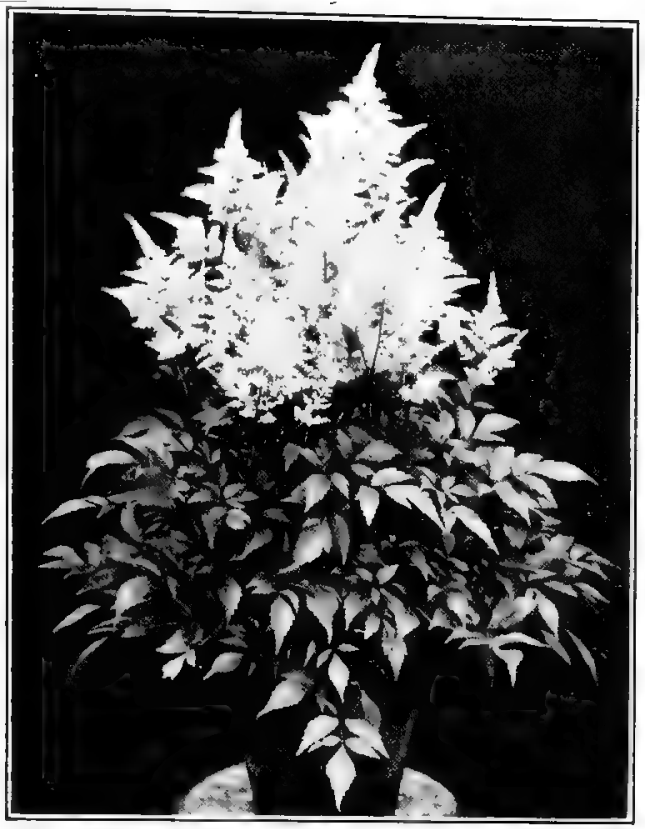

Fig. 268.-SPIRAEA JAPONICA. There are a number of fine varieties of this Spiræa all of them beautiful and desirable Easter plants (See Astilbe, page 269) gradually remove the shade. A house of $50 \mathrm{deg}$. is about right.

Still another way to handle them is to shift the plants from $21 / 2 \mathrm{~s}$ into $5 \mathrm{~s}$ in May and plant pot and all in a frame. I have done this with success and by Fall had well set plants ready for a shift. With such treatment, special care must be given in watering. The soil between the plants may be wet while in the pots you will find it dry. Cleveland Cherries can also be propagated by means of cuttings. Select a few extra fine specimens, remove all the fruit, and place the tips in sand. The plants will keep on breaking and all kinds of cuttings may be had during the Winter months. Such stock will have more fruit, but won't make as large plants.

All the other Solanums, which we know as Peppers, are best grown on in pots during the Summer months and a frame is the best place for them. They make too rank a growth and not enough fruit when planted out, and when lifted they lose too many leaves.

$\begin{array}{cc}\text { SPEEDWELL } & \text { SPIRAA JAPONICA } \\ \text { See Veronica } & \text { See Astilbe }\end{array}$

\section{SPIRAEA, SHRUBBY VARIETIES}

Spiræa Vanhouttei, in many localities called the Bridal Wreath Spiræa, is the finest of them all, whether you behold it in full bloom, 
a mass of graceful branches thickly set with flowers, or during the balance of the season with its derise, dark green foliage. It is especially fine when grown as a single specimen and pruned each year directly after it is through flowering. If left alone, it will soon become top-heavy and bare below, to be broken down by the first heavy snow.

Spiræa Vanhouttei is the easiest of all shrubs to handle; it sells as well as any; it can stand a sunny or a shady position, wet or dry; it will get along with but little attention and flower each year; when once or twice transplanted, it can be lifted with a ball of soil at any time of the year; it will grow quickly into a large, showy plant; it is good to look at whether in flower, in foliage or during the Winter months in a dormant state with its mass of upright yet graceful branches; it flowers freely the first season no matter how small the plant; it is hardly ever infested with insects or disease; and it is just as good as a single plant in the lawn or korder as when planted

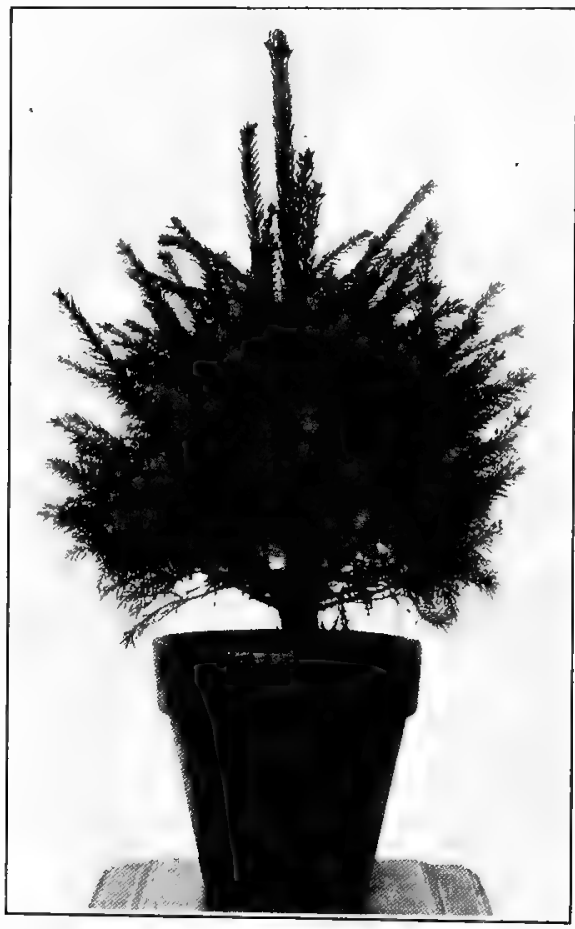

Fig. 269.-A Potted Norway Sphuce. Always carry a good number of Norway Spruces in pots during December. Wellshaped plants lend themselves nicely for Christmas decorations and with just a little trimming can be made still more attractive. (See page 476) in masses. What other shrub has all those qualifications?

You can also lift 3- to $4-\mathrm{ft}$. plants which have been transplanted several times, plant them in large pots in November, carry them in a frame up to January, move to a 40 -deg. house and later on into one of 50 deg., and gently force them for Easter You may not sell many of such plants, but they will come in handy for decorative purposes, or the sprays can be cut.

Any florist, whether he sells nursery stock or not, who has a few feet of ground, should plant a few rows of this splendid shrub. If you have no other place, plant a hedge of it around your home.

There is a long list of desirable Spiræas. One is S. prunifolia. In some localities this also is called Bridal Wreath, but I think Vanhouttei is more entitled to that name. S. prunifolia has small, button- 
like, double flowers and foliage similar to Plum leaves. With us the tips often freeze during a cold Winter.

The Nine Bark Spiræa (S. opulifolia) is a native in many places where we find it in moist positions. It will grow $12 \mathrm{ft}$. in height in time and should be used only for heavy mass plantings. S. Thunbergii is one of the dwarfest and earliest flowering varieties, fine along the edge of shrubbery beds, with taller growing stock as a background.

S. Anthony Waterer is the best of the deep pink or red flowering sorts. Of low, spreading habit and producing flowers all Summer, its only bad feature is the discoloring of the old flowers which really should be kept picked off. S. Billardii produces large panicles of clear pink flowers and makes a fine, upright shrub. It flowers in July and is just the thing in a shrubbery border. S. salicifolia (Willow-leaved) is another fine, pink, Midsummer-flowering variety. These are only a few of the many fine shrubby Spiræas there are to choose from; all are well worthy of cultivation. Among several hardy herbaceous sorts $S$. tomentosa, or Steeple-bush, a common weed in some places, is useful in the border or wild garden.

\section{SPRUCE}

See Picea; also page 203 and Fig. 269

\section{STATICE (SEA LAVENDER)}

Statice latifolia is the hardy Statice of which so much in a dry state is used by the trade during Winter. It is imported from Europe where it is 'grown by the acre. The plants flower during July and August and when in full bloom the whole plant is cut off just above the leaves, the stems are tied and the bunches are hung up in a shed to dry. However, it can also be grown here and not only used as an everlasting during the Winter months, but also in a fresh state the same as Gypsophila. If you haven't use for all of the flowers, cut them and dry them for Winter. This Statice is easily grown from seed sown in early Spring in a frame, the plañts being set out in rows and allowed fully $1 \mathrm{ft}$. of space. It will flower the second Summer and the plants should not be disturbed if you want them to produce a lot of flowers.

Statice Suworowii is a very attractive annual form with long, graceful spikes of pink flowers fine for cutting and excellent to go with other flowers. It blooms during June from plants started indoors or in a hotbed, but as good a way as any is to sow seed early outdoors, when the plants will come into flower about July first.

$S$. sinuala is a very pretty annual Statice easily grown from seed sown outdoors in May. It will be in full bloom by the middle of 


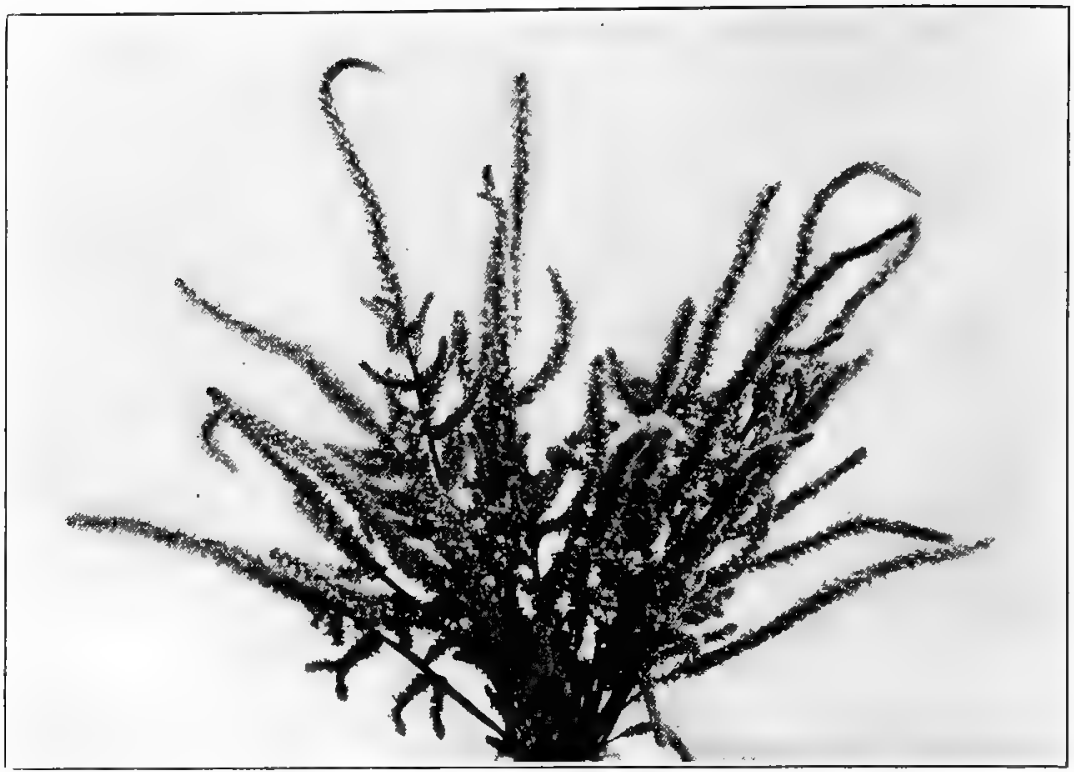

Fig. 270.-Statice Suworowir. Of the four or five annual Statices, none is more beautiful than this, which, when sown outdoors in May, will produce 10= to 12-in. spikes of rose-pink flowers, which go well with other blooms, especially in basket arrangements. If you use Summer flowers, plant a good-sized row of this variety in May and another a little later

July and has light blue flowers. S. sinuata candidissima is the white form. and while it is good, the blue is the more desirable.

\section{STEVIA SERRATA}

This is a small flower of great usefulness to the florist. It takes the place of Gypsophila during Winter and helps make any box of flowers you send out more beautiful. It is delightfully fragrant, comes on long stems, lasts a long time when cut and can be grown in a cool house. In fact, it does better in such than in a warm one. We have it with us from the time the midseason Pompon 'Mums are ready, up into February and even longer.

\section{Cultural Notes}

There is the single tall-growing variety which we have had always with us, a double form, and a dwarf one which, to my mind, is the best of all. If planted a little close it will grow plenty tall enough for all purposes, while the tall sorts, if at all crowded, will grow spindly and be hard to manage, the stems breaking if you are not exceedingly careful.

A few stock plants potted up and carried in a coldhouse will give you hundreds of cuttings if placed in a 50-deg, house by Febru- 
ary. You can take cuttings up to May, all of which will grow into flowering plants. They can go to the field in Summer and be benched about October first. Or you can carry them in pots up to July and bench them about the time the Carnations are housed. Still another way is to grow them in pots altogether and carry them in a frame during Summer; or in September pot up some of the plants in the field to be placed in a coldhouse and brought to warmer quarters as wanted during the Winter months. The plants can stand any temperature above 32 deg., but will be ruined if allowed to freeze.

With the dwarf double sort, pot culture is not very desirable. If you want the stock for cut flowers, the plants grow too short in pots. In order to have a long season of flowers, simply keep the plants in a low temperature and let them come along slowly.

\section{STOGKS}

In order to be at their best, Stocks must be grown under glass. In that way they make fine cut flowers for which the retail grower finds a ready sale from early Spring on up to Memorial Day.

They are also desirable for outdoors as Summer bloomers, when fine spikes are obtained. $\mathrm{Or}$ they are of value grown on in pots and to be had in bloom around Memorial Day. Many plants in $21 / 2$ s grown from seed sown in early March can be disposed of during the Spring months. Such plants for bedding or planting out are far superior to such as have to be moved with naked roots.

For Growing UNDER GLass

Of the many fine varieties, there is none better

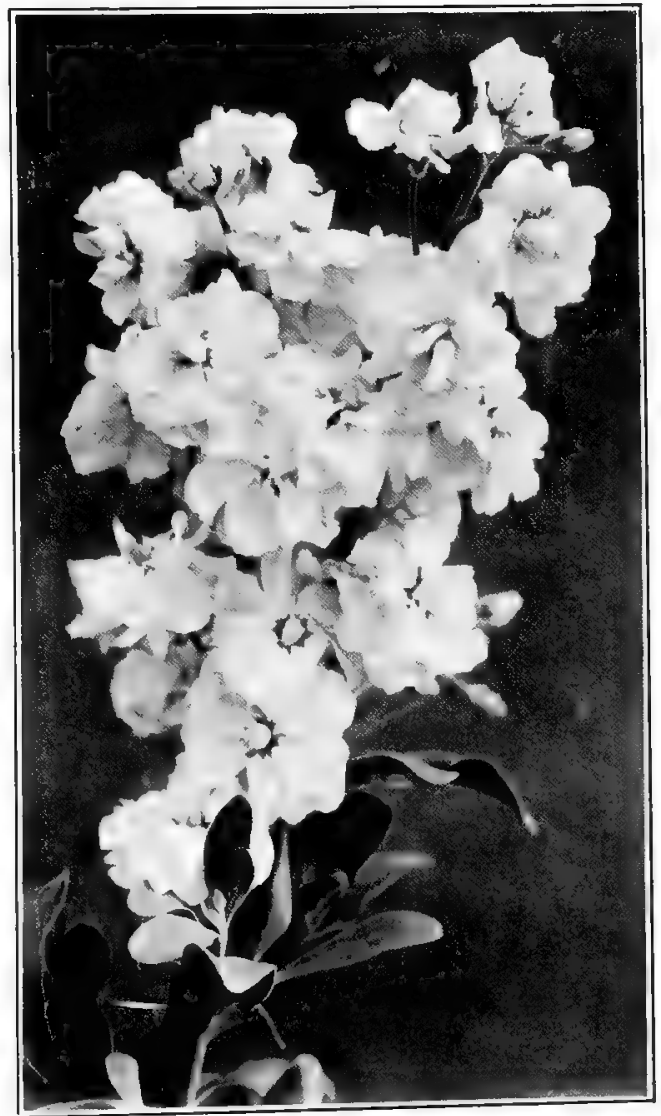

Fig. 271.-Stocks, Variety Beauty of Nice. This is good for both Summer-flowering outdoors and for early Spring cutting under glass 
than the Giant Early Brompton Stocks. These are the ones that will give the longest spikes. Among them we have Beauty of Nice, a beautiful soft pink, and to my mind, the only kind for the retail grower to grow who has only a limited space to devote to their culture. He should grow just one color in order to be able to cut several dozen spikes to fill an order with. Usually a customer doesn't want mixed flowers; he prefers one color or shade. You can use a soft pink for more purposes, perhaps, than any other color.

Mont Blanc is a fine white and Queen Alexandra the best light blue or soft lilac. For those who want a red shade, Crimson King is the one. Try to obtain a good strain of seed, such as comes from a specialist, and it will give you a good percentage of double flowers.

Sow in early August in flats, transplant into $21 / 2 \mathrm{~s}$ later and bench about the end of October, perhaps to follow early 'Mums. In that case it is well to mix a little clean soil with what is in the bench. Plant about $1 \mathrm{ft}$. apart and don't let the thermometer go above 48 or $50 \mathrm{deg}$. The plants can be pinched back once and should start to flower about March. It is always well to grow a few extra ones on in pots for replacing if necessary.

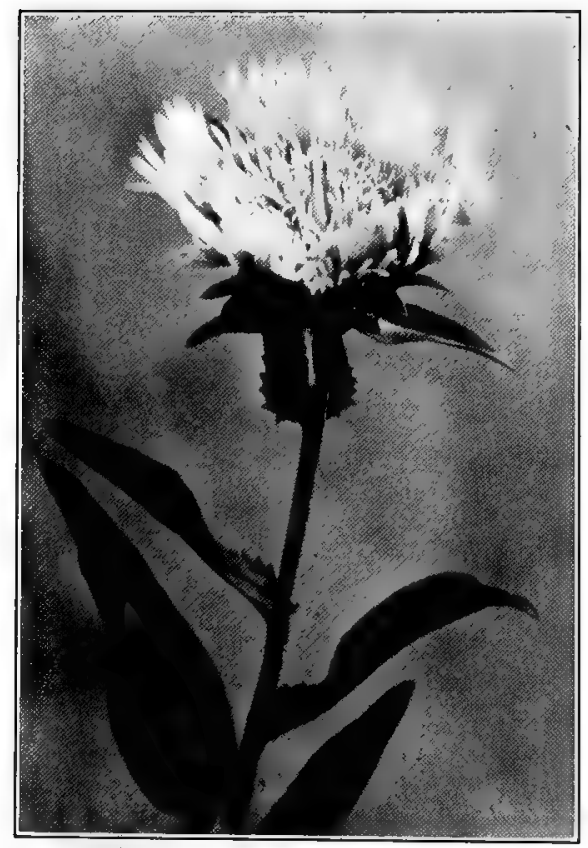

Fig. 272. Stokesia cyanea. A fine showy perennial coming into bloom in July, and a good keeper when cut. It is most effective when planted in groups along the edge of the hardy border
For a May crop, sow out in December and treat the plants the same way. Plants from seed of the Ten Weeks Stocks sown in February grown on in pots will make fine flowering stock for Memorial Day. But these, of course, won't have the same spikes as the others. There are always single flowering plants among your doubles, but even for these one can find use.

For those who retail what they grow, Stocks may also be considered as flowering pot plants. A plant in a 5- or 6in. pot with from five to seven flower spikes will sell quickly around Memorial Day. Sow seed in February and keep the plants shifted. Pinch them once when about 4 in. tall and grow on in a cool house. They like a stiff loam and good drainage. 


\section{STOKESIA GYANEA (GORNFLOWER ASTER)}

Stokesias are splendid perennials, perfectly hardy and producing on fair-sized stems double, Cornflower-shaped and Gornflowercolored blossoms from July up to time of frost. You want them less as a cut flower than as a good hardy plant to recommend to your customers. Stokesias are best grown from seed, and with the help of a greenhouse; they are best sown in February so as to have well established plants ready for the field in May.

\section{STRAWBERRY BUSH} See Euonymus americanus

\author{
SUMACH \\ See Rhus \\ SUNFLOWER \\ See Helianthus
}

\section{SWAINSONA}

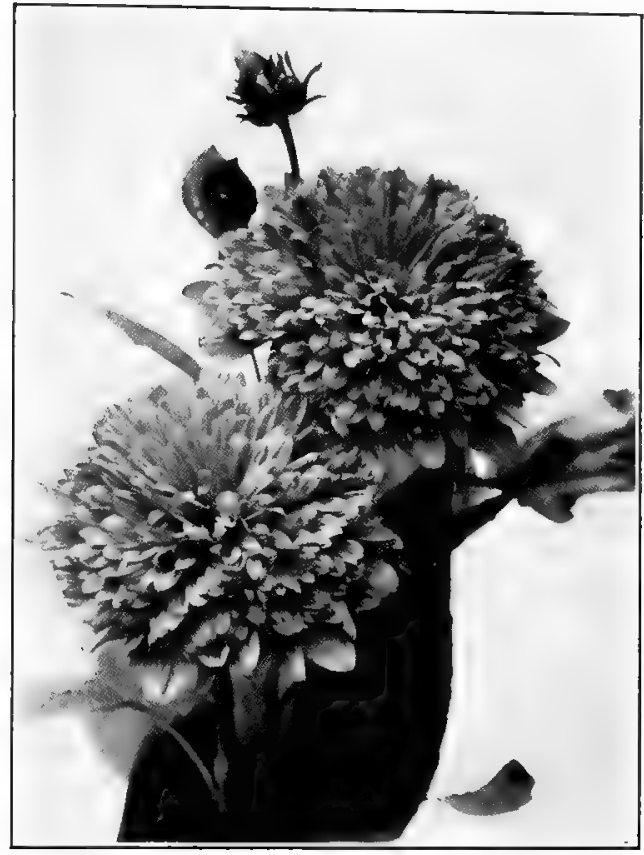

Fig. 273.-The Hardy Double Sunflower. When the Golden Glow (Rudbeckia) is past its best the hardy double Sunflowers take its place and make a fue showing in the perennial border

Swainsona makes a desirable cut flower for the florist and is valuable even though it doesn't flower during the Winter months. The plants can be grown and flowered in pots and the graceful, airy, white flowers with their soft foliage make excellent material for the wedding bouquet or the spray.

For best cultural results root softwood cuttings during February or March in good bottom heat and well-established 21/2-in. plants will be in bloom by July. Keep the plants shifted and pinched and allow plenty of headroom; overwinter in a 48-deg. house, and by July they will be a mass of flowers. Plants may be planted out on a solid bed and if kept pruned and taken care of will be good for three years or more.

The florist out in the country, in particular, will appreciate a few good specimens planted out, at the end of a Carnation house perhaps. The flowers, especially when on long stems, always come in handy for cutting no matter at what time of the year they are ready. 


\section{SWEET PEAS}

I CONSIDER Sweet Peas not only important florist flowers, but also flowers in which every retail grower should interest himself. There are today many fine sorts for both indoors and outdoors, and their popularity and adaptability for so many purposes make them extremely desirable. I don't know of any time of year when the florist cannot use well-grown Sweet Peas to good advantage, no matter what other flowers there may be in the market. The fact that Sweet Peas should be freshly cut in order to be at their best, is another inducement for those who care to grow on at least a part of their requirements.

\section{General Requirements}

While in many sections of the United States Sweet Peas do well outdoors, there are many more where they are not always a success. Like garden Peas they delight in cool weather. They also need plenty of sun and moist soil, but give the best of them a week or two of real hot July weather and they will soon show the effects of it. To really behold them at their best, especially some of the

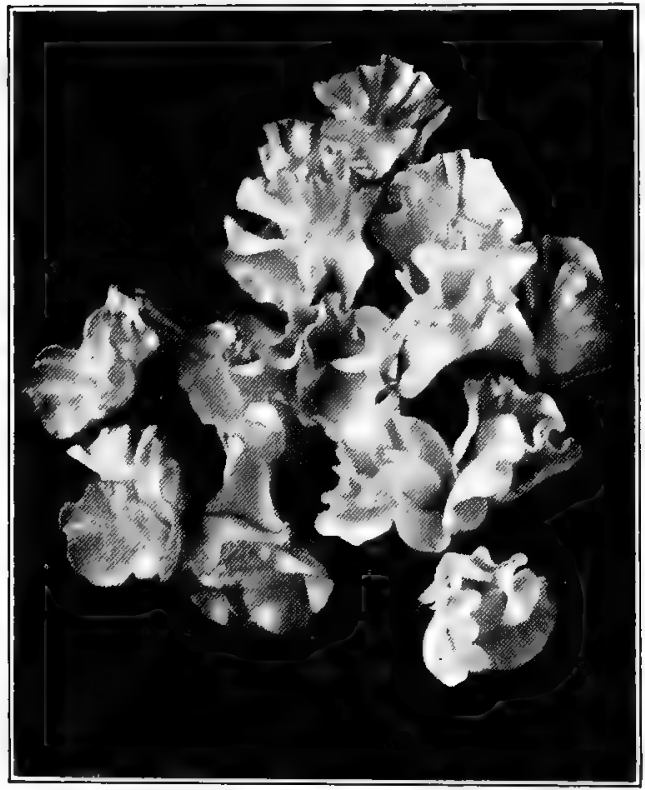

Fig. 274.-ORchid-Flowering Sweet Peas. Wonderful improvement has been made in Sweet Peas and still grander varieties are constantly being introduced, some of them especially well adapted for indoor flowering improved Spencer variety, they should be grown under glass, where, in early Spring, we can get them with perfectly developed flowers, and the effective long stems. Here; again, we frequently meet conditions common to many other flowers, namely, that with the everincreasing glass area devoted to their culture, the wholesale grower doesn't always find a paying market when everybody is shipping Sweet Peas, while the retail grower who has just enough plants to cut from to supply his regular trade sells all of them at a good price. Then, if special occasion arises, he can easily purchase what extra flowers he is in need of. 
If you have the space and the headroom, grow Sweet Peas, whether for Midwinter, for early or late Spring, or for early Summer; but don't attempt to have too many at the time when they are flowering in every garden, as they then hardly pay you what it costs to cut them. It is not that you shouldn't grow them outdoors, but there is more money in it for you if you let your glass help you get the flowers in at a time when they cannot be had outdoors. If you have no facilities for raising them under glass during the Winter months, at least start a good batch of plants during late February or early March to be planted out so they will flower outdoors in early June. This, in many localities, means flowers weeks ahead of those cut from plants sown in the open.

\section{Sweet Pea Gulture Under Glass}

The Sweet Pea specialist with houses arranged for the crop uses practically the same methods in sowing and cultivating as one would outdoors. Next comes the florist who perhaps makes Chrysanthemums in. solid beds the principal crop and follows them with a sowing of Sweet Peas for an early Spring crop. This same method is often followed, but on a smaller scale, by the retail grower.

You can grow Sweet Peas under glass as successfully on raised benches as in solid beds, but, in general, benches are better adapted for the early or so-called Christmas-flowering sorts. Solid beds are best for the later-flowering ones of which the roots can go down into the soil and develop greater resistance since they have to support from 6 to $8 \mathrm{ft}$. of growth in a temperature which may run up to $80 \mathrm{deg}$. and over on sunny Spring days. In growing for early Midwinter flowering, you are apt not to produce as heavy growth in a bench as in beds, and the roots being confined will also have a tendency to give earlier flowers. If one cannot devote a bench or part of one to the growing of Sweet Peas, they can be successfully flowered in narrow boxes, say 6 in. wide by 5 in. deep inside and any length desired - or even in 5-in. pots, allowing about four plants per pot. Another way open to the smaller grower is to plant a few seeds around the purlin supports in his Carnation bench. While this cannot be considered a benefit to the Carnations, yet Sweet Peas can be grown in this manner and made to pay by those who may not have any other place available.

\section{Peas for Early Flowering}

That the early varieties may be in flower around Christmas, seed should be sown during September. Even if a whole bench cannot be had it is as well to sow a few plants. Use expensive seed and if you have not decided just where they are to flower, sow from five to seven in each of several 4-in. pots, allowing all the space you can between them. If done the first week in September, place the 


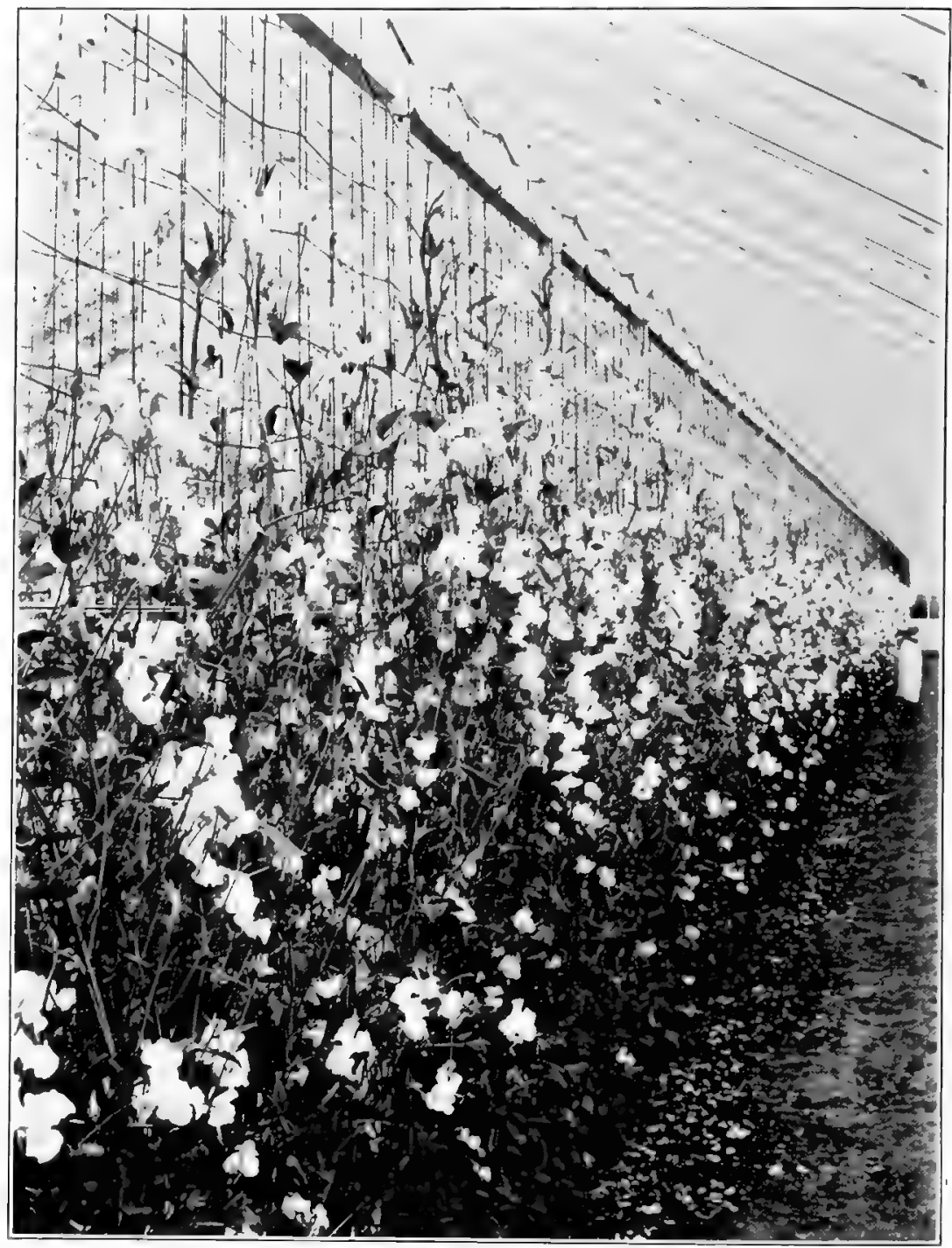

Fig. 275.-Sweet Peas Unden Glass. Without sufficient headroom you simply cannot grow Sweet Peas under glass. Proper support also is necessary to insure straight stems

pots after sowing out in a frame or, what is just as good, in a cool house. If you use white-seeded sorts it is always well to place a thin layer of sand below and on top of them, as some sorts among the whites don't germinate as freely as the colored ones. Later on thin your plants out to three of the strongest.

The sooner the plants are benched after the middle of October the better, for if not taken out of the pots before they become pot- 
bound, they are very apt to become stunted; this would result in the formation of buds that would never amount to anything. Bench the plants as they are in the pots about 6 in. apart, allowing 15 in. between the rows; the soil you use for the Carnations will do nicely, and the temperature also. You will want at least 7 or $8 \mathrm{ft}$. of headroom for the plants, also wires along the rows and near the glass, with heavy twine between as supports.

Another way is to plant on solid beds, $6 \mathrm{ft}$. or more in width in which two double rows can be planted. Fasten two heavy wires lengthwise over the bench, about $1 \mathrm{ft}$. from the outer edges and plant the double rows so as to have the wire in the center. By this method you may not obtain quite as early flowers, but the plants will stay in bloom much longer and keep on producing longer stems. You should have at least $8 \mathrm{ft}$. of headroom.

\section{Peas for February and Later Flowering}

Seed sown either in benches or beds to follow a crop of early or midseason Chirysanthemums will not of course give plants for Midwinter flowering, but by the end of February or the first part of March, extra fine flowers will be ready and they will keep on coming. Sowings of seed may be made all Winter for indoor flowering, even as late as March if you can spare the room.

If you sow in rows don't forget to thin out when the plants are about 3 in. high. Each plant should have at least 3 in. of space. If you crowd them, all you can expect is one stem running straight up; those that have room will branch out and make by far the best plants. The retail grower cannot make any mistake in making several sowings of seed in $3 \frac{1}{2}$-in. pots during the Winter months. If by the time the plants are ready to be planted out you have no place to put them, and have to throw them out, not much harm is done; and often, when some other crop happens to fail, the plants will come in handy and enable you to save a lot of time that you would have lost if you had to sow the seeds.

It is almost thirty years ago that the writer grew a bench of Sweet Peas under glass. They were Blanche Ferry and the seed was sown in pots in October and the plants set out in a bench emptied of W. H. Lincoln Chrysanthemums. They started to flower by the early part of May but didn't amount to much until the end of that month. While we haven't changed a great deal in matters of culture or treatment, for your very best Peas sow in north and south rows in a solid bed about the middle of January. Some of the newest sorts, in a bright, sunny house with good ventilation, after the bed is dug over deeply and given a light dose of well-decomposed manure 


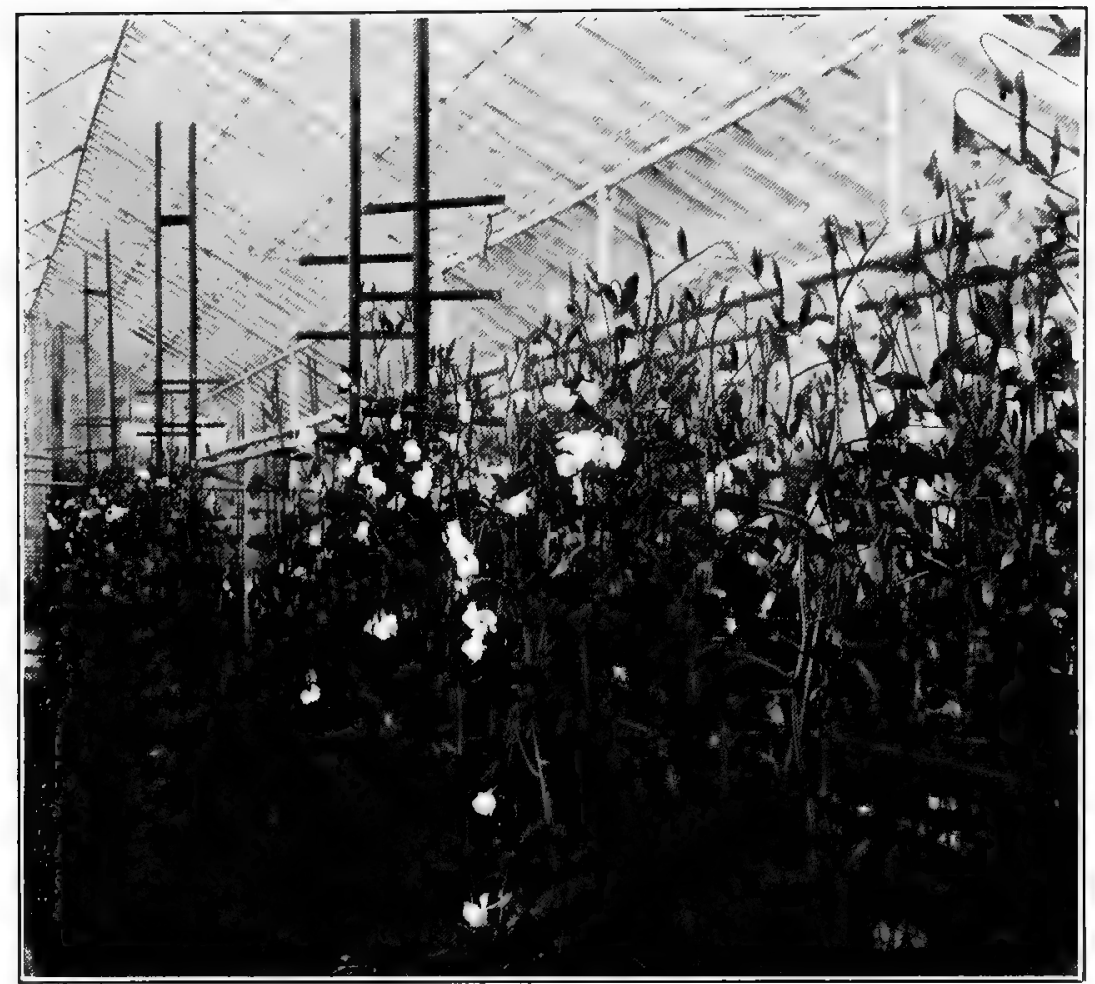

Fig. 276.-Another House of Sweet Peas. For early or Midwinter flowering you will be most successful with Sweet Peas planted in benches. For early Spring flowers most growers prefer solid beds, in which case the seed is sown after the beds are cleared of Ghrysanthemums

will make a great growth and start to flower in April with 18-in.-long stems and wonderful flowers. The crop will be good until the end of May and if you cannot sell every flower and make good money on them, then nothing will sell.

\section{For Early Outdoor Flowers}

You can beat the earliest outdoor-sown Sweet Peas by two weeks or more if you sow in pots by the end of February or the first of March. Allow about three plants to a 4-in. pot and if you need the room they can be put in a coldframe by the middle of April, hardened off a little, and planted out by the first of May. There are times when the heat in the houses will cause these plants to run up a little; instead of staking them, a better way is to cut them back, for they will soon break from below again. I have seen Sweet Peas planted out the last week in April and cut down by frost; but after 
a week or so of warm weather the plants broke again from below, soon made up for lost time, and flowered fully ten days earlier than the outdoor-sown plants.

\section{General Outdoor Gulture}

In sections where Sweet Peas do well outdoors it really doesn't make much difference how you sow them and what you do to them. It's the climate that makes them such wonderful masses of flowers, and when you haven't got the climatic conditions to assist you, no matter what you do nor how good the sorts you plant, they will prove a failure. What you can do to help things along is to plant early and in a deeply cultivated seed bed so the roots can get down into the cool soil. A mulch as soon as hot weather sets in also is of benefit. To sow thickly means waste of seed as well as weak growth-plants with just one stem and a few flowers on the very end of it.

Even supposing that you cannot always sell the cut flowers, or that they have short stems, if you use principally white, light pink and light lavender shades, they often prove useful, especially. for design work. Seed doesn't cost much, nor does a good-sized row take up much space, nor can it be said that every season is an unfavorable one for Sweet Peas. The florist who has use for flowers during the early Summer months should always include them in his list, if for no other reason than that with them on hand, when he wants a few blossoms he will know where to get them.

\section{SYMPHORIGARPOS (SNOWBERRY)}

The white Snowberry, because of its graceful hab $t$ and because in Fall and early Winter it is covered with white berries, is a very desirable shrub. Another good feature is the fact that it will do fairly well in shady places. The florist can also make use of the cut branches during Fall, for they will go well in baskets. If you have large wreaths to make up of brown Magnolia leaves, the foliage of the Snowberry with its white berries is just the thing to add; and if you have a wreath or cross on a base, you couldn't do better than to fill the entire base with it. In order to obtain the most berries or fruits and the most graceful growth, you must cut the plants back severely each Spring; this holds good even with the plants in the shrubbery border. If not pruned back well and cleaned of the old, hard wood inside, the plants soon will lose their beauty. $S$. orbiculatus vulgaris is the red form, better known as Coral Berry or Indian Currant. It is not nearly as showy as the Snowberry, yet it is valuable as a shrub. It, also, needs looking after with the shears each Spring. 


\section{SYRINGA (LILAG)}

\section{(See also Philadelphus)}

The Lilacs are favorites with everybody and in spite of all the many fine new sorts which have been introduced during the past thirty years, the old-fashioned, common Lilac is by most of us considered the best of all. It may bloom and remain in good shape for only one short week in the year, yet that one week of Lilacs means more to many people than twenty weeks of something else.

To have a good number of Lilac plants coming on is always a good investment for the retail grower in a country town. The plants cannot help but grow into money. They become, if given plenty of room, more valuable every year. There are always people who will not object to paying a high price for large specimens; they had rather pay that price and get an immediate effect than pay less and wait for results.

A Lilac ten or fifteen years old, which has been transplanted several times, can be moved with a ball of soil even when in full bloom; if kept watered, it will go on growing. As with the Spiræas,

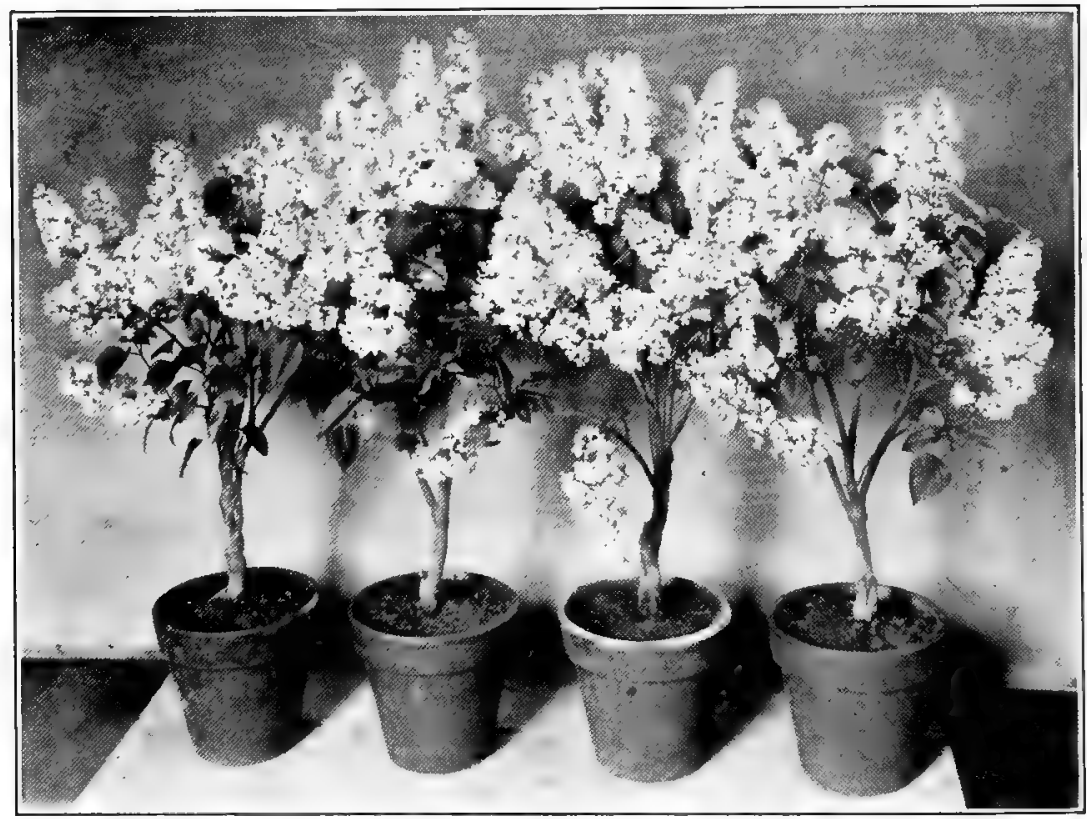

Fig. 277.-Lituacs in Pots. The forcing of Lilacs into bloom under glass is an easy matter and requires merely heat and water-that is, if you have to start with potgrown stock, such as the plants shown here 
so with the Lilacs: a good number planted out each year will soon develop into fine specimens and there should be no trouble in disposing of them. Not only should the common purple and the white sorts be carried, but also some of the other beautiful varieties which only have to be seen to be ordered. Among the latter none are perhaps better known than Charles $X$, a fine reddish deep purple; Marie Legray, one of the best large flowering whites; Louis Vanhouttei, deep red; and Emil Lemoine, double light purple. All of these Lilacs make slow headway while small; it takes years to obtain good specimens. But they are well worth waiting for. Grow some on for cut flowers, some for plants to be sold small as well as when large, and some for flowering under glass:

\section{LILACS FOR FORCING}

The best Lilacs for forcing are plants which have been grown in pots. This sort of handling results in a dwarfer growth and usually more flowering wood than you will find on plants grown in the open. To grow plants on in pots is beyond the retail grower. Not that he cannot do it, but such plants require constant care and attention and on a small scale it wouldn't pay. There are today in this country, men who are getting interested in growing, for a couple of years in pots, Lilacs suitable for forcing. In time, this will prove profitable, not only with Lilacs, but with Deutzias, Spiræas, Forsythias, flowering Plums and Crabs - in fact, with almost any of the early Summer-flowering shrubs. Why not? Also it will pay the florist to use this stock for forcing. He cannot have too much of a variety. There is a lot of labor attached to producing good-sized plants in that way, even though most of them have had field culture for the first two or three years, and it is this fact which, more than anything else, prevents nurserymen from going into it. Since the War, there hasn't been an oversupply of anything in the nursery line; the scarcity and high cost of labor have constantly been felt, while there appears a decided increase in the demand. As long as this keeps on, the nurseryman cannot very well be expected to bother about devoting his time to pot plants for the florist's use.

\section{Pot-grown and Field-grown Stock}

A pot grown Lilac is preferable for forcing not only because it has a shorter growth and more flowering buds, but also because these buds respond more freely to forcing. The plants are ripened off better and earlier than those planted out. By the time the leaves drop in late Fall the flowering buds of a Lilac are all formed the same as in a Hydrangea. This holds good not only with the ones in pots, but with the ones in the field as well.

If you want to grow on plants best suited for forcing out in the open, the stiffer the soil the better. Such soil usually has a ten- 


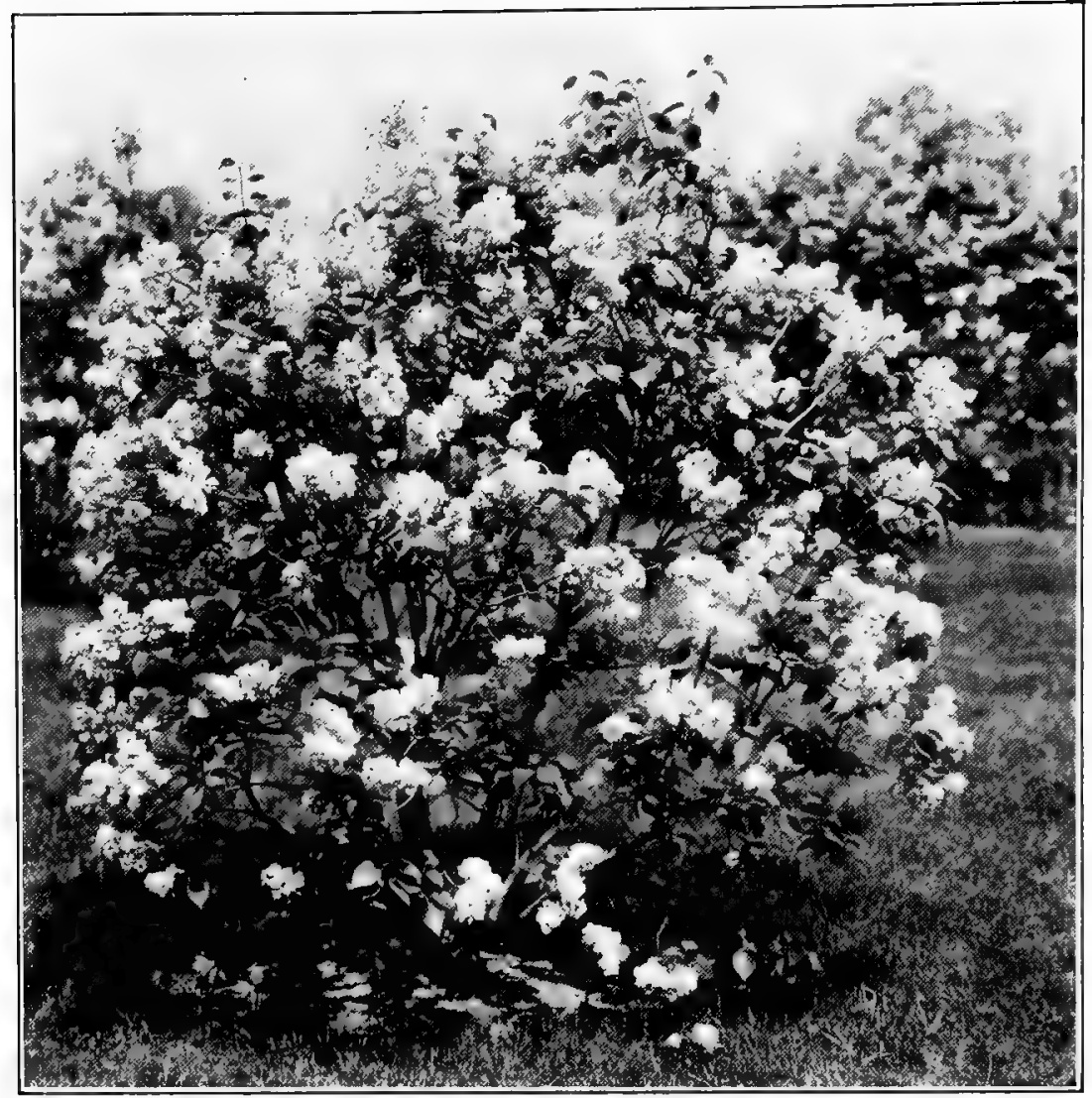

Fig. 278.-A Specimen Outdoon Lilac. A Lilac hedge in bloom is beautiful, but no more so than a single specimen if given plenty of space for its proper development

dency to produce a short, stocky growth which makes the most flowering wood. You can lift plants in late Fall, leaving as much of a ball on as you can. If not too large, pot them up; otherwise heel them in a frame and keep watered.

The plants can be brought in for forcing about January. Place them in a hot, dark place and not only keep them watered, but also spray them three or four times each day with warm water. They can stand from 70 to $80 \mathrm{deg}$. or even more, if you keep the wood moist. Later batches when brought in will require less forcing.

Pot-grown Lilacs can be handled quite differently and don't need a pitch dark place. They also are ideal Easter plants, for which date they can be allowed to come along slowly in a 55-deg. house from one month before Easter on. Of course a great deal depends on weather conditions and you can increase the temperature if you find the plants slow. Plants which are left over after Easter 
can be cut back and replanted in the nursery where in a couple of years they will again develop into salable stock.

\section{TAGETES (MARIGOLD)}

The tall-growing Marigolds are showy Summer flowers but not of much use to the florist except for decorative work, where a bold effect is wanted. The dwarf sorts may be considered for bordering. However, you should always sow out a few rows in a frame in April; sqme of your customers are bound to want a few of them for planting out. Tagetes signata pumila is one of the finest of all dwarf border plants and will do well even in partly shaded positions. It has fine, fern-like leaves and single, deep yellow flowers and stays in bloom all Summer. You can grow a few plants on in pots or sow seed outdoòrs.

\section{TAMARIX}

As yet the Tamarixes are strangers to most florists. They may have heard the name but that is about all, and the majority of them keep on buying Asparagus Sprengeri throughout the Summer when a row of Tamarix $50 \mathrm{ft}$. long would furnish all Summer long the finest kind of greens. This is not to say that it would answer for all purposes for which Asparagus can be used. But this much is certain, that a row of Tamarix would pay as well if not better than anything else in the garden.

There are several varieties of Tamarix and all are good, as they have the same fine feathery, Asparagus-like foliage on graceful stems. While they are beautiful when in bloom, it is the green we can cut from the plants which appeals to us most. They are classed among the shrubs and will grow $10 \mathrm{ft}$. and over. In some localities they are not quite hardy and will freeze down quite a way. That, however, doesn't hurt in the least, for it is the young growth you want. The branches when cut should be placed deep in water and kept for a day in a cool, dark place. After that use them the same as Asparagus.

The out of town florist who can help himself can get along nicely with this green during the Summer months for almost every occasion. Plenty of Tamarix and Gypsophila elegans means much during July, August and September, and where is the florist in the country who cannot have these two?

Your nurseryman will supply you with 2- or 3-ft. stock. Cut the plants back to within a few inches of the ground and plant them about $3 \mathrm{ft}$. apart. If this is done in April, you will cut the first green in early July and keep it up all Summer. You will get twice as much the next year. What counts today is to be able to grow on whatever can be grown on your own place and that does not require much atten- 


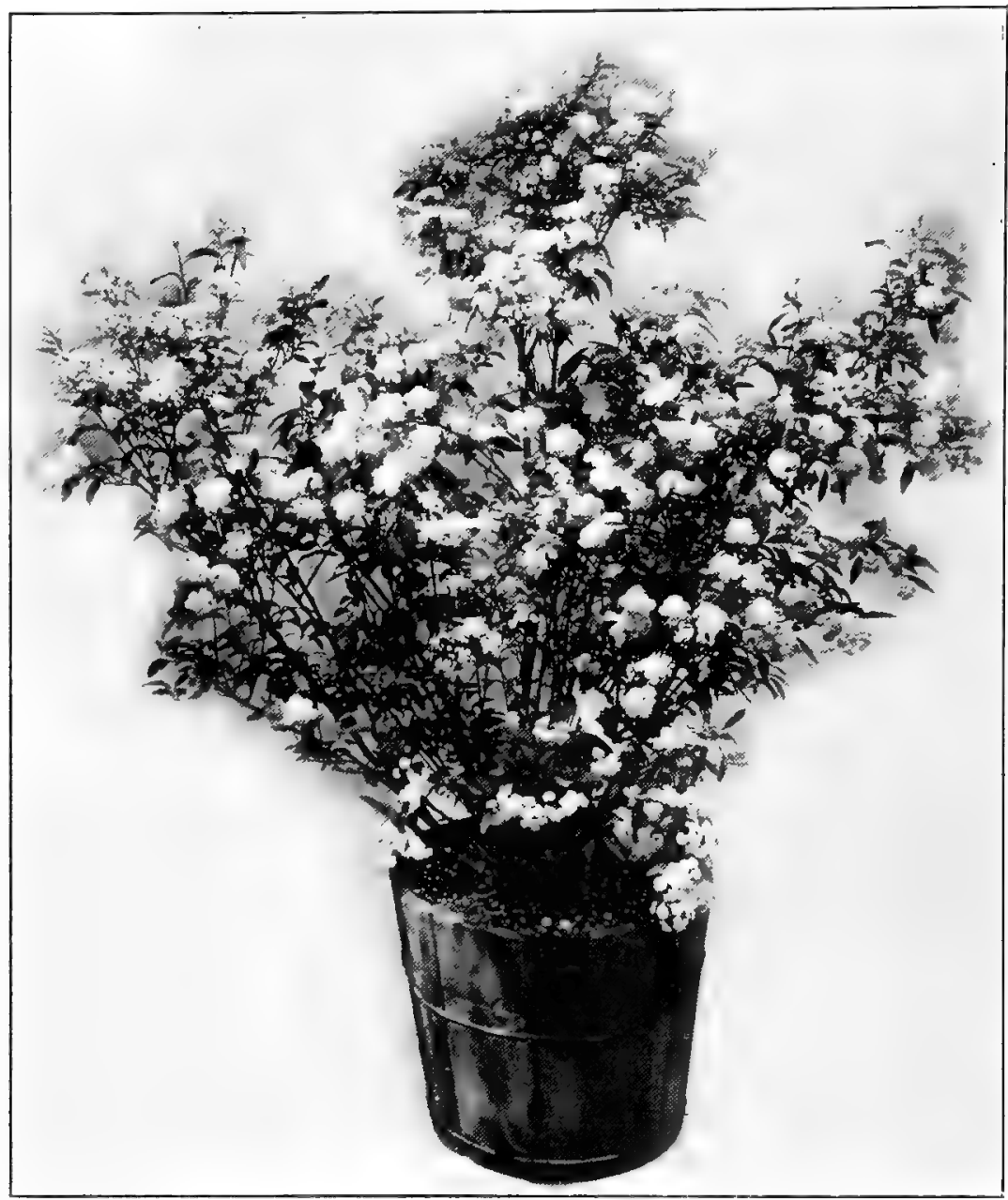

Fig. 279. - SPIRAa ReEvesir FLORE PLENO FORCED IN TUB. As with this variety so with almost any of the other shrubby Spiræas such as $S$. Vanhouteii, $S$. prunifolia $S$. Thunbergii and others; they can all be potted up in late Fall, kept cool until early February, then slowly forced into bloom. (See page 523.)

tion. You or your help may prefer to use A. Sprengeri for green, but if you have to purchase it, whereas you can have a few plants of Tamarix to cut from, the green of which will answer every bit as well, the real question is, Which will mean the most money for you? 


\section{THALICTRUM DIPTEROCARPUM (MEADOW RUE)}

Among the several dozen species of Thalictrum there are but few of value to the florist. However, T. dipterocarpum has become quite a favorite of late years. It forms a good companion for $\mathrm{Heu}$ cheria sanguinea, growing from 3 to $4 \mathrm{ft}$. in height, with Columbinelike foliage. Its tender stems are full of light lavender flowers with yellow anthers. In a cut state it will last four to five days and groups of it planted in the perennial border make a fine showing during Midsummer. The plant is quite hardy and is easily increased through division in early September.

\section{THUNBERGIA ALATA (BLACK-EYED SUSAN)}

Always sow in February a little seed of Thunbergia alata. The plants make showy little climbers and are good for the edge of a porch box or hanging basket. Planted with Cobæas they cover the lower part of those plants and produce their single white, yellow, or orange flowers with dark centers all Summer.

While the species is as old as the hills, when your customers see the plants in your houses in Spring, many of them will want to know what they are, and the name Black-Eyed Susan suits them splendidly.

\section{THUYA (ARBORVITÆ)}

The Arborvitæ is one of the conifers, and, like the Norway Spruce, is used a great deal in planting where a moderate priced evergreen is wanted. There are a number of beautiful varieties, but the American Arborvitæ or White Cedar is more used than any other. The plants are useful whether small or large. By planting out a number each year, you will be able to dig stock whenever you have to fill an order for window boxes, or when a patron wants a couple of specimens planted at the gate or the front entrance, or when a call comes in to fill a few tubs.

All this doesn't imply that you cannot purchase well-grown plants from your nurseryman, maybe fully as reasonably if not more cheaply than what it will cost you to grow them on yourself. But the thing is to have a few on your own grounds, especially if you are not located near a nursery. If you will look through a catalog you will find quite a number of varieties, and if you have the room, you cannot make a better investment than to purchase a few of them. With just a little care at the start until the plants get a foothold, you will in a few years have some showy specimens-which your patrons won't let you keep very long.

\section{TORENIA FOURNIERI}

In former years Torenias used to be extensively used for bedding. Solid beds or long borders would provide masses of blue all Sum- 
mer, but now we hardly ever see them except in public parks or on large, private estates. However, if you want to show people something a little different from Geraniums and Salvias, sow seed in a 55-deg. house in February, and grow the plants on in pots. A mild hotbed will just suit them about March. They will be in $31 / 2$ s by May and in full bloom by the time you fill the outdoor beds.

\section{TRADESGANTIA (WANDERING JEW)}

Wandering Jew is considered so common by many florists that no attention is paid to it. Yet the retail grower can make it a most useful plant, especially the variegated forms. The tops of plants about 4 in. long, pinched off and potted up four or five of them to a $31 / 2$-in. pot about October first, will, in a 55-deg. house, make fine material to use during December in filling made-up baskets, such as you prepare for the holidays.

I don't say that everybody will want them in an arrangement but there are many who don't object in the least. A good way is to keep on starting a few plants all through the year so as to always

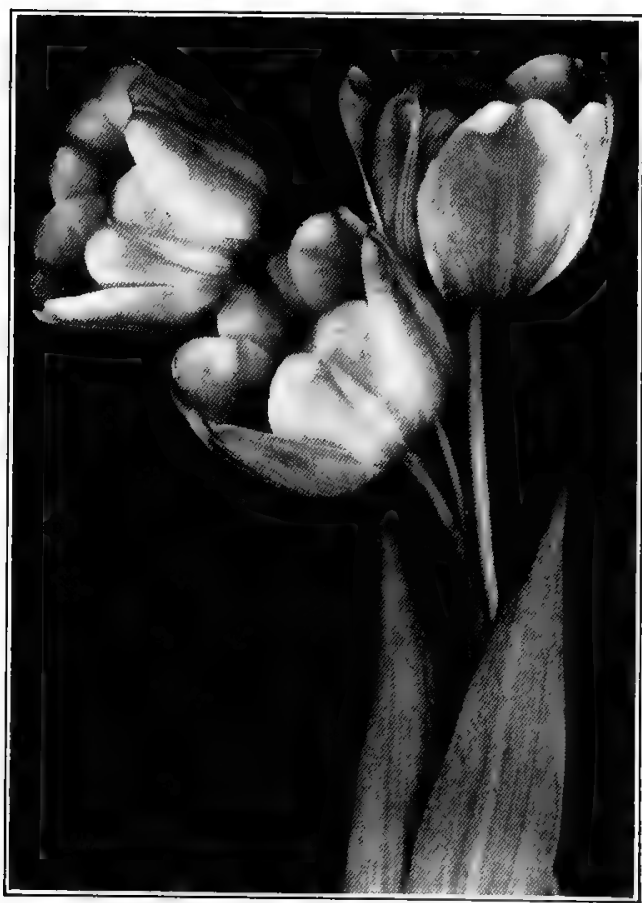

Fig. 280.-Darwin Tulips. As soon as the Darwins begin to appear in February or early March it becomes hard to - sell the early sorts. But this class is equally as valuable for outdoor as for indoor planting have bushy $31 / 2^{-}$and 4 -in. plants on hand. Placed along the edge of the bench in the show house, they always look attractive, and frequently they can be made use of in filling indoor window boxes.

You can also make up very showy hanging baskets with them. They won't last very long, but that doesn't matter, for there are always occasions when an inexpensive basket is wanted just to make an attractive show for a short time.

\section{TRITOMA UVARIA (RED-HOT POKER PLANT)}

These Tritomas are used extensively by the florist during the Fall months for decorating their show windows where they always attract at- 
tention because of their bright orange and yellow colors. Also when planted in groups in the hardy border they are hard to beat, flowering as they do so late in the season.

There are today quite a number of hybrids and among them some great improvements over $T$. Uvaria. Seed sown in February with a little bottom heat will germinate quickly and most of the seedlings, if planted out in early May, will flower the first season. All will present a great sight the second Summer. Protect the plants well and they will come through even a severe Winter.

\section{TRUMPET FLOWER See Bignonia}

\section{TUBEROSE (POLIANTHES TUBEROSA)}

Tuberoses used to be grown by the florist by the thousands, both indoors and outdoors. But that was years ago and other things without quite so strong an odor have taken their place. There is still call for them however, for planting in among the oldfashioned flowers of the border, and a good way to meet this demand is to have your seed house supply you with a few bulbs in early March and start them in flats on the return pipes the same as you would Cannas. Later on pot them up and be able to show plants ready to flower by the middle of May.

\section{Mexican Single Tuberoses}

You will find the so-called single Mexican Tuberoses desirable Summer bloomers. While a few will be sufficient, there are always some patrons who prefer them to other flowers. When planted in masses among perennials, these single Tuberoses are very showy. You may well think about planting them near a group of Iris or Peonies, in such a way that they will take the place of the latter when they are out of flower.

\section{TULIPS}

TULIPS, Narcissi and Hyacinths are the three leaders among bulb stock forced in greenhouses during the Winter months. With each year the Tulips in particular become more and more popular. This is due in part to the Darwins, which are today such great favorites with the public. Yet there are many thousands who are not yet acquainted with them, and endless other such thoụsands will come along each year.

To my mind the average retail grower doesn't make the most of the Tulips. It is true that there are men today who force Darwins extensively for their cut flower trade, but they sell enough bulbs retail in the Fall to pay for every bulb they force. Ever so many more Tulips, both early and late-of the Darwin, Cottage and Breeder varieties-could be sold if we would push them the way 


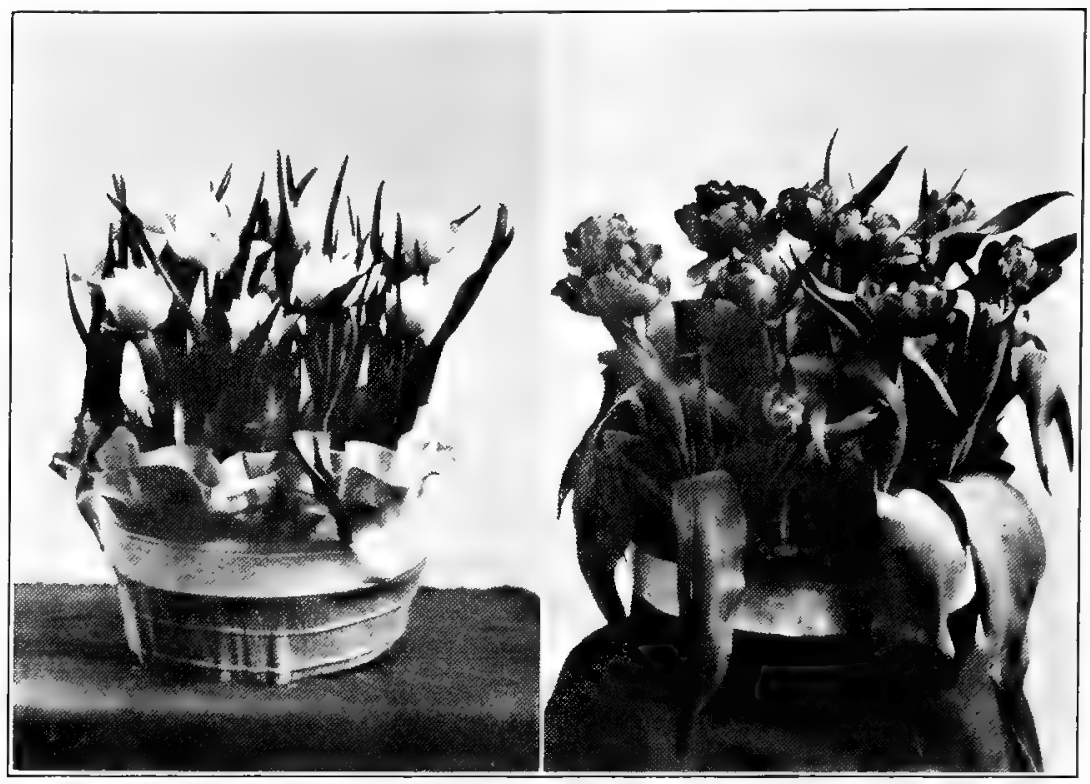

Fig. 281.-Two Goon Pans of TuliPs. Left, Murillos, of which seven or eight make a showy, inexpensive Easter plant. Grow cool to get short, stiff stems and good coloring. Right, Couronne d'Or, a fine double yellow. Best grown rather slowly in 8- to 10-in. pots, then kept in a cool place for a few days before Easter

they deserve to be pushed. There isn't a lover of flowers with a little 'garden patch who wouldn't prove ready and willing to plant a few Tulips for Spring flowering, if we went after him. Aside from all this, Tulips can be made to pay good profits when grown merely for their cut flowers.

\section{Handling Tulips Under Glass}

Their treatment is almost the same as that of Narcissi, except that Narcissi can be kept in flats or pans underneath a bench in a coldhouse, while Tulips, in order to give good results, should go outdoors where frost won't hurt any of them. Nothing but wellrooted stock should be brought in for forcing. If a flat or pan to be forced isn't thoroughly rooted or potbound don't attempt to bring it into bloom, for nothing but short stems and crippled flowers will. result.

For early forcing such varieties as La Reine for white; Proserpine for pink; and Yellow Prince are among the best. And they will not only do finely for early forcing, but are good sorts to have right up to March when, as the Darwins begin to appear, it becomes hard to sell them here. As with the Narcissi, you should figure out what 
number you can use each week from early January on up to the middle of March, and then plant and force accordingly.

Among the red, and red and yellow, early sorts, we have Belle Alliance and Keizerkroon. The double Tulips are the best for pans and are among the most showy and best selling Easter plants. Murillo, the double light pink; is one of the great favorites, and is not only fine for pans, but is fully as good for cutting; When well done it will almost resemble a Peony. So will Couronne d'Or, that splendid bronze yellow, and so will Salvator Rosa.

In Darwin varrieties there is a long list of fine sorts. One of the best is Rev. H. Ewbank which, because of its heautiful heliotropelilac color, is quite different from any other Darwin.

Clara Butt; "salmon; Gretchen, soft blush; . Massachusetts, bright pink; Pride of Haarlem, carmine rose; White Queen, cream white; and Baronne de la.'Tonnaye, another bright pink, are all well known and are equally. good for outdoor planting.

\section{at May-feowering or CotTage Tulips}

These beautiful Tulips are especially fine for outdoor planting and should be more grown by florists. Their large flowers, long

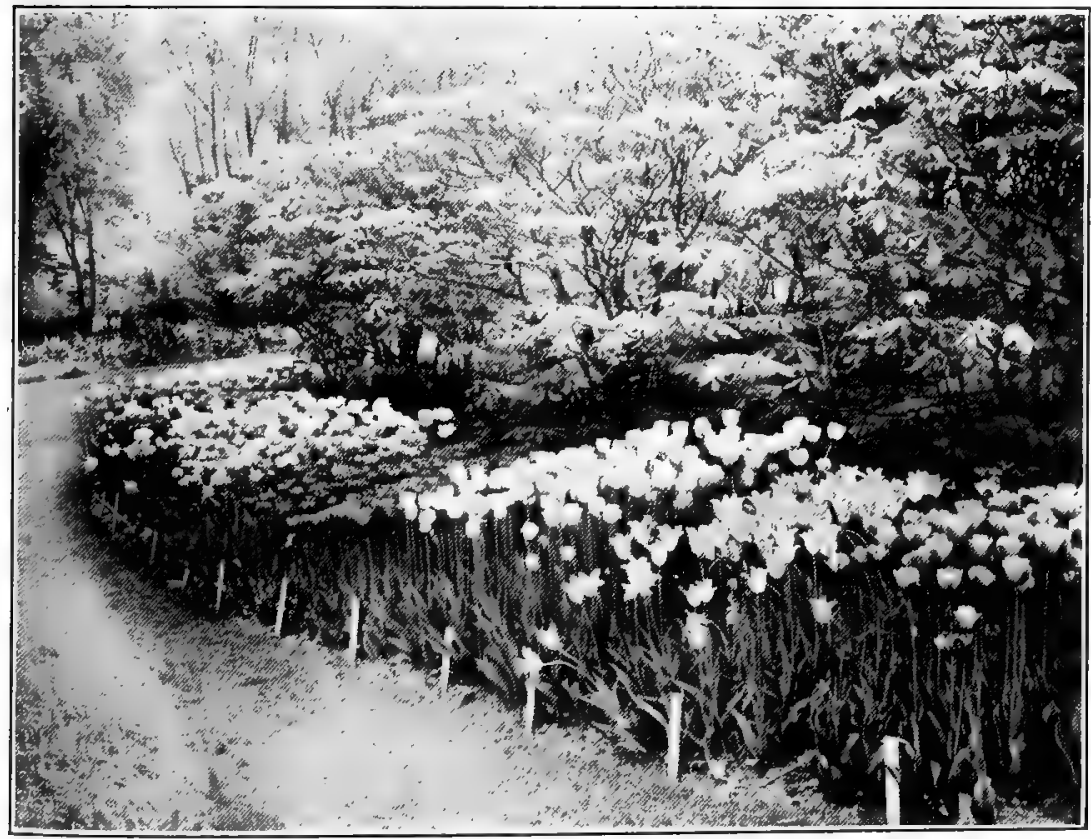

Fig. 282.-TuIPS IN VARUETY. It isn't a bad idea for the florist interested in outdoor Tulips, especially the Darwin and Cottage sorts, to study their possibilities. This he can do by planting a few of each available variety and labeling them, as shown here 
stems, good keeping qualities and fine colors make them ideal cut flowers. Among the many good ones the following are just a few of special merit: Gesneriana spathulata, brilliant scarlet; $G$. lutea rich golden yellow; G. Orange Globe, a fine orange; and Bouton d'Or, a clear yellow.

If you have occasion to recommend late-flowering Tulips to be planted in clumps in the hardy border, include some of these.

\section{Parrot Tulips}

This is another fine class of Tulips for border planting, most effective when planted in clumps of from twenty to thirty bulbs each. Among the most showy we have Cramoisie Brilliant, a scarlet red; Gloriosa, yellow and red; Perfecta, spotted; and Margraaf, orange.

\section{Bizards and Byblooms}

While these Tulips are not so desirable as the Darwin and Cottage varieties for cutting, they are excellent for border planting and come into bloom as late as any we have. Those who care especially for red, orange, and brown shades should plant these. They are also desirable where a permanent effect is wanted.

\section{UMBRELLA PLANT}

See Cyperus

\section{VALERIANA OFFIGINALIS (HARDY GARDEN HELIO- TROPE)}

The Valerianas are perennials easily grown from seed. If you sow in February under glass, you will get a few flowers the first Summer, but it is in the following July that the plants will be loaded with long stems and heavy heads of light rose-colored flowers with a Heliotrope fragrance. They can be used as cut flowers but every one of your patrons having a hardy border will want a few plants. The name alone will appeal to them.

\section{VERBENA}

Verbenas are great bedders and will bloom all Summer. Some excellent strains are grown from seed and they also are easily increased through cuttings, but the average florist doesn't use enough of them to justify carrying stock plants through the Winter months.

In order to have, by the middle of May, heavy 31/2- and 4-in. pot plants with four to six flowers and as many buds, sow seed in early February and grow in a cool house; pinch several times and keep shifted. There is but little call for two-inch stock which used to be all the go in years gone by. Your customers want more than just one stem with a little flower head on top. They had rather pay a quarter or more for a bushy specimen, and to grow such stock 
takes time. Also you cannot do it in a hothouse. Grow less of them, but grow the best you can and grow them as well as you know how -and there will be more money in it.

\section{VERONICA (SPEEDWELL)}

The Veronicas, of which there are half a dozen or so varieties, are all fine perennials, producing good cut flowers besides. With their graceful spikes of white, lavender, and blue flowers, they are most attractive when in groups. The taller growing sorts should be staked. Most of the Veronicas do best when divided each Fall and transplanted, but all of them will produce seed and can be sown under glass to be planted out in May.

\section{VIBURNUM}

There are a number of beautiful Viburnums which grow into large specimens. Some have most showy flowers in early Summer that are followed, as is the case with V. Opulus, the Highbush Cranberry, by clusters of crimson-red berries in Fall. The best known is $V$. Opulis sterilis, the common Snowball, while the one with the best foliage is $V$. plicatum, or the Japanese Snowball. The latter is a mass of white flowers in Spring and has large Weigela-like leaves, purplish tinted.

Be sure to include some of the Viburnums in your list of desirable shrubs.

\section{VINCA (MYRTLE, OR PERIWINKLE)}

While we see most of the hardy Myrtle (Vinca minor) in the cemeteries, there is plenty of good use for it on the home grounds. It will thrive and cover the surface where there is hardly enough sun for other things; it makes an ideal border; it can be used along the edge of the water garden or in the rockery; and each Spring and Fall we have customers asking for a few plants to be set out on graves. So it is well to have a stock of it on hand, especially in view of the small amount of care the plants require.

\section{Vinca major variegata (The Variegated Vincas)}

The variegated as well as the green Vincas that we use for porch boxes, vases and hanging baskets, are plants of which the retail grower hardly ever has enough during the Spring months. And that isn't all. By the time he is sold out, with the season not nearly over, he often finds that the hardest thing to obtain is good Vincas. No matter how fine your Geraniums and the other stock you have for filling porch boxes, if there is a lack of vines along the edge or if the Vincas you have there are too short, there usually is trouble and dissatisfaction. 


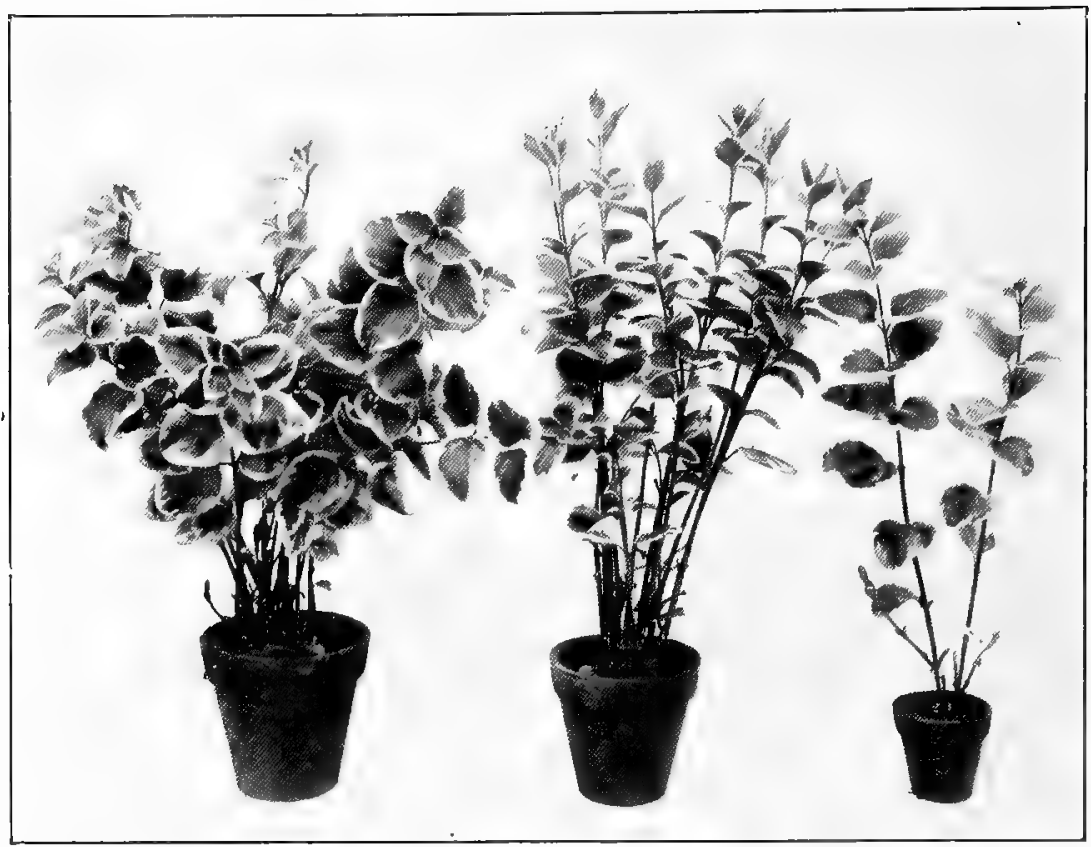

Fig. 283.-VARTEGated'VINCA. This makes one of the best trailing plants for window and porch boxes and hanging baskets. The larger the plants and the smaller the pots they are in, the more useful they will prove

\section{How to Grow Vincas}

You can root Vincas at any time of the year when cuttings that are not too soft can be had. This usually is during. Fall or Midwinter. Three or four eyes is all you want and these cuttings don't need to consist of end tips. If you root them during Winter, carry the little plants along in small pots up to April, when they can be planted out in the field and perhaps pinched back a couple of times. By October lift the plants, cut them back to about four inches, divide the heavy ones and pot up into $3 \mathrm{~s}$ or take the clumps or plants and bring them into a coldhouse where they can be planted closely in deep flats and kept moist up to January. Or the plants can be potted up into $4 \mathrm{~s}$ as they are and packed in on a bench.

Just what you do with the field plants up to January doesn't make much difference so long as you don't place them in too warm a house or let them suffer for want of water. A period of rest does them good. One of the most successful men I know brings his plants, after they are cut back, into a 'Mum house and plants them closely on a solid bed. By January they are divided into clumps just large enough to go into 31/2-in. pots. A rich, well-manured "soil is used and, by the way, old Rose bench soil or such as was used for 
'Mums is just the thing; add a little bonemeal to it, and it will come in handy again later on. The plants are placed in a Carnation house temperature up to the early part of March, when they go to a Rose house after having had a shift into $4 \mathrm{~s}$. They may not need a shift just at that time, but this move saves handling later on.

\section{The Best House for Vincas}

Along the edge of the Rose benches is the ideal place for Vincas from the middle of March on. The plants here will make a rank growth and if kept wet enough and given a dose of liquid cow manure every two or three weeks after the plants are potbound, they will develop those desirable thick, heavy, large leaves.

The next best place, if a Rose house can't be had, is the Carnation house. Good results can be had here, only they take a little longer. Many growers prefer to pot up their field-grown stock in Fall, claiming that they get better results and that the plants have a better chance to start root growth. That may be so, but what counts most are the months of February, March and April. It is during these months that the plants make their grow th. You cannot grow a good Vinca on a dry bench or in a 40-deg. house during Spring You must supply heat, moisture and good soil and then some more moisture if you want fat vines. Nothing is more pitiful than a starved Vinca.

There are florists who carry their plants in 31/2-in. pots and plunge the pots into the soil of the Rose or Carnation bench. The roots of the plants will in time grow through the bottom of the pots and feed in the bench. This, of course, will result in wonderful growth, but if you ever received such plants and used them in boxes, you know what happened. No matter how much water such plants get they will go back, for the reason that all of their live roots were cut off when the pot was taken out of the soil. That is a mighty poor way to do things.

Even the florist with cool houses only can grow on at least a part of his requirements, but the plants may not be at their best much before the early part of June. In that case it is best to purchase the stock needed for filling early orders. Usually there is no trouble in obtaining all the Vincas wanted up to Memorial Day. With enough orders ahead one is justified in reserving his own stock to draw on for late use and in buying to fill early orders.

\section{Vinca ROSEA}

If you want to plant a border or formal bed with something that will be a mass of bloom from May until November, plant Vinca rosea or $V$. alba. The individual flowers don't amount to much, but there are so many of them on each plant that they make up for it. In order to have plants in $31 / 2 \mathrm{~s}$ well branched 
and in bloom by the middle of May, you should sow seed in December or early January. Make use of bottom heat and carry the young stock in a house of no less than $55 \mathrm{deg}$.

\section{VIOLA CORNUTA (TUFTED PANSIES)}

These Violas, to which group the Pansies belong, while of not as great importance as the latter, are nevertheless desirable bedding plants and worthy of more attention on the part of the florists.

They are especially desirable when a mass effect is wanted, and they can be planted in partial shade. I have seen them a mass of bloom all Summer and the varieties, Blue and White Perfection are among the best for solid bedding and for use in connection with late yellow or red Tulips as a border or in between the plants themselves. Viola cornuta lutea splendens with its sweet-scented, yellow flowers, makes a great showing. Again, you can use these Violas for groups along the hardy border or in places a little too shady for the large-flowering Pansies.

In cultural needs, they don't differ much from your other Pansies. Sow during Summer outdoors, transplant, and if you overwinter them in the open, give just a little protection.

\section{VIOLETS}

In order to grow Violets for the wholesale market, you must, first of all, be located in a section where they will do well. The next thing is to do nothing else but grow them. And, last, but not least, you must make them pay. The writer at one time grew many thousands of the still popular Marie Louise in frames for the New York market. That was in the ' 80 's, and there was at that time as much money in growing them as in almost anything else in the flower line-and less expense. We fought leaf spot then, as we do today and made money one year and none the next-also the same as we do today. To my mind, the retail grower will hardly find time to grow Marie Louise successfully if he has just a bench of plants. He may do it for a year or two, but there are very few who make it pay in the long run. What will pay him, however, as long as he has to have Violets, is to grow Princess of Wales, the single, deep blue variety of delightful fragrance. While in cultural treatment this Violet doesn't differ a great deal from Marie Louise, it will do and pay with half as much care.

If you plant small stock out in the field, keep the plants cultivated during the Summer months and the runners cut off. From September on up to the end of October you can move the plants indoors to a cool house and either plant them on a solid bed or, what is even better, on a bench. You don't want plants as big as a bushel basket. I rather prefer those of medium size, allowing about one foot of space between them in the rows. The plants should start 


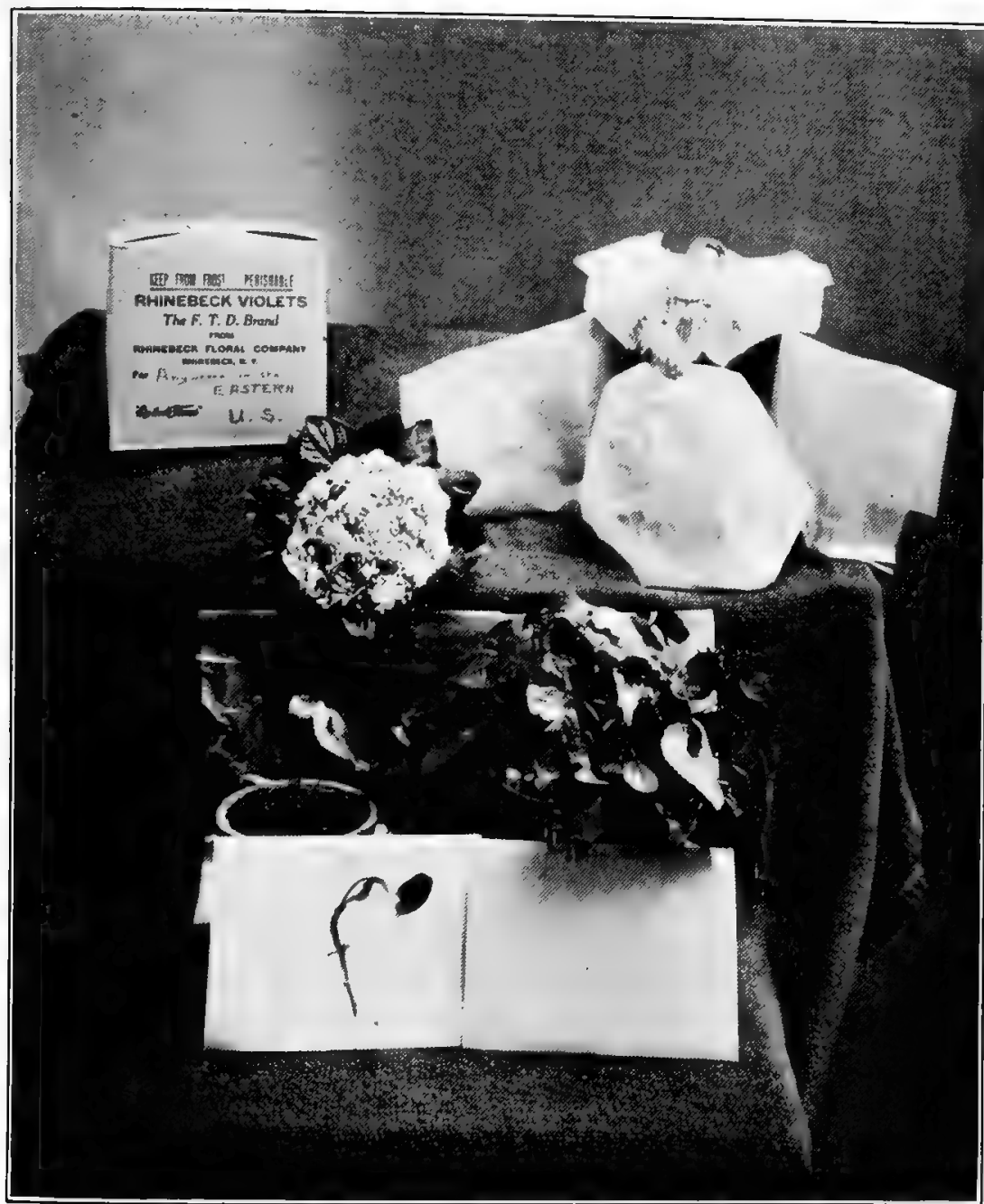

Fig. 284.-Five Stages in Gommeranal Violet Growing. Left, at bottom; typical Violet cutting ready to put in sand, about April 15 th. Above it, young plant when shifted from cutting bed, about July Ist. Right, good, healthy plant ready to pick from, about Oclober 1st. Above, finished bunch of Violets, method of wrapping and packing, and shipping box. (Courtesy Nelson Coon, Rhinebeck, N.Y.)

to flower soon after they are housed and if kept in a 40- to 45-deg. house. will keep it up more or less all Winter. Keep the runners and all spotted or bad leaves cut off, and keep the soil fairly moist and well cultivated. That is about all you can do besides fumigating. In early Spring or when you are ready to throw the plants out, select the smallest rooted runners, cut them back a little and pot up into $2 s$ to go into the field by May. 


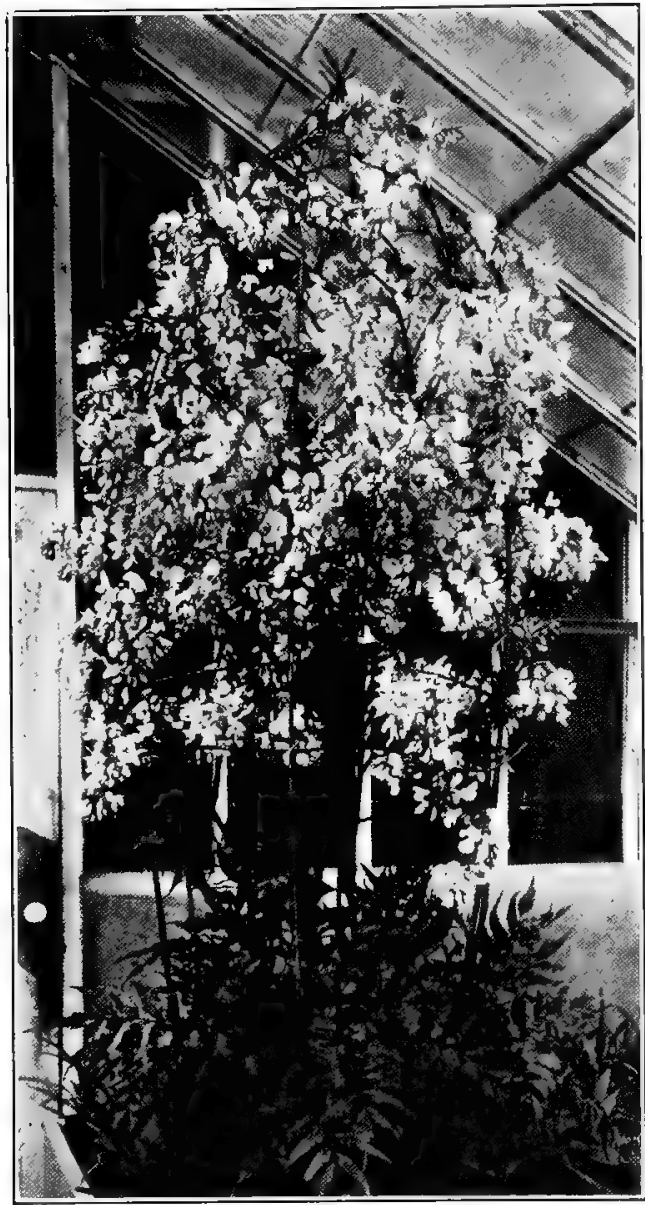

Fig. 285.-Wistarua BRACHYBotrys. While $W$. sinensis is the best for outdoors where it has a chance to climb, Wistaria brachybotrys, a early Spring flowering because of its dwarf habit Japanese species, make the best pot plant for

In the same house you grow these Violets you can manage Pansies, Forgetme-nots, Polyanthus Primulas, $\mathrm{M}$ ignonet $\mathrm{te}$ and Calendulas.

\section{Double Russian VIOLET}

Even if there were nothing else to be said in favor of this Violet but that it is perfectly hardy (standing even ten or more degrees below zero), and that its double blue flowers are as fragrant as any freshly picked, greenhouse-grown Marie Louise, this would justify your recommending it to your customers.

I don't believe there is any one with a hardy border or room for a few perennials who wouldn't appreciate a batch of Lily of the Valley, as well as a few clumps of these Violets, and if you just mention the fact that you carry a stock of them, you are sure to sell some.

About as easy a way as any to carry these plants is to select a half-shady spot and plant small stock out about 12 in. or so apart, Strawberry-fashion. The plants soon cover the ground, and each Spring you can thin them out and dispose of your surplus. Those who need large quantities can root the side shoots and runners and grow them on in $21 / 2$-in. pots in a coldhouse or frame.

WALL FLOWER

See Cheiranthus

WANDERING JEW

See Tradescantia 
WEIGELA

See Diervilla

WILLOW

See Salix

WISTARIA

The Wistarias are, without a doubt, among the "most handsome and showy hardly climbers we have. When ten or more years old, and given plenty of room, a specimen in bloom is indeed hard to beat. There is one trouble, and a serious one, your customers may have; that is, that their plants keep on growing and don't flower. This in most cases results from having sold them plants grown from seed. It may be unknown to you, but it is a fact that grafted plants flower freely even wh n small, while seedlings may flower and may not. At least, most of them don't until they are very old. In order to avoid this trouble, when you order stock be sure and obtain grafted plantsand be willing to pay more for them.

\section{XERANTHEMUM ANNUUM}

If you have use for so-called everlasting flowers, you should include in the list a few Xeranthemums. They are as desirable as any of the others and more so than Helichrysums, being more graceful. Treat the same as other annuals, outdoor sowing being almost as satisfactory as starting them under glass. They come in a beautiful rose color, white, and red and will grow fully three feet high. For early results sow in a hotbed and transplant later into the field. It doesn't cost much to grow a few rows and the country florist especially often has good use for the flowers during the Winter months. 


\section{YUCGA FILAMENTOSA (ADAM'S NEEDLE)}

There are times when a group of Yuccas is just the right thing in the planting of home grounds. While they are most showy when in full bloom, with heavy stems loaded with large, creamy white flowers, their Iris-like leaves form a good contrast against the shrubs or other plants in a border, even when the plants are out of bloom. At the base of a large rockery, on the outskirts of a pool, at the edge of large shrubbery beds, or even in the perennial border, they can be used to advantage. They do as well in full sunlight, moreover, as in part shade.

They are increased by division and all you have to do is to get a few plants well established in order to be able to work up enough stock to supply the usual demand.

\section{ZINNIAS}

The Zinnias are fine Summer flowers and even the florist should plant a lot of them to keep up the show. They will stand almost any kind of weather and keep on flowering until late in the Fall. The retail grower should always grow on a good-sized batch of them in $2 \frac{1}{2} \mathrm{~s}$ for Spring and another batch should be kept coming along in a coldframe. There is more money in selling the seedlings out of the frame at fifty cents a dozen than can be realized later from the sale of their flowers when garden owners on every hand also are able to cut plenty of blooms.

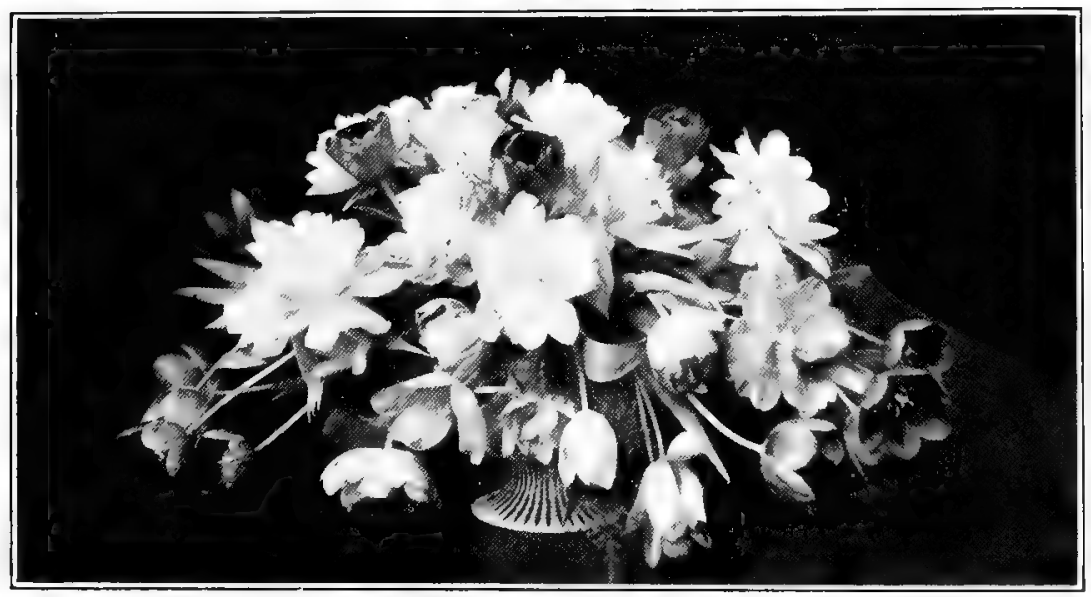




\section{LIST OF ILLUSTRATIONS}

Portrait of the Author.

PAGE

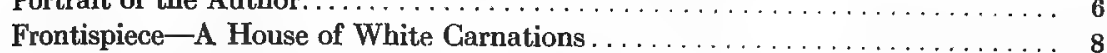

FIG.

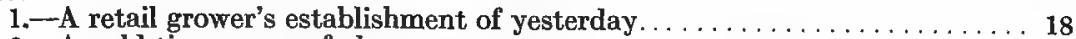

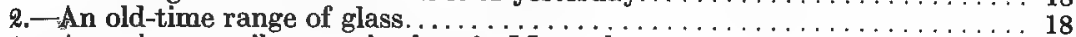

3.-A modern retail grower's place in Massachusetts................ 20

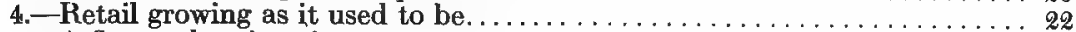

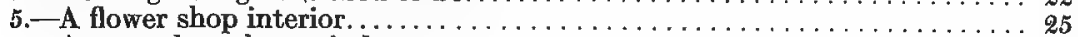

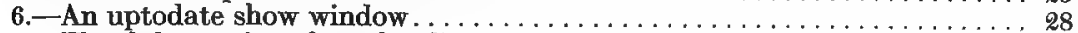

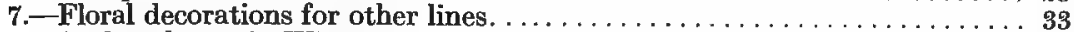

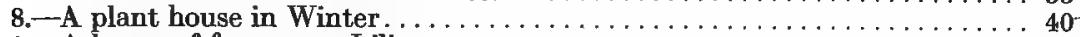

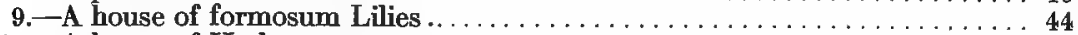

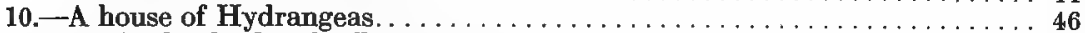

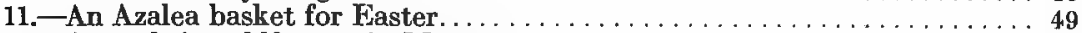

12.-Annuals in coldframes in May.... . . . . . . . . . . . . . . 52

13.-Setting out Hydrangeas from pots. . . . . . . . $\ldots \ldots \ldots \ldots \ldots \ldots \ldots$

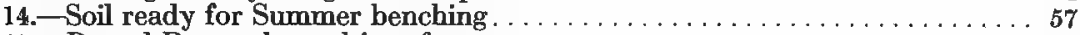

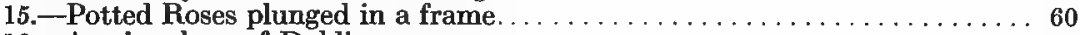

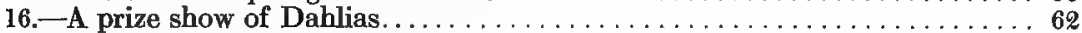

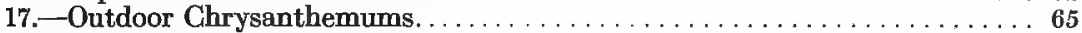

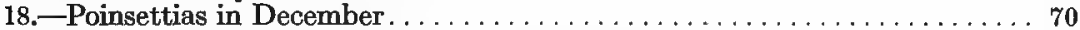

19.-A practical establishment of three houses and store............ 74

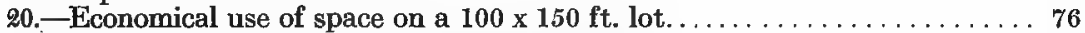

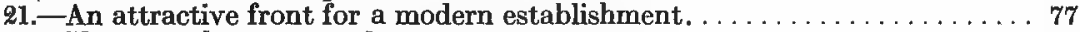

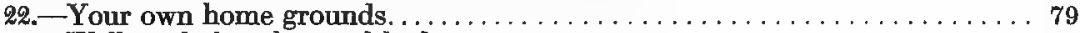

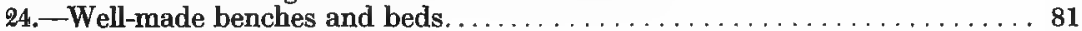

25. - Inside an ideal propagating house $\ldots \ldots \ldots \ldots \ldots \ldots \ldots \ldots \ldots \ldots$

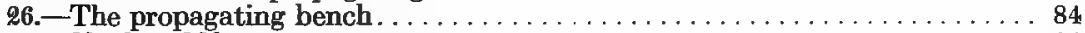

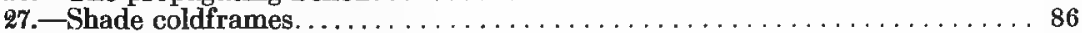

28. - A Canna bed bordered with Celosia and Coleus. . . . . . , . . . . . . 90

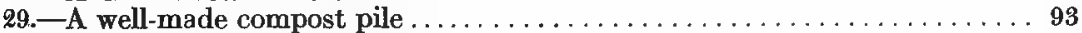

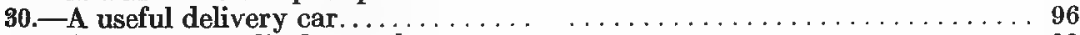

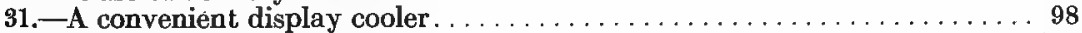

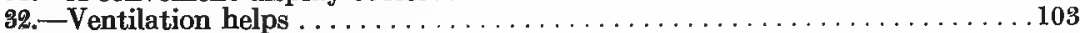

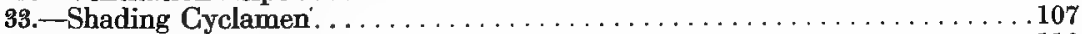

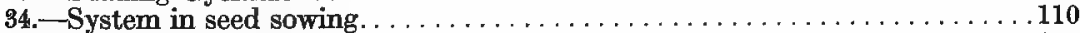

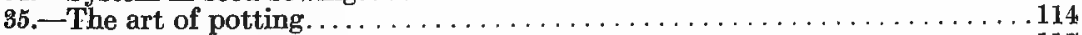

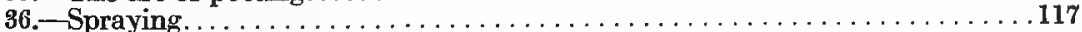

37.-The florist's ideal showground. . . . . . . . . . . . . . . . . . 120

38.-A florist's showground of 25 years ago. . . . . . . . . . . . . . . 122

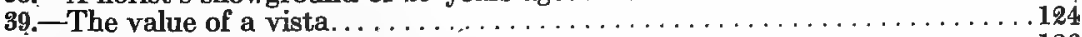

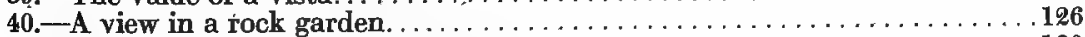

41.-A brick wall bordered with perennials. . . . . . . . . . . . . . . 129

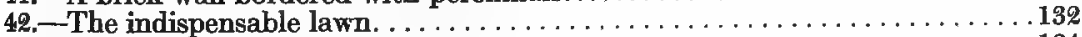

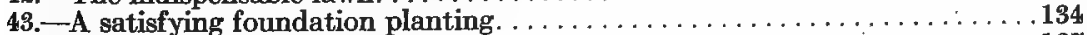

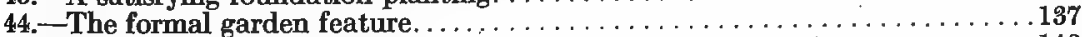

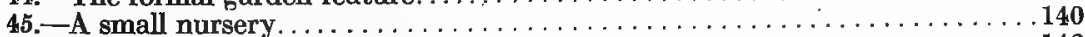

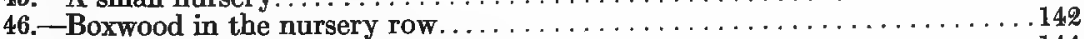

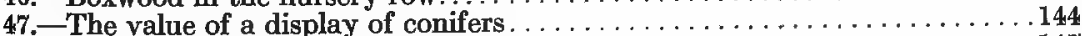

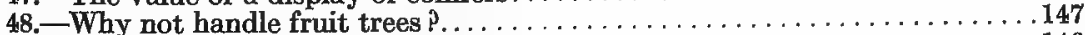

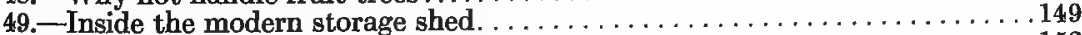

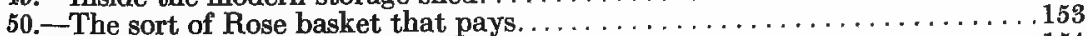

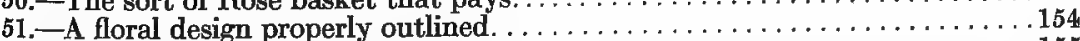

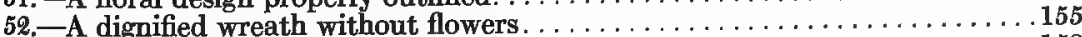

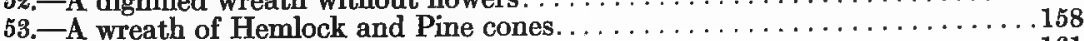

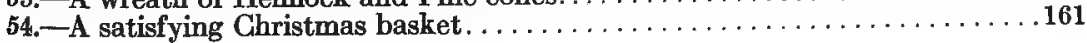


FIG.

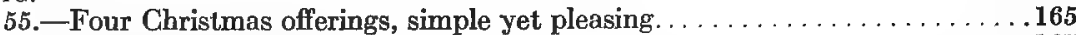

56. - A real Holly wreath. . . . . . . . . . . . . . . . . . . . . . . . . 167

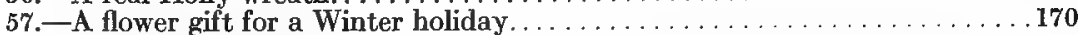

58.-Hyacinths for Easter. . . . . . . . . . . . . . . . . . . . . . . 173

59. - Another tasteful Easter arrangement. . . . . . . . . . . . . . . 174

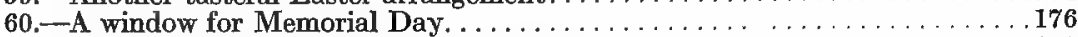

61. - A St. Valentine's Day business-getter. . . . . . . . . . . . . . . . . . . 178

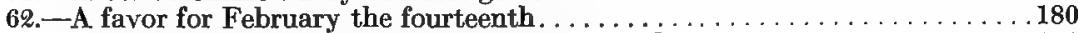

63.-A typical Easter combination of popular stock. . . . . . . . . . . . 181

64.-Annuals in the hotbeds in April. . . . . . . . . . . . . . . . . 183

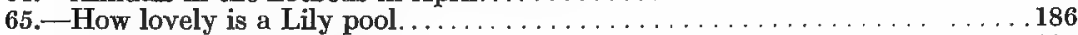

66. -The charm of the window box. . . . . . . . . . . . . . . . . . 189

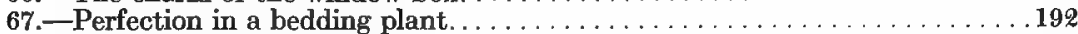

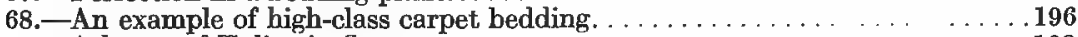

69. - A house of Tulips in flats. . . . . . . . . . . . . . . . . . . . . . . 198

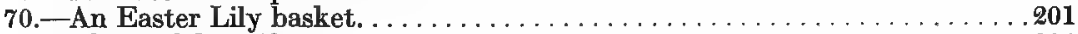

71.-The useful conifers. . . . . . . . . . . . . . . . . . . . . . . . . . . 204

72.—A well-known hardy fern. . . . . . . . . . . . . . . . . . . 207

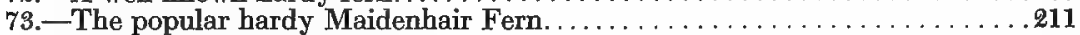

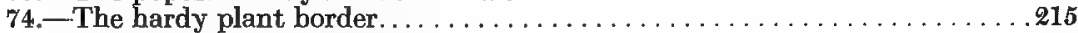

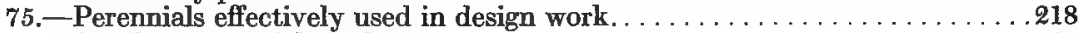

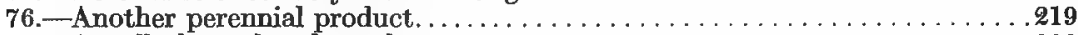

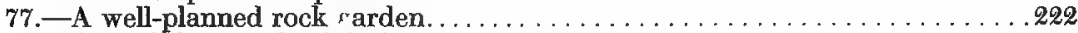

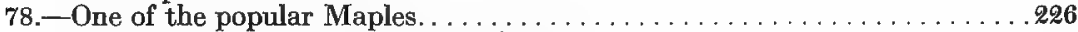

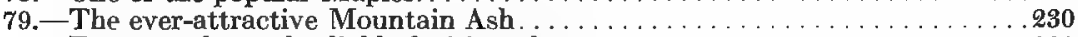

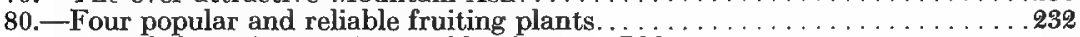

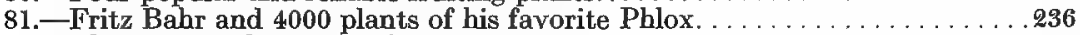

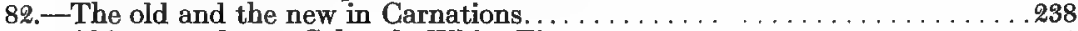

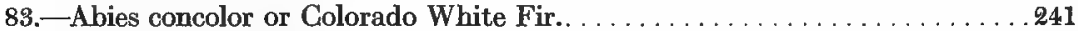

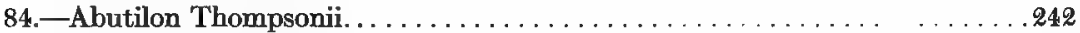

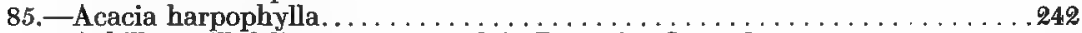

86. - Achillea millefolium roseum and A. Ptarmica flore pleno. . . . . . . . . 244

87. - Maidenhair Fern (Adiantum cuneatum) . . . . . . . . . . . . . . . . 246

88.-Double Hollyhocks. . . . . . . . . . . . . . . . . . . . . . . . . . . . . 249

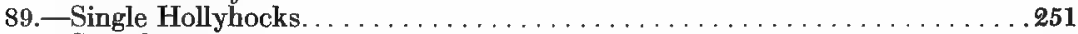

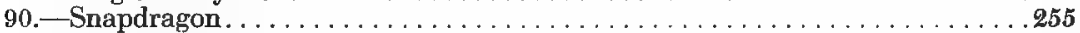

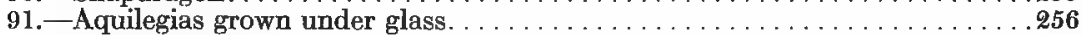

92.-Areca lutescens. . . . . . . . . . . . . . . . . . . . . . . . . . . . .258

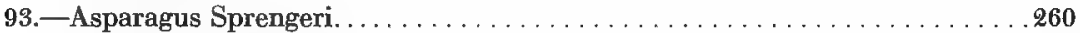

94._Asparagus plumosus. . . . . . . . . . . . . . . . . . . . . 262

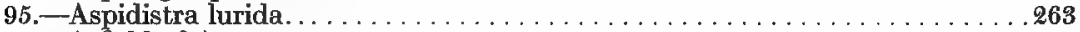

96. A field of Asters . . . . . . . . . .

97.-Dostalek's Aster. . . . . . . . . . . . . . . . . . . . . . . . . 265

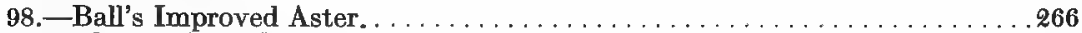

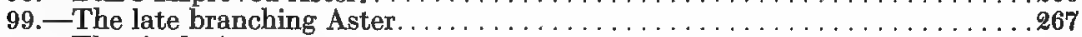

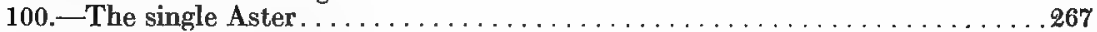

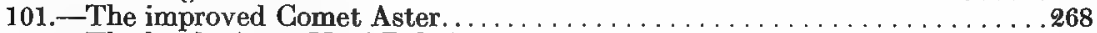

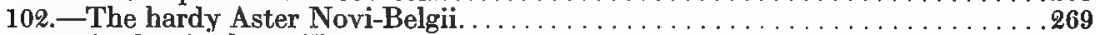

103.—Azalea Anthony Koster. . . . . . . . . . . . . . . . . . . . . . . 271

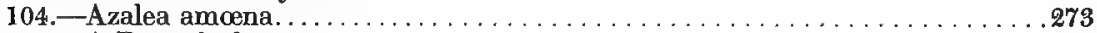

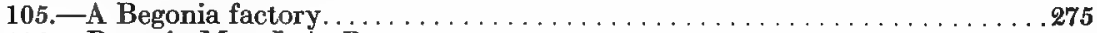

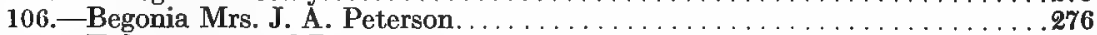

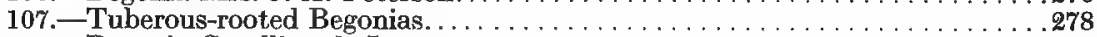

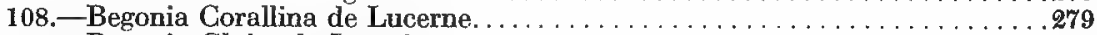

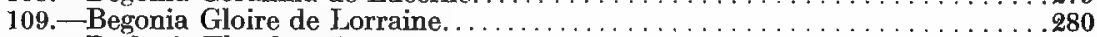

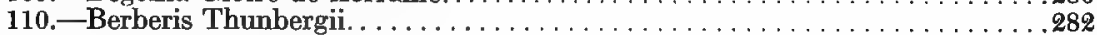

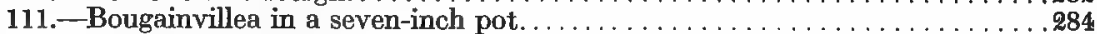

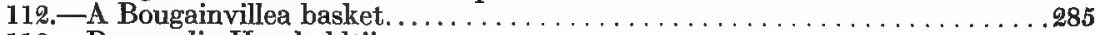

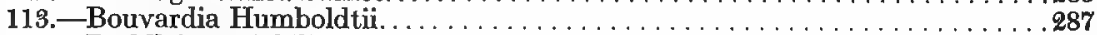

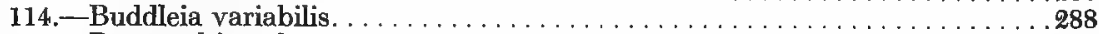

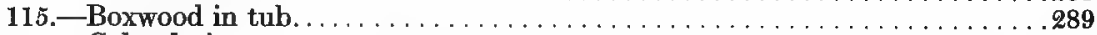

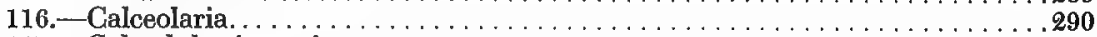

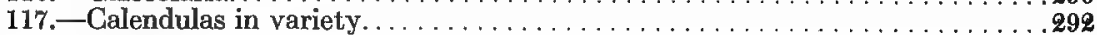

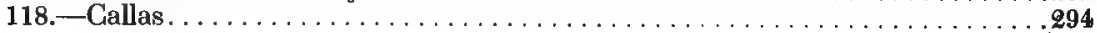


FIG.

119.

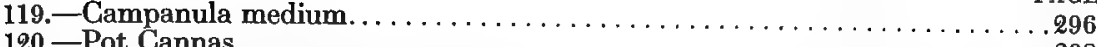

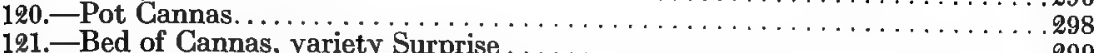

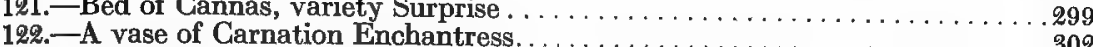

193 A vase

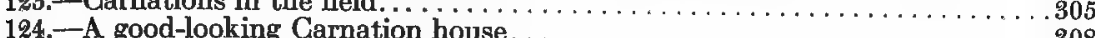

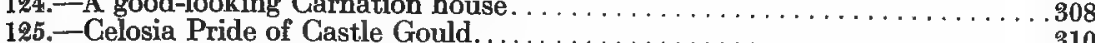

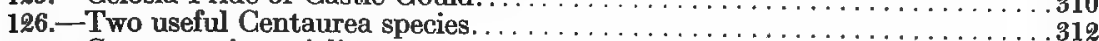

127.-Centaurea imperialis........

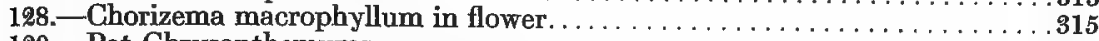

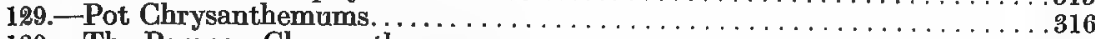

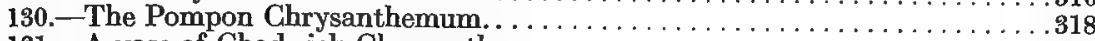

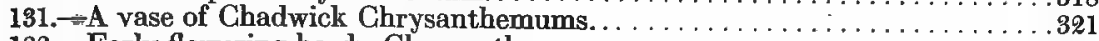

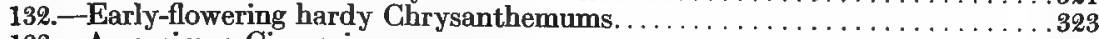

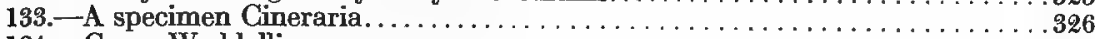

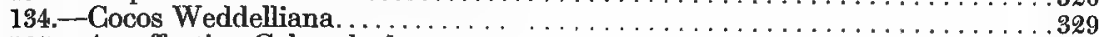

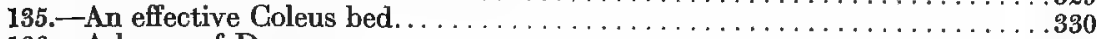

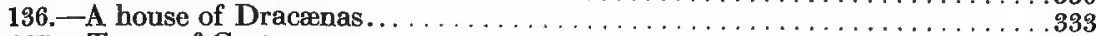

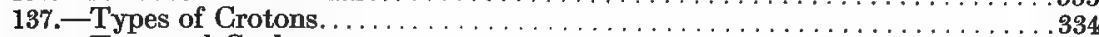

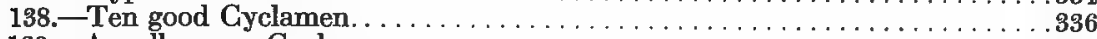

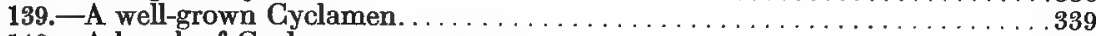

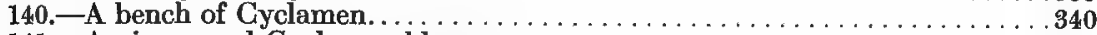

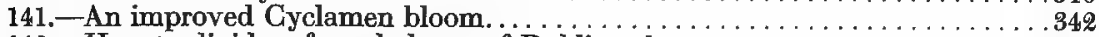

142. - How to divide a forced clump of Dahlia tubers. . . . . . . . . . .

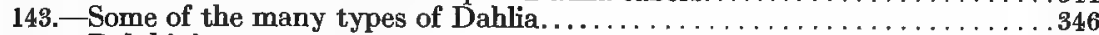

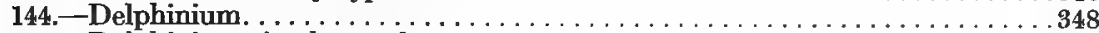

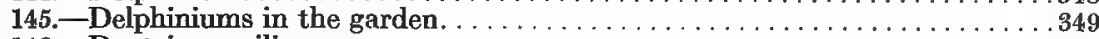

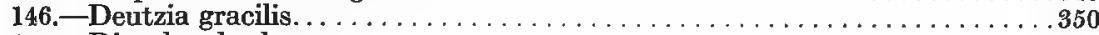

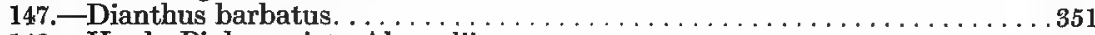

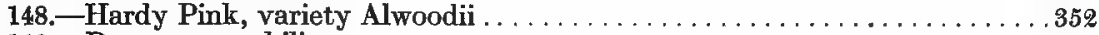

149.-Dracæna amabilis. . . . . . . . . . . . . . . . . . . . . . . . .

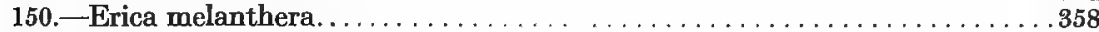

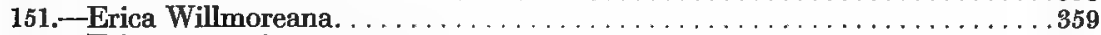

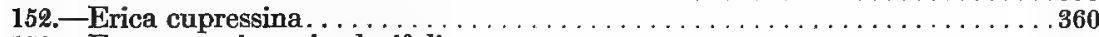

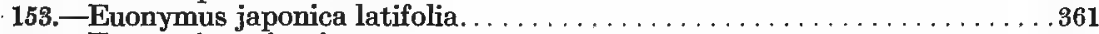

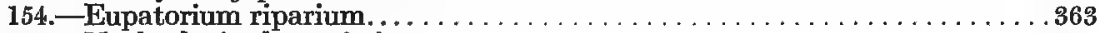

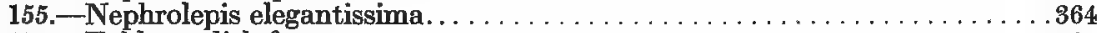

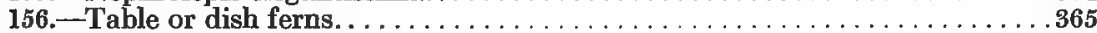

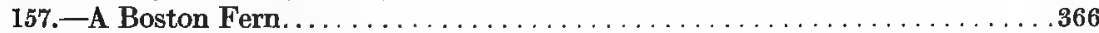

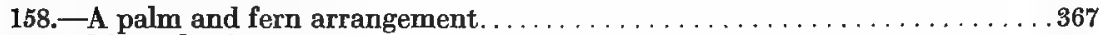

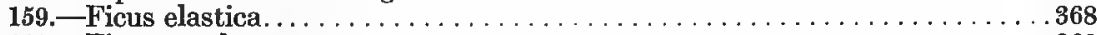

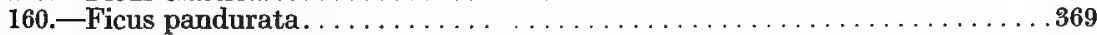

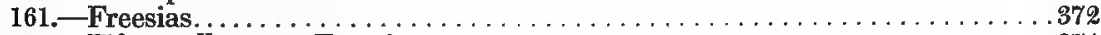

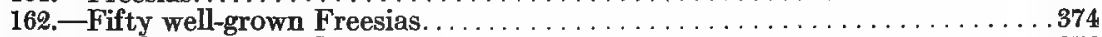

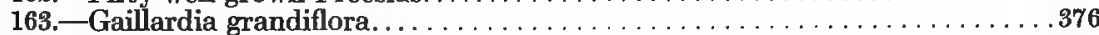

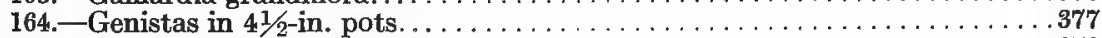

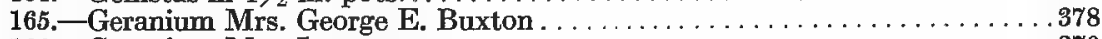

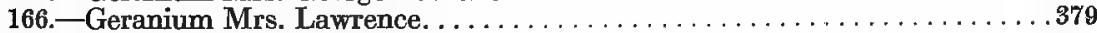

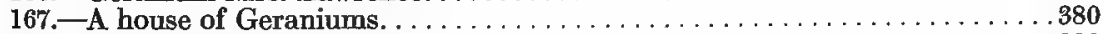

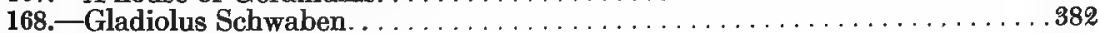

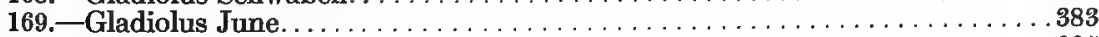

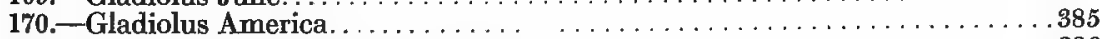

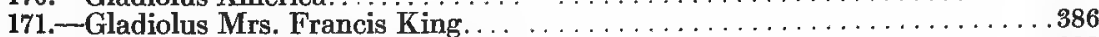

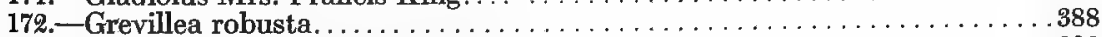

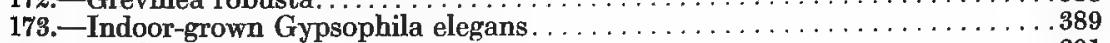

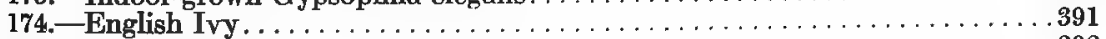

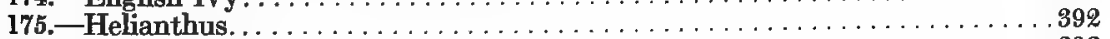

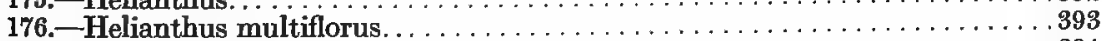

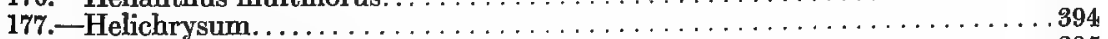

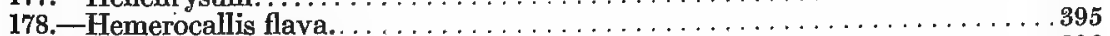

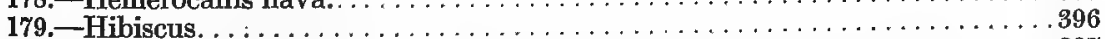

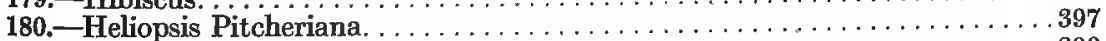

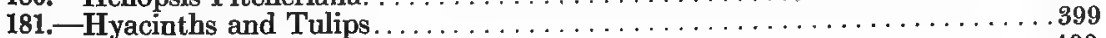

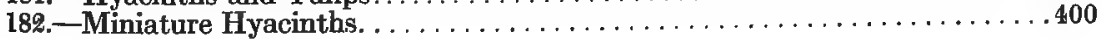


FIG.

183.-Hydrangea Otaksa.

184. - A standard Hydrangea. . . . . . . . . . . . . . . . . . . . . . . . .

185.-Hydrangea arborescens. . . . . . . . . . . . . . . . . . . . . . . .404

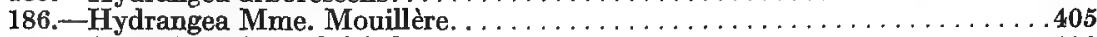

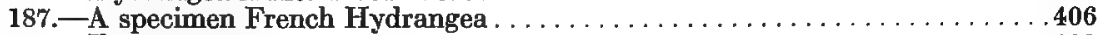

188. -Ilex crenata. . . . . . . . . . . . . . . . . . . . . . . . . . . . . . . .408

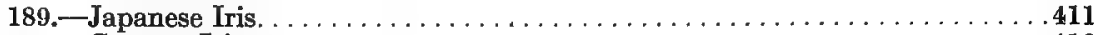

190.-German Iris. . . . . . . . . . . . . . . . . . . . . . . . . . . .

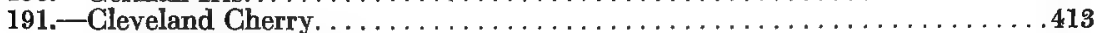

192.-Kalmia latifolia in flower. . . . . . . . . . . . . . . . . . . . 414

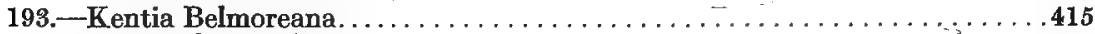

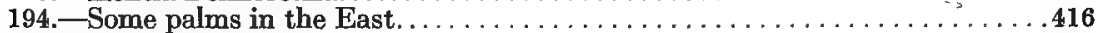

195.- Summer Larkspur.................................417

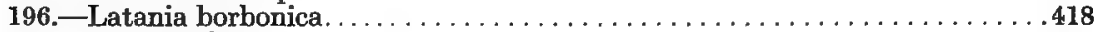

197. - Easter Lilies....... . . . . . . . . . . . . . . . . . . . . . . . . . 420

198. -Lilium tigrinum. . . . . . . . . . . . . . . . . . . . . . . .422

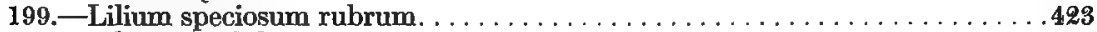

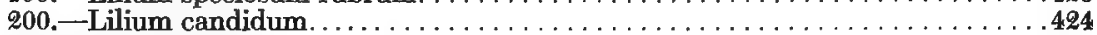

201.-Growing hardy Lilies in America... . . . . . . . . . . . . . . . .

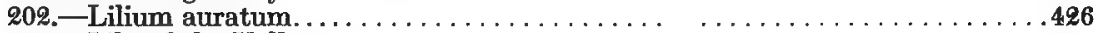

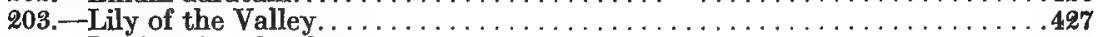

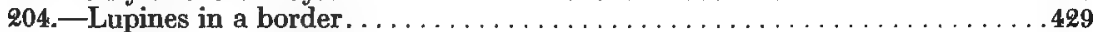

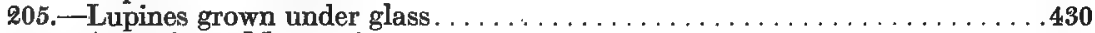

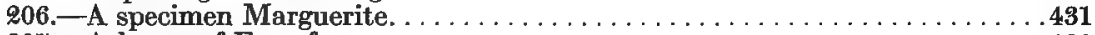

207.-A house of Feverfew.........

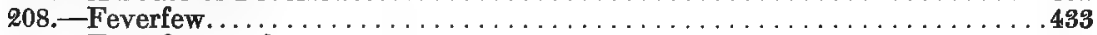

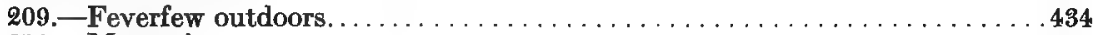

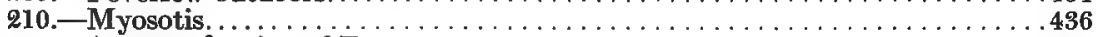

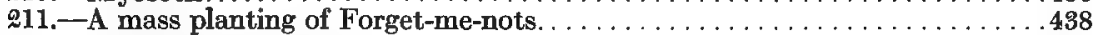

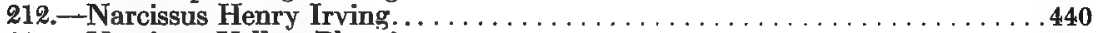

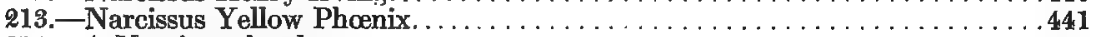

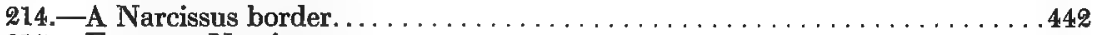

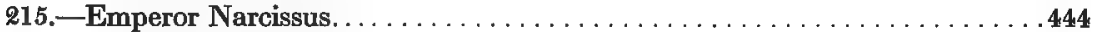

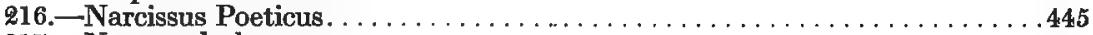

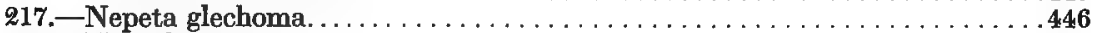

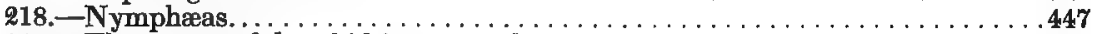

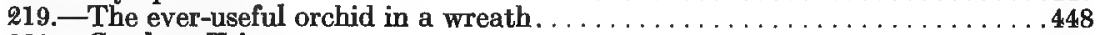

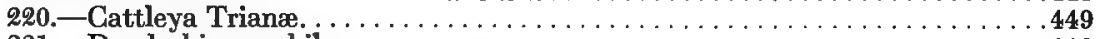

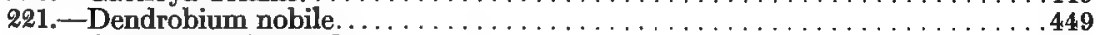

222.—Cymbidium Pauwelsii. . . . . . . . . .

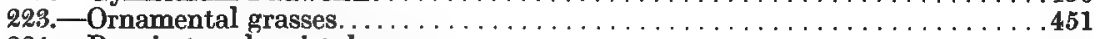

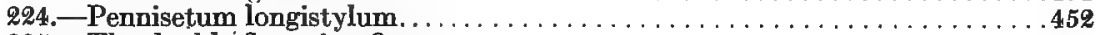

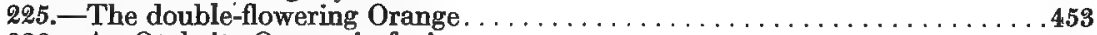

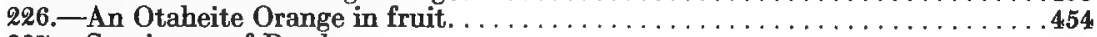

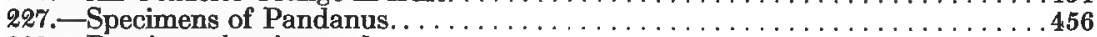

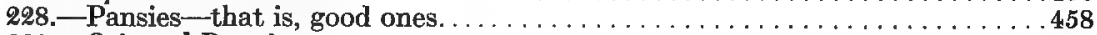

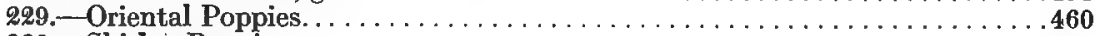

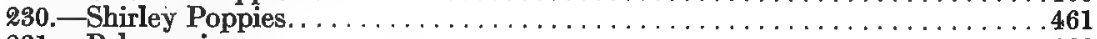

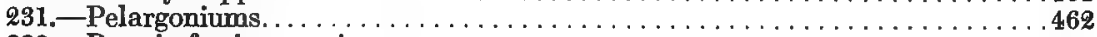

232.-Preonia festiva maxima. ........

233.-Single Peonies. . . . .

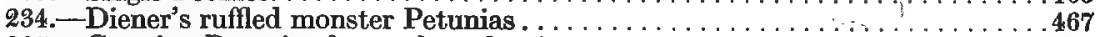

235.—Growing Petunias for seed production. . . $\ldots \ldots \ldots \ldots \ldots \ldots \ldots \ldots \ldots, 468$

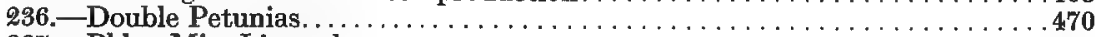

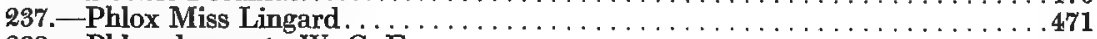

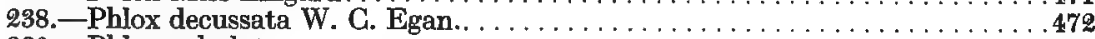

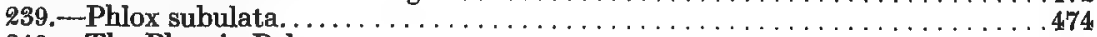

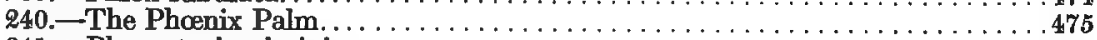

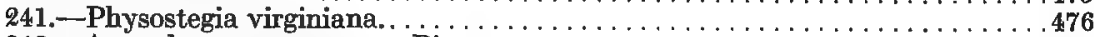

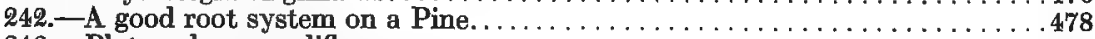

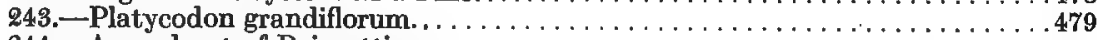

244.-A good pot of Poinsettias........

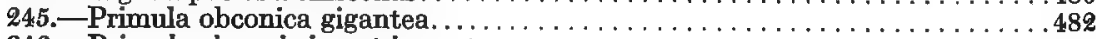

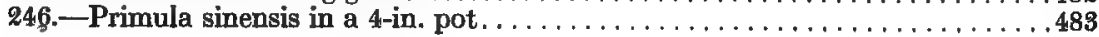


FIG.

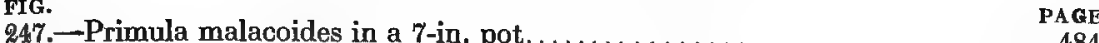

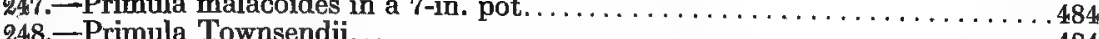

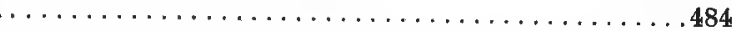

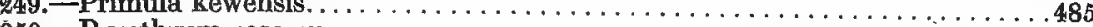

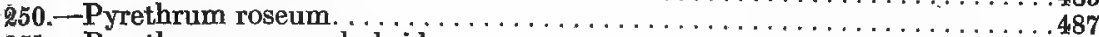

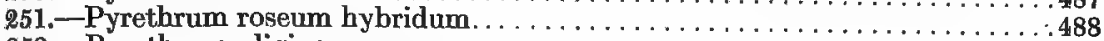

252.-Pyrethrum uliginosum . . . . . . . . . . . . . . . . . . . . . . .489

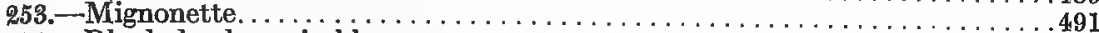

254.-Rhododendrons in bloom . . . . . . . . . . . . . . . . . . . . . 493

255.-The successful Rose grower's reward. . . . . . . . . . . . . . . . .

256.-A Rose house. . . . . . . . . . . . . . . . . . . . . . . . . . . . . .499

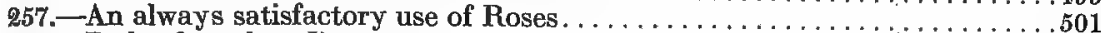

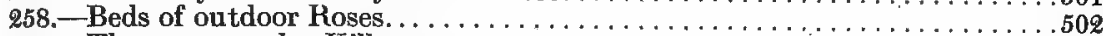

259. The ever-popular Killarney. . . . . . . . . . . . . . . . . . . . .504

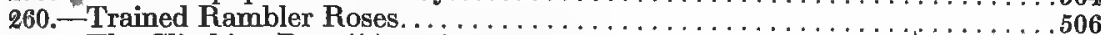

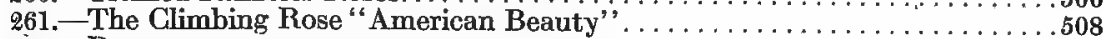

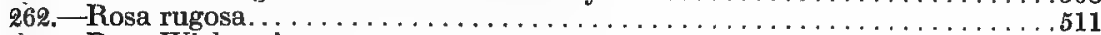

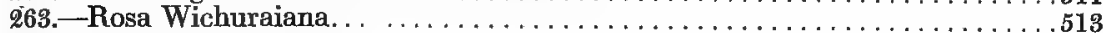

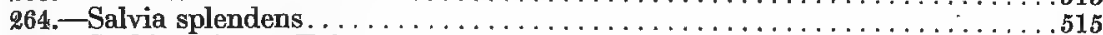

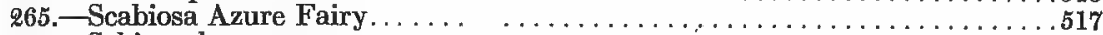

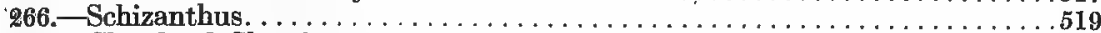

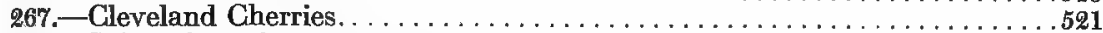

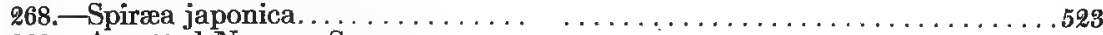

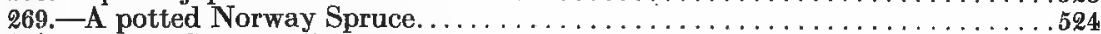

2\%0.-Statice Suworowii. . . . . . . . . . . . . . . . . . . . . . . .526

271.-Stocks, variety Beauty of Nice . . . . . . . . . . . . . . . . . . . 527

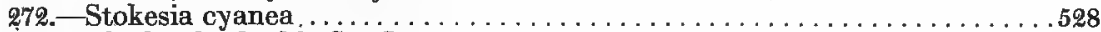

273.-The hardy double Sunflower. . . . . . . . . . . . . . . . . . . . . . .529

274.-Orchid-flowering Sweet Peas. . . . . . . . . . . . . . . . . . . . .530

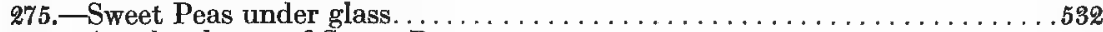

276.-Another house of Sweet Peas. . . . . . . . . . . . . . . . . . . . . .534

277. -Iilacs in pots. . . . . . . . . . . . . . . . . . . . . . . . . 536

278. - A specimen outdoor Lilac. . . . . . . . . . . . . . . . . . . . . . . .538

279. Spiræa Reevesii flore pleno forced in a tub . . . . . . . . . . . . . . . . .540

280.-Darwin Tulips. . . . . . . . . . . . . . . . . . . . . . . . . . .542

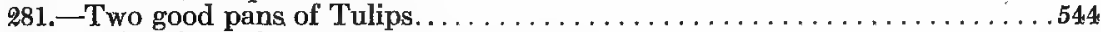

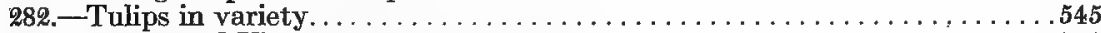

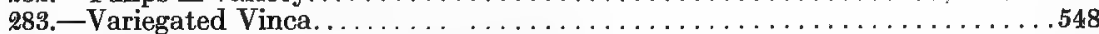

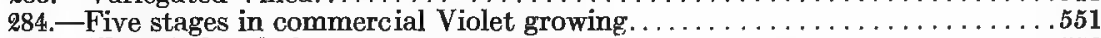

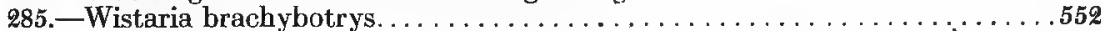

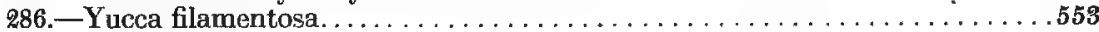

Although it is impossible to acknowledge the sources of all illustrations listed above, it is desired to thank especially the following:

Peter Bisset, (Fig. 263)

George Burgevin, (Fig. 38)

John Lewis Childs, Inc., (Fig. 169)

Nelson Coon, (Fig. 284)

Robert Craig Co., (Figs. 137, 260)

The Florists Exchange, (Various)

Foley Greenhouse Mfg. Co., (Fig. 21)

J. L. Schiller, (Figs. 150, 151, 154, 249,
Gude Bros. Co., (Fig. 123)

Koster \& Co., (Figs. 25, 46, 201)

Lord and Burnham Co., (Figs. 19, 20)

J. A. Peterson, (Fig. 105)

G. Thommen, (Figs. 1, 2, 194)

Chas. Zeller and Son, (Fig. 4)

A. L. Miller, (Figs. 80, 84, 85, 108, 111, 115,125 , and others) and others) 






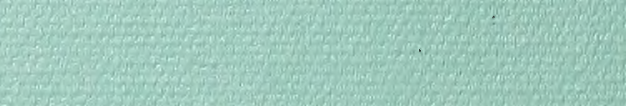

